Katrin Frisch

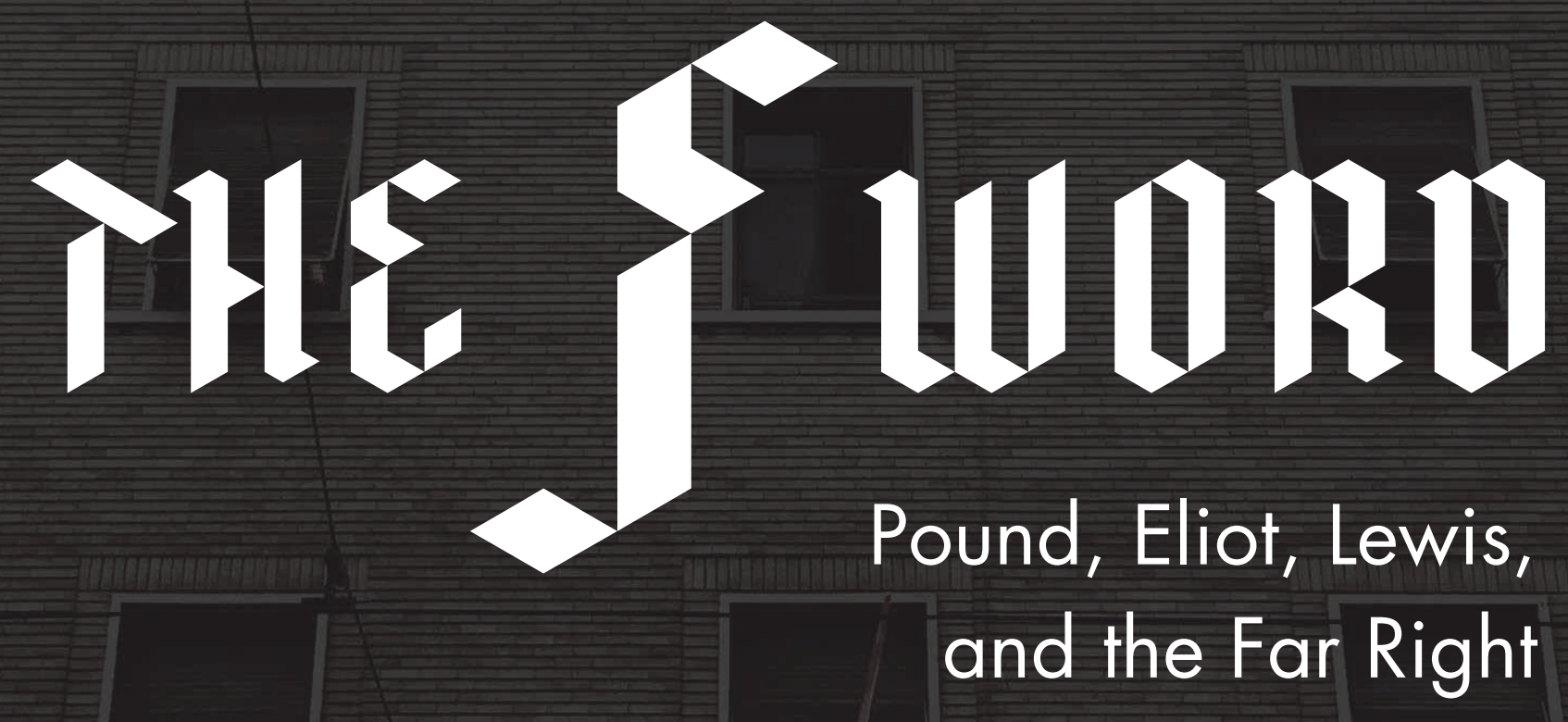

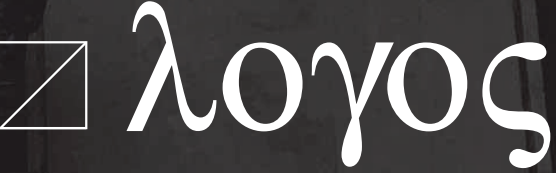



Katrin Frisch

\section{The F-Word}

Pound, Eliot, Lewis, and the Far Right 
Bibliografische Information der Deutschen Nationalbibliothek

Die Deutsche Nationalbibliothek verzeichnet diese Publikation in der Deutschen Nationalbibliografie; detaillierte bibliografische Daten sind im Internet über http://dnb.d-nb.de abrufbar.

\section{(C) (1) ()}

Das Werk einschließlich aller seiner Teile ist urheberrechtlich geschützt.

Das Werk steht unter der Creative-Commons-Lizenz Namensnennung-Share Alike 4.0 International

(CC BY-SA 4.0, https://creativecommons.org/licenses/by-sa/4.0/legalcode.de). Ausgenommen von der oben genannten Lizenz sind Teile, Abbildungen und sonstiges Drittmaterial, wenn anders gekennzeichnet.

Dieses Buch entstand aus einer Dissertation (eingereicht mit dem Titel: The F-Word: Interdependencies of Right-Wing Ideology and Modernist Writing: Pound, Eliot, and Lewis) am Institut für Anglistik/Amerikanistik der Humboldt-Universität zu Berlin in Kooperation mit dem King's College London. Ermöglicht wurde die Promotion durch ein Promotionsstipendium der Studienstiftung des deutschen Volkes.

Die Veröffentlichung wurde aus Mitteln des Open-Access-Publikationsfonds der Humboldt-Universität zu Berlin gefördert.

https://orcid.org/0000-0002-6669-5015

Covergestaltung: Mike Moses Wunder

Gedruckt und Veröffentlicht durch den Logos Verlag Berlin GmbH 2019

ISBN 978-3-8325-4972-5

Logos Verlag Berlin GmbH

Comeniushof, Gubener Str. 47,

10243 Berlin

Tel.: +49 (0)3042851090

Fax: +49 (0)3042851092

INTERNET: https://www.logos-verlag.de 


\section{TABLE OF CONTENTS}

ACKNOWLEDGMENTS

1. INTRODUCTION 1

2. LOOKING AT THE F-WORD AND BEYOND 11

Right-wing ideology 13

Fascism and Nazism 18

The matter of anti-Semitism $\quad 22$

The matter of racism 26

A very short history of right-wing ideology 28

Right-wing ideology in literature $\quad 36$

3. THE POEM AS PROPAGANDA - EZRA POUND 39

'Der Jud will Geld' 47

A 'stupid suburban prejudice'?

'MA QVESTO' 64

'His rod hath made god in my belly' 79

Mere words? - The poem on trial 87

4. T. S. ELIOT - THE CONSERVATIVE COLLABORATOR 95

'I was neither living nor dead' 108

'They wash their feet in soda water' 117

'It's them pills I took, to bring it off 124

'I'll convert you! Into a stew!' 133

'The jew is underneath the lot 144

Final thoughts 155

5. NO MEN IN NO MAN'S LAND - WYNDHAM LEWIS 157

'I was never real. Am I?' 168

'We are primitive and proud of it!' 178

'You do not believe in the sex-goods you deal in...' 190

'It's too marvellous he's Black!' 198

'Oh! I am not progressive' 209 


\section{6. 'WHICH BOOK RED PILLED YOU?' \\ - RIGHT-WING RECEPTION}

Who is the New Far Right

Early right-wing reception of Pound and Eliot

Contemporary right-wing reception

Counter-Currents

Kerry Bolton: Artists of the Right

The Occidental Quarterly

Sezession

Final thoughts

7. DO CIVILIZED PEOPLES EXECUTE THEIR POETS? 269 


\section{ACKNOWLEDGEMENTS}

If it takes a village to raise a child, it takes about an equal amount of people to write a book. It all started with a term paper for a seminar on Modernist Poetry. Stephan Lieske's feedback and encouragement gave me the confidence to pursue the matter further. My research culminated in a Master's thesis on Vorticism and the Proto-Fascist Tradition, which was jointly supervised by Prof. Dr Eveline Kilian (Humboldt-University Berlin) and Prof. Dr Max Saunders (King's College London), who would afterwards also become supervisors of my $\mathrm{PhD}$ thesis, originally titled The F-Word: Interdependencies of Right-Wing Ideology and Modernist Writing: Pound, Eliot, Lewis, on which this book is based. I have profited from their knowledge, guidance, and expertise. Eveline Kilian's meticulous readings of my drafts helped me to improve my literary analyses and hone my arguments. I was fortunate to be part of Eveline Kilian's colloquium, which always offered a supportive space to discuss unfinished ideas and raw material. I also want to extend thanks to Dr Jon Day, whose extensive feedback was a great help to me when I revised this $\mathrm{PhD}$ thesis in preparation for its publication. I also relied on the generous funding of the Studienstiftung des deutschen Volkes, without which I could not have embarked upon this journey. Their scholarship programme also gave me the opportunity to meet like-minded people, some of whom eventually became friends.

I am furthermore indebted to the brilliant set of people also known as the cabin crew: Shirley, Julia, Kathrin, Barbara, Rebeca, and Schu. Their support and general awesomeness have made my days lighter and the book in its final state better. I especially want to thank Shirley and Julia for all the work they put into this project. Shirley's moral support has kept me going, her intellectual support helped me grow as an academic. Julia is the most assiduous proofreader I know, who would pore over my text as if it was her own. She also spent countless hours with me talking through my arguments, doubts, and ideas. I am beyond grateful to count them among my closest friends.

Many other friends have supported me during the time of my $\mathrm{PhD}$. I want to thank Kai, Katharina, Júlia, and Ina for reading and commenting on individual chapters or passages and for sharing their knowledge with me. Marty, Stephan, Steffi, Diana, Jakob, and Izzy offered advice whenever I needed it, but mostly, they helped me to keep sane. Similarly Trish, Pablo, and Josie made me feel at home when I was living in London: I cherish the many hours we spent together. Writing this thesis has often filled me with dread and self-doubt, so I owe a debt of gratitude to all who reassured me 
that this project was worthwhile to keep going, who sympathetically listened to my rants, and believed in me even when I did not. Special thanks go to Mike, who designed the cover. Finally I want to thank my family, especially my Mum, who always supported me, even if they did not always understand why one would voluntarily spend years analysing right-wing literature. 


\section{INTRODUCTION}

Few concepts have had a more fascinating trajectory than right-wing ideology. Officially born as a political concept in the wake of the French Revolution, it grew with renewed force in the beginning of the twentieth century, reaching its climax in the fascist regimes. The story many democratic Western nations like to tell about themselves is that after the defeat of the Axis forces, rightwing ideology and many of its radical proponents went into hiding. During the Cold War for many Western states the enemy was lurking on the Left. And while in several countries the conservative democratic Right were in charge, they usually distanced themselves from the more radical right-wing elements that dwelled on society's fringes. Sometimes, these radical elements violently forced their way into the heart of society, as evidenced by racist violence in the U.S. as a reaction against the Civil Rights movement, the British race riots, and specific right-wing motivated attacks such as the Oklahoma City Bombing in 1995, the Bologna massacre in 1980, the Oktoberfest bombing in 1980, the Norway attacks in 2011, and the Christchurch massacre in 2019 to list only the deadliest. Yet overall, it seemed that radical right-wing ideas had lost their relevance, when suddenly a few years ago the far right made its surprising comeback. Today we have relapsed, some would say, into the politically unstable times of the 1930s.

This story is not entirely true. Not only does it leave out the perspective of many marginalised groups, who have continually lived under consistent threat from right-wing forces, it also glosses over the complicity between political mainstream and right-wing ideology and its advocates. The Allied forces in the Second World War may have triumphed over the fascist regimes, but they have not defeated these regimes' underlying ideology. Right-wing ideology, even its more radical and extreme forms, did not merely dwell on the margins of societies, but had a powerful influence on political discourse and political practice. What is noteworthy is that very often the far right were used by the political mainstream as 'imaginary antagonists', useful tools to sway public opinion and to paint the political mainstream forces in a more positive light. Right-wing ideology is not as marginalised as it is sometimes presented. This holds especially true for the first decade of the $20^{\text {th }}$ century. While in hindsight fascism is usually considered the evil other, fascist and other extreme right-wing ideas circulated widely in all western democratic societies. Looking back at the crucial decades that paved the way for the right-wing dictatorships and the Second World War it becomes clear that the unprecedented rise of fascist movements cannot be considered a historic aberration at 
odds with the progressive developments of Western democracies in the $20^{\text {th }}$ century, but that it was in fact deeply rooted in those same developments. A realm that illustrates these complicated dynamics is that of Modernist literature. It is especially here that retrospective views ignore the rich reservoir of right-wing ideas in favour of highlighting the stylistic innovations many Modernist artists and movements created. In fact, radical stylistic innovation is often equated or confused with a progressive world-view. This has led to an invisibility or understatement of the importance of right-wing ideology in and for Modernism: not because the authors concerned are no longer read but because their political allegiances remain - deliberately or not - unmentioned, downplayed or distorted. Yet what cannot be disputed is that almost all Western countries boasted a great number of artists, writers, and intellectuals who positioned themselves somewhere on the Right.

Listing the many artists and writers of the Right reads like a who-is-who of $20^{\text {th }}$ century Modernism. In Italy the Futurists wholeheartedly flung themselves into the camp of the Fascists and advocated for Futurism to become the official state art of Mussolini's Italy. Many prominent Futurists like F. T. Marinetti, Mario Carli, Carlo Carrà, Bruno Corra, and Mario Sironi among others got actively involved in or supported fascist politics. ${ }^{1}$ Yet Futurism's allegiance to fascism does not seem to have tarnished the legacy of Futurist artists too much. The situation in Germany offers a more complex picture. While 'official' National Socialist writers like Josef Magnus Wehner, Hans Zöberlein, Edwin Erich Dwinger and Eberhard Wolfgang Möller wrote to great acclaim during their time, they are virtually unknown in Germany today. ${ }^{2}$ In contrast, the reception of more prominent writers shows the conflicting dynamics of honouring artists and intellectual talent while coming to terms with the politics that might have influenced the works of these authors. Ernst Jünger, whose famous Great War memoir In Stablgewittern today seems to be a lot more popular in Britain than in Germany, was firmly at home in the circles of the Konservative Revolution in Germany, ${ }^{3}$ yet he remained a life-long critic of the National Socialists. Jünger is a good example of why it is important to see the Right, in particular the far right, as a heterogeneous spectrum if we want to illustrate intra-right-wing allegiances and strife. Today Jünger is still popular on the Right but he is by no means only read by the Right. Another writer, Gottfried Benn is widely known to have had sympathies with the ideas of the Konservative Revolution, and initially collaborated with the National Socialists, a stance which he later repudiated. Yet his works remain popular. It even seems that his literature, which feasts on disgust and other deliberately dark and ugly matters is strangely more palatable to many than Jünger's vitalism and heroism. Less well known seems to be the affinity some leading Expressionists like Ernst Ludwig Kirchner and Emil Nolde had 
with National Socialist ideology. ${ }^{4}$ Although their art was beloved by a number of high-ranking National Socialists, Expressionism was officially classified as entartete Kunst (degenerate art). For many Expressionist artists this verdict proved disastrous, for some, like Nolde, it was mixed with feelings of disappointment. His (published) writings testify to his allegiance to official race policies and he tried many times - to no avail - to be granted to work as an artist again. This setback proved beneficial after the demise of Nazi Germany, as it helped Nolde to pose as a victim and adversary of National Socialism. ${ }^{5}$ The case of Martin Heidegger illustrates the complicated attempts of coming to terms with an influential and respected philosopher who was deeply embroiled in National Socialist ideology. The debate, newly triggered by the publication of his Schwarze Hefte as well as selected letters, which testify to the deep influence National Socialist ideology had on his thinking and philosophy, also revealed how long Heidegger's allegiance to National Socialism had been excused and downplayed. ${ }^{6}$ A similar case can be made for Paul de Man, the Belgian-born literary critic, whose 'fascist roots' only became widely known posthumously, at a time when de Man had made a name for himself as a greatly acclaimed theorist in the U.S. ${ }^{7}$ Heidegger and de Man perfectly illustrate the complexity of the debate: both were influential for many thinkers on the Left and yet they are inextricably linked to the extreme Right. It shows that the history of ideas has always been subject to political crosspollination. ${ }^{8}$

Another country that had a strong right-wing intellectual circle was France. ${ }^{9}$ Thinkers like Charles Maurras or Georges Sorel, whose Reflections on Violence offered a powerful theoretical underpinning for the creation of fascism, were influential in and outside of France. Moreover, the so-called second generation of right-wing writers, men like Robert Brasillach, Lucien Rebatet, Pierre Drieu de la Rochelle, and Louis-Ferdinand Céline produced works that were read by readers from across the political spectrum. It is noteworthy that French right-wing writers faced the direst consequences for their political allegiance, possibly a testimony to France being torn by Nazi occupation. Brasillach was sentenced to death, while Drieu de la Rochelle committed suicide in prison to escape his potential execution. Rebatet and Céline left the country to avoid a similar fate. Although they received a trial in absentio they could return to France after some years had elapsed and could spend the rest of their lives there without further prosecution. This short overview is by no means exhaustive. One could list many more countries and writers, from Nobel prize winners like W.B. Yeats and Knut Hamsun to pioneers of popular new genres like H. P. Lovecraft or Henry Williamson. This book will focus on three writers: Ezra Pound, T. S. Eliot, and Wyndham Lewis. As the 'Men of 1914' they stylised themselves as the harbingers of a 
new Modernist art. All three of them were at the forefront of artistic innovation, but crucially also in allegiance with different right-wing ideologies forming in the $20^{\text {th }}$ century. Both of these facts are seldom disputed. What this book wants to show is how inextricably bound their artistic creation was with their ideological allegiance.

Approaching this topic, one has to confront two popular misconceptions. The first very persistent misconception is that the far right lacks an intellectual tradition; their members are often imagined as unintelligent and uneducated in the general discourse. This usually correlates with the assumption that members of, or people with sympathies for, the far right stem predominantly from the lower classes. Despite contrary evidence, the image of the aggressive uneducated right-winger endures. This stereotype stands in stark contrast to the many right-wing writers and thinkers, who play a crucial role in the cultural history of the West, and who are also essential elements in an imagined counter culture that opposed such fundamental values as democracy, liberalism, and equality. For too long this dilemma of canonising and honouring those voices, who spoke for the reactionary and authoritarian movements has not been adequately addressed. Thus, it is no surprise that rightwing Modernist writers have also drawn an explicitly right-wing readership, not only from the conservative Right, but also more crucially from the far right. The right-wing revival of 'their' intellectual tradition is made doubly productive for the Right as it legitimates their ideological undertaking and, moreover, it persuasively asserts their place in the creative history of the Western World. While the far right's claim to respectability seems somewhat outrageous, the core of their argument has some validity: namely the paradox of right-wing artists who are both part and opponents of the imagined trajectory of progressive modernity.

It is important to stress that the label 'right-wing' for the artists mentioned above is not a retrospective assignment of value, applied because what they wrote is no longer part of the sayable, i.e. can not be uttered in public without repercussions. Pound, Eliot, and Lewis went beyond merely reproducing the mainstream prejudices of their times and actively promoted movements that stood in direct opposition to the general drive towards liberal democracy. The oft-repeated argument that they lived during a time when anti-Semitism and racism were the norm even in democratic societies (which, one could argue, they still are) should not serve as excuse nor as explanation. There is a double fallacy in this popular argument. Firstly, a right-wing statement does not become less right-wing if it is uttered among people who more or less agree with said statement. It would be too reductionist to read 'rightwing' as relative and to omit more important factors such as power distribution and discourse formation, which influence who is allowed to say what and 
which ideas are ostracised or marginalised. Secondly, as Anthony Julius has noted: 'Even if one conceded that the dominant literary spirit was hostile to Jews [...] it does not follow that anti-Semitism was of a strength to compel adherence'. ${ }^{10}$ In the same vein Julius remarks that it begs the question why exactly those artists who are celebrated for eschewing convention are, on the level of ideology, excused for being wholly conventional. This also holds true for racism, sexism, classism, and other ideological subsets that degrade an imagined - and subsequently real - other. Approaching the politics of writers and artists thus requires great care in assessing their politics within the framework of their respective societies.

Pound, Eliot, and Lewis, have all to varying degrees, been subject to studies that explored their ideology. All too often, however, these studies have not tackled the issue adequately. In most cases right-wing ideology is abbreviated to fascism, which produces a distorted evaluation of these writers' ideology and of right-wing ideology in general. In some studies, using fascism as an analytical category made it possible to exculpate and exclude certain writers from scrutiny. In fact, using fascism as an analytical category for literary studies poses a number of problems, which will be discussed in chapter 2. Therefore, this study will use the more inclusive concept of 'right-wing ideology' as a spectrum, in which fascism occupies one end but is not the constitutive element. Moreover, when assessing writers' politics, studies have often relegated these into the realm of the biographical, implying that artistic output is autonomous or at least has to be judged differently. This approach was supported and facilitated by critical traditions such as New Criticism, who professed to focus on the materiality of language and leave such worldly matters as ideology aside. Yet this supposed 'ideology-free' reading of literature should be approached with caution. In the case of New Criticism it can be demonstrated that those critics at the forefront of the movement essentially agreed with Eliot's conservative ideology. The inherent right-wing ideology in Eliot's poetry became an unspoken agreement and did not need to be further addressed.

The key critical tradition that brought ideology back into the debate could be said to have been the Marxist tradition. As a matter of fact, Pound, Eliot, and Lewis have already come under scrutiny from some of the Marxists' key theorists. Frederic Jameson has written a seminal study titled Fables of Aggression: Wyndham Lewis: The Modernist as Fascist. Yet the book that seems to carry its damning verdict in the title does in fact exculpate Lewis almost completely. The title is a ruse and Jameson's analysis is biased in its understanding of fascism as well as its selection of Lewis's works. Terry Eagleton in his Criticism and Ideology takes a closer look at Eliot's The Waste Land. While Eagleton's analysis is generally shrewd, he further cements the common argument that 
'the 'form' of that poem is in contradiction with its 'content". ${ }^{11}$ Both studies are valuable for reinserting 'ideology' into literary studies, but they should not be treated as the final word on the topic. First, some studies like Jameson's seem to suffer from crucial methodological flaws, which distort the analysis. Secondly, written from a Marxist perspective these studies approach fascist and right-wing ideology respectively from a very specific ideological angle and this is rarely reflected upon. Since it is impossible, so I would argue, to approach the topic of ideology in literature from an objective, i.e. ideology-free, standpoint, there is a need for a diverse range of studies on the subject. However, despite the prominence of the writers and the significance of right-wing ideology, especially fascism, the debate seems listless and has continued to lose its drive in recent years. Some of the most productive new approaches to literary studies, such as gender, queer and postcolonial studies have in part passed over these representatives of the 'white male heterosexual order'. While it is understandable (and undeniably relevant) that these new critical approaches have largely focussed on marginalised, oppressed, and ostracised voices, it is precisely their critical approach that is needed to dissect Eliot's, Pound's and Lewis's ideology along the lines of gender, race, and sexuality, as these three categories are significant in the assessment of (especially rightwing) ideology. Another category that has been constantly overlooked, despite the Marxists' investment in the cause, is that of class. While it is true that class is an important category in Marxist studies, this approach has often produced a simplified assessment of its role in literature with a focus on Marxist class binaries and capitalism. While this is not to suggest that the Marxist point is moot, there is an argument to be made that the category of class deserves an approach similar to other critical movements such as gender studies. This is particularly relevant for literary works that come out of a tradition and society with very rigid ideas of class and a problematic approach to the lower classes even among its left-wing authors. ${ }^{12}$ The category of class has to be, in accordance with other categories, recognised as constructed and at the same time its very real ramifications have to be understood and made visible. This prefigures that an intersectional approach would further enhance the debate.

This study cannot fill all the gaps that have just been enumerated. What this study is trying to do is to take the critical approaches and insights of gender, queer, and postcolonial studies, as well as bring in the category of class, and apply them to the works of Pound, Eliot, and Lewis to illustrate the significance of right-wing ideology for their literary creation. Hopefully this will also initiate a new cycle of critical studies on these writers. Additionally, this study argues for a reassessment of the role of right-wing ideology for the Modernist project in general, and these three authors in particular. The Modernism of Pound, Eliot, and Lewis did not develop in spite of their reac- 
tionary politics, but in harmony with them. Contrary to what Eagleton claims, style and content do not stand in conflict with each other, but augment each other. Moreover, many of the stylistic features of their Modernist writing are directly linked to violent discursive practices such as racial and class appropriation. Crediting the literature these men have produced means coming to terms with the right-wing ideology that influenced them as well as a social context that sanctioned many of these practices and discourses. Looking at the context in which these men wrote also reveals the literary parallels between Pound's, Eliot's, and Lewis's writings and those of like-minded writers in Britain and on the continent. It would be seriously misguided to ignore the rich reservoir of prejudices, imagery, and concepts that sustained these writers, while, in turn, the manifold repetition of these elements maintained the reservoir. The right-wing elements in the literary works of Pound, Eliot, and Lewis are not accidents that can be ignored or explained away but have to be understood as central to their literary endeavour. Right-wing ideology played a crucial role in these men's literary productions and thus has to be credited, even if reluctantly, as part of the Modernist movement

While the first and major part of this book will offer a literary analysis of works by Pound, Eliot, and Lewis, the shorter second part will illuminate a hitherto neglected topic: the reception of literature by today's far right. The insufficiency of the academic debate on the topic of right-wing ideology and literature has created a vacuum the Right is eager to fill with their own narrative. Creating a counter-canon, the Right has tried to establish an alternative intellectual history, which features many notable writers and artists, who are included on account of their art as well as their politics. These developments have not yet come under scrutiny of academic studies despite the recent surge of the (far) right in the West. This oversight might be due to the still prevailing notion that the far right has no intellectual tradition. This would explain why the interdependencies of right-wing movements and pop-cultural phenomena like rock music, the metal scene, and, more recently, meme culture have been studied far more extensively. While the importance of online culture for the far right's agenda cannot be overstated, the intellectual arm of the far right increasingly relies on an image of respectability and thus high culture. The evocation of a rich intellectual heritage does not only support the claim to respectability, it also offers an ideal platform to attack liberal elites and their supposed cultural hegemony. By subverting the notion of the Left's cultural dominance while exploiting the gap left by the inadequate academic responses to the topic, the far right has found an ideal way to enter the discourse. This study will take a closer look at a number of outlets, movements, and individuals of the far right in the U.S., Britain, Germany, and Italy to show how they construct a distinctly right-wing literary tradition. What 
should be added is that the intent of this study is not to celebrate the cultural legacy of right-wing ideology. On the contrary, it wants to make visible and problematize the interdependencies of right-wing ideology and cultural production in order to explain the (far) right as a phenomenon deeply rooted in Western history and cultural development. By treating (far) right-wing ideology seriously as an ideology with an intellectual tradition, this study will produce a deeper understanding of a phenomenon that has all too often been simplified and distorted instead of analysed and explained.

To approach the issue in a meaningful way, this study will proceed as follows. First a detailed theory chapter will address the phenomenon of rightwing ideology. Judging from previous studies on the subject, it is uncommon for a literary study to dwell extensively on issues outside the realm of its usual subject matter. Yet, there is a danger in relying on a silent agreement over ideological terms like 'right-wing', 'fascism', and others. Crucially for a study on literature, one would lose the precision necessary for a detailed close reading. Moreover, it would obscure the fact that all of these terms are highly contested. Not only do these terms have differing definitions, but the process of defining a term like 'right-wing' or 'racism' is a highly ideological act that can reflect and/or perpetuate certain power dynamics. Addressing the complexities behind the concepts used in this study does not eradicate these problems but it makes the process transparent. Furthermore, related concepts such as fascism, Nazism, and anti-Semitism will be given due consideration. 'Rightwing' can have different meanings in different contexts; this will be taken into account as well as the historical trajectory of the concept. While I would argue that the core of right-wing ideology has been remarkably stable during the last two centuries, it is important not only to assess its specific permutations during the lifetimes of the three writers analysed here, but also to contextualise right-wing ideology in the power dynamics of its time. What follows are three analysis chapters, each devoted to one author. For each author I have selected one representative main text, which will be supplemented by a range of secondary texts, both literary and other. The aim of these analyses is not to pick the passages that may cause offence, but to show that a right-wing structure lies beneath the text itself, a structure that informs all of its components, with those offending passages (which are mostly very well known) only being the most crass and visible examples. The term 'right-wing structure' in this context means a system of meaning-production that relies on and promotes rightwing ideology and which influences content (what is being said?) as well as form (how is it being said?). My argument that key Modernist texts by Pound, Eliot, and Lewis are based on a right-wing structure implies that they can be read as part of a certain discourse. More crucially this would also mean that some of the stylistic innovations of Modernism can be traced back to a right- 
wing structure. The Modernism of Pound, Eliot, and Lewis has to be understood not only as a reaction against older traditional modes of writing but also as a response to the political landscape they found themselves in. Thus, literature could be used to usher in a new fascist millennium, as in Pound's case, or defend established hierarchies against societal change, as in Eliot's case. The fact that this ideological baggage remains potent long past its publication will be the focus of the last part of this book. While an explicit counter-canon set by the Right is certainly not a new phenomenon, there has been an increasing return to specific 'right-wing classics' in recent years. This study is taking a closer look at the reception of Pound, Eliot, and Lewis by today's far right to assess the role of canonical literature in the ideological discourse. Curiously, although the issue of 'right-wing Modernism' would offer a fertile ground to launch an attack against the so-called liberal mainstream, writings on the topic are often marked by an inward gaze and offer little antagonistic force. Produced by the far right for the (far) right, these responses serve as internal validators' both upholding and creating a narrative about who the far right is or wants to be. Looking at right-wing reception of Modernist texts offers a glimpse into the potency of the ideological structure that is so often denied or overlooked by 'conventional' academic scholarship.

When I began my work on this project the topic seemed to many interesting but distant. The far right, so often back then deemed the lunatic fringe, did not appear to be a threat to the mainstream discourse. After all, a resurgence of the far right did not fit the self-image of many Western democracies. Nevertheless, in more and more Western countries the Right is on the rise again. The reasons for the resurgence of the (often populist and far) Right have often been sought in the political, economic or social realm. In this way the right-wing revival is seen as a reaction against multiple transformations that seemingly disturb traditional set-ups. The cultural realm is frequently dismissed as something that 'merely' represents and reflects its surroundings. Yet this reductive approach overlooks the capability of cultural artefacts to create knowledge, power structures, normalcy, and deviancy. One repeatedly overlooked reason for the (after all not so unsuspected) resurgence of the Right is the fact that right-wing ideas and ideals still occupy a central role in many cultural products that are consumed and revered by the mainstream and establishment of many Western societies. Looking at the interdependencies of right-wing ideology and Modernist writing does not merely reveal the reactionary politics behind the experimental façade (for this fact alone is quite well known) but addresses the impossibility of divorcing the artwork from its inherent ideology. In the case of right-wing Modernism this proves to be a boon for the (far) right but a dilemma for everyone disagreeing with rightwing politics. Yet in times of the Right's ascendancy, the response can no 
longer be evasion of uncomfortable arguments. Likewise though, censoring offending material cannot be an adequate answer to the task at hand. Instead what is needed is a nuanced analysis of the role of right-wing ideology in Modernist literature and in turn an evaluation of the role of Modernist literature for today's (far) right - without censure but with critical meticulousness and this is what this study sets out to do. 


\section{LOOKING AT THE F-WORD AND BEYOND}

A book on the politics of Ezra Pound, Wyndham Lewis, and T.S. Eliot that eschews the term 'fascism' and opts instead for the vague 'right-wing' seems to be running away from the decades of debate that have discussed the role of fascism in these authors' lives and works. The titles that have worked on this issue have never been shy of using the f-word: ranging from Andrew Hewitt's Fascist Modernism, to Frederic Jameson's classic Fables of Aggression: Wyndham Lewis, The Fascist as Modernist, from Paul Morrison's Poetics of Fascism to Alastair Hamilton's The Appeal of Fascism: A Study of Intellectuals and Fascism, 1919 $1945 .{ }^{13}$ This trend can also be observed in publications on the same matter in other countries: from French Literary Fascism to Die Brücke ins Geisterreich: künstlerische Avantgarde zwischen Kulturkritik und Faschismus. While it is undoubtedly true that fascism played a major role in the $20^{\text {th }}$ century and arguably, has had a bigger impact on the previous century, the people who lived during its times as well as their descendants than any other ideology, the obsession with fascism has led to an oversimplification of the debate that is often more interested in determining whether someone (or something) was/is fascist or not, than to offer a nuanced analysis of the interplay between Modernism and ideology. In short, the concept of fascism has often been reduced to a binary that fits into our modern discourse on the topic (i.e. to be fascist versus anti-fascist and thus to be bad versus good). Yet this does not only lead to a simplification but also to a falsification when the political allegiances of writers and artists of the first half of the $20^{\text {th }}$ century are discussed. Paradoxically it seems that especially the central importance of fascism as a political phenomenon undermines its potential as a useful analytical category. This is furthermore exacerbated by the way the term 'fascism' has been predominantly used, as Roger Griffin has aptly summarised when he says that 'the term has predictably been passed on to post-war generations as an emotionally charged word of condemnation for any political regime or action perceived as oppressive, authoritarian or elitist'. ${ }^{14}$ Fascism can and is nowadays often used to describe anything that is strongly disliked, out of sync with its historical meaning and consequences. Not only extreme right-wing groups and movements are titled fascist but one can also find terms such as 'left-wing fascism', 'Labour fascism', 'Israeli fascism', and, popularised after 9/11, 'Islamic fascism'. The term fascism has, in most circumstances, become a synonym for evil, possibly the greatest evil imaginable, losing its specific meaning. 
What makes matters even more complicated is that despite the ubiquity of the term there exists little consensus on what fascism actually is. It is predominantly capitalist from a Marxist point-of view, while the liberal viewpoint sees it as mainly antidemocratic and authoritarian. Focussing on the ideological positions fascism opposes casts it into the role of 'the political other'. This inherent dilemma - that there is no fixed definition of what fascism actually is - should caution (literary) scholars when using the term 'fascism' and to make transparent why they are choosing one particular definition over others. But in most studies this is not the case. Stanley Payne lamented that 'the great majority of the hundreds of authors of works on fascism or individual fascist movements make little or no effort to define the term and simply assume that their readers will understand and presumably agree with the approach, whatever that may be'. ${ }^{15}$ Yet even on the basis of a carefully researched and reflected definition of fascism, the study would relapse into the aforementioned binary, i.e. the object of study is either deemed fascist or not fascist. There are a number of downsides to this, with the most grievous being that it perpetuates a schematic vision of the political field of the $20^{\text {th }}$ century into fascist versus non-fascist at the expense of understanding the political spectrum as a fluid continuum. A glance at the space of the political spectrum where fascism is located will reveal not only convinced fascists but also allies, collaborators, and bystanders, that did not necessarily see themselves as fascists or can be defined as such but - not unimportantly - tolerated, profited from, cheered, and accepted fascism, or, at least, shared common enemies. Therefore instead of focussing on fascism I wish to include its ideological neighbours, even if this means entering taxonomically slippery land. The lens through which I want to look at the works of Pound, Lewis and Eliot is the broad spectrum of right-wing ideology. While this will in the end, hopefully, result in a clearer picture of the role of politics in these authors' works, it will at first make the issue even more complicated. However, by incorporating the whole right-wing spectrum, I can offer a more comprehensive reading of the role of politics in Modernism. For the fervent debate on the possible fascist allegiance of Pound, Lewis and Eliot does not only indicate the emotional burden of fascism but also the limits of approaching Modernism through the lens of fascism only. Having the whole right-wing spectrum in mind allows me to register the fluidity and changeability of these authors' ideology over time - for example to assess the impact of the Holocaust. At the same time, expanding the scope from fascism to right-wing ideology does not eliminate the underlying dilemma that has motivated the debate on 'fascist Modernism' in the first place: the fact that these authors' works play a major part in European cultural history despite them being ideologically opposed to such values as liberty, equality, and democracy. 


\section{Right-wing ideology}

In his usual provocative manner, Terry Eagleton introduces his study on ideology by stating that ' $\mathrm{w}$ ] hat persuades men and women to mistake each other from time to time for gods or vermin is ideology. ${ }^{16}$ In his mocking tone he picks up the popular sentiment that ideology is often negatively connoted, namely as a distortion of truth. Ideology, so many people believe, is synonymous with misguided and false thinking. Consequently, by understanding ideology in exclusively negative terms, it is most often ascribed to the political adversary, assuming that it is ideology that keeps them from seeing the facts plainly. However, as is often the case with political concepts, the term ideology has many, partially conflicting, meanings. Coined at a time of political upheaval, namely during the French Revolution, Antoine Destutt de Tracy saw the term primarily as the science of ideas: 'For de Tracy the aim of ideology was to establish a solid and unquestionable method by which correct ideas could be scientifically identified so as to foster the use of reason in the governance of human affairs for the betterment of society as a whole. ${ }^{17}$ Simultaneously its more widespread meaning of ideology denoting a set of false ideas also gained currency. Today the term has lost little of its relevance, yet it still polarises when one asks what it actually stands for, as Eagleton demonstrates by listing sixteen different definitions ranging from ideology as 'the process of production of meanings, signs and values in social life' via 'systematically distorted communication' to 'socially necessary illusion' and others. ${ }^{18}$ In contrast, in the 1960s some scholars, led by Daniel Bell, had already proclaimed the end of ideology and the collapse of the Soviet Union seemed like a further vindication of their theory. ${ }^{19}$ Reading Bell's study it becomes clear that he adheres to an understanding of ideology that pitches ideological politics against civil politics. ${ }^{20}$ Ideology, writes Bell,

deals with social movements that seek to mobilize men for the realization of such beliefs ['the political expression of eschatological creeds played out in secular terms'], and in this fusion of political formulas and passions, ideology provides a faith and a set of moral certitudes [...] by which ends are used to justify immoral means. ${ }^{21}$

When used by movements in power, Bell continues, 'ideology becomes a coercive force used by the rulers to maintain conformity'.22 In Bell's definition ideology has an obvious negative connotation and seems closely tied to the totalitarian movements of the $20^{\text {th }}$ century. This kind of ideology was replaced in the West, according to Bell, by a 'focus, within a framework of liberal values, on problem solving as a means of remedying social ills and inadequacies'. ${ }^{23}$ Bell's binary model does not allow him to see liberalism as yet another ideology and 
thus Bell can comfortably announce in the introduction that his perspective is 'anti-ideological, but not conservative'. ${ }^{24}$ As Eatwell and Wright note 'Bell and other "endists" soon came under fire for posing as objective observers while they were themselves deeply ideological: they "were really American propagandists, using apparently, objective social science and philosophical methodology to legitimize their own beliefs and political system'. ${ }^{25}$ Ideology remains a highly relevant and controversial subject. Yet Bell et al.'s core idea, namely the assumption that there exists a neutral, objectively correct standpoint from which ideology (usually someone else's ideology) can be assessed, has proven remarkably stable.

The opposition between ideology and objectivity is a construct that is very often upheld to legitimise power structures. Refusing to acknowledge one's own ideological position is not a way to escape ideology, it only further entrenches it. This has important ramifications for academic studies and any fields of knowledge production. For the way in which ideology is addressed (if it is addressed at all) in literary studies is in itself an ideological act. The reign of New Criticism, for example, has long hampered detailed analyses of ideology and literature. What made this more poignant is that New Critics did not lack interest in the links between Modernism and right-wing ideology, but were complicit in the ideology many of these works espoused. Trying to situate literature outside ideology, helps to make those works unassailable, and, in turn, their ideology unassailable. As a consequence, those who address ideology in literature, especially those who problematize right-wing ideology, are frequently brandished as emotional activists with an agenda as opposed to the unbiased academics coming to the authors' defence. ${ }^{26}$ Refuting arguments like these with textual evidence is nigh impossible, for every new claim would just add further proof to their underlying assumption. What bears repeating is that those who claim to be free of ideology are in some ways just complicit with the ideological position in question.

In fact, we are all bearers of ideologies. I concur with Michael Freeden that "[i]deologies [...] map the political and social worlds for us. We simply cannot do without them because we cannot act without making sense of the worlds we inhabit. ${ }^{27}$ Yet, we seldom make ourselves aware that we interpret the political and social world through ideology. Already T.E. Hulme identified that ideology is often invisible to its bearer:

They ['these unexpressed major premises'] are unperceived because they have become so much part of the mind and lie so far back that we are never really conscious of them at all. We do not see them, but see other things through them, and consequently take what we see for the outlines of things themselves. Blue spectacles making a blue world can be pointed out, but not these pseudo-categories, which lie, as it were, 'behind the eye'. ${ }^{28}$ 
Consequently, ideology constitutes a set of ideas that are simultaneously analytic and creative. In this I agree with Freeden and also Martin Seliger who understands ideologies as mixtures 'of analytic and descriptive statements on the one hand, and moral and technical prescriptions on the other'. ${ }^{29}$ Ideology helps us to make sense of the world around us and at the same time to shape the world we live in by basing our actions on our interpretation of the world. Ideology is a moral narrative that acts as a filter and a lever. In a first step it decodes the cues we are confronted with on a daily basis, with the significant part being that the decoding process works in a way to make the processed information logical or meaningful. In a second step ideology becomes the catalyst for action based on this decoding. Although all individuals see the world through the filter of ideology, they do not have individual ideologies but rather adopt a pre-existing ideology (even if slightly modified) that belongs to some sort of group. In that way, ideologies are what Eagleton calls 'unifying..$^{30}$ Sharing an ideology, i.e. agreeing on an interpretation of the world and on a way to change it for the better, lends not only unity to a group but could be seen as to actually form the group and its identity out of its diverse members. In this way it influences not only the group itself but also how this group and its members are perceived from the outside and interact with others. When I am using a broad concept such as 'right-wing ideology' it is especially the unifying feature that seems troubling to some as it may suggest that everything from conservatism to fascism forms a unified homogenous group. This is not the case; however, I would argue, that there is a shared core to all right-wing sub-ideologies that makes them partially related. Additionally, ideology offers its bearer coherence, uniting various concepts into a meaningful logical narrative about the world. This does not mean that ideologies do not suffer from internal contradictions but they seldom manage to threaten the construct as a whole. A common, conscious or unconscious, strategy to secure or strengthen internal coherence is the reference to the ideological other'. For the Right the ideological adversary is naturally the Left.

The ubiquity of the terms 'left' and 'right' in the political context sometimes obscures the curious fact that we use spatial metaphors to denote political concepts. Despite taking their names from a distinct spatial context, namely the seating arrangement in the National Constituent Assembly, it is noteworthy that 'left' and 'right' have remained the dominant terms for the two main political sections in Western societies. This matters because the spatial metaphors 'left' and 'right' do not possess any inherent ideological meaning, which surely had an impact on the proliferation of differing definitions of the Left and the Right. However, in the beginning both terms clearly signified a specific political position as they were first coined during an assembly on the topic of human rights: on the right sat the defenders of the monarchy and 
adversaries of the Revolution, on the left the supporters of the republic and the Revolution. ${ }^{31}$ The Declaration of the Rights of Man and of the Citizen despite not including women and not revoking slavery - lay the groundwork for the birth of the concept of political equality and has to be understood as a fixed reference point for both Left and Right. This still holds true even though the demarcation line between the Enlightenment and the AntiEnlightenment was less clear-cut than often imagined. In fact many positions advanced by thinkers of the Enlightenment would find ample support from today's Right. In terms of race, class, and gender the philosophes often remained within the established discursive frames of hierarchy and inequality. ${ }^{32}$ Without wanting to simplify the Enlightenment too much, the new age of reason was to be heralded in by white middle class men of genius. Women, people of colour, and the lower classes had at best a supplemental role in this endeavour. Thus one could argue that conventional Western political narratives of 'left' and 'right' do not trace back to the Enlightenment but rather to the myth of Enlightenment. By positioning the Enlightenment as the birthplace of modern liberal democracy as well as its inherent values and pitching it against then existing forms of power and knowledge production (the monarchy and the church), helped to define the boundaries of Left and Right. The myth has enabled parts of the democratic liberal Left to see themselves as the successor of a long line of moral superiority. But is has also benefitted the Right by allowing them to pose as the disempowered victim in a society that has still largely left traditional power dynamics and inequalities intact. It is a testimony to the power of this myth that the left/right dichotomy has become a staple of political debate. However, a critique of the left/right dichotomy was already voiced in the beginning of the $20^{\text {th }}$ century - most interestingly by fascists who considered their politics 'neither left nor right' and socalled Querfront strategies in Weimar Germany. ${ }^{33}$ Furthermore in recent times it has often been challenged on account of its supposed inability to mirror the current political landscape with its steadily shifting allegiances. Despite this critique and caveat I want to uphold the left/right dichotomy. Norberto Bobbio, one of the most popular contemporary supporters of the left/right dichotomy, argued that there is probably no better proof for its validity than

the presence, even where there is pluralism, of a left wing which tends to perceive the centre as the right wing in disguise and a right wing which tends to perceive the same centre as a cover for the left which does not wish to show its true colours. ${ }^{34}$

What this quote quite forcefully shows again is how much political discussion is shaped by perceived binaries. As Teun van Dijk reminds us in his study on ideology 'there are few words in the language that may be as socially and ideologically 'loaded' as a simple $w e$ ', which is explained by ' $[t]$ he close relationship 
between group identity, identification and ideology'. ${ }^{35}$ There are three reasons why I think the left/right dichotomy should not be too hastily discarded. First, it underlines the importance of the 'imaginary self for ideologies. By 'imaginary self I mean the in-group that is subsumed under the term 'we'. This sense of self is partially established in opposition to 'the other'. Frequently 'the other' covers a plurality of groups and identities, whose unifying principle is that they are not part of the 'imaginary self. In National Socialist Germany the Volk served as the 'imaginary self, an identity that was mostly constructed on racial boundaries and health. Furthermore non-allegiance to the regime could cast individuals from the in-group and turn them into 'the other', here specifically into Volksverräter. Secondly, the left/right dichotomy allows to collect diverse but related mind-sets under one term. This is especially important when one notes that studies on ideology often treat different ideologies (conservatism, fascism, socialism etc.) as separate entities, when it is obvious that '[i]deologies are not hermetically sealed: they have porous boundaries and will frequently occupy overlapping space ${ }^{36}$. Thirdly, it draws attention to the core values of ideologies. Looking for a shared core will make the 'overlapping spaces' more visible and it guards against oversimplified readings that equate the extreme ends of the binary, as the horseshoe model does. ${ }^{37}$

The core value of right-wing ideology, so I would argue, is inequality, or more precisely the belief in and promotion of inequality. This should not be confused with recognition of inequality as it manifests itself in a given society. For the Right inequality is an ideal; for the Left it is a social construct that needs to be eradicated. Especially for right-wing extremism many scholars agree that 'inequality' (usually coupled with other qualities) lies at the heart of it. ${ }^{38}$ I wholeheartedly agree but would like to enlarge the scope and see inequality - to varying degrees and in different shapes and sizes - as the basis of the whole right-wing spectrum. Thus the left/right dichotomy reflects the binary of equality versus inequality and different ideologies can be located on the spectrum by their position towards inequality or equality. The concepts of inequality and equality determine ideas of the 'imaginary self': who is considered inherently part of it? and who can (and cannot) become part of it? In the case of right-wing ideology this leads to exclusionary discourses and practices. The 'imaginary self is furthermore an important determinant as its wellbeing - the more alarmist term 'survival' is especially popular in right-wing discourses - is the motivator for ideological action. Secondly both equality and inequality pertain to ideas of hierarchy and power. ${ }^{39}$ Furthering equality often means levelling hierarchies and power imbalances. On the contrary, promoting inequality means establishing and strengthening hierarchies and power imbalances, again in an effort to benefit the imaginary self. In short right- 
wing ideologies revolve around the core concept of inequality, promoting exclusionary strategies and reinforcing (power) hierarchies to benefit the 'imaginary self' against 'the other'.

A shared core does not mean that these strands are synonymous - although there are overlaps in some parts - nor that they necessarily agree on means and ends or who constitutes the imaginary self. Yet they all rest on the assumption that an endorsement of inequality is for the benefit of the imaginary self. What comes into play here are also the different modes of action: a right-wing ideology can opt for conserving a status-quo, intrasystemic change, or extra-systemic change. The method determines the position between centre (conserving the status-quo) and fringe (extra-systemic change). Right-wing ideology that favours intra-system change is often oscillating between centre and fringe and therefore difficult to grasp in taxonomic terms as has become obvious in the dilemma how to label (and subsequently, how to treat) the different populist movements that have sprung up in the Western world in recent years. Moreover, some terms pertaining to the Right can be both read as either mode of action or value based. 'Reactionary' and 'revolutionary' are often used to describe modes of action, when they originally referred to the seating arrangement in the National Constituent Assembly designating the side in favour of the Revolution as well as its tenets and on the other its adversaries. ${ }^{40}$ To avoid confusion, I will use reactionary in this book to signify anti-Enlightenment values, while 'revolutionary' will be used as a mode of action, more precisely a mode that exalts in a perpetual forward movement or that strives for a complete system change. When Benito Mussolini claimed 'I am a reactionary and a revolutionary' he positioned himself at the revolutionary end of the anti-Enlightenment tradition, or, in short, in the fascist camp. ${ }^{41}$

\section{Fascism and Nazism}

Despite my avowal in the beginning that I have no intention to solely focus on fascism due to its foreseeable pitfalls, no discussion of right-wing ideology would be complete without it. There are two reasons why this will be useful and necessary. Although I intend to work with the whole right-wing spectrum in order to locate my selected authors in a more fluid continuum, there is no doubt that fascism is undeniably part of it. Moreover Pound and Lewis were (at least temporary) adherents of fascism, self-proclaimed and in Pound's case active supporters. While I previously deplored the fact that the term has become a loose cover-all term, an insult rather than an apt description, I have 
yet to offer a more precise definition. Indeed, fascism is 'a term that notoriously resists definition', ${ }^{42}$ sometimes resulting in 'the denial that any such general phenomenon as generic fascism can be defined'43. Yet despite this resistance to definition, there are, in fact, a great number of varied and even conflicting definitions. The term's many (conflicting) definitions also hail from its inherent meaninglessness: it is, after all, a signifier without a signified, or rather a signifier for another signifier. ${ }^{44}$ Hence, the universal stylisation of fascism as 'the political other' seems to be the smallest common denominator. ${ }^{45}$

My aim is to define fascism as a political phenomenon in its own right, which means I do not want to explain fascism by showing what it is not. In fact, I agree with Zeev Sternhell who writes that 'one should not exaggerate the "anti" quality of fascism'. ${ }^{46}$ Furthermore, Sternhell brushes aside a variety of other 'too-simple' definitions, a move I equally support. Thus, fascism is neither 'a sort of shadow cast by Marxism', nor 'only a form of antiliberalism', nor 'a "variety of Marxism", nor 'a simple anti-proletarian reaction that took place at a stage of declining capitalism'. ${ }^{47}$ All these consider fascism either as a co-agent or as an aberration of another larger phenomenon instead of a selfcontained movement that has sprung from a distinctive tradition. Similarly, limiting fascism to its anti-qualities does not only support the construct of fascism as 'the other', but also pretends that fascism consists exclusively of negative values. Yet it is vital to acknowledge fascism's affirmations (in contrast to its rejections) to fully understand its scope and attraction. My second premise for defining fascism is to regard it as, in Sternhell's words, 'an independent cultural and political phenomenon that was not less intellectually self-sufficient than socialism and liberalism'. ${ }^{48}$ Taking fascist ideology seriously is a heavily debated practice. Griffin and Paxton both agree that 'the real nature of fascism'49 can best be deduced from fascist actions and not fascist ideas. ${ }^{50}$ Griffin lists three basic objections: taking fascist ideology seriously would distract from (i) its historical contexts and preconditions, (ii) its intellectual inferiority, and (iii) the immense human suffering it has caused. ${ }^{51} \mathrm{In}$ fact, Griffin explicitly criticises scholars who take fascist thought seriously due to the "[grave] danger of generating misleading impressions about the nature of fascism'. ${ }^{52}$ However, the supposed intellectual inferiority of fascism stands in contrast to the large number of intellectuals and artists, who were interested or invested in fascism. Taking fascist ideology seriously can reveal how well many of its ideas resonated with theories, art movements, and intellectuals in general. What drove writers and artist into the fascist camp were not fascist actions, but primarily fascist ideas. I am not arguing to focus on ideas instead of fascist actions, but want to show how ideas and actions are inextri- 
cably linked. In this way, taking fascist ideology seriously does not assuage its crimes and atrocities - they stand unchallenged.

Rethinking fascism also means reconsidering its conception. Fascism was not born in 1919. Mussolini did not give birth to fascism. All he did was to put a new name tag onto a philosophical concept that had been developed for more than a hundred years and had been shaped by many thinkers, politicians, and, indeed, artists. Fascism 'before it became a political force, was a cultural phenomenon'. ${ }^{53}$ This observation is important precisely because it shows that fascism proper was not a rejection of twentieth century politics, but a rejection of the world-view that had been established during the Enlightenment and on which the current liberal system based itself. Many scholars (such as Griffin and Paxton) readily point to the fact that fascism did not bring forth a coherent ideology. However, this is not because fascist groups from Mussolini's Fasci di combattimento onwards did not think it necessary, but due to the fact that the essential ideology, i.e. what would then by slight modification become fascist ideology, already existed. Most of the core tenets of fascist ideology were neither new, nor a product of the cultural or political reality of the twentieth century, nor a reaction to it; instead, they were/are a continuation of the ideas of the Anti-Enlightenment tradition. ${ }^{54}$

Similar to attempts to define other right-wing strands, scholars often resort to listing fascism's characteristics. Payne offers a typological description with thirteen qualities organised in three categories, Paxton lists nine 'mobilizing passions'. ${ }^{5}$ Whilst Payne's and Paxton's check lists offer valuable additions for interpreting fascism, they disregard the core of fascist ideology in favour of comprehensiveness. Griffin's search for the nature of fascism brings up the exact opposite, a concise definition:

Fascism is a genus of political ideology whose mythic core in its various permutations is a palingenetic form of populist ultra-nationalism. ${ }^{56}$

I consider this to be more useful than Paxton's or Payne's definitions since it highlights the revolutionary core of fascist ideology while at the same time evoking Classical key concept. Nevertheless, I would rephrase Griffin's idea of palingenesis as the fascist minimum. Instead, I believe the core of fascist ideology to be the myth of permanently overcoming decadence. Palingenesis implies a passive renewal, like the birth of a new society out of the ashes of the old order. Fascism with its endorsement of violence centres on the idea of actively destroying the old order. Violence is not only seen as a means to support fascism's revolutionary agenda, but also as an end in itself, i.e. as an expression of vitality and valour. The fascist revolution was/is meant to be brought about by an elite of 'new men' who will enlist the nation in their struggle for a change of systems. The myth of a permanent overcoming in- 
cludes fascism's revolutionary core, its endorsement of violence, and the idea of myth, as well as the attack on (perceived) decadence. Furthermore, in fascist ideology, a continuation of the theories and concepts of the antiEnlightenment tradition can be found. The fascist mind-set centres on total inequality often imagined as natural, which manifests itself in the fascist claims for elitism, authority, hierarchy, and national genius. Although fascism opposes the Enlightenment's values and their modern manifestations, it is neither anti-modern nor irrational, but instead constitutes a different modernity with its own rationale. Fascist ideology in its theoretical stage (i.e. before it became a political power) had no need to compromise and could preserve its 'pure' character, this stage could be called proto-fascism. In summary, fascism is revolutionary in its character, and reactionary in its ideas.

Closely related to fascism is Nazism. Often fascism serves as the more general term that can be applied to the Italian as well as the German model or any other permutation. As I have explained above my definition of fascism looks at the idealised political phenomenon rather than at an actual movement. In contrast when talking about Nazism I refer to a specific form of fascism in a certain location (Germany) during a certain time (1933-1945). It includes ideology but also the actions that have sprung from this ideology. In essence Nazism is comparable to fascism as defined above. The significant difference is the marked emphasis on an amalgam of anti-Semitism, 'scientific' racism, and völkisch nationalism, which led to the concrete purging of its internal enemies, especially the Jews, first as a means to establish a homogenised Volk and later as an end in itself. Despite many post-war denials there is an evident continuity from the abstract demands to purge Germany from the Jews and Jewish influence due to their/its parasitical character ${ }^{57}$ made available to a large public in Hitler's Mein Kampf ${ }^{58}$ to the actual exterminatory practices of the Holocaust. Nazism has become the ultimate embodiment of right-wing ideology taken to its utmost extreme. As the most deathly and devastating incarnation of right-wing extremism, Nazism became the historical as well as the symbolic backdrop against which Eliot, Pound, and Lewis had to position themselves. Their responses, from acquiescence to embrace, illustrate just how accepted Nazist ideals - such as anti-Semitism, eugenics, lethal chambers and euthanasia - were in the midst of society, even in Britain. ${ }^{59}$ When the National Socialists put these concepts into practice they also exposed these concepts' inherent inhumanity, which before had often been cloaked in sophisticated language and scientific terms. It is a testament to the power of language that things that are downright offensive and detestable to all but few in real life can become acceptable or agreeable when put into the right kind of words. Although Eliot, Pound, and Lewis all lived to see widespread disclosure of the full extent of the Holocaust, readers will find little 
testimony in their works that something significant had happened which would necessitate any reflection upon their parts. They were not alone. When confronted with the horrors of the death camps many German people replied with the now infamous phrase 'Wir haben es nicht gewusst'. ${ }^{60}$ Indeed, many people all over Europe fell back to the comfortable position of not having known what had been happening in Germany. ${ }^{61}$ In this way, Nazism, and especially the Holocaust, acted as a caesura in the European consciousness. The idea that the $20^{\text {th }}$ century can be divided into a pre- and post-Auschwitz phase can be found as an implicit claim in many studies on the politics of Eliot, Pound, and Lewis whenever their anti-Semitism and adherence to right-wing ideology is downplayed as something that was ubiquitous and resulted in no harm. One argument in particular is often brought into the debate, namely that it would be unfair, or at least distorting, to assess pre-Holocaust extreme right-wing ideology and anti-Semitism the same way as their post-Holocaust counterparts. While it is true that contemporary anti-Semitism and right-wing extremism (including Holocaust denial) with the actuality of the Holocaust in mind have a different kind of severity, the insistence of their incomparableness distracts from the fact that it were these modern, historically grown, sentiments ranging from extreme right-wing anti-Semitism to mild forms of it that made the Holocaust possible in the first place. In the long shadow of the Holocaust, anti-Semitism has become the most contested ideological element, especially in the writings of Eliot and Pound. Due to its central role in Nazism it also has sometimes become synonymous with right-wing extremism, which simplifies a complicated phenomenon with a long history and a distinct British home-grown version.

\section{The matter of anti-Semitism}

While anti-Semitism is often central to ideologies on the Right, not every antiSemite is automatically also right-wing. Especially the on-going debate about the Israeli-Palestinian conflict has triggered many responses that move uneasily between criticism of Israel's Settlement Policy, anti-Zionism and antiSemitism. Moreover, the stereotype of the capitalist Jew, enriching himself by exploitation, still serves as a handy scapegoat among the anti-capitalist Left. Accordingly, Anthony Julius identified anti-Semitism as a

repertoire of attitudes, myths, and defamations in circulation at any given time. It is a kind of discursive swamp, a resource on which religious and political movements, writers and artists, demagogues, and the variously disaffected, all draw, without ever draining. ${ }^{62}$ 
To see instances of anti-Semitism in Modernist writers as fool-proof validation of their right-wing tendencies is a simplification at best. Therefore, I will show throughout my analysis how their anti-Semitism ties into their rightwing ideologies and also, equally important, which differing roles antiSemitism plays for these authors. To do so, I now introduce a short definition of anti-Semitism and explain how and where it fits into the right-wing spectrum.

In his study on anti-Semitism in England, Julius identifies four kinds of enemies of Jews, with only one being linked to anti-Semitism. Julius wants to clarify 'that while every anti-Semite is an enemy of the Jews, not every enemy of the Jews is an anti-Semite'63. The boundary between both types is blurry. he differentiates between rational voluntary, rational involuntary, opportunistic, and, most importantly, irrational enemies. ${ }^{64} \mathrm{It}$ is the latter group that, in Julius's opinion, should be described as anti-Semitic. He goes on to specify that

...Jews have enemies to whom their Jewish character is determinative, but whose enmity does not derive from opposition to any genuine Jewish project or stance. The hatred of these enemies mostly derives from imaginary grievances, imputed to an imaginary collective identity, 'the Jews' or 'Judaism' [...]. Their enmity is determined not by Jewish projects but by their own projections. Jews become the bearers of these irrational projections. ${ }^{65}$

In addition, anti-Semitism is further fuelled by a reversion of the victim/enemy dichotomy:

They [anti-Semites] suppose themselves to be innocent, victimized, and under siege, and the Jews, guilty persecutors intent upon their domination or extermination. [...] The Jew is the 'aggressor', the 'real enemy'-whether in the guise of banker, newspaper proprietor, revolutionary, or Zionist ${ }^{66}$

It is obvious how certain publications such as the infamous Protocols of the Elders of Zion ${ }^{67}$ fed this belief, despite the fact that it did not take long to expose the writings as fake. The idea of a Jewish conspiracy (for world domination) continued after the Second World War and even after the public announcement of the Holocaust, which proves not only its tenacity, but also shows how detached the idea is from events in the past and present. Julius argues that it was mainly the fact that 'Jews were taxonomically slippery'68 that led people, in an age when racial classification and eugenics were in their prime, to regard Jews as a threat, precisely, because they could not be classified. This imagined threat very soon paved the way for conspiracy thinking, which has remained at the heart of anti-Semitism. Based on Julius definition, it would be important when looking at the literary texts in questions to decide whether the Jewish figures serve as 'bearers of irrational projections' or whether 'antiSemitism [is exploited] for literary effect-[with the Jew as] the available vil- 
lain, the ready trope' (a form of the opportunistic enemy). ${ }^{69}$ Yet in literature the dividing line might be slim and open to interpretation, for a seedy Jewish literary figure could be both the ready trope and a bearer of irrational projections. To circumvent this problem I want to add Zygmunt Bauman's definition, which highlights the fact that anti-Semitism is not only an attitude but also a practice: “Antisemitism' stands for the resentment of Jews. It refers to the conception of the Jews as an alien, hostile and undesirable group, and to the practices that derive from, and support, such a conception' ${ }^{70}$ Julius describes the inner logic of anti-Semitism, while Baumann also highlights the dynamics of anti-Semitism. It is especially the second part of Baumann's definition that will be useful for literary analysis as it shifts the focus from motive to practice. If literature is read as a practice, a written interaction, and less as the mirror of the author's mind, anti-Semitism in literature goes far beyond intentions of maliciousness, which are hard to prove anyway. On the other hand Julius's distinction between irrational and opportunistic enemy helps to classify anti-Semitism in conjunction with the particular literary tradition into which the text inscribes itself. To consider how the use of clichés and prejudiced representations derives from and supports an anti-Semitic discourse offers an analysis that is open to interpretative variety but immune to apologetic attempts to downplay anti-Semitism.

Both Julius's and Baumann's definition do not specify where antiSemitism is located in the political spectrum. Indeed, if anti-Semitism is open to everybody, what then is characteristic of right-wing anti-Semitism? History shows that there is a special connection between anti-Semitism and right-wing ideologies, with Nazism as its most extreme example. Yet there are also instances that complicate the picture: Arthur de Gobineau, the founder of racial classification, was not anti-Semitic, ${ }^{71}$ also Mussolini's Fascist State was, at first, not anti-Semitic, it even had Jews working in its government. ${ }^{72}$ This changed when the German-Italian Axis strengthened its collaboration. The key here is how Jews were or are classified. As mentioned above, with Jews being 'taxonomically slippery', it was up to a point open for debate in rightwing ideologies whether Jews were classified as part of the 'imaginary self' or 'the other'. ${ }^{73}$ As a result of this 'slipperiness' the Jews, in right-wing antiSemitism, were imagined to possess protean qualities. In right-wing antiSemitism, so I would argue, the Jews - as a plural entity - are not viewed to have stable qualities and attributes - besides having a powerful detrimental influence. They are seen as continually shape-shifting but remain in their entirety at the core 'the other', usually based on a key category such as religion, race or culture. This explains why right-wing anti-Semitic propaganda can depict Jews with a range of contradicting qualities and still make sense to its recipients. Of course, when looking at National Socialism, in particular, we can 
also find very prosaic additional motives for anti-Semitism, economic jealousy for example. ${ }^{74}$ Yet it is the imagined shape-shifting quality of the Jews that made them the ideal scapegoat, who could still be seen as a threat after being dispossessed, incarcerated, starved, and close to death.

In Britain, anti-Semitism took on a singular development. As evidenced by the continuing presence of Jews in literature, anti-Semitism lived on even after the Jews were expelled from Britain in $1290 . .^{75}$ This demonstrates that prejudice can survive without the object of said prejudice being present. It is also a testimony to the power of stereotypes, which can take on a life of their own without any real world validation. In the years between 1655 and 1660 the debate about readmitting the Jews drew strong opposition until Oliver Cromwell overrode it and Jews were again allowed to settle in Britain. ${ }^{76}$ However despite Jews entering politics, earning different posts up to the rank of prime minister and serving in the British military, anti-Semitism was still widespread and up to the end of the Second World War not a taboo. Bryan Cheyette has suggested that what is particular to British anti-Semitism is that Jewish 'stereotypes derive their meaning from within a liberal tradition' and adds: 'This tradition has recently been dubbed the 'antisemitism of tolerance', which validates Jews 'not on the grounds of their Jewish identity, but on the basis of their conformity to the values and manners of bourgeois English society'. ${ }^{77}$ The term 'antisemitism of tolerance' is a paradox if there ever was one, but it may serve as a reminder why British anti-Semitism was (and in many studies still is) trivialised and repeatedly deemed harmless. If the Jew, as Cheyette suggests, can both function as 'a good self who embodies the values of bourgeois England, or a bad other who denies these values', ${ }^{78}$ the blame for anti-Semitism rests squarely on the shoulders of the Jews themselves. In this way the 'antisemitism of tolerance' seems to be almost stylised as a corrective, a force that pretends to encourage the inclusion of the other, whereas 'conventional' anti-Semitism is open about its exclusionary intentions. However, the differentiation between both kinds of anti-Semitism should not be strained too far, especially since a clear division is only possible in theory but less so in practice. If Britain's unique kind of anti-Semitism should be acknowledged, then only insofar as it stands in relation to the broader phenomenon of anti-Semitism from which it draws and simultaneously uses for validation. This does not mean that British anti-Semitism was homogenous, when, in fact 'the range of attitudes to Jews in Britain, and thus the range of responses to their persecution in Nazi Germany, was complex, and often apparently incoherent'. ${ }^{79}$ 


\section{The matter of racism}

It is obvious that racism and anti-Semitism share a common logic in that they class and divide people based on a certain category of membership. Like antiSemitism, racism is commonly associated with the Right, when, in fact, it is written into the very structures of the Western world. Racist ideas shaped large parts of Western history and Western knowledge production. Philosophical musings on the inherent inferiority of people of colour as well as the emergence of 'scientific racism' legitimised racist policies, colonialism, the slave trade, and genocide. Thus to think of racism as simply a 'primitive ideology coupled with a barbaric praxis' is to seriously underestimate its complexity. ${ }^{80}$ While the Right embrace racist ideas and actively act upon them to the point of violence, they are often protected by a society's institutions that are complicit in their racism.

Writing about right-wing ideology in literature, it is tempting to reduce racism to an individual's prejudices. Very often when racist language or depictions in literature are addressed the discussion revolves around questions of motive or whether something was intended to demean people of colour. However, similar to anti-Semitism, the way a text inscribes itself into racist discourses is a much more interesting focus. The racial figure that played a prominent part in Modernist imagination is that of 'the savage'. Highlighting the positive connotations many Modernists bestowed upon 'the savage' cannot cast aside the racist undertones. For the figure of 'the savage' always taps into racialised discourses on civilisation and evolution, turning 'the savage' into 'the other' on a binary of nature versus culture or civilised versus uncivilised. In the case of Modernism, racism in literature is less about using racist slurs (although readers encounter those as well), but more about how these texts draw from certain discourses, keeping those discourses alive. Moreover, institutionalised racism also plays an important role in an assessment of literature, especially concerning canonised writers and movements such as Modernism. ${ }^{81}$ It is no coincidence that its predominantly white writers could (and still) receive wide acclaim for borrowing and or appropriating forms and contents of non-white cultures, when the same acclaim was denied to the true originators. It is important to note that the context of Modernist writers actually encouraged racist practices, especially when they resulted in an art that was deemed exotic, strange, and, above all, new. When I analyse racial appropriation and other forms of literary racist practices, institutional racism, even when it is not explicitly discussed, always remains in the background as a force that legitimates and promotes so-called individual racism. 
Delving into some of its historical peculiarities furthermore shows how much racist ideas shaped Western thinking. According to Christian Geulen's Geschichte des Rassismus the starting point of this distinctly modern phenomenon can be placed at the time of the Spanish Reconquista. ${ }^{82}$ The Reconquista began with a Christian rebellion against the Muslim rule in Spain and lasted for a couple of centuries resulting in the complete recapture of the Iberian island and the elimination of the Muslim and Jewish communities. ${ }^{83}$ The reason why this could be seen as the birth of racism, despite the fact that we find classifications of otherness in many contexts before this is that during the Reconquista the term race was for the first time used to determine 'seemingly natural categories of belonging'. ${ }^{84}$ Since racism is nowadays always firmly associated with the (non-democratic) Right, it is important to note that racial classification played a major part in Enlightenment thinking. Racism and racial classification had a large impact on thinkers and intellectual circles later in the $19^{\text {th }}$ and first half of the $20^{\text {th }}$ century precisely because it was perceived as scientific and fact-based. Instead of turning their backs on the term 'race', many thinkers of the Enlightenment were fervent supporters of it. Moreover colonialism and segregation could for a long time coexist with liberal democracy without disturbing its underlying Enlightenment concepts of equality and fraternity. In the matter of race, the supposedly opposing factions of the Enlightenment and anti-Enlightenment tradition shared a lot of common ground. Racial classification helped to organise the universalist concept of humanity by making it possible to 'scientifically' explain differences and peculiarities among humans, thereby producing new divisions. The $19^{\text {th }}$ century saw an even greater proliferation of race theories. The most comprehensive study on the topic, Arthur Gobineau's Essai sur l'inégalité des races humaines (An Essay on the Inequality of Human Races), published between 1852-54, considered the cycle of race-war and miscegenation as a universal law of humanity. According to Gobineau, the purer a race the more advanced in terms of progress and civilisation it is. On the other hand, mixing with other less distinguished races leads to the ultimate demise of this formerly pure race. It is interesting to note that Gobineau saw both processes as natural stages in a recurring cycle as 'advanced races' would be led, spurred by their superiority, to conquer other races, which then inevitably leads to a mingling of both conqueror and conquered. ${ }^{85}$ By seeing historical development determined by quasi-biological processes, Gobineau united history with biology. In England it was mainly Herbert Spencer who promulgated these ideas. ${ }^{86}$ Theories on miscegenation and race-war also brought forth the new discipline of eugenics, founded by Francis Galton in 1883, which hoped to manipulate this 'natural process' and apart from race and class quickly included all groups it deemed inferior such as mentally and physically differently abled people, criminals, 
and homosexuals.$^{87}$ In the early $20^{\text {th }}$ century, eugenics, especially so-called positive eugenics, was favoured by people across the political spectrum. It was again the Nazi regime that unfolded the deadly potential of eugenics and thus helped to abandon it as a serious scientific discipline. ${ }^{88}$ Racism, however, lived on. While 'scientific racism' has been discredited as a pseudo-science, cultural markers have replaced biology as elements in racist discourses. Cultural markers are increasingly used as group determinants to suggest incapability of coexistence. Within the Right the emergence of ethnopluralism as a concept mirrors this shift. At the same time, part of the far right still upholds the validity of scientific racism, especially concerning aspects such as intelligence, athletic prowess, and sexual activity. While their methodology might be new, their ideas on race are not; already Eliot's Sweeney tapped into the racist discourses of the brute sexual predator.

\section{A very short history of right-wing ideology}

To understand right-wing ideology, it is not enough to look at the theoretical concept but one also needs to take into account the historical development and shifts the phenomenon has undergone since its emergence on the political scene. Setting the French Revolution as the germinating point does not presuppose that right-wing ideology as a mind-set did not exist prior to this it certainly did - but it was this event that led to a politicisation of right-wing ideology in opposition to the revolutionary forces. To evaluate the conceptual roots one has to look at the writers and thinkers who positioned themselves against the tenets of the Enlightenment to form what can be viewed as the Anti-Enlightenment. Sternhell summarises the developments:

If the French Enlightenment, or rather the Franco-Kantian Enlightenment, and the English and Scottish Enlightenments produced the great intellectual revolution of rationalist modernity, the intellectual, cultural, and political movement associated with the revolt against Enlightenment constituted not a counterrevolution but a different revolution. It was not a countermodernity but a different modernity that came into being and that revolted against rationalism, the autonomy of the individual, and all that unites people: their condition as rational beings with natural rights. That second modernity was based on all that differentiates and divides people - history, culture, language... ${ }^{89}$

He problematizes the idea to understand the anti-Enlightenment tradition as a countermodernity, which, again, implies the notion of right-wing being antimodern. The adherents of the anti-Enlightenment tradition - from Hegel, 
Carlyle, Burke to Maistre, Maurras and Spengler among others - all shared the core belief of fundamental human inequality, consigning them to the right wing. While the Enlightenment and anti-Enlightenment tradition were philosophical movements, it is fair to see the French Revolution as the first violent clash of the two ideologies that sprung from both movements.

The second major violent clash dominated the $20^{\text {th }}$ century. In the meantime something had shifted. The formation of communism brought a new challenge to the equality/inequality binary - but this time from the left. Criticising capitalism as the economic foundation of society to uphold human inequality brought a new factor into the debate. With its revolutionary narrative of the proletarian strike, communism situated itself at the far left of the political spectrum, a threat to adherents of inequality as well as more moderate followers of the Enlightenment's idea of equality. But more was to come. Out of his allegiance to Karl Marx's theories as well as to the concepts of the Classical tradition, the Frenchman Georges Sorel created a philosophy that was essentially revolutionary and reactionary. Especially his revision of Marx led him to introduce two new elements: violence and myth. For Sorel, a reversal of decadence back to a moral society relied on 'a state of war in which men voluntarily participate and which finds expression in well defined myths'. ${ }^{90}$ Violence, which Sorel separates from the term 'force' (the imposing of 'a certain social order in which the minority governs'), denotes 'the destruction of that order'. ${ }^{91}$ Sorel thought to find both these ideas in Marx's proletarian strike, a myth he eagerly adopted, but altered to suit his particular theories. Very importantly, violence was understood not only as destructive, but also as creative and 'the motive force of history'. ${ }^{92}$ Although the positive aspect of violence had already been favoured by some anti-Enlightenment thinkers such as Ernest Renan or Johann Gottfried Herder, Sorel argues that violence was not merely a means to an end but inherently positive. That is because violence automatically begets the moral virtues that are seen as antidotes to decadence - vigour, vitality, virtue, and valour. This provided the basis for fascism's later full endorsement of war as 'the sole hygiene of the world'. ${ }^{93}$ Essentially, Sorel developed the blueprint for fascism: a revolutionary core around which he grouped the concepts of the anti-Enlightenment tradition. As the genesis of what was to become fascism shows, some of its foundational ideas came from without the anti-Enlightenment tradition. Yet, although fascism was sometimes described (and liked to stylise itself) as beyond the left/right dichotomy it undoubtedly found most of its (initial) supporters on the Right. Yet when fascist movements came into power, notably in Germany and Italy, supporters could be found across the whole populace, and thus across the whole political spectrum. The dynamics of widespread support have to be understood as the complex interplay of contextual devel- 
opments, such as the global recession, and successful populist strategies employed by the Fascists and National Socialists in their rise to power, but also as regimes. Despite the populist measures of the Nationalsozialistische Deutsche Arbeiterpartei (NSDAP) and the Partito Nazionale Fascista (PNF) that targeted the populace as a whole, or more correctly the Volk, the 'imaginary self, fascism with its endorsement of elitism, authority, hierarchy and national genius places itself far away from the idea of human equality. The egalitarian measures (think: Gleichschaltung, mass produced products, and $K d F$ ) we find in actual National Socialist politics do not contradict these reflections. The Volk that profited from some forms of social equality could only do so after all elements of difference had been purged. Even then an internal hierarchy remained, in which a higher position had to be earned by accomplishment usually coupled with (racial) privilege. ${ }^{94}$ The idea of equality in the Third Reich was largely communicated visually via sameness and uniformity, not in terms of actual equality. ${ }^{95}$

The emergence of fascist ideology also modified the political spectrum as a whole. With communism and fascism at its poles, a new middle ground torn between equality and inequality developed. Without wanting to oversimplify the political spectrum, it is fair to say that, for example, democratic nations like Great Britain in the 1930s and 40s (as opposed to fascist states and the Soviet Union) subscribe to Enlightenment notions of equality but also continue to support systems of inequality, for example a capitalist economy or class-based divisions as well as racist and patriarchal systems. ${ }^{96}$ Using the left/right dichotomy raises the question of who inhabits the middle ground and what the middle signifies. Left and right being spatial metaphors in contemporary popular discourse they are often understood to mean left and right from a hypostatised middle. This middle is often presented as an ideological middle ground - the grey area where left and right meet. Some would even go further and consign a moral value to the middle ground, with the middle symbolising such values as moderation, compromise, and thus the very core of the self-conception of a pluralist democracy. While some centrist positions can certainly be labelled as the middle ground between left and right - embracing a system that promotes equality in some aspects but upholds inequality in others - the middle has to be understood not as an ideological position but as a structural position. I would argue that in democratic pluralist society that which is referred to as the middle is in fact the seat of power. Side-byside explorations of ideologies tend to treat all parts of the spectrum as equal contestants in the political field. Yet, a look at actual politics, historically or in the present, reveals that these ideologies exist in a perpetual power struggle. Assessing right-wing ideology in literary works largely produced in democratic Western societies and in movements existing in democratic Western societies 
today can only be done accurately when right-wing ideology is set against the backdrop of the power dynamics exuding from the middle. It is the middle that defines and is able to re-define left and right in relative terms. I would claim that the differences we seem to perceive when we compare right-wing mind-sets throughout the decades are not inherent but depend on the changing power dynamics surrounding them. To make the distinction clear: I would argue that right-wing ideology has an absolute and a relative value. The absolute value corresponds to the core of. Its relative value depends on the power dynamics of the middle against which it is set. The core value of the Right remains the same but the relation between this core value and the hegemonic middle changes. The inherent values (and practices) of the Right remain rightwing, yet viewed in context they may be at one time hegemonic and at others counter-hegemonic.

One of the most prevailing arguments that comes up in the debate about problematic politics embraced by intellectuals, anti-Semitism or racism for example, is the statement that back then these prejudices were the norm and not the exception. Nevertheless, a right-wing mind-set does not become less right-wing when it is surrounded by like-minded people, but it can either be part of the norm or not. This shows that (some) right-wing attitudes were more accepted in the past than they are nowadays, which is closely tied to the 'position' and power of the middle. This should not tempt scholars of the $21^{\text {st }}$ century to trivialise utterances that obviously betray an anti-democratic rightwing mind-set. Whether something is seen as acceptable or not is closely tied to what is seen as normal, i.e. the norm set up by the middle. Anthony Julius has succinctly summed up this often-encountered argument in his study on anti-Semitism in Eliot's poetry:

T.S. Matthews, who knew Eliot quite well, argued that because Eliot's times were anti-Semitic, his anti-Semitism should be forgiven. It was unavoidable. The culpable anti-Semites are those who choose to be hostile to Jews; those other who merely 'reflect' the anti-Semitism of their milieu, should not be judged harshly. Yet anti-Semitism is a social prejudice. As a group phenomenon it is not an appropriate case in which to plead moral safety in numbers. Widespread wickedness does not make individual evil less reprehensible. Writing an anti-Semitic poem does not reflect the anti-Semitism of the times; it enlarges it, adding to the sum of its instances. Eliot's work contributed to the anti-Semitism of his times. ${ }^{97}$

After 1945 it became clear that anti-Semitism is not merely a 'stupid suburban prejudice 98 but a hateful attitude with deadly consequences. If post-1945 antiSemitism is treated this way, we have to seriously ask ourselves why pre-1945 anti-Semitism is regularly excused, especially if existent among non-fascist 
peoples. Therefore a consideration of right-wing ideology needs to include a questioning of the power dynamics governing the political spectrum.

The rise of fascist regimes in the $20^{\text {th }}$ century and at its nadir the Holocaust lastingly changed Western perception of non-democratic right-wing ideology, although not as thoroughly as is sometimes suggested. While all the significant fascist movements took place on the continent, for my purposes it is also important to focus on the complex interplay of fascism and other strands of right-wing ideology that took place in England, which seemed to have been torn between its democratic legacy and the at times widespread admiration or at least approval of fascist politics. Fascism, so it seemed to many British citizens in the early $20^{\text {th }}$ century, offered a viable political agenda as Barbara Storm Farr notes:

Most of Britain's major newspapers stressed the positive aspects of fascism and emphasized Mussolini's restoration of governmental authority and strength rather than the resulting loss of parliamentary government. To a sector of the political right fascism, as it was perceived, presented a solution to Britain's social, political and economic problems and an inspiration, not to be copied, but to be adapted to British traditions. Fascism in England, therefore, represented an attitude - a "patriotic" concept, not a doctrine, and it concentrated on political action rather than ideology..$^{99}$

This shows that the perception of 'fascism in the making' was very different than it is today and, more importantly, different than it is usually presented to have been back then. From our post-Holocaust standpoint it is also important to note 'that fascism was intellectually respectable in the 1920s and 1930s in ways that we can no longer imagine;...' ${ }^{100}$ What stands relatively unchallenged is the fact that although Britain had quite a number of fascist movements none of them enjoyed lasting success, for various reasons. The most popular, the British Union of Fascists (BUF), managed to earn a lot of attention, but this did not translate into votes. This, however, does not mean that the British public and politicians were not receptive to fascist ideas. Mussolini's Italy received a lot of positive attention, and there were also a number of people who (openly) praised Hitler and National Socialism. What was often the case is that Fascism and Nazism were admired for some things they supposedly 'got right', while the down-sides were often ignored or diminished up until the Second World War had taken hold of Britain. In this light, Martin Pugh argues 'that fascism was much more central to British inter-war history than has traditionally been appreciated', ${ }^{101}$ not because the fascist movement was a lot stronger than usually assumed, but because many Conservative and Liberals also adopted some fascist ideas. To rely on the relative insignificance of the BUF and other British fascist groups as an indicator for Britain's lack of interest in fascism 'is to ignore the traffic of ideas and personnel between 
[the Conservatives and British fascists] during the 1920s'. ${ }^{102}$ Consequently, 'the British Fascists and the Conservatives occupied overlapping positions on a broad spectrum rather than two wholly distinct positions'.103

The appeal of fascist ideas and fascist movements coincided with widespread anti-Semitism. That British anti-Semitism is much more difficult to grasp is highlighted by quotes such as '[a]lthough I loathe anti-Semitism I do dislike Jews' (Harold Nicolson), 'it was accepted more or less as a law of nature that a Jew was a figure of fun' (George Orwell) ${ }^{104}$ and the fact that 'Hitler is known to have drawn on Chamberlain's anti-Semitic writing for his own race theory'. ${ }^{105}$ Anti-Semitic sentiments were ubiquitous and could be found in newspapers, among government officials, as well as in literary and nonfiction works. The Protocols of the Elders of Zion, which was published in Britain in 1920 under the name The Jewish Peril, proved remarkably popular. In fact, it was in the beginning distributed by Eyre \& Spottiswoode with 30,000 copies printed for the first edition, and a second and a third following in August and September of the same year. ${ }^{106}$ To argue that British inter-war anti-Semitism was obnoxious but at least not dangerous ignore its complicity in anti-Semitic policies. From violent attacks on Jews mainly in the East End aside, the British official decision to hamper Jewish immigrants to enter Britain by introducing stricter visa regulations shortly after the persecutions in Germany had reached a new zenith in 1938 accompanied by newspaper headlines such as 'Britain Becomes Dump For The Nazi Exiles' shows that German antiSemitism did not automatically lead to moral outrage in Britain as some have argued. ${ }^{107}$ Anti-Semitism remained virulent up into the Second World War, as evidenced by a prevalent notion that the war was waged in the interest of Jews:

The current view is that the anti-Semitism of those years [1930s] was deep and broad, and that it bore the weight of the preceding half-century of antiSemitic practice, which itself contributed to an indigenous proto-fascist political tradition. This strength and depth was evident in the emergence of fascist parties, in certain aspects of the policy of appeasement, in the reception of Jewish refugees, and in the apparently quite widely held view in late 1939 that 'the Jews' were to blame for the anticipated war. ${ }^{108}$

Anti-Semitism as well as right-wing tendencies in Modernist writings were firmly part of the general discourse and found many resonating sentiments throughout society.

It is not only the actual politics that matter, but also the general cultural atmosphere that determined what could be said and what not. As Anthony Julius remarked: 
By the 'public sphere' I mean that fraction of the 'sayable' in the culture that is more than merely privately in circulation. It defines the public conversation; it determines what range of comment can get a hearing, what is given authority by being published - and what, by contrast, is ruled out of public contention. ${ }^{109}$

None of my selected authors was born in Britain; all of them migrated to London, in Eliot and Pound's case from the US and in Lewis's case from Canada. Lewis was also the youngest, coming to England at the age of six, thus he received an English education and, before the First World War broke out, managed to travel the European continent. Yet, the Edwardian tranquillity was soon disrupted by the guns of August, with Lewis marching off to war. When the Great War ended, Britain had won the war, but it had also suffered incurable losses - not all in the form of human lives. As Modris Eksteins writes: [f]or the Germans this war was a war to change the world, for the British this was a war to preserve a world. The Germans were propelled by a vision, the British by a legacy." 110 Many changes in civilian life that the war had brought could not be entirely reversed, and many of the challenges Britain faced in the 1920s have their roots partially in the war. It was also in the 1920s when these three writers found many issues in England that they condemned and examples of political leadership in other countries which seemed like a favourable alternative. Britain became more democratic, for example by suffrage reforms, which enlarged the electorate (from 8 to over 21 million voters) to include women and working class men. ${ }^{111}$ It was also a time of an increasing number of strikes that made it obvious that even though 'the masses' did not yet have real political power, they could no longer be ignored. Moreover, previous literacy reforms resulted in a new mass readership in the 1930s with lasting effects on the book market - a development that also troubled Modernist writers. ${ }^{112}$ Statements about the downsides of democracy, a disgust of masses, criticisms of gender and class politics, and admiration for fascism were by no means singular instances that could only be uttered privately, but, on the contrary, resonated with many people. ${ }^{113}$ The political climate in which Eliot, Pound and Lewis wrote was, at least in the first half of the $20^{\text {th }}$ century far from hostile towards the political views of these (and other like-minded) writers. For Lewis this was already beginning to change as the Second World War drew closer, whereas in Pound and Eliot's cases it remained remarkably stable. Yet, none of these authors, Eliot in the very least, was ever truly a pariah in society. ${ }^{114}$ They always found outlets to publish their writings and they, Pound and Lewis, remained critically acclaimed as artists even after questionable engagements. This shows very broadly that all the sentiments they expressed or wished to express were part of the 'sayable', or in the rare cases they were not, forgivable. 
The Second World War changed many - albeit not all - things. Britain's Appeasement politics came to an end when Germany made bolder claims for German Lebensraum. The war against Germany made it necessary for British fascists and others who had shown great interest in National Socialism to reveal which side they were really on. And for most, their patriotism won. Some famous exceptions include Pound, who had left England in 1920 for France and finally Italy, and William Joyce, also known as Lord Haw-Haw, who went to work for Hitler's regime. Many of the more famous people from the BUF as well as some allies and associates were interned under Regulation 18B.115 The war had quenched the greater part of the fascist movement(s) in Britain and the government tried to extinguish the rest. The end of the war and especially the liberation of the concentration camps, which brought to light the full scale of Nazi atrocities, are usually considered to have had a huge impact bringing forth many a change of heart and reconsiderations. Yet, just as this does not hold true for Germany, it does not for Britain. For example, despite the Holocaust, anti-Semitism in Britain lived on. Julius shortly summarises that 'Hitler did not make anti-Semitism impossible"116 and Stone quotes that '[e]ven after the defeat of Nazism; 'Conservative anti-Semitism;' [...] continued much as before', since the British conservative anti-Semitic tradition believed that it had nothing in common with the violence of Nazism." ${ }^{117}$ And although it was impossible for quite some time after the war to openly support fascism or similar ideologies, extreme right-wing ideas continued to exist on the fringes.

The attitude of many British people towards fascism was far more complex than it is often presented. That Britain ultimately fought the Axis should not distract from the fact that it was itself a place of pervasive antiSemitism, anti-democratic sentiments, and admiration for fascist agendas. The consternation that resulted from the exposure of the Nazi crimes did not directly lead to an interrogation of right-wing ideology per se. New challenges of the $20^{\text {th }}$ century called forth new right-wing answers in the form of both the conservative Right like the New Right under Thatcher and the far right as evidenced in the race riots. Electoral victories of far right-wing parties in some English constituencies and in the European Election as well as a surge in racist hate crimes following the Brexit referendum in 2016 are just the latest signs of the prevalence of far right-wing attitudes among the population (a trend that can be observed in many European countries). Although some issues have become more complex, at the bottom there remains the old question of who is allowed to be part of the 'imaginary self' and who is 'the other'. 


\section{Right-wing ideology in literature}

In my following analyses I will look at selected works of Pound, Eliot, and Lewis individually. For each artist I have chosen a text that is deemed to be of great(-est) significance in their oeuvre. This will be supplemented with other selected pieces of fiction and non-fiction, in order to show the continuity of ideas and views, as well as to offer some context to aid understanding. In order to analyse their texts in a meaningful way and to avoid presenting an enumeration of ideological instances, I chose an approach that keeps in mind the unity of the work. My guiding question for all these works will be: which role does right-wing ideology play and how does it materialise in and/or shape the work? As I defined right-wing ideology to revolve around a core of inequality I will analyse how inequality works in conjunction with categories such as race (which will include anti-Semitism), class, and gender (including sexuality). As the concept of power (and power distribution) is a crucial but tricky element of right-wing ideology, as imagined power often deviates from the actual power dynamics, it will receive due attention. ${ }^{118}$ What this comprehensive approach will reveal is that right-wing ideology does not merely manifest itself in these authors' works as occasional racist, misogynist or classist remarks, but that one can find a structural 'othering' based on these categories. These others are constantly imagined as threatening the stable identity of the self and the system, in which the self holds the seat of power. Although it is seldom made explicit, the self is white, male, heterosexual, middle class. It is exactly the lack of overt reference to these markers, the fact that they remain unmarked, that implies their normative value. Everything that is different is at once marked, and in a second step devalued and marginalised unless its presence is useful to keep the hegemonic system in place. Pound, Eliot, and Lewis constantly evoke a system in crisis, in which order and power are threatened. At the same time their writings are attempts to restore the hegemonic and hierarchical system mainly by the use of narrative and poetic devices and forms of discursive violence (appropriations of racial and class idioms, use of prejudice and stereotypes). The literary text influenced by right-wing ideology is thus a text that constructs and upholds the belief in and promotion of inequality. Additionally, the 'settings and allies' ${ }^{119}$ will be determined in each analysis, i.e. what was the text's context and with whom or what was in tune. This will also reveal how Eliot, Pound, and Lewis made use of the traffic of ideas, which spread particular right-wing concepts all over Europe. All too often explanations for particular themes in their writings are traced back to these writers' biographies while they actually drew from a rich reservoir of ideas and prejudices. ${ }^{120}$ 
Crucially, these writers' ideology, their normative sets of ideas on reality, shaped their art even when it does not deal explicitly with politics. When Stephen Spender writes that 'the fact that men like Maurras, Ernst Jünger, Yeats and Pound observed standards in their work which were independent of their politics, makes them tragically mistaken but does not affect their art', he tries to shear off infamous politics to save famous literature. ${ }^{121}$ Yet there is little basis for his claim, although he is by far not the only one to make it. Spender correlates bad art with bad politics ('The men who are judged most severely turn out to be the inferior artists'), and assumes that the reverse must also be true. ${ }^{122}$ Taking Spender's argument as a starting point, I want to offer a counter argument and show just how much Modernist literature (in my case by Eliot, Pound, and Lewis) was dependent on politics and ideology. As a corollary this also suggests that right-wing ideology is closely related to Modernist aesthetics. What I hope to show is therefore that these writers' works do not simply feature instances of prejudice and right-wing ideology, but that the literary text is contingent on the right-wing structure it embraces. There can be no doubt that right-wing ideology is of greater significance to an understanding of Modernism than previously thought.

Before I proceed, I need to add a word on language use. The dilemma of exposing right-wing structures in literature is that one reproduces precisely those words and imagery that peddle hate and prejudice. Drawing attention to the discourses and source texts of these prejudices is necessary to illustrate links and intertextual dynamics, but it also drags these texts back to the surface, when they had rightly been largely forgotten. Writing this book I have chosen to leave quotes intact, even if that means keeping the discursive violence intact. When I reproduced problematic phrases and arguments in my analysis, I have been careful to address and explain the underlying logic. In parts a right-wing argument has to be laid out to show the ideological significance of certain phrases or arguments, something that was often lost on the more uninitiated proofreaders, whose feedback went into writing this book. The same holds true for the primary sources by the New Far Right I discuss in the second part of my analysis. Already the choice to include a number of voices of the New Far Right to explain their own ideological position might be criticised. The question of who speaks (and by extension who gets cited in scholarship) as well as its political dimension are pertinent issues to reflect and act on. By focussing on and challenging the Right - the convinced ideologues, the collaborators, the apologists - this book centres their voices and, in a way, reproduces hegemonic power dynamics, and this is a dilemma this study cannot escape. 


\section{The Poem as Propaganda EZRA POUND}

With a book of Confucius in his pocket and expecting the worst, he went with the partisans who had come to his home on 2 May 1945. After Mussolini's death, the same fate awaited many of those who had been loyal to the Duce. Yet instead of being killed he ended up in an American prison camp at Pisa. For several weeks he was incarcerated in an open-air cage, sleeping on the bare concrete floor. After a breakdown he was allowed to move into a tent. In November he was transferred to the United States where he awaited his trial. Ezra Pound was not the only poet with fascist allegiances who was put on trial for treason. With the execution of Brasillach in France in 1945, the outcome of Pound's trial was by no means certain. Yet beyond jeopardising the poet's fate, the case opened up a debate about free speech and its limits in a democratic society. After the poet's indictment for treason following his radio broadcasts in support of Fascist Italy, Pound's 'Pisan Cantos' emerged as the winning entry of the newly created Bollingen Prize. The ensuing scandal revealed the conflicting attempts to come to terms with the controversial matter at hand. Andrew S. Gross has aptly summarised the contradictions, which sprung from the fact that the award was sponsored by the Library of Congress:

How could Pound be honored by one branch of government while facing indictment by another? Pound's supporters argued that the award proved artistic freedom was alive and well in the United States; only totalitarian regimes forced artists to tow the party line. This free speech defense of poetry made lyricism the proof positive of liberalism. The argument proved influential, but it had the ironic effect of making a fascist poet the symbol of democratic culture, a prisoner the spokesman for free speech. ${ }^{123}$

To evade the matter, Congress terminated its involvement with the Bollingen Prize, while the jury released a statement that tried to separate the politics from the poetics:

To permit other considerations than that of poetic achievement to sway the decision, would destroy the significance of the award and would in principle deny the validity of the objective perception of value on which civilized society must rest. ${ }^{124}$

The Pound case, while formally resolved, reverberates until today. It not only raises questions about the role of free speech and censorship in liberal demo- 
cratic societies, but it also scrutinizes the relationship of politics and poetics. Does the politics of a poetic text matter? And can mere words be treason? ${ }^{125}$ A lot of attention has been bestowed upon the poet himself while his poetry - especially during Pounds time at St Elizabeths, a hospital for the criminally insane where he was sent after being deemed unfit to stand trial - was being actively de-politicized in an attempt to separate it from the ideology of its creator. The process of stripping the Cantos of its politics was mainly advanced by James Laughlin, founder of New Directions (Pound's major publisher in the U.S.), during a time when Pound's politics attracted more attention than his poetry. Over the course of several years Laughlin managed, with the help of the New Critics and the New York Intellectuals - who both had ties to New Directions - to craft a new image of Pound. 'Laughlin aestheticized Pound, and used other authoritative voices such as T. S. Eliot, Ernest Hemingway, and Archibald MacLeish to argue both for the value of Pound's work and for the need to read his poetry aesthetically, without concern for what it was saying', writes Gregory Barnhisel and concludes that this strategy lasted until the poet's death. ${ }^{126}$ Yet, although the poet might be gone, the poetry lives on and so does the controversy. While the aesthetic approach to Pound's poetry can still be found in many studies, dissenting voices are now mingled into it.

Some of the more notable of these voices are Eva Hesse's Sinn und Wahnsinn, Robert Casillo's The Genealogy of Demons, and Tim Redman's Ezra Pound and Italian Fascism. There are also various articles by Matthew Feldman, Andrew Parker, John Lauber, Reed Way Dasenbrock, Victor Ferkiss and Eli Goldblatt that have explored the intersection of politics and poetics in Pound. ${ }^{127}$ All of these usually focus on one key element in Pound's Cantos: anti-Semitism (Casillo, Parker), Fascism (Redman, Lauber, Dasenbrock), economy (Hesse) and gender (Goldblatt). In my project I want to weave all these threads into the complex phenomenon of right-wing ideology. What I hope to show is the central role right-wing ideology plays in the Cantos as a whole. In fact, while critics have continually sought to demonstrate the incoherence of its individual parts, the Cantos relies on a structure of inequality to make its parts cohere. I would even go further and argue that Pound's Cantos not only relies on a structure of inequality but also promotes inequality. Thus the Cantos is a successful synthesis of poetry and propaganda combining the aesthetic and the political into an inseparable union. In contrast to oftenposited assumptions that right-wing and/or fascist instances only make up a small part of the poem and could be dismissed without damaging the integrity of the whole, I hope to reveal that right-wing ideology in the Cantos is structural. This means that it is present even in those passages that are not overtly anti-Semitic, authoritarian, misogynist, or fascist. The most obvious instances 
are merely the most visible peaks of the underlying ideology, similar to the well-known image of an iceberg with only a small tip showing and most of it underwater.

To highlight the structure of inequality in the Cantos, I will analyse the elements that have most often been the focus of attention - as detailed above these are anti-Semitism, fascism and nationalism, economics, gender dynamics as well as the individual in society - and show their interconnectedness. This will uncover that these ideological instances are far more than just isolated occurrences: they hold the poem together while they are in turn structured by the poetic form. Only this complex approach can, I think, match the inherent complexity of Pound's epic. My readings will be supported by cross references to other texts written by Pound to reveal that the topos of inequality is not integral only to the Cantos but could be viewed as an underlying topos of most of Pound's work. These considerations will be completed by insights into the publication history of the Cantos, which exposes the struggle to determine the final form of the text. Pound the author might be dead, yet his politics live on in his poetry. Thus, when Richard Eberhardt commented on the publication of the 'Pisan Cantos': 'Fifty years will remove the politics and leave the poetry' he could not have been more wrong. ${ }^{128}$

From the very beginning on the Cantos has been a challenge for readers, critics, and scholars alike. Although the early instalments were not well received and generally ignored by a wider audience, Pound and his epic poem gained momentum in the 1940s with the publication of the 'Pisan Cantos', his trial and the awarding of the Bollingen Prize. From then on the new-found support had not only a profound effect on the Cantos itself, it also shaped its publication history. Despite the epic's later popularity (and notoriety) it was to remain unfinished. Therefore, to talk about the Cantos as a whole, one has to be aware that its internal order and especially its end remain contested. ${ }^{129}$ To get an understanding one has to start with the very basics: The Cantos is an epic poem, about 800 pages long, that was written over a time-span of four decades and consists of nine parts. Interestingly the two most popular parts of the Cantos were both written during a time when Pound was in a dire situation: when writing the 'Pisan Cantos' he was incarcerated in a Pisan prison camp after he had seen his favoured political state crumble; in his (unfinished) 'Drafts \& Fragments' he contemplated, in a state of constant illness and feeling of being out-of-touch with the world, the successes and failures of his life and art. Both differ significantly in tone from the other parts by being a lot more sombre and melancholic (and arguably more poetic). While I am not interested in a biographical reading of his epic poem one can see a number of parallels between the poet's life and the way he chose to form his text. The first part with its rich mythology reminds the reader of Pound's early poems. 
Already these first 30 cantos, but especially the ensuing parts (31-71), showcase new poetic techniques: they provide a rich tapestry of many voices, coded anecdotes and numerous historical facts copied, often verbatim, from a large variety of sometimes obscure books. As the Cantos progresses the general theme changes in favour of the political and economic. It might not surprise that during the late 30s and 40s Pound tended to write more non-fiction articles on topics such as economics than literary works. Pound's new poetic techniques did not elicit many favourable responses. Noel Stock, once an ardent devotee of Pound, writes almost exasperatedly:

We understand a number of passages in a general way: the author does not like brokers or gun-sellers; he has an obsession about Central Europe, which makes him like one of his own Central European characters; Mr Blodgett was wrong when he said that 'Sewing machines will never come into general use'; gun-sellers sell guns and only ever do good in order to do evil. But we get tired of cryptic utterances implying meaning and depth without providing any. ${ }^{130}$

While Stock could be accused of simply trying to settle old scores, even Pound's publisher Laughlin curtly noted about cantos 51-71 in particular: 'this section [is] incomprehensible, and where comprehensible [is] propaganda'. 131 The 'Pisan Cantos' introduces a strong stylistic break and it is particularly this section which has enamoured readers. They were composed in an environment almost completely devoid of books (very unlike Pound's previous study in which he worked on his text), so Pound had to return to the material world on the one hand - the camp, its inmates and officers as well as nature - and the chimerical on the other. The 'Pisan Cantos' stand out as cantations of loss, defeat and introspection, the stylistic transformation often misconstrued as an ideological transformation. This section proved to be a momentary break, not a permanent change of course, which was made painfully obvious by the ensuing sections. When Pound wrote the next part, 'Section RockDrill', he was still a patient at St Elizabeths, a psychiatric hospital, where he had been institutionalised after being deemed unfit to stand trial. During this time Pound received continuous support: some despite his politics, some because of his politics. A group of followers routinely gathered on the lawn of St Elizabeths to listen to Pound's words, a custom Pound coined Ezuversity. People reached out to him via mail and many famous poets tried to achieve his release. All of this inspired in him (and his followers) a sense of martyrdom, which he was suffering through; a martyrdom that was imposed upon him because he had spoken the truth and had rebelled against the system. ${ }^{132} \mathrm{It}$ is exactly this mind-set which one finds in the sections 'Rock-Drill' and 'Thrones'. Formally they are a return to previous parts, laden with economic details, quotes and references. Any sense of reflection remains notoriously 
absent. The final instance, 'Drafts \& Fragments', remained exactly what the title indicates and has, maybe more than any other part, fuelled the war between the different readings of the Cantos. The Cantos lacks a definite end, the paradise Pound was hoping to write remained unwritten. Unsurprisingly, publishers and critics alike tried to do what the aging poet failed to achieve: to make (the) things cohere. Different drafts were suggested for the final ending, but no final consensus exists on the 'correct' one. This controversy was only rivalled by the dispute about how Pound's 'Italian Cantos' (72 and 73) should be handled, as they contain obvious fascist propaganda but are conveniently written in Italian and were during Pound's lifetime published separately. Thus, the one definite edition of the Cantos does not (and cannot) exist. The diversity of the Cantos's individual parts as well as their differing geneses might make it difficult to speak of one consistent poetical work. Moreover, the Cantos seems to avoid all attempts to be pressed into a rigid form, so much so that some scholars contend that it does not possess any unity at all due to the specific poetic methods Pound employed:

By emphasizing the degree to which "real" poetry consists of precisely shaped "gists" and "piths", and by relying so strongly on Imagistic methods, Pound indirectly deprived himself of a unifying principle that might have framed his crystalline fragments. ${ }^{133}$

Yet, other scholars, like Barnhisel, read the poem differently, despite the internal diversity: 'For Pound, it had unity - in his overarching vision of what was lacking in society and what needed to be done to remedy this deficiency'. ${ }^{134}$ Following Barnhisel I would like to suggest a reading that highlights the ideological trajectory as the glue holding the poem together, emphasising the uniting 'force' in the Cantos, rather than its disruptive aspects. This uniting force is the Cantos's inherent right-wing ideology.

What bears repeating is that analysing the poet's ideology and the poem's ideology are two different things. For Pound the poet, the question whether he was fascist can safely be answered with a definitive yes: during a significant part of his life Pound considered Italian Fascism (and later also Nazism) or any idealised political ideology resembling fascism as the best form of government and fully endorsed or at least accepted its consequences. John Lauber has elaborated on this point and is worth to be quoted extensively:

It should no longer be necessary to speak with careful qualification of Ezra Pound's "alleged" fascism, or "alleged" anti-Semitism. The man who saw in Mussolini the greatest European leader since Napoleon (and believed that both were brought down by Jewish usurers), who in his wartime broadcasts praised Mein Kampf for its "keen historical analysis" and advised his hearers to read the Protocols of the Elders of Zion, who in those same broadcasts spoke 
of "kikes, sheenies and oily people" and referred to American "Jewspapers," who in his Cantos quotes approvingly a forged statement by Franklin warning Americans to keep out the Jews, who gave most of his energies during the last year and a half of the war to propagandizing for Mussolini's Salo Republic and was described by its officials as "the collaborator Ezra Pound" - that man can accurately be termed a fascist. ${ }^{135}$

The question about the ideology of the Cantos warrants a more extensive answer. Not necessarily because a poem's ideology is more difficult to ascertain, but because it is more fruitful to analyse in what ways ideology functions or is made to function in a literary text. The ideological backbone of the Cantos is the belief in and the promotion of structural inequality. Adding to that is the Cantos's very explicit embrace of historical fascist politics or other (idealised) societies that follow strict patriarchal authoritarianism.

Reading the Cantos, I would even go so far as to suggest that it alternates between poetry and propaganda, a distinction fiercely defended and sustained by many Pound critics. Yet looking at Pound's complete output it seems fair to say that for Pound these two did not exist as two separate categories and that the Cantos can be seen as the ultimate synthesis. ${ }^{136}$ While propaganda is often understood as a tool of totalitarianism, at its core, it describes the propagation and dissemination of a certain version of what is considered 'the truth'. In his study on propaganda, Heinz Starkulla has noted that the term propaganda was used for a variety of phenomena: for religious as well as political (mostly revolutionary) missions, political journalism in general and also advertisement. ${ }^{137}$ It was mainly due to the totalitarian regimes of the $20^{\text {th }}$ century that propaganda took on the now ubiquitous meaning as an aggressive tool to disseminate lies and to manipulate the masses. Yet, Starkulla reminds his readers that propaganda also played an important role in the democratic nations during the Second World War. ${ }^{138}$ Thus he resumes that propaganda emerges from the existence of a pluralism of vying worldviews. ${ }^{139}$ The term propaganda should therefore not be limited to authoritarian endeavours to aggressively manipulate the masses, but more generally to concerted attempts to construct one world-view as the sole possessor of truth with attempts at widespread dissemination. Pound's Cantos combines poetics with a host of historical facts in an effort to construct an alternative history. While readers do not need to accept Pound's version of history, the poem nevertheless makes no secret about its demands for truth. Coupled with this demand for truth is the epic's revolutionary fervour, challenging accepted history, while advocating a series of solutions for supposed problems to bring about a change of systems. Read in this respect, the Cantos needs to be understood as a literary piece that is closely intertwined with politics. In Pound's words, the Cantos is a political weapon. ${ }^{140}$ Determining the Cantos as uniting 
poetry and propaganda, one needs to grapple with one of the key difficulties of the Cantos: its inaccessibility.

Hesse has described the complicated relationship between Pound and the masses, writing that '[Pound] saw society as the enemy of his artistic output, while he, at the same time, considered himself their mouthpiece. The subtle distinction he makes in his works between humanity [Menschheit] and the masses [Masse], reveals this internal conflict. ${ }^{141}$ Reading the poem as propaganda, while keeping Pound's disdain for the masses in mind, one needs to ask how effective the Cantos really is - or can be - as propaganda under these circumstances. Both Carey and Hesse have argued that Modernist literature can be read as a concerted effort against the newly emerging mass audience:

The intellectuals could not, of course, actually prevent the masses from attaining literacy. But they could prevent them reading literature by making it too difficult for them to understand - and this is what they did. The early twentieth century saw a determined effort, on the part of the European intelligentsia, to exclude the masses from culture. In England this movement has become known as modernism. ${ }^{142}$

There is an important distinction that needs to be made here. Writing to his mother, Pound maintained that ' $[\mathrm{a}] \mathrm{n}$ epic in the real sense is the speech of a nation thru the mouth of one man.' ${ }^{143}$ Caught in the complex dynamic of artist, readership, masses and nation, it is important to note that the poem may stylise itself as the 'speech of a nation', yet the masses are not those who are addressed. ${ }^{144}$ Or as Hesse puts it: 'although he claims to speak for all due to his superior sensibility as an artist, he does not actually speak to all, but only to the minority of the gifted and cultured, who offer intellectual and political guidance to the incapable masses below them'. ${ }^{145}$ Speaking to the few and for the many already reveals part of the poem's inherent right-wing structure by rejecting basic democratic principles. That the fault lines between those individuals worthy to be addressed and those that constitute the unworthy masses run along the categories of race and gender should not come as a surprise. This can be traced back to Gustave Le Bon's study on crowd psychology The Crowd: A Study of the Popular Mind, published in 1895. In his study, Le Bon likens the crowd to women, children, and non-white people, all united in their inferiority to the white male individual. Predating the advent of most modern democracies and yet foreshadowing the new political significance of the masses, Le Bon's study offered a theory that underlined the necessity to uphold hegemonic power dynamics. It is no contradiction then to read the Cantos as propaganda, while also highlighting its inaccessibility. Pound's epic inherited and continues his time's prejudice of crowds and envisions an ideal society in which the semi-conscious masses are guided by a small elect minor- 
ity. ${ }^{146}$ Thereby the Cantos not only reproduces the inequality that existed in society but reinforces it.

The epic form had further significance for Pound. In his Make it New Pound stated that ' $[\mathrm{a}] \mathrm{n}$ epic is a poem including history. No one can understand history unless he understands economics'. ${ }^{147}$ If Pound chose the epic form primarily because it offered an ideal canvas for his political and economic ideas, it is not surprising that many issues one can find in the Cantos can likewise be found in his non-literary work. This suggests that a consultation of Pound's non-literary texts, his essays, political articles and broadcasts, would help to reveal and enforce the significance of ideology in an epic that tried to rewrite, or at least reassess, history. The correlation between Pound's non-literary texts and poetic writings already refutes the claims that poetry and propaganda were two entirely different things in Pounds life. Secondly, the function of history, again according to Pound, is to offer a moral narrative. This sentiment he had adopted from Confucius and it can also be found in canto 89: 'To know the histories / to know good from evil /And to know whom to trust' (89/610). Approaching the Cantos, history, at first glance, seems haphazard and chaotic, yet on closer inspection it becomes clear that there is almost a fixed set of historical key points to which the Cantos continuously returns. Listing them in thematic clusters, the most prominent are: the mystified past, i.e. ancient mythology, but also the lives of troubadour poets; the United States during the presidency of John Adams, Thomas Jefferson, John Quincy Adams, and Martin van Buren, the Far East in the form of Chinese history from ca. $2000 \mathrm{BC}-1736 \mathrm{CE}$ and accounts of the Na-Khi; the Italian past (mostly pre-Renaissance, Malatesta, Bank of Siena); and Italian present (Mussolini and Fascist Italy); what Pound terms Mitteleuropa (which includes England and Eastern Europe) in the first half of the 20th century and earlier; and finally the Second World War and its various fronts. What links these (temporarily and spatially) diverse periods in history is the idea of a shared ideological trajectory. History, so the Cantos argues, is a perpetual struggle between two opposing forces, which come in different (national) permutations, but whose core remains the same. The core evil in the Cantos is usury and all its facilitators. This observation highlights the central role economics play in the poem. Yet usury in the Cantos goes beyond economics and has a strong racial and gendered component, which as the poem progresses is brought together in the figure of the feminine, sexually deviant Jewish other. In league with unruly women, homosexuals, and other minorities, Jews in the Cantos are conspiring to shape world history to their advantage. These antagonistic forces, especially the Jews, are classified as contra naturam, against nature but also disturbing the 'natural order'. This already foreshadows how much Pound's poem relies on well-established anti-Semitic stereotypes. 
Fighting the core evil, according to the Cantos, are - and have been throughout history - the able few, select men, who are praised for their masculine will of action. This historical struggle culminates in the present in the Fascist state, which led by Mussolini overcomes usury and reinstates the natural order. With Fascism's demise the cycle of history moves on yet again. Using this binary the Cantos does not only include history, but it essentially rewrites history. It creates, at its core, a simplified version of historical truth(s), which lends itself for propagandistic efforts, something that will become apparent when looking at the right-wing reception of Pound's epic.

This sweeping pared-down summary of the core trajectory of the Cantos cannot do justice to the complexity of the poem. It does not capture the plethora of historical references, the polyphony and the multi-layered composition in general. However, it highlights the inherent right-wing structure, which runs like a thread through the epic. The following chapters on economics, anti-Semitism, Fascism, and gender dynamics will devote themselves to showing how each of these aspect feeds into the poem's right-wing structure. While they will unpack the entanglement of various categories and forms of discrimination, they do so at the expense of the poem's textual intricacy, highlighting the consistencies, while abandoning, for the moment, the text's breadth. To many, the textual complexity and the idiosyncratic style seem to deny the possibility that the Cantos embraces a rigid ideology. Alec Marsh addresses this crucial point, in the words of Burton Hatlen: 'the poetry is ideologically closed but formally open'. ${ }^{148}$ I want to make it clear that in my study I am not interested in using the Cantos as proof of Pound's politics, but rather to highlight the politics the Cantos as a poem of renown endorses or has the potential to endorse. While the inherent ideology of the Cantos coincides with Pound's political commitment at the time, the crucial observation is, that the poem's politics survive the poet. Or in Chace's words:

His writing, however, is now a part of history and will always carry with it the sentiments out of which it was, in part, formed. Also a part of history are his apologies. Welcome as they are, they cancel nothing; the poetry and the prejudice are forever united. ${ }^{149}$

\section{'Der Jud will Geld'}

Pound's statement on the nature of the epic reveals the elementary role economics play in the Cantos. His keen interest in economy also stemmed from a painful awareness of the relationship between art and the marketplace: 
Pound lived through this transitional period [between patronage and state funding]. The artist was alone, struggling to survive, eyeing the rich who would not host him and hating the commercial option of selling his wares to the masses. Art and Commerce had to cohabit, with Art being the weaker partner and rightly resentful. Being anti-commercial, anti-capitalist, antimoney became second nature to the artistic genius, a badge of honour. ${ }^{150}$

As Pound considered artists the antennae of the race, so the art world also became an indicator for larger societal dynamics and the first to suffer from economic pressure: 'The effects of social evil show first in the arts. Most social evils are at root economic. I personally know of no social evil that cannot be cured, or very largely cured, economically.' 151 The cure, according to Pound, were the Social Credit theory advocated by C. H. Douglas and the idea of stamp money as supported by Silvio Gesell. In the Cantos these two models are not only advertised as solutions that would enable society and the arts to flourish, but the poem is also profoundly influenced by the underlying assumptions both brought with them. On the surface the economic policies espoused in the Cantos seem to be attacking inequality, primarily inequality in the form of interest-based capitalism. However, a more accurate analysis shows that while the system of interest and the distribution of capital are duly criticised, the underlying structures of inequality are not only left intact but further promoted. In fact, the economic policies one finds in the Cantos are interdependent with the poem's right-wing structure.

The first key issue I want to look at is Pound's supposed critique of capitalism. Both Gesell and Douglas's models as well as the Cantos can be seen as critiques of capitalism. Yet, none of the three propose an extrasystemic critique of capitalism, viz. a critique that hopes to accomplish or envisions the end of capitalism. Douglas considered capitalism the best of all systems; he only hoped to make it fairer. ${ }^{152}$ As Eva Hesse and Richard Sieburth have noted, the embrace of Douglas and Gesell facilitated that Pound could freely criticise the capitalist system without questioning the core of capitalism: inequality. Sieburth concludes: 'Pound's monetarism is perfectly consonant with his political conservatism, for by dismissing production as an economic issue, he thereby dismisses the need for (or historical inevitability of) any fundamental structural changes in society.' 153 This might, at first glance, seem contradictory to Pound's own position as an author struggling to earn enough for a living. Yet his analogy of artists as the antennae of the race not only implies that artists are to first to recognise new currents and impulse, which they then disseminate among the masses, but that they need to stand out from the crowd. The dismissal of capitalist structures in the Cantos can therefore only go so far as to leave these hierarchies untouched. Douglas's Social Credit and Gesell primarily focussed on a fair distribution of capital. 
Even more than the fair distribution of capital the Cantos dwells on its opposite, the accumulation of capital (in the wrong hands) by the use of usury. The Cantos's obsession with usury stems from the idea that it constitutes the greatest economic evil and thus the root of all evil.

Although Pound had discovered Social Credit quite early in his life, his obsession with usury only took off in the 1930s, but lasted until the end of his life. He first targeted usury as an abstract evil yet eventually started to personify usury and in turn his attacks became more personal, and decidedly antiSemitic. Moreover, he did not only berate usurers for their predilection of individual gain over communal wealth but accused them of actively destroying a state and its culture out of malicious intent. William Chace has noted how Douglas had already supplied a model that favoured finding fault in individuals rather than in economic structures and practices:

Douglas [in contrast to Marx] was concerned not with classes, in whose reality he seemed hardly to believe, but with individuals, predominantly monopolistic financiers, whose private activities were an infection within the system. [...] In his search for the mainsprings of war and international conflict, [Ezra Pound] settled upon an analysis that allowed him to blame specific people... ${ }^{154}$

Usury, according to the Cantos, gnawed at the fundaments of the system. Subsequently usury evolved from an anti-social act, since it could trigger war and social demise, to an unnatural act, something that fundamentally opposes 'natural law'. As the Cantos embraces the idea of 'natural' hierarchies, everyone who opposes or transgresses these hierarchies is by definition a usurer. In turn, 'usurer' became a catch-all term for Pound, which could be applied to any person Pound could find fault with. Lauber lists the diverse groups of people, some of which have nothing to do with distribution of credit at all, who in the Cantos fall into this category:

the usurer, the monopolist, the materialist, the monotheist, the dogmatist, the provincial, the snoop, the abstractionist, the synthesizer, the syllogizer, the warmonger, the 'liberal,' the impeder of communication, the obfuscator of history, the volitionless intellectual, the bourgeois, the fact-evader, and the de-sensitizer [...] all of these types can be subsumed in the category "usurer.".155

The Cantos introduces usury and usurers fairly early, in Canto 12. Although this canto already makes clear that usury is an act against nature and equates usury with sodomy in a reference to Dante, it lacks the scathing language of later cantos. Its attack mainly works in conjunction with its surrounding cantos. It is framed by the Malatesta cantos and a canto on Confucius, both examples from history which the Cantos deems commendable, even if they are, 
as in the case of Malatesta, not without internal conflict. Yet when readers finally reach the so-called 'Hell Cantos' (14 and 15) they are faced with pure Poundian vitriol in the style of his Vorticist poem 'Salutation the Third'. The 'Hell Cantos' include personal attacks on a number of individuals who have been (possibly subsequently) edited out and substituted by dots and the last letter of their name. They also resemble another famous earlier poem by Pound, Hugh Selwyn Mauberley, especially its part IV and V. In fact it was here that Pound first mentioned usury: 'came home, home to a lie / home to many deceits, / home to old lies and new infamy; / usury age-old and age-thick / and liars in public places'. ${ }^{156}$ Canto 14 and 15 seem like a continuation of this earlier attack on London. In Hugh he likened the hellish battlefield to the equally infernal London; in the Cantos London becomes the 'last cess-pool of the universe', 'the hell-rot', 'the slough of unamiable liars, / bog of stupidities, / malevolent stupidities, and stupidities, / the soil living pus, full of vermin' (14/62-63). The imagery used here evokes the battlefield of the Great War, hell, Dante's Inferno, but also the hostile environment of marshes. More than Hugh the Cantos makes it clear that the root and reason for the state of things is usury. Just as Dante put the usurers into the deepest recesses of his hell, Pound is eager to associate all individuals linked to the 'hell-rot' London with usury. After the politicians are attacked ('their wrists bound to their ankles, / [s]tanding bare bum / [...] / [a]ddressing crowds through their arse-holes' $(14 / 61))$, the focus rests on '[p]rofiteers drinking blood sweetened with sh-t, / And behind them ......f [most likely Basil Zaharoff, in later cantos he appears under the pseudonym Metevsky] and the financiers' (14/61). ${ }^{157}$ During the Great War Sir Basil Zaharoff was the wealthiest arms manufacturer, who saw no objection in selling weapons to opposing sides in conflict. ${ }^{158}$ Pound, who wrote that he took up the study of history and war to oppose the same, ${ }^{159}$ seems to have found his ideal bête noire in Zaharoff. His presence in Canto 14 can be read to suggest that the war, that is so chillingly portrayed in Hugh's part IV and V, was solely caused by profiteers and financiers. It is no coincidence that London, the place where war profiteers live and work, is visually likened to the stench-filled trenches of the Western Front. But also the press and publishers, 'the betrayers of language /[...] / And those who lied for hire; the perverts, the perverters of language' (14/61) receive their share of hate. Again these groups are linked to usury: 'the perverts, who have set money-lust / Before the pleasures of the senses' (14/61). These lines imply that 'betrayers of language, just like usurers, commit crimes against nature and are thus perverts, a reference to Dante's grouping together of the usurers with the perpetrators of sodomy. Another example can be found two pages later with the first explicit mention of usurers 'squeezing crab-lice, pandars [i.e. pimps] to authority' (14/63). This time the vitriol is directed at scholars, yet the accusa- 
tion works in just the same fashion as before: at the root usury is to blame. The idea that usurers actively (and maliciously) control the circulation of knowledge reverberates in Pound's writing and was further aggravated the more he ran into trouble finding publishers for his books and articles. For example, in Guide to Kulchur he scented conspiracy writing that ' $[\mathrm{u}]$ sury endows no printing press. Usurers do not desire circulation of knowledge. ${ }^{160}$ In Canto 15 readers eventually encounter 'the beast with a hundred legs, USURA' (15/64) surrounded by admirers, another evocation of Dante. The presence of Geryon, who originally dwells between the $7^{\text {th }}$ and $8^{\text {th }}$ circle in Dante's hell, suggests that London is populated by the same people as the corresponding circles in the Inferno, thus we find profligates, sodomites, usurers, panderers, flatterers, corrupt politicians, and hypocrites among others. ${ }^{161}$ More importantly it also indicates that all nefarious activities can be traced back to usury. In this way, the Cantos goes further than Hugh, in which usury was a presence but neither all-encompassing nor the root of all evil. However, similar to Hugh and Dante's Inferno the poet-persona here is able to cross hell with the help of Plotinus, who turns the mud into stone. In later cantos this will be repeatedly mirrored by Mussolini's successful draining of the marshes to make them arable, an action which seems to have resonated deeply with Pound, not only for practical reasons, but also for its symbolical reverberations. ${ }^{162}$ After reading Cantos 14 and 15 it becomes clear that Mussolini's act also implies the drying up of the bog of usury and a return to the 'natural' order. In this way, fascism is already presented as the political antidote to the rotten-at-the-core Anglo-American world. Moreover, Fascist Italy is placed among notable periods in history, which all, according to the Cantos, have overcome usury, a characteristic often implied rather than spelled out as Meghnad Desai observes:

...there is one unifying theme linking culture, religion and economy: usury. The decline of Christianity is traced to the repudiation of Canon Law. The reader has to infer that this refers to the prohibition of usury and this is why the Renaissance marks a watershed for Pound. Whatever was before, especially the Mediterranean civilization of the thirteenth and fourteenth century, was to be placed above the Renaissance and Christianity as it evolved after that. Calvin emerges as a villain. America's history is divided into the good days when Congress was in control of the money, and the days when bankers took over after the Civil War and the return of Gold and monetary orthodoxy. ${ }^{163}$

While the Cantos also occasionally hints at the economic models of Douglas and Gesell eliminating usury remains a deeply political issue and mandates a political system change. ${ }^{164}$ This becomes evident as the Cantos progresses, for 
overcoming usury is not only a way to rectify the distribution of capital, but a matter of (cultural) survival.

No canto brings out this sentiment as clearly as Canto 45, which begins: 'WITH Usura' and then proceeds to list all the supposed detrimental consequences of usury. These include the deterioration of food, art, agriculture, crafts and life in general. Twice the canto states explicitly that usury is a crime against nature and all the given examples are in different ways illustrating this exact same idea. In fact, Michael North has concluded that 'there is no particular reason for the Usura Canto to be as long as it is, and nothing to prevent its being twice as long. Each line is fundamentally interchangeable with every other line. Behind this stylistic fact lies the ideological fact that all of usury's foes are interchangeable'. ${ }^{165}$ Often hailed as one of Pound's most poetical cantos it is also a perfect synthesis of Pound's economic programme and his poetic notions. Seemingly a refutation of Arthur Griffith's 'Can't move 'em with a cold thing like economics' (19/85 and 78/501), it presents indeed a moving elegy of a culture destroyed by usury. Implicitly, however, it is again a praise of Mussolini as Pound's creation of art, i.e. the Cantos itself, makes it clear that he resides in an environment where usury has been vanquished. Therefore, the elegy doubles as political programme: destroy usury or usury will destroy you ('Corpses are set to banquet / at behest of usura' (45/230)). This reading is supported by the fact that the lyrical canto ends with a short factual definition of usury: 'A charge for the use of purchasing power, levied without regard to production; often without regard to the possibilities of production' (45/230). This and the subsequent cantos make clear that despite being presented as the arch-villain usury also remains particularly elusive as a concept, an elusiveness that is mirrored in the metaphorical imagery of the Cantos as Robert Casillo has noticed:

Pound thus represents usury in terms of irreconcilable opposites. Usury is a "murrain" or a "marasmus" (wasting) $(\mathrm{GK}, 109)$ and "fat"; it comes from the arid wastes of Arabia Petraea as well as from the fecund swamp; it is sensory starvation (those who have "set money-lust / Before the pleasures of the sense," 14/61) and sensory overcharge; it is the economics of scarcity and also of dangerous abundance, the "profusion" (SR, 18) of "opulence" (GK, 282) and parasitic luxury. One can understand why Pound fails to define usury, since usury is an overdetermined concept in which contradictory metaphorical ideas are already embedded. Pound is not the enemy of usury per se, for he is not really sure what usury is. Rather, usury is the name which Pound gives to indistinction itself. ${ }^{166}$

This is highly revelatory as we find a similar metaphorical indistinction in the Cantos's portrayal of Jews. ${ }^{167}$ Yet, it is just one of many ways the Cantos links usury to the Jews. 
Canto 52 plays a pivotal role in the ideological trajectory of the Cantos as a whole. It connects various diverse historical periods and economic ideas. It is also the first canto to make a strong connection between usury and the Jews, culminating in anti-Semitic discursive violence while pretending to focus on economics. It can be read as an answer to Canto 45 , celebrating '...the true base of credit, that is the abundance of nature' (52/257). This is followed by a seemingly obscure passage: "Goods that are needed' said Schacht (anno sedici) / commerciabili beni, deliverable things that are wanted' (52/257). Starting with the date in brackets, Pound is using the calendar of the Fascist Era, which started with the March on Rome and died along with Fascist Italy. Thus anno sedici, or year 16, corresponds to October 1937-October 1938. Pound's use of the Fascist Era is telling. ${ }^{168}$ It places the Cantos firmly as a record of history from the vantage point of Fascist Italy. Moreover, it shows a rejection of the democratic Western world, which this canto continues with the direct criticism of the West's allegiance to usury, and the subsequent celebration of China. The presence of Schacht here, that is Hjalmar Schacht, a German economist and president of the German Reichsbank during the 1930s, is ambiguous. ${ }^{169}$ At first glance, his comment on commerce seems to contradict the ideal of the abundance of nature being the true credit. Yet, by placing Schacht with the explicitly Fascist date and the Italian translation of the quote it seems that the canto spells out the then existing Rome-Berlin Axis that was strengthened after Germany supported Italy's invasion of Ethiopia. Moreover, the reference to Schacht is followed by the lines exhorting the negative influence of Jews and usury as well as to the detrimental effects of wars on society. Read in this context, Schacht's quote might allude to beneficial economic tactics. A number of Schacht's economic policies - introduction of public-work programmes as well as the 'New Plan', which aimed at limiting imports, and the introduction of the Mefo bills ${ }^{170}$ - might have resonated with Pound's economic ideals. When yet another economic crisis hit German in the mid 30s, Schacht supported free-trade in favour of re-armament and military spending. Moreover, after the Reichspogromnacht in 1938, Schacht developed a plan to aid Jewish emigration, by using Jewish property as migration funds. ${ }^{171}$ Schacht's presence in the Cantos serves as a stand in for free market policies, a rejection of war (spending), but also an economic solution to the 'Jewish question'. Sandwiched between 'the abundance of nature' and usury, the reference to Schacht seems to offer a middle-ground or transition period, moving towards the good, as suggested by the proximity to Italian Fascism. This cooperation is threatened by neschek ('neschek is against this'), the Hebrew word for usury, hence by Jewish usury. The presence of Jewish usury is interspersed with voices who explicitly bemoan the detrimental influence and bad behaviour of (arguably only rich) Jews including a (forged) 
quote by Benjamin Franklin stating 'better keep out the jews / or yr/ grand children will curse you' (52/257). Other remarks such as 'also super-neschek or the international racket / specialité of the Stinkschuld / bomb-proof under their house in Paris' (52/257) add to the strong anti-Semitic tone of Canto 52. Usury and Jews are not only presented as ultimate threats to a wellfunctioning society, but actually benefitting from its destruction, while being saved by their wealth. After pouring hatred upon 'jews, real jews, chazims, and neschek', canto 52 abruptly, introduced by the remark that even the (Catholic) Church is no longer able to fight usury (compare the 'toothless Church' with neschek, which means both usury and bite), turns into a meditation on Confucian philosophy. Confucian China is pitched as the opposite of the usury-infested Western world, but also linked to the Axis Berlin-Rome. In June 1937, so roughly anno sedici, Schacht met with Chinese Finance Minister H. H. Kung in Berlin to strengthen the Chinese-German friendship. ${ }^{172}$ In canto 52 we also find Kung, although this Kung stands for Confucius, yet Pound's preference for Confucius's alternative name, makes the ambiguity possible. Moreover, China, for Pound, had more to offer than Confucian philosophy, namely

[t]he importance of Confucian culture is this: Greece did not have the civic sense for the construction of an empire. The Odyssey is almost without an ethical sense. Greco-Roman philosophy reaches us either in fragments or is too diffuse. All was undermined by Judaism during the Middle Ages, etc. Having a solid base, systematic but succinct, China has rebuilt its empire on different occasions. ${ }^{173}$

It is Confucianism that is Pound's answer to the problem of usury. A rather drastic visualisation of this can be seen in 'Heaven's Son feed[ing] on roast pork' (52/261) which links back to the chazims (actually chaseirim, Hebrew for pig), a continuation of the medieval slur Judensau, as Casillo notes. ${ }^{174}$ Read in this way, Confucianism bites back and is able to do what the 'toothless Church' no longer can, to curtail usury and Jewish influence. Canto 52 is not made up of two disjointed parts, instead it links two seemingly unrelated histories into one historical trajectory: usury has corrupted the Western world; this is mainly due to the so-called big Jews; Germany and Italy are making progress to free themselves from the ties of Jews and usury ('of the two usuries the lesser is now put down' (52/258)); thus they can be linked to (Confucian) China, which has been free from 'Judaic influence'.

While the 'Hell Cantos' give a full glimpse into Pound's nightmarish vision of a culture corrupted by usury and Canto 45 is entirely devoted to the corrosive influence of usury on any culture, all of these are notably lacking in (overt) anti-Semitism. As it has been remarked by a number of scholars Pound's anti-Semitism developed gradually from the 1930s onwards. ${ }^{175}$ As 
Desai notes Pound's early money pamphlets are devoid of any anti-Semitic accusations that became so characteristic in his later writings and especially his broadcasts. ${ }^{176}$ There are a few anti-Semitic instances in some of his earlier writings, such as 'Salutation the Third', Hugh, and 'Patria Mia', but these were indeed isolated instances and not a recurring theme. Yet, within a time span of ten years the Cantos would narrow down its harshest attacks from the broad dismissal of all of London as in Canto 14 and 15 to the very specific targeting of Jews in Canto 52. Pound's growing anti-Semitism can best be observed in his non-fiction writings. At first Pound closely followed the lead of Douglas in 'associat[ing] certain actual and supposed Jews, such as the Rothschilds and Sir Basil Zaharoff, with international finance, war profiteering (munitions sales), and the dominations of the press. But Pound did not yet condemn the Jews as a group or view all usurers as Jewish. ${ }^{177}$ The latter sentence is important as it reveals that Pound transitioned via the stereotypical anti-Semitism that was deeply ingrained in Anglo-American societies to his full-blown anti-Semitism with strong racial overtones. This might also explain why National Socialism and Hitler became more interesting to him in the late 30 s and early 40s (and thus found their way into the Cantos), while he had at first belittled and ridiculed Germany and its leaders. Whether his admiration for Germany came first and he subsequently adopted NS racial beliefs or vice versa, remains a matter of speculation. While readers already encounter antiSemitism in the first fifty cantos, it is Canto 52 that introduces the explicit connection of Jews and usury when it speaks of 'neschek [...] the serpent' (52/257). Moreover, even though it singles out the Rothschilds as its central aim for attack in contrast to poor Jews ('poor yitts paying for Stinkschuld' (52/257)), I cannot concur with Terrell's reading that these lines show 'Pound's apparent intent [...] to deplore the way anti-Semites in the 1930s blamed all Jews, including poor ones, for the destructive financial practices of a very few'. ${ }^{178}$ Yet the canto's subsequent lines make no such distinction and even bring out the supposed chasm between Jews and non-Jews. The word 'Stinkschuld' also offers further proof. Although its main purpose is to serve as a stand-in for the proper name 'Rothschild' in order to avoid any libel action when the Cantos was first published, the choice of name, which literally translates into 'stinking debt' is supposed to evoke the close connection between Jews and usury. Andrew Parker concludes that 'it must be recognized that Pound consistently identified the usurer with the Jew - a gesture which assigns to the latter the same "unlimited" powers and influence which he typically associates with the former'. ${ }^{179}$ This reached its height in the radio broadcasts when Pound began to speak of 'Jewsury', 'jews-papers' and the 'federal union, or JEW/nion'. ${ }^{180}$ The radio broadcasts easily surpass the Cantos (or any other of Pound's writings) in viciousness, yet the Cantos is not lacking 
in vitriol and reaches its anti-Semitic climax in the 'Pisan Cantos' when the Jews are held responsible for having led the non-Jews into war in order to make profits. The presence of these lines in the 'Pisan Cantos' (which was written and published after the Second World War) is horrifying on many levels, yet focussing on economics here, it repeats the old idea that Jews were the big financiers pulling the strings behind the scenes. The root of all evil, so the Cantos here implies, is 'Jewsury', making Jews and usurers interchangeable.

After the 'Pisan Cantos' the anti-Semitism tied to economics diminishes notably. While this could be credited to a lessening of anti-Semitism on Pound's part, a look into the last part 'Drafts and Fragments' reveals that this development might have rather been due to what could be published after the Second World War and what not. 'Addendum for C' written circa 1941 is strikingly similar to Canto 52, which might not surprise seeing the proximity in years when both cantos were composed. However, its position in the last instalment as well as its title, suggesting that it should be added to Canto 100, gives it an added significance. While Canto 100, published as part of the 'Thrones' section in 1959, features many economic details, it is devoid of any overt anti-Semitism. The suggestion of 'Addendum for C' is that this needed to be remedied, which would explain why an older fragment would be added to a much later canto. 'Addendum for C' emphasises that usury is still the root of all evil just as it is still primarily Jewish: 'The Evil is Usury, neschek / the serpent / neschek whose name is known, the defiler, / beyond race and against race / the defiler' (A for C /818). Interestingly, Terrell reads this section in a positive light and suggests that 'Pound] uses the Hebrew word to show that the Jews from the time of Moses had rules against usury. ${ }^{\text {'181 }}$ On the contrary, I would suggest that these lines again imply the synonymy of Jews and usury. This could be corroborated by other instances from this canto. Thus, neschek is ' $[\mathrm{t}]$ he canker corrupting all things, Fafnir the worm, / Syphilis of the State, of all kingdoms' (A for C /818). This is precisely the vocabulary Pound used in his radio broadcasts and other writings to refer to the Jews, for example: 'as the United States has been invaded by VERMIN, among whom the Rothschild, and Sassoon, and Warburg, are more deadly than syphilis. ${ }^{.182}$ Both names, Rothschild and Sassoon, are also mentioned in this canto, although in a censored form that gives the first letter and replaces the rest with black dots. Its anti-Semitism makes this canto stand out from many that were published in 'Thrones' or later. Although it is known that Pound was very ill at the end of his life and that therefore the publication of 'Drafts and Fragments' was largely in the hand of Laughlin, it seems an odd choice that the inclusion of this particular canto was deemed necessary, or, in the light of Laughlin's earlier attempts of de-politicising Pound's poetry, appropriate. In all likelihood the fragment was considered too significant to be dropped, 
which strengthens my conclusion that the latter cantos' lack of anti-Semitism was less due to a change of conviction than a change of what was deemed acceptable. Until the very end the link between usury and Jews remains a truism throughout the whole epic. Even if it is less noticeable after the 'Pisan Cantos' it occasionally comes to the surface as a statement that seems to need no further explanation, or indeed, validation: 'Der Jud will Geld' (89/620).

The economics in the Cantos seem riddled with ambiguities, but follow a definite trajectory. Pound's epic rejects economic inequality in the form of unequal distribution of money, while at the same time it defends and promotes other forms of inequality. The language used to attack usury sways between great elegiac poetics or in words that would nowadays be classified as hate-speech. The supposed ugliness of usury as well as the beauty of its conquering are connected like the two sides of a coin: both seldom visible at the same time, but always present. The celebrated Canto 45, which contains no overt anti-Semitic instances, is retrospectively tainted by the connection of anti-Semitism and usury in later cantos. If this reading might seem unfair it should be noted that the last instalment of the Cantos contains one of the most vicious anti-Semitic attacks on usury. Although penned much earlier the fact that it was deemed necessary to be included shows that usury and Jews remained closely intertwined. This is especially significant seeing the prominent place usury holds in the whole of the Cantos. Even if not always explicitly mentioned it is clear that usury is the force that corrupts all areas of civilisation such as politics, culture, the arts, and finally civilisation itself. It is apparent that an economic or political system, in order to be judged favourably in the Cantos, needs to tackle usury. Yet what is most often overlooked is that the Cantos advocates that usury can be overcome not by introducing measures of equality but by strengthening 'good forms' of inequality. The expulsion of the Jews, the authoritarianism of Fascist Italy, NS Germany, and Confucian China as well as the appreciation of arts and artists are all presented as effective measures in the fight against usury that has turned the Anglo-American world into 'the last cess-pool of the universe' (14/62). This shows that as valid as some of the economic ideas Pound supported might be, in the Cantos they remain inextricably linked to anti-Semitism.

\section{A 'stupid suburban prejudice'?}

More than any other ideological topic, the issue of anti-Semitism in the Cantos has been in the centre of many debates and has seemingly split scholars roughly into three camps: those who see Pound unjustly accused of anti- 
Semitism ("Pound had pointed out some years before [the Bollingen controversy] that his critics would "use any stick to beat me," and the issue of antiSemitism in his work is merely one of the desperate measures to which liberals resort in their ceaseless attempts to discredit him' says Clarence lins ${ }^{183}$ ); those who acknowledge Pound's anti-Semitism, but do not consider the issue important or enduring enough for extensive attention ('to the best and most serious part of the younger generation whom I address, and some of whom I teach, these issues are as dead as the religious wars .... "Let us forgive the past and get on with the job" declares Christine Brooke-Rose); and those who see it as central to Pound's work. ${ }^{184}$ When Andrew Parker wrote his article in the 1980s, he notes that it is the first two camps who still dominate the assessment of Pound's anti-Semitism by 'denying its existence as such, or by "explaining it away" as a purely regional phenomenon which must be taken with a grain of salt'. 185 Today more than 30 years later things may have changed, partially due to such publications as Casillo's Genealogy of Demons, so that one can finally confront the matter as unabashedly as Desai does when he begins his study on Pound's economics with the words: 'Ezra Pound was a fascist and an anti-Semite. There it is. ${ }^{186}$ Yet still, the fact that Wendy Flory in her essay for the Cambridge Companion to Ezra Pound can downplay Pound's anti-Semitism by making a case that rabid anti-Semitism may be far less lethal than 'silent' anti-Semitism and finally taps into a full apologist stance when she sees Pound as the scapegoat for 'all those individuals of the silent majority in Germany, in occupied France and Belgium, in Britain and the United States who, by quietly aiding or standing quietly by, made the Holocaust possible', ${ }^{187}$ shows that the continuation of the debate is very necessary indeed. The presence of explicit and vicious anti-Semitism in a decisive literary work of the $20^{\text {th }}$ century is not something that can be ultimately resolved, but needs to be addressed constantly. Adding to the research that has been done on this topic, I hope to show how anti-Semitism fuels the rightwing ideological structure of the Cantos and how much it shapes its poetics.

First it needs to be established that ' $\mathrm{t}$ ] he anti-Semitism of the Cantos cannot be dismissed as an aberration; it is central, and proceeds inevitably from a habit of thought which is displayed everywhere in Pound's writings'.188 In fact, I wholly concur with Casillo when he maintains that:

It is erroneous for a number of reasons to think that anti-Semitism stands like an unbidden guest within Pound's supposedly harmonious semantic household. Not only does it dwell manifestly within the text, but it figures within its verbal and especially its metaphorical economy. [...] Pound's antiSemitism belongs within his metaphorical system and is linked to the rest of his writing by a chain of metaphorical displacements and substitutions. AntiSemitism is thus part of the economy of Pound's language — not as a single 
theme so much as a cluster or tangle of varied images and metaphors which are deployed throughout Pound's writing. ${ }^{189}$

The Jews in the Cantos operate as the one group that can serve as a stand-in for all evils, fulfilling the classical scapegoat role. As mentioned above both 'usury' and 'the Jews' remain highly elusive concepts despite their ubiquity in the poem. It might be fair to argue that it is exactly the Jew's indefinability that makes them, in the ideology of the Cantos, the ideal and most threatening culprit. This corresponds neatly to Julius's analysis in Trials of the Diaspora when he writes that:

Jews were taxonomically slippery. They eluded classification, and in the very perplexity they caused - the sense that they could not quite be categorized, that they were beyond or behind the ordinary frames of reference by which the world was to be understood - they began to be regarded as a threat. ${ }^{190}$

Metaphorically they become the blank space that can be filled at will. It is again Casillo who notes that 'Pound's conception of the Jews becomes increasingly ambiguous, contradictory, and overdetermined as his anti-Semitism reaches its height'. ${ }^{191}$ In the Cantos Jews are made to inhabit the extreme ends of various binary oppositions: 'Nature and anti-Nature, excess and sterility, luxury and asceticism, paternal repression and hetaeristic freedom, materialism and abstraction, instinctual life and the violation of the instincts, capitalism and Communism'. ${ }^{192}$ The inherent logic of these seemingly contradictory attributions becomes evident by establishing how this corresponds to one of Pound's most dearly held convictions of Confucian thought: The unwobbling pivot. The stable centre as the ideal is introduced early in the Cantos, namely in Canto 13, the first Confucius Canto, which is located in-between - and acts as a contrast to - Canto 12, the first occurrence of usury, and the 'Hell Cantos'. These 'framing' cantos illustrate excess and its deleterious effects. In contrast, the Confucius Canto radiates harmony spreading Confucian wisdom as an antidote: 'And he [Confucius] said / "Anyone can run to excesses, / It is easy to shoot past the mark, / It is hard to stand firm in the middle" $(13 / 59)$. This ideal of standing firm in the middle recurs in the Cantos in the imagery of the tower as well as the capable leader. ${ }^{193}$ Moreover, it seems to have been a motto Pound as poet aspired to, only to realise at the very end ' $[\mathrm{t}]$ hat I lost my center / fighting the world' (118/822). The crime of the Jews is that they are not 'firm in the middle' while at the same time being located at the centre of society. This explains their supposed harmful influence and why, at least in the beginning, some Jews, namely the poor uninfluential ones, escaped the poem's wrath.

In the previous chapter I discussed the connections between the Cantos's economics and anti-Semitism. Yet, anti-Semitism in the Cantos goes far beyond the economic realm. A good example can be found in Canto 35. De- 
ploring the current state of Mitteleuropa, this canto is again put in juxtaposition with the framing cantos and their central (laudable) figures (John Adams in Canto 34, and Cavalcanti in Canto 36). In Canto 35 readers encounter a number of people from different countries associated with the cultural industry in Vienna: Mr Corles (actually Alfred Perlès, Austrian writer), Mr Fidascz (actually Tibor Serly, Hungarian violinist and composer), and 'that ass Nataanovitch (actually Leopold Stokowski, British conductor of Polish descent). ${ }^{194}$ Here Vienna is presented as entirely bourgeois and internationalist, making use of Jewish stereotypes. The canto becomes more explicit noting 'the almost intravaginal warmth of / Hebrew affections, in the family, and nearly everything else...' (35/172-3). This short phrase associates sexual depravity, feminisation (another classic stereotype made popular by Otto Weininger's book Geschlecht und Charakter ${ }^{195}$ ) and clannishness with Jews. A few lines further down one comes across 'the general indefinite wobble [...] some communal life of the pancreas...sensitivity / without direction' (35/173). This contrasts quite explicitly with Pound's ideal of the unwobbling pivot. Pound also used the same language in an article for Mosley's British Union Quarterly, when he spoke of ' $[\mathrm{t}]$ he Semitic poison [being] in the Semite tempered by Semitic instability, by the Semite's wobble from one excess to the other'. ${ }^{196}$ Casillo concludes that Pound 'satirizes in this canto what he considers typically Jewish cowardice, cheap theatricality and sentimentality, cultural prostitution and mercantilism, in short, the virtual opposite of his system of values'. ${ }^{197}$ The anti-Semitism in this canto lacks the viciousness of the later cantos, yet it demonstrates its ubiquity in the Cantos. Just as Pound considered the Jews to infiltrate all parts of society, so anti-Semitism infiltrated all parts of his Cantos.

The Jews in the Cantos are elusive and ubiquitous, located at the extreme ends of the spectrum yet in the middle of society. Moreover, they also stand outside Pound's concept of history, while at the same time playing an important role as the primeval evil. Pound's idea of history is neither circular nor progressive. It also does not seem to fully subscribe to simple binaries based on ethnicity and culture as we can find among National Socialist ideology or later American white supremacist circles, with which Pound was associated. ${ }^{198}$ However, the anti-Semitism in the Cantos follows conventional lines. The link between usury and Jews is a common trope dating back to the Middle Ages. ${ }^{199}$ The Cantos continues this narrative, making the Jews not only the eternal antagonist, but implying their supposed unchanging nature and intentions. Looking at Canto 35, Lauber observed that '[i]t offers specific cases of forgery by Jews, dating from the fifteenth century and the twentieth (thus showing that the characteristics of the race do not change)' ${ }^{200}$ The Jews are presented as the unholy alliance that have for centuries pulled the strings by mingling in societies and pushing forward their own agenda, while actively 
undermining the truth. If that sounds familiar it does because it resembles the infamous Protocols of the Elders of Zion. From his correspondence and his radio broadcasts we know that Pound not only read the Protocols, but also felt that they supported his own ideas about the Jews, even - indeed especially - after it was established that they were a forgery:

Certainly they are a forgery, and that is the one proof we have of their authenticity. The Jews have worked with forged documents for the past 24 hundred years, namely ever since they have had any documents whatsoever. And no one can qualify as a historian of this half century without having examined the Protocols. ${ }^{201}$

The infiltration of the Press and industry, the equation of Jews and the snake, ${ }^{202}$ the deliberate sacrifice of their own kind ('the poor yitts') to help their own end, and finally the aim of exterminating the non-Jews are themes that can be found both in the Protocols and the Cantos. Of course, Pound's radio broadcasts surpass the Cantos in viciousness, but, as Lauber quite correctly notes, 'the Cantos themselves are anti-Semitic in the most fundamental sense: they present continuing Jewish conspiracy against the Gentile world'. ${ }^{203}$ The afore-mentioned Canto 52 comes closest in viciousness, yet the 'Pisan Cantos' seem much more disturbing. I have already looked at canto 74 with a focus on economy and now wish to return to it, to address an even more troubling layer of anti-Semitism: 'The yidd is a stimulant, and the goyim are cattle / in gt/ proportion and go to saleable slaughter / with the maximum of docility. but if / a place be versalzen,,?? (74/459-460). A similarly worded passage emerges a few pages later: 'and the goyim are undoubtedly in great numbers cattle / whereas a jew will receive information' (78/463). Taking a closer look at the passage, it seems at first to resume the tactics one encountered earlier in the poem: the Jews as scapegoat, the Jews as usurers, the Jews as responsible for war, and finally the Jews as turning the demise of non-Jews into profit. Ferrall suggests that taken together with the first lines of the 'Pisan Cantos', where 'maggots shd/ eat the dead bullock' (74/445), Pound's earlier association of Jews with parasites makes clear that he deemed the Jews responsible for Mussolini's death and it 'anticipates Pound's references later in the canto to the "goyim" as "cattle" who "go to saleable slaughter" because of the "stimulant" of the "yidd". ${ }^{204}$ Especially jarring is line 460: that 'a place be versalzen', i.e. made uninhabitable due to its abundance of Jews, ${ }^{205}$ after six million Jews were killed in the Holocaust, is nothing that can - as some Pound apologists suggest - be taken with a grain of salt. What makes this passage worse is that the Cantos here echoes the Protocols, and the fantasy of the Jewish plans of world domination and the elimination of its enemies. The use of goyim, the Hebrew word to refer to non-Jews, establishes a Jewish/nonJewish-binary and also reverses the perpetrator/victim dichotomy. It is inter- 
esting to note that the 'goyim' also have blame accorded to them for being too gullible and too docile. In this way these lines serve as wake-up calls sowing mistrust. This again mirrors the Protocols, which constantly assumes a tone of hubris to construct a patronising confidence of the Elders in their ability to outsmart the 'goyim'. The Second World War, the tragic end of Mussolini and Fascist Italy are captured in the Cantos as validation - just as the First World and the Russian Revolution did for the English translation of the Protocols that they have all taken place 'according to plan'. ${ }^{206}$ In this way these cantos offer an update to the Protocols and at the same time a verification of this blatantly forged text. Feeding into the worst kind of anti-Semitism, they can be justly considered Holocaust denial. Whether Pound at the time of writing knew about (the extent of) the killings that were perpetrated by the Nazis during the Second World War is a matter of debate, but not important to my argument. ${ }^{207}$ These cantos were published after the Second World War, were deemed prize-worthy in 1949 and were never altered during Pound's lifetime. The Cantos and 'his remarks both public and private served to encourage those who knew, condoned and acted'. ${ }^{208}$ In fact, they still do. ${ }^{209}$ Pound the poet may have changed his opinion in later life (although whether he wholeheartedly did so is a matter of debate ${ }^{210}$, yet Pound's poem stands unchanged.

Another important issue concerning anti-Semitism in the Cantos, which has not garnered the necessary attention, is Pound's language use. As he liked to emphasise, the correct usage of words is paramount, not only for poets but for everyone. Pound frequently complained that economic problems could only be solved when they are couched in the right language. This idea Pound took from Confucius quoting in his Guide to Kulcbur. 'To call people and things by their names, that is by the correct denominations, to see that the terminology was exact'. ${ }^{211}$ Keeping this in mind, what becomes apparent is that the Jews in the Cantos are associated with language that deviates from the norm, reinforcing their status as the other. First of all, the Cantos denies the capitalised form to the Jews: throughout the whole poem, save for one instance ('Jew God' (50/247)), the Jews are referred to as 'jews'. In Casillo's words: 'This shift from the capital (signifying head, signifying phallus) to the lower case is [Pound's] way of cutting the Jews down to size-a linguistic gesture all the more striking since Pound, in his Fascist polemics and selfpromotion, favors a "capital" style."212 The use of the lower case can be interpreted in different ways. While the Jews are considered to have too much influence and are therefore the biggest threat or biggest evil, the typography suggests their being insignificant. It also seems to suggest that the distinction between 'small Jews' and 'big Jews' is not feasible - the 'jews', whether big or small, are all the same. Moreover, it is also a way to deny them their correct 
denomination and hence their correct treatment. Eliot who similarly linguistically cut down the Jews felt compelled to edit some of his poems after the Second World War, revealing that it was more than simply language play (but more on Eliot later). Another term that is used for the Jews in the Cantos (and also in Pound's other writings) is 'chew'. More than a simple play on the similarity of sounds, the association of 'Jew' and 'chew' could either hint at their supposed destructiveness (as in devouring) or at their, again similar to Eliot, supposed inferiority reducing them to a purely biological organism. Moreover, it could also equate the Jews with usury by forming a lingo-causal chain of Jew-chew-neschek (the bite)-usury. In his radio broadcasts Pound hinted at yet another reading, when he said that 'They [the press] are either men who KNOW NOT, or men who say not, and who put up a word screen, or esCHEW certain issues'. ${ }^{213}$ Here Pound not only makes again the connection between the press, the usurers and the Jews, but he also hints at the fact that eschewing certain issues is part of the Jewish conspiracy. Another possible interpretation of chew could be that it might be Pound's attempt to comically mimic 'Jewish pronunciation' of the word Jew. This is especially relevant in the light of a much bigger issue, namely that all Jews in the Cantos speak in non-standard English. This has only been noted (or remarked upon) occasionally by scholars, for example by Desai who writes that ' $[t]$ he lisp is obviously meant to be a sign of Mond's Jewishness'. ${ }^{214}$ The lines Desai refers to are: 'Napoleon wath a goodth man, it took uth / 20 yearth to crwuth him / it will not take uth 20 years to crwuth Mussolini' (78/497), which is repeated almost verbatim three cantos later 'It will not take uth twenty yearth / to cwuth Mutholini' (80/517). Yet this verbal strategy is not only applied to Mond but can be found on a regular basis in the Cantos. Further examples appear in cantos $16,22,35,38,52$ and 86 . Of course, the Cantos regularly plays with languages and accents, but this is more than just a way to ridicule Jews for supposed speech defects or their inability to correctly pronounce English. Even if some of these passages contain no attacks or 'incriminating material' (as opposed to the Mond passage above, which clearly hints at Jewish conspiracy), the language use adds insult to injury. Thus, it is a way of marking them as the other and, more seriously this time, of branding them as a distinct race that neither wants nor can fully assimilate, forever destined to stand out. Put simply the Jews are the eternal outsider in the midst of society. The nonStandard English applied to them becomes the verbal equivalent of the Yellow Star.

There are many more examples for the Cantos's inherent anti-Semitism, yet they all fall into the same poetic strategies as listed here. The Jews are shown as inhabiting the extremes of the spectrum, therby violating the Confucian doctrine of the firm middle while at the same time remaining in the 
midst of society. They are the capitalists and the communists - which both work against Pound's idealised notion of the state. In short, they are the primordial evil lurking everywhere. By associating the Jews with banking, usury, the infiltration of the press and in general a world conspiracy against the Gentile world, the Cantos recycles stereotypical anti-Semitic notions, which were rampant during Pound's time. Yet this does not make the anti-Semitism in the Cantos any less problematic. What Julius has so accurately observed in the case of Eliot that '[he] did not reflect the anti-Semitism of his time, he contributed to it'215, also holds true for Pound. The Cantos's unflinching conviction that the Jews cannot (and never will) change, feeds this belief of the Jews as the eternal culprit in history, despite the horrors of the Holocaust, which the Cantos not only passes over in silence, but in fact re-writes. Moreover, the Cantos's idiosyncratic language use concerning the Jews further highlights their supposed otherness. It also cements their status as a race distinct and unassimilable. And while the Cantos propagates no explicit solution to the 'Jewish question', they celebrate those historical examples that offered various solutions. The banishment of the Jews from England as well as the prohibition of usury are mentioned in Canto 108. Mussolini's draining of the swamps is repeatedly lauded and can be read as a metaphor for the expulsion of the Jews and usury, as the Jews in the Cantos are commonly associated with the chthonic. Finally, Benjamin Franklin's alleged statement ('better keep out the jews' $(52 / 257)$ ) is presented as the ultimate antidote to Jews and neschek. These instances call to mind Julius's description of the Englishman's Jew being 'wicked, malignant, but ultimately conquerable'. ${ }^{216}$ There is no need to go to Pound's more explicit anti-Semitic writings to find examples of even greater malice; there is also no need to discuss how much Pound knew about the Holocaust as it unfolded or whether the anti-Semitism of other writers was even worse. In the end, the fact that Pound was surrounded by even greater evil does not diminish the anti-Semitism in the Cantos.

\section{'MA QVESTO'}

Many scholars have focussed on Pound's non-literary writings as well as personal communication to deduce his fascist leanings. I want to emphasise the inherent fascist politics in the Cantos, since the poem, in contrast to the poet, lives on and its politics with it. Moreover, it will become apparent that Pound's epic poem is especially suitable (or especially vulnerable) to be read as a eulogy to fascism. Composed over a time span of several decades, the fascism in the Cantos is far from stable: not present at first, then starting to 
furtively glance through until it has forcefully asserted its presence. With the death of Italian Fascism, it goes into hiding (but never really vanishes again). It is precisely this trajectory that makes the fascism of the poem so potent and also so disturbing. Whereas the poem's first half increasingly revels in fascism's greatness, its second half mourns its demise, the fault line running between the 'Italian Cantos' 72-73 and the 'Pisan Cantos'. Therefore, when presenting the varying fascist instances in the poem I will also take care to show the transformation the epic undergoes. The death of Italian Fascism did not cause the fascism of the poem to die, yet it prompted a change of tone and style. A change that is sometimes mistaken as a recantation of fascism, while it is, in fact, and here I wholly agree with Nick Selby, a re-cantation of fascism. ${ }^{217}$

There is no reference to fascism in the first instalment of the Cantos. This does not mean that it is devoid of politics as it contains attacks on usury, politicians, financiers, war profiteers as well as other European leaders deemed responsible for the war. As I have demonstrated above the method of juxtaposition would allow these instances to be read in a way that they could be deemed anti-Semitic and fascist. Yet, there is a more salient reading of these first thirty cantos: they pave the way to fascism. Pound remarked in a $\mathrm{BBC}$ interview how the first half of the Cantos 'is a sort of detective story', a search for the crime and for the culprit. 218 The crime and culprit, as has become apparent by now, is usury and later 'Jewsury'. The first set of cantos presents the search of the crime scene, collecting clues. What it does not offer is a viable solution to the crime. Thus the rottenness of contemporary England is juxtaposed with the mystified past of Odysseus, with Confucius, or with Malatesta, painfully aware of the fact that at present they are destined to remain in the past. In this way, these cantos are not yet propagandistic but analytic: they merely show the problems that need to be solved. Complementary to my previous readings I wish to focus on two instances from this set of cantos. In Canto 19 readers get glimpses of the moral bankruptcy of the capitalist system. Yet more than a critique of the inequality of capitalism, it focuses on the underlying (supposed) conspiracy that keeps the system alive and immune from enemy attack. It starts with the word 'Sabotage?' (19/84) and continues with one instance of big companies swindling individuals out of their ideas and inventions. More importantly it recounts (and maybe embellishes) the meeting of Pound with founder and leader of Sinn Féin Arthur Griffith (although no names are mentioned), which is worth to be looked at more closely:

So we sat there, with the old kindly professor,

And the stubby little man was up-stairs.

And there was the slick guy in the other 
corner reading The Tatler,

Not upside down, but never turning the pages,

And then I went up to the bed-room, and he said,

The stubby fellow: Perfectly true,

"But it's a question of feeling,

"Can't move 'em with a cold thing, like economics."

And so we came down stairs and went out,

And the slick guy looked out of the window,

$[\cdots]$

O my Clio!

Then the telephone didn't work for a week.' (19/84-85)

Pound and Griffith meet and talk about the economy, which leads Griffith to exclaim that although economics is at the root of everything it cannot be sold to the masses because it is not emotional enough to rouse them. Their talk is being observed by a detective, who (so it is implied) alerts authorities who subsequently cut off the hotel's telephone and this is the way history (' $\mathrm{O}$ my Clio') is shaped. As founder of Sinn Féin it is entirely possible that Griffith was being observed by British authorities. Nevertheless, the Cantos here presents a conspiracy theory together with a line of causality, which as most conspiracy theories cannot be proven as true, yet it is exactly this element, the lack of evidence, which is then taken as proof for its authenticity. The Cantos thus makes ample use of its ambiguous nature of a 'poem containing history': it incorporates history but is not bound to the limitations of available and confirmable facts. Ironically, a few pages earlier the Cantos celebrated exactly this humbleness in respect to the limitedness of human knowledge in Confucian China: 'And even I can remember / A day when the historians left blanks in their writings, / I mean for things they didn't know, / But that time seems to be passing" $(13 / 60)$. The Cantos are not shy in filling the blanks, in fact, owing to Pound's idea of the artist as prophet, especially the poets could fill the blanks before the historians would be able to validate their prophecies. The second example from the first instalment that leads the alert reader to fascism is Canto 30, more specifically Artemis's 'Compleynt against Pity'. What seems at first to be another glimpse at the mystified past is, in fact, a condemnation of 'unnaturalness'. As the earlier cantos have made quite clear it is usury, sodomy, democracy and equality that are against nature: 'Pound's point is that democracy and usury $[\ldots]$ interfere with natural struggle by permitting the unworthy to live'. ${ }^{219}$ 'Compleynt against Pity' bemoans the lack of beneficial violence to weed out the good from the bad, a notion that lies at the heart of fascism. Violence as a positive force figured prominently in Sorel's thinking, but was also echoed in the Futurist battle cry of 'war as the only hygiene of the world'. Artemis, the goddess of the hunt, serves as the mystical 
precursor to this beneficial violence. The constant evocation against pity in combination with Artemis as the speaker ('Pity spareth so many an evil thing / Pity befouleth April' (30/147)) makes clear that the poem advocates if not outright violence so at least 'nothing more lethal than a rigorous attitude towards life'.220 The style of the poem also foreshadows the Usura canto 45, and so Artemis becomes the answer to usury. It is only a short step from Artemis weeding out the weak to the fascist axe clearing away the rubbish: 'USURY is the cancer of the world, which only the surgeon's knife of Fascism can cut out of the life of nations'. ${ }^{221}$ Casillo summarises it aptly: 'In short, "Compleynt against Pity" is inseparable from the fascism which it in fact adumbrates'. ${ }^{222}$

The next section of the cantos, 'Eleven New Cantos' (also 'Nuevo Mundo Cantos'), offers a juxtaposition of the United States of the founding father and early presidents, with Pound's contemporary Europe as well as Mussolini's Italy. This suggests that the nuevo mundo is not necessarily America, but also Fascist Italy. It is not by accident that the first canto of this section, Canto 31, is largely devoted to Thomas Jefferson, while this section's last, Canto 41, introduces Mussolini. It is again the method of juxtaposition that is at work here and that allows readers to equate both political leaders. During the time these cantos were written Pound also worked on the manuscript for Jefferson and/or Mussolini, written in 1933 and published in 1935. Thus, both texts can be understood as complementary reading. When William Cookson tries to deny or downplay Pound's fascism by asserting that

The Cantos represents an attempt to restore the Anglo-Saxon heritage - it is against unlimited sovereignty and therefore fundamentally anti-fascist. Pound was a Jeffersonian who believed that the state, the res publica means, or ought to mean 'the public convenience, 223

he does not see that in the Cantos (and in Jefferson and/or Mussolini) the Duce is considered not only on par but as the living successor of Jefferson. Both have a will to action and both head a government, which earns Pound's seal of approval because: 'A GOOD government is one that operates according to the best that is known and thought. And the best government is that which translates the best thought most speedily into action. ${ }^{224}$ Additionally, the equation of Jefferson (and other early American presidents) with Mussolini serves another purpose. Pound was critical of exporting Italian Fascism to England or the US, yet by showing the similarity of Jefferson and Mussolini and their supposed closeness in ideas, he could convincingly argue that fascism was not purely an Italian phenomenon, but a system that could just as well work in the US, even under the term 'democracy'. ${ }^{225}$ As David Ten Eyck observed, Pound's equation of the United States of the early presidents and Mussolini's 
Italy is also based on Pound's understanding of the term democracy. 'Pound coined the term 'organic democracy' to describe the political vision of the American founders'. ${ }^{226}$ Ten Eyck goes on to quote from an article by Pound entitled 'The Fascist Ideal' (1936), in which he writes:

The founders of the U.S.A. did NOT state that all men are equal; they said they are born free and equal, meaning born OUT of chattel slavery, and equal in the sight of the law. This applies, and has been better stated, in Fascist Italy. Italians are equal in the eye of the law, and 'differ only in grade of responsibility.' I reiterate the need for anyone who wants to understand Italy of the Second Decennio to distinguish between ORGANIC and inorganic or chaotic democracy. ${ }^{227}$

Moreover, what Cookson also omits in his short explanation, cited above, is that the Cantos makes quite clear that unlimited sovereignty is not only found in the single emperor but also 'in a majority of a popular assembly, /an aristocratic council, [and] an oligarchical junto' (33/160). Thus aristocratic rule, the newly emerging mass democracies as well as a world ruled by international finance (meaning the Jews) are to be rejected just the same. The fact that the Cantos includes this Jeffersonian quote at length and then equates him with Mussolini suggests that Mussolini is not to be deemed a single emperor.

A closer look at Canto 41 will clarify Mussolini's importance in and for the Cantos. It starts with a recollection of Pound's first and only meeting with the Duce. Its dominant position in this Canto and its reiteration in the following cantos underlines the importance of this meeting between artist and fascist ruler. More than just a personal anecdote of the poet, it hints at the important position of artists in society, or specifically in a fascist society. When the poem cites Mussolini lauding the Cantos - "MA QVESTO," / said the Boss, "è divertente." [I like it ... it is amusing]' (41/202) - it is not only the poem that is put in a favourable light, but also Mussolini. The fascist ruler is presented as having a superior understanding of the nature of things 'catching the point before the aesthetes had got there' (41/202). If artists are the antennae of the race, the wise ruler, so the poem suggests, should heed their words. In Mussolini's case, the ruler could even become an artist or artifex: 'Treat him as artifex and all the details fall into place. Take him as anything save the artist and you will get muddled with contradictions. Or you will waste a lot of time finding that he don't fit your particular preconceptions or your particular theories'. ${ }^{228}$ It also equates the ruler and the artist, suggesting that they are both alike in character and importance. ${ }^{229}$ Similarly, the other quote that appears later in the Cantos is Mussolini's reply 'Why do you want to [put] your ideas in order?' (87/589) after Pound had explained his economic ideas to him, serves as proof that the Duce had both artistic sensibility and an understanding of Pound's preferred economic principles. ${ }^{230}$ Canto 41 strongly sug- 
gests that Mussolini is the ruler most apt to solve society's supposed woes: he understands and appreciates the arts, he drained the swamps (something that had not been done for 2000 years) and he punishes the (Jewish) ${ }^{231}$ financiers and usurers. These three actions are of high symbolic value illustrating that Mussolini combines some of the most valuable characteristics a good leader should possess: he is an artist (or patron of the arts), he is a man of action, and he fights usury. Also the language used here propagates fascist ideology, including the leadership principle, devotion to the leader and a fascist rewriting of history. Mussolini is called 'the Boss' implying that his leadership is in no way questioned. Moreover, the devotion of the Italian people is given a voice by 'the commandante della piazza', when he is made to say: "Noi ci facciam sgannar per Mussolini" [We would let ourselves be butchered for Mussolini]' (41/202). ${ }^{232}$ The Cantos also starts to use the Fascist calendar, the significance of which I have described above. This taken together with further instances that rationalise Mussolini's politics - putting Mussolini's war in Ethiopia into the context of Hanno colonising the African West Coast in Canto 40 as well as defending Fascist state censorship by quoting the Duce 'where there is no censorship by the state / there is a great deal of manipulation' (41/205) - show that the Cantos from the 'Nuevo Mundos' section onwards has begun to fully embrace fascism.

This trajectory is kept up by the following two sections of the Cantos (42-51 and 52-71). Readers will find the now familiar methods of juxtaposition and equation used extensively. The 'Fifth Decad of the Cantos' emphasises the importance of economy contrasting the Monte de Paschi, a commendable bank (Canto 42-44), with usury (Canto 45-46). In short, cantos 4251 revolve around usury and its elimination. Cantos 52-71, the 'Chinese and Adams Cantos', also form a juxtaposition, this time focussing on the political similarities of Fascist Italy, various Chinese dynasties and the United States of the early presidents. I have already looked at Canto 52 in detail and how its divergent parts are linked via ideology. Moreover, the subsequent cantos on Chinese history are repeatedly interrupted by references to Mussolini and Fascist Italy. In Canto 53 the Italian word ammassi (grain pool) momentarily suspends the meditation on Chinese history and establishes a connection with Fascist Italy's successful agricultural scheme. In this way the canto equates two able leaders, Yu and Mussolini, so when three Chinese ideograms YAO CHUN YU praise the eminent wise Yu a page later, one can read this as praise for Mussolini as well. This technique of equating a positive example from Chinese history with a positive example from Western history via the inclusion of a short references can be found multiples times in the "China Cantos', for example in cantos 55, 56, and 57. Especially Canto 56 exhibits two references to Fascist Italy and one to Hitler in a retelling of Chinese his- 
tory. With Canto 62 the so-called 'Adams Cantos' begin and already the fact that the history of China and the early history of the United States are conjoined in this section makes the equation of both systems obvious. Moreover, in the 'Adams Cantos' the technique 'equation-via-reference' is also used. This can be demonstrated with the allusion to Hitler found in Canto 56 and Canto 62: In Canto 56 the lines go 'This is called Destiny / Schicksal to bring peace to the Empire' (56/308). Again as with Fascist Italy before, there is no direct reference or mention of Hitler or Germany, it is simply evoked by the 'intrusion' of the German word into the English text on Chinese history. However, in Canto 62 the reference becomes more explicit: 'Providence in which, unfashionable as the faith is, I believe / Schicksal, sagt der Führer' (62/345). Written in the late Thirties and published in 1940 the German word 'der Führer' serves as a stand in for Hitler, which most readers would have understood. The reading here seems clear: Mussolini, Yu, Adams, Hitler as well as several other Chinese emperors all belong to a group of able leaders. This again mirrors the argument in Jefferson and/or Mussolini, in which Pound explicitly compares and equates both statesmen. Moreover, in Jefferson and/or Mussolini, Pound introduced one of his favourite mottos, which can also be found in the Cantos (first mentioned in Canto 53):

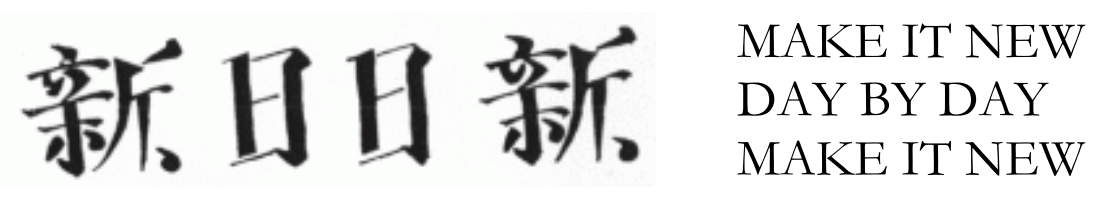

This famous motto is often seen as pertaining to Modernism, but in the context of the Cantos as well as Jefferson and/or Mussolini it has serious political reverberations, namely that continued renewal serves as an ideal paradigm for political action. When Pound explains the meaning of 'Make it New' as 'Confucius on "La rivoluzione continua", a term often associated with fascism, especially Italian Fascism, he equates Confucianism with Fascism, thus bestowing Confucian wisdom on fascist action. Moreover, 'reading' the hsin ideogram (the first and last in the above image) as 'show[ing] the fascist axe for the clearing away of rubbish', adds political significance to the motto of renewal, a notion that was foreshadowed in 'Compleynt Against Pity'. 233 The temporal proximity of Jefferson and/or Mussolini and Cantos 52-71 suggests the essay's function as a guide to the Cantos, ensuring that readers would understand the ciphers and references. Although covering diverse historical and present examples, Cantos 52-71 can make them cohere. This steady flow of ideas is interrupted by the introduction of the 'Italian Cantos' 72-73.

The 'Italian Cantos' stand out from the epic in many ways, first and foremost because they are written in Italian. They were also the last part to be published, although they were composed during the Second World War. It 
took even longer until they were inserted into the 'correct' numerical position, i.e. between Cantos 71 and 74 and no longer hidden in the Appendix. And yet, despite the differences they fall very smoothly into my reading of the Cantos as a fascist chronology, because more than any other cantos they can be read as fascist propaganda. Written in Italian, in order to be published in Italian magazines during the war, shows that they were also supposed to be used as propaganda for the Italian people to keep up the fight, the central motif of both cantos. In Canto 72 the poet persona meets the ghost of the recently deceased F. T. Marinetti, who asks for the poet's body so that he can go back to war. The poet declines, arguing that he needs his body himself and that Marinetti should rather look for the body of a young and otherwise useless man: 'Find some young man / I mean take some young 'un, lily-livered, beetle-brained, / an' buck 'im up a bit, put an ounce of sense in his head,' (72). 234 Moreover, the poet maintains that he will aid the war effort, not by fighting on battlefields but with words: 'But I'll put you in my song, I give my word to you, it's yours.' (72). After Marinetti the poet meets other spirits, who all in turn proclaim their fervour to fight: 'We shall return! WE WILL return!' (72). The canto seems to be modelled again on Dante's Inferno. Yet opposed to the 'Hell Cantos' where the poet persona saw London turned into the living hellbog and the people transformed due to their vices (especially usury), here in Canto 72 the setting is the hell of the real battlefield with the people the poet persona meets as valiant fighters. Read in juxtaposition with the 'Hell Cantos' England is corrupted from the inside-out and therefore like hell, whereas Fascist Italy is pure and righteous, and therefore turned into a hell by outside forces (read: the Jews and their fellow-conspirators). Hence one can find in the almost Dantean narrative many of Pound's familiar political convictions:

[God] shat that arch-usurer

Old Nick Geryon, prototype of Churchill's masters

[...]

dung piled up to Bologna

with ravaging and raping, and at Bagnacavallo

Moroccans and other such filth -

a shame, even to name them

[...]

I have seen a lot of dirt in my time;

history is full of that dirty lot, the betrayers of a city or a province,

but what sort of abortion

sold all Italy, the whole Empire!'

[...]

'I am that Ezzolino who would not believe

the world was made by a Jew.' (all from 72). ${ }^{235}$ 
Canto 73 continues in this fashion: 'Roosevelt, Churchill, and Eden, / the Jews, the bastards, / swindlers, the whole lot liars,' (73/438). Here the Cantos echoes the language used in the radio broadcasts, Pound recorded during the same time, denouncing the Allied leaders as Jews, and no longer simply as the supporters of Jews. Pound would also use 'jewified' names such as 'Rosenfeld' (for Roosevelt) or 'Weinstein' (for Churchill) in his broadcasts and letters to stress this point. ${ }^{236}$ Accusing Roosevelt, Churchill, and Eden and therby the Jews of starting the war can also be found in his broadcasts when he wrote that 'Hence of course Mr. Eden's war. Mr. Churchill's war, Mr. Roosevelt's WAR'. ${ }^{237}$

Italy's answer to the Allies' war is recounted in Canto 73 by the spirit of Guido Cavalcanti. It is the story of a peasant girl, who after being raped by Canadian soldiers, leads a troop of them, who asked for the way, into a mine field sacrificing herself and killing twenty soldiers. After she dies, she is depicted as walking arm in arm with Germans, thus stressing the ItalianGerman alliance. This gruesome tale of propaganda 238 receives an ode-like quality as it is turned into a love song by Cavalcanti (and Pound), for it is made quite clear that Cavalcanti fell in love with the girl and her courageous act: 'and I felt desires / of love reviving / in despite of my years. / They have such ways, the girls. / in Romagna'. This gives way to the old Horacian warhymn 'Glorious, it is glorious / to die for one's country'. Compared to Hugh, which had chastened the war with the words 'died some, pro patria, non "dulce" non "et decor", the 'Italian Cantos' fully embrace death as a patriotic act. Apparently, dying for the right cause could indeed by glorious. Reading these two war poems side by side emphasises the propagandistic qualities of the 'Italian Cantos', their disregard for human life over the celebration of human sacrifice. Even though the previous cantos were never shy in voicing political opinions, the 'Italian Cantos' stand out in their partisanship for Fascist Italy and its supposedly righteous war against the Allies and 'Jewsury'. Moreover, and this significantly adds to their propagandistic quality, the 'Italian Cantos' are relatively easy to understand compared to the rest of the Cantos. They present a more or less linear narrative and need very little explanation to bring their central points across. The reversion to simpler language and the relative lack of obscure 'ideogrammic' juxtapositions suggest that these cantos were aimed at a wider audience. Just as the usual war propaganda they spoke to the masses (and not a select few), telling the Italians to keep on fighting by presenting to them a line of 'heroes' who had fought and died pro patria - and are now celebrated in song. Canto 73 fittingly ends on an idealised notion of Italy's future when Fascism will have triumphed and 'the children all / wear black'. Soon Pound had to realise that this future would never materialise. 
Finding himself confined in the prison camp in Pisa, he began to contemplate Italy's defeat. Thus the 'Pisan Cantos' was born.

The melancholic poetics of the 'Pisan Cantos' fit the general theme of loss and disappointment. Undoubtedly they contain some of the most beautifully crafted passages of the Cantos, yet this should not distract readers from the fact that they are suffused with fascist ideology, or more precisely the woe about the defeat of Fascism. The view that the 'Pisan Cantos' are Pound's realisations of his errors and his return to nature, myth and religion is not borne out by these cantos. Instead, reading the 'Pisan Cantos', one constantly stumbles upon fascist references that show no trace of remorse or repudiation. I agree with Selby, when he critically observes 'that it is precisely through the 'lyricism' and 'mythified observations' of these cantos that Pound reconfigures rather than displaces his political concerns'. ${ }^{239}$ 'The 'Pisan Cantos' are trying to make sense of Fascism's demise and they do so with the help of concepts such as 'sacrifice' and 'myth', which lie at the core of fascism itself. Already the beginning employs the idea of sacrifice:

THE enormous tragedy of the dream in the peasant's bent shoulders

Manes! Manes was tanned and stuffed,

Thus Ben and la Clara a Milano

by the heels at Milano

That maggots shd/ eat the dead bullock

DIGONOS, $\Delta$ írovos, but the twice crucified

where in history will you find it? $(74 / 445)$

It is apparent that the defeat of Fascism is seen as the tragedy of the dream. The peasant here links back to the peasant girl in Canto 73, who sacrificed herself for her country and now is joined by Mussolini and his mistress. Moreover, Mussolini is described as the twice-born and twice crucified, followed by a question that implies that he is singular in history. Also the language used here betrays these cantos' unbroken adherence to fascist ideology. 'Maggots' was the fascist slang for anti-fascist partisans but also hints back at Pound's earlier attacks calling Jews vermin and parasites. I have shown earlier that the 'Pisan Cantos' exhibits some appalling instances of anti-Semitism, yet it also repeatedly employs fascist terminology and language, trying to keep the Fascist legacy alive. It is also not by accident that this tribute to Mussolini inhabits the focus position at the very beginning. As Ronald Bush has shown with the help of the manuscripts, these lines were not the first Pound composed in Pisa. Quite on the contrary, '[i]t was likely among his last decisions at Pisa to affix the page with the lines on Mussolini' ${ }^{240}$ to the very beginning. Yet it is not only in the beginning that readers meet Mussolini and his fellow fascists. Returning to the concept of myth, the answer to the loss of the Fascist dream is the evocation of historical and for Pound quasi-mystical places such 
as Ecbatan and Wagadu. ${ }^{241}$ By pairing Fascist Italy with Ecbatana and Wagadu, the Cantos suggests that the greatness of Fascist Italy will survive its material destruction - and that it eventually will be rebuild. Meanwhile the Cantos create an imaginary home for the remnants of Mussolini's Italy. The roll call of Fascist personnel makes quite clear who is to inhabit this imaginary home. Here the 'Pisan Cantos' makes use of yet another Fascist custom, which is evoked by the inclusion of the phrase "Presente!". This slogan was shouted at Fascist gatherings by everyone present when during roll call the name of someone who had died fell, suggesting that this person or his spirit was still present. In the Cantos it is repeatedly used to infer the presence of a Fascist persona. Yet the 'Pisan Cantos' does not shy away from more explicit roll calls: apart from Mussolini it mentions Giachino Nicoletti, Hitler, Gianpietro Domenico Pellegrini, Guiseppe Volpi, Giorgio Paresce, Vidkun Quisling, Allesandro Pavolini, Fernando Mezzasoma, Pierre Laval, and Philippe Henriot - all of these were associated with Italian Fascism or other fascist or NS Governments. The Cantos celebrates these people and moreover keeps their names alive in poetry, or as the 'Italian Cantos' proclaimed, they are put into song. The melancholy of the 'Pisan Cantos' is an offer of tribute mingled with grief to those who fought for fascism and lost. Despite the death of Fascist Italy the 'Pisan Cantos' incorporates fascist signifiers, which, it refuses to give up, or as Selby suggests: 'Pound's] poetic city is built, finally, from a bundle of Fascist mottoes'.242 Prominent among the fascist signifiers, the 'Pisan Cantos' continues to employ the Fascist calendar. Furthermore, there are references to Mussolini's manifesto that was adopted as the principles of action by the short-lived Republic at Salò, and also to a recurring fascist axiom that 'We are tired of a government in which there is no responsible person having a front name, a hind name and an address'. The 'Pisan Cantos' also includes Mussolini's statement that 'Liberty was not a right but a duty', to which is added 'those words still stand uncancelled' (74/499). It is difficult to argue that these are the words signify a recantation of fascism. It might seem repetitive or, indeed, needless to remark that the 'Pisan Cantos' considers the Jews as responsible for Mussolini's death - "hang'd dead by the heel .../ [...] / "For a pig," Jepson said, "for a woman." For the infamies of usura," (78/502) - and Fascism's demise: 'It will not take uth twenty yearth / to cwuth Mutholini' (80/517). There is certainly a lot more to the 'Pisan Cantos' than fascism, yet it cannot be denied that its steadfast adherence to fascism is integral to this section. The most disturbing aspect of the 'Pisan Cantos' is, that it, more than other instalments of the Cantos, succeeds in marrying poetic beauty with repugnant political convictions.

If Pound's time at Pisa brought no significant change to his poem's adherence to fascism, it is not surprising that neither did his time at St Eliza- 
beths. Quite on the contrary his (supposed) position as political prisoner who was allegedly locked away to keep him silent helped to convince him that he was 'on to something'. The 'Rock-Drill' and 'Thrones' sections manifest this conviction by relentlessly hammering in a plethora of familiar facts, quotes and references into the reader. These are not as explicit as in earlier instalments, which reinforce the sense of being under surveillance. In fact, I would read this change in style as a direct critique of his country's supposed revocation of free speech. The indictment for treason and the ensuing trial had shown that even 'mere words' can be seen as traitorous. At first glance especially 'Rock-Drill'243 seems mostly preoccupied with Confucian philosophy. I have already touched upon the equation of Confucius and Mussolini, and the idea of Confucianism as an anti-dote to usury. So it should not come as a surprise that references to Mussolini mingle with the multitude of Chinese ideograms. Canto 86 recounts an episode that is supposed to serve as further proof that the Rothschilds and other wealthy Jewish families are in control of states. This ends with a question: 'but what will they trust in now?' and promptly delivers the answer in the form of Mussolini's statement "Alla non della", in the Verona statement' (86/584). In short, Fascism, is still, the answer to usury. Mussolini's presence is even made more explicit in the next canto, when the meeting of Pound and Mussolini is referred to again with the quote: "Why do you want to / "- - perché si vuol mettere- / your ideas in order?"” (87/589). I have already explained the significance of these words in the context of the Cantos. The fact that it is still partially Mussolini's voice that can be heard implies that this section, similar to the 'Pisan Cantos', tries to keep his legacy alive. In 'Rock Drill' this quote moreover emphasises the fact that Mussolini's thought is still important and his remark serves as a counter to those who would put a poet in the madhouse for to his ideas. While the insanity plea most likely saved Pound the poet from a much harsher punishment, it helped to spin the narrative of these later cantos of the artist, who instead of being celebrated for his ideas by the ruler, is locked away by the government on account of them. The way that these later cantos repeatedly hark back to Fascist Italy invites readers to compare the two political systems. Fittingly, 'Rock-Drill' does not use the Fascist calendar, suggesting that its vantage point is no longer Italy but America. The significance of Mussolini's quote is further underlined by its re-appearance in canto 89 - in which also Pound's daughter Mary's anecdote with the Jew who wants money and a short reproach of the the fascists Philippe Henriot's and Giovanni Gentile's assassination can be found - as well as in Canto 93. Another instance of juxtaposition similar to the Rothschild-Mussolini one above occurs in Canto 91 when 'Democracies electing their sewage / [...] / a dung flow from 1913 / and, in this, their kikery functioned, Marx, Freud / and the american beaneries / Filth under filth,' 
(italics in the original 91/633-634) is contrasted with the honourable sacrifice of 'Nanni (Torquato) [who] / wasn't shot till after Salò. / Threw himself in front of a friend (Arpinati) / but cd/ not save him.' (91/634). Reminiscent of the 'Hell Cantos' the democratic Jew-infested cess-pool is contrasted to the noble idea of fascist sacrifice, evoking the 'Italian Cantos'. There remains little to unpack as 'Rock-Drill' makes use of earlier imagery and well-known rightwing clichés. In Canto 92 there is again a similar instance when Carlo Delcroix, who was blinded in the Fascist struggle, is opposed to the ' $[t]$ wo evils: usury in the bank rot / \& theft in les soc/ anonymes' (92/641). Interestingly 'Rock-Drill' also includes a number of references to Hitler. In Canto 90 the passage 'Evita, beer-halls, semina motuum, / to parched grass, now is rain / not arrogant from habit / but furious from perception,' (90/626) evokes Hitler's beer hall putsch as a semina motuum, a seed for revolution, which is deemed as good and vital as rain to parched grass. That the one 'furious from perception' is most likely Adolf Hitler becomes apparent in 'Thrones' when the quote is repeated as 'Adolf furious from perception' (104/761). The phrase 'furious from perception' can be read not only as a pun (furious and Führer), but again as an equation of artist and ruler, both being characterised by their ability to perceive things before others do. Evita in this reading is Eva Braun, and at the same time refers to Eva Peron, wife of the Argentine president Perón, who made Argentina during his presidency a safe haven for many National Socialists. This positive appraisal of Hitler becomes even more disturbing in the light of Canto 108, which details the expulsion of the Jews from England. This suggests that there are different solutions to the 'Jewish question', but that it still awaits to be finally solved. Mussolini makes a number of reappearances in 'Thrones'. Readers get glimpses of Mussolini, 'seven Cardinals attended his funeral' (96/673), of Italy still in mourning about the loss of Fascism 'Black shawls still worn for Demeter in Venice' (102/748), ${ }^{244}$ the lament that 'we thought we could control Mussolini' (98/706 and 102/749), the treason against Mussolini, which he always expected 'tranne nella casa del re' [except in the house of the king] (103/753), and Mussolini sending troops to Spain to help Franco in Canto 105. Moreover, both sections, 'Rock-Drill' and 'Thrones', incorporate the hsin' ideogram, which Pound read as signifying the permanent revolution of fascism. What seems like a haphazard collection of anecdotes - or gists and piths - is conjoined by a fascist undercurrent, or more precisely an undercurrent mourning the demise of historical fascist regimes.

Yet, post-war right-wing extremist movements also found their way into these sections of the Cantos. As Alex Houen and Marsh have shown, Pound was well aware of and associating with groups who actively worked at an American version of fascism. From his personal correspondence and his 
visitors' recollection it is known that Pound still held his old political views and that he liked to associate with people like John Kasper, a devout Pound admirer who fought for racial segregation and was repeatedly apprehended for inciting racial violence - all with the support of Pound. ${ }^{245}$ Pound's correspondence with Kasper discloses that Pound was supplying American rightwing and white supremacist forces such as Kasper himself, John G. Crommelin, Pedro del Valle, and possibly George Lincoln Rockwell with written material for their events. When Kasper asked Pound:

'Can you write some short quotable slogans. Nothing highbrow.../ And 5 minute speeches. and 15 minutes speeches.

on Segregation/States rights.

Mongrelization/Separation of Races.

NIGGERS.

and JEWS: the Admiral has taken up THE Question openly and it hasn't hurt him. The kike behind the nigger....'

Kasper's subsequent letter to Pound thanking him for his efforts ('The Admiral sends his warmest regards and appreciation of all effort from D.C. he has used at least $1 / 4$ of Grampian summaries./The pome [poem] will be used SOMEHOW.') makes apparent that Pound was happy to comply. ${ }^{246}$ Both Crommelin and del Valle can be found in Canto 105, where they are celebrated as defenders against 'the swine' and their ' $\pi \alpha v o v \rho \gamma i$ ' $\alpha$ ', i.e. villainy (105/771), linking it back to the 'chazims and neschek' of Canto 52. Kasper was quick to realise the importance of the inclusion of 'their cause' into the Cantos, writing to Pound: 'New lines re Cromm/ and D.V. [del Valle] mighty fine and much appreciate seeing contemporary hist[ory]/ fitted between the permanent'. ${ }^{247}$ Additionally Marsh has revealed that many of the later cantos include references to the political issues Kasper was actively involved in:

The swine backed with their panourgia refers to Pound's and Kasper's shared view of "the kike behind the nigger." As we know, Pound did not believe that Americans of African descent would have been motivated to assert their rights as citizens without prompting from the Jewish Communists who ran the NAACP. This theme is reiterated through the later cantos: "freemen," Pound insists (always in Southern context) "do not look upward for bounties" (88/604, 100/735); "freedom not favored by tenantry" (89/604). We have seen that Pound believed that slavery was not the key issue that caused the American Civil War: "The slaves were red-herring" he asserts in Canto 103 (103/752); and in Canto 89 "The Civil War rooted in tariff (89/616). Financial machinations, not conflicting modes of production and labor systems caused the war. In fact, in Pound's view, they caused all wars. In sum, African-Americans were unlikely to fight for their own rights; other people with financial stakes in the outcome had put them up to it. ${ }^{248}$ 
As with the many other references to fascism the presence of white supremacists and their causes in the Cantos does not only keep them alive, but gives them the added benefit of association with a modern literary masterpiece.

The last part of Pound's epic, 'Drafts \& Fragments', is also often seen as a recantation on behalf of the poet, who now sees his errors: 'I lost my center / fighting the world', and asks for forgiveness 'Let the Gods forgive what I / have made / Let those I love try to forgive / what I have made' (both: Notes from 117/822). I have already touched upon the anti-Semitism of this section. Now I wish to add a more pessimistic reading that suggests that there is no recantation but instead a sense of failure. Canto 110 returns to Italy and readers again encounter the now familiar $h \sin ^{1}$ ideogram. There follows a moment of introspection: 'That love be the cause of hate / something is twisted,' (110/800). While it is true that there is a sense of regret here for the hate that Fascism unleashed, this quote also associates Fascism with love. In this light, the passage from canto 117 'M'amour, m'amour / what do I love and / where are you?' (117/822) leaves a bitter aftertaste, in that the love that is mourned here might be Fascist Italy. This reading can be corroborated by comparing it to an earlier text of Pound 'A Visiting Card' (1942), in which he invoked the strong interrelation of 'love' and 'Italy' by visualising their textual connection, 'Roma' being an anagram of 'amor'. ${ }^{249}$ The 'haunting sense of loss'250 that this section, similar to the 'Pisan Cantos', evokes is thus always the loss of Fascism. The failure that these last poems express ('I cannot make it cohere') is connected to the Cantos itself, the hope to write paradise or to create paradise on earth. If this is read as remorse it is not a remorse about being wrong or being cruel (or, more precisely, for inciting hatred) but about failing to be a prophetic artist (the antenna of the race), or in Pound's words: 'I am not a demigod' (116/816). In this light it seems almost absurd how much weight is given to these last lines in the hope that they could remedy the political viciousness present in the preceding cantos. This might be especially true for Canto 120 (in my version part of 117 , the section starting with 'I have tried to write paradise' and ending in the above quoted lines asking for forgiveness), which was repeatedly pushed to be used as the final canto. ${ }^{251}$ No doubt, these lines are moving, but are they a sign of true remorse or honest recantation? Almost apologetically Ferrall writes '[b]ut at the risk of being moralistic [...], it might be observed that it is not from the Gods or those he loves that he should be asking forgiveness'. ${ }^{252}$

Looking back at all these instances it is difficult to deny that fascism plays a pivotal role in the Cantos. I would go further and maintain that the poem can be read as fascist propaganda, or especially in the second half as a tribute to fascism. Bacigalupa called the Cantos 'the sacred poem of the NaziFascist millennium'253 and I hope it has become apparent why he may be cor- 
rect in calling it that way. The most disturbing aspect about the Cantos's fascism is not the mere fact of its existence, but its successful fusion with poetic beauty that ensures its survival. The Cantos offers no counter to the reader who approaches the poem as a validation of the righteousness and greatness of fascism. Those critics who try to explain the fascism away or who downplay its importance might make matters worse as they relegate the discussion of the poem's politics to the margin of the debate. Neither ignoring nor highlighting the Cantos's fascism will make it disappear, but putting it into the spotlight could, at least, tame it. The Cantos's non-linear understanding of history makes it quite clear to the reader that just because the historical Fascist movements have been defeated, fascism itself is not dead and can - or even will - again rise phoenix-like from the ashes. In the light of the present surge of right-wing forces all over Europe it might also serve as a cautionary tale.

\section{'His rod hath made god in my belly'}

The gender dynamics in the Cantos have not yet received as much attention as other ideological issues. Nevertheless they say a lot about the ideology of inequality at the root of Pound's epic. Hesse has remarked how the avant-garde has brought forth the 'avant-garde macho as an international phenomenon'. ${ }^{254}$ And while it is true that the avant-garde also boasted some female artists, the quintessential avant-gardist was male and additionally seemingly convinced of male superiority. This was certainly a reflection of the changing rights and roles of women in society, but it also reverberated in the art and literature produced by these men. Moreover, it fed into the largely right-wing ideology of many artists and was in turn nourished by precisely this ideology of inequality. Especially extreme right-wing ideologies like fascism and Nazism celebrated a hard, violent and virile masculinity, while they shoved women back into the private sphere. Pound's Cantos wholly subscribes to the idea of male superiority. It presents a world where history is shaped by strong men and where intelligence and creation is a male domain. Women are relegated to the decorative realm: as muses and mistresses, lovers and even non-human forces. Those who do not comply with those gender stereotypes are chided: powerful women are seen as threatening order, weak men are despicable, and 'unmanly' men are put on a level with usurers. Thus, the gender dynamics of the Cantos complement the general right-wing structure. ${ }^{255}$

My previous readings have shown that the people who make history individuals like Jefferson, Adams, Mussolini, Confucius, Malatesta - are all men. While history has undoubtedly been dominated by men, Pound's pre- 
ferred examples favour those instances that reinforce the notion of the naturalness of male dominance. In order to shape history, the individual, according to Pound, needed a strong will to action. Moreover, Pound's idealised notion of great leaders corresponds neatly to other sources that subscribed to the fascist ethos. Antonio Beltramelli, writer of a biography on Mussolini, saw in 'Sigismondo Malatesta [a] "warrior and artist" with "the heart of a poet," whose "desperate energy" and "passionateness" impressed itself in every deed, a true forerunner of Mussolini'. ${ }^{256}$ It is not by chance that this idea bears a striking similarity to the fascist notion of the 'new man' - which is also the title of Betramelli's biography. The similarity between Beltramelli's and Pound's descriptions of Malatesta and Mussolini illustrates that Pound largely adopted an already existing idiom. Apart from the equation of artist and ruler, the Cantos employs the age-old stereotypes of man as active, man as the creator of culture, and the ideal of the warrior. The last instance, man as warrior, is maybe the most debatable as only a handful of Pound's celebrated men fulfil this ideal. However, for Pound every man who fought or rebelled against the system could be classified as a warrior, regardless of which weapon sword, pistol, pen or song - he chose. This allegiance to stereotypical notions of 'hard' virility coupled with the conflation of poet-artist and warrior can also be read as a reaction to gender developments that affected male poets during Pound's time. Cary Wolfe, citing Frank Lentriccha, discusses the ambiguous position of the male poet in the late $19^{\text {th }}$ and early $20^{\text {th }}$ century America:

the situation of the modern male poet in America was a structurally schizophrenic one in which the poet must confront that impulse in himself to engage in an activity so thoroughly coded as feminine (because presumed to be contemplative and passive, not productive and active) that it cannot be reconciled with its opposite, the economically productive, masculine public sphere. ${ }^{257}$

By linking poet and warrior Pound could circumvent this dilemma and present poetry-making as a serious and indeed very masculine 'business', which incidentally would then also absolve Pound, ego scriptor, from the accusation of being effeminate. This becomes especially clear in the 'Italian Cantos', in which the poet persona is equated with soldiers in a shared effort of waging war. While Pound may challenge some contemporary gender developments pertaining to masculinity, but he never questions the idea that masculinity is per se superior to femininity. Pound's ideas of the artist as an emblem of masculinity as well as a validation of the superiority of masculinity supposedly find their roots in human biology as Pound considers manliness as associated with sexual prowess, and, enlisting Rémy de Gourmont - whose Physique de L'amour Pound had translated - the belief that 'artistic genius is intimately connected with biological masculinity'. ${ }^{258}$ In his postscript to the translation, 
Pound conjectures that 'the brain itself, is, origin and development, only a sort of great clot of genital fluid held in suspense or reserve'. ${ }^{259} \mathrm{~A}$ few lines further it is made clear that Pound is thinking here of male genital fluid as he compares the brain as 'maker or presenter of images' with the 'power of the spermatozoide [as] the power of exteriorizing a form', and continues that the spermatozoide is the only 'known substance in nature capable of growing into brain'. ${ }^{260} \mathrm{He}$ then links this idea to the production of culture, first finding it in the symbolism of phallic religions, man really the phallus or spermatozoide charging, head-on, the female chaos' and also in his own experience: 'Even oneself has felt it, driving any new idea into the great passive vulva of London, a sensation analogous to the male feeling in copulation'. ${ }^{261}$ The connection of brain and sperm, love-making and art-making, as well as ejection and artistic creation makes indisputably clear that artistic genius, for Pound, was inherently and biologically male. It is these ideas of masculinity that pervade the Cantos. The male creator, whose will to action shapes the public realm, be it the political or cultural sphere, is presented as the norm and at the same time as a marker for greatness. For the great men of the Cantos are precisely heralded because they exhibit those traits, suggesting that they are the exception rather than the norm.

On the other hand, all those who fall short of this ideal are duly chastised for it. They are the men in the Cantos who lack sexual prowess or whose sexual prowess is contra naturam: feminised Jews, eunuchs, old men and 'sodomites'. All of these types figure as the 'evil other' whose detrimental influence on the course of history is tied to their supposedly flawed masculinity. I have already shown how the Jews are deemed feminine with Judaism as the 'the almost intravaginal warmth of / Hebrew affections,' (35/172-3). Hence Casillo reads the use of the lower case in the word 'jew' as signifying both the loss of the head and the phallus. ${ }^{262}$ In this way the circumcised Jews become the castrated Jews and in a third step the beheaded Jews. ${ }^{263}$ These associations can also be found in the poem's metaphors when the Jews are linked either to images of barrenness, signifying asexuality and infertility, or to images of the swamp, and therefore, as we are going to see, standing for the 'feminine principle'. I have already addressed the inherent contradictions in the presentation of the Jews, but in this case it becomes clear that it is especially sex as an un(re-)productive pleasure, which is associated with them. Unsurprisingly the castrated and infertile Jews are likened to usury: Money as a dead material is not able to multiply on its own, it is infertile, which nevertheless does not hamper its role as a symbol of wealth and luxury instead of it being simply an item facilitating the distribution of goods. Moreover, as usury is also the creation of monetary wealth uncoupled from the creation of natural wealth, and thus contra naturam, usury is also linked to homosexuality. This idea is already 
present in Dante, yet it fits neatly into Pound's concept of male creation out of female chaos. Homosexuality is deemed biologically as well as culturally unproductive. In the Cantos homosexuals are repeatedly scorned or verbally assaulted. In Canto 12, for example, there is the 'Tale of the Honest Sailor': a sailor wakes up in hospital out of a drunken stupor and is presented a child, which actually was born to a whore, with the words 'Here! This is what we took out of you' (12/56). Subsequently, the sailor quits drink, rears the child, becomes wealthy and when he is lying on his death bed, confesses to his son: 'I am not your fader but your moder [...] You fader was a rich merchant in Stambouli.' (12/57). The supposedly funny aspect of the story is that the sailor not only admits to his homosexual practices, but also has no grasp of how reproduction works. It is quite telling that this story is shared among bankers, the first usurers readers meet in the Cantos. The juxtaposition of the usurious bankers and the homosexual sailor makes the connection - that already Dante drew between usury and sodomy - quite clear. Jim X (often identified as John Quinn, Pound's wealthy American patron) shares the tale because he is bored, but also disgusted by the bankers. The tale serves not only as a diversion from boredom but also as a critique. Canto 12 does not make clear whether the bankers understand it as such, but more importantly it is for the readers to understand that usurers and sodomites share a circle in Hell. This connection between usury and sodomy is repeated in Canto 77, which speaks of 'the buggering bank' (77/488), and more explicitly links to Jews in Canto 107, 'Flaccus' translator [i.e. Elizabeth I] wore the crown / The jew and the buggar dragged it down:' (107/782). That homosexual men are not considered real men is made clear in the 'Malatesta Cantos': Malatesta, who is presented as the paragon of the virile warrior, prepares his soldiers for the battle against the papal forces: 'All I want you to do is to follow the orders / They've got a bigger army, / but there are more men in this camp' (10/47). Goldblatt concludes that 'Sigismundo is alluding to the rumor of the time that many men in papal service were homosexual. Apparently this meant to Sigismundo, as to Pound, that homosexual soldiers could not be men; that is, they could not possess the virtues of condottieri. ${ }^{264}$ Another special group of emasculate men are the eunuchs who haunt the 'Chinese Cantos'. While China is often presented as a model state, from time to time it lapses into disastrous reigns. The culprits are often eunuchs, ${ }^{265}$ for example in Canto 54 'Han HUON was run by eunuchs / HAN LING was governed by eunuchs / wars, murders and crime news /HAN sank...' (54/281), or in Canto 55 'yet he [HIEN-TSONG, depicted as a good and able ruler] died of the elixir / fooled by the eunuchs [...] MOU's first son was strangled by eunuchs, / Came OUEN-TSONG and kicked out 3000 fancies [...] yet he also was had by the eunuchs after 15 years reign' (55/291). There are many more instances that show eunuchs either 
conspiring or meddling with state money in bad governments, or in turn eunuchs being driven out or being banned by able governments. Put bluntly, eunuchs are the Chinese Jews: bereft of their masculinity and pulling strings in the background, compensating for their lack of masculinity by dragging down governments. As Pound saw China as completely devoid of Jewish influence, the eunuchs fill the important gap of the 'evil other'. Last but not least, old and hence implicitly impotent (in both power and sexuality) men are also frequently blamed for the sour state of society. This strategy is especially found in the beginning, when the Cantos, true to Pound's dummbeit nicht bosheit adage, sees the failing of men not as malice but as weakness. There are the politicians who are powerless against usury, but also those who succumb to the charms or the rule of women. Especially the latter constitutes a serious impeachment of the natural order, which can be demonstrated by a closer look at the women in the Cantos.

Despite the many female characters and personae in Pound's epic, I agree with Goldblatt that the women in the Cantos are delegated to the margins as

[they] do not speak for themselves, and hardly appear at all in the public stage of the poem. Madame Gineva, Sigismundo's first wife, is mentioned only when she dies (IX.34.23). Polixena, his second wife and Francesco Sforza's daughter, is also mentioned by name only at her death (IX.35.25).' [...] Isotta, the mistress/goddess of the Tempio, is mentioned more often in the poems, but she never herself appears or speaks. ${ }^{266}$

Women occupy the stereotypical roles of wife, lover, mistress, muse or victim. ${ }^{267}$ Thus, they are usually the appendage of a great man and enter history only on this account. ${ }^{268}$ Clara Petacci received her place in the 'Pisan Cantos' because she was Mussolini's mistress; Isotta is remembered because Malatesta adored her and built the Tempio as a legacy to this love. Like Isotta's presence in the Tempio, women are only the matter out of which art is made, not artists themselves. Hence, women are associated with imagery that suggests malleability. They are presented as passive, especially, as Alan Durant noted, in scenes of coition suggested by passive constructions such as '[b]eaten from flesh into light', '[h]ath swallowed the fire-ball', '[h]is rod hath made god in my belly', or the simple 'fucked girls' (all 39/193-196). ${ }^{269}$ Peter Makin has observed how women are associated with 'softness, obfuscation, [and] intrigue', primarily in the 'China Cantos'. ${ }^{270}$ Women are also frequently associated with the swamp, an image Pound also used in his postscript to his Gourmont translation when he tried to ascribe a 'cognate role to the ovule': 'the ovular bath could still account for the refreshment of the female mind, and the recharging, regracing of its "traditional aptitudes;" where one woman appears to benefit by an alluvial clarifying, ten dozen appear to be swamped'. ${ }^{271}$ It is 
therefore no surprise, as Casillo discerns, that Pound's 'works repeatedly suggest a secret resemblance between women, usury, and the Jews. So close is their resemblance that, for about a third of The Cantos, they are nearly indistinguishable from and hence interchangeable with each other'. ${ }^{272}$

However, not all women in the Cantos are weak and passive. As passivity and softness are deemed natural qualities for women, these attributes are most often found with women who are considered models of femininity and thus deserving praise. The opposite are women who are contra naturam: active, powerful, hence threatening male order. In the earlier cantos a pun on the Greek words for 'destroyer of men, destroyer of cities' - "E $\lambda \alpha \nu \delta \rho o \varsigma$ and 'E $\lambda \varepsilon \dot{\pi} \pi \tau \mathrm{o} \lambda \mathrm{ic}$ ' $(7 / 24)$ - is used to link Helen of Troy and Eleanor of Acquitaine. ${ }^{273}$ This pattern is continued as Noel Stock notes:

She is the same woman, or the same type, appearing and reappearing in different historical periods. She is 'De Tierci's wife' and Tyndarida in canto 5; Eleanor, wife of Louis VII and Henry of Anjou, and mother of Richard I, in canto 6; Eleanor and perhaps Helen in 7; and Helen in 8. She is referred to indirectly through the words of the Trojan elders, 'let her go back', in 20. She is De Tierci's wife and Helen in 23, and Helen ('dove fu Elena rapta da Paris') in 24. This notion of woman the destroyer turns up again in the Pisan Cantos and later. ${ }^{274}$

Power in women is ultimately classified as destructive and consequently these women will not be singled out for praise. As Hesse notes 'when Eleanor of Aquitaine transgresses accepted gender norms, she is censured by describing her as "spoiled in a British climate" when her husband Henry Plantagenet prefers the beautiful Rosamunde to the emancipated and intellectual [Eleanor]' and concludes that 'of course, Henry had the public discourse of his time on his side just as the (male-dominated) historiography'. 275 Pound is equally happy to overlook Eleanor's political achievements in order to make her fit his gender dynamics. Even the Muses are depicted in a derogatory way to support the poem's notion of male superiority. Calliope and Truth calling each other 'Bitch!' and 'Slut!' in Canto 8 has, despite it being a very short scene, strong reverberations within the Cantos's gender dynamics. Goldblatt has analysed the scene brilliantly:

These lines are obviously meant to be funny, but in order for the humor to work, we must picture Truth and Calliope as two senseless wenches screaming at each other to no purpose. All the prejudice against women as animallike and incapable of logical thought comes out in this one bilious joke. Pound also uses here traditional misogynistic language to separate two concepts - history and poetry - that he is in the process of combining into one. He implies that the two will bicker endlessly unless we see that there is no difference between them. To see history and poetry as separate is "woman- 
ish" and leads to nothing; to write history in a poem is the only manly thing to do. ${ }^{276}$

Yet, the greatest threat to male order comes not in the form of the powerful empress or bitching Muses, but in the female antithesis to order itself. In Canto 29 we can read: '...the female / [i]s an element, the female / [i]s a chaos / [i]s an octopus / [a] biological process' (29/114) and is almost repeated verbatim a few lines further '[s] he is submarine, she is an octopus, she is / [a] biological process' (29/145). Goldblatt has again found the right words when she writes: 'I would [...] call them pure misogyny. [These lines] name in clear language one of the oldest ideas in the misogynist tradition: women are the destroyers of order because women represent "Nature" and "her" tendency to tear down that which men build up'. Ironically, femininity again is made to inhabit both extremes: it is chaotic nature in contrast to ordered culture and at the same time presented as a threat against the 'natural order'. Goldblatt observes how this holds true for the male 'antagonists' as well: 'Therefore, the men in the world who serve to destroy order, whether they are "papists," Jews, Buddhists, or Taoists, must at base also be aligned with the feminine'. 277 Thus while women are marginal in the Cantos, the feminine serves as an important antagonist in the power dynamics of the epic, a continuous threat that must be resisted, controlled or overcome by powerful men.

Moreover, those who threaten order have their individuality denied to them. The powerful women in the early cantos are all subsumed under the same name, implying that no matter which Helen or Eleanor is in charge, they are equally damaging. The eunuchs in the 'China Cantos' lack names. Similarly the powerful Jews are grouped together under their respective family names Rothschild, Sassoon, Mond - and no attempt is made to distinguish between individual family members: 'Said Mr RothSchild, hell knows which Rothschild' (46/233). By doing so, the (supposedly) bad characteristics and actions of one member can be transferred to the whole group. In contrast the great men of history have their individuality asserted, despite their similarities. These gendered dynamics of the individual versus the masses correspond to Le Bon's study on crowd psychology, in which he states that:

among the special characteristics of crowds there are several-such as impulsiveness, irritability, incapacity to reason, the absence of judgement and of the critical spirit, the exaggeration of the sentiments, and others besideswhich are almost always observed in beings belonging to inferior forms of evolution - in women, savages, and children, for instance. ${ }^{278}$

In the Cantos those deemed feminine lose their individuality in the group, in short they become an amorphous mass. At the same time the crowd has the same qualities attributed to it as the feminine antagonists. The crowd is usual- 
ly negatively depicted in the Cantos, for example, as a threat to the individual in Canto 1, as being depraved in Canto 14 ('the multitudes in the ooze' (14/61)), as gullible and manipulable in Canto 16, as emotional and stupid in Cantos 19 and 78 ('Can't move 'em with a cold thing, like economics.'), and as feminine in Canto 99. On the other hand there are those individuals that know how to work and control the masses: 'there is no doubt that D'Annunzio / could move the crowd in a theatre' (93/650) or 'Noi altri borghesi / could not speak efficiently to the crowd / in piazza' [implying: not as efficiently as Mussolini] (98/706). This shows that while the crowd itself may be despicable, mastering the crowd is an admirable feat. As the poem suggests this is an exclusively male trait, mirroring the 'natural order' of men mastering women. For women to gain individuality in the Cantos means subjecting themselves to the male individual, an idea reminiscent of Weininger, who maintains that the feminine 'is soulless, has no self, no individuality, no personality, no freedom, no character, and no volition';279 and whose existence is dependent on (sexually) attracting men. ${ }^{280}$ This shows that the poem goes beyond simply subscribing to a gendered hierarchy; in fact, it promotes the devaluation of all those who disturb the supposedly natural gender order.

The Cantos presents a clear gender pattern that continually elevates masculinity and degrades femininity, cementing conventional gender hierarchies. While Helen Dennis can read the gendered identities in Pound's work as a 'sane response to the excesses of Victorian discourses about women's bodies as either angelic or pathologically hysterical, but never normal', it would be more accurate to state that Pound's epic follows the conventional stereotypical gender notions of his time. ${ }^{281}$ This was not lost on contemporary readers of the Cantos, as Peter Nicholls relates when he quotes Marianne Moore's reaction:

When Marianne Moore reviewed Pound's A Draft of XXX Cantos in 1931, she found herself having to confront again that barb about the female as chaos and was provoked to ask: 'is not the view of woman expressed by the Cantos older-fashioned than that of Siam and Abyssinia?' The question was predictably on target, for it's not just that Pound's misogyny was thoroughly traditional, but that it was also in a perfectly conventional way twinned with a sentimental 'feminolatry', as Moore called it. ${ }^{282}$

Equally conventional is the Cantos's ideal of masculinity. Similar to the pervasive avant-garde macho ideal, the Cantos celebrates virile and hard masculinity with a will to action to form the world to his liking. A good statesman has to possess these qualities, but so does the artist. Linking artistic creation to sexual prowess, Pound the poet inserted himself into this type of 'new man' drilling his words into the 'malleable mud'283 that is humanity. Conversely all men who do not fit into this type are denigrated and classified as feminine. This 
makes quite clear that women and the female are not on the same level as men and masculinity. At no point does the Cantos question male superiority since masculinity stands for the hard, active, and creative ordering principle. Femininity, on the contrary, is a force that needs to be put in order. When the female principle reigns, chaos and calamity ensues as the Cantos shows with innumerable examples ranging from Helen of Troy, to the eunuchs in the 'China Cantos' and Jewish usury in general. There are a few female figures who seem to stray from this line - Artemis in 'Compleynt against Pity' or the girl in Canto 73 come to mind - yet on closer reading, they also follow the pattern described. Although Artemis is the goddess of the hunt, and thus active and creative, in this short poem she is shown powerless and bemoaning her state. And while the poem is sympathetic to her loss, it suggests that someone else, preferably a man like Mussolini, needs to put things right so that Artemis can fulfil her given role again. The girl leading the Canadian soldiers to their death might seem powerful and threatening male order because she actually kills twenty men. That is until the reader realises that - besides her having no name and having her story told by a man 284 - her act actually makes her the disturbing embodiment of the devoted woman: lover and victim, sacrificing herself for her honour, her leader, and her fatherland.

\section{Mere words? - The poem on trial}

While the poet's trial ended with his commitment to a psychiatric hospital, his poem stands perpetually on trial. The politics of the poem have not only been subjects of many studies, but also influenced its publication history. In my last chapter I want to discuss the various ways publishing and censorship have shaped the Cantos. Moreover, during my research I also noticed the trend that especially introductory guidebooks to Pound and the Cantos often tried to downplay or shirk the politics of the poem. Although I have already discussed some references from Terrell's $A$ Companion to the Cantos of Ezra Pound, Cookson's $A$ Guide to the Cantos of Eqra Pound and The Cambridge Companion to Ezra Pound edited by Ira Nadel in my previous chapters, I want to offer some concluding remarks about these guides to the Cantos that seem to be deliberately circumnavigating the political controversies of Pound and his poem.

The title of the last section of the Cantos, 'Drafts \& Fragments', already gives away that the poem was left unfinished - Pound's paradise remained unwritten. Moreover, these last poems had to overcome many hurdles before they could be officially published. Pound's failing health and increasing sense of failure made him unable to work regularly on his poem and reluctant to 
publish anything. Indeed, it might only be due to the encouragement of others that he finally agreed to tentatively release those final poems bit by bit. What made matters worse a bootleg edition of Pound's last instalment surfaced, published by the aptly named 'Fuck You Press'. As a consequence, Laughlin urged Pound to quickly agree to the release of an official version not least to secure the copyright. This episode marked the beginning of the troubled legacy of the last instalment of the Cantos. Stoicheff offers a succinct summary:

The case of the "Let the gods forgive what I / have made" lines, which have been editorially added, deleted, and then repositioned several times over the publishing history of the volume, represents one of a number of crucial inclusions and revisions that were not his [Pound's]. It illustrates how Drafts \& Fragments has become, since its first appearance, a site where conflicting responses to his fascism, anti-Semitism, and other contentious issues of his inseparably public and poetic lives are interpreted and reconstructed. ${ }^{285}$

In my subchapter on fascism in the Cantos I how some of Pound's final lines are read as the ultimate recantation of the poet's politics. And while it is true that 'Drafts \& Fragments' is dominated by introspection and a pervasive sense of failure, these matters alone do not make for a recantation. I would agree that the change of style - from the authoritarian hammering in of 'facts' to the reflective meditations - bestows a more conciliatory tone upon these poems. The poet is no longer the authoritarian leader guiding the masses, but reflects on the path that lies after and before him. This may also be because of the tragic realisation that the supposedly able rulers of the $20^{\text {th }}$ century (Mussolini and Hitler) are long dead and it seemed that the authoritarian way had not stood the test of time. All of this remains speculation. However, what seems worth repeating is that the final instalment - maybe more than many other parts of the Cantos - is open to many diverging interpretations. It does lend itself to a reading of remorse and recantation, but these sentiments are inscribed into the gaps of the final poems and do not spring from the words that are actually there. Yet it can just as well serve as a reinforcement of the sense of loss for the fascist dream and of the failure to build paradise on earth under the banner of Fascism. Asking the gods to forgive what he has made, leaves conveniently open what it is specifically that the poet had made.

The attention accorded to Pound's final lines stands in stark contrast to the deliberate omission of the 'Italian Cantos'. The first time these were included in the collected cantos was long after Pound's death, and even then they were first 'hidden' in an appendix to the epic. In present editions they are included in their proper chronological place, with a tamed translation of Canto 72 . This shows that even with the poet gone, the debate about his fascism prevails. As there is no use denying the inherent fascism of these two cantos, 
the strategy, so it seems, was to deny them their status as official cantos. Yet the 'Italian Cantos' play an important role in the epic as a whole. They illustrate the apex of the fascist trajectory of the epic. Moreover, their celebratory tone and defiant belief in the fascist victory is necessary to make the enormous tragedy of the 'Pisan Cantos' palpable. To refuse them their status as proper cantos - despite all the differences - is to destroy the ideological trajectory that holds the poem together. A similar view is held by Bacigalupo when he concludes that ' $\mathrm{f}]$ ar from being irrelevant and embarrassing digressions, Cantos 72 and 73, we may safely conclude, are central' to the Cantos. ${ }^{286}$ While these textual alterations have usually been made to salvage the poem from its inherent fascism, the success has been at best limited. More than that it seems to betray a fear of the poem's politics.

A similar phenomenon can be observed in the (introductory) guidebooks to the Cantos. While Terrell's and Cookson's guides are invaluable for Pound scholars, they also have a problematic aspect to them when it comes to the poem's politics. When I scanned Terrell's countless glosses, I observed a discrepancy between their treatment of fascist and anti-Semitic instances of the poem on the one hand and of many other less controversial topics on the other. By way of illustration let me list some examples. For Canto 52 his glosses included the already discussed interpretation that 'Pound's apparent intent is to deplore the way anti-Semites in the 1930s blamed all Jews, including poor ones, for the destructive financial practices of a very few'. ${ }^{287}$ To this is added a quote from Pound in which he does indeed deplore the antiSemitic practices of his time. Curiously enough, the same quote is used again, this time to counter the anti-Semitism in 'Addendum for C' to which is added that 'at the time this was written Pound was aware that he was being attacked for anti-Semitism, which he vigorously denied. Thus, he uses the Hebrew word to show that the Jews from the time of Moses had rules against usury'. ${ }^{288}$ Terrell admits that Pound was anti-Semitic while at St Elizabeths. However, neither the date of the quote (1930s) nor Pound's time at St Elizabeths coincide with the date of composition of 'Addendum for C' (ca. 1941). There are other instances that shed light on Terrell's treatment of Pound's antiSemitism. The most offensive lines in the 'Pisan Cantos' ('the yidd is a stimulant...') have glosses that contain the translations of the terms 'yidd' and 'goyim', yet no further explanation was deemed necessary. Another gloss further highlights the uncritical stance of Terrell's companion. In Canto 77 the 'mass graves at Katin [Katyn]' are mentioned. The gloss explains: 'The soviets had refused to allow an international investigation, but Pound had reliable inside information that told him that the Russians directed and carried out the massacre' and adds that this information was supplied by Pound's daughter Mary de Rachewiltz. While it is true that the Soviets refused to allow an inter- 
national investigation, Joseph Goebbels organised a team with forensic pathologists from twelve countries to verify the German verdict after the Webrmacht had found the mass graves (in early 1943) and concluded that it must have been a massacre by Soviet forces. This commission confirmed the Webrmacht's suspicion, a conclusion further validated by the Polish Red Cross, who had also investigated at the site. Already in April 1943 Goebbels, with the explicit aim to divide the allied forced, started a propaganda campaign to distract from Nazi atrocities. Moreover, the Katyn massacre was reframed as a specifically Jewish-Soviet crime, a way to sustain the anti-Semitic lore of Jews slaughtering non-Jews (when, in fact, many of the victims were Jewish). ${ }^{289}$ It was soon broadcasted on all available media in the whole of the German Reich and its occupied territories. At this time Italian Fascism had by now more or less collapsed and was bullied into compliance by Germany, who later that year set up Mussolini's Salò Republic. Even in the years before, Mussolini was 'referred to viciously in Germany as Gauleiter (the person in charge of a Nazi Party territorial section) of Italy'. ${ }^{290}$ With Italy as one of its Gaus German propaganda would have undoubtedly reached the Italian people. In the meantime, the Anglo-American public was mostly presented the Soviet version, namely that the Germans had been the perpetrators. ${ }^{291}$ Hooked on National Socialist propaganda, Pound's knowledge of what happened in Katyn was closer to the truth, but to say that he had 'reliable inside information' is troubling on many levels. It distracts from the fact that Pound was swept away by fascist propaganda like so many other people (even if said propaganda had a kernel of truth in it this time). Thus, the reference to the Katyn massacre in Canto 77 is a perpetuation of German propaganda: when the poem evokes Katyn it serves as a further indictment of the Jews as perpetrators and slayers of innocents, claims the 'Pisan Cantos' repeatedly make. Attributing the reference to Katyn to 'reliable inside information' attempts to obscure Pound's adherence to fascist propaganda, and moreover it stands in stark contrast to the often uttered defense that during the war he did not know what was happening on the battlefields. ${ }^{292}$ This criticism should not be taken as an outright attack on Terrell's otherwise admirable Companion, however, in the light of Pound's politics it is worth mentioning that sometimes the explanatory glosses are also glossing over the more problematic instances.

Cookson's guide is even more untroubled by the Cantos's fascism. He refuses to label Pound a fascist, although this partially stems from Cookson's rejection of the label as a blanket term of abuse. While this objection is certainly valid, Pound's devotion to the Duce and Fascist Italy makes him if not a fascist then, at least, a Fascist. ${ }^{293}$ Implicitly Cookson admits Pound's adherence to Italian Fascism for he is at pains to stress how different Italian Fascism was to Nazism, and that it is time 'that the constructive, positive actions 
of Mussolini, like those recorded in XLI, were given due weight'. Moreover, he adds

Pope Pius XII described [Mussolini] as "the greatest man I have known, and without any doubt a profoundly good man - I have seen too many proofs of his goodness to doubt it." "Where in history will you find it?" (LXXIV, 439/445). Future historians may recognize that the Italian leader achieved much towards "the resurrection of Italy" (LXXIV, 456/462) during more than a decade of rule before the tragic embroilment with Hitler led to his downfall. ${ }^{294}$

By interspersing passages from the Cantos with other quotations and the hope that future historians will validate these, it seems that Cookson is not only untroubled by Pound's Fascism but also silently agrees. Cookson's treatment of Pound's anti-Semitism follows along similar lines: "There are very few antiSemitic passages in The Cantos (there are no Jews in the hell cantos, XIV-XV), nor is there anything in Pound's work comparable to the anti-Semitic lines in Eliot's Poems 1920 which manifest a physical revulsion to certain Jews. ${ }^{295}$ One could challenge these claims on many levels. Fundamentally Cookson likes to downplay Pound's anti-Semitism by explaining that neither its quantity nor its quality is especially worrisome. That Cookson seems to be oblivious to how anti-Semitism actually works is betrayed in a footnote to a line from Canto 73 ('Roosevelt, Churchill, and Eden, / the Jews') in which he writes that 'it is worth pointing out that Pound is here calling Roosevelt, Churchill and Eden "Jews" in the old O.E.D. sense which transferred the word to people who were not Jewish by racial origin: "a name of opprobrium ... applied to a grasping or extortionate money-lender or usurer"". ${ }^{296}$ Not to realise that when a term has become a label of contempt based on a stereotypical cliché may already be an anti-Semitic act, explains why Cookson can only find very few anti-Semitic passages in the poem. Furthermore, he defers from accusations of anti-Semitism by mentioning that Pound was friends with individual Jews (and even dedicated a book to Louis Zukofsky), that Pound also hated other monotheistic religions, that his anti-Semitism was purely economic (and therefore less problematic, one assumes) ${ }^{297}$ and finally the fact that one of Pound's friends 'dismissed the accusation with the remark "He was incapable of meanness". ${ }^{298}$ These stock book arguments are only convincing to those who did not need any convincing to begin with. They are also testament to how little weight Cookson bestows on the question of anti-Semitism in Pound's poetry.

Approaching the topic from a different standpoint, Wendy Flory, writing on Pound's anti-Semitism in the Cambridge Companion, still reaches a similar conclusion. Although she deplores the lack of serious analysis of Pound's anti-Semitism, she seems determined to avoid discussing Pound's anti- 
Semitism herself. Flory is making a partially valid argument by criticising the over-zealous condemnations of Pound and by suggesting that the scholarship on anti-Semitism should also focus on the less vocal supporters, noting that a rabid verbal anti-Semitism does not automatically coincide with lethal antiSemitic practices, just as the reverse is equally untrue. I also agree with Flory in her calling out the hypocrisy of Post-Structuralists in attacking Pound but embracing Heidegger. However, the focus on the 'complicity of bystanders, the extent of collaboration within Nazi occupied countries and the indifference in Britain and the United States' ${ }^{299}$ should not be used to downplay Pound's anti-Semitism. Consider the following passage:

Pound-as-antisemite served as a convenient place-holder for all those whose antisemitism was not being confronted. In the context of a pervasive, institutionalized American antisemitism that no one wanted to acknowledge, the denouncing of Pound as the "real antisemite" became an effortless alternative to any serious analysis of the problem of antisemitism in America. ${ }^{300}$

Such an assertion would rather fit into an introduction to Holocaust scholarship: yet, in this case it seems to deflect from the real issue at hand, namely Pound's anti-Semitism. Flory goes on to subscribe to the notion that Pound was suffering from 'paranoid psychosis', thereby reducing Pound's accountability for what he said and wrote. Moreover, she concurs with Cookson by stating that the Cantos does not contain many anti-Semitic passages and similarly she restricts these to only overt mentions of Jews. Although she proceeds to list anti-Semitic instances from the Cantos, she does not explain their significance in or for the poem as a whole. For example, the anti-Semitism in the 'Pisan Cantos' is described as a spill-over from Pound's radio-broadcast, which seems to imply that the broadcasts are somehow less truly Pound than the Cantos. Seeing that Flory devotes more consideration to portraying Pound's possible psychosis than dealing with his poetic anti-Semitism already implies that the latter is not worthy of sustained attention. Coming to terms with the treatment of anti-Semitism in Pound scholarship she writes that

the strategy of focusing on Pound's poetry and setting aside the issue of his antisemitism was often attacked as apologist, it has proved in retrospect to have been the most productive recourse. It established The Cantos as an important subject of literary study, making the poem far more accessible by providing source information and demonstrating ways of approaching this highly complex work. Further, even had a carefully analytical account of the nature, causes and culpability of Pound's antisemitism been possible, it would not have found a readership willing to give it a hearing. ${ }^{301}$

There is a fallacy in Flory's argument here. Although she earlier identified the complicit anti-Semitism in the US and Britain, she does not draw the parallel 
between the lack of interest in analysing (or hearing about) Pound's antiSemitism and a society or cultural strata that is themselves anti-Semitic or at least oblivious to the problematic aspect of anti-Semitism. In the same manner that she complains about '[s]weeping poststructuralist denunciations of modernism as fascism and of Pound as always inherently a "rabid antisemite" she finds fault in all works that expose Pound's anti-Semitism claiming that they are either sensationalist (Torrey's The Roots of Treason) or have methodological flaws (Casillo and Andrew Parker). Yet when she attacks said poststructuralist denunciations she does so with the explanation that 'such tactics provide an easy alternative to and a distraction from the far more painful task of analyzing the realities and implications of the full range of wartime antisemitism - in this case, among intellectuals in Germany and in countries under German occupation.' 302 Flory's conclusion seems to contradict her initial outset of raising awareness for American and British anti-Semitism and their complicity in the Holocaust and that it should be noticed how these issues influence assessment of overt anti-Semitism, as I the case of Pound. While I agree with Flory that hypocrisy in such matters must be addressed, she unfortunately exhibits the same flaws that she imputes to the scholars she does not agree with. When she compares Pound's guilt to Heidegger's she is trying to find a rationale by which to calculate whose writer's anti-Semitism has done more harm:

[w] here Pound's antisemitic rantings brought harm to no one but himself (and his family), Heidegger lent the prestige of his reputation and academic position to the validation of Hitler's regime and energetically implemented the antisemitic "cleansing laws" against colleagues and students at Freiburg University $^{303}$

Yet, as I argued above, Pound did lend prestige to the project of Fascism and still does. She concludes

We can also see how, as the result of a continuing angry refusal to examine the facts of his case, Pound as "designated fascist intellectual" has served since 1945 as stand-in for all those individuals of the silent majority in Germany, in occupied France and Belgium, in Britain and the United States who, by quietly aiding or standing quietly by, made the Holocaust possible. ${ }^{304}$

To choose these as the closing words in an introduction to Pound signal to the Pound novice that Pound's anti-Semitism is no longer a matter that warrants serious attention.

Finishing my chapter on Pound's politics with a critical discussion of these three guides was an attempt to highlight the complicity of Pound scholarship in obliterating Pound's political traces. Focusing on Pound's fascist and anti-Semitic politics does not mean, as some people tend to believe, to dispar- 
age his poetic output. On the contrary, I believe that Pound's creative genius stands unchallenged. But so do the historical consequences of right-wing ideologies then and now. Bringing both together is neither a way of saying that the Cantos is flawed because of its ideology nor that the Cantos is a modern masterpiece despite its ideology. Understanding that the poetry many people came to love or were heavily influenced by was created out of an adherence to an ideology most people abhor, fear, and, ultimately, also lost their lives to acknowledges the inherent moral dilemma that even the most abhorrent ideologies and regimes occasionally create art we consider good, valuable or enriching to our lives despite our rejection of the ideology it emanated from. Right-wing ideology lies at the heart of Pound's Cantos. Reading the Cantos means recognising the politics in the poem and the hurt and harm they caused and still cause. If Pound scholars do not talk about these issues someone else less suited to the task will. 


\section{T. S. ELIOT The Conservative Collaborator}

Positioning Eliot is a difficult matter. The poet of The Waste Land is also the creator of the source text for one of the most successful Broadway musicals: Cats. Eliot, the lover of the Metaphysical poets, Dante, and other classics equally enjoyed rag-time, jazz, and music hall. ${ }^{305}$ Himself an American expatriate he extolled the virtue of the blood-and-soil kinship of the community and its native environment. Where Pound was painfully explicit, Eliot mostly remained excruciatingly elusive. And yet: despite all the paradoxes, wavering and elusiveness, Eliot's ideological world-view is surprisingly clear and well defined. As I will show in the introduction to this chapter, one can find a clearly pronounced conservatism in Eliot's writings. Even more crucially, in his evasions one can detect Eliot's embrace of more radical right-wing notions. The term I use to describe Eliot, conservative collaborator, is meant to convey his conservatism coupled with an allegiance to the far right. This particular ideological outlook is not only present in Eliot's essays, but also informs his poetry. What is more, the oft-repeated statement that the progressive or revolutionary form of his verse stands in stark contrast with its reactionary content can, on closer inspection, not be confirmed. This claim has been given credence by its ubiquity. Maud Ellmann maintains that Eliot (and Pound) 'wrote poetry whose experimentalism poses a puzzling contrast to their political authoritarianism'. 306 In a similar fashion Richard Shusterman tries to deny the label of conservatism for Eliot by insisting that 'his clear connection with the Church of England and the Conservative Party make it easy to pin him with the label "conservative" and thus to forget his innovative achievements in poetry and criticism, and his advocacy of the need for change and continuous development in these fields.' ${ }^{307}$ Eagleton has a more nuanced take, writing that in The $W$ aste Land the

ideological implications are at odds with the 'progressive', pioneering, typographically-conscious forms of the poem itself; but it is precisely in this conjuncture of 'progressive form' and 'reactionary content' that the ideology of The W aste Land inheres. Both elements are united by a certain 'élitisim': the 'avant-garde' experiments of a literary coterie match the conservative values of a ruling minority. ${ }^{308}$

While Eliot's style is undeniably experimental and quintessentially Modernist, this should not be confused with adherence to a 'progressive' world-view. On 
the one hand conflating progressive with liberalism feeds into the persistent notion that the Right is fundamentally anti-modern; in love with the past and shunning the future. On the other, it ignores that Eliot's 'progressive, pioneering' form is also itself the locus of right-wing ideology such as appropriation, elitism, and discursive violence. In this way, form and content create an ideologically coherent whole. Right-wing ideology, so I will argue in this chapter, constitutes a dominant force in The $W$ aste Land and its precursor collection Ara Vos Prec, ${ }^{309}$ more than is generally acknowledged.

As with Pound, Eliot's political preferences are widely known but his position in the political spectrum remains contested. In my previous chapter I located Pound on the fascist end of the right-wing spectrum - at least for a significant amount of time while he was writing his Cantos. A similar argument cannot convincingly be made for Eliot. While there are some isolated voices, which have used the label of 'fascist' for Eliot, ${ }^{310}$ there can be made a strong case that this is not an exact description of his politics. Although some of Eliot's political standpoints - such as his preference for a homogenous society as well as communities bound by blood and soil, his prejudices against Jews, his critique and rejection of democracy and liberalism ${ }^{311}$ - resonate with fascist doctrine, Eliot never fully supported fascism, neither as ideology nor as one of its national permutations. As with many other issues, Eliot remained very elusive on fascism as such, constantly trying to divorce the actual political movements from the underlying ideas:

I have thought of dealing myself with the question of Fascism, and have recently worked through four or five books on the subject. The more I read about it the more uninteresting it seems, but it might be worth while to say even that. What I am trying to do is to find out whether there is any idea in Fascism at all; if not it might be at least worth while to say so. [...] The question is not to examine particular facts of government, but the importance of certain political ideas. ${ }^{312}$

Eliot would continue, even throughout the Second World War, to uphold his distinction between political idea and political fact, a decision that betrays more callousness than academic objectivity. By divorcing idea from practice, Eliot attempts to make himself immune to (ideological) criticism. Beer quite rightly notes that

Eliot whose oft-repeated motto was that he is interested in political ideas but not in politics' yields more than anyone else to the temptation of escapism. Politics is always political practice. In political practice the problem of violence plays a central role, which Eliot is adamant to ignore. Yet political ideas can be divorced from reality and be discussed in an almost clinically intellectual atmosphere untainted by any practical facts or considerations. ${ }^{313}$ 
This escapism into the realm of the 'clinically intellectual atmosphere untainted by any practical facts' shows that non-allegiance to fascism does not automatically turn someone into an adversary of fascism. Adding to that, in those cases when he found clear words, Eliot seems to have considered fascism as one of many bad options (the others being communism and liberalism) but ultimately as the smaller evil. After confessing 'to a preference for fascism in practice', he is quick to add that 'neither fascism nor communism is new or revolutionary as idea. ${ }^{314}$ From a $21^{\text {st }}$ century perspective this reasoning seems rather grotesque, yet in Eliot's ideas-only approach he could write unfazed: 'They [fascism and communism] have both been already partially absorbed by the popular mind, so that, in the intellectual sense, there is nothing "shocking" about them; [...] They are both, in other words, perfectly conventional ideas. 315 The widespread support and interest in fascism then can be explained according to Eliot by people's disillusionment with democracy and who are thus

inclined to welcome any regime which relieves us from the burden of pretended democracy. Possibly also hidden in many breasts, is a craving for a regime which will relieve us of thought and at the same time give us excitement and military salutes ... I am all the more suspicious of fascism as a panacea because I fail so far to find in it any important element, beyond this comfortable feeling that we shall be benevolently ordered about, which was not already in existence. ${ }^{316}$

The one element that Eliot explicitly criticised in fascism (as well as communism) is its paganism, which conflicted heavily with his own Christian convictions: 'The fundamental objection to fascist doctrine, the one which we conceal from ourselves because it might condemn ourselves as well, is that it is pagan'.317 This was published in 1939. The danger, or rather the presumptuousness, of fascism (and again communism) was that they posed as 'an alternative 'supernatural faith" 318 Looking at Italian Fascism, which had a pronounced religious element, "he pointedly raised the question of whether the Christian idea and fascist ideology were compatible, implying a negative answer via quotations from Mussolini on the nobility of war as such, scepticism towards ecclesiastical authority, the state as an absolute, and imperialist aggression. ${ }^{319}$ Eliot even went so far as to insinuate that '[i]f you will not have God (and He is a jealous God) you should pay your respects to Hitler or Stalin. ${ }^{320}$ Eliot's embrace of Christianity became the theoretical bulwark against a possible allegiance to fascist ideology. 321

What becomes apparent when reading Eliot's criticism of fascism is that as criticism it is highly unsatisfactory. Unless one considers the following lines substantive criticism: 
There are other objections too, in the political and economic sphere, but they are not objections that we can make with dignity until we set our own affairs in order. There are still other objections, to oppression and violence and cruelty, but however strongly we feel, these are objections to means and not to ends. ${ }^{322}$

Eliot seems to suggest that Britain and NS Germany have problems in the political and economic sphere with the same degree of gravity. He never spoke out against the prosecution of the Jews, or against any other of fascism's inhumane policies and practices. Moreover, in 1939 Eliot felt comfortable to proclaim that any objections against fascist and NS violence and cruelty 'are objections to means and not to ends', implying that acts of persecution against Jewish citizens on all societal levels, culminating in the infamous Reichspogromnacht, a symbol of the dimensions the Nazi terror had already reached by 1938, were bad form but the underlying policies were not reprehensible. I am not suggesting that Eliot approved of later Nazi policies like the Final Solution, but Eliot advocated cultural homogeneity and seemed aware and prepared to accept that some measures were needed to reach this aim. Furthermore, when criticising fascist atrocities his empathy seemed more to lie with the reputation of the countries in question than with the victims of hate crimes.

These are strong charges, so why insist that Eliot was not fascist himself if he was either blind or indifferent to the very serious consequences this ideology had for its victims? There are multiple answers. First, the Right needs to be understood as a spectrum. As I said in my theory chapter, the simplifying nature of some studies to see fascist allegiance as a binary matter (splitting people into fascist and anti-fascist) is not only grossly distorting but also problematic. Eliot was not fascist, but neither does it seem right to label him anti-fascist. In fact, Eliot can be located firmly in the right-wing spectrum - somewhere in the vicinity of fascism but never embracing it. It furthermore highlights intra-right-wing allegiances: despite not supporting fascism, Eliot supported doctrines that either fed into or paved the way to fascist ideology. If Eliot seemed prepared to accept even some of the more dire consequences of fascist policies, it is because they seldom conflicted with Eliot's own ideas about how society should function. Only when it did - as in the case of Christianity - did he speak out. Eliot had no interest in fascism as a set ideology or movement; however he 'did accept many of the ideas associated with fascism', writes John Harrison, 'but he preferred to derive them from a source more congenial to himself, ${ }^{323}$ and this source was the French thinker Charles Maurras. Leon Surette concludes: 'Eliot's rejection of fascism, then was not on the grounds of its anti-democratic and totalitarian character, not because of its overt celebration of violence, but because he found it inferior to the an- 
ti-democratic and totalitarian doctrines of Charles Maurras and the Action Française!'324 Eliot seemed not to see or more likely did not want to see that Maurras's ideas were often virtually synonymous with fascist doctrine, so much so that Maurras himself became (despite his anti-German sentiments) a collaborator in the Vichy regime. Up until Maurras death in 1952, Eliot praised and defended the thinker who, according to Eliot, had so much positive influence upon him. ${ }^{325}$ The significance is, as Tom Villis suggests, that just because the label 'fascism' does not accurately fit into a British context or here specifically to Eliot - does not mean that the underlying ideas did not have some currency:

The use of fascism as a framing tool is doubly distorting when applied to a British context. Not only would such a study fall prey to the same logical errors of post hoc ergo propter hoc, but the real 'fascist' parties in Britain never achieved power or widespread support. Nevertheless, the absence of this motivating concept - fascism - has meant an underestimation of the similarities parts of British thought had with the European cultural rebellion that preceded it. This rebellion did not necessarily lead to fascism, especially in Britain. Nevertheless, it had similarities with movements in other European countries which have been characterized as fascism's progenitors. ${ }^{326}$

So if Eliot was no supporter of fascism, but could at the same time hold (proto-)fascist ideas he had adopted from Maurras, this complicates Eliot's positioning in the right-wing spectrum.

While Eliots's ideological views did not remain absolutely stable, they showed marked continuities. One significant element that influenced his ideological outlook was his conversion to Anglicanism in 1927. Erik Tonning notes that

[o]ne consequence of this fundamental shift in Eliot's thinking may sound peculiar to received opinion: the younger Eliot (often seen as more 'radical', less 'reactionary', than Eliot the convert) was demonstrably more sympathetic to movements of the Right (chiefly the Action Française, but also early Italian Fascism) than the consciously Christian Eliot would later become. Postconversion, Eliot criticizes fascism in the same breath as Communism, for setting itself up as a competitor, an alternative 'supernatural faith'... ${ }^{327}$

However, Eliot's conversion, while putting Christianity into the focus of his ideology, did not fundamentally change most of his ideological beliefs: some were additionally validated, others were slightly modified to harmonise with Eliot's Christianity. What Tonning also omits is that post-conversion Eliot was indeed more radical - in the sense of: (aggressively) advocating or effecting change of society's flaws by targeting the problems' roots 328 - since all of his longer essays (After Strange Gods, Notes towards the Definition of Culture and The Idea of a Christian Society), in which he dealt with societal issues, were writ- 
ten and published after 1927. All of these had a straightforward impetus: to disseminate Eliot's ideas and to use his position to advance said ideas. Taking these three essays as well as earlier writings from the Criterion and his private correspondence as a basis, I want to extract Eliot's ideological word-view and, furthermore, hope to show the continuities in his thinking.

The one significant constant in Eliot's ideology is his rejection of liberalism and democracy. As I have already discussed with Pound, some critics are led astray when Eliot, like Pound, occasionally voices his allegiance to democracy. Thus critics like Jason Harding can conclude that

oddly enough, in 'The Literature of Fascism' Eliot could sound at times like a social democrat: "The modern question as popularly put is: "democracy is dead; what is to replace it" whereas, it should be: "the frame of democracy has been destroyed: how can we, out of the materials at hand, build a new structure in which democracy can live"". ${ }^{329}$

Yet what should be noted is the underlying definition of democracy. For Pound, democracy was the limited democracy of the United States of America during the time of the first presidents. Likewise Eliot's idea of democracy revolved around a radically reduced suffrage. Both poets' concept of (ideal) democracy stood in stark contrast to the then existing democracy that was developing in Britain and the US. Both feared that an extension of suffrage would lead to the dissolution of 'true' democracy, in which the demos entitled to vote was (or would be) comprised of a minority of educated, middle-class white men. In this way Pound and Eliot could criticise the political developments in Britain and the US, while remaining loyal to the idea of democracy:

It is one thing to say, what is equally sad and certain that from the moment when the suffrage is conceived as a right instead of as a privilege and a duty and a responsibility we are on the way merely to government by an invisible oligarchy instead of government by a visible one. But it is another thing to ridicule the idea of democracy. A real democracy is always a restricted democracy, and can only flourish with some limitation by hereditary rights and responsibilities. ${ }^{330}$

Pound and Eliot shared the belief that an increasing suffrage would only lead to disaster: 'It is a commonplace that the increase of the electorate, in Britain, is the destruction of Democracy; that with every vote added, the value of every vote diminishes'. ${ }^{331}$ In this way a democracy with a growing suffrage would pave the way for an oligarchy. Based on this idea of democracy, Eliot could write in 1939: 'Certainly there is a sense in which Britain and American are more democratic than Germany; but on the other hand, defenders of the totalitarian system can make out a plausible case for maintaining that what we have is not democracy, but financial oligarchy'. ${ }^{332}$ Democracy, as it was shap- 
ing around him, was an inherently empty label for Eliot: 'The term 'democracy', as I have said again and again, does not contain enough positive content to stand alone against the forces that you dislike-it can easily be transformed by them. ${ }^{3} 33$ What was needed as a remedy for democracy and liberalism was order, hierarchy and authority - and after his conversion - a strong sense of Christianity. Thus when reviewing 'British Socialist Harold Laski's Introduction to Politics, Eliot took umbrage at Laski's liberal principle "that neither race nor creed, birth nor property, shall be a barrier against the exercise of civic rights." Eliot blusters in response: "Such a sentence merely provokes a fresh explosion of questions. For what end does the state exist? And why should not race, creed, birth and property, any one or more of them be a desirable barrier? And what are civic rights?" 334 This thinking shows Eliot to be a part of a long tradition of thinkers to which also Maurras belonged - the AntiEnlightenment tradition. As Kenneth Asher pointedly summarises: 'The hallmark of this tradition was the courage to discriminate, resulting in political and religious hierarchy as well as artistic decorum, itself the elegance that comes from a recognition of the gradation of styles. ${ }^{\prime} 35$ Asher indicates how the advocacy of inequality and the resulting hierarchy also shapes artistic thinking and artistic output. Artistic creation is deeply ideological, and in Eliot's case based on a preference for and promotion of inequality, which sits at odds with the basic tenets of liberalism and democracy as it was developing during Eliot's times.

Another pillar in Eliot's ideological world-view is his belief in cultural homogeneity. Already Maurras, who was fiercely anti-Semitic, aggressively advocated for homogeneity, which Eliot adopted. Here again contrary to Tonning's conclusion, the older Eliot became more radical - not because his views on homogeneity changed and became stricter, but because his adherence to homogeneity grew more pronounced in the changing circumstances of the $20^{\text {th }}$ century. His most infamous assertion, as quoted above - that a society should be homogenous with religious unity being of major importance making a too large number of free-thinking Jews undesirable - was uttered in 1933 and published in written form in 1934. At the same time the Nazi seized power and passed a multitude of new laws and regulations (Nuremberg Laws), which paved the way for future acts of terror. But even without the greater international framework, Eliot's desire for homogeneity seems misguided in a country like the United States, where he held his lecture, that had seen a tremendous amount of immigration and mingling of different peoples during the first half of the $20^{\text {th }}$ century:

from 1820 to 1930 , no less than thirty-eight million people had immigrated. Two and one-half million Jews had entered the country between 1880 and 1913 alone. In 1933, one hundred and twenty million people, fourteen mil- 
lion of them foreign-born, were living in the United States. It is in this context that Eliot's praise of a homogenous citizenry must be seen. ${ }^{336}$

Yet Eliot persisted in his advocacy for a homogenous society and feels unperturbed to write in his Notes towards the Definition of Culture from 1948 (and republished in the 1960s):

Certainly, an individual may develop the warmest devotion to a place in which he was not born, and to a community with which he has no ancestral ties. But I think we should agree that there would be something artificial, something a little too conscious, about a community of people with strong local feelings, all of whom had come from somewhere else. I think we should say that we must wait for a generation or two for a loyalty which the inhabitants had inherited, and which was not the result of a conscious choice. On the whole, it would appear to be for the best that the great majority of human beings should go on living in the place in which they were born. ${ }^{337}$

Apart from the irony that Eliot was himself an expatriate, the fact that he advocates homogeneity during a time when millions of people all over Europe had been forcibly displaced - or had become victims to industrialised slaughter because they were seen as disturbing national and cultural homogeneity seems to leave him unfazed. Based on his argument for the separation of political ideas from political practice, he seems unwilling to imagine that the actions during the Second World War were the practical consequences of said ideas. It therefore comes as no surprise that the Holocaust had virtually no influence on Eliot's ideological world-view, judging from the fact that it left no trace on his recommendations for society:

Newspapers around the world expressed shock and outrage at accounts and images of piles of human bodies and of emaciated survivors. Despite all of that there is no indication [one] can find in Notes [Towards a Definition of Culture] or the Appendix that Eliot recognized that horror as a fact that he needed to take into account in his assessment of the past and future of European culture. Nor had Eliot changed his mind about the tenor of his thesis when Notes was reissued in 1961:... 338

Eliot's persistent advocacy for homogeneity exposes him as an intellectual collaborator: while outwardly criticising fascism, he still used his influence to give intellectual credibility and legitimacy to some of its founding ideas - irrespective if he did so consciously or not.

Eliot's preference for cultural homogeneity paired with his promotions of order and authority naturally also leads to an endorsement of hierarchy. While more recent studies, such as Chinitz's T. S. Eliot and the Cultural Divide, dispel the myth that Eliot only disseminated high culture and that he was in- 
deed interested in different forms of popular culture, actively weaving those strands into his poetical works, one can find enough evidence that Eliot supports a system of inequality under the guise of 'natural' hierarchy. I am using the word natural here, although Eliot does not, because it captures his thinking that there is a quasi-biological causal connection between intellectual capacity as well as cultural achievement and categories such as class. A society's class system is thus not a manifestation of power and privilege but a naturally grown system that divides the more (intellectually) capable from the less capable. Citing Eliot's interest in popular culture as a genuine concern for the lower classes produces a very distorting image indeed. For one only has to look at Eliot's ideas on education and equal opportunities measures to realise that his main concern about the lower classes was that they should remain exactly where they are and be complacent about their position in society. Similar to his ideas about suffrage, he believed that the more people received an education, the less worth the education would in turn become:

I hope that we shall not consciously or unconsciously drift towards the view that it is better for everybody to have a second-rate education, than for only a small minority to have the best. For the first problem of education, surely, is to elaborate, preserve and develop the best education for the superior minority. The second problem is that of the selection of the minority to receive it. I say the second problem, because I think it is better that the best education should be given to an ill-chosen minority that that it should not be given at all. ${ }^{339}$

It was in this vein that Eliot also

opposed a higher school-leaving age (in 1940 it was 14), asking, "Is this further education necessarily going to make the majority wiser or better people?" He suggested that most people had an "optimum", or educational ceiling, after which more education became an "excessive and deleterious strain". 340

Education and equal opportunities would dissolve the bounds that keep society together: 'Equalisation of opportunity, then, and democratization of education, are in danger of becoming uncritical dogmas. They can come to imply, as an ultimate, a complete mobility of society—and of an atomised society'. ${ }^{341}$ Giving way to equal opportunity means, according to Eliot, entering a vicious cycle where equal opportunities breed disintegration of society, which in turn breeds more people to push for equal opportunities:

It is an ideal which can only be fully realised when the institution of the family is no longer respected, and when parental control and responsibility passes to the State. [...] The popularity of the belief is perhaps an indication that the depression of the family is accepted, and that the disintegration of 
classes is far advanced. [...] The disintegration of class has induced the expansion of envy, which provides ample fuel for the flame of 'equal opportunity. ${ }^{342}$

It is true that Eliot is not entirely consistent in his arguments vacillating between advocating the best education for the most capable irrespective of their class background and promoting a class system, in which membership to a certain class was already an indicator for an individual's capability. Pressed to explain his discrepancies, he seemed to lean towards a class society:

But today it seems to me more important to argue the case for a class society because the generally accepted idea is one of equalitarianism. And when one considers the classless society, even so far as it has adumbrated itself in the present situation of the world - its mediocrity, its reduction of human beings to the mass... the reduction which Plato foresaw, the reduction to a mass ready to be controlled, manipulated, by a dictator or an oligarchy_observing all those things one is emotionally disposed toward a class society. ${ }^{343}$

Only a class society where 'a smaller group at a higher level will have equal power with a larger group at a lower level'344 would be a stable and safe society, because a 'democracy in which everybody had an equal responsibility in everything would be oppressive for the conscientious and licentious for the rest $^{\prime 345}$. His ideas on culture reflect Eliot's promotion of homogeneity coupled with hierarchy and inequality: 'You cannot expect continuity and coherence in literature and the arts, unless you have a certain uniformity of culture, expressed in education by a settled, though not rigid agreement as to what everyone should know to some degree, and a positive distinction-however undemocratic it may sound-between the educated and the uneducated'. 346 This would also influence the reception of his poetic output, because 'education indeed is so chaotic that "you cannot make a quotation or an allusion to which the whole of any company can respond"'. ${ }^{347}$ Consequently struggling with poems such as The $W$ aste Land is not because Eliot deliberately planted an obscure amount of literary reference into it, but indicates a failure of the education system. Eliot uses the same logic when he explained: "We can only say that it appears likely that poets in our civilization, as it exists at present, must be difficult", and Chinitz adds, "[e]vidently this would not be the case under more favorable conditions. Obscurity is an unfortunate if unavoidable by-product of rapid and unassimilated social change'. ${ }^{348}$ Analysing Eliot's statements reveals that his main interest lay in the survival of culture, which he understood as an abstract entity and not a collection of individuals. Thus Eliot can arrogate himself the right to patronize dissenting readers, writing that if s/he "finds it shocking that culture and equalitarianism should conflict, if it seems monstrous to him that anyone should have advantages of birth-I do not ask him to change his faith, I merely ask him to stop paying lip-service 
to culture'. ${ }^{349}$ 'There is no better retort to this than John Harrison's conclusion that 'if Eliot wishes to preserve the high level of minority culture by keeping it that of the minority, he must stop paying lip-service to the members of the lower levels, their culture and their happiness'.350

The last - and maybe most controversial - issue that needs to be discussed here is that of anti-Semitism. ${ }^{351}$ Was Eliot anti-Semitic? And if so, how problematic is it? While the first of these questions is popular among critics, it would be more worthwhile to ask about the instances of anti-Semitism in his works. How do these instances interact with the rest of the literary text? And finally which effect do these instances have on readers and society? While the analysis part of this chapter will deal with the second and third question, this short introduction will answer the first. By itself this question has very little value, but it may help to put Eliot's literary anti-Semitism into context. To put it bluntly: the answer is yes. There are anti-Semitic instances in certain poems, which is fairly well known although the severity of the anti-Semitism remains a contested matter. ${ }^{352}$ It is also true that these poems belong to the earlier period of Eliot's poetic output and that later poems and plays no longer evince such tendencies. There are furthermore anti-Semitic remarks in his essays. The debate on Eliot's anti-Semitism has spawned an emotional debate already during the poet's lifetime, with Eliot adamantly denying any charges. To sensibly discuss these charges, it needs to be settled how anti-Semitism can be defined, which I have done in my theory chapter. I want to highlight again the crucial elements and match these with examples from Eliot's texts. AntiSemitism, according to Julius, is not enmity towards tangible Jewish projects but rather towards projections. The projection comes first and is only in a second step corroborated by finding examples of Jewish individuals that fit those projections. Moreover, while anti-Semitism can be found across the political spectrum, a decisive element of right-wing anti-Semitism is proscribing a protean quality to the (fictional entity of) Jews. Just as Julius speaks of them as 'taxinomically slippery', 353 I remarked that they are seen as continually shape-shifting but remain at the core 'the other'. Moreover, Julius also insists that one can see anti-Semitism as a reservoir - of tropes, metaphors, stereotypes - from which everyone can draw. I also included Bauman to shift emphasis away from motive or intention to practice. Eliot's depictions of Jews (his Bleisteins, Rachel née Rabinovich, the unnamed Jew in 'Gerontion' and debatably Sir Ferdinand Klein) fulfil these criteria. They are unstable, shapeshifting and boundary crossing (or in short: protean). Not one of them is portrayed in a way to evoke sympathy, or in case of the dead Bleistein, pity. They all share some qualities with each other (as well as other marginalised figures), but stand apart from the 'English' characters. In sum, they are 'the other', they are protean and they provoke antipathy. Moreover, their presence in Eli- 
ot's poems not only shows that he could draw from a tradition and presence of anti-Semitism in British society, for the meaning of these poems rests on a knowledge of anti-Semitic tropes and stereotypes. The fact, that he could publish and republish (even after the Second World War) these poems without or with little resistance is another indicator that it was either accepted or at least overlooked in the publish sphere. Or as George Orwell remarked, when he came to defend Eliot against accusation of anti-Semitism, it was widespread and normal. ${ }^{354}$ However, as Julius stated, 'Eliot did not reflect the anti-Semitism of his time, he contributed to it ${ }^{3} 35$ and he did so by consciously inscribing stereotypical and negative representations of Jews into his poems. Thus I believe the argument about Eliot's anti-Semitism for many critics is less about whether there are anti-Semitic instances in his writings, but whether they were put there out of a lazy habit (reflecting) or out of maliciousness (contributing). While the question about intent must remain unanswered, I would argue that their mere presence spread damaging anti-Semitic stereotypes during Eliot's time and with their continuing republication keeps these alive. Plus, just because anti-Semitism was widespread and normalised during Eliot's time, 'it does not follow that anti-Semitism was of a strength to compel adherence'. 356

Considering my other question of how grave the anti-Semitic instances in his poems are, the answer is usually sought in the anti-Semitism that surrounded these poems. When compared to more rabid anti-Semitic writing (Pound's, for example) they might seem rather trivial. Yet some critics beg to differ, interestingly especially those who try to evade accusations of antiSemitism in Pound's works. ${ }^{357}$ Before the Second World War Eliot's writings make use of anti-Semitic tropes; in After Strange Gods he deprecated 'excessive tolerance' towards free-thinking Jews; and in a review in his magazine The Criterion, the book The Yellow Spot, which as one of the first detailed the devastating extents of the Nazi persecution was slandered as unreliable and sensationalist. While Eliot's is quite certainly not the author of this anonymous review - by all accounts it was Montgomery Belgion who penned the piece - his role as the editor makes clear that he approved of its content not only by giving it space in his magazine but also due to the fact that the review was never given a counter-review. 358 After the atrocities of the Holocaust became known he cloaked himself more or less in silence on the matter of the Jews. The 1962 edited edition of his Notes towards the Definition of Culture shows that he felt compelled to explain his earlier remark about Jews. Yet he had no qualms about republishing his early poems ('Burbank' and 'Gerontion' included). His silence on the Holocaust as a historical fact has been noted earlier. It seems that Eliot is, like many of his apologists, unwilling to realise that although his anti-Semitic remarks and instances are far removed from the excesses of the 
Nazis, they belong to the vast spectrum of anti-Semitism. In the matter of literary anti-Semitism, Eliot is guilty of, in the words of Bauman, 'cooperation by non-resistance'. 359

I have devoted considerable space to the discussion of Eliot's politics. The main reason for this is Eliot's perpetual evasiveness. Craig neatly summarised the difficulty of assessing Eliot's politics when he writes:

The case of Eliot is without doubt the most problematic, and is so in part because of the fundamental evasiveness of Eliot's writings. Just as the objective correlative is explained only in terms of a negative instance, so his politics are defined in terms of refusals of positions rather than their assertion. In one sense, of course, Eliot refuses to be political at all, because all that pertains to the world of action is necessarily failed in the perspective of the eternal, but he also refuses to be political because he claims only to be interested in political ideas, not in politics, and even then to be interested from a point of view of jaundiced scepticism. ${ }^{360}$

Yet there is no escape from ideology. In contrast to the debate about Eliot and anti-Semitism, most critics unequivocally position him somewhere in the right-wing spectrum, only differing in the degree of radicalism. His preference for authority, order, hierarchy, and homogeneity, which manifests itself in Eliot's suggestions for restricted democracy, restricted social as well as geographic mobility, all betray his underlying allegiance to a system of inequality. This system of inequality thrives in Eliot's poetry by acts of 'othering' based on gender, race and class and often results in discursive violence. Or as Michael Levenson summarised it: 'Throughout his career Eliot's perception of political order required the extrusion of a poison, most often associated with women, Jews, or other "foreign populations," and during the thirties, he consistently tested the limits of extremity'. ${ }^{361}$ Furthermore, his 'lukewarm'362 opposition to fascism and his preference for an organically grown culture and tradition as well as the fact that in his writings Eliot more often attempts to recreate idealised past, ${ }^{363}$ place him at the conservative end of the right-wing spectrum with an affinity for more radical ideas. Indeed, some of Eliot's central ideological beliefs could be found in the most extreme permutations of right-wing ideology such as National Socialism, giving credence and authority to these ideas by incorporating them in his writings. Notwithstanding the changing cultural and political situation in Britain and Europe, Eliot's works keep those ideas circulating. By maintaining that Eliot's reactionary ideas stand in a paradox with the 'radical' (read: experimental) and 'progressive' form of the poem, apologetics sometimes attempt to remove the sting of those very ideas. Yet there is less 'progressiveness' in the form than usually assumed, since these 'experimental' forms are rather an outgrowth of Eliot's allegiance to right-wing ideology. There is no paradox between form and con- 
tent in his poetry - they both subscribe to right-wing ideology. The paradoxes that one may encounter are those inherent in the British right-wing conservatism contemporaneous to these poems' composition.

The one work that seems to embody the oft-repeated argument about the paradox between experimental poetic form and reactionary content is The Waste Land. My further analysis will take a closer look at Eliot's most famous poem - incorporating some of his earlier poems to illustrate the argument to show how form and content stand in concord. The radical form is not a symbol of progressiveness but bolsters the right-wing politics of the poem. Following Maud Ellmann, I will read the poem as revolving around the leitmotif of the 'general collapse of boundaries'364. Yet I would go further and claim that on a descriptive level the poem is disturbed by the collapse of boundaries, yet on its performative level it effectively contains these threats and successfully re-establishes those boundaries. To show this I will take a closer look at the categories of class as well as race, gender dynamics and the portrayal of Jews as these are the sites where, in the eyes of the Right, collapsing boundaries occur, threatening the supposed natural order. Another theme that is rampant in The Waste Land and is therefore another focal point of my analysis is the perceived threat of decadence and degeneration, important concepts of the right-wing tradition and embraced by thinkers such as Maurras, Spengler, and T. E. Hulme. Here again the collapse of boundaries is already implied. The poem presents a society in the grip of degeneration, and yet it does more than just expose: it shores its fragments against these supposed ruins. In the end, The Waste Land becomes a bulwark against the degenerated society it so grimly puts on display.

\section{'I was neither living nor dead"}

Degeneration and decline are key motifs in Eliot's poem - in fact, they are key motifs in most of his early poetry - which is already apparent to readers once they have laid eyes on its title, a first impression further validated by the epigraph of the withering Sybil wishing for the release of death. ${ }^{365}$ The perceived threat or fact of degeneration The $W$ aste Land sees in society is deemed to be a direct result of the collapse of boundaries, 'be they sexual, national, linguistic, or authorial'. 366 In the poem the moral concept of degeneration comes in the guise of things like pollution, sexual intercourse (especially rape), acts of intrusion and mingling as well as the simultaneity of life and death; all of these are instances of porous and collapsing boundaries. Harrison has noted that Eliot 'use[s] the degeneration of the sexual act as the symbol of the 
degeneration of a civilisation'. ${ }^{367}$ Tratner adds how Eliot (and other writers) brought together 'theories of sexuality, the failure of masculine leadership, and the horrors of immigration' culminating in disdain for democracy as well as the masses and above all a society that did not conform to the ideal of homogeneity. While Eliot paints a generally depressing picture of life and humanity in The Waste Land (and also Ara Vos Prec), it is 'the other', be it in terms of gender, race, or class, who is singled out for censure. The concept which Eliot's early poetry employs to redefine boundaries is disgust. In his Anatomy of Disgust, William Ian Miller, takes a closer look at the concept:

Some emotions, among which disgust and its close cousin contempt are the most prominent, have intensely political significance. They work to hierarchize our political order: in some settings they do the work of maintaining hierarchy; in other settings they constitute righteously presented claims for superiority; in yet other settings they are themselves elicited as an indication of one's proper placement in the social order. Disgust evaluates (negatively) what it touches, proclaims the meanness and inferiority of its object. And by so doing it presents a nervous claim of right to be free of the dangers imposed by the proximity of the inferior. It is thus an assertion of a claim to superiority that at the same time recognizes the vulnerability of that superiority to the defiling powers of the low. The world is a dangerous place in which the polluting powers of the low are usually stronger than the purifying powers of the high. ${ }^{368}$

Eliot's poetry taps into a long tradition of using disgust to 'recognize[ and maintain] difference', which also saw a resurgence among the French Right. The added significance of disgust in Eliot's (but also the French Right's poetry) is that, and here I follow Miller, disgust in a political setting is inherently anti-democratic by 'subverting the minimal demands of democracy':369

It does not admit of equitable distribution, and it works against ideas of equality. It paints a picture of pure and impure. And the compromises it makes across those lines are by way of transgression as sin, lust, or perversion. Hierarchies maintained by disgust cannot be benign; because the low are polluting they constitute a danger; a policy of live and let live is not adequate. ${ }^{370}$

Used as a political concept, disgust ties in neatly with right-wing ideology in general: it constructs, first, boundaries, and then, hierarchies, it devaluates the 'other' and simultaneously presents them as threatening, and finally it suggests that resolve can only come in the form of exclusion and a strengthening of boundaries. ${ }^{371}$ It seems no coincidence that popular right-wing concepts such as degeneration and decadence both seem to rely on disgust as one of its core concepts. In this chapter I will focus on how degeneration holds The Waste Land together, linking it to such concepts as the city, eugenics and pollution, 
and show in what ways the form of the poem emphasises the threat of degeneration and partially tries to contain it.

The poem's first section 'The Burial of the Dead' is aptly titled to introduce the themes of life and death. Yet as the famous first line indicates, things seem to have turned upside-down: the living are dead, the dead are threatening to become alive again, life-bestowing spring is cruel, winter comforting and kind. The simple reversal of the natural order, however, is not the threatening element here, but the fact that the boundary between life and death seems to have been obliterated. In lines 60-63 ('Unreal City / Under the brown fog of a winter dawn / A crowd flowed over London Bridge, so many, / I had not thought death had undone so many.'), London Bridge turns into the linking element that traverses boundaries. ${ }^{372}$ The crowd becomes menacing because they embody the living dead: alive but unconscious. Eliot just like Pound divided society along the lines of consciousness: it consists of 'a small "number of conscious human beings" within a mass society which is otherwise "largely unconscious" (Idea 28) and disposed to intellectual sloth (14)'.373 'Fear death by water', the clairvoyante predicts a few lines earlier, and fittingly the crowd flows over the bridge like the water that flows under it. ${ }^{374}$ Thus the city and/or society overflown by the masses also means a watering down of existing structures, symbolised by Saint Mary Woolnoth, which the masses pass unnoticed. ${ }^{375}$ Only the speaking persona dwells to listen to its tolling that ends, so the persona forebodingly remarks, on a dead sound. This passage pitches the masses against tradition, and just as the continuous flow of water erodes stone, so the indifferent masses can erode tradition. Kenneth Asher succinctly summarises the perceived threat of indifference in The $W$ aste Land:

By the time of The Waste Land, Eliot is fully convinced that one either sustains the tradition or is perversely parasitic upon it. Worst of all is to be perversely parasitic through indifference, for this argues a disdain of the tradition far more unregenerate than that demonstrated by those who court damnation. The latter at least acknowledge history's authority though they rebel against it; the former, more completely self-absorbed, do not feel obliged to take any stand at all. [...] The indifferent, [...], Eliot regards as the living dead, and it is they who make up the vast majority of The $W$ aste Land's population and will roam through Eliot's poetry for the rest of his career. ${ }^{376}$

Moreover, in contrast to Pound's 'Hell Cantos' that transform London into hell, but 'a Hell for the other people' 377 as Eliot had remarked, London as hell in The Waste Land offers no escape. One of the personae exclaims: '... I could not / Speak, and my eyes failed, I was neither / Living nor dead, and I knew nothing,' (38-40), a possible reference to Dante's Inferno. ${ }^{378}$ The death by water is not so much the actual drowning as it happened to Phlebas the Phoenician Sailor or Bleistein from the manuscript - who are indeed dead and there- 
fore non-threatening - but the drowning of the senses, i.e. the loss of consciousness, and the death of the individual in the overflowing mass and the death of tradition. The linking of death and the loss of individuality was a topos that had already gained traction before The Waste Land was written. In Blast 2, published in 1915, in which some of Eliot's earlier poetry was published, Lewis's short story 'The Crowdmaster' revolves around this particular issue. When Tom Normand analyses 'The Crowdmaster', his words fit Eliot's The Waste Land just as well:

[L]oss of individuality through participation in the crowd was described by Lewis as a kind of death: 'Death is, however, only a form of crowd. It is a similar surrender ... The crowd is an immense anaesthetic towards death.' Submission and surrender to the crowd provoked a loss of identity, will and consciousness - the death of individuality which was here compared with actual, physical death'. ${ }^{379}$

One remembers that in 'Prufrock' it is also the fate of drowning, albeit not death by water but the metaphorical drowning, that awaits the eponymous hero. Nevertheless, seeing that 'drown' is the final word, 'Prufrock' emphasises the existential dread and this coupled with the line '[t]ill human voices wake us' then also implies the 'loss of identity, will and consciousness'. In The $W$ aste Land - and here the containment of the threat comes into play - the process is reversed: the poem starts with death by water and ends in dearth of water. ${ }^{380}$ Thus, as Beer has noted, the popular notion of reading the main theme of The $W$ aste Land as post-war disillusionment is a premature verdict. Beer quite correctly points out that Eliot, who had never subscribed to the liberal 'illusions' of modernity, could hardly have been disillusioned after the war. ${ }^{381}$ On the contrary, similar to Pound, he rather saw his convictions confirmed. Adding to that, The Waste Land is not only a portrait of a society in decay but also an attempt to remedy it. Reading the poem in the light of rightwing ideology, it becomes clear that, despite the melancholic tone, it does not end in defeat.

This is especially apparent when one traces the water imagery throughout the poem and keeps in mind the importance of boundaries. As seen above, the first parts abound in water imagery that signifies the collapse of boundaries. This is continued in the ensuing parts with odours drowning the senses in line 89, the Shakespeare quote about Ferdinand's drowned father (who as we know is not dead) 'Those are pearls that were his eyes' (125), followed by the question 'Are you alive, or not?' (126), and Ophelia's last words, before she drowns herself, in line 172.382 In 'The Fire Sermon' the poem presents a juxtaposition of a once seemingly idyllic past, symbolised by Edmund Spenser's '[s]weet Thames, run softly...' (176) and modernity represented by the river now polluted by 'empty bottles, sandwich papers, / [s]ilk hand- 
kerschiefs, cardboard boxes, [and] cigarette ends' (177-178). Water is thus connected to pollution, to misery ('By the water of Leman I sat down and wept...' (182)), and to death. The affect of disgust can be palpably felt in this part when readers encounter litter, slimy rats (1.187-188), uncouth people $(\mathrm{Mr}$ Eugenides and the 'young man carbuncular' for example) and rape. The persona 'fishing in the dull canal' (189) seems out of place here, as the river does not appear clean enough to sustain life. The title of the next section, 'Death by Water', suggest that water again becomes a threatening element, yet looking closer at the ten lines this does not seem to be the case. Phlebas is dead, but his death only serves as a reminder of human mortality, while his body rests at sea, forever united with Bleistein. Passage $V$ then is very explicit about its lack of water: 'Here is no water but only rock' (331), 'cracked earth' (369) with 'empty cisterns and exhausted wells' (348), 'Ganga was sunken' (395). Yet the water is not completely gone: 'I sat upon the shore / Fishing, with the arid plain behind me' (423-4). While there is a certain sterility to this scene, the act of fishing seems less out of place here than in the polluted city. Here is a sense of order, water and land being separated, indicating that a boundary has been re-established. Likewise the order of power has also been reestablished: the water is not overrunning others, it no longer drowns, instead, the persona, the Fisher King whose power and masculinity have been restored, exerts control. London Bridge, the link which made boundary crossing possible in the first part, is 'falling down falling down falling down' (426). In the end there is shanti, 'the peace which passeth understanding'. The boundary is restored; order is restored and with it comes peace.

Some might object to reading the dryness of the fifth part as positive, since water serves as a key symbol for fertility. Yet as the first section of The $W$ aste Land shows, fertility is not a positive thing per se. Fertility that is excessive and out of control, and which disturbs the 'natural order' served as a negative example in right-wing ideology as well as contemporary discourses on eugenics and social welfare. The Waste Land illustrates the threat of fertility, turning water from life-giving to life-threatening. The problem is not water, but too much water:

...Eliot's poem captures the distinctly modern crisis of overproduction. April's fertility, sprouting excessive vegetation, makes it the cruellest month; floods and drowning recur as themes; Lil is almost killed by her own fertility; while typists and clerks are bored by the mechanical repetition of sex. The Victorian public moralists that Eliot lectured on in his extension courses were inspired by medieval agriculture's independence with natural abundance, cyclical and social order. Post-war overproduction turned these idylls into nightmares. ${ }^{383}$ 
The final section strips the water of its power and puts it in its place, and this, so The $W$ aste Land makes clear, can only be done with more tradition. The final lines of the poem are almost all lifted from other literary texts, and the persona comments 'These fragments I have shored against my ruins' (430). It is (literary) tradition that safeguards against degeneration. The early versions of The Waste Land show that the contrast between tradition and lack thereof had been originally even more poignant. Instead of a reference to Chaucer the first section of the early $W$ aste Land almost exclusively alluded to popular contemporary songs. Some critics such as David Chinitz have judged this as proof of Eliot's widespread interest in popular culture countering the assumption of Eliot as the staunch elitist. However, the effusion of popular songs is woven into depictions of debauched urban life with too much drink and sexual connotations, i.e. a panorama of decadence. The final version of The $W$ aste Land is a lot tamer and also more elitist. The allusions to old fertility myths evoke the ideal of tradition and also hark back to the ideal of closely-knit homogenous societies. Yet as issues such as fertility have been perverted by unchecked progress, old blessings have become new curses. The $W$ aste Land bemoans the loss of tradition but with its multi-layered text it also re-introduces tradition. The multi-lingual and multi-referential text is not accessible to the 'unconscious masses' but only to the conscious minority. The poem itself establishes a new boundary between those who understand the text and those that do not. As the form of The $W$ aste Land reinforces societal boundaries, it reproduces inequality, which it sees as the necessary response and solution for the problem of collapsing boundaries and thus degeneration.

Pollution, the intrusion by a contaminant, is another topic that feeds into the key motif of degeneration. As Julia Kristeva in Powers of Horror has discussed, pollution is linked to boundaries:

In the first place, filth is not a quality in itself, but it applies only to what relates to a boundary and, more particularly, represents the object jettisoned out of that boundary, its other side, a margin. [...] The potency of pollution is therefore not an inherent one; it is proportional to the potency of the prohibition that founds it. It follows from this that pollution is a type of danger which is not likely to occur except where the lines of structure, cosmic or social, are clearly defined. ${ }^{384}$

The concept of pollution requires boundaries, while the act of pollution also signifies the transgression of or at least permeability of boundaries. In The Waste Land the modern city is the locus where pollution most often takes place. It teems with rats and is cloaked in brown fog. Nature has already been contaminated, the river 'sweats / [o]il and tar' (266-267) and the trees are dusty. It is clear that the pollution is caused by modernity, the oil, tar and dust are due to commerce and industry, the 'empty bottles, sandwich papers / 
[s]ilk handkerchiefs, cardboard boxes, [and] cigarette ends' (177-178) are the cheap commodities of the modern crowd. However, Eliot's Thames is much more polluted than the actual Thames was at that time. Readers might be tempted to take the trajectory of the past clean Thames to its polluted state in the beginning of the $20^{\text {th }}$ century as a historical certainty, when, in fact, this is more of a commonly accepted narrative. ${ }^{385}$ This partially obscures that in The $W$ aste Land the trajectory of pollution carries a strong moral component. One could read in this a strong critique of the vapid commodity culture and unhampered capitalism. Yet this criticism is not targeted at the unprecedented rise of industrial capitalism because it produces wealth at the cost of inequality, but because the belief in the primacy of the economy stands in opposition to wholesome tradition, the kind one finds in Eliot's Four Quartets. ${ }^{386}$ Moreover, industrial capitalism is connected to the tradition-eschewing crowd, a notion one also finds in Eliot's essays, for example in The Idea of a Christian Society:

Britain has been highly industrialised longer than any other country. And the tendency of unlimited industrialism is to create bodies of men and womenof all class - detached from tradition, alienated from religion, and susceptible to mass suggestion: in other words, a mob. And a mob will be no less a mob if it is well fed, well clothed, well housed, and well disciplined. ${ }^{387}$

Thus the polluted city and the flowing crowds in The $W$ aste Land are linked and both feed into the poem's fear of degeneration.

This fear of degeneration often materialises in the form of disgust, which is associated with the marginalised other. Against the general bleak backdrop of The Waste Land, some characters are portrayed as disgusting, usually those that threaten boundaries, while others are not. Disgust in turn provokes radical reactions: intolerance and exclusion. By linking 'the other' to disgust, The Waste Land can resolve the problem of pollution by banishing the supposed pollutants. Phoebas the Phoenician, sailor and merchant, drowns, forgetting about 'the profit and loss' (314). His fate now stands as a warning for all those, 'Gentile or Jew', who hope to turn a profit by commerce. After the death of commerce follows the destruction of the cities: the ' $\mathrm{f}]$ alling towers [of] Jerusalem Athens Alexandria / Vienna London' (373-375). 'London Bridge is falling down' (326) and only a chapel, though empty, still stands. Connecting it to Saint Mary Woolnoth, the structures of tradition have survived the swarming crowds and other pollutants of modernity. What seems at first glance as an utterly barren landscape in part $\mathrm{V}$ is actually a landscape without pollution. Yet there is more to pollution than the tangible brown fog and litter; its moral component carrying a sexual component:

The vignettes of contemporary characters - loitering prostitutes, Sweeney and Mrs. Porter, Mr. Eugenides, the typist and clerk, and the various Thames 
maidens - indicate that the pollution is moral as well as environmental. The central event in this poem of crisis is rape, and as both violence and desire are contagious, the effects of Philomel's violation have spread from the center to the periphery in all directions. Contagion is evident in the presence of the disease-carrying rats, in the movement of the polluted river, and in the air circulating in and out of unwholesome lungs. ${ }^{388}$

In short: sex is pollution. ${ }^{389}$ Everyone in The Waste Land involved in sexual activities, irrespective of their social position, is presented as polluted. Sweeney, as readers know from Eliot's earlier poems, is half-man, half-animal; he meets Mrs. Porter, who, together with her daughter, wash their feet - a possible euphemism for cunts 390 - in soda water; the typist waits in her untidy home for the 'young man carbuncular' (231); the Smyrna merchant, who asks the persona for a weekend together at the Metropole (a line usually read as hinting at homosexuality), is unshaven and speaks demotic French; Lil, after five children and an abortion looks 'antique' (156); the unnamed couple in 'A Game of Chess' are beset by mental affliction; the other unnamed couple in 'The Fire Sermon' are in an equally bad position: 'After the event / He wept' (296-297) and she is associated with 'broken fingernails [on] dirty hands' (302303). The primal sexual pollution is rape, and yet strangely - or, in fact, fitting to the polluted city - it is the raped rather than the rapist who is depicted as dirty: Philomel when turned into a nightingale cries "Jug Jug' to dirty ears' jug jug also being a slang term for sexual intercourse. ${ }^{391}$ In a deleted scene Fresca who 'aroused from dreams of love and pleasant rapes' spends some time of her day with '[o]dours, confected by the cunning French [to] disguise the good old hearty female stench'. ${ }^{392}$ There are two disturbing assumptions one can draw from these readings: the first is that women are by default 'polluted', i.e. (morally) degenerate, secondly they seem to invite rape (Fresca is aroused by 'pleasant rapes', the typist invites the young man and offers 'no defence' to his 'assaults'), an act of pollution. They are in a state of degeneration and generate more degeneration, because it is women who invite acts of boundary crossing. It is no wonder that almost all women are banished from the poem's last part. ${ }^{393}$ Being a contaminant themselves they cannot be purified, but need to be removed - an act of exclusionary violence the text commits in part V. Pollution in The $W$ aste Land is a public and a private phenomenon, or rather problem, and both spheres are closely interrelated. Ellmann observes that

the text conflates the city with the body and, by analogy, the social with the personal. Abortions, broken fingernails, carious teeth, and "female smells" signify the culture's decadence, as well as bodily decrepitude. The self is implicated in the degradation of the race, because the filth without insinuates defilement within. ${ }^{394}$ 
It would be more accurate to note that it is not merely the body, but in most cases specifically the female body that is seen as defiled. ${ }^{395}$ And in a world of collapsing boundaries the defiler and the defiled can be one and the same.

While the dry and barren landscape at the end of poem seems to be, at first glance, the eponymous wasteland, reading The $W$ aste Land with the topos of degeneration in mind reveals a rather different picture. The city teeming with life is polluted, defiled, degenerated; the arid plains of the end are pure, untainted, and timeless. Although it seems hard to believe that the barrenness of the final wasteland offers a more hospitable place than the bustling city, The Waste Land is not the only Modernist text to prefer the barren over the buzzing. Writing on Joyce's Ulysses, Wyndham Lewis, in Time and Western Man, comes up with a very similar verdict:

Much as you may cherish the merely physical enthusiasm that expresses itself in this stupendous outpouring of matter, or stuff, you wish, on the spot, to be transported to some more abstract region for time, where the dates of the various toothpastes, the brewery and laundry receipts, the growing pile of punched 'bus-tickets, the growing holes in the baby's socks and the darn that repairs them, assume less importance. It is your impulse perhaps quickly to get your mind where there is nothing but air and rock, however inhospitable and featureless, and a little timeless too. ${ }^{396}$

This again shows that the three writers I analyse here not only roughly shared a world-view but that it materialised into certain observable topoi and literary patterns. Also the imagery used follows a clear pattern: Stone and rock represent tradition that can stand the test of time, water and other fluids symbolize modern (and often supposedly negative) phenomena such as crowds, but also women and Jews. Rock with its rigid form stands for order and boundaries; water, the shape-shifting element, traverses boundaries. It also fits the ideals of the Classical tradition espoused by Hulme, Eliot and others that prefer hardness and firm outlines to the supposed flabbiness of the Romantic flowing 'time-philosophy'. There is more to Eliot's language use: The Waste Land is famous for its extensive incorporation of intertextual references. John Barry has convincingly shown that The $W$ aste Land seems to draw extensively, without ever explicitly paying debt to it (either in the text or the accompanying notes), from Oswald Spengler's Decline of the West. Both texts show

marked similarities in analogical method and word structure. Decline adopts seasonal ideas of history similar to Eliot's historical juxtapositions in The Waste Land. In fact, Eliot's understanding of the historical process is more closely comparable to Spengler's than to the well-known anthropological works of J. G. Frazer and Jesse Weston. ${ }^{397}$ 
It is apparent from the Criterion that Eliot knew Spengler's works and had read them. ${ }^{398}$ Even if it cannot be proven that he read Decline of the West before he penned The Waste Land, the similarity between both texts testifies to a shared world-view: one that sees the world in a state of decline and European tradition and culture in decay; a decline that is directly associated with democratic and liberal achievement. The fact that these views were widespread during the 1920s does not make them less right-wing. Apart from tapping into the discourse of degeneration, the poem's right-wing structure becomes especially apparent when the power dynamics involving the categories gender, race, and class are analysed. While The $W$ aste Land is often touted for its polyphony and inclusion of a diverse cast of people a closer look will reveal how the white, male, middle-class self has to be guarded from the threat of the boundary crossing other.

\section{'They wash their feet in soda water'}

The gender dynamics are particularly revealing in an ideological reading. They testify to the perception of an acute threat, a perception that partially verges on paranoia. If we follow Eliot's notes, the 'most important personage in the poem, uniting all the rest' is Tiresias, the mythological seer who has lived as both a man and a woman. ${ }^{399}$ Moreover, so Eliot claims, 'all the women are one woman', and likewise all men are one man. ${ }^{400}$ Yet as with many of Eliot's notes, this should be taken with a grain of salt. While there is some truth to the 'all-are-one' statement, it is worthwhile to note when this is not the case. Interestingly, The $W$ aste Land boosts a multitude of female characters, who outnumber their male counterparts. However, as Cyrena Pondrom has observed female and male characters receive very differing treatments:

Whenever a complex subjectivity is fully realized, it is masculine; female characters are generally presented in single dimension. These female figures fall in three general categories: images of desire or seduction to whom the male is unable to offer love; manipulative and sometimes threatening figures seeking male attention and often offering sexual commerce; and pathetic images of women merely exploited and used. ${ }^{401}$

Gendered dynamics in the poem underline the poem's ideological structure and are made to feed anti-liberal and anti-democratic fears. In this way The Waste Land continues the troubling legacy of Eliot's earlier poetic output, which pitches women and men against each other in a supposed power struggle that only one group can win to the detriment of the other. In their darkest recesses Eliot's poems solve this perpetual struggle in a trivialization of ag- 
gression and violence against women, which as one of Eliot's favourite poetic personae, Sweeney, remarks, is both natural and normal: 'Any man has to, needs to, wants to / [o]nce in a lifetime, do a girl in'. ${ }^{402}$

The last section on degeneration has shown that women are perceived as threatening due to their sexuality. Moreover in their depraved sexuality, they are often linked to other (supposedly) morally depraved characters. Again this is a notion one also finds in other instances of Eliot's earlier poetry: sexually active women are in league with Sweeney - Eliot's famous ubermongrel who is half Irish, half Black, lower class and half animal - with Jews and other outcasts, continually attacking white male hegemony. ${ }^{403}$ In Ara Vos Prec women host Sweeney, Princess Volupine prefers Sir Ferdinand Klein ${ }^{404}$ to Burbank, Agamemnon is covered in the 'liquid siftings' of the nightingales, a cipher for prostitutes. The Waste Land continues this tradition of presenting female sexuality as a threat, linking it to the decline of culture. However, there are important changes compared to the Ara Vos Prec poems. While women are still predominantly sexualised, they have lost a good deal of agency; thus in The $W$ aste Land women are mostly passive and yet they are still presented as the corrupters as they seem to invite the sexual advances, and even sexual assaults, of men. Secondly, in The $W$ aste Land Eliot uses gender to bypass class differences. ${ }^{405}$ While earlier poems were usually limited to one class per poem, The $W$ aste Land unites women of all classes in their moral degeneracy. In 'A Game of Chess' readers are presented, first, an upper-class woman, followed by the middle and then lower-classes. The unnamed lady of the first part is described in richly luxurious tones: her chair seems like a throne, her surroundings emit an air of luxury and profusion, and she likewise is adorned with jewels and her perfume is like a beast lurking for its prey, which it troubles, confuses and drowns. In short the woman is a predator and yet strangely passive. The clue to her sexuality lies again in her surroundings: 'Above the antique mantel was displayed / [...] / The change of Philomel, by the barbarous king / So rudely forced;' (97-100). Using the rape of Philomel as an adornment adds a disturbing component to this scene. More disturbingly still, in this context with the woman as passive predator, there is a suggestion of Philomel having invited her own rape. It was her being irresistible, her drowning Tereus's senses, that made the king assault her. The deleted Fresca scenes support this reading. Although originally to be located in the third section of the poem, both scenes share a number of similarities: both women seem to belong to the upper classes, they lead a life of leisure and luxury and both rely heavily on perfumes. Both scenes also employ the concept of disgust by suggesting that the women smell - consider: 'Odours, confected by the cunning French. / Disguise the good old hearty female stench'406; in the final poem only the abundance of perfume remains. This, according to Miller, 
taps into a tradition that goes back to the Middle Ages and was later especially popular with Jonathan Swift. ${ }^{407}$ Making women smell implies (sexual) transgression and pollution, which in The $W$ aste Land is mostly synonymous. Miller writes that 'women reek of sex and sexuality' and Fresca as well as the unnamed woman of 'A Game of Chess' are linked to the most transgressive form of sex: rape. Fresca is aroused by 'pleasant rapes', while the rape of Philomel is a reverie that sits uncomfortably among the cupids and dolphins. It suggests that women's overpowering sensuality begets violent sexual transgression and thereby moral degeneracy. Thus the nightingale's cry announces not only the name of her attacker but asks for more sex: 'jug jug'. This scene is followed by the conversation of what can be assumed to be a middle-class couple. ${ }^{408}$ It is tempting to read them as a heterosexual couple, yet there is no definite indication in the poem to warrant such a reading. ${ }^{409}$ In contrast to the other two scenes this one has relatively few sexual connotations. What it offers instead is a glance at neurosis and a general sense of breakdown, which for my purposes will become important when I look at class. The sense of neurosis is especially apparent in one of the figures, conventionally read as female, who threatens to breach acceptable conduct when she proclaims: 'I shall rush out as I am, and walk the street / [w]ith my hair down, so' (132133). Yet it is an empty threat and the scene ends in a mode of paralysis. If one reads the other speaker as male, he seems to be the one who keeps the situation, and with that the woman, under control. Despite the breakdown of communication, the man exerts a certain authority and control. ${ }^{410}$ However, one could also offer a different gendered reading, this time taking into account the lack of clear gender markers. The nervous personal breakdown of one persona, coupled with the communication breakdown would then be reflected in the breakdown of definitive gendered identities. This not only reflects the general topos of collapsing boundaries, but also foreshadows the emasculations in parts III and IV.

When Lil, the lower-class woman of the third section, enters the scene, the topos changes from sterility to fertility, or more precisely the threat of fertility: 'She's had five already, and nearly died of young George' (160). Paul Morrison has noted that Lil's story reiterates that of Philomel:

Philomel's mutilated mouth becomes Lil's bad teeth ("You have them all out"), and the most horrifying of rapes is refigured as legalized, routinized sexual violence ("What you get married for if you dont [sic!] want children?")—. ${ }^{411}$

Yet her health, so it is implied, is not the issue to worry about, but her appearance and her ability to please her husband. ${ }^{412}$ There seems to be a curious but common double standard displayed here, namely that the man has the 
license to move on while this option is denied to the woman. The burden of childbearing and the consequences of sexuality solely rest on women; and the role of wife is inextricably linked to that of the mother leaving her with little choice: 'What you get married for if you dont want children?' (164). Fertility in a lower-class setting is equated with excess of fertility, and the man who plays a part in human reproduction is left out of this equation. All three women, irrespective of class, are haunted by their supposedly depraved sexuality, which seems to invite transgression, degeneracy and death by fertility.

This theme is continued in the story of the typist whose mechanical cohabitation with the 'young man carbuncular' (231) is not only one-sided - it is the man who '[e]ndeavours to engage her in caresses' (237) and then 'assaults at once' (239), while she offers 'no defence' (240), his actions 'are unreproved, if undesired' (238) - but, in fact, closer to rape than to consenting sex. After he is gone, her verdict is equally bleak: 'Well now that's done: and I'm glad it's over' (252). Indeed the scene seems to be a criticism of modern sex in general, but unsurprisingly it is the woman who earns more blame, because she is depicted as inviting sex and at the same time passive and silently resenting it. Despite her passivity it is suggested that she has a natural urge for sex, which she cannot control, even though she does not enjoy it. In short the picture that is painted of the typist here is the classic stereotype of a woman whose lack of self-control leads her to debase herself. Moreover, the designation of her as a typist, an employed woman working in the city and living by herself, suggests that modernity with female emancipation in its suit, exacerbates the problem. Looking at the women described, Eliot's remark that all women are one woman seems to hold true. None of them are painted in a positive light and thus elicit no sympathetic reactions from readers (unless pity might be counted as sympathetic, yet pity is always also condescending). They are all presented as morally degenerated, associated with an uncontrollable sexuality, while at the same time strangely passive. They are robbed of their agency, and yet are to blame for the actions that unfold. The Waste Land counters the democratic achievements of modern liberal England with a dystopian picture, in which loose women - in both sense: sexually active and uncontrolled by men - bring ruin upon themselves and in turn on society.

The connection between women and democracy is not a coincidence: The Waste Land quite consciously links women and images of democracy to paint both as harbingers of cultural degeneracy. Again this was not a novel idea during Eliot's time. Women's emancipation was closely linked to the democratic advancements of society in general. With women entitled to vote and work, some interpreted this as an attack on traditional (read: male dominated) power structures. Eliot was one of those who thought the increase in suffrage constituted a lethal blow to 'real' democracy and he remained scepti- 
cal about female employment. ${ }^{413}$ Moreover, as I have discussed above, another popular notion in the early twentieth century was to equate crowds, the symbol of democracy and urbanisation, with women. I have already quoted the passage from Le Bon's study, which was widely read during that time, with its claims that crowds and women share certain characteristics such as incapacity to reason, impulsiveness and exaggeration of the sentiments. Similar ideas can also be found in The Waste Land. Tratner has observed how Eliot's poem links crowds and women through the use of imagery:

Besides being an image of the masses, water also seems to serve in this poem to represent female responses to male advances: either women are unresponsive, indifferent, remaining dry and unstimulated sexually (e.g., the typist), or they are too excited and exciting, too wet, taking control and engulfing the male, as the woman in the game of chess drowns the male in her synthetic perfumes. The poem suggests that these women are involved in mysterious ways in the emergence of anarchic mobs. ${ }^{414}$

Just as women's sexuality and emancipation is suggested to bring cultural degeneration, likewise crowds are portrayed as a power that erodes tradition. A closer look at the typist, the quintessential modern woman in the poem, will reveal further links between women and democracy. The typist scene suggests that even though democratic processes and emancipation might have (economically and politically) liberated women, this has not led to an improvement of their lives. On the contrary, it has caused a certain sterility and brought new restrictions, which in turn have bad reverberations for society as a whole. ${ }^{415}$ Some Eliot scholars see the typist scene in a more positive light. Rainey, in The Annotated Waste Land, celebrates the novelty of including such a modern type: 'It is difficult today to appreciate just how innovative Eliot was in making a typist a protagonist in a serious poem. Prior to The Waste Land typists had appeared almost exclusively in light verse, humorous or satirical in nature'. ${ }^{416}$ Yet Rainey seems to care little how she is portrayed in the poem. It should go without saying that inclusion does not equal appreciation. Eliot's typist, who remains unnamed, remains a type. A portrait of a modern woman standing for all modern women. ${ }^{417}$ And the poem is quite clear what the results of emancipation and modernity are: the erosion of tradition. The meal she prepares for her guest is 'food in tins' (224) and after the event she 'puts a record on the gramophone' (256). Both are symbols of modern life, but both also signify the loss of tradition, the art of cooking, of being a good host, of 'real' music. The typist is the anti-angel of the house, and The $W$ aste Land makes sure that this is not seen as an improvement. The second result of emancipation and modernity is that the typist loses some of her humanness. She is joyless, 'bored and tired' (236), unresponsive, almost lifeless. In the end, she 'smoothes her hair with automatic hand' (255), having become me- 
chanical just like the music that fills her room and the food she eats. She is leading a meaningless life devoid of real pleasures, so fittingly she also engages in (supposedly) meaningless sex. As Rainey points out this was already a common trope during the time The Waste Land was composed. Listing some novels that feature typists as protagonist, all published between 1911 and 1922, Rainey remarks: 'In four of these novels the heroine engages in what would now be termed consensual premarital sex'. ${ }^{418}$ In The Waste Land the typist follows this trope, but she seems in no way to enjoy sex. The man is portrayed as unattractive, her unresponsiveness suggests rape rather than consensual sex, and afterwards she is relieved that it is over. It almost seems as if she feels obligated to engage in sex. This could be read in two ways. Either the poem ironically suggests that to be modern, women have to conform to certain behaviours whether they enjoy them or not. Or, in context with the other depictions of women and their overflowing sexuality, even when women are liberated they are still slave to their sexuality. The depiction of the typist, who seems as dry as her 'drying combination' (225), supports the first reading. The $W$ aste Land pokes fun at female emancipation, implying that it forces women into roles they will not enjoy. Women's liberation is not a real liberation and it destroys culture in its wake. Pre-marital sex is an attack on the tradition of marriage but also on the traditional role of the mother. The typist's messy flat and the cheap artificial meal signify the neglect of household duties. In the manuscripts she also possess a 'false Japanese print, purchased in Oxford Street' ${ }^{\prime} 19$, which links the modern woman to the decay of art and vapid consumer culture. ${ }^{420}$ In short, the modern woman, just like the crowd in earlier parts of the poem, is responsible for the erosion of tradition. Her inclusion in The $W$ aste Land is used to paint a portrait of a modern society, only to reveal its paucity and deficiency. ${ }^{421}$

Yet not only women fall victim to their own emancipation; The Waste Land suggests that they also attack the heart of traditional society: male hegemony. Unsurprisingly, this is again connected to female sexuality. DuPlessis aptly captures this when she writes: 'The sexual license of uncontrolled females, impotence of struggling men, mongrelised, cosmopolitan predators, and a failing social hegemony are linked together.' ${ }^{422}$ Unrestrained female sexuality has the power to destabilize the existing order and violates boundaries. As Tratner mentioned above, water imagery is used to depict female sexuality. The women in The Waste Land drown men in perfumes or in children. Moreover some women are even more closely connected to water, such as the Rhine Maidens and the Thames Maidens. In the passage 'By the water of Leman I sat down and wept...' (182), Leman is the French term for the Lake of Geneva, where Eliot was staying for his mental rest cure, but is also an archaic term for mistress. ${ }^{423}$ Fearing death by water thus also means fearing 
death, or at least undoing, by women. ${ }^{424}$ Accordingly some of the women are portrayed as predators or even as victims of drowning themselves who pull their potential saviour with them underwater. The mentally distraught woman in section II, implicitly reminds her partner of the drowning scene from The Tempest, while the male partner in section III starts weeping after sex. The latter can be read as an act of being unmanned, as this passage is immediately followed by the 'Death by Water' section. Fittingly Grover Smith has noted that the name Phlebas might have multiple meanings:

the name 'Phlebas' was contrived from the Greek phléps, phlebós, 'vein'. The word (like the Latin vena, I should have added) has a secondary meaning, 'phallus'. 'Phlebas', an accusative plural, can mean 'phalluses'. It has been suggested, most persuasively by Nänny (1981, pp339-40), echoing Lees (in Tate, 1966, p.349), that the name might simply be a respelling of the Latin flebas, which means 'you were weeping. ${ }^{425}$

Both meanings taken together might imply a connection between weeping and the drowning of the phallus, i.e. the loss of masculinity. Just as water kills men, women kill masculinity. In this context the persona weeping by the water of Leman may imply grief for his lost masculinity and not a lost lover. To re-establish male hegemony, women, just as the water, must be tamed. The only woman of part $\mathrm{V}$ is associated with 'empty cisterns and exhausted wells' (384), metaphors for wombs and vaginas no longer fertile as observed by Carol Christ who sees 'an exhausted and blackened vagina, suggested in the images of empty cisterns, exhausted wells, and bats "with baby faces" crawling "head downward down a blackened wall"”. ${ }^{426}$

In Eliot's poem women and democracy pose a threat to male hegemony: 'The mob is out of control, silencing the male authority-and the male author.' ${ }^{427}$ The depiction of women in The Waste Land is troubling, to say the least. They are predators and victims at the same time. One could argue that men are also portrayed as either victims or attackers, yet not at the same time. Plus, when they are victims their portrayal elicits sympathy, while they remain without reproach when they attack. The poem exhibits an obvious double standard here. Women are described as luring men into sex and yet they are the ones who have sexual violence done to them. To justify this, they are portrayed as fantasizing about rape and inviting their own attackers, unable to morally process what is happening to them. Potter has remarked how in Eliot's earlier poetry ' $[\mathrm{t}]$ he female body is the site of a repulsive violence, and women lack a meaningful moral register by which to understand this violence', ${ }^{428}$ The same holds true for The Waste Land. DuPlessis sums up the representation of women in Eliot's poetry thus: 'Eliot's depiction of female figures often reveals hostility, shock, distaste and manifests a mordant masochism at female sexual energy and power'. ${ }^{429}$ All the examples I have dis- 
cussed in this chapter validate this conclusion. It is fair to say that The Waste Land exhibits a marked misogyny. There is a tendency in Eliot scholarship to attribute this negative depiction of women to Eliot's unhappy marriage and his own sexual inhibitions. However, this omits the connection The Waste Land draws between women, modernity, democracy and the erosion of culture in general. Moreover, the poem taps into common right-wing sexist discourse of its time. Portraying women as strange predator-victim hybrids indicates that they are unable to function on their own in society, making women's political participation and contribution to public life in other forms than as housewives and mothers, i.e. in strong traditional bonds with a man governing over them, impossible and undesirable. Female suffrage as well as female emancipation thus become harbingers of decline. The supposed female threat, which the poem mostly presents as threats against individual men and their masculinity, legitimizes any action that will restore the much-needed order. The last part not only suggests asceticism on a personal level, but also the curtailing and exclusion of women in general. As other poetic works by Eliot show, even murder is a legitimate option. Only one female character seems to be safe from any discursive violence and any allegations: Marie. What might have saved her is her distinct place in a traditional and hierarchical structure. Or in other words: her class status.

\section{'It's them pills I took, to bring it off'}

The Waste Land offers a rich mix of voices of all classes and exhibits an intertextual mesh of both high and popular culture. This might give the illusion that underneath its elitist surface dwells a much more inclusive and allembracing spirit. However, things get more complicated when the role the lower classes and popular culture play in the poem as a whole is scrutinized. Similar to representations of women, the mere inclusion of lower class scenes and characters is often confused with an appreciation for the lower classes and popular culture. While it is true that Eliot and The Waste Land show(ed) an interest in the lower classes, this does not automatically mean that this interest is tied to genuine respect and empathy. On the contrary, I argue that the lower classes in Eliot's poems serve certain functions, none of which include a critique of an unequal system that keeps the lower classes at the bottom of society or a true appreciation for lower class culture. Despite Eliot's often-voiced antipathy for the bourgeoisie ('the middle classes are morally corrupt'), ${ }^{430}$ The Waste Land constructs a society in which the middle class and middle-class ideals are the unquestioned norm. While the middle classes are 
not necessarily portrayed in a wholly favourable light, the notion that only the middle class possesses a form of culture that is needed to safeguard society against degradation permeates Eliot's early poetry. Often middle-class norms and culture are not explicitly presented, but can be found in negation: middleclass culture is what 'the other' lacks: interest in culture, education, eloquence, modesty and a sense of decency. Again and again the lower classes are berated for their supposedly moral failings based on discriminatory norms they could hardly fulfil. For example, in Ara Vos Prec the actions of Sweeney and his kind are presented as amoral. Yet Sweeney always remains unperturbed; for him his actions are not amoral, which supposedly makes him doubly reprehensible. He breaches morals that are obviously not his, and his disregard for these morals makes the transgression even worse. The inclusion of the lower classes and popular culture helps to support the poem's ideological structure and, in fact, stands in concord with contemporary conservative politics. Moreover, the poem voices a critique of social mobility and reinforces in its very form a separation of classes, which despite all its polyphony and mixing of styles it cannot and does not want to challenge. Once more, it becomes apparent that the possible collapse of boundaries - class boundaries in this case - is seen as a threat to society. At its core The Waste Land remains an elitist poem that supports and strengthens a system of inequality and existing social hegemonies.

On the matter of class, the final version of The $W$ aste Land in some respects differs greatly from the manuscripts. The manuscripts boast a great number of references to popular culture and scenes of modern life. Pound's incisions and corrections removed a large number of these instances and thus The $W$ aste Land as it was finally published shows a marked elitism and a certain transcendentalism or timelessness due to its recurring allusions to religion and ritual. As I already mentioned the incorporation of popular material does not necessarily make a poem more inclusive. The same holds true for the depiction of class. Looking at the final poem readers realise that especially section II is concerned with different classes. Jonathan Monroe has remarked how critics often mistake this section to be divided into two parts, when it would be more accurate to split it into three. ${ }^{431}$ The change in class is mirrored by the change in language:

Noting the same shift perceived by Bedient, here described in terms of a movement from "a quite richly literary diction ... to a comparatively unprocessed modern spoken English," Craig points out that there is "a change of social class" in this section of the poem which "spans the gamut from wealth to poverty. [...] Expensive living [...] gives way to ordinary" (197-98). ${ }^{432}$

The language used is also the key to reading the classes presented. The first part with its 'richly literary diction' depicts an affluent, possibly aristocratic 
woman. ${ }^{43}$ The richness of the language mirrors the richness of the described interior. Her aristocratic lineage can be gauged by the allusions used here: the chair is not only like a burnished throne, the passage also refers to a description of Cleopatra in Shakespeare's Antony and Cleopatra. ${ }^{434}$ The rape of Philomel, which disturbs the scene, is part of the Classics canon. However, despite the wealth and lineage the woman in the scene has to offer, there is nothing positive about the scene. The woman, despite her earlier mentioned predatoriness, is not only strangely passive but also barely alive. She lacks the most important elements that would bring her to life in the poem: speech. Here again is another similarity with Philomel, who is also no longer capable of human speech and instead weaves her story into a rich fabric. Philomel's 'words' are the only speech in that section, and it is either non-human language or strangely archaic language (because Elizabethan). The scene seems to suggest that the upper classes are outdated and barely existing at all. The pictures on the walls are described as 'other withered stumps of time' (104); an evocation of death that is mirrored in the woman's lack of agency. There is a sense of melancholy pervading the scene, yet the remoteness of the persona makes any sense of sympathy impossible.

This changes with the abrupt shift to the second scene. Here readers encounter a couple whose language indicates their middle class status. Apart from very minor exceptions the language is notably unmarked: it does not contain visible accents, faulty grammar or archaic language. The literary references point to both high (Shakespeare, John Webster, Thomas Middleton) and popular culture (Shakespearian Rag by Gene Buck and Herman Ruby), although the former outweigh the latter. ${ }^{435}$ The deliberate use of unmarked language suggests that the middle class is the (invisible) social norm that is pitched against the visible, because linguistically marked, other. The woman's distraught behaviour and the breakdown of communication make it clear that suffering, especially mental suffering, lies at the root here. In contrast to the former scene, however, there is a certain timelessness to this scene. Mental pain, loneliness, and failed communication are presented as universal human woes of the past and present. Monroe writes that

[s]andwiched between the high cultural, upper-class "Belladonna" scene and that of the working-class pub, the couple's nervous pseudodialogue needs thus to be read as symptomatic not merely of a personal situation, but rather also as representative of the torn, ambivalent, compromised, even schizophrenic relationship - as much to itself as to those equally classbound above and below... ${ }^{436}$

This sense of transcendence is made explicit when the woman exclaims: "What shall I do now? What shall I do? [...] What shall we do tomorrow? / "What shall we ever do?" (131-134). Moreover, the insertion of the section's 
title into the phrase 'And we shall play a game of chess' (137), highlights the centrality of the middle class scene. It is not only the middle but also central part.

The last part unmistakably shows the lower classes indicated by the use of language but also by the way they are depicted. The use of ungrammatical language and the absence of any literary allusion mark their speech. The personae also fulfil other lower class clichés: they are visually unappealing, and have lots of children, a stereotype common in eugenic discourses at the time. While they do get dialogue and actual speech, in contrast to the woman in the first scene, it is repeatedly interrupted by the bartender's cry. Content-wise it forms a frame with the first scene, as both deal with male sexual advances. Although Lil presents the toll childbirth takes on the body, having narrowly avoided death, there is no sympathy offered to her: 'What you get married for if you dont want children?' (164), a line supplied by Eliot's first wife Vivien. ${ }^{437}$ In the figure of Lil the poem recycles a host of anti-lower-class clichés: negligence, lack of determination, and financial irresponsibility. It suggests that Lil's problems are entirely self-made, when in fact, they are interdependent with the power structures that surround her. Thereby The Waste Land can cast her as a tragic figure of her own undoing, while glossing over the structural inequality at play here. Some scholars tend to see Eliot's interest in the lower classes in a rosy light even when they try to be critical. Quoting Gregory Jay, Chinitz tries to address Eliot's ambivalence: 'His "often affectionate imitation of [working-class] voices," which "conveys a respect for ... ordinary lives and feelings," is offset by an "almost physical disgust for the materiality of existence-for the object world that dominates the lower classes" 438 The above scene gives no indication of affection nor 'respect for ordinary lives and feelings'. Imitation or appropriation does not equal appreciation. ${ }^{439}$ It is about time that the crude practice of imitating 'lower-class accents' is called into question. Although The $W$ aste Land gives the lower classes a voice they are only allowed to repeat the same clichés in the clichéd idiom that already existed in the public discourse..$^{40}$

The $W$ aste Land is also serious about maintaining the separation of classes. Thus while all classes are represented in the poem, they are not allowed to mingle. In the section just discussed all three classes occupy their own space. In fact, there is no passage in the text where members of different classes meet and interact. Moreover, social transgressors, i.e. those who move into another class, are usually ridiculed, although there is a big difference between those who want to rise and those who fall. The first embodied persona to speak in the poem is Marie and she is the only woman who is not portrayed in a negative light. Her speech introduces the theme of nostalgia as she shares recollections from her childhood. The line 'And down we went.' (16) 
does not only comment on the sledding, but is an indicator for her social decline as well as the general sense of decay and degeneration that permeates the poem, the notion that things go downhill from here onwards. And although the scene offers little information on Marie, there seems to be a certain melancholy pervading it: her confused insistence concerning her true identity ('Bin gar keine Russin, stamm' aus Litauen, echt deutsch.' (12)), her fright of sledding coupled with her longing to be in the mountains as they offer freedom and her nostalgia in general make her seem a tragic figure. Set against a backdrop that implies (self-induced) death, namely the Starnberger See, Marie could be associated with a general sense of demise. In contrast to Lil, Marie is a tragic figure highlighting the greater tragedy surrounding her. There is also the notion that Marie still embodies a sense of tradition, something that cannot be taken from her. This is later mirrored by Saint Mary Woolnoth in King William Street, the last bastion of tradition in London's financial district. ${ }^{441}$ The $W$ aste Land is sympathetic towards those who fall, as they are seen as victims, and a symbol of bygone greatness which was destroyed. It is quite a different story for those who rise. I have already looked at the typist who has gained financial independence yet has lost her grip on tradition. The young man she invites is portrayed in a similarly negative light. Chinitz has observed that

[th]is "small house agent's clerk" in "The Fire Sermon" ("One of the low on whom assurance sits / As a silk hat on a Bradford millionaire") exemplifies the social climber beautifully and is treated with the appropriate contempt, his carbuncles duly noted. ${ }^{442}$

In the original manuscripts the treatment of the young man was even more scathing: he leaves the typist '[a]nd at the corner where the stable is, / Delays only to urinate and spit'. ${ }^{443}$ Again the emphasis of his supposed uncleanliness and bodily effluvia evoke disgust. Chinitz remarks that during Eliot's time the resentment for social mobility was equally popular among middle class conservatives as well as the lower classes. In fact, the trope became a music hall staple:

Still more pervasive than the expression of actual Tory sentiments, however, was the quiescent fatalism of music-hall songs. Over and over they communicated the sense that life was full of hard knocks and that since there was no changing it, the best course was to smile stoically and persevere. The class system in particular was "simply a fact of life" that had to be accepted. The rich might be laughable, but they were entitled; social climbers who tried to improve their status were the single most common target of derision; political activists were full of "hot air" (Jones 493). Though such attitudes probably helped music hall transcend its initial working-class appeal-they were, so to speak, marketable values-they did originate in working-class culture 
(Russel 97, 110; Jones 462). Eliot's character portraits are saturated in these attitudes. ${ }^{444}$

The beauty of this for Eliot was that he could incorporate popular culture and legitimate his right-wing ideas at the same time. This is one instance where the incorporation of popular culture does not make the poem more inclusive, but instead supports its inherent right-wing views.

As the manuscripts reveal, the presence of popular culture in The Waste Land would have been much more pronounced: 'What is certain is that the manuscript of The $W$ aste Land shows Eliot drawing on popular song to a greater extent than he uses the Grail myth in the final version.' ${ }^{445}$ Yet, even if they had remained, they would not have made the poem less troubling in terms of class. Initially The $W$ aste Land began with a scene of the nightly antics of some young middle class men:446 they drink, eat and smoke, see a show, one of them seeks a sexual encounter with a woman, they go to a club and celebrate the night before the persona 'got out to see the sunrise, and walked home'. ${ }^{447}$ This section is satiated with references to popular songs. ${ }^{448}$ One of the men, Steve, seems like a middle class Sweeney. He goes to 'Myrtle's place', which can be read as a boarding house and possible brothel. He asks for a prostitute, but is denied on account of his drunkenness. Instead he gets 'a bed, and a bath, and ham and eggs [and] a shave'. ${ }^{449}$ This behaviour exactly mirrors Sweeney's, who in 'Mr. Eliot's Sunday Morning Service' 'shifts from ham to ham / Stirring the water in his bath', and excites a small panic in 'Sweeney Erect' when he before shaving ' $t$ t]ests the razor on his leg'. ${ }^{450} \mathrm{Mrs}$ Turner is annoyed by his behaviour as '[i]t does the house no sort of good'. ${ }^{451}$ In Sweeney Agonistes he seems to be frying eggs. ${ }^{452}$ Yet while Sweeney is the uber-mongrel threatening society and a slap in the face for anyone with optimistic notions about mankind ('The lengthened shadow of a man / Is history, says Emerson, / Who had not seen the silhouette / Of Sweeney straddled in the sun'453), Steve, on the other hand, is not singled out as a similar threat to culture. This alternative beginning of The $W$ aste Land shows a group of mischievous but after all harmless men. There is no suggestion that their behaviour has any negative consequences for society. There is a double standard displayed here: For the middle classes the old adage 'boys will be boys' counts, for Sweeney and his ilk there are no such inborn 'mitigating circumstances'. Analysing the use of references to popular culture supports this reading. They occur in a scene that exclusively focuses on vapid nightlife activities. Some of these might be considered in bad taste, but that is the worst charge that is brought up against them. Popular culture - even though Eliot might have shown a genuine interest in it - so the scene suggests, is equally vapid, sometimes in bad taste, but inconsequential and ephemeral. Moreover, the scene includes no references to high culture, which implies that next to the 
preference for the separation of classes the poem also advertises a separation of high from popular culture. The double standard this scene exhibits in conjunction with Eliot's earlier poems dispels the idea that his poems show admiration for the lower classes. It seems that the primary function the lower classes serve is as poetic material.

While I have already discussed that inclusion does not mean appreciation, I now want to probe even deeper and show that Eliot's poetical practice is not only not in support of the lower classes, but that it can be downright harmful. Although Eliot includes the lower classes in his poetry, he couches them in a language of disdain and even disgust. Consider again Miller: 'Disgust has a vice; it is a moral sentiment of extraordinary inclusiveness and does more than register a simple aversion toward the objects of its focus. It degrades them in some moral way'. ${ }^{454}$ The lower classes in The Waste Land are degraded for art's sake. Moreover, and maybe more importantly, making them disgusting presents them as polluting and threatening, which ultimately leads to a reversal of the aggressor/victim dichotomy: Eliot's poetry presents those who are most vulnerable and powerless in society as aggressors, while hegemonic mainstream society becomes the victim in need of defence. In times of social progress and social upheaval that brought new rights to the lower classes advancing their status as fully-fledged citizens, Eliot's early poetry taps into the deep reservoir of conservative ideas, eugenic fears and social prejudices. Instead of the fully-fledged citizens they were slowly becoming in real life, the lower classes in Eliot's early poetry remain poetic material, symbols to validate the poems underlying ideology. At worst, his early works constitute a form of 'poetical slumming', offering their elect readership a pleasantly horrifying but ultimately escapable journey through society's supposed underbelly. Slumming, a popular pastime among the richer classes in the London of the $19^{\text {th }}$ century, denotes the practice of visiting slums for entertainment. ${ }^{455}$ Having gained a global component, it is still popular today, with affluent tourists taking tours through poor and 'notorious' neighbourhoods in countries of the global South. Slumming (or slum tourism) has its advocates and its critics. The former stress the possibility to raise awareness and money for the local economies. The latter emphasize the moral and ethical components. Kennedy Odede writes in an article for The New York Times that '[s]lum tourism turns poverty into entertainment, something that can be momentarily experienced and then escaped from'. ${ }^{456}$ Even when people engage in slumming in order to understand poverty, the line between entertainment and awareness is a slim one; in fact it would be more accurate to say that both are inextricably mixed. Eliot's earlier poems do something similar: they offer the lower classes as a tableau, as something to look at, turning them into material for entertainment and art. 
I have already taken a cursory glance at the Sweeney poems. Sweeney with his unbridled sexuality, lust for violence, and questionable humanness is the prime example of the abject. This does not suggest that Sweeney is not an interesting character; he proved fascinating and opaque enough to be one of Eliot's most recurring characters. Nevertheless, it needs to be stressed that Sweeney is less a character for readers to sympathise with and more one to goggle at. I will discuss the matter of race in more detail below, but to anticipate parts of the argument and to show the intersections with class, it should be mentioned here that Sweeney is 'the other', both in terms of race and class. This combination is no coincidence but highlights his important role in the poems' ideological structure:

$\mathrm{He}$ is a figure who encodes attitudes toward threatening politically active races, classes, and groups who are (in terms the poem proposes) beneath Culture in one sense while exhibiting a lurid, complete, and tempting culture of pleasure, avariciousness, and sadism. Eliot's mongrelized figure is invested with allusive mixes of lower classes and aggressive ethnicities. It is also clear that the "Sweeney" figure embodies Eliot's terrific and mobile ressentiment - and admiring jealousy. The mongrel is admired and deplored; it destroys and revitalizes. It is sexually potent and culturally active. ${ }^{457}$

Sweeney's antics are entertaining and horrifying insights into the more sinister recesses of society for Eliot's readership. The Sweeney poems are indisputably neither appreciative of nor empowering for the lower classes. On the contrary, the poems suggest that the Sweeneys of the world already have too much corrosive influence on the foundation of Culture and society, while they have no culture of their own to offer. The practice of poetical slumming goes beyond Eliot's Sweeney poems. ${ }^{458}$ In 'Gerontion', which Eliot originally intended to use as a prequel for The Waste Land, the sordid landscape and house, not to mention its owner, offer a similar 'allusive mix] of lower classes and aggressive ethnicities' as the Sweeney poems. Instead of sympathy or social criticism readers can find the same combination of voyeurism and pleasant disgust. ${ }^{459}$ Moving on to The Waste Land a parallel pattern can be observed. In 'A Game of Chess', the first section abounds in the description of the lavish interiors; while the second section is dominated by the couple's dialogue. Both scenes say very little about the appearance of the characters involved. Again the middle classes lack a marker, this time visual, further highlighting the otherness of the lower classes. The lower class scene does not give us a glimpse of the surroundings (the only information we get that it is set in a pub is by the bartender's cry), but we do get an impression of one of the speakers. The depiction of Lil, maybe unsurprisingly so, echoes then contemporary right-wing views of the lower classes: 'Anthony Ludovici described lower-class England in terms quite close to Eliot's in a 1921 political tract, The 
False Assumptions of Democracy: England was on its way to becoming "one long ugly street, full of ugly toothless people, pretending that their clammy urban passions are more exalted than the rut of rats." 460 This taps into conventional contemporary eugenic discourses during Eliot's time and, more importantly, the emphasis on ugliness triggers disgust. While no class in this section of The Waste Land is painted in a favourable light, only the lower classes are portrayed in a way to elicit disgust. John Cooper also mentions the similarity of the views displayed in Eliot's poetry and the British conservative gazettes:

His attitudes towards [the lower classes] were thoroughly Tory and predictably unsympathetic, including the association of the dangerously emancipated Sweeneys with the foulest psychotic behaviour, the secret desire, for example, to 'do a girl in' (CP 134). He simply repeated, without any redeeming or original insights, the same attitudes to be found in the leader pages of the right wing press in Britain at the time. ${ }^{461}$

Eliot makes ample use of the existing discourse on the lower classes. He only reframes it by not talking so much about the lower classes, but by letting them do the talking themselves, yet uttering the same sentiments. This is combined with a presentation of the lower classes that validates eugenic fears. Lil and Albert already have five children, ${ }^{462}$ which has taken its toll on Lil's health, and Sweeney exhibits a rampant sexuality. It seems that reproduction among the lower classes is something they unconsciously engage in (or in the case of lower class men consciously so). ${ }^{463}$ One can find the same sentiment in Eliot's other writings:

"If the families who now sleep three or four in a room are to have habitations with a room apiece, there is everything to be said for the readjustment. But will they?... [O]ne would like to know whether the London workman can be given enough room for all his family, at a rent that he can pay? or will he merely increase his family?" 464

The same questions seem to permeate the scenes in The Waste Land. Especially 'A Game of Chess' evokes the fear to be outnumbered and overrun by the lower classes. The Waste Land's horror of unbridled fertility finds one of its main targets in the lower classes. Again the glimpse into lower-class life serves an ideological purpose. With the (pleasant) disgust are mixed the fears of what the consequences of the endless proliferation of lower-class life might be for society as a whole. Eliot was quite clear in his verdict when he said that in former times the struggle for existence was enough to keep down the defective element in the population; but under present conditions these people are protected and multiply'. ${ }^{465}$ This verdict betrays Eliot's eugenic panic and can also be found in the writings of prominent eugenicists like William Inge and E. W. MacBride, both of whom Eliot had read and reviewed. ${ }^{466}$ Similarly, 
in The Waste Land, as Juan Leon suggests 'the city festers as the breeding ground of disturbing populations and eugenic terrors' and yet he concludes that 'Eliot's eugenic fears must be considered ... in perspective. They were far less an anomaly than a characteristic of his age'. ${ }^{467}$ That is true, however, supporting eugenics betrays an underlying belief in inequality, especially since eugenic policies are often targeted at marginalized and/or vulnerable groups in order to strengthen the existing hegemony of power.

As I have shown in this chapter, the matter of class in The Waste Land is not as ambivalent as some scholars make it out to be. The society The Waste Land has set up follows Eliot's ideological world-view: a separation of classes and a strengthening of tradition. Despite the inclusion of the lower classes, their representation feeds off and further nourishes conservative prejudices and eugenic fears of the lower classes as inferior yet threatening in their cultural ignorance and unbridled fertility. Likewise, the use of references to popular culture does not counter the poem's elitism; on the contrary the use of popular culture reproduces existing inequalities. Eliot may have taken inspiration from popular entertainment forms like music hall, but his poetic works show little reciprocity. His strict ideas on education underline the assumption that The Waste Land may use the lower classes as poetic material but did not see them as readers. I used the term class appropriation in my title to highlight exactly this one-way engagement that is based on existing power structures. Eliot's interest in the lower class and popular culture is limited to those areas where it is useful for him either as inspiration, poetic material or validation of his ideological beliefs. The $W$ aste Land and Eliot's other early poetry merely use lower-class figures as projections of middle class fears and agonies. This dynamic does not only hold true for class, but also for the issue of race.

\section{'I'll convert you! Into a stew'}

In The $W$ aste Land the category of race seems less important at first glance, yet a closer look reveals that the poem interacts with issues of race on many levels: it borrows from African American Vernacular English (AAVE) and jazz rhythms, harks back to what it deems to be native ritual and Eliot's prominent mongrel Sweeney makes a short comeback. All of these elements are contrasted to the unmarked whiteness that pervades The $W$ aste Land, which in turn highlights the 'racial other'. Reading The Waste Land as part of Eliot's earlier poetry makes clear that race appropriation is a thread that ties all of Eliot's early oeuvre together. Similar to the issue of class, Eliot's preoccupation with race remains problematic: racial relations and racist traditions offer a res- 
ervoir of poetic material but also present a threat at the same time. Sweeney is the one character who combines all these conflicting elements. Eliot's most experimental play, Sweeney Agonistes, makes ample use, not only of Sweeney, but of all other forms of racial appropriation as well. ${ }^{468}$ As I will show in this sub-chapter the appropriation of racial elements helped to bring about a literary modernization, making it symbolic for the intertwinement of right-wing ideology and experimental style. Michael North has made a similar claim when he says that 'it seems that linguistic mimicry and racial masquerade were not just shallow fads but strategies without which modernism could not have arisen'. ${ }^{469}$ Yet there is more than 'linguistic mimicry and racial masquerade'; Eliot also employed different racist stereotypes and pitched a world of myth and ritual against the modern 'civilized' world. This already shows that Eliot's occupation with race did not only produce strikingly modernist literature but also reproduced racial inequality. Eliot's poetry being celebrated for its racial appropriation was only possible due to the inherent racism of a society that considered AAVE as deviant, non-whites as savages and had created a wealth of racist stereotypes. Colonialism and Imperialism had furthermore produced a strong sense of the 'racial other', who was mostly regarded as inferior, sometimes nobly superior but seldom equal. ${ }^{470}$ Eliot's poetry has to be read as part of the then existing discourse on race. Eliot's poetry was influenced by Black culture, which had already been processed by a racist culture of mimicry before it entered Eliot's writing. Drawing from the many racist discourses of his time, his poetry simultaneously feeds back into them.

Special attention needs to be devoted to Sweeney, even though he only plays a marginal role in The $W$ aste Land. Nevertheless, his short presence in the poem connects The Waste Land and its themes to the earlier Sweeney poems. I have already mentioned that Sweeney is a sort of 'uber-mongrel' as he combines a wealth of attributes. First of all he might be identified as Irish, as Sweeney is an Irish name, and Black, as he is regularly linked to offensive Black stereotypes such as cannibals. ${ }^{471}$ In fact, he could be read as an Irish man in blackface, which highlights the minstrel tradition and the white mimicry the poem performs. This combination of Irishness and Blackness is less surprising as it may seem at first glance. Victorian and early $20^{\text {th }}$ century caricatures of the Irish depicted them with a physiognomy that was presented as utterly different from 'standard Caucasian' faces and in fact closer to what was deemed 'typically Black' physiognomy. It is obvious that this racist depiction was based on distorted views of human evolution that placed both Irish and Blacks closer to primates or other earlier evolutionary forms of the homo sapiens. DuPlessis writes:

In both England and America in the latter half of the nineteenth century, the Irish had moved, in popular consideration, from depictions that made them 
into simple peasants, and feckless, sometimes witty drunks, to apes. In "historical physiognomy," they were depicted visually as simianized figures with flat nose, long projecting lip, sloping forehead, and forward jutting jaw, visually coded as inferior. These codes were loosely based on a spectrum depicting species evolution. So as "species" went, the Irish were subhuman, "white chimpanzees". ${ }^{472}$

In the early poems Sweeney is linked to African animals ('The zebra stripes along his jaw / Swelling to maculate giraffe.'473), strengthening the connection between Sweeney, Africa (i.e. the colonies) and the animal world. ${ }^{474}$ Above, I have detailed Sweeney's social position and the attributes that are connected with it. Taken together with his racial attributes the figure of Sweeney presents the idea of racial (and class) determinism. The lower classes are lower classes because they behave like lower classes. He looks and behaves like an animal, therefore he is an animal; he is an animal because he is made to behave and look like one. This determinism gallantly explains the low position of all 'othered' people, whether by racial or social terms, in society: they are at the bottom of society because this is where they belong due to their inherent inferiority, and their inferiority comes due to their position at the bottom of society. And yet: despite their inferiority the Sweeneys of the world are presented as a powerful threat to society. They are, as DuPlessis correctly notes, 'the primitive louts that are somehow, barbarously, at - or inside - the gates'. ${ }^{475}$ The characteristics that make him (appear) inferior are also precisely those that make him dangerous to established hegemony:

His sexual triumph (like that of "Sweeney Erect") is apparent, and is posed in the most degrading terms: sex is coterminous with a low drunkenness, prostitution, and strange positions. The social triumph may be in destabilizing imperial claims (the Irish Sweeney), in displaying Eurocentric culture (the Christian Church and Agamemnon figure displaced by Black Sweeney), or in displaying an enervated patriciate with animalistic, crude, and cruel sexual acts. $^{476}$

Also in The $W$ aste Land Sweeney fulfils this function of symbolizing the threat to established society and culture. Only three lines are devoted to him, and yet they carry the weight of all previous appearances and thus inject The $W$ aste Land with a further dose of racist ideology. 'But at my back from time to time I hear / The sound of horns and motors, which shall bring / Sweeney to Mrs. Porter in the spring.' (196-198). The lines that follow place Mrs. Porter in a definitive profession, i.e. prostitution. ${ }^{477}$ Yet the lines hide a lot more than Sweeney visiting yet another brothel. The sound of horns and motors disturb the reference to Marvell's 'To His Coy Mistress': instead of 'Time's winged chariot' it is the very earthly, and debased, Sweeney hurrying near. A replacement that suggests that fear of death has been substituted by a fear of copula- 
tion and fertility, more precisely the überfertility of the lower classes. Degenerate modernity encroaches into the territory of tradition. The second line is likewise based on a traditional work of literature, John Day's The Parliament of the Bees. ${ }^{478}$ The lines in the original spell out the story of Actaeon and Diana, ending tragically for Actaeon, who, as a punishment for seeing the goddess naked, is turned into a stag and torn apart by his own hounds. Again this reference links Sweeney to the animal world. Moreover, it recounts both Sweeney's detrimental influence on society but also foreshadows his downfall. His link to Actaeon might indicate that Sweeney will suffer a similar gruesome fate. However, the fact that Sweeney and Mrs. Porter displace and replace tradition (here symbolised in the form of canonical literature) also signifies the threat they pose. After all it is in the spring that Sweeney visits Mrs. Porter, and the spring, as The $W$ aste Land famously announces, is the cruellest month. This internal reference connects Sweeney and Mrs. Porter to the topos of fertility, or more precisely fertility that is out of bounds. I have shown earlier how water imagery is linked to excessive fertility, so naturally Mrs. Porter is not only modelled on bathing Diana, but is furthermore also explicitly shown to wash in soda water. Taken together with the original lines by Marvell, the theme of 'Death by Water' can also be read into this short passage. Despite the humorous tone of these three lines they seem to make a serious comment about society and culture being under threat from the 'other'. Sweeney's character is an attempt to give the fear of the racial and the social other a face; a face that is both fascinating and disgusting, but always suggestive of inferiority. Commenting on Eliot's use of racist clichés, Clive Bell once remarked that Eliot's 'antagonizing labours seem to have been eased somewhat by the comfortable ministrations of a black and grinning muse"". ${ }^{479} \mathrm{It}$ seems that this black and grinning muse was no other than Eliot's creation Sweeney.

Sweeney is, in fact, the perfect symbol for Eliot's poetic interaction with race. He is a staple character of Eliot's early work; his recurrence might be explained by the great attraction and potential this figure had for Eliot. At the same time his creation was only possible by emphasising the supposed otherness and deviance of the non-white. The same holds true for Eliot's use of (what he deemed) AAVE and jazz rhythms. As North has succinctly shown:

The real attraction of the black voice to writers like Stein and Eliot was its technical distinction, its insurrectionary opposition to the known and familiar in language. For them the artist occupied the role of racial outsider because he or she spoke a language opposed to the standard. Modernism, that is to say, mimicked the strategies of dialect and aspired to become a dialect itself. $^{480}$ 
This racial appropriation, style appropriation to be precise, ${ }^{481}$ only works because Eliot spoke from the dominant and privileged position, which makes it clear that the use of AAVE was also a question of power. By 'blackening' up their language white Anglo-American poets could play with language-based hegemonies while they still relied on social hegemonies that made their language play possible in the first place. ${ }^{482}$ North details how AAVE worked differently for white and Black writers:

Linguistic imitation and racial masquerade are so important to transatlantic modernism because they allow the writer to play at self-fashioning. Jazz means freedom to Jakie Rabinowitz [the protagonist of The Jazz Singer] partly because it is fast and rhythmically unrestrained but also because it is not ancestrally his: to sing is to make a choice of self, to do his own dubbing, as it were. For African-American poets of this generation, however, dialect is a "chain." In the version created by the white minstrel tradition, it is a constant reminder of the literal unfreedom of slavery and of the political and cultural repression that followed emancipation. Both symbol and actuality, it stands for a most intimate invasion whereby the dominant actually attempts to create the thoughts of the subordinate by providing it speech. ${ }^{483}$

Maybe unsurprisingly, similar to the lower class idiom Eliot uses in The Waste Land, the AAVE is merely a white mimicry of the actual variety. ${ }^{484}$ Moreover, the use of AAVE, while clearly an act of appropriation, seems to have been an attempt to reflect Eliot's own supposed mixed linguistic makeup, and thus his fear of being 'the other':

Someday I want to write an essay about the point of view of an American who wasn't an American, because he was born in the South and went to school in New England as a small boy with a nigger drawl, but who wasn't a southerner in the South because his people were northerners in a border state and looked down on all southerners and Virginians, and so was never anything anywhere. ${ }^{485}$

The 'drawl' is seen as detrimental in everyday speech, yet in poetry it becomes an asset for the white poet. This explains the underlying double standard and shows how inclusion and representation do not equal appreciation. DuPlessis writes: "The use of the word "nigger" could be seen in relation to the appropriation of black-based images; one must demean the owner to take the beloved product'. ${ }^{486}$ When Eliot made use of Black stereotypes, AAVE mimicry and racist songs, especially in Sweeney Agonistes, they are partially responsible for the very stylistic radicalness of the play, making it the most avant-garde piece of Eliot's oeuvre - before he abandoned the style and tried his hand at more conservative, stylistically as well as content-wise, theatre. Yet at the same time while the play gains from the influences, it also demeans the owners of these elements. Blackness in this play becomes a clichéd metaphor that 
stands for everything that is wild, uncivilised, and murderous. Here again Eliot makes use of stereotypes that see Black people on a lower evolutionary level - a pre-stage to civilised (i.e. white) humans. This sleight of hand also makes it possible for Sweeney Agonistes to speak to its audience, or rather its readership, as a whole, betraying at the same time, that its intended audience is exclusively white. The projection of the 'racial other' transcends class barriers and everyone, so the play insinuates, carries a core of the pre-civilised:

Eliot uses race and gender as unifiers for the disparate classes (and intelligence levels) of his (presumed) audience. In "Sweeney," the gender narrative of mordant misogyny, the racial-sexual narrative of cannibals (with a kind of swinging ragtime self-parody), and the racialized primitivism of the "HOO HOO HO" are put at the service of a cross-class address about guilt and horror lurking under normalcy. ${ }^{47}$

I would even go further than DuPlessis and maintain that despite the 'mordant misogyny', the racial appropriation in the play can bridge the gender gap in the audience/readership at the expense of the racial 'other'. Looking at Eliot's earlier work, there is a clear evolution from the 1920s poems at one end via The $W$ aste Land to Sweeney Agonistes. The $W$ aste Land, which in its original stage was much closer in style to Sweeney Agonistes, thus paved the way for the experimental style of the play. Here again it is justified to mention that the radical style of both pieces stands in no way in contrast to the right-wing ideology they promote. This becomes especially clear when we take into considerations that Eliot's racial appropriation stems less from Black artists themselves but rather from the already charged traditions of minstrel shows.

Charles Sanders's article on how minstrel shows form 'a "familiar compound ghost" behind the many-textured arras of The Waste Land' claims that Eliot was 'raising that mode of popular entertainment "to a kind of art.". 488 Although he convincingly argues his case that the minstrel tradition found its way into Eliot's poem, what is most impressive about Sander's article is that he can do so without ever mentioning race - let alone problematizing it. He links minstrel shows to the British tradition of music hall and while he makes note of the class dimension here he brushes it off by quoting Eliot's dismissal of the bourgeoisie and his love for Marie Lloyd. ${ }^{489}$ Yet Eliot's incorporation of both, music hall and minstrel shows, is inextricably bound to the inherent power dynamics; power dynamics in which the finished poem is the beneficiary and at the same time can easily rise above the level of its sources. This is problematic in two ways. First, if Eliot's use of these forms turns popular culture into high art it begs the question what it is exactly that makes this transformation possible. It might be that, for example in The Waste Land, these elements are given additional meaning by coupling them with elements from high culture. If the finished piece quite deliberately plays with the juxtaposi- 
tion of high and low culture, this presupposes the conviction - in author, poem and its readers - of a clear boundary between both types. Conjoining popular and high culture in this way, Eliot's writings helps to preserve this boundary - again an instance where The Waste Land presents a collapse of boundaries but also guards against such a collapse. Secondly, by turning traditions such as minstrel shows into art also preserves their inherent racism and elevates it by being incorporated in high culture. For example, by re-using stock characters of minstrel shows, such as Tambo and Bones in Sweeney Agonistes or Sweeney in implicit blackface, turns these insulting entertainment tropes into metaphors. Sweeney becomes the savage in us all, a reading that only works because of the racist undertones of the original trope. The characteristics Sweeney, Tambo, and Bones personify are, in fact, those which the minstrel tradition had ascribed to Black people and which, for example, made it impossible for many Black artists to use AAVE, as it had become a signifier for a certain stereotype. North quotes James Weldon Johnson, writer of 'Under the Bamboo Tree', the song Eliot modified and used in Sweeney Agonistes, on the problem of dialect: 'Dialect is impossible for a serious black poet of the 1920s because it is "based upon the minstrel traditions of Negro life," on "a happy-go-lucky, singing, shuffling, banjo-picking being,"” ${ }^{490}$ Eliot incorporating 'Under the Bamboo Tree' thus becomes not an homage to Johnson, but a homage to the tradition of minstrel shows. Therefore, I also think it is incorrect and maybe downright naïve, when Sanders claims that Eliot's inclusion of the minstrel tradition makes his poetry, especially The Waste Land, more inclusive:

And so, in the minstrel semicircle which assimilates the music-hall, and through our Tiresias-Mr. Interlocutor, in the snatches of our Meistersinger Wagner's operas echoed by Thames-maidens; in "doing" the "authorities" (Virgil, Dante, Shakespeare, as well as Marie Lloyd) "in different voices" of different lands, their national boundaries no less blurred than the corporealsexual boundaries that define and isolate all individuals we are transported back to the choral semi-circle of Greek drama and beyond to echoes of rituals and ceremonies existing perhaps before records outside of the archetypal images of a collective unconscious came to be and crystalized into specialties known as "arts." In sum, we are reminded of a common humanity, continued subconsciously in forms of public entertainment and thriving in the very bones of us all. ${ }^{491}$

The minstrel tradition is not a symbol of a 'common humanity'; on the contrary it highlights racist power structure and a system of inequality based on race. It seems that Sanders mixes up the acts of minstrel shows with genuine products of Black artists. Interestingly, minstrel shows were not only divisive when it came to race but were, in fact, an American tradition used to criticise 
the English establishment and hegemony. What makes them so insidious is that they supposedly celebrate a certain 'Americanness' distinct from its English predecessors, but they do so at the expense of Black Americans. North succinctly summarises this complex dynamic:

In fact, preemptive mimicry of blacks is a traditional American device allowing whites to rebel against English culture and simultaneously use it to solidify their domination at home. Robert C. Toll suggests that minstrel shows gained in popularity during the antebellum period because they both fed and fed upon American cultural defensiveness. On one hand, minstrel shows in all their crudity offered an outlet for egalitarian sentiments outraged by the conventional English stage. On the other hand, minstrel shows offered the white American common man an example even he could feel superior to, the black American common man, who was used to exemplify just those qualities white Americans were most nervous about. Minstrel shows allowed white audiences to have it both ways, to mock tradition, aristocracy, European culture by comparing them to something earthier, more natural, more "American," while simultaneously distancing all these qualities in a figure to which even the commonest white audience could condescend. ${ }^{492}$

Looking at North's description it should also become evident why I earlier claimed that Sweeney was a figure in blackface. Eliot's creation perfectly fulfils the role of the minstrel as stereotypical Black common man. He mocks tradition and (European) culture with his more natural (read: instinctual, sexual) nature, while his primitive savagery allows readers to distance themselves from him. Moreover, while he is presented as a threat to society and order, this threat comes cloaked in a simple-minded happy-go-lucky type. Thus for Eliot the minstrel tradition was doubly beneficial: It already had all the elements to criticise and revolt against the literary establishment but it remained so closely tied to prevalent ideas of social and racial hierarchy that it could easily accommodate Eliot's right-wing ideology. This shows once more that the radical experimental style of Eliot's earlier writings is not linked to a progressive ideology, but coheres with his right-wing ideology. The way the minstrel show tradition is incorporated into his writings reveals that Eliot relied on the inherent right-wing elements - racial stereotyping, (linguistic) blackface, and racism in general - to make these elements work in the final product. Sweeney only functions if readers understand the racial attributes and stereotypes that make him a modern 'savage', a trope popular among Modernist artists.

Eliot, as well as Pound, Lewis, Henri Gaudier-Brzeska and others associated with them, constantly returned to one trope to describe their position in modern society: the 'savage'. Although it might not be the first image that comes to mind when thinking of Eliot, the 'savage' and the 'primitive' figure 
prominently in his earlier writings. Possibly inspired by minstrel shows, the 'savage' in Eliot's writings fulfills two crucial roles: he was the 'other' who, in a right-wing context, threatened order and hegemonies of power, but he was also the rebel who defies modern democratic society and progress. Therefore Chinitz can discern a trajectory in the figure of Sweeney from 'other' to 'self:

One would not have anticipated this from, say, "Sweeney Erect," where Sweeney appears to exemplify the human beast. But in Sweeney Agonistes, Sweeney has come to speak for Eliot; he is the one character in the play with spiritual insight—an insight gained through sin and suffering. That Sweeney's alleged sin is the murder of a woman, a crime that obsesses Eliot throughout his oeuvre, strengthens their apparent kinship. ${ }^{493}$

I would not wholly concur with Chinitz on this point, although it is certainly a valid reading. I would rather twist it a little differently and say that both Eliot and Sweeney play with the role of the outsider of modern society. And while not apparent at first glance, race has a lot to do with it. Remembering Eliot's remark about his 'drawl', it is one of many instances with which Eliot (and also Pound for that matter) cultivated his status as an outsider, as someone who does not fit in. I use the word 'cultivated' deliberately as I would argue that it was a stance that was employed when it was useful and avoided when it was not. Their local American accents were not enough, so both poets employed racial markers to make themselves and their literature appear to challenge modern society - at the expense of the people they copied. How problematic this role of the artist as 'savage' could become can be illustrated by a quotation from Pound who once remarked: 'I wuz riz among nigguhs / the uneven forms of the camp meetin... dos jes get right down into my blood /regular strophes BORE ME' ${ }^{494}$ North correctly concludes: 'In this crude and offensive way, Pound ties defiance of the standard language, presented here as an essentially black habit, to his own literary experimentation'. 495 Pound makes use of AAVE-mimicry to challenge literary convention, but he can only do so by simultaneously denigrating the original speakers. In fact, he needs their supposed primitiveness to paint himself a rebel against progress and the establishment. This becomes even more absurd and offensive, when it is coupled with Pound's belief that he is 'racially alien to the mass of the population'. ${ }^{496}$ And while Pound was always more outspoken than Eliot, similar sentiments can be found in Eliot as well. He also relied heavily on the trope of artist as 'savage', yet gave it even another twist: 'The artist, I believe, is more primitive, as well as more civilized, than his contemporaries, his experience is deeper than civilization. ${ }^{397}$ It would be wrong to conclude that in the artist, primitiveness and civility were inextricably bound together; on the contrary, the artist perform an accepted notion of 'primitiveness' as the need arose. ${ }^{498}$ Eliot and other poets had the power to pick up the mask of the 
'primitive', employ a host of racial attributes and stereotypes, but drop it again as soon as it had served its purpose. Moreover, the coupling of the 'primitive' and civilised in the artist relied on a conception that was inherently binary as well as hierarchical, upholding the idea of the 'primitive' as the counter-image of the civilised. After all there is no need to employ the primitive if it would not be recognized as such. And thus by its mere use alone the idea of the 'primitive' as 'uncivilized other' is perpetuated.

With that in mind one can, for example, approach the use of ritual in The Waste Land and understand how it is tied into this system of 'primitive' versus civilised, this time pitching a positive 'primitive' past against a modernity that calls itself civilised but has, in fact, become degenerate. Even the use of jazz rhythms can be explained in that vein, although they seem to signify a whole different world than the mystified past of rites. Starting with the use of anthropology in The Waste Land, the evocation of 'primitive' ritual offers a welcome critique of modern society and progress. At the same time, it relies on ideas of progress that puts different human societies on a hierarchical scale. Once more, the 'primitive' becomes the precursor, an earlier stage in the development of human civilization. DuPlessis describes this dynamic in more detail:

Primitivism always negotiates political and historical gain for its white users, for as a discourse, primitivism denies history, real time, and maturity to its native denizens, erasing the existence of tribal peoples as functioning adults and as serious artists, operating in historical and situational circumstances, in favor of infantilizing visions which preserve for Western civilization a role as capstone. ${ }^{499}$

Even if the yearnings for the 'primitive' past or the 'primitive other' are genuine they are always part of the hegemonic discourse. Of course, the recourse to primitivism was not only a handy censure of modernity, it also proffered a vision of alternative politics. The 'primitive' and ritual found their way into The $W$ aste Land precisely because they reinforced the right-wing ideology already inherent in the poem. Chinitz poignantly observes how the yearning for the 'primitive' in The Waste Land is linked to the figurative violence found in Eliot's later essays:

Primitive cultural totality reflected the social integration of the tribe; and the sense of belonging to a community cemented by shared values, conventions, and modes of perception is exactly what Eliot missed in his own century-a loss expressed poignantly in The W aste Land. Eliot's attraction to the homogenous community reveals an obvious dark-side in its exclusion of outsiders, issuing in, for example, the notorious proscription of "any large number of free-thinking Jews" in After Strange Gods. ${ }^{500}$ 
Moreover, the 'primitive' society is employed to counter not only the collapse of racial boundaries but also of class boundaries; consider again Chinitz: 'that the model of the ritual-bound primitive community also offers a certain political convenience for a thinker committed to the patterned regularity of social class structure is also obvious'. ${ }^{501}$ The use of jazz rhythms works on a similar trajectory. Although a decidedly modern phenomenon, jazz is employed to rebel against the confines of civilized modernity and order, which was primarily possible due to 'its African-American origins, which allowed it to be figured as a "primitive" alternative to Western culture'. ${ }^{502}$ Even if one concurs that jazz is rather a cultural hybrid, in the words of African-American theorist Cornel West 'There is no jazz without European instruments', ${ }^{503}$ its employment in Eliot's earlier writings is not to appreciate it for its own sake but to cherish it for its power to dislodge established rules of languages, rhythm and sound. The same holds true for the 'savage' and the 'primitive'. In Eliot's poetry they are useful as a counter-narrative to modernity and yet they only function at the expense of the people and cultures they supposedly praise.

Racial appropriation in Eliot's writings works in many ways. The elements Eliot wove into his poetry were chosen for their racial attributes but were lifted from a white tradition that had taken and distorted them. Moreover, these elements of racial appropriation only function in Eliot's writings because they rely on the inherent racism that comes with them - the stereotyping and the racial othering. As a white Anglo-American author, Eliot was in a position that made him a double beneficiary of using racial elements. Employing them gave him handy tools to escape the confines of literary convention and establishment, while offering him an easy criticism of modernity. At the same time their reliance on stereotypes, racial prejudice and hierarchy cemented his superior position in the social hegemony as well as his vision of a society of order and inequality. Thus his use of racial appropriation is no homage to Black culture but rather constitutes a double insult: 'This language appears natural and unaffected by affronting English propriety, but it achieves this effect only by mocking blacks. These white Harvardians can approach the lower depths by slumming in slang while simultaneously solidifying their position as white by using racial slurs'. ${ }^{504}$ His prominent figure Sweeney combines almost all of the racial attributes that can be found in Eliot's poetry. Fascinating and disgusting at the same time, Sweeney's presence signifies the latent threat of the 'racial other'. Yet he is not alone. There is another figure in Eliot's poetry, which shares with Sweeney a place in the dark recesses of society threatening its very structures: the Jew. 


\section{'The jew is underneath the lot'}

Maybe no other ideological issue has been more hotly debated than Eliot and the matter of anti-Semitism. Too often the charge of anti-Semitism is seen as an act of slander, as Eliot called it, 505 rather than the outcome of literary analysis that sees these poems inscribe themselves into the anti-Semitic discourses of its time. Similar to the ways race, class, and gender is negotiated in Eliot's poems, their anti-Semitism reinforces the poems' inherent right-wing ideology. Not merely by the fact that anti-Semitism often, though not always, betrays an association with right-wing ideology, but because Eliot's Jewish characters feed into the fears of decay, degeneration, and the collapse of boundaries, which can only be overcome by their exclusion, putting them into their place or worse, their death. The reason I grant an extra chapter to Eliot's Jewish characters, despite the ways their depiction intersects with matter of race, class, and gender, is not only because the on-going debate on the topic of anti-Semitism seems to demand it, but because their treatment in Eliot's writings follows the anti-Semitic convention of classing the Jews as unclassifiable. Thus they have their own rules set out for them. This chapter will explore what these rules are and why it matters to label those of Eliot's poems that fulfil the necessary criteria as anti-Semitic.

Eliot's most prominent Jew is possibly Bleistein. He first surfaces in 'Burbank with a Baedeker: Bleistein with a Cigar' and then would have resurfaced in The $W$ aste Land, had not Pound decided to cut him out of the final poem. Bleistein is in all ways a base character. He seems to be of poor origin or to have fallen into poverty, as well as being 'underneath the lot', ${ }^{506}$ at the bottom of the evolutionary ladder, and finally at the bottom of the sea. Before taking a closer look at the Bleistein figure in both poems, his name warrants some attention. Literally translated the name simply means 'lead stone', fitting his position at the bottom of society and the sea. Patricia Sloane researched the name and unearthed the real-world Bleistein: 'Bleistein is named after a father and two sons who dealt in furs. Their shop, Messrs. Bleistein, was on Upper Thames Street at Garlick Hill (near the Church of Saint James Garlyckhythe), when Eliot worked at Lloyd's Bank and for about fifty years afterwards'. ${ }^{507}$ While it is plausible that Eliot was inspired by the name of the shop, the name Bleistein soon developed its very own meaning; in fact, it became a universal stand-in for 'Jew', as a communication between Eliot (as editor at Faber \& Faber) and Pound shows:

When he received [Pound's 'Chinese Cantos'] at Faber, Eliot had some problems with Canto LII, which provides the transition to the world of the Chinese Cantos. He suggested omitting the name of Rothschild from the lat- 
est groups of cantos so as to avoid libel or substituting the name of Bleistein as the metrical equivalent. ${ }^{508}$

In the final version of the Cantos the stand-in became the proverbial 'Stinkschuld', yet the fact, that Eliot thought that 'Bleistein' would have fit these lines ('Stinkschuld's sin drawing vengeance, poor yitts paying for Stinkschuld') equally well, shows that Bleistein had become a stock character, not unlike Sweeney, that could be re-used to quickly conjure up a certain type supposedly existent in society.

Looking at Bleistein in the 'Burbank' poem, the first attribute readers come across is his having a cigar. Sloane enters into an argument with Julius, whether the cigar could be seen as an anti-Semitic stereotype:

Is Julius correct in identifying it as "an anti-Semitic cliché" that "the Jew has a cigar" (Anti-Semitism 99)? Even in the early twentieth century, the cigarthe proverbial "phallic symbol" - may have been more notorious as a psychoanalytic cliché than an antisemitic cliché, if it can even be called an antisemitic cliché at all. André Aciman ("Reflections of an Uncertain Jew") may be more to the point in recognizing the cigar as a manly man's symbol of worldly success. As such, it might (or might not) be resented when seen among any outsider or pariah group, including women and Jews. ${ }^{509}$

There is truth in both views. The cigar is not the most common accessory in anti-Semitic propaganda, but some prominent, especially German, examples feature cigars such as the cover of Johann von Leers's Juden sehen Dich an and the children's book Trau keinem Fuchs auf grüner Heid (pictured). Published in the thirties they could not have served as inspiration for Bleistein, but they indicate that the stereotype of the cigar-smoking Jew existed as a trope. Moreover, Sloane argues that the cigar was more a psychoanalytic cliché, yet psychoanalysis (due to its founder Freud and its emergence in Vienna, a city with a large Jewish population; Bleistein also comes from Vienna) was often associated with Jews. The cigar in the title has to be read in conjunction with Burbank's Baedeker. Burbank might be in Venice to enjoy its cultural heritage; Bleistein with his cigar has no such aims. In fact, his cigar mirrors the declining 'smoky candle end of time' in line 20, signifying that Bleistein the Jew brings decline to Venice. ${ }^{510}$ After the title, readers encounter Bleistein again in stanza four.

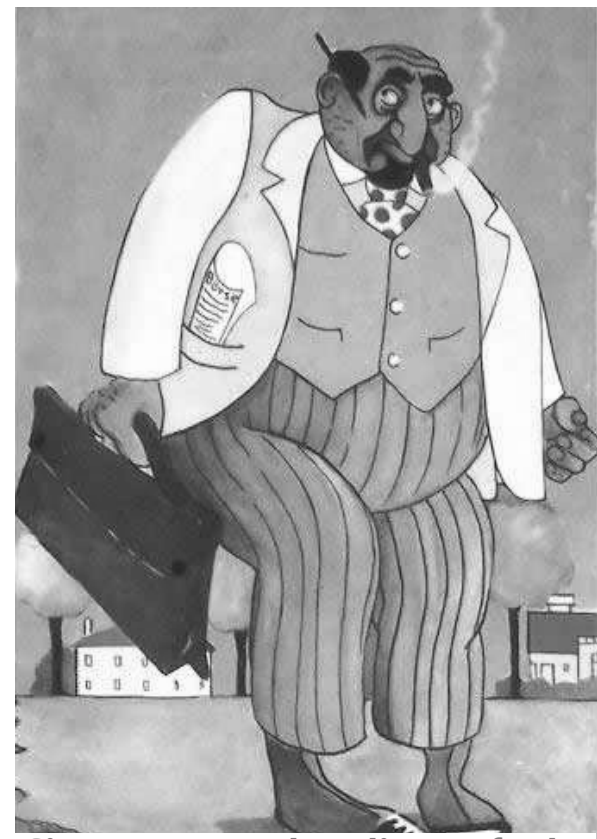

Cigar, saggy bending of the knees, protrusive eyes: this is not Bleistein, but the similarity suggests that the imagery was part of the public discourse. 
To the first impression is now added Bleistein's appearance and nationality: 'a saggy bending of the knees / And elbows, with the palms turned out / Chicago Semite Viennese'. ${ }^{511}$ His body is reminiscent of Sweeney's, ${ }^{512}$ marking them both as deformed and unhealthy, but also of the many propaganda depictions of overweight Jews. The focus on bodily abnormality and ill health, underlines the reading that Bleistein and Sweeney are considered unhealthy elements in society, possibly spreading disease and infecting the body politic..$^{513}$ Moreover, like Sweeney, Bleistein is mixed in terms of identity. By giving Bleistein a hybrid-nationality, the poem evokes the familiar reading of Jews as having no fixed national identity and no cultural identity, and thus the exact opposite of Eliot's ideas of national and cultural homogeneity. ${ }^{514}$ Moreover, Bleistein and Sweeney are also symbols of immigration and its supposed dangers. In the following stanza the insults continue: 'A lustreless protrusive eye / stares from the protozoic slime / At a perspective of Canalleto'. ${ }^{515}$ These lines offer a wealth of possible interpretations. ${ }^{516}$ Important for my reading are the facts that Bleistein receives an attribute, the protrusive eye, which was common in anti-Semitic depictions of Jews, ${ }^{517}$ and secondly, that he is linked to 'protozoic slime'. Hence the Jew Bleistein is depicted as evolutionary inferior, in fact, he is now positioned on the lowest rung of evolution, far removed from the first traces of humanity. 518 I observed the same dynamic with Sweeney and the racial other being linked to animals. Bleistein, however, is even inferior to these figures. He is lower than the rats, as the poem's following lines inform the reader. Bleistein's complete dehumanisation implied by his being lower than animals and likened to the most primitive life-form is not challenged by his possession of status symbols like the cigar. On the contrary, apart from the fact that the cigar can be read as an anti-Semitic cliché, it could also suggest a transgression that the lowly Bleistein should mix with a status symbol of the wealthy.

The poem leaves no doubt about the inferiority of Bleistein. Yet, the sixth stanza implies more than just the Jew's inferior position, it also hints at his destructive influence on society as DuPlessis has noted: "underneath the lot" intimates the most controlling, basic and primary, a prime mover. This belief that Jews were a secret power behind events was a recurrent ideological fantasy.... ${ }^{519}$ Interestingly, the line in question, does not specifically speak of Bleistein, but of 'the jew'. Similar to Pound, Eliot used the lower-case in the original publication, reinforcing the general 'lowliness' of Bleistein. The character of Bleistein reveals that 'Burbank' recycles a wealth of anti-Semitic clichés. This has led some critics, for example Robert Fleissner, to argue that 'Burbank' 'objectively and satirically portrayed the rampant anti-Semitism that was all too evident in certain circles at that time, for [Eliot] was a connoisseur of social comment'. ${ }^{520}$ However, Bleistein is a thoroughly negative character, a 
verdict that is furthermore verified when he is compared to the non-Jewish Burbank, ${ }^{521}$ despite the fact that Burbank is likewise not depicted in the most positive light. ${ }^{52}$ Yet even when one reads Burbank as a superficial and rather pathetic character, he does not evoke the disgust Bleistein does. Burbank could redeem himself if he would try; Bleistein is unredeemable. Both Burbank and Bleistein can comes across as caricatures, which might invite the reader to see the whole poem as satire, and yet Bleistein differs in no way from the more explicit anti-Semitic propaganda. As Emanuel Litvinoff correctly observed, Bleistein could as well be a figure from Der Stürmer. ${ }^{523}$ Thus, 'Burbank' thrives on anti-Semitic imagery, whether it is read in earnest or as ironic comment.

When The Waste Land, more precisely the deleted 'Dirge', ${ }^{224}$ is added into the equation, the scale tips in favour of reading the anti-Semitism as earnest maliciousness. 'Dirge' would have complemented and served as a graphic example to the 'Death by Water' topos. Traces of it can still be found in the final poem. It is partially modelled on Ariel's Song from Shakespeare's The Tempest. The line 'Those are pearls that were his eyes' are the surviving remnant of Bleistein's presence in The Waste Land. The original song by Ariel is sung to Ferdinand and this detail hints at a relationship between Bleistein and Sir Ferdinand Klein, which I am going to explore below. For now, 'Dirge' is directed at an unnamed addressee, the first line talking about 'your Bleistein'. It suggest that it might be directed at three types of addressees, (1) the fictional Ferdinand, (2) an audience already familiar with Bleistein (as Eliot's readers would have been), or (3) as the last line indicates, when it uses the word brother, at an audience who share Bleistein's Jewishness. The last being the most unsettling reading as it turns the poem into a threat for those who are still alive implying that the same fate might be in store for them. Also the title 'Dirge' seems misplaced, as there is no mourning in the poem. Instead it almost revels in the ways Bleistein's corpse is taken apart by sea creatures. In addition, some critics have made valuable observations about the language and imagery used here. Julius has remarked upon the coupling of contradictory Jewish stereotypes, the filthy poor one and the decadently rich. ${ }^{525}$ Sloane points to the possible link between the crabs, that eat up Bleistein, and the 'scratch scratch scratch', detecting 'scatological undertones'526, and thus bringing up the association between Jews and sexually transmitted diseases. This adds to Bleistein's Graves' disease, which would explain the protrusive eye in 'Burbank'. Jews are represented here as carriers of disease. Echoing Hyam Macoby's 'more salutary [...] understanding of 'Dirge' as a poem that attempts to depict the 'purgation' of Bleistein', Cheyette attempts to see the death by water as more than just a watery funeral: 'As opposed to the allencompassing 'dry season' of Eliot's preceding representations, the defeated 
Bleistein in 'Dirge' is given a redemptive 'sea-change' as he is rolled 'gently side to side' in a perverse act of baptism (echoing Eliot's implicit pun which 'gently' transforms 'the Jews' into 'Gentiles').'527 This links 'Dirge' to yet another Shakespeare play, namely The Merchant of Venice, in which Shylock is ordered to be baptised, an act of mercy as an alternative to having him killed. In contrast, Bleistein, according to Cheyette, has both punishments meted out to him. It is very difficult and almost impossible to let 'Dirge' pass as satire. In contrast to 'Burbank', 'Dirge' can hardly be read as a mere reflection of the anti-Semitism that surrounded Eliot. Indeed it would be difficult to find any examples of a similarly graphic description of a dead Jew's fate (even in Nazi propaganda). The problem with 'Dirge' is not that it depicts and describes the fate of a dead person, nor even a dead Jew. What makes 'Dirge' problematic is that it revels in the demise of dead Bleistein and simultaneously delights in highlighting Bleistein's Jewish identity. Julius notes that ' $[\mathrm{t}]$ he poem does not just communicate an anti-Semitic message. It enacts that happiest of antiSemitic diversions, the humiliating of a Jew'. ${ }^{528}$ Although completely fictional, the jocular tone in combination with the gruesome imagery makes not only for a chilling read, but also for the disturbing interpretation that the death of a Jew elicits no grief but delight. Taken together with the possible implicit threat at the end makes this piece of Eliot one of his most sinister.

While Bleistein is often seen as the stereotypically poor Jew, although not entirely accurate, his nobler counterpart is Sir Ferdinand Klein: 'He is the corruption at the top, Bleistein is the rottenness below'.529 This character works very differently from Bleistein with the result that one of the main debates surrounding Klein is the question of whether he is actually Jewish or not. Julius reads Klein as the Jewish counterpart to Bleistein: 'Klein and Bleistein are a complementary pair: the one effortlessly philistine, the other bogusly aristocratic, and both Jewish'.530 Sloane offers a different but still compelling reading when she argues that Klein is depicted in a way to elicit an anti-Semitic response; more precisely, he is never explicitly labelled as Jewish but given some stereotypical attributes, which thus lead the prejudiced reader into the trap of seeing Jews where there are none:

John Gross notes the presence in Burbank "of a second undesirable Jew, Sir Ferdinand Klein" (Commentary November 1996). Gross's statement is astonishing for the number of assumptions built into it. Readers who believe that only Jews are named Klein, that the name Klein "sounds Jewish," that sexual contact between a Jew and a person assumed to be a non-Jew (we do not actually know Princess Volupine's religious faith) render the Jew "undesirable," or that one does not expect English Jews to have titles ("Sir Ferdinand..."), poured out a virtual catalogue raisonne of unpleasant stereotypes. In mitigation, those who offer this mean-spirited picture of Sir Ferdinand Klein ex- 
plain it as "what Eliot means," rather than what they mean themselves. Today, with so many iterations of the theme in print, it becomes difficult to ignore the obvious: the hateful stereotypes of Jews put forward as "what Eliot thinks" come not from Eliot but from his readers. ${ }^{531}$

Other scholars like DuPlessis have read 'Burbank' in a way that it reflects (and possibly contributes to) the anti-Semitic debates that existed in Britain (and also in the U.S.):

Why would Eliot depict two Jews? For one, this literalizes the sense of being overrun, the displacement of Burbank sexually, economically, and culturally. It summarizes the bicultural problem - Jews immigrating both to England and to the United States. The two Jews in turn relate to the longstanding distinction between rich and poor Jews, between (loosely) Sephardim and Ashkenazim, or between two generations of immigrants. The attack on two classes also corresponds to a meretricious question (debated in Britain) during the multi-decade debate over Jewish immigration asking whether the lowerclass Jew, with his diseases and cheap pestiness, or the upper-class Jew with his cosmopolitan financial manipulations was a worse menace (Lowenstein 1993, 52). In this poem, Eliot echoes this debate, ending with a condemnation of both Jews. ${ }^{532}$

I would argue that the poem offers a reading in which the absence of the explicit label of 'Jew' in the ambiguous presentation of Klein becomes the proof of his Jewishness. The debate about Klein's possible Jewishness might seem unnecessarily inflated compared to explicitly hostile anti-Semitic portrayal of Bleistein. Yet Klein's possible covert Jewishness feeds into a prominent antiSemitic and right-wing discourse: the fear of Jewish infiltration after simulated assimilation. In this scenario the Jews become invisible to their supposed 'host nation' as a distinct group, while they maintain in-group fidelity and try to advance their group status at the expense of the host nation. Especially the status of Jews as unclassifiable nourished the fear that they could easily assimilate and blend in (something Sweeney could not do). Contemporary debates about Jewish names illustrate one area where the uneasiness of Jews becoming invisible was prominent, which led to condemnation of those Jews who had changed their name as it was seen as an act of treachery. Here is an excerpt from the children's book introduced above: 'Noch andere, die nannten gern / Sich Fischbein, Herz und Mond und Stern / Und Dreifuß, Blaß und Fels und Stein / Und Schloß und Großmann und auch Klein. ${ }^{533}$ Thus while Sloane warns fellow scholars not to fall into the trap of considering Klein a Jewish name ${ }^{534}$ because it is different, i.e. non-English, Bauer's book warned a German audience to mistrust names as they may sound German but belonged to Jews. Eliot drew on the theme of Jewish name-changes in 'Sweeney Among the Nightingales, the poem following 'Burbank' in Ara Vos 
Prec, when he introduced Rachel née Rabinovich. ${ }^{535}$ Klein might stand for the assimilated Jew, who leaves the onlooker in constant puzzlement as to his identity. In the British liberal tradition this might make him the 'good Jew' in comparison to Bleistein, who clings to his Jewish identity (and is duly punished for it). Cheyette has written about the idea of assimilation in relation to Jews:

Within liberalism, as one historian has argued, 'the desire to see the Jews adapt to the norms of the dominant culture was sufficient reason to present the negative image of the Jew and suggest it be erased by means of assimilation'. [...] This tradition has recently been dubbed the 'antisemitism of tolerance', which validates Jews 'not on the grounds of their Jewish identity, but on the basis of their conformity to the values and manners of bourgeois English society'. Within this culture, the Jew is represented as either a good self who embodies the values of bourgeois England, or a bad other who denies these values. ${ }^{536}$

However, despite his attainment of a title, he is Sir Klein after all, his unEnglish name still marks him as the 'other'. The reading of Klein as assimilated, and therefore good, Jew falls further apart when Burbank is taken into the equation. Burbank introduces and ends the poem, yet in the middle he is upstaged by Klein and Bleistein, as well as Princess Volupine. She, just as Bleistein, is diseased: her 'meagre, blue-nailed, phthisic hand'537 shows that she suffers from tuberculosis. ${ }^{538}$ Moreover, her being entertained by Klein makes her doubly linked to the two Jews; all three of them are in league against Burbank and thus white Western society. Note for example that Bleistein, Volupine and Klein all rhyme, whereas Burbank stands out.

Klein, who enters the scene only in the last line of the penultimate stanza - although there is some prosodic foreshadowing earlier - is portrayed in a wholly unfavourable light, even literally, in the smoky light of the declining candle. DuPlessis has observed the textual strategy that links Klein to anti-Semitic fears of decline to warrant another extended quotation:

And "The smoky candle end of time / /Declines." The corresponding pun on Klein, who is one de-kleining conjugation of the verb "to jew," is made textually; his smallness parallels the unmanned waxy candle burning down. The association of decline with a Jew is also made by situating the internal rhyme words "Declines" and "Klein" in unusual and unusually eloquent prosodic positions. The words both occur at the very end of a sentence, yet each is doubly enjambed over a line break and at the very beginning of a new quatrain. These are the only two words to be so treated in all of Eliot's contemporaneous quatrain poems: by this tactic, decline and the Jew are prosodically fused in the fundamental poetic texture. This reading of prosody on social philology corresponds to the endemic analysis that linked decline to Jewish presence. ${ }^{539}$ 
Additionally the poem's auditory aspect (as opposed to its visual one when read), plays another puns on Klein. First, the penultimate stanza ends on 'She is entertained by Sir Ferdinand'. 540 The reader caught unaware might interpret this line as Princess Volupine mingling among her equals, exchanging middleclass Burbank for the upper-class Sir Ferdinand. Yet when his full name is revealed in the last stanza as Sir Ferdinand / Klein, the enjambement becomes a sort of punch line. The reader, expecting a British nobleman, is after a pause confronted with an 'un-English' name. The 'otherness' of Klein becomes the trigger for the joke here. ${ }^{541}$ This deceiving of those who listen to the poem for the first time continues in the same line, which reads in total: 'Klein. Who clipped the lion's wings'. ${ }^{542}$ Read out loud the actual punctuation of this line and the following (i.e. the question mark that eventually ensues) can quickly vanish, turning the line into 'Klein, who clipped the lion's wings'. If the lion is read as a symbol for England, this becomes a very simple statement about the negative influence of Jewish presence in and on England. Hence the question the last stanza asks and Burbank ponders seems to be already answered by the isolated and highlighted position of Klein. The ensuing line '[a]nd flea'd his rump and pared his claws?' again highlights the ambiguity surrounding Klein. Julius shows how both readings fit into the anti-Semitic discourse: 'Clipping, fleaing and paring: do these emasculate or simply manicure? Has Klein subdued the lion or is he merely its ignoble personal servant? [...] Klein is both domesticator and domestic, or in a stronger version both degrader and degraded'. ${ }^{543}$

Now arguably Klein can also be found in The Waste Land. If 'Dirge' is modelled on Ariel's song, it should not surprise that the addressee of that song, Ferdinand, is also hidden in The Waste Land. The 'you' of 'your Bleistein' might be exactly that reference. It would also mean that Bleistein is, in fact, Klein's father. Thus The W aste Land becomes the answer to 'Burbank'. If Klein in 'Burbank' has not only won Princess Volupine but is also shown to possess corrosive influence on English society, The $W$ aste Land casts him into a place where he is about to lose. Taking 'Dirge' into account, section IV of The $W$ aste Land also recounts the story of a merchant drowning, of Phlebas the Phoenician. Sloane notes that the Phoenicians could be considered Semites as they would have spoken 'an ancient Semitic language related to Hebrew'. ${ }^{544}$ Semite is also the word used to describe Bleistein in 'Burbank', Sloane adds, although here simply to denote him as Jewish. ${ }^{545}$ Phlebas the Phoenician does not only share the same fate as Bleistein, but may function as an ancient version of Bleistein. 546 The 'Death by Water' section ends in the warning 'Gentile or Jew / [...] / Consider Phlebas, who was once handsome and tall as you'. If one considers Ferdinand to be the addressee, the 'Gentile or Jew' captures the image of him that was already built up in 'Burbank', 
namely that of an assimilated Jew that can no longer be distinguished from the population of his 'host country'. Yet why should Ferdinand Klein be the addressee here? The hint comes earlier in The Waste Land when Madame Sosostris lays the tarot cards for an unidentified customer: 'Here, said she / Is your card, the drowned Phoenician Sailor, / (Those are pearls that were his eyes. Look!)'. The death of Bleistein is foreshadowed, the quote from The Tempest identifying the customer as Ferdinand. ${ }^{547}$

Whether this reading of the reappearance of Ferdinand Klein is wholly feasible or not, looking at Jewish presence in The Waste Land shows that Jews are clearly linked to certain imagery, water being the most prominent. Bleistein in 'Burbank' is linked to the 'protozoic slime', suggesting not only an inferior life form but also life (and death) under water. Moreover, slime's aggregate state is neither solid nor liquid, it is in-between, a hybrid, unclassifiable. Klein helps Princess Volupine to 'climb the waterstair'; and the whole of 'Burbank' is set in Venice, a city where people do not flow down the solid streets, but the streets themselves are waterways. The Jew in 'Gerontion' was 'spawned', again implying an inferior life form and a connection to aquatic animals. ${ }^{548}$ In the manuscript version of The Waste Land Bleistein drowns, while death by water is connected to Phlebas the Phoenician and possibly Ferdinand Klein. I have detailed above how water functions as a marker for certain elements that seem to threaten society and tradition. ${ }^{549}$ It stands for democracy, the erosion of boundaries, the watering down of tradition and order, as well as for excessive fertility. Coupling the Jewish figures with water imagery suggests that they are a force responsible for all these attacks on traditional society and social hegemony. This is another instance where Eliot's poems lifted ideas from present anti-Semitic discourses, claiming Jews to be the instigators and also beneficiaries of liberalism, democracy, and emancipation movements. Nevertheless, as 'Dirge' would have made so menacingly clear, the Jewish threat is, after all, conquerable. Julius points out that 'Eliot's Jew, however, is prey, not predator' 550 and later adds that the typical Englishman's Jew is 'wicked, malignant, but ultimately conquerable'. ${ }^{51}$ Bleistein not only drowns, his body is returned to where he figuratively came from. Meanwhile he is devoured by sea creatures, his superiors as it is suggested. 552 Thereafter, Jewish presence diminishes in Eliot's poetry, although it sometimes crops up in the form of 'veneration for the biblical prophets and heroes, who embody the Judaic sources of the Christian Saints', forming a striking contrast to the 'modern Jews' populating Eliot's earlier poetry, as Cheyette has observed: 'By situating morally acceptable pre-Christian Jews in the biblical past, however, there is always the fear that their degenerate 'free-thinking' counterparts will return to 'adulterate' present-day Christendom'. ${ }^{553}$ In fact, the Jewish characters in his early poems cannot be described as free-thinking, 
but merely as degenerate: the owner in 'Gerontion' just squats on the windowsill, Bleistein stares in incomprehension at the culture around him, Klein entertains the Princess, Rachel devours grapes like an animal. Furthermore, the places they are associated with are equally despicable: the house in 'Gerontion' is seedy, just as the brothel that is possibly the scene of 'Sweeney among the Nightingales'. The Ara Vos Prec collection also insinuates that the Jews are all in league, working together with other people who populate the underbelly of society. Some linguistic indicators point to a possible reading that some Jews re-occur even when they are not explicitly labelled as Jewish. In 'Sweeney among the Nightingales', the following figure emerges: 'Therefore the man with heavy eyes / [...] / Leaves the room and reappears /Outside the window, leaning in'. ${ }^{554}$ This image mirrors the rather strange description of the Jew in 'Gerontion', who squats on the windowsill. Furthermore the unidentified man in the 'Nightingales' poem is described as having a 'golden grin' 555 , a description that re-appears in 'Dirge' as Bleistein's corpse shows 'teeth, gold in gold'. ${ }^{556}$ Could the man in 'Nightingales' be Bleistein? Or is the unidentified man also the owner in 'Gerontion', and the house has since been turned into a brothel? Even if they are not the same characters, these recurring images suggest affiliation or even similarity, denying the Jews their individuality, again turning them into a type. ${ }^{557}$ Moreover, just like the element water they are associated with, Jews cross and obliterate boundaries. First and foremost, they cross national boundaries. Bleistein is 'Chicago Semite Viennese', and Sir Ferdinand Klein also seems to have two nationalities or cultural identities, a reading supported by the enjambement that stretches out his full name over two lines and two stanzas and thus making him cross formal boundaries as well. The unnamed Jew in 'Gerontion' is '[s]pawned in some estaminet in Antwerp / Blistered in Brussels, patched and peeled in London'. ${ }^{558}$ All of them fulfil the cliché of the Jews as a rootless and internationalist people and thereby the opposite of the idealized notion so prominent in right-wing ideology of the strong bond between a people and the place they inhabit. Jews are the only people, so the logical conclusion in right-wing thought, who lack a homeland. In consequence the Jews always remain invasive and parasitic no matter where they live. Looking at Eliot's Jews in general shows that there is little originality in his choice of imagery and attributes. In fact, Eliot fully exhausted the reservoir of anti-Semitic stereotypes and clichés that existed in the public around him. In this way he did reflect the anti-Semitism of his times, but he also contributed to the ubiquity of anti-Semitic representations.

The Jew and the lower class mongrel Sweeney work together in Eliot's poetry, yet they function differently: 'The Jew lies outside the tradition, Sweeney beneath it. Only in a democracy could they arrogantly parade their 
vulgarity'. ${ }^{559}$ Yet, as Burkhardt Schmidthorst suggests, both groups, Eliot's Jews and his lower-classes, stand in opposition to the cultured readership Eliot addresses. ${ }^{560}$ They - alongside women - also seem to be in league, constantly conspiring against (white middle-class Christian) culture. Especially in Ara Vos Prec a continuous threat seems to exude from these groups, although it is never acted out. With reference to the Jews, Eliot's poetry makes ample use of the then existing (and still prevalent) notion of Jewish conspiracy against non-Jews. The poetry's insinuations coupled with references to such anti-Semitic prejudices are only intelligible due to the anti-Semitic discourse surrounding them. When Eliot's early poems were published, his negative portrayals of Jews would find themselves in plentiful company:

antisemitism was more of a theoretical preoccupation than a practical creed in the early 1920s, and the quantity of publications that peddled the idea of a Jewish world conspiracy was far more impressive than the number of organisations that wanted to get these ideas out of the drawing room and onto the streets. The battle against the Jews was conducted largely in the columns of newspapers and journals such as the Morning Post and the Patriot, and this reflected the fact that a lot of anti-Semitic propaganda at this time was symptomatic of middle-class worries about industrial unrest and aristocratic anxieties about industrial development, rather than working-class fears about immigration. ${ }^{561}$

The contents of these poems was firmly part of the 'sayable', and not only in the more seedy right-wing fringes but in the middle of society. When politics of the 'sayable' change, it rarely implies that some things can no longer be uttered, but that they will no longer remain free from censure. Eliot realized as much, when he finally felt compelled to edit his 1920 poems before a new release in 1963 and changed the lower-case spelling of 'jew' to its correct upper-case form. ${ }^{562}$ This very late change of heart suggests that the lower-case spelling 'jew' was not a random part of the Modernist challenge to typography, but had a deeper meaning, either provocative or simply insulting. Julius concludes that ' $[\mathrm{b}] \mathrm{y}$ recasting the typography of the poems Eliot acknowledged the offence they gave while signalling his refusal to withdraw them'. ${ }^{563}$ Has the Holocaust skewed the debate into what Orwell remarked as '[s] ome people go round smelling after antisemitism all the time'?564 Do we read the representations of Eliot's Jews as sinister and offensive because we know that the ubiquitous negative portrayal of the Jews was one of many things that made the Holocaust possible? As Sloane suggests: 'It becomes difficult to argue that if a non-Jew is on a window sill, [...], this is inoffensive, but if the person on the window sill is a Jew, the image is offensive. ${ }^{565}$ Apart from the fact that the window squatting is not the offensive part in 'Gerontion', the identity of the figure matters not because being a Jew makes every negative 
portrayal automatically offensive; but because only 'Jews' (as a type) had a reservoir of stereotypes and clichés assigned to them to make this and other poems feasible. Eliot's Jews are not only inherently offensive, but the poems rely on an anti-Semitic tradition that was readily available in the public sphere; a tradition so abundant in prejudices that no other marginalized group could have taken the place of the Jews in these poems.

\section{Final thoughts}

I have divided my analysis into subchapters along the categories of gender, class, race, and the depiction of Jews, and each time it was shown that Eliot's poetry situates itself on a top tier of the hierarchy of power, using its voice to further inequalities and to prop the existing social hegemony. The style, especially of The $W$ aste Land, which is often labelled 'radical' and 'experimental' does not stand in opposition to the right-wing content. This idea, of the stylecontent paradox in Eliot, is based on the fallacy that equates right-wing ideology with tradition and a backwards look, associating radicalness with progress and democratic social change. Yet radicalness, in art as well as politics, is just a mode of action, not a programme, and it can work equally well in the name of right-wing ideology. Both Eliot's early long and shorter poems were written in a context of certain power dynamics. These power dynamics found their way into the poetry, as class and racial appropriations or stereotyping to name just some examples. The use of the many tropes that give The Waste Land and the 1920s poems their experimental tone, the dialects, the mix of popular and high culture, the characters of the marginalised 'other' only work in conjunction with the standard or 'the normal' they are pitched against. These tropes never subvert the normative tendency of the social hegemony, they also do not create sympathy or empathy, but they leave the system intact, reinforcing the boundaries that distinguish the normal from the 'other'. Remembering that The $W$ aste Land centred on the fear of collapsing boundaries, its fear of transgression fuels the reestablishment of boundaries to separate groups based on gender, race, and class. The privileged position from which these poems speak manifests itself in the double benefit the poetry receives from the use of 'the other': first, these 'othered' elements offer a welcome criticism of the literary establishment and the political status quo, and second, they bolster the position of the voice that appropriates them. Thus, very importantly, there is no appreciation for the 'other' as people, but only as trope or symbol. In fact, in Eliot's poetry the promotion of tradition and homogeneity depends on the devaluation of 'the other'. Eliot's poetry manifests a 
palpable disgust towards the 'other' by cloaking women, Jews, the lower classes and the 'racial other' in a language of the abject: pollution, filth, sexuality, bodily fluids and functions. While there is a certain general misanthropic pessimism in all of Eliot's earlier poetic work, only the 'other' are equated with a strong (almost physical) feeling of revulsion. Making the 'other' disgusting implicitly legitimises and naturalises rejecting them. Moreover, especially in Ara Vos Prec groups that fall into the category of the 'other' are routinely dehumanized, by linking or even describing them as animals. ${ }^{566}$ It is important to note that this is nothing specific to Eliot's poetry alone but links him to contemporary discourses, for example the eugenic discourse, as well as other right-wing writers, such as Maurras, Robert Brasillach or Julien Rebatet of the French Right. Consider Sandrine Sanos's interpretation of this French rightwing circle:

In fact, tracing how they moved from decadence to abjection and then insurgency illuminates how "the abject" functioned politically. It displaced the long-standing anxieties regarding uncontained threats to the self, nation, and civilization and gave those threats shape and meaning - this pervasive disgust legitimated the violence advocated by the Young New Right, made their task urgent, and identified those threats to their normative vision of the bounded male self. ${ }^{567}$

The obvious parallels between these writers and Eliot should encourage one to see the greater (transnational) dynamics underneath. While it might not be feasible to speak of a right-wing idiom, Eliot inserted himself and partook in a certain right-wing discourse that included a particular set of metaphors, imagery, leitmotifs, and formal structures with a fixed meaning attached to them. Eliot's earlier poems and The $W$ aste Land are texts where discursive violence takes place. It makes its presence forcibly known to those who are singled out as its target. Yet, it does not necessarily determine individual readers' reactions. Writing on the right-wing elements in Eliot, many scholars feel the need to emphasise that Eliot's poetry can be enjoyed despite these elements, some fearing the spectre of censorship. Certainly, there are arguments that can be made against reading Eliot, but this is not the argument I am making here. Instead, I want to illustrate the ways in which Eliot's poetry offers itself to a coherent right-wing reading, drawing in those who seek out the poetry precisely because of it; and this is part of Eliot's legacy, too. 


\section{NO MEN IN NO MAN'S LAND WYNDHAM LEWIS}

'If Virginia Woolf is the modernist critics love to love - at least contemporary critics -,' writes Kelly Anspaugh 'then Wyndham Lewis is the modernist critics love to hate. ${ }^{568}$ True, Lewis's life and writings offer critics a multitude of reasons to hate him: from his self-appointed stance as 'The Enemy', a position from which he deliberately confronted everyone including friends and patrons, to political polemics such as Hitler. And yet, Anspaugh's view is not exact. While Lewis still has not received as much acclaim as other great Modernist writers, he has polarised critical reception far more than any other of his contemporaries. There is virtually no consensus on which of his fictional works can be deemed his greatest achievement. Moreover, his political writings have become subjects of fierce debate. Is Paleface blatantly racist or a more complex, albeit problematic, study of race?569 Is The Jews: Are They Human? a philo-semitic pamphlet in support of the Jews, or an attempt at political retraction employing a wealth of anti-Semitic stereotypes?570 In short, was Lewis a visionary who dared to stand alone ${ }^{571}$ or an intellectual blinded by the political circumstances and his own privilege? Should he be labelled a fascist, proto-fascist, anti-Marxist, revolutionary conservative, reactionary, or seen as right of centre? ${ }^{572}$ Are his right-wing tendencies negligible; 573 did he shift from the Left to the Right (and back again), 574 did he revert to a 'pro-democratic posture' in the late 1930s or not? ${ }^{575}$ Or was he standing outside politics?576 These unresolved debates testify not only to a rift (or multiple rifts) that separate/s Lewis's critics, but also to an inherent quality of the writing itself. While it is true that Lewis has some devoted followers, it is the fact that his writings seldom offer straightforward theories and assessments that keeps the debate alive. Already during his lifetime, Lewis himself was aware of these divergent analyses of his politics and jokingly remarked in his self-published magazine The Enemy that his politics were 'partly communist and partly fascist, with a distinct streak of monarchism in [his] Marxism, but at bottom anarchist with a healthy passion for order'. ${ }^{577}$ While tongue-in-cheek, this statement rings closer to the truth than its jocular tone might suggest. Lewis's writings challenge some more conventional ideological and political binaries. Thus unsurprisingly, debate ensues when critics attempt to reinsert him into established binaries. Looking into these complexities is not a way to escape debate but an attempt to retrace why Lewis's writings elicit such differing responses. 
This will prepare the ground for an analysis of The Childermass, which defies classification maybe more than any other of Lewis's novels.

To resolve the problem of positioning Lewis on the political spectrum, a closer look at his philosophical and political writings is necessary. Critics have often complained that Lewis's bad reputation solely rests on hearsay and cherry-picked extracts, for example from his book Hitler. ${ }^{578}$ What complicates the matter is that Lewis was a prolific and versatile writer, which means that critics have to wade through a huge amount of books - some of which, if we are to believe Lewis's later claims, were hastily and shoddily written. ${ }^{579}$ Talking about politics also necessitates steering away from anachronistic readings; this includes the problematic practice of some critics taking Lewis's late judgements on his earlier writings and political stances, for example from his second autobiography Rude Assignment, at face value. Instead of a broad survey spanning Lewis's life my analysis will have two foci: firstly and predominantly, his writings from the 1920s, and secondly, his post-World War II writings. The reason for this is the genesis of The Human Age trilogy, which consists of the early book The Childermass (1928) and the two later books Monstre Gai (1955) and Malign Fiesta (1955). There is not only a time rift between the first part and the two sequels, but also a stylistic and narrative shift. The obscure novel The Childermass was once planned to be part of a gargantuan tome named Man of the World, in which it would have co-existed with the satire The Apes of God as well as non-fiction works such as The Art of Being Ruled, Time and Western Man, and Paleface among others. Therefore it is worth exploring the links between The Childermass and the philosophical-political works published during the same time.

Lewis's writings that would have formed The Man of the World spring from a period of intense labour after he had served in the First World War. ${ }^{580}$ What complicates the assessment of Lewis's politics, beyond the sheer mass of his writings, is that Lewis was quick to voice changes in his attitude as events progressed. This led some critics - and some contemporaries such as George Orwell - to assert that at some point in his life Lewis performed a political u-turn. Orwell in an issue of The Partisan Review from summer 1946 welcomed Lewis into the communist camp - much to the chagrin of Lewis. ${ }^{581}$ This volte-face reading is nowadays vocally defended by Alan Munton, who sees Lewis swaying from Left to Right and back to the Left. ${ }^{582}$ However, there are also continuities in Lewis's writings, which may cast doubt on this interpretation. Near the end of his life, Lewis himself seems unsure whether to highlight the continuities or the changes in his thinking, as testified by his confusing assessment in Rude Assignment: herein he states that he is in complete disagreement with much of the contents of "Left Wings", ${ }^{583}$ although some pages earlier he claimed that ' $\mathrm{t}$ ] he advice [he] gave [in Left Wings Over Europe] 
was the correct advice'. ${ }^{584}$ Similarly Lewis writes about The Art of Being Ruled that he does 'not think quite the same now as then', ${ }^{585}$ but then proceeds to list all arguments with which he still agrees, which incidentally, are the main arguments of the book, and he closes Rude Assignment with the verdict that 'The Doom of Youth'-[...]—-'Time and Western Man', the centre part of 'The Art of Being Ruled', and parts of other critical books of that group contain nothing which disagrees radically with [his] present view of things'.586 What can be gleaned from this with certainty is that the political issues Lewis's was invested in remained them same. The titles of his books give away what these central issues are: The Doom of Youth denigrates the youth-cult; Time and Western Man discusses what Lewis calls 'the time-cult'; The Art of Being Ruled looks at the relationship of rulers and the ruled. These overarching themes also feature reflections on the political nature of certain categories: For in Lewis's world-view attacking the time-cult also meant attacking notions of race; thinking about the rulers versus the ruled forced Lewis to rethink notions of class (divisions) and gender. Despite his idiosyncrasies Lewis lays out a coherent ideological world-view. While his adherence to certain political movements, fascism in particular, changed, many elements of his ideological matrix remained surprisingly stable.

To adequately analyse the changes and continuities in Lewis's ideological matrix The Art of Being Ruled is an ideal place to start. As the title suggests the focus of the book rests on the ruled more than on the rulers. It is in the domain of the ruled that one finds the ideological structures that enamoured Lewis to fascism and, importantly, which experienced no significant shift during his life. Contemplating the general populace, Lewis does not differentiate between classes in the conventional sense but divides them into occupational classes, an idea that had been taken up by syndicalism (which was popular during that time). This is important for it offers him the possibility to set up artists/intellectuals as a separate class. ${ }^{587}$ Apart from occupational classes, the populace can be divided into two complementary categories: 'natures' (or natural humans) and 'puppets' (or mechanical humans). ${ }^{588}$ The natures are self-willed, intelligent humans possessing a distinct personality and determination, while the puppets desire 'to be looked after, disciplined into insensitiveness, spared from suffering by insensibility and blind dependence on a will superior to their own'. ${ }^{589}$ This natural division, so Lewis claims, is obliterated by the democratic insistence on the concept of freedom as well as by the Enlightenment concept of abstract humankind. This 'democratic, "enlightened" régime' supposedly leads to a war between the two fractions and misery on both sides as the puppets are forced to act upon their newfound freedom while the natures are dragged back to the status of puppets leaving them pitched against each other in hostility. ${ }^{590}$ This could be solved by creating 'two 
rigorously' separated fractions based on 'a deep racial difference, not a superficial "class" difference. ${ }^{591}$ This would, in Lewis's mind, remove feelings of inferiority but also arrogance and feelings of superiority (Lewis criticises 'highbrows' who look down upon those who have no aspiration towards intellectual enjoyment and 'high culture').

The other division laid out in The Art of Being Ruled, the rulers versus the ruled, broadly corresponds to the division of natures and puppets. Something that seems to play no part in the discussion of puppets and natures but is of great importance here are gender dynamics. Sex, as Lewis calls it, is constructed and not merely a biological factor:

Men were only made into "men" with great difficulty even in primitive society: the male is not naturally "a man" any more than the woman. He has to be propped up into that position with some ingenuity, and is always likely to collapse.

We have defined with some care what was intended by the term "woman," and we can now do the same for the term "man." The term MAN implies a variety of indispensable but not necessarily pleasant things, quite independently of the specific sex characters, although it can only be attached to an individual falling within the subdivision of the adult male. ${ }^{592}$

A man, writes Lewis, is 'an entirely artificial thing' and the same holds true for so-called masculine characteristics: "no more for one sex than for the other are the heroic ardours, "intellectuality," responsibility, and so forth, that we associate with the male, natural. Men had grown to regard them as natural, because in the first place they had seemed profitable'. ${ }^{593}$ Therefore he concludes:

The male is by nature (uninflated by vanity and physical exercise) as muscleless, slight, and as we say "feminine," both physically and mentally, as the female. There is no mysterious difference between the nature of the sexes, except the secondary differences we have been considering. ${ }^{594}$

It is for these reasons that 'man' is in need of protection from the damaging influences of modern democracy, such as feminism and homosexuality: 'Remove the arbitrary psychological machinery that in this way constitutes the mere male "a man," or tamper with it too much, or overtax it, and he collapses and becomes to all intents and purposes a woman. The functional difference, then, alone separates them' ${ }^{595}$ For a right-wing thinker - during the 1920 s no less - this is quite an unconventional perspective on the category of gender. ${ }^{596}$ However, probing deeper into Lewis's gender dynamics shows that apart from these reflections he was walking on well-worn paths. Despite criticising the concept of the naturalness of masculine traits, his gendering of the ruler/ruled binary makes use of conventional gender dynamics: 
This division into rulers and ruled partakes of a sexual division; or rather, the contrast between the one class and the other is more like that between the sexes than anything else. The ruled are the females and the rulers the males, in this arrangement. A stupid, or slow-witted, not very ambitious, conventional, slothful person (what has been aptly called bomme moyen sensual, the human average) has necessarily a great many feminine characteristics. These involve him, too, in a great many childish ones. And the relation of the ruler to the ruled is always that of a man to a woman or of an adult to a child. (By "man" here is meant any ruler-like person, of whatever sex, age, or class.)

Although the last sentence explicitly states that a 'man' can be of any sex, Lewis makes lazy recourse to traditional gender stereotypes that see activeness and determination as male and passiveness and lack of will as female - not to mention the pairing of stupidity and femininity as the above passage suggests and which Lewis later reiterates when talking about 'the natural feminine hostility to the intellect'. ${ }^{598}$ In another passage Lewis links women to children, with whom they supposedly share essential characteristics. 599 This thinking betrays Lewis as a disciple of Le Bon's crowd psychology. Unsurprisingly Lewis castigates feminism and the child-cult as threats to society (because beneficial to the democratic political leaders and industry ${ }^{600}$ ) and to 'the man'. As a corollary, contemporary emancipation movements produce, what Lewis calls, an epidemic of sexual inversion: "The "homo" is the legitimate child of the "suffragette". ${ }^{601}$ Interestingly, Lewis suggests that the followers of modern emancipatory movements are victims rather than active agents. According to Lewis, feminism, for example, is a movement that lures in women under false pretences, like granting them liberty by fighting for their access to the labour market, but which only profits Big Business (because women are cheaper labour forces than men) but not the women themselves. ${ }^{602}$ Yet while feminism and homosexuality prove deceitful to their gullible followers they are even more disastrous to heterosexual men, as Erin Carlston aptly summarises Lewis argument:

Feminists believe that they are advocating women's freedom, and homosexuals that their goal is to legitimate their own passions. Both fail to realize that they are merely instruments of a system that strives to reduce heterosexual white men to the economic and social status of superexploited colonized labor "in order to lower wages". ${ }^{603}$

It becomes obvious that for Lewis, most people fall into the category of the puppets, and thus the ruled. In the 1920s, democracy and liberalism jeopardised this ideal binary of rulers and the ruled, which presented a major incentive for Lewis to look for a political alternative. Nicholas Brown shows that it is Lewis's stance towards the ruled that makes him sway to the Right: 'The ease and consistency with which Lewis's powerful critiques of liberalism are 
folded back in favor of a bitterly aggressive attempt to defend his own precarious position of relative privilege with regards to women, laborers, the colonized, and so on make him, for us, an unambiguously reactionary figure'.604 Even in the 1950s when his view on democracy had changed his attitudes towards homosexuality, the child-cult, and feminism had not, indicating that Lewis remained on the political Right.

The Art of Being Ruled is also the one text where readers will find an unmistakable embrace of fascism on Lewis's part. ${ }^{605}$ Yet, and more importantly, the text shows Lewis carefully mounting an attack against democracy and liberalism. It is the egalitarian core of liberal democracy that lies at the centre of Lewis's attack. Thus it is the concept of inequality that structures his ideological matrix, and not anti-Marxism, as Jameson suggests in his seminal study Fables of Aggression when he claims that 'the structural center of [Lewis's] work [lies] in his implacable lifelong opposition to Marxism itself.' ${ }^{606}$ Alan Munton, among others, has already, rather sharply, addressed this wilful flaw or omission on Jameson's part when he writes that:

The case for "Lewis as fascist" [the subtitle of Jameson's study] is one that Jameson does not even attempt to make, thereby contradicting the masculinist assertiveness of his title. Jameson's first withdrawal from the word "fascist" occurs early in the book, and confirms the argument, made above, that Lewis had nothing in common with European fascist intellectuals of the 1930s and 1940s: [...] But Lewis was also an intellectual of the 1920s (who was by the 1940s a supporter of Roosevelt's New Deal), and the crucial text of that decade is The Art of Being Ruled, the text that Jameson does not, and cannot read. He cannot read it publicly because he knows that what it contends about ideology and hegemony is precisely the foundation of Jameson's] own argument. ${ }^{607}$

Yet Munton, convinced that the labels 'fascist' or 'proto-fascist' do not fit Lewis, also lets Lewis off the hook too easily. For The Art of Being Ruled offers an insight why Lewis became temporarily enamoured with NS Germany in the Thirties. Here Lewis writes: 'when two principles are opposed, and one of these is that of english liberalism, in most cases I should find myself on the other side, I expect'. ${ }^{608} \mathrm{He}$ accuses democracy and the individualism it engenders as the cause for the decline in European power and considers the parliamentary system doomed. ${ }^{609}$ Lewis, moreover, is very suspicious of freedom, claiming that most people do not want freedom and, very importantly, that the freedom democracy, as it was developing during the 1920s, offered was not real freedom but a sham, because the individuals of a democratic society were not acting on free will but were coerced to perform what a powerful elite consisting of financiers, the industry and the media envisioned. ${ }^{610}$ This makes democracy doubly insidious in Lewis's eyes: first, it pretends to give its 
citizens freedom but actually hides its power of coercion, which, secondly, makes it possible to present political events such as the First World War as willed by the populace. ${ }^{611}$ So his search for an alternative centres on these arguments and hence it should not surprise that Lewis found both fascism and, in the beginning, communism (which he also calls 'sovietism' or 'leninism') satisfying, although his preference lies with the former: 'I am not a communist; if anything, I favour some form of fascism rather than communism' ${ }^{612}$ It is noteworthy to stress that Lewis considered both fascism and communism to share essential traits, above all their authoritarianism, so much so that he describes fascism as

[a]n extreme version of leninist politics - although, making its entrance from the opposite end, it is still weighted with a great many impure elements of an opposite order to those impairing sovietism [...;] [o]r, if you like, it is leninism adapted to an ancient and intelligent population. ${ }^{613}$

Furthermore, he observed that Marxism was at the root of both 'sovietism' and fascism: 'All Marxian doctrine, all étatisme or collectivism, conforms very nearly in practice to the fascist ideal. Fascismo is merely a spectacular marinettian flourish put on to the tail, or, if you like, the head, of Marxism: that is, of course, fascism as interpreted by its founder, Mussolini'. ${ }^{614}$ Consequently, Lewis's political advice for his country was simple and repeated almost verbatim within a couple of pages in the thus aptly titled chapter 'Fascism as an Alternative': 'And yet for anglo-saxon countries as they are constituted today some modified form of fascism would be best'; and more precisely:

[fascism] is the sort of socialism that this essay would indicate as the most suitable for anglo-saxon countries or colonies, with as much of sovietic proletarian sentiment as could be got into it without impairing its discipline, and as little coercion as is compatible with good sense. ${ }^{615}$

Lewis considered 'sovietism' and fascism powerful, and honest political alternatives, offering 'real freedom' (as opposed to the supposedly sham freedom of liberal democracy) to its citizens. ${ }^{616}$ Rehearsing these selected lines from the book it is difficult to see how Munton can claim that 'Lewis was in some meaningful sense on the Left until about 1930. During the mid-1920s he deals with ideas that open more naturally towards socialism and anarchism than they do towards the right and to fascism'. ${ }^{617}$ Munton establishes a binary (socialism-fascism), which Lewis does not subscribe to and which later national permutations of the extreme Right (think: National Socialism) did not subscribe to either. ${ }^{618}$ Composed in the 1920s The Art of Being Ruled is first and foremost a critique of democracy and its values, and only secondly it is an appeal for an alternative. It also seems that it was less grounded on a fixed political movement but more on practicality, for Lewis concludes: 'In short, to get 
some sort of peace to enable us to work, we should naturally seek the most powerful and stable authority that can be devised'. ${ }^{619}$ Lewis's non-dogmatic openness on this point - a powerful and stable authority could technically be everything from Stalinism to fascism but also monarchy and theocracy ${ }^{620}$ might also explain Lewis's shifting over his life-time on this point, veering sharply to the Right in the 1930s and finally, after Fascism's demise, coming out in favour of the more democratic Right in his later life. ${ }^{621}$

One of Lewis's most comprehensive books, Time and Western Man, is almost entirely devoted to what Lewis called the time-cult, supposedly spearheaded by the theories of Henri Bergson and Albert Einstein; yet his almost obsessive hatred for the time-cult can also be perceived in his other writings, such as The Childermass. 'The greatest threat to the individual,' writes Sharon Stockton, 'for Lewis, is what he perceives as the time-based reality of Henri Bergson, the nature of which is constant flux, and the effect of which is a time "filled with disorder and stupid violence" (Rude Assignment 13). ${ }^{\prime 22}$ Discussing Lewis's complex argument in Time and Western Man goes beyond the scope of this book, yet what needs to be stressed is that Lewis's engagement with 'time-philosophy' was at heart ideological. To fully understand Lewis's obsession and adamant denigration of the time-cult, it has to be understood as a complex matrix interdependent with various other pillars of Lewis's ideological system. Thus the time-cult is connected to other phenomena Lewis dismissed as damaging society and literature such as primitivism, and the youth cult:

The doctrine that he [the adherent of the time-cult] expounds of serial "appearances" (in conformity with the time-law of relativist physics) is a form of primitivism, and so, at one remove, related to the child-cult. Take the water and ice illustration. We are in the presence, with that argument, of a description of the savage or primitive mind, surely, or an attempt (unconsciously or otherwise) to approximate to it. For that is precisely how the primitive mind would, naïvely, as well say, regard those "appearances." Much less than for a civilized man would the water be one thing that "froze." It would be, discretely, a deep-green fluid apparition - water: or suddenly for no reason, a glassy white apparition - ice. From that point of view einsteinian physics is the physics of the primitive mind, the physics of the naïf. ${ }^{623}$

During the same time Lewis also wrote individual studies on primitivism (Paleface) and the youth cult (Doom of Youth), which demonstrates their important position in Lewis's ideological matrix. In Rude Assignment he judges all three books as lasting and valuable contributions to contemporary debates, despite the backlash Paleface received. The critical reception has not significantly changed. Many critics nowadays consider Time and Western Man one of Lewis's best critical books, while Doom of Youth, which mainly consist of a col- 
lection of press cuttings on the topic, is seldom seen as worthy of a full discussion; Paleface still polarises.

Indeed, Paleface is a dense and complicated text on a sensitive topic, written in Lewis's customary cynical tone. Yet it would be too easy to stamp it as a simple racist tract, as part of the argument addresses an important issue, which has lost little of its validity. For Paleface discusses white writers who use people of colour as a convenient trope to establish an antidote to white (i.e. modern) civilisation. Thus, while authors such as D. H. Lawrence and Sherwood Anderson celebrate non-white cultures for their freedom from oppressive conventions and romanticise their connection to nature, Lewis, quite rightly, considers these depictions as well as the - at least as he perceived it widespread obsession with Black culture problematic. So far this argument offers a legitimate critique that is still relevant today, as Terence Hegarthy also observed, when he remarked that 'it was Lewis who first classified Uncle Tommism'. ${ }^{224}$ However, from here Lewis's argument veers into a form of white supremacy that today might fall under the label of ethnopluralism. ${ }^{625}$ Lewis sees the preoccupation with people of colour in literature as well as cultural influences such as jazz (which remained a major target throughout Lewis's life) as an anti-white agenda. Although he acknowledges non-white culture as of equal worth and realises that the gap between white and black achievement is not a sign of an inherent lack of ability but the product of a long system of oppression and exclusion, he falls back on routine arguments that have lost nothing of their popularity among the Right. ${ }^{626} \mathrm{He}$ downplays white supremacy and racism by shifting the argument to highlight the plight of oppressed white people, i.e. the lower classes. ${ }^{627} \mathrm{He}$ bemoans the fact that there are no advocates for the Palefaces (a remarkable claim in 1929 seeing that the twenties saw the publication of such books as Madison Grant's The Passing of the Great Race as well as multiple books by Lothrop Stoddard such as The Rising Tide of Color Against White World-Supremacy, which would become bestsellers), ${ }^{628}$ and he fears that an appreciation of people of colour and their culture would not lead to equality but a reversal of racial power hierarchies (an accusation he bases on, or at least sees corroborated by, a contemporary rightwing German novel called Atlantis). ${ }^{629}$ Consequently Lewis suggests, instead of showing interest in non-white people, Europeans should draw closer together to form one big pale melting-pot. ${ }^{630}$ Paleface is a defence of white culture and an attack against harmful primitivism - harmful for the people who are turned into tropes but also harmful for white culture, which gets inundated with anti-white sentiment. The book mixes ethnopluralist platitudes with a handful of insightful observations. As is so often the case, Lewis's writing is best when devoted to the analysis of literature but becomes problematic when he tries to obsessively project those dynamics onto society as a whole. Ivan 
Phillips put it aptly when commenting on Bridson's too idealistic reading (that Paleface was 'fully in sympathy with the cause of Black emancipation') with: 'In sympathy, but not in full understanding' and concluded that ' $[\mathrm{t}]$ he argument of Paleface is complex, perverse, not always pleasant, and sometimes downright disagreeable. It needed refinement and shaping, and perhaps to be written by someone of a different ethnicity, class, generation, and temperament than Wyndham Lewis'. ${ }^{631}$

That the time-mind according to Lewis is so susceptible to primitivism is also due to its hankering after pseudo-revolution, a perpetuating newness which instead of being truly revolutionary finds its sources in the pre-modern or from cultures outside Europe. According to Lewis, only a small percentage of art is revolutionary, as for the rest:

the much greater mass of work which uses a very little of that newness to flavour something otherwise traditional enough, and which, if properly understood, is in no sense revolutionary; or else which looks novel because it is attempting to get back to standards or forms that are very ancient, and hence strange to the European. ${ }^{632}$

Curiously this includes Fascism (as happening in Italy) and the ideas of Georges Sorel, one of its intellectual forerunners:

The Fascist Revolution again, to revert to the political scene, is an imitation of antiquity. [...] It is interesting to remember that it did not begin that way, but in an exclusive glorification of the Present. For fascism is an adaptation, or prolongation, only, of futurism. But however "revolutions" may begin, they always end in what Marinetti named passéism; ${ }^{633}$

and,

Sorel - a disciple of Bergson - in his Réflexions sur la violence, sings the same bergsonian song; only in his case it is a sanguinary one, whereas Bergson is more "detached," and is not so specific as to what happens to you once you surrender yourself to the flux-god. ${ }^{634}$

This shows that in the time between the composition of The Art of Being Ruled and Time and Western Man Lewis's fervour for fascism had sobered up a bit, and yet, as the latter book makes unmistakably clear, it was not supplanted with a new appreciation for democracy. While he concedes that in The Art of Being Ruled he was too unfair when he used the term democracy to signify only its contemporary permutation, he adamantly persists that

no artist can ever love democracy or its doctrinaire and more primitive relative, communism. The emotionally-excited, closely-packed, heavilystandardized mass-units, acting in a blind, ecstatic unison, as though in response to the throbbing of some unseen music - of the sovietic or fourierist fancy - would be the last thing, according to me, for the free democratic 
West to aim at, if it were free, and if its democracy were of an intelligent order. ${ }^{635}$

The Childermass, which stems from the same period as The Art of Being Ruled and Time and Western Man, is sometimes read as a fictionalisation of the political and philosophical thoughts, with one of its characters, usually Alectryon, seen as Lewis's mouthpiece. ${ }^{636}$ Yet this reading does not wholly persuade. Firstly, being composed as one part of the large Man of the World, which would have comprised The Art of Being Ruled and Time and Western Man would have made a simple repetition of the philosophical and political ideas unnecessary. As a work of fiction, The Childermass adds a (or multiple) layer(s) of unreliability, which cannot easily be resolved. As SueEllen Campbell has correctly observed, in his novels, Lewis 'sometimes creates characters whose ideas clearly resemble his own but whose behaviour demonstrates the dangers of these ideas'; ${ }^{637}$ this I would argue also applies to The Childermass and is one indication how the novel is more ideologically complex than the corresponding non-fiction books. The hyper-fictionalised setting - an after-world, where elementary logic and earthly rules do not apply - presents a strange agon to debate worldly politics. The unresolved philosophical debate in the political arena might be an attempt to be supra-political - a reading sometimes suggested for The Revenge for Love. ${ }^{638}$ Yet Brett Neilson has convincingly argued that a supra-ideological position of the text is impossible:

First, if the narrative system of The Revenge for Love questions the coherence of all discursive schemes, there can be no extra-ideological viewpoint from which Lewis might launch a critique of ideology. As Ernesto Laclau argues, the recognition of the irreducibility of the rhetoric-discursive operations of a text removes the possibility of an extra-discursive ground from which such a critique of ideology might proceed. This does not imply that "ideological critique is impossible - what is impossible is a critique of ideology as such; all critiques of ideology will necessarily be intra-ideological". ${ }^{639}$

The same seems to hold true for The Childermass (and the rest of The Human Age). It uses ideological dynamics to map out its fictional universe. Its form, especially in the second half of The Childermass, gives an impression of a metaideological stance. However, its content abandons those ambitions. It reveals how ideology works, yet its limited focus and selective arrangements align the novel's politics with those of The Art of Being Ruled and Time and Western Man. Readers need to work out what is correct by themselves as almost everything in the novel seems unreliable, remains unresolved or is perpetually changing. This does not mean that all ideological positions are treated equally. Similar to The Art of Being Ruled, the novel is more invested with the ruled than the rulers. While the ruled, namely the puppets, remain in the dark about the political process and treat it as a mere spectacle, agency is placed upon the reader, 
while the characters play out a rehearsed show-piece like marionettes. It is this stance towards the ruled, the puppets who are unable to see through the political spectacle, that betrays the novel's inherent right-wing matrix. This is coupled, similarly to The Art of Being Ruled, with a disdain for feminism, homosexuality, and a preference for fascism. In Monstre Gai and Malign Fiesta contempt for homosexuality and the feminine are still rampant, while fascism has lost its allure. Stylistically more straightforward than The Childermass the two sequels question the once so clear-cut binary of rulers and the ruled especially in regard to intellectuals. Pullman, who had been a puppet in The Childermass receives agency only to realise that he, now as a nature, remains a pawn in the power play of politics. Thus it is not so much the politics that changes throughout the books, but the relationship between the intellectual and politics.

\section{'I was never real. Am I?’}

The Childermass has had a rather odd history. When it was published in 1928

it was widely and usually derogatorily reviewed. Of course, much of this was Blimpish disapproval of the difficulty of the prose. [...] For [Raymond] Mortimer The Childermass was diseased; it contained "a positively pathological absence of all intellectual control. No doubt the book will have a great success among those whose admiration for a writer increases in proportion to their inability to understand what he is saying." [...] Writing in The New Statesman for July 7, 1928, Connolly took occasion to consider, and consider brilliantly, the whole neoclassical attack. He found it invalid, and The Childermass Fascist. [...] Lionel Trilling, writing in the New York Evening Post for September 22, 1928, and writing with his customary perspicuity, was even more severe in his judgement. Lewis prose was "arrogant, " his ideas traditional. ${ }^{640}$

In Rude Assignment Lewis's conclusion strikes a more conciliatory note: 'Its appearance in 1928 caused no controversy: there were no assailants with whom I have to settle account. [...] Its history has been the most peaceful of any of my books'. ${ }^{641}$ Nevertheless, in the 1950s The Childermass was turned into a radio play by the $\mathrm{BBC}$ and, moreover, the $\mathrm{BBC}$ acted as patron to finance two sequels. This choice is certainly striking, seeing that The Childermass was neither hugely popular nor controversial after publication. Moreover, it is a book that is notoriously difficult to make sense of. Its key characteristics seem to be indeterminacy, its defiance of boundaries and a sense of constant flux. In short it resists easy classification on all levels. This might be why it remains one of Lewis's most unnerving narrative texts. 
It is set in a sort of limbo, called the Time-Flats (an obvious jibe at the time-cult), which mostly defies earthly rules. On the first pages, readers meet the two main characters Pullman (also Pulley) and Satterthwaite (usually Satters) whom we follow for the first half of the book as they aimlessly wander the Time-Flats. This pair and their toxic co-dependent relationship is reminiscent of Arghol and Hanp from Lewis's Vorticist play The Enemy of the Stars (1914). There is little progress on the level of plot and readers are possibly as lost as the two main characters themselves. What makes this book a further tour de force is Lewis's language use, his constantly changing idiom and externalised style. The latter term is often used to describe Lewis's method to let characters appear as if they were marionettes in a play with very little agency and no inner life. This is especially applicable to The Childermass in which readers view Pullman and Satters (and all other characters) from the outside without ever getting a glimpse of their consciousness. ${ }^{642}$ The characters are dead not only in the sense that we encounter them in the after-world, but in the sense, to use the terms Lewis employs in The Art of Being Ruled, that they seem like puppets or automata. Miller reads it similarly, writing that

[p]erhaps the most extreme example of Lewis's destruction of formed character and significant form is his "theological science-fiction" The Childermass. In this book, no action or character is "real" or "autonomous," since both character and action emerge out of the demonic manipulation, in ideological and political debate, of the imperfectly manifest souls of the war dead. ${ }^{643}$

This is further complicated by the fact that Pullman and Satters repeatedly change in terms of age, appearance, gender and power dynamics. Everything is possible and nothing seems real.

As soon as readers might get accustomed to the strange pair, Pullman and Satters are side-lined when the book shifts its attention to what I will call here the political spectacle. Together with Pullman and Satters readers enter a sort of amphitheatre where the Bailiff, the official in power, holds sway. The political spectacle has two functions: here the Bailiff decides who is allowed to proceed to Third City, the locus of the real after-life, yet this trial is couched in a mass entertainment spectacle. The double performativity of this part is highlighted by the use of the dramatic form. While the first part of The Childermass follows, despite all its idiosyncrasies, the genre conventions of narrative texts, the second part forms a strange hybrid of narrative and dramatic. This further adds to the externalised style as some characters, apart from short introductory remarks, only appear in dialogue form. When various characters, most notably the Hyperideans, the designated enemy fraction that I will discuss in detail below, start to challenge the Bailiff's authority these dialogues become agons of competing world-views but also competing truths. With little to no corroborating or contradicting evidence from the surround- 
ing text, readers have to decide themselves whom to believe or whether to distrust all characters equally. In the end Pullman and Satters leave before the political dispute between the Bailiff and the Hyperideans can be settled. The book begins and ends in medias res. Only the sequel Monstre Gai reveals that Pullman and Satters made it to Third City. Yet this new place is still home to the same old ideological disputes, which will be discussed further below. Returning to The Childermass and especially to the category of the ruled, there are three major sets of puppet-characters: the pseudo-couple 644 Pullman and Satters, the audience of the political debate (the Bailiffites but also most of the Hyperideans), and the peons (racialised working class slave souls).

Pullman and Satters are the first characters readers encounter. The focus of the first half of the book rests solely on these two, suggesting that they are the novel's protagonists. And yet, in the second half they are demoted to extras in the political spectacle. Arguably they are constructed in a way to evoke no sympathy, let alone empathy from the reader. Geoffrey Wagner is even more candid when he maintains that 'Satters and Pulley we detest, and should detest, from the start'. ${ }^{645}$ Indeed, in The Childermass they remain unlikeable until the very end - either due to shortcomings in intelligence, character or appearance. Moreover, they represent certain types: Pullman is the sort of intellectual Lewis attacks in Time and Western Man, an intellectual who consciously or unconsciously follows the time-cult, whereas Satters is the eternal schoolboy and therefore symbol for the youth-cult. ${ }^{646}$ In the beginning Pullman is presented as the intelligent and learned one, without whom Satters would be lost. Yet despite his intelligence he is not what Lewis terms in The Art of Being Ruled a 'nature' - as his erudite explanations are not products of his own deduction but copies of the official lingo, and thus repeated almost verbatim in lieu of 'real' thinking. For example, when both meet the peons for the first time Pullman explains that 'they are the masses of personalities whom God, having created them, is unable to destroy' and repeats the exact same sentence whenever they are in the presence of peons again. ${ }^{647}$ Throughout the book Pullman remains the uncritical observer, sermonizing official wisdom in support of the Bailiff in so obvious a way as to be impossible not to be recognized by the reader. In contrast to Pullman, Satters in his everhelpless-always-baffled behaviour comes across as his annoying dim-witted sidekick. This effect is enhanced by the 'steining' (Lewis's terminology) - use of an infantilized highly repetitive language in the manner of Gertrude Stein he frequently employs:

Pulley has been most terribly helpful and kind there's no use excusing himself Pulley has been most terribly helpful and kind-most terribly helpful and he's been kind. He's been most terribly kind and helpful, there are two 
things, he's been most kind he's been terribly helpful, he's kind he can't help being-he's terribly. ${ }^{648}$

Elucidation on Satters's style comes from a remark Lewis made in Men Without Art. 'In dealing with (1) the extremely aged; (2) young children; (3) halfwits; and (4) animals, the internal method can be extremely effective. In my opinion it should be entirely confined to those classes of characters. For certain comic purposes it likewise has its uses, especially when used in conjunction with a full-blooded Stein-stutter...'. ${ }^{649}$ Satters is created to embody the perpetually young half-wit, especially in contrast to the thoroughly intellectual Pullman. However, his persistent questioning shows him to be much more discerning: he notices the dynamics of the world surrounding him and with the eagerness of a schoolboy exclaims all those truths Pullman does not see, or does not want to see:

'What are those hills?' [asks Satters]

'Hills? Where? There are no hills. They're nothing!' Pullman crossly exclaims. 'I didn't know.'

'Nothing at all, not hills.'

The distance to the city varies; Satters repeatedly looks over, lunging his head to catch it at its changes and at last says:

'Doesn't that look smaller sometimes?'

'What?' Pullman looks round indignantly.

'Sometimes it looks smaller to me than others.'

'Certainly not! Whatever makes you think! !650 $^{650}$

This early passage in the book suggests that Pullman is wilfully oblivious to the world around him if it does not fit into his ideology. His explanation as to the moving city, namely that 'it looks like it. But it isn't so. It's only the atmosphere', ${ }^{651}$ touches on the very basic denominator of what an ideology is and does: it interprets external events and makes them fit into a greater narrative. Pullman cannot deny the movement Satters perceives, yet he persists on the difference between appearance and reality. In short, for Pullman appearance has become reality. Munton aptly describes Pullman's ideological process:

...indeed, Pullman wants the untruths of this world to be true because he has accepted the interpretation of reality that is offered by the controller of this afterworld, the Bailiff, 'the irritable magistrate' (C p. 235) who embodies the zeitgeist. This Mr Punch-like figure questions and explains and bullies; but Pullman submits his intelligence to him in a process of voluntary internalisation. ${ }^{652}$

Satters's absence of erudition enables him to perceive his environment almost unfiltered. He is thus less prone to fall victim to the charm of the Bailiff: 
'I like the beggar!' [says Pullman]'

'I know I can see you do, there must be some good in him I have no reason: he just terrifies me. ${ }^{653}$

Satters cannot explain his attitude towards the Bailiff, it is only based on feeling. This hints at the clash between intuition versus intellect. Yet while Satters's intuitive perception is often presented as correct, he often lets himself be swayed by Pullman's educated explanations; not only because he is the more weak-minded of the two, but also because he buys into the idea of the superiority of the intellect. There is one key scene in which Satters questions the rules and is not content with Pullman's answers. In this scene the surroundings become increasingly hot and Satters decides to take off his clothes, to the chagrin of Pullman. As is so often the case in Lewis's novels it ends in a violent fight in which Pullman strikes Satters down with a stick. After reconciliation Pullman pleads with Satters to put on his clothes again:

'Why is it necessary?' [asks Satters]

'Simply because-It's best to have them on, that's all, they prefer it here. It's a bore but there it is!'

'I know. And why is it I have to do that? Because we're held down to this magic we are enslaved...'

'I've heard that before. You've been-I can see you've been keeping your ears open more than you pretend. You shouldn't listen to what people say. ${ }^{964}$

But Satters is not convinced so Pullman continues:

There is the proposition however Satters: those are the terms on which we exist, it seems. It's no use kicking what's the point anyway? [...] We are organic with the things around us. This piece of cloth'-he takes up a pinch of his sleeve coat- is as much me as this flesh. [...] When I first came here I was afraid to clean my nails I didn't know what was me and what wasn't. ${ }^{655}$

Suddenly in this scene Pullman comes across as the weak-minded and gullible one, an impression that is reinforced by Satters's retort:

Rot. You talk rot, you're not right, you don't mind me telling you I hope! I've never heard a man talk such goddam Bedlam rot as you do. It's you who listen to what people tell you not me my poor old son you're potty. Clean your nails! Why shouldn't we leave off our coat if it's too hot to wear it?

Satters's use of 'my poor old son' also switches the age dynamic, further cementing the upturned hierarchy between the two. Here it is Satters again who proves to be the more astute character. And yet The Childermass offers no such easy readings: both characters remain elusive and their relationship fluctuates. Pullman leaves the scene and prays until Satters reappears, fully dressed, and the old power dynamic is re-established. Moreover, throughout the book Sat- 
ters is described as appallingly unattractive, making it difficult to see him as a figure for identification. ${ }^{657}$ Both characters remain fundamentally unsympathetic. It is their actions that mark them as puppets. Pullman consciously aligns himself with the official ideology, he represents the intellectual elite although he actually does not think (for himself), he only repeats what is accepted as the official truth. Satters perceives the world around him unfiltered by the official ideology and becomes increasingly unconvinced by Pullman's explanation, and yet his petulant childishness and lack of free-will (after all Pullman is his guide without whom he feels lost) makes it impossible for him to develop a constructive critical stance. Even when Satters realises the ridiculousness of the system they inhabit he is unable to come up with an operational alternative. In a typical Lewisian fashion the characters serve as negative mirror-images to the romanticised version of the artist/intellectual and the primitive/child-mind (Lewis's terms) which Lewis perceived in the works of his contemporaries such as Joyce, Stein and Anita Loos ${ }^{658}$. Pullman and Satters's 'puppetness' is enhanced by the fact that they are constructed as a pseudo-couple. Jameson writes:

The partners of the pseudo-couple are neither active, independent subjects in their own right, nor have they succumbed to the schizophrenic fetishization which characterizes contemporary consciousness. They remain legal subjects who nonetheless lack genuine autonomy and find themselves thereby obliged to lean on one another in a simulation of psychic unity which is little better than neurotic dependency. ${ }^{659}$

Neurotic dependency fits the Pullman-Satters relationship quite well and also dispels the reading that Pullman is master over Satters even though this is sometimes hinted at (Satters was Pullman's fag at school, while Pullman later became a teacher, and it is this constellation to which they often revert back to). Despite their centrality in the first part of the book they play a subordinate role in the second part in which they are simply a part of the audience, and thus largely passive.

In a change of scene Pullman and Satters join the masses of appellants, when suddenly the focus shifts: 'Two characters who have occupied the opening scene, they conventionally stand aside to observe the entrance of the massed cast in stately procession...' ${ }^{660}$ Here also the form of the narrative changes as the political debate is largely presented as a dramatic play. This is no coincidence: as readers we are now made aware that we enter a theatrical world, a world of performances. The masses are actors cast as audience, while the main drama, the play of power, happens on stage. Here everyone in the audience belongs to the puppets with limited free will and limited agency. As Pullman suggested earlier in the novel these political courts are seen as a form of entertainment. There is a vague reminder of Walter Benjamin's interpreta- 
tion of fascist politics as incorporating spectacle to give its citizens the impression of political participation without granting them real political participation. ${ }^{661}$ The Childermass seems to make a similar claim, indicating that no matter which political system a society embraces it always results in a spectacle with perceived participation supplanting real participation. This recalls Pullman's earlier explanation that the city only seems to move, while in fact it does not. That the same holds true for the political process in the Bailiff's court is apparent to readers but not to Pullman. Or perhaps, as Munton suggests, Pullman does see through the spectacle but has opted for cooperation:

The defensiveness, the hesitations, and the attribution of an unlikely humour all tell the reader that Pullman knows the Bailiff is evil, but is willing nevertheless to submit to him. When Macrob, an articulate and intelligent Scot who objects to the 'reality' test, grabs the Bailiff's nose and pulls it hard, the Bailiff's men tear him apart. An executioner's basket is brought, 'and the fragments of Macrob are stuffed and stamped into it' (C p. 235). The Bailiff declares a fifteen-minute interval, and as the filled basket passes him, Pullman says of the Bailiff: "He's always massaged during the interval, the Bailiff's gone you see, let's stretch our legs shall we?"' (C p. 236). This is complicity. ${ }^{662}$

Whether selective perception or complicity, readers - now that we can listen to and watch the Bailiff - are made aware that it is ideology that The Childermass problematizes. The unquestioned adoption of the dominant ideology, i.e. the ideology of the Bailiff, makes Pullman a questionable character, someone who cannot be trusted. Lewis's externalized style and the use of the dramatic form - making readers part of the audience - enable readers to perceive the discrepancies between (political) action and words, for example when the Bailiff speaks of kindness but kills those who question his authority. Thus The Childermass does not describe how ideology works, as The Art of Being Ruled for example does, but it acts out how it works.

Pullman is not alone in his complicity. The audience fulfils an important function in the political spectacle. Emphasising the theatrical side of politics - as is/was common in totalitarian regimes using such forms as parades - curtails the perception of agency: when one accepts one's role as part of an enthralled audience individual deviant behaviour becomes less likely. Despite its apparent passivity, the audience is not a simple backdrop to the political action. Analysing the social dynamics of mass executions by NS men, Harald Welzer describes the importance of bystanders who watch(ed) but did not actively participate in the killings:

The execution of the deed creates communality; the audience verifies by its presence that the proceedings are in order. There are no interventions to break the practical agreement on the killing. The active dimension of specta- 
torship in the context of acts of violence is generally underrated: spectators, purely by their presence and the absence of intervention, attest that the frame of reference in which the agents operate is both valid and beyond dispute. ${ }^{663}$

Thus the audience legitimates the dominant ideology. When Pullman rates these political spectacles as entertainment he signals his endorsement. ${ }^{664}$ The critique that is written into The Childermass is that Pullman, as an intellectual willingly or unknowingly - complies and thereby remains a puppet. Looking back at The Art of Being Ruled, Lewis wrote in Rude Assignment that '[t]he majority want to be fed, clothed, and housed properly, to be provided with plenty of coarse entertainment - bread and circuses, in a word — and that is all. They do not, and never will, wish to acquire, or allow you to impose on them, 'culture". ${ }^{665}$ This is the crowd Pullman joins. The Childermass identifies entertainment as a political (arguably democratic) tactic and in reverse the political as entertainment. The masses receive their bread and circuses and at the same time are duped into compliance and passivity while being constantly persuaded that the show is for their sake. ${ }^{666}$

While political participation is generally derided in The Childermass, the third group of the ruled, the peons, do not even have access to the political arena. ${ }^{667}$ They are disenfranchised and yet still strangely powerful as Pullman and Satters learn on their journey through the Time Flats. As Pullman explains in the beginning of the book, the peons are 'the masses of personalities whom God, having created them, is unable to destroy'. What might strike the attentive reader is the word 'personality'. Puppets, according to Lewis, do not have individual personalities, they just express a personality which they suppose is uniquely theirs but is in fact instilled in them by society and the media. ${ }^{668}$ This might give the impression that the peons are actually superior to the normal appellants that populate the Bailiff's court. Having a 'real' personality would make the peons more dangerous, because difficult to rule and this might be another reason why they are not allowed to participate in the political spectacle. As they have no access to the court the peons are doomed to wander the Time Flats forever. A common reading identifies the peons as the working classes ${ }^{669}$ or associates them with communists ${ }^{670}$ due to the hammer and sickle insignia. Yet the peons differ from other lower class characters, Barney and his ilk, whom readers meet during the political spectacle. Brown has observed that the peons are given racial attributes:

But over this class aggression race aggression is deftly superimposed: the peons wear turbans (20), the sputum that covers Satters's cheek is stained with betel-juice (25), they speak only fragments of broken English (25), and their color is that of a "yellow smear" or a "rusty putrefaction" (20) as opposed to the pink faces (168) of the Baliffites. What had appeared to be an evasion of 
modern relations of production turns out to be motivated after all, as the class terrain is plainly not that of Europe but of the colonies. In relation to them Pullman becomes not the bourgeois or the intellectual but, in another embodied cliché, the white District Commissioner, the seasoned (but liberal) Old Coaster among "his" natives:... ${ }^{671}$

This seems convincing, although it leaves out the observation that there appears to be the very likely threat that everyone can turn or be turned into a peon, as another passage makes clear:

Pullman looks up. Satters gazes into a sallow vacant mask, on which lines of sour malice are disappearing, till it is blank and elementary, in fact the face of a clay doll.

'Why, you are a peon!' Satters cries pointedly, clapping his hands.

Pullman recovers at his cry, $[\ldots]$ and the normal Pullman-mask emerges, but still sallow, battered and stiff lipped. ${ }^{672}$

Pullman reacts visibly angered and tries to shift the conversation into another direction. Yet Satters - triggered by an earlier incidence when he met an old friend, Marcus, whom Pullman identified as a peon - is adamant to pursue the topic:

'Are peons-What was I going to say? Are the peons-'

'Men?'

'No, not men; I mean are they always peons?'

Pullman is in a huff; he moves the previous question. The dialogue prevents him from leaving.

'They are not always peons.'

'Always is a big order. Once a peon, always a peon: is that what you mean? Not necessarily.'

'Yes I expect sometimes-They are human like us, aren't they, in a way, Pulley?'

'Not like us.'

'Not like us? What is the difference? Are we very different? I believe we only think we're so different. ${ }^{973}$

Here Pullman breaks off the conversation, claiming he needs to leave. The topic is definitely an uncomfortable one for him and that might be because it uncovers some ideological discrepancies - an inconsistency that might shake the foundations of his ideology. The peons symbolize the 'other' on which any ideology relies as an abstract entity. They are depicted as an amalgam of the working class, communist, and the racial others because these were the groups that the dominant ideologies during Lewis's time depended on either as supposed antagonists or supposed allies. The peons' ambiguous nature they are immaterial and yet can pose a very material threat; they evoke Pullman's pity and yet he warns Satters to stay away from any interaction with 
them - seems to be a comment on the likewise ambiguous handling of these groups in real life. They were useful and, depending on the ideology, valued as abstract embodiments of certain ideas, which did not necessarily lead to an appreciation of the real people behind these concepts. In the Bailiff's world the peons are needed as 'the other'. Being on the lowest rung of the TimeFlats' social hierarchy, they bestow a false sense of superiority to the other groups of the ruled. Yet again, the peons combine inferiority and danger, as they threaten the supposedly stable boundaries.

The fictional world of The Childermass offered Lewis ideal conditions to present the group of the ruled, which he had also discussed in The Art of Being Ruled. In the novel they are twice dead, puppets that roam the after-world. The Childermass also insists as the example of Pullman shows that being an intellectual does not save you from being/becoming a puppet. Pullman's failure as an intellectual who submits uncritically to the official ideology is contrasted with Satters who embodies the dim-witted schoolboy whose innocent but astute observations challenge Pullman's and the official viewpoint. Every time Pullman evades Satters's probing questions his behaviour can be read as a sign of complicity. This, so The Childermass seems to suggest, is the treason of the intellectuals, differing from what Julien Benda analysed in his book of the same name published in $1927 .{ }^{674}$ The ruled also serve an important function in that they legitimate the political actions of the rulers. The political performance, symbolised by the debate in the Bailiff's court, pretends to cater to the masses while at the same time it needs their validation. The puppet-master needs his puppets and vice versa. This dependency of ruler and ruled also finds its equivalent in the pseudo-couple Pullman and Satters. The relationship between the ruler and ruled seemed to have been particularly important to Lewis when judging political systems. In The Art of Being Ruled Lewis criticises liberal democracy as being more insidious than sovietism and fascism in the way it treats its puppets:

All the traditional obliquity and subterranean methods of the Orient are, in this duel, exhibited by the westerner and the democratic régime. It is we who are the Machiavels, compared to the sovietist or the fascist, who makes no disguise of his forcible intentions, whose power is not wrapped up in parliamentary humbug, who is not eternally engaged in pretences of benefaction; who does not say at every move in the game that he is making it for somebody else's good, that he is a vicar and a servant when he is a master. It is true that he promises happiness to the masses as a result of his iron rule. But the iron is not hidden, or camouflaged as christian charity. ${ }^{675}$

It might be no coincidence that this description fits quite neatly to the Bailiff, whose power is all wrapped up in 'humbug' and 'pretences of benefaction'. 


\section{'We are primitive and proud of it!'}

At first glance there seems to be only one ruler in The Childermass, namely the Bailiff. Yet this is not the complete picture. There is, on the one hand, Hyperides, whose followers openly challenge the rule of the Bailiff. On the other, there is the higher official for whom the Bailiff works, let us call him 'god' for the moment. If The Childermass was merely the fictional version of The Art of Being Ruled one could rest content with stating that the Bailiff represents liberal democracy as Lewis pictured it and the Hyperideans advocates for either fascism or an alternative authoritarian anti-egalitarian system. While this reading is not wrong it does not do justice to the complexity and vagueness of the novel. After all, the Bailiff as well as Hyperides and his more prominent followers, Alectryon and Polemon, remain too vague in order to be read as straightforward representations of political ideas. The political debate at the end of the novel has no winner (but also no losers); the issues at stake remain suspended and unresolved. Moreover, as with the ruled, whom can readers trust, especially when words and actions diverge? Munton has aptly summarised the importance of the issue of trust in the novel: 'The Childermass is unsettling to read once we realize that nothing in it can be trusted. It is equally unsettling to realize that all political structures depend for their persistence upon the forms of deception satirized in the Bailiff. By bringing his fictional reality into doubt, Lewis brings the political reality into doubt'. ${ }^{676}$ This becomes a key issue as politics and ideology are built on trust and distrust. Beyond a debate between liberal democracy and fascism, The Childermass explores central questions of ideology in general. This would also explain why it is political questions that dominate the Bailiff's court and not theological ones. ${ }^{677}$ In this chapter I will look at the Bailiff, Hyperides and Alectryon and trace how they are constructed as part of the ideological matrix that underlies the novel. While all of them seem to stand for a certain ideological position, focussing on the roles these characters play, i.e. their performance, in the political spectacle and how they interact with each other and the audience seems to offer greater insight into the mechanism of The Childermass, which might seem supra-ideological on the surface, yet reveals a deeper right-wing structure.

The Bailiff is the central character of the second part of the novel, maybe even of the whole book. And just like Pullman and Satters he seems thoroughly detestable. It seems fitting then that the Bailiff could be read to represent all those ideological positions that are criticised in The Art of Being Ruled, Time and Western Man and Paleface. He can be read as a representative of capitalism, ${ }^{678}$ an embodiment of the zeitgeist ${ }^{679}$ or both in a 'conspiratorial 
allegiance between gangster capitalism and the zeitgeist'. ${ }^{680} \mathrm{He}$ 'encompasses virtually all the cultural phenomena that Lewis identified as outward expressions of that decline [of society]: Dadaism, feminism, homosexuality, communism, relativism, and of course, "Time";,681 and he is also "liberal and Bergsonian'. ${ }^{682}$ This short list of interpretations of the Bailiff's politics shows that critics are often guided by the politics Lewis (supposedly) opposed. Thus critics can read the Bailiff as either communist or capitalist or liberal democratic; or identify him as a feminist even though women are prominently absent from The Childermass. All too often the Bailiff is read as the simple anti-figure, or more precisely the anti-Lewis-figure. This is only possible, because the figure of the Bailiff in The Childermass is conveniently vague. First and foremost, the Bailiff is a humbug; he thrives on deception; his words and deeds do not necessary align. Hence the primary question concerning the Bailiff is: what is real and what is show? Not even his spectacularly ugly appearance - he has a hunch and paunch, '[n]o neck is visible, the chin appearing to issue from and return into the swelling gallinaceous chest' and on top of all that his movements are similar to those of chickens and frogs ${ }^{683}$ - is truly authentic, for the Bailiff is able to shift shapes but chose this unappealing exterior for a purpose. Yet for what purpose readers are only left to wonder.

Even more unappealing is the Bailiff's performance of politics. Challenged by Polemon, Hyperides's adjutant who is in charge of keeping the Hyperideans in order, the Bailiff explicates his political stance:

What ideas have we? Whatever they may be they are today everybody's so we must be all right! That is not an idle boast. Except for these few malcontents [the Hyperideans] there is an absolute flat unanimity it's almost monotonous. We are the humble children of Progress. [...] We are not Greeks [like the Hyperideans] the Lord of Hosts be praised, we are Modern Men and proud of it - we of the jazz-age who have killed sexishness and enthroned sensible sex, who have liberated the working-mass and gutted every palace within sight making a prince of the mechanic with their spoils, we deride the childish statecraft, the insensitive morals, the fleshly-material art, the naïve philosophy of the Hellene. [...] We are primitive and proud of it! ${ }^{684}$

What is interesting about this statement is, again, that it is quite vague. What for example is exactly meant by sexishness as opposed to sensible sex, childish statecraft or insensitive morals? Of course one could look for clues in the Bailiff's other speeches and possibly his actions. Yet what this speech, as many other of the Bailiff's speeches, seems to show is the emptiness of (political) words and phrases. It is true that Lewis located this practice especially on the side of supporters of liberal democracy, complaining that terms like 'freedom' were little more than word-shells. What the Bailiff is reproached for most by his opponents is not necessarily his political position but the fact that 
he is an impostor: he does not believe in the political values he preaches, but only uses them to cement his rule. This reading is matched by the Bailiff's behaviour. He frequently assures his audience that the actions on stage (especially the violent outbursts such as the killings of Barney and Macrob) are not in his name and he deeply resents and regrets the behaviour of his personal servants. In the same line, he stresses the point that, after all, he is not master but only a servant fulfilling his job. Yet he has seemingly absolute power acting on principles no one seems to understand save himself. At the same time, he tries to appear as one of the people, even as servant to the people:

While the Bailiff's title suggests that he has only a secondary level of power as one empowered to maintain order in a court - he has, at least in The Childermass, absolute power over the appellants. His criteria for letting petitioners into the city beyond are both relatively well demarcated and uninterpretively enigmatic. $^{685}$

Yet apart from the Hyperideans no one seems to mind these obvious discrepancies. This might be because to the mass of the audience he appears primarily as entertainer and entertain he does. As I discussed above the political spectacle locks the audience in an ambiguous state of passivity and activeness. The behaviour and presentation of the Bailiff demonstrate the skewed power dynamics politics bring forth when they cross the line to performance for the masses. Scott Klein has aptly summarised the whole set-up and is worth to be quoted at some length:

The Bailiff's self-presentation is expressly a performance, part puppet-show, part Greek tragedy, performed for the mob. It presents both philosophical dialogue and bread-and-circuses, complete with visual effects out of silent films and an interval that features an orchestra that, in the most 'modern' style mixes Mozart with jazz. Pullman has earlier thought of the appellants literally as 'the audience' (C p. 56), and at the book's halfway point it assumes the form of a play - or perhaps more accurately, an extended Platonic dialogue. [...] By turning stylistically into a piece of political theatre, The Childermass asks how aesthetics can in turn reflect issues in contemporary ideology. To what degree is power, and rule, a matter of show rather than substance? ${ }^{686}$

The Bailiff is frequently associated with ideological stances that Lewis criticised in his non-fiction works of the same time - liberalism, democracy, homosexuality, primitivism, the time cult, the youth cult - and yet the figure of the Bailiff serves not only as a critique of these phenomena. In fact, The Childermass questions the function of deception and performance in the realm of politics in general and of liberal democracy in particular.

Finally, there is the question of god for whom the Bailiff acts as a stand-in. In The Human Age god would have appeared in the fourth novel, 
which remained largely unwritten. ${ }^{687}$ However, I would argue, that The Childermass differs considerably from its sequels in its understanding of basic theological concepts. Paradoxically the two sequels that play in the more conventional afterworld (Monstre Gai in a sort of heaven and Malign Fiesta in hell) reveal very 'realistic' settings: Third City is similar to the British welfare state of the 1950s; Matapolis seems like a cross of Dante's Inferno and Nazi concentration camps. The world in The Childermass is truly fantastic, jumbling a wild array of symbols to create a setting that cannot easily be matched to some real world model. It is as abstract and illogical as the theories Lewis had attacked in The Art of Being Ruled and Time and Western Man. If space works like time in The Childermass why should not the conventional idea of god be replaced by another abstract concept? Lewis, I would suggest, might have been influenced by Max Stirner, who figured so prominently in Lewis's other highly abstract play, The Enemy of the Stars. ${ }^{688}$ In his book Der Einzige und sein Eigentum, Stirner had already deplored the fact that the abstract entity 'humanity' had become a god-like instance as a new higher good and unquestionable reference point. 689 Stirner's grievance about the concept of 'humanity' is exactly its abstractness, the vicious deception that 'for humanity' does not necessarily mean 'for the actual people'. ${ }^{690}$ Stirner located the trope of replacing god with abstract humanity in the Enlightenment, and this is where Lewis also locates the term 'abstract man'. The advice to discard abstract man in The Art of Being Ruled makes sufficiently clear that for Lewis this concept lies at the root of the ills of liberal democracy:

Our minds are still haunted by the Abstract Man, that enlightened abstraction of a common humanity, which had its greatest advertisement in the eighteenth century. That No Man in a No Man's Land, that phantom of democratic "enlightenment," is what has to be disposed for good in order to make way for higher human classifications, which, owing to scientific method, men could now attempt. ${ }^{691}$

The higher entity for whom the Bailiff in The Childermass works is thus not the conventional god of Christianity or any other monotheistic religion, but exactly this abstract humanity. This explains why the admission process is depicted as wholly unsound and as a farce. Lewis managed to create the Bailiff as an illustration of the dynamics and processes of $20^{\text {th }}$ century politics. He is a successful composite uniting a wealth of ideological concepts that emerged in the wake of the Enlightenment. This is made palpable by his opponents, namely Hyperides and his followers.

As with the Bailiff, readers learn about Hyperides and his followers before actually meeting them. Pullman tells Satters about a group opposed to the Bailiff, and just as his admiration for the Bailiff is biased so is his objection to the Hyperideans: 
'...-you know that sort of bolshie crowd that lives in an enclosure away from the rest_-' 'I know the_-that classical crowd,' [...]

'Classical! Well yes, they call themselves that. They dress themselves up to look like peripatetics, you know Aristotle's school, who used to walk about; $[\ldots]$ there's nothing else very classical about them. That's the lot I mean anyway, they poison the air of this place. I can't understand why the Bailiff puts up with it. I shouldn't. ${ }^{, 692}$

This passage is interesting for two reasons. Firstly, Pullman identifies the Hyperideans as 'bolshies'. Here again readers are invited to reconsider their assessment of Pullman when they later meet the Hyperideans in person, especially one of their representatives, Alectryon, who is explicitly adorned with right-wing symbols and associated with right-wing groups. Pullman's comment suggests either an ideological proximity of both bolshevists and fascists, a reading that corresponds to The Art of Being Ruled, or it exposes the mental laziness of the intellectual Pullman, who instead of analysing Hyperides's political positions, lumps him in with the most convenient political other he can think of. Secondly, Satters shows greater political acumen. He labels the Hyperideans classical on account of their dress, an assessment not appreciated by Pullman. The Hyperideans being Greek - although they are not all of them togaed peripatetic Greeks to be precise ${ }^{693}$ - could be read as an ideological placement, namely into the Classical, and thus, anti-Enlightenment, tradition. Moreover, they disrupt the Bailiff's political spectacle - which usually functions as a one-man-show - on two fronts: on the one hand, they counter his political statements, on the other they also break up the power dynamics of the show and turn it into a Platonic dialogue. As peripatetics they roam instead of sit, thus refusing to become part of the complicit audience. If The Childermass presented a fictionalisation of Lewis's political works of the same time, the Hyperideans should be the undeniable victors of the political debate and/or they should be, in contrast to the Bailiff, the more trustworthy and sympathetic characters. Yet this is not the case. Pullman's comment when the Hyperideans enter - 'the high-brow circus you know, the followers of the socalled philosopher, Hyperides, not that that's his name either.' ${ }^{694}$ - suggests that the Hyperideans engage in deception, just as the Bailiff does. Hyperides's real name is supposedly Jones, but there is no further clarification whether this information is correct or not. ${ }^{695}$ Readers have to decide whether they trust Pullman or Hyperides. If one believes Pullman then the Hyperideans use the same political tactics as the Bailiff, which would make them equally deceitful, manipulating and hypocritical. As a corollary that would mean that all politics engage in deception, or put less drastically, it would guard the reader from taking everything the Hyperideans say at face value. 
Despite his important position in the novel, there is little research on the character of Hyperides beyond the general evaluation that he represents the politics of the Right. The antagonism between Bailiff and Hyperides, The Childermass makes clear, is no short-lived phenomenon: 'They are the oldest opposites in the universe, they eye each other: all this has been enacted before countless times, on unnumbered occasions all these things they are now about to say have been uttered, under every conceivable circumstance'. ${ }^{696}$ This passage indicates that both the Bailiff and Hyperides are not simply stand-ins for modern political phenomena, or if they do, that these phenomena both have a long heritage to claim. The antiquated costumes of Hyperides and most of his followers underline the antique roots of this eternal opposition. This might go towards explaining why the souls of the dead are divided into political factions: in The Childermass there are only two factions and they have divided (Western) humankind ever since. If readers accept Hyperides as the voice of this eternal opposition, then his voice will sound remarkably familiar. Schenker observed the most likely sources for Hyperides's statements: 'If the reader cannot discern the Bailiff's shortcomings for himself, he will have them pointed out to him by Hyperides, the leader of the opposition in the next world, who at times rehearses the arguments of The Art of Being Ruled and Time and Western Man almost verbatim'. ${ }^{697}$ Thus Hyperides berates the Bailiff for his 'loving-kindness'-mask, his anti-intellect policy, his anti-male policies, his favouring of homosexuality and primitivism, and his utter disregard for the human state. ${ }^{698}$ Reduced to these parallels, The Childermass appears to be a simple fictionalisation of Lewis's political arguments. But, and this seems to me the pivotal point, Hyperides does not persuade. The argument remains unresolved and especially their second debate (on pages 329ff) is strangely balanced (the Bailiff even receives more textual space, or as befits his ideology, more time). In fact, at the very end, and in private conversation, the Bailiff is able to turn the tables on Hyperides, by arguing that not only are they alike, so are their followers:

Bailiff. 'You would not indulge yourself but can you deny that our opinions are much of a muchness? No. Here is your crowd, over there is mine. In quality they differ little. What is it that excites you to this indignant effort on behalf of this mass of uninteresting people?'

Hyperides. 'It is not people that interest me so much as the principles that determine their actions.'

Bailiff. 'You're stimulated by an idea, which you perceive behind this crowd? Perhaps then it is crowds that interest you-for clearly none of these persons taken singly would correspond to any idea capable of exciting. Further it is an idea that no person singly could sustain.' 
Hyperides. 'Why not?'

Bailiff. 'You mean yourself? But you are a crowd, not a person perhaps at all.'

Hyperides. 'You wish to turn the tables on me, puppet, by suggesting that I am no more a person than yourself I see. ${ }^{699}$

This conversation continues with the Bailiff observing that they use the same tactics only with differing motivations to sway the crowd. They are both crowd-masters but they have little in common with the crowd they lead (exceptions like Polemon duly noted). Both use hypocrisy, deception and violence while accusing the opponent of exactly these means. In all these remarks the Bailiff is strangely persuasive. To give further validation to the Bailiff's case the descriptions of the Hyperideans give readers an impression of an aggressive mob rather than an assembly of Greek philosophers: 'At the slightest hint they take fire, in everything over-zealous. They leap into every suggestion of a breach, theirs is the Legion of Lost-Causes, they have the tattered grandeur of an Imperial Guard at its Waterloo, a cambronnesque The Guards die, they do not surrender is painted all over them, they advertise doom in all their attitudes with a heroic rejoicing. ${ }^{7} 700$ They are a raucous set, speaking, or more accurately, shouting unison with one voice, usually limiting themselves to insults levelled at the Bailiff. Almost animal-like they react with crude frenzy when the Bailiff exclaims:

'-and I become a Circe for these swine!'

There is a rushing gasp, the trigger snaps, a roar of protest is released.

'Swine!'

'Swine!'

Hyperideans \{ 'Swine!'

'Swine!'

[...] Polemon advances in front of the litter, and faces the Bailiff. ${ }^{701}$

The behaviour of the Hyperideans, who have become, so the text states, a 'litter', proves the Bailiff's point. These brute crowds, who operate on the principles of 'action' and 'violence' and who gather behind the intellectual justification of their select leaders, are quite an accurate depiction of the more violent followers of Maurras or Mussolini. In that light the Bailiff's enquiry why Hyperides would be so proud to be leader of this pack and to disparage the Bailiff for his followers seems more than justified. This would be a very uncomfortable admission for those who see The Childermass as a fictionalisation of The Art of Being Ruled and Time and Western Man. Hyperides may rehearse the arguments of these two books but he fails to persuade the Bailiff, 
his followers and arguably the reader. The debate could end here, but the Hyperideans send another speaker into the debate: Alectryon.

In a way, Alectryon is the novel's strangest character. Like Polemon he is one of the exceptions from the rabble-followers of Hyperides, an indication for the internal hierarchy among the Hyperideans. Yet while Polemon has appeared throughout the debate as a mediator (and was singled out by the Bailiff as a worthy opponent), Alectryon is unknown to the reader until the very end when he steps on to the podium..$^{702}$ The public debate between Alectryon takes place towards the end of the political spectacle and follows a private conversation between the Bailiff and Hyperides. Polemon introduces the public debate: 'Alectryon here who was within earshot and has marked what you said has been deputed by us to correct you. Have you any objection to debating publicly what you have just now advanced in private? ${ }^{703}$ Even before Polemon submits the request, readers find an almost page-long description of Alectryon, which presents him as a most singular and almost perfect being:

Standing beside Polemon is a young man a head taller than the Hyperidean chief whip [...]. He is the handsomest of all the Hyperideans with a large and languishing russet petasus tied beneath the chin. A black cloak falls straight to his heels fastened with a Bangkok swastika temple design imposed upon a rough brooch and he carries a black leather portfolio of continental cut. His face has no feminine imperfections but is cast on the severest lines of an eager and wolfish symmetry, in lean silver-bronze [...]. He appears scarcely more than adolescent: his manners are of such a striking gentleness as to suggest some romantic postulant of a much-tried order in a militant epoch and his expression conveys no blemish of passion at all except settled pity too formal to be oppressive. When he is smiling it is an inaccessible radiation: [...] As he bends down gravely towards his master, Hyperides looks up at his astonishing disciple with a pleased surprise. ${ }^{704}$

This is in many ways a remarkable passage. First, maybe the most striking thing for today's readers is his outfit, which invariably reminds one of the long-cloaked versions of the SS uniforms. ${ }^{705}$ The swastika was already established in the early 1920s as a symbol of the budding NSDAP, so Alectryon's political placement seems unambiguous. ${ }^{706}$ The combination of the swastika buckle and the black cloak are eerily prescient but after all seem coincidental. What else is noteworthy is that his being adorned with a swastika sets him apart from most of the other Hyperideans. ${ }^{707}$ Thus already his dress makes him stand out from the crowd, but also his general appearance and character, which the passage describes in almost gushing tone, add to his distinctness. The sheer effusiveness of the tone should make readers wary. He is the only character (apart from perhaps Polemon, who is described as 'priest-like, ${ }^{708}$ but is never granted a more comprehensive description) who is painted in 
such a positive light: it is as if the text pleads with the reader to like this particular character as there is nothing about him that could possibly be disliked. This should raise a question: in how far is personal appearance important for the political spectacle? The Bailiff, famously ugly, remains unimpressed by Alectryon, 'All is not gold that glitters' is his answer. ${ }^{709}$ And true, the presentation of Alectryon should make readers pause to consider whether the enthusiasm that is poured into the description is not somewhat of a ruse. As Alectryon is about to enter a stand-off with the Bailiff, readers should keep in mind the Bailiff's answer to the insults directed at him by the Hyperideans: 'Your followers always return to my face. That is not only unkind but unintelligent'. ${ }^{710}$ Alectryon might be there to deceive readers just as anyone else to fall for good looks as somehow proof for good political practice. It seems almost like a prescient insight that a character is included who is remarkably handsome and seemingly a National Socialist, since especially the Nazis made ample use of beauty, be it in the human form or architecture, as a validator for their ideology. Moreover, the Nazis operated on juxtapositions of the deformed, entartet other and the healthy beautiful self. ${ }^{711}$ Bringing these thoughts to The Childermass offers a new perspective on Alectryon. He is set up by the text to stand out from the crowd and it seems that the Hyperideans are using Alectryon as an external validator for their position before he has even uttered a single word in the debate. By overemphasising his outstanding appearance and qualities, the novel exposes the dynamic behind this particular tactic, and every time readers fall for it, it serves as a reminder just how potent this tactic can be.

In the debate with the Bailiff, Alectryon embodies the Classical standpoint. Before the public debate between the Bailiff and Alectryon begins the two have a private conversation, in which readers already get a glimpse of Alectryon's ideology:

Alectryon (in flat recitative). 'An absolute incompatibility existed between my views and those you expressed.'

Bailiff. 'Yours were hopelessly aristocratic., ${ }^{712}$

This corresponds very neatly to a statement from Time and Western Man, 'The "classical" is the rational, aloof and aristocratical; the "romantic" is the popular, sensational and "cosmically" confused. That is the permanent political reference of these terms', ${ }^{713}$ and thus confirms the ideological standing of both opponents, at least concerning the binary of classical versus romantic. Incidentally, their scuffle about Alectryon's biography - in which both give different accounts, again highlighting the novel's issue of trust - also suggests that he represents the white melting-pot as opposed to the Bailiff who stands for the racial melting-pot. ${ }^{714}$ This is very much in line with Lewis's arguments 
in favour of international white alliance as he voiced them in The Art of Being Ruled and Paleface. In this initial conversation Alectryon's support of (proto-) fascist groups, namely the Action française, an extreme anti-liberal, antienlightenment group led by Charles Maurras, and the Stablhelm, Bund der Frontsoldaten, a German league of ex-soldiers supporting anti-democratic and antiSemitic politics, is mentioned. ${ }^{715}$ Alectryon's ideological position on the Right is thus unmistakeably indicated by a number of elements as to leave no doubt even before he starts the debate. As soon as they breach the subject of politics another quality of Alectryon, which disturbs the image that has been created, comes to light, namely that he has a stammer:

'...from which archetypal puppet [Moses] I inherit the slight stammer you m-m-may have rem-m-marked.'

Bailiff. 'No. Did Moses stammer?'

Alectryon. 'He, sir, was named the Stammerer in consequence of his stammer: Aaaron did all the s-s-s-s-s-s-speaking, ${ }^{716}$

This small passage is yet another absurd instance in the conversation between the two, but it repeats already familiar patterns. Readers will be forced to stand with the Bailiff, because neither he nor we have noticed Alectryon's stammer prior to this passage (although he has been talking a lot before). Moreover, Alectryon will continue the debate without any further stammering, which raises two questions: can readers trust his remark that he is a stammerer; and if he never stammers before or after this remark why does it matter anyway? Is Alectryon fooling with the Bailiff, or is the text fooling with the readers? Alectryon's stammer might be a performative act to deceive, namely to prove by referring back to Moses that his mother is indeed Jewish. This would highlight that all political fractions make use of performance. The more we learn about Alectryon the more obscure he becomes. When Lewis would complain in his non-fiction books that parliamentary debate was like a Punch-and-Judy show, The Childermass acts this out. ${ }^{717}$ This scene reveals the absurdity of the political debate as a whole. When Alectryon finally gets to discuss politics, his position is very close to that Lewis holds in The Art of Being Ruled and Paleface: he is a proponent of natural hierarchy and of antidemocratic sentiment, he complains of the exclusion of those who object to democratic values, he calls out the class-war, the missing Blutsgefïbl among whites, he objects to jazz and homosexuality, the latter being caused by feminism, both of which devalue masculinity. ${ }^{718}$ Especially Alectryon's arguments on homosexuality mirror the reasoning in The Art of Being Ruled almost verbatim. In this part of the debate, Alectryon even usurps the Bailiff's opposing position by answering for him (to save him the trouble), using the exact same phrase each time ('non sequitur it's a lie'). What is so poignant about this sce- 
ne is that exactly when The Childermass almost word for word reproduces Lewis's non-fiction writing, the structure of political debate is obliterated and it becomes an oration instead.

When Alectryon finally ends his four-page-monologue, the reader may be surprised to learn that the Bailiff agrees with Alectryon's argument, at least up to a point. What is revealed in the end is, that while Alectryon defends the 'white male' from all onslaughts he perceives in contemporary society, the Bailiff's vision is even more misanthropic than that: for him all humans are quasi animals and they are not worth fighting for:

But I can tell you this - to be serious for a moment-that if you are human they are not: and if you succeeded in removing the bandages they would trample you to death for robbing them of their illusions, that's what they are like. We understand these herds, you do not, we are expert drovers. ${ }^{719}$

If Alectryon is anti-humanist, the Bailiff is anti-human. If he is seen throughout the book to advocate democracy, capitalism, homosexuality or liberalism these ideologies served as farcical masks to cover his abhorrence of humans in general. ${ }^{720}$ This could now be interpreted in two ways: either it could suggest that democracy, liberalism, and capitalism have a fundamental hatred for humanity at their core or that they are used to conceal an anti-human ideology from the ruled masses. In both readings the Bailiff's position strikes one as objectionable because it is misanthropic and dishonest: 'In the future fools will not be suffered gladly, the weak will not be encouraged to go on living and suppressing the strong. ${ }^{721}$ This is reminiscent of Social Darwinism, eugenics and the repressive and exterminatory politics that were later based on these theories. To this Alectryon remarks that 'only your hatred is creative it is your only way of being creative', ${ }^{722}$ which as Tom Normand suggests is a good summary of Lewis's own position, but even more poignantly could be read as a synopsis of fascist ideology, as propagated by Sorel for example. ${ }^{723}$ Thus both opponents seem to inhabit a position somewhere on the Right in the end, with the difference that the Bailiff is in power and conceals his real intentions. When Alectryon leaves the stage Hyperides returns to ask his questions, which 'are always the same':

Why am I and my friends here? What do you want with us? What is this farce we are required to play? And for whose benefit are we supposed to be playing it? ${ }^{724}$

The Bailiff grants no answers and delays the debate for another time, leaving Polemon to exclaim exasperatedly 'Who is to be real-this hyperbolic puppet or we? Answer, oh destiny!', strangely reminiscent of Mussolini's speech in parliament shortly before his fascist regime was installed. ${ }^{725}$ The novel itself seems to suggest that it is the Hyperideans who are real, as the Bailiff returns 
to 'the citadel of Unreality'. ${ }^{726}$ More importantly, however, The Childermass ends on the notion that the answer to Polemon's question does not even matter, or at least that it does not matter to the ruled, as the final dialogue between Pullman and Satters indicates:

Satters. 'Can't we go, Pulley?'

Pullman. 'Don't you want to find out which of the two is real?'

Satters. 'I couldn't care less, Pulley! Could you? What does it matter which isn't real! I was never real. Am I?'

Pullman. 'I suppose you were. In the way that a toadstool is.'

$[\ldots]$

Pullman. 'Step out. Pick your feet up. If you must go nowhere, step out. ${ }^{7727}$

Again Pullman embodies the obedient supporter, whereas Satters's stubborn reaction cuts to the core: what difference does the dispute between the two factions of rulers make for him? The answer is: none.

Satters's reluctance to follow the continuing debate reveals the underlying critique The Childermass heaps at the political spectacle. The combatants in the arena - the Bailiff, the appellants, and the Hyperideans - do not matter as much as the spectacle may suggest because they are all puppets anyway, ${ }^{728}$ and the real puppet master pulling the strings remains hidden. It also remains unclear how much power the two main opponents really have: the Bailiff's title seems to contradict the power he wields in the arena, yet he also seems oddly like an imprisoned actor who has to play his part and endure the disturbances by the Hyperideans, who in turn, despite their feelings of superiority, have to yield to the Bailiff's or his superior's will. This indeterminacy in the political spectacle The Childermass stages might attract the same interpretation as The Art of Being Ruled sometimes receives: namely a book which is not ideological itself but rather a critique of ideology per se. ${ }^{729}$ However, besides the problematic implication that a critique of ideology is necessarily extraideological (which according to the definition of ideology I use in this study is impossible), this reading neglects those ideological values and positions the novel does not criticise and those which it underhandedly advances. The symbolic truce between Bailiff and Hyperides reveals the very similar mechanism of both ideologies but it reveals even more. The Childermass betrays an underlying belief in the inequality of humans and the need to distinguish between puppets and natures. Although the Bailiff might superficially stand for the heritage of the Enlightenment - liberty, equality, fraternity - he does not believe in these principles nor acts on them. Thus, and here I would disagree with Schenker, it is not Hyperides who unmasks the Bailiff, but the Bailiff himself. He might be more popular and successful but only because he em- 
ploys the means to conceal his real motives. The supposed meta-ideological position of the novel, in which the Bailiff and Hyperides war against each other without result, is not a neutral position but acquiescently employs a right-wing doctrine. By the Bailiff's admission the only possible way to rule people is by division, paternalism, and incapacitation (Entmündigung). Moreover, the continuing critique, or rather devaluation, of democracy results in a devaluation of 'politics', which has usually characterised right wing movements. Dasenbrock has aptly summed this up when he writes that:

The reason for Lewis's critique of ordinary politics also brings him close to fascism. Ordinary politics didn't matter because the real decisions were being made elsewhere. Political life was a gigantic false bottom. Lewis's entire body of work can be said to be a fiction of paranoia, a fiction in which suspicions about other people's motives and even about their authentic existence is both encouraged and generally confirmed. And clearly a comparable paranoia is central to the fascist worldview, to the fascist way of imagining the world, particularly to its Nazi variant. ${ }^{730}$

The Childermass employs all these elements: the characters cannot be trusted, the answers to the questions of who and what is real remain forever coveted but unresolved, the political spectacle is a farce. In this reading the seemingly negative portrayal of the Hyperideans can also be reconsidered: it is not they who are flawed but the (political) system in which they (have to) act. David Ayers maintains that 'in the unreal and non-historical setting which is the chilly laboratory of The Childermass, no absolute truth can be vouchsafed. Instead, the primary aim is to strip away legitimation from the Bailiff, and from the entire Jewish-inspired, time-obsessed Zeitgeist which he represents'. ${ }^{731}$ Yet, it is not the Hyperideans who successfully challenge the Bailiff's performed politics, but the unquestioned right-wing structure, which runs through the fabric of the novel.

\section{'You do not believe in the sex-goods you deal in..."}

Gender in The Childermass is a more complex matter than the all-male cast makes it seem. Despite the lack of 'conventional' female characters (women are presumably in a different camp), ${ }^{732}$ gender is surprisingly fluid in The Childermass, which can only be made sense of if Lewis's theoretical gender model is taken into account. The gender dynamics of the novel are paramount to understanding the ideological construct on which the narrative is built. It is thus surprising that gender matters have rarely been dealt with in critical stud- 
ies and even in the rare occasions that gender dynamics have elicited comment it has been superficial at best. ${ }^{733}$ This is also strange considering that Lewis devoted a significant amount of his book The Art of Being Ruled to the discussion of gender dynamics. Lewis's underlying gender concepts were quite remarkable for the 1920 s, coming from a right-wing perspective no less. The gender dynamics in The Childermass are just as intriguing, for in the novel gender does not function as a static binary category, but as fluid. This sounds astonishingly progressive for a novel from the 1920s, and yet it does not prove that Lewis during that time was more left-wing (pace Munton). On the contrary, this deconstruction of the normative gender model in the end again is made to serve the novel's right-wing ideological matrix.

The prominence of feminism and homosexuality in The Art of Being Ruled has been duly noted by scholars such as Dasenbrock writing that ' 1$]$ arge sections are also devoted to accounts of how feminism and the increasing prominence of homosexuality are changing contemporary society. Lewis does not necessarily endorse any of these movements, but he does not overtly attack them either, and all of these are given much more space than fascism'. ${ }^{734}$ This is not entirely correct. The reason Lewis devotes so much attention to these two issues is because they implicate for him what he calls 'the sex-war'. Similar to the other 'Lewisian wars' (age-war, class-war, race-war etc.), the sex-war is yet another element to destabilise society by undermining the 'natural' order. While Lewis understands gender as a construct (up to a point), he subscribes to the notion that the (white) male is inherently superior to the feminine. This feeds into his larger ideological construct that the 'true white male' is under attack and his demise would lead to the demise of society as well. Understanding Lewis's premise for the discussion of feminism and homosexuality, it is puzzling why Dasenbrock fails to see the attack Lewis's book mounts against these two issues. For Lewis's departure of attack against feminism and homosexuality is precisely his constructivist understand of sex. Thus a man, and Lewis mostly talks about men, ${ }^{735}$ is made not born: 'Men were only made into "men" with great difficulty even in primitive society: the male is not naturally "a man" any more than the woman. He has to be propped up into that position with some ingenuity, and is always likely to collapse'. ${ }^{736}$ Furthermore he explains that there is nothing natural about so-called male qualities:

The position of the male today, and the symbolism of the word MAN, are purely artificial: no more for one sex than for the other are the heroic ardours, "intellectuality," responsibility, and so forth, that we associate with the male, natural. Men had grown to regard them as natural, because in the first place they had seemed profitable. ${ }^{737}$ 
Lewis rejects, at least partially, the natural determinacy of gender. The 'man' is a construct and so are his supposedly inherent natural attributes. This latter quote also testifies to Lewis's understanding of gender dynamics and power: certain positive characteristics are seen as 'naturally male' because it proves beneficial to them, keeping the male hegemony in place. ${ }^{738}$ This thinking can also be found in his other books of the period, for example, in Men Without Art he writes almost exasperatingly:

Now there is one obvious division or opposition staring you in the face and inviting you, on one side and the other, to drop into its pigeon-hole and be at peace - that is the classification by gender: the Masculine and the Feminine departments of the universe. Is it necessary for us to repeat here for the thousand and first time how illusionary this division is found to be upon inspection: to point out that many women are far more grenadiers or cavemen than they are little balls of fluff; and that, on the other hand, many men are much more fluffy and "girlish" than are their sisters: that a veneer of habit, and a little bit of hair on the chin and chest, is about all that fundamentally separates one sex from the other? ${ }^{739}$

Stopping here, these are good examples why scholars (especially from the Left ${ }^{740}$ keep singling out Lewis as a worthy critic of society who was prescient in some issues and ideas that are still significant to debates today. ${ }^{741} \mathrm{But}$ Lewis did not stop here. Lewis's fluid gender model allows him to present 'the man' as being in a precarious place. Feminism and homosexuality, which according to Lewis are causally linked ("The "homo" is the legitimate child of the "suffragette."), ${ }^{742}$ besiege 'the man' and his dominant position in society. The great disadvantage of 'the man' is that his 'being man' is a laborious process that could easily be reversed by societal pressures: 'Remove the arbitrary psychological machinery that in this way constitutes the mere male "a man," or tamper with it too much, or overtax it, and he collapses and becomes to all intents and purposes a woman'.743 This quote makes clear that gender for Lewis is a construct but at the same time it implies a hierarchy between men and women seeing that it is the collapsed man who becomes a woman. What Lewis's gender model ultimately achieves is that he puts the dominant subject in the position of perceived victimhood, a recurring pattern in right-wing arguments. All of this Lewis classifies under the phrase 'sex-war', and it might not surprise that he is determined that the attackers are not interested in a truce:

But subtly and in the nature of things, it is no longer a question of adjusting an inequality, but of advancing (as of a superior nature) the qualities of the "down-trodden," of the "weaker" sex. [...] Such a war as the "sex war," as was to be expected, does not end in a stabilization in which the man and the 
woman exist on equal terms. It necessarily ends in a situation in which feminine values are predominant.

That the "sex war" is not at the finish (whatever it may have been at the start) an egalitarian movement is certain. It is not an insurrection with an egalitarian watchword any longer, but a "war" for domination, not "equal rights." ${ }^{744}$

It should have become obvious by now that Lewis's discussion of feminism and homosexuality does constitute an attack, precisely because he perceives their occurrence in society as an attack on 'the male'. Foreshadowing my argument on race in the chapter below, it is important to see gender, especially masculinity, as linked to race in Lewis's greater ideological matrix. Thus 'the male' always implies 'the white male' and his demise could, ultimately, have dire racial consequences: " $t$ ] here is "defeatism," but also a deep racial tendency of withdrawal from the absurd position of heroism that could only end in the extermination of the white race' ${ }^{745}$ If liberal democracy gave rise to feminism and homosexuality, and they in turn endanger not only 'the white male' but the continued existence of the white race, then a political alternative can only be found among those political movements that revolve around the celebration of 'the male'. Similar gender dynamics inform The Childermass to which I shift my attention now.

The Childermass exhibits a homophobic paranoia, which feeds into the novel's right-wing ideological matrix. Yet, while the few scholars looking into homosexuality in the novel have been preoccupied with identifying which of the characters are gay, little has been said of how homophobia functions in The Childermass. Munton identifies the Hyperideans as gay, ${ }^{746}$ Wagner sees Pullman and Satters as 'male homosexuals'. ${ }^{747}$ Arguably only the Bailiffites are undoubtedly labelled as homosexual in the text. Wagner's claim that Pullman and Satters are gay is brought forth without any references to the novel to prove it. ${ }^{748}$ If we follow Wagner's interpretation they might be read as gay due to their genderfluid identity: throughout the novel they frequently change genders, for example Pullman becomes 'little Miss Pullman, the new governess', and later '[n] urse Pullman is silent, she notices nothing, except that her eyebrows rise'. ${ }^{749}$ Similarly Satters is at times cast into a female role: he is linked to Gertrude Stein and repeatedly presented as a baby (and hence linked to the feminine as opposed to the male). At the political spectacle Pullman and Satters seem to assume the role of an old married couple, with Satters described as Pullman's 'better-half speaking like an 'Anglo-Saxon matron'. ${ }^{750}$ Throughout the show Satters needs to be constantly soothed as the actions on stage frequently upset and scare him. It seems obvious that Satters has a stereotypically feminine role thrust upon him, making him the weaker part of the two; Satters's trembling 'massive feminine hand' is opposed to Pullman's 
'masculine sang-froid'. ${ }^{751}$ And they are not alone. All of the Bailiffites seem to exist in similar constellations:

Many of those they pass are also arm-in-arm, immersed it appears, in a similar relationship, detachable master-spirit with rooster strut and bashful satellite, one who speaks bold and high, the other retiring and low with a sideway gazelle-like glitter of the eye. Both usually possess painted lips, but around the paint of the one is often a delicate whisker. ${ }^{72}$

Further stereotypes are listed such as toy dogs, Teddy-bears, 'which [the Bailiffites] regard as mascots and play with when they think they are observed', and Japanese parasols. ${ }^{73}$ If all these clichés have not made the case clear enough, Pullman's gaze is directed towards a certain set of 'Vielle [sic] Noblesse of Gomorrah, [...] who have been famous propagandists and great fighters for votes for Homos, for the Homo's Rights (My Passion right or wrong! As a slogan for example) or just for Freedom'. ${ }^{754}$ While these depiction stresses the ridiculousness of the Bailiffites, their presence also constitutes a threat, by evoking contemporary discourses of (moral) degeneracy. The novel boasts many more examples, but these should suffice to show that the novel itself is infused with a sort of homophobic panic. In fact, The Childermass fulfils the dystopian vision Lewis set out in The Art of Being Ruled where he muses that feminism with homosexuality in tow will only stop in a complete reversal of the social hegemony, a notion he still entertains in Time and Western Man. ${ }^{755}$ The novel plays out this new reality in which everyone who follows the Bailiff is gay and effeminate, with barely any 'real men' left. ${ }^{756}$ In the light of these gender dynamics we need to return to the Hyperideans. Munton writes that '[d]espite possessing many of the correct Lewisian arguments the Hyperideans' reality is limited by their chosen 'Greek' identity as homosexuals; they can never become sufficiently complex to be 'real'. ${ }^{757}$ Yet the Hyperideans' Greek identity and its connection to homosexuality are more complex than Munton's reading makes it seem. Consider Hyperides's monologue on this matter:

It is not a charge to describe a person as an addict of inverted sex-love if he dresses the part and insists on being recognized as such any more than to call us Hellenes, for as such we would be identified. It is the pattern on which you manufacture your pseudo-infant-minions about which I was talking and it is because they are organized self-consciously against all our more abstract and less feverish human values, under your direction: that is why we protest. What they do among themselves neither concerns nor interests us, we are as you say not Greeks for nothing though not in the sense you intended. As it is, you are drilling an army of tremulous earthworms to overthrow our human principle of life, not in open battle but by sentimental or 
cultural infection... [...] You do not believe in the sex-goods you deal in... ${ }^{758}$

More important than the Hyperideans' Greek identity is the fact that they differentiate between homosexuality as private practice and as a public, and thus, political movement. This argument comes up again in the debate between the Bailiff and Alectryon:

Alectryon. 'We are accused of laughing at homosexuals instead of being impressed.'

$[\ldots]$

\section{Bailiff. 'Yes?'}

Alectryon. 'It is said that the homosexual fashion should either arouse our indignation or moral passion or else nothing, we should affect blindness or else be it. It is in claiming as our humble right a third position, neither that of moral passion nor one that is complacent nor helpful, that we meet with a difficulty at your hands.'

$[\ldots]$

Bailiff. 'Do you not find it an abomination?'

Alectryon. 'We take no interest in it. We are indifferent to homosexuality.'

Bailiff. 'It is disgraceful to be indifferent!'

Alectryon. 'No. We claim that our attitude is highly disinfectant. ${ }^{, 759}$

While here claiming to be indifferent to homosexuality, a few pages later Alectryon displays a remarkably different attitude towards homosexuality as a political phenomenon: 'There we should satisfy you better in so far as we provide powerful reasons against this fashion' ${ }^{760}$ While this discrepancy could again be read as an issue of un/trustworthiness, it is likely that Alectryon like Hyperides earlier differentiates between moral indifference to homosexuality as private practice and political indignation at homosexuality as a social movement in alliance with feminism, as only the latter is perceived as threatening the existing hegemony of the male. To put this view into perspective it helps to look into another text by Lewis, namely the infamous Hitler. Herein Lewis satisfactorily notes that the National Socialist is not interested in sexual vice:

So the fact that the Nazi is not a sex-moralist at all should be reckoned, I think, as a very good mark indeed, politically and otherwise. [...] This does not mean to say, however, that the Nazi would regard the public orgasms of the night-life Bankleute as edifying. On the contrary. But he would neglect that in order to concentrate upon issues of far more public moment. To put this in a nutshell-The Bank is more important than the Backside. And the young Nationalsocialist has firmly grasped this fundamental truth, in a manner that 
no average political Anglo-saxon would-who always allows his pocket to be picked provided you fix his attention upon something that is 'wicked' or naughty. ${ }^{761}$

This matches Alectryon's point of view almost perfectly: he is no sex-moralist - and this is what lies beneath the phrase 'we are indifferent to homosexuality'. Alectryon criticises homosexuality not from a moralist standpoint but from a political one, a standpoint that casts the 'white male' into the position of the victim. To use Lewis's own words, for Alectryon the Bank is more important than the Backside. ${ }^{72}$ The inherent homophobic panic of the text quietly acquiesces in Alectryon's argument that homosexuality (and feminism) are an onslaught on the 'white male'. While parts of Alectryon's character remain ambiguous, he seems most in line with the novel's inherent right-wing matrix. Therefore, it seems little surprising that it is Alectryon, rather than Hyperides, who most closely mirrors the arguments made in The Art of Being Ruled, as Trotter so aptly points out:

Alectryon, the Hyperideans' chief spokesman, carries cheerfully on where The Art of Being Ruled had left. [...] The afterworld imagined in The Childermass is exclusively male, and it is no surprise, therefore, that Alectryon, again in accordance with The Art of Being Ruled, should develop his paranoid defence of the man of conspicuous undemocratic abilities by means of a critique of the cult of homosexuality, which he regards simply as a fashion promoted by consumer capitalism. "The "male", Alectryon says, "has today been thrust into the defensive and watchful role.' These are, transparently, Lewis's views. [...] Lewis establishes a certain distance from his own views when he allows the Bailiff to damn Alectryon by association with right-wing cadres, with students of the 'French-Action' or 'Steel-helmet type. But the Bailiff is scarcely a disinterested observer. The vigour of Alectryon's argument, and the attention given it as the narrative moves towards its climax, suggests that Lewis was not yet through, in 1928, with paranoia. ${ }^{763}$

Alectryon's gendered identity offers another important detail: his unswayable masculinity makes him immune to the Bailiffs influences. When readers first meet Alectryon, it is stated that he has no 'feminine imperfections'. He stands in stark contrast to the Bailiffites, who, as the novel has made abundantly clear, look and act in a stereotypically feminine way. His name might be a further indicator of his masculinity, as Wagner suggests, for he is 'a Greek who clearly stands for masculinity since he is called Alectryon (meaning cock [the animal])'. ${ }^{764}$ I would even go further and say that the Bailiff is not only powerless against Alectryon, but secretly agrees with him on some positions. If it is true that the Bailiff condemns homosexuality (he calls homosexuality a filthy vice $\left.^{765}\right)$ he, at least, seems to see it as beneficial to his rule. Femininity, according to Lewis - and Le Bon for that matter - makes a subject more credulous 
and susceptible to manipulation, the ideal prerequisite for the successful political spectacle to run smoothly. Accordingly the Bailiffites, including Pullman, never question anything the Bailiff does, and only object to the depiction of stark violence, a quality that reinforces their stereotypical femininity. Even the Bailiff, in the end, admits that he draws political use out of homosexuality, to the detriment of humanity as a whole, as Alectryon suggests.

Ultimately, this confirms the underlying homophobic thread of the novel. Clichéd homosexuality is used as a tool for comedic purposes, as the Bailiffites are cast as a set of laughable figures. The use of homosexuality and misogyny are further used to underline the right-wing agenda of the book. The gay audience, and thus the feminised audience, are unable to see through the democratic power play, and even less able to intervene. This would confirm Lewis's thesis presented in The Art of Being Ruled that power is divided along gender lines: "And the relation of the ruler to the ruled is always that of a man to a woman or of an adult to a child. (By "man" here is meant any ruler-like person, of whatever sex, age, or class). ${ }^{766}$ Only those 'male men' with integrity are able and willing to challenge hegemonic rule: Barney's and Macrob's bloody demise ${ }^{767}$ as well as Alectryon's monologue strengthen the argument of the 'white male' as victim, the former played out in acts of graphic extermination, the latter as the accompanying theoretical explanation. Despite the total absence of female characters, The Childermass manages to show a misogynist tendency by associating the feminine with attributes such as weak, gullible, and vain. The utter devaluation of the feminine and the total absence of female characters makes The Childermass also a paragon example to show, in my opinion, the flaw in Jameson's reasoning when he muses:

I wonder if I will be understood when I suggest that Lewis' expression of this particular idée fixe is so extreme as to be virtually beyond sexism. Misogyny in Lewis no longer exists at the level of mere personal opinion, [...]. Indeed, the stable subject or ego which could alone "entertain" such opinions has in Lewis been dissolved, so that they come before us in a virtually freefloating state, as unbound impulses released from the rationalizing censorship of a respectable consciousness intent on keeping up appearances. ${ }^{768}$

The Childermass does not need a stable subject to entertain such notions, because the novel itself is built upon a misogynist and homophobic matrix without which the narrative would not function. It is also very telling that the homophobic panic inscribed into The Childermass is so overt and yet its powerful effect so obscure that those critics who commented on the topic have been unable or unwilling to analyse how the underlying gender dynamics function in the novel and yet felt it important not only to single out certain characters as gay but also to mark exactly these characters as unlikeable. ${ }^{769}$ The underlying gender dynamics keep Lewis's novel firmly entrenched in a 
right-wing ideological matrix, which makes it doubly worrying that gender is constantly overlooked when The Childermass is addressed. The promotion of the vulnerability of the 'white male' actively supports (proto-)fascist views that conjure up apocalyptic scenarios of the disappearance of the white race. The slaughter of the innocents, which the title evokes, does not only reference the actual killings on the battlefields of World War One, but the presumed extermination of a whole generation of males in an ideological war. One finds exactly this dystopian vision played out in The Childermass where the no-man has occupied the barren no-man's land the Great War has left.

\section{'It's too marvellous he's Black!'}

Similar to its gender dynamics, contemporary discourses on race inform the novel's inherent right-wing matrix. The Childermass not only features nonwhite and Jewish characters but its argument also relies on their presence and the associations they evoke. This is not surprising as it springs from the same phase as Lewis's Paleface. Indeed, it seems that The Childermass furthers the argument Lewis develops in his study on the Modernists' infatuation with the exotic. As I explained above Paleface is a keen observation on the downsides of primitivism, yet it also advances a racialised position that envisions the unification of the white race as an antidote to mindless exoticism. As I will argue here The Childermass employs a very similar argument even if it does not spell it out as explicitly as Paleface. One could differentiate between the use the novel makes of The Art of Being Ruled from which it lifts parts of its arguments almost verbatim, and its use of Paleface, which it does not quote but acts out instead. The Childermass also functions as a satirical response to the books and authors, which Paleface criticises, such as Anderson and Lawrence. The racist scenes in The Childermass clearly ridicule the sentimental writings of these authors; however, Lewis's exaggerated use of AAVE and clichés does not only poke fun at the white writers who revelled in blind exoticism but also at the black subjects who are the unwilling participants in this writer-feud. In short, for the reader familiar with Lewis's work, the racialised depictions in The Childermass primarily serve to mock contemporary writers, and yet the novel only achieves this aim by perpetuating racist stereotypes. The matter seems even more complex when anti-Semitism is taken into account. Some scholars argue that Lewis was no, or at least not a conventional, anti-Semite. ${ }^{770}$ Lewis rightwing ideological stance was less dependent on (paranoid) hatred towards the Jews, ${ }^{771}$ but he was happy to employ anti-Semitic clichés, at times possibly unconsciously so. ${ }^{772}$ Lara Trubowitz has argued that 'antisemite and racist 
though he may be (and he is both), Lewis is also a compelling theorist of antisemitism and racism and ought to be read as such'. ${ }^{773}$ I would caution, that his theories on racism and anti-Semitism always have to be read with his political position in mind. This uncovers that while he is apt in picking apart racist and anti-Semitic dynamics, his analyses often feed into a larger argument that is at its core often racist and anti-Semitic. ${ }^{774}$ Curiously from the $1920 \mathrm{~s}$ onwards, Jewish characters started to emerge in his novels. In the 1928 revision of Tarr, a vicious Jewish character enters the scene, who had been absent in the earlier 1918 version. In The Apes of God, the prominent and disagreeable Julius Ratner plays a major part. David Ayers argues that 'from 1924 onwards Lewis is concerned, both in new works and in newly revised works, to expose the machinations of the conspiracy and to imply, at least, the identity of the conspirator. The conspirator, when identified, is shown to be a Jew, or to have several characteristics which Lewis ascribes to Jews. ${ }^{775}$ The Childermass falls into this period so it makes sense to take the less explicit but still noticeable references seriously. In the novel, I would argue, Jewishness is associated with the Bailiff and his performed ideology. It links Jews with liberal democracy (and all its negative consequences) and deception, a very common argument during Lewis's time. Moreover, the novel also links Jewishness with effeminacy and femininity, another widespread notion, ${ }^{776}$ made popular, among others, by Otto Weininger's book Geschlecht und Charakter, published in $1901 .{ }^{777}$ In the novel people of colour as well as Jews are marked as the others, who are both threatening but also fascinating. By satirising the widesspread exoticism of his contemporaries, Lewis produced a text that at once problematizes the mindless exoticism, but which also cannot (or does not want to) escape its own racist and anti-Semitic world-view. As a result, even though the main function of some racialised scenes in The Childermass is to heap scorn at fellow (white) writers, the use of racist clichés and anti-Semitic notions situate the novel firmly in Lewis's right-wing ideological matrix. While couched in language that is meant to be humorous they still serve the novel's serious ideological argument.

The political spectacle in The Childermass is ripe with racialised elements, so much so that even the interval is used to stage an episode with heavy racial overtones:

The orchestra, assembled upon a trestle platform at the left-hand corner of the enclosure, with a mixed Jewish and negro personnel begins. [...] The minor chord of the opening is interpreted with traditional correctness. After that, first with the connivance, then at the suggestion, and finally in the midst of the furious insistence of the black chef d'orchestre, the Mozartian allegro becomes effaced.... ${ }^{778}$ 
In short, there is a jazz band playing. For a novel written in the 1920 s this would not be noteworthy, yet this short scene should be read as an accompaniment to an argument from Paleface, which is worth to be quoted in full:

The 'cultural' present that the Negro has made to White America, and through America to the whole White World, can be summed up in the word 'jazz.' It is a very popular present and White people everywhere have tumbled over each other to pick it up, and it has almost superseded every other form of activity. But what it is impossible not to ask is whether it deserves quite so large a 'reward' [i.e. cultural recognition] as Mr. [Alain] Locke claims for it. The White arts that the Paleface has turned away from in order to cultivate those Black arts, were certainly as good as the latter: and all that the 'Afroamerican' has succeeded in supplying is the aesthetic medium of a sort of frantic proletarian sub-conscious, which is the very negation of those far greater arts, for instance, of other more celebrated 'Coloured' races, such as the Chinese or the Hindu. The Chinese or the Hindu would never have been captivated by nor even paid any attention at all to that sort of inferior Black art. But the White has: and it is very unreasonable of him still to deny social equality to the Negro: about that there is no question at all, under the circumstances. $^{779}$

In Paleface, as in many other books, Lewis frequently mixes what he considers would be good for art in general with what would be good for humanity. Lewis is all in favour of granting equality to Black people, he just does not see why this should mean that their art, in this case jazz, should be granted equal recognition as well. Or why jazz would serve as an indicator of Black prowess. Apart from the fact that Lewis personally does not like jazz, his more significant point of critique is that white people have turned away from superior arts to cultivate and cherish jazz, which could only be due to blind exoticism. The interval in The Childermass implies that Black and Jewish people destroy white culture (Mozart) with white people enjoying the process (the Bailiffites and Pullman start to dance) instead of intervening. The grouping together of Jews and Blacks in this jazz scene might have its origin in the popular movie The Jazz Singer, which appeared in 1927, and tells the story of the Jewish Jakie Rabinovitz who becomes a professional jazz singer, blackface and all. While the movie revolves around the conflict of traditions (which it in the end resolves), The Childermass groups both Blacks and Jews together in their status of threatening outsiders. In case the language of the episode does not clearly enough convey a negative attitude towards jazz, it will be Alectryon's task to reinforce this notion:

Bailiff. 'Your sect condemns jazz?' 
Alectryon. 'To that ice-cream tomtom of the savage New-Rich, that is our post-war Magnate-Plebs, who have adopted jazz as their folk-music, we are indifferent.'

Bailiff. 'You are indifferent to the ice-cream tomtom of the savage New-Rich you are off-hand with their folk music?'

Alectryon. 'Not I-that sugared savagery for the salon makes me sea-sick my stomach is delicate. That's my private reaction. ${ }^{780}$

Before delving into the politics of this scene, a look at the tone reveals another ideological element in The Childermass. Part of the political debate takes place in humorous dialogue bordering on the absurd, which helps to hide the ideological element of the novel. Just as the Bailiff masks his true ideology in show, the novel hides its politics in a performance of humour. Now looking at what is being said, again it is noteworthy that Alectryon first targets the white listeners of jazz. Moreover, one can assume that the Hyperideans' indifference to this 'post-war Magnate-Plebs' is similar to their indifference to homosexuality: indifferent here thus means they are not morally outraged. Yet again as with homosexuality, the adoption of jazz by white people, is problematic in terms of politics. Interestingly Alectryon's admission that jazz makes his delicate stomach sea-sick seems not to betray a lack of vigour but on the contrary emphasises his masculinity by stressing a physical incompatibility between him and the sugary, i.e. effeminate, jazz. The critique of jazz shows quite clearly that while the target of the attack are white people who mindlessly adopt the style (or simply like the music), the blow also hits the Black people who are responsible for this supposedly inferior art that threatens Western, i.e. white, artistic integrity. This notion finds its ignoble climax in yet another scene in the novel. As Wagner summarises:

At the bottom of it is Lewis' belief, so far from that of Anderson or Lawrence, that it is senseless to encourage Negro aspiration since the Negro has no cultural reserves in the true sense, and is simply infecting the world with lowered standards. Jazz is taken as symbolic of these and Lewis' dislike of Negro jazz, so popular of course in European café society of the twenties, is epitomized in the nigger-heaven episode of The Childermass. ${ }^{781}$

The episode Wagner mentions is so crudely racist that it is difficult to understand from today's perspective that its primary target were writers like Lawrence, Anderson, and Van Vechten, whose book title Nigger Heaven crops up as a phrase in the Bailiff's speech. The whole episode is too long to be quoted here in full, but an extract will give the unacquainted reader an idea of the style:

Bailiff. 'Aaaaah!'

Appellants in Chorus. 'Aaaaah!' 
Bailiff. 'Aaaaah!'

Appellants in Chorus. 'Haaahaahaaaah!'

Bailiff. 'Ole black clam—see de roof? it's all baby-nigger.'

'All his roof is negro baby!'

Appellants in Chorus. \{ 'Oh how exciting! he's after all Afro, who'd have thought it!'

'Our black baby!'

Bailiff. 'Yes Black Baby yes Black Baby!'

'It's too marvellous he's Black! We thought he was White.'

'It's too marvellous he's not after all Blank!'

Appellants in Chorus. \{ 'He's not a dirty White as we have been

led to suppose not a Blank which is too marvellous!'

'Oh our Bailiff's black inside him only

his outside's dirty Paleface.'

'Hail Black Bailiff! We are lucky we are lucky!'

Bailiff. 'With rabbit-palate see to rattle—rattle-snake for pretty baby!'

He seizes his unruly member.

Bailiff. 'Tongue he too fat and forty for de White palaver.'

Bailiff. 'Nigger-heaven hell what's zat but ze ganz same ding als babywallow! Am I right aaam I right? Am I up to slum? Nexpleece!! ${ }^{172}$

There is little need to point out that Lewis here used blatantly clichéd, not to say racist, idiom to represent AAVE. Although the crude language use is the first thing to strike the reader, the main focus of this passage is a different one. The Bailiff mimicries AAVE to sway his followers into frenzied support. His admiring followers become stand-ins for the white intellectual middle class that, in Lewis's eyes, became infatuated with the supposedly exotic, to which everything connected with Black Americans belonged. As the passage insinuates, admiration for one thing, in this instance Black culture automatically entails the devaluation of its opposite, here White culture. This is exactly the argument Lewis makes in Paleface. While in Paleface Lewis explicitly spells out the, for him undoubtedly terrifying consequences, i.e. the doom of the white race, The Childermass offers this reading only between the lines. However, the cheap theatricality of the scene and the ridiculous dialogue offer no other reading than that all this spectacle is a huge farce and as a whole markedly inferior to the reasoned discussion the Bailiff later holds with Hyperides and Alectryon. Also the Bailiff's half-cryptic statement that '[n]igger-heaven 
hell what's zat but ze ganz same ding als baby-wallow' suggests that AAVE is equated with baby language, which follows the familiar primitivist notion to see Black people as less developed. In accordance with Lewis's arguments in The Art of Being Ruled this also means that Black people firmly belong to the category of the ruled. What makes the matter even more complex is that the Bailiff is not actually depicted as a Black person, but only assumes the role of a Black orator because he knows that it pleases his audience. What one can read into this scene is the double standard present in society that celebrates white people adopting Black culture, while Black people are made to suffer negative consequences for it. This might constitute an astute observation on Lewis's part, yet the fact that this is embedded in a racist context suggests otherwise: the problem is not this double standard, but white people's willingness to adopt Black culture to gain recognition, while neglecting 'white culture'. Again the Bailiff is a great manipulator, who does not necessarily subscribe to the maxims he preaches.

Another instance that proves this latter point is the Bailiff's entourage that mainly consist of people of colour, which is brought up repeatedly throughout the novel. He employs 'barefooted Nubian carriers', a 'negro wields a winnowing fan', his two main bodyguards Mannaei and Jackie are 'dark giant[s]', and the rest of his staff is usually described as 'heiducks and black'. ${ }^{783}$ In the course of the novel Mannaei and Jackie will each kill one of the appellants in order to defend the Bailiff. In each case the Bailiff acts shocked and horrified at the extent of violence, calling his bodyguards brutes and beasts, although he seems to silently approve of their deeds, as neither of his bodyguards faces any consequences (except being sent behind the stage). This division of labour is an important part of the political spectacle as it allows the Bailiff to enforce strict rule while presenting himself as a kind and charitable ruler. This acts out Lewis's main charge at democratic rule, namely that it hides its authority behind supposed charity. Moreover, the Bailiff relies on the inherent racism of the audience who are blinded by their prejudices so that they do not connect the kind white ruler with the violence his Black servants act out on his implicit demand, and who then are duly reproached for it: 'He's a real White Man isn't he the old Bailie? Those brutes get out of hand you know!'. 784 Their taking sides for the Bailiff emphasises his manipulative power as well as the hypocrisy of the audience, who were so enthralled by the Bailiff's earlier blackening-up. One could concede that the novel here rather exposes the dynamics of racism instead of employing them. In fact, it does both. Again, as with anti-Semitism, Lewis proves himself to be an astute observer of societal dynamics, yet this does not mean that The Childermass is free from racism itself. A further example to demonstrate this double-edged technique is the Bailiff's discussion with Alectryon; in the beginning the Bailiff 
rejects Alectryon because he is supposedly 'a dirty Dago', and insists on being questioned by a blond Anglo-Saxon. ${ }^{785}$ That the Bailiff, who employs a fully non-white entourage refuses to be questioned by a white person not deemed white enough supposedly shows his main betrayal against the white race. This follows the argument in Paleface, where Lewis regrets the expansionary urge of white people and prefers a white European melting-pot: '

If the White World had kept more to itself and interfered less with other people, it would have remained politically intact, and no one would have molested it: the Negro would still be squatting outside a mud-hut on the banks of the Niger: the Delaware would still be chasing the buffalo. We could have been another China. ${ }^{786}$

There is no doubt here about the greatness of white Europe. It may be this line of thinking that led Nicholas Brown, writing about Hitler, to consider Lewis's racism less a product of an unshakable belief in white superiority than a practical necessity, to preserve Europe and more importantly European unity:

Lewis's is a completely political racism, almost, paradoxically, a nonracist racism. In Hitler, European domination is neither justified by white racial superiority or by the moral liberal cultural superiority implied by Europe's "civilizing mission." Instead, "race feeling" is simply a means toward preserving European power and privilege to which they have no inherent right, but simply happen to have. "White Consciousness" is no more than a matter of Europeans" "practical [that is, economic] interests" [...]. "White Consciousness," therefore, is purely and explicitly a strategy for the defense of existing privilege, stripped of its ideological aura. ${ }^{787}$

While already the idea of a nonracist racism as well as 'privilege, stripped of its ideological aura' is absurd in itself, this argument conveniently omits that Europe, despite what Lewis and Brown may think, is not and has not been completely white. The underlying concept of Lewis's arguments on race is ethnopluralism, whose underlying premises are still racist, even if they differ from the scientific racism. Thus it does not really matter whether Alectryon is a Dago (as the Bailiff claims) or not (as he himself insists), the fact that the Bailiff reacts so violently against him, a European, makes the Bailiff, as Lewis saw it, an enemy of white solidarity and a possible warmonger. This shows again that the attack in The Childermass is primarily aimed at white people who seem to betray their fellow whites and therefore trigger inner-European war. Black people in the narrative are 'merely' means to an end. They and their culture are denigrated to objects. The Childermass illustrates that Lewis did not admonish his fellow writers for employing racial/cultural appropriation, but for employing it out of blindly primitivist motives. The Bailiff's crude appropriation of AAVE and his anti-white stance is a condemnation of a certain set 
of white people; Black people are collateral damage. Nevertheless, the damage is done.

There is another element that complicates the matter of the Bailiffs supposed hypocrisy and betrayal of the white race. It is never explicitly spelled out but there are a number of elements that mark the Bailiff as Jewish. There is a dilemma here which I fully realise: since the Bailiff is not explicitly labelled as Jewish, my reading of him as Jewish might say more about my own prejudiced reading and less about the prejudices the text imparts. ${ }^{788}$ The reason why I will nevertheless proceed is because I think that this reading fits into the greater ideological matrix of the text. Moreover, and more importantly, I am not suggesting that the text is openly anti-Semitic, but I want to argue that it exploits some common anti-Semitic prejudices in favour of its ideological argument. When the reader meets the Bailiff for the first time he is described as wearing a long caftan and sandals, attention is also drawn to his nose (the attribute 'beaked' is used here, while later he admits that his beak as well as his hunch might be unpleasing sights). ${ }^{789}$ Here The Childermass uses anti-Semitic clichés without overtly attributing them to Jews. In Malign Fiesta the caftan is brought up again, yet this time an important element was added to it: 'He was very neatly dressed in a sort of black kaftan, on his left breast a star'. ${ }^{790}$ The matter of the Bailiff's Jewishness is not addressed any further, yet the Judenstern, or yellow badge, should have gained enough notoriety by the mid-Fifties to be unambiguously understood. ${ }^{791}$ No such definite insignia can be found in The Childermass, which does not necessarily weaken the argument. On the contrary, the Bailiff's unmarked Jewish identity goes very well together with his general shape-shifting. ${ }^{792}$ For example, there is disagreement whether the Bailiff is white or black, and every time he transforms himself there is someone in the audience to proclaim that this is his true identity. This fits very neatly to what Julius has described as Jews being 'taxonomically slippery':

The black/white binarism was easy enough. Everything that was good, and beautiful, and true, could be assigned to the right side, and everything that was vicious, and ugly, and false, could be assigned to the left side. But what of the Jews? Were they black or white? [...] Jews were taxonomically slippery. They eluded classification, and in the very perplexity they caused - the sense that they could not quite be categorized, that they were beyond or behind the ordinary frames of reference by which the world was to be understood - they began to be regarded as a threat. Who are they? ? $^{793}$

The Bailiff seems to traverse the boundary between black and white: he mainly associates with Black people, yet he profits from the prejudices brought against them, as described above. In this light his initial refusal to debate Alectryon brings up yet another point: the discourse this scene alludes to 
might be the issue of the (supposed) unwillingness of Jews to assimilate and identify themselves with their home countries, a matter that was widely discussed in Britain and plays a central role in British anti-Semitism. The Bailiff, who seems fully assimilated and hence not clearly identifiable as Jewish, does not offer reciprocal recognition: he does not identify himself with the white race. ${ }^{794}$

There are other important elements to hint at the Bailiff's possible Jewishness. In one of the many disputes with the Hyperideans the Bailiff is accused of driving 'back mankind into the protozoic slime'. ${ }^{795}$ This phrase seems too specific to be just a coincidental reference to Eliot's 'Burbank' poem in which Bleistein's eye 'stares from the protozoic slime'. ${ }^{796}$ The Childermass repeats the prejudice inherent in this phrase, namely that Jews exist on a lower rung of civilisation, and that his intention is to drag the rest of mankind with him. This is achieved by attacking the (white) male, as Hyperides suggests: 'The male principle is scarcely your favourite principle where the human herd is concerned! ${ }^{797}$ Alectryon later repeats this argument as one of his central charges against the Bailiff. What is implied is yet another anti-Semitic prejudice, namely the attribution of the feminine with Jews. In Hitler Lewis, in his very idiosyncratic manner, criticises the Nazis' obsession with Jews with the following words:

'For better or for worse', in the words of the English marriage service, there is the Jew! Feminine, and in many ways very unpleasant—all people have their bad sides-yet some modus vivendi has to be found; and as a 'middleman' of uncanny penetration, may he not even have an important function? ? $^{798}$

As Andrea Loewenstein has aptly noted '[i]n Hitler, as in the subsequent books in which Jews played a prominent role, Lewis envisions only male Jews. To him a Jew was, by definition, a man who, like the invert, straddled the line between masculinity and femininity. Female Jews, who could not be fit into this formula, did not exist in his assumptive universe'. ${ }^{799}$ This observation also fits The Childermass and especially the Bailiff. The connection Loewenstein draws between the invert and the Jew can be found in the relationship between the Bailiff and his followers, who as we have seen are all gay. That this predominance of feminised male Jews with an almost complete absence of female Jews is also characteristic of Nazi propaganda shows that this was a particularly widespread stereotype that seemed to be validated simply by its ubiquity. When Lewis visited Berlin in the Thirties he criticised the Nazis' obsessive anti-Semitism, but his counter-argument makes likewise use of antiSemitism. The same also holds true for Lewis's reviewers when Hitler was finally published in Britain. There was no éclat upon its publication, on the contrary: 
the Times Literary Supplement not only described the book as brilliant and persuasive, but also praised Lewis's treatment of and attitude toward Jews in it - an attitude that the reviewer clearly shared.

Mr. Lewis gets on to firmer ground... when he expounds upon the real character of Hitlerite anti-Semitism. He reminds the British public that "the vulgar Jew of the British caricaturist is largely a reality in Central Europe...Jews dominate German life....he [Hitler] logically wants to eliminate them."

None of the other reviews mentioned his attitude toward Jews. Just as Hitler's own openly proclaimed anti-Semitism had not made him unpopular with the English people in 1930, Lewis's support of that stance was not even considered worth mentioning by his reviewers in that year. ${ }^{800}$

Moreover, with the Bailiff as Jewish his attachment to liberal democracy employs yet another stereotype current at that time, infamously made prominent by the Protocols. In the latter text the presumed Jewish Elders exchange nuggets of advice to gain world power such as these: 'To secure this we must have everybody vote without distinction of classes and qualifications, in order to establish an absolute majority, which cannot be got from the educated propertied classes' or:

Far back in ancient time we were the first to cry among the masses of the people the words "Liberty, Equality, Fraternity," words many times repeated since those days by stupid poll-parrots who from all sides round flew down upon these baits and with them carried away the well-being of the world, true freedom of the individual, formerly so well guarded against the pressure of the mob. ${ }^{801}$

The Childermass repeats these ideas that liberal democracy is the product of a Jewish conspiracy, with the change that it emphasises the agency of homosexuals, non-white people, and those white people who prefer the exotic to the familiar (white) all united against the 'real white male' in this conspiracy. This joint attack highlights the isolation and almost hopeless situation of the white male, a position represented by Alectryon and other Hyperideans in the debate. The novel suggests the supposedly natural superiority of men like Alectryon, and at the same time shows how these men are hopelessly locked in the absurd political performance. The reactions from the audience, Pullman and Satters among them, ${ }^{802}$ indicate that they enjoy politics only for the sake of performance. The Bailiff as the entertainer of the masses, the proverbial puppet-master, takes up the idea of the Jews pulling the strings of the democratic power play. The Bailiff imposes his will onto the people under the pretence of serving the will of the people. The ambiguity of the Bailiff's function and official position feed into this paranoia about who is actually in power. Is he in charge or is he merely following orders? His general hypocrisy suggests the former rather than the latter. Along with his protean qualities 
and his two-facedness, the figure of the Bailiff recycles a number of elements of anti-Semitic discourses without explicitly marking them as Jewish. By associating him with the feminine, with homosexuals and the racial other, the text nevertheless inscribes itself into the discourse of the white male being under threat by these forces. Having the Bailiff admit towards the end of the debate that he actually abhors humankind in general, mirrors the above quote from The Protocols that the political movements the Bailiff pretends to support are, in fact, to the detriment of all human beings.

The best way to describe The Childermass in the context of race and antiSemitism is that it is casually racist and anti-Semitic. Neither people of colour nor Jews are the main targets of the novel's attack; they merely constitute collateral damage. The novel's use of AAVE heaps scorn on those white people who are misguided in their blind exoticism to favour people of colour over their white peers. However this condemnation only works on the assumption that loyalty to your own race should be the preferred option and that anything else is not only a sign of stupidity but also betrayal. Here the attack on advocates of exoticism fits neatly into the novel's greater ideological matrix that sets white solidarity as a standard that needs to be defended. While the novel explicitly satirizes the white audience's infatuation with Black culture, the satire only works by implying the inferiority of Black culture. Likewise, the coloured personnel of the Bailiff represent the medieval and atavistic aspect of the Bailiff's rule, an idea that the audience, Pullman included, takes up immediately. In this way The Childermass exposes and utilises the structural racism in society for its dramatic purpose. Similar strategies can be observed with regard to anti-Semitism. While there are no explicit attacks on Jews, the implicit recourse to anti-Semitic prejudices was surely not lost on contemporary readers of Lewis. The Childermass uses conventional anti-Semitic clichés implying that liberal democracy was not only in itself a problematic development but that it was also driven by and only benefitted certain 'outsider' groups. Both racist and anti-Semitic stereotypes, especially those that suggest an exaggerated influence of either non-whites or Jews purposely feed into the depiction of the 'white male' as victim, an obvious reversal of the existing power dynamics. I called the use of these elements casually, not to make light of the offence and prejudice the text thus creates, but because Lewis lifted them out of the public domain without making any crucial alterations. The text uses these clichés but it does not transform them. When Julius speaks of anti-Semitism as an easy trope this seems to be exactly the case here. Racism and antiSemitism as tropes found their way into The Childermass not because they are absolutely needed for the argument, but because they are an effortless way to reinforce the main pillars of the ideological matrix of the novel. There is no denying that Lewis's writings on race and anti-Semitism are complex and not 
simplistic linear arguments. However, all his writings including his critiques of anti-Semitism and exoticism, finally serve to propagate his own brand of right-wing ideology.

\section{'Oh! I am not progressive'}

The final section of this chapter will trace the dynamics of the ideological matrix throughout Monstre Gai and Malign Fiesta. It will show that instead of an ideological turnaround, the ideological matrix built up in The Childermass will be tweaked, slightly altered and revised in the sequels but never fully repudiated. The character of Pullman will be the guiding figure through this section as he embodies the central crisis: when the intellectual willingly collaborates with the state is he then part of the rulers or the ruled? Written almost three decades later, Monstre Gai and Malign Fiesta seem to differ considerably from The Childermass. In Monstre Gai Pullman and Satters have gained admission to Third City. Both find it difficult to settle in. While Satters joins a gang, Pullman finally collaborates with the Bailiff in exchange for a privileged lifestyle. The novel ends in a (much shorter) political spectacle, which escalates into revolution and compels the Bailiff to flee, taking Pullman and Satters with him. In the third novel, Malign Fiesta, readers meet Pullman, Satters, and the Bailiff in hell. The plot follows a similar dynamic as Monstre Gai. Pullman and Satters are trying to find their place in this new world, and Pullman eventually collaborates with the 'head of state', the devil himself. This collaboration elicits an ever-growing internal conflict within Pullman and leads to his eventual breakdown. He is, however, rescued by angels and brought to heaven, where the fourth novel would have been set. In both sequels readers follow Pullman's development, who has developed into a sentient character. Although he still collaborates with the system in power his motivations and internal conflicts are made transparent. In contrast to The Childermass the two sequels offer straightforward narratives eschewing the obscurity of the first novel with its dense language and its unfathomable characters. They are biting satires, but they lack the radical form of The Childermass. ${ }^{803}$ This is maybe not surprising as they sprang from the pen of a much older more mature Lewis, who watched from his dismal exile in Canada the political alternative he had favoured in the hope that it would prevent another war in the Thirties do the exact opposite. After the war the atrocities of the Holocaust became widely known and he resettled from Canada to the British post-war welfare state, where he benefitted from a late cultural recognition. While in The Art of Being Ruled Lewis had envisioned that only in an authoritarian, possibly fascist, gov- 
ernment artists would be granted official state recognition, it was in the democratic post-war Britain that Lewis received a form of patronage when the BBC paid him to work on the two sequels. ${ }^{804}$ All these factors had a visible impact on the continuation of the trilogy. However, it would be too rash to see a complete ideological change between The Childermass and its sequels, as observed by Munton. ${ }^{805}$ Despite all the changes the ideological schism between part one and the rest is not clear-cut: while some shifts take place, some old sentiments still linger on.

The major change between the Pullman of The Childermass and the Pullman of the later novels can be summed up in a few words: in Lewis's terms, he turns from a puppet into a nature. This is a significant shift: it suddenly makes Pullman a character to identify with as he becomes someone to act upon his own motives. Moreover, and more importantly, Pullman becomes a subject that critically analyses the given political situation instead of parroting the ideology of the rulers. Where The Childermass saw him as the self-defeating intellectual who willingly aligned himself with the dominant ideology, the sequels give witness to a character who is caught in but also sees through the power dynamics of the ruling ideology and its leaders. However, this difference diminishes when Pullman again collaborates with the respective rulers of the cities he inhabits. As Daniel Schenker has pointed out, the critical flaw in Lewis's ideas of the natural superiority of the intellectuals is that 'stupidity should be no match for intelligence under any circumstances', which Lewis resolves by putting the blame on the intellectuals themselves:

since genius could not be defeated by numbers, genius must have defeated itself. In The Childermass, we see the highly intelligent Pullman, the greatest writer on earth, applaud the alternately tyrannic and demagogic acts of a nameless functionary, acts that undermine the position of thoughtful men like himself... ${ }^{806}$

What Monstre Gai and Malign Fiesta acknowledge is that the intellectual's choice between collaboration and resistance is severely skewed in favour of the former; and once collaboration is offered it is difficult to retreat. This sympathy towards the 'treason of the intellectuals' is wholly absent from The Childermass and only comes up with Monstre Gai, which adds considerable depth and self-critical introspection. In The Childermass Pullman subserviently follows the governing Bailiff in order to be left in peace - and readers are supposed to duly criticise him for this choice, for the sole fact that it is the wrong ruler he chose to follow. In Monstre Gai and Malign Fiesta the same process is repeated twice: Pullman first collaborates with the Bailiff and later with Sammael. In both instances he is soon overcome by scruples but has to realise that he traded privileges for personal autonomy. It also becomes clear that his arrangement and later collaboration with the rulers happens less out of 
political conviction but for a host of reasons, some extrinsic some intrinsic. The novels present us with the understanding that just because a ruling government offers appreciation, patronage, and a safe place for the intellectual to work does not make it a good government. This is a clear break with Lewis's argument from the twenties, especially The Art of Being Ruled, that an effective government that also appreciates intellectuals (especially artists, liberating them from the clutches of capitalism) is ultimately a good government, and that this government is most likely authoritarian. However, this turn from his earlier flirtation with fascism does not shift the ideological matrix in The $\mathrm{Hu}$ man Age to the left, it only seems to deepen the schism between the artist and politics in general.

Something similar can be observed in the field of gender dynamics: throughout the Human Age, the role of gender and sexuality remain relatively stable in the ideological matrix and continuously serve the right-wing dynamic. After their absence from The Childermass, female characters now enter the scene in the sequels. Yet they remain marginalised and exploited. In Monstre Gai women do not populate Third City but instead live in and rule a neighbouring city, with catastrophic consequences:

"It [The Yenery, the place where all the women live] is filthy!" exclaimed the P.P. [Police President] "It is disgusting. All the sanitary services are in the hands of women. No men are allowed inside on whatever excuse, except myself. Just as all the dustmen are women, so women are responsible for the Police Force. Women surgeons only are found in the hospitals, and the sewage system is female. None of these services are efficiently run. There is a complicating factor. A good deal of the money the women receive from the State is spent in purchasing bootleg whisky. [...] The last time I visited the Yenery, crowds of women followed me about, even stoning my car, vilifying the male sex. It was very uncomfortable indeed. ${ }^{807}$

The Yenery is a self-governed ghetto, so it seems. ${ }^{808}$ The women are presented as both incapable and inferior, yet they are threatening 'the male' and thereby male hegemony. This is reminiscent of Eliot's Sweeney poems that employed the same paradox of the degraded inferior 'other' who poses a strangely fascinating and powerful threat to established society. When Pullman meets the female officer, who like Eliot's lower classes and Pound's Jews is marked by ungrammatical non-standard English, he feels 'violently attracted by her'. 809 The same dynamic is continued in Malign Fiesta. While women now populate the same world/city as men, they remain puppets. In contrast to The Childermass and Monstre Gai, where women had been superfluous or at best a nuisance, they now become instrumental in the re-establishment of the human age. However, they are only allowed to serve sexual and procreational purposes; the relation to the male regulates their function. The woman as lov- 
er, wife, mother or sex-object re-establishes a male-based power dynamic in obvious opposition to the feminism which Lewis already attacked in The Art of Being Ruled. This supposed appreciation of women that hides a deeper misogyny is illustrated by a perverse scene in which Sammael takes Pullman on a ride in his car where a young naked woman lies tied and drugged only to be later raped and dismembered by demons. Sammael, whose clear dislike of women is mirrored in this scene, had invited Pullman in order to test his loyalty. Now Pullman is obviously revolted by the whole act, yet his revulsion is channelled into an internal moral conflict, where suddenly his relation to the deed becomes a mirror of his own moral righteousness. The women and the violence done to them serve as vehicles for the male character's moral development, a conventional sexist trope ${ }^{810}$ How little women actually matter (as subjects) to Pullman becomes apparent in a later scene: when Sammael kills and discards the brides that where assigned to him, Pullman considers this merely an organisational nuisance. Even though Malign Fiesta ends with Pullman's breakdown triggered by his moral dilemma, and his subsequent remorse and final abduction by the angels, his internal turmoil remains unconvincing. Pullman is too preoccupied with his miserable ego, to feel any sympathy or compassion for others. Put differently, Pullman is vexed by his allegiance with Sammael not because he thereby supported a system that has brought misery upon others, but because it has brought misery upon himself. This seems to be the dilemma of the intellectual, as Lewis perceived it. Pullman realises that even when intellectuals collaborate with the rulers, in some aspects they will always remain part of the ruled.

Yet while women at least can become an object of pity and selfremorse, the portrayal of homosexuals remains unchanged throughout The Human Age. They offer comic relief and support the overall right-wing ideological matrix of the books. In The Childermass almost all of the appellants were gay so it is no surprise that Third City is almost exclusively populated by homosexuals. While there was a sense of bewilderment among critics as to who was actually gay in The Childermass, Monstre Gai is a lot more obvious. It employs a set of tired clichés combining them into the stereotype of the physically and mentally weak, vegetarian, car-eschewing, liberal homosexual who spend most of their time in coffee houses or shopping. ${ }^{811}$ Again there is no need for women as gay men take over the role of the feminine. This also includes sexual interactions, as Pullman realises when - to his horror - a man asks him for sex:

I have been here a long, long time, and I confess... I have those feelings. I also experience love...oh yes, far more truly than I could in the generally accepted way." Pullman noticed that the other's voice was becoming slightly 
thick and guttural. "My master... how ingenious, how delightful it would be if we found ourselves in bed together. I would pretend I am a little girl" ${ }^{812}$

Pullman is disgusted, yet curiously the disgust of the sexual advance of the male is translated into disgust of female sexuality:

Just because I have not got... oh fou-ee!...a great apparatus teeming with germs, chock full of dangers... of which a somewhat milder form of leprosy is not the worst-just because I have not got the famous female stink, you scorn my proposal!" [...]

Pullman continued to stare at this performance-hostilely however.

"Can you find nothing disgusting to do," he jeered, "to provide yourself with the authentic female whiff?" ${ }^{813}$

Here the text makes obvious how its rejection of homosexuality is tied to the rejection of the feminine. The text here inscribes itself into the long-standing literary tradition of associating the feminine with the disgusting, a dynamic that I also observed in Eliot's poems. The scene equates the polluted body with polluting, i.e. supposedly morally transgressive, behaviour. I discussed earlier that disgust can be read as a signifier for a right-wing structure as it serves as 'an assertion of a claim to superiority that at the same time recognizes the vulnerability of that superiority to the defiling powers of the low' ${ }^{814}$ As in The Childermass there is a clear binary separating the male, i.e. the 'real heterosexual' man, from the female, i.e. women and feminised men. That Third City is almost fully inhabited by gay men makes an obvious ideological statement: it equates gay men, i.e. the female, with crowds (see Le Bon) and democracy. The male, on the other hand, represents the lone individual whose determination to stand above the crowd makes him an outsider and therefore makes him vulnerable, as Pullman, shortly after the incident, ponders: "If I kick a man out for 'making proposals' of the most normal kind, Oh! I am not 'progressive'. I shall find myself shown the door-or at least be reproved for my bourgeois tastes". .815 This is the conventional shift one often finds in the right-wing ideological matrix, namely the idea that the white heterosexual male is under threat of being made, in the first step, deviant and disempowered in a second. Monstre Gai manages to portray this world-view in some way successfully by creating a double-fictional setting (by virtue of being a fictional non-earthly setting), which allows for a reversal of power dynamics. One has to bear in mind that when Monstre Gai was written homosexuality was still a criminal offence in Britain threatening homosexual men with prison sentences and forced sterilisation. The ideology underlying Monstre Gai picks up and justifies the homophobic panic that also produced the anti-homosexuality laws; in this way the ideological matrix produces an inherent logic. Of course, the homophobia of Monstre Gai only works with Pullman 
as the polar opposite in this binary. Thus Pullman, whose gendered ambiguity in The Childermass led critic Geoffrey Wagner to infer that he and Satters were homosexuals, in Monstre Gai has to be 'outed' as a heterosexual, which is mainly done by showing his homophobia, his disgust at homosexuals and homosexuality. ${ }^{816}$ Furthermore Pullman's view is shown to be in accordance with the ideological point of view of the overall text: Consider the following scene when Pullman, after disaster has struck Third City, strolls through the streets:

It was not the time for the bearded stranger [i.e. Pullman] to come prowling around, note-book in pocket; but he did draw out the scribbling pad he always took with him, and jotted down a few observations regarding the disconsolate pansy, weeping in front of the enormous photograph [of a naked gay couple] - a piece of gigantic intimacy, even the mole above the left nipple was there, and many other little things which the poor weeping pervert knew so well. ${ }^{817}$

The heterodiegetic narrative's voice makes it abundantly clear that Pullman is participating in an act of trespassing where moral decency is concerned. However, the narrative not only joins Pullman in his voyeurism but it does so using a language that shows that it also views the grieving man as an object of derision. The text is motivated by the same impulse as Pullman: curiosity not empathy. Pullman's lack of empathy is explicitly called out by the text, while its use of derogatives such as 'pansy' and 'pervert' bring to attention the narrative's own ideological position. In contrast to The Childermass the two sequels are asking readers to show empathy - but only for Pullman's moral dilemmas. In this way they correspond to Lewis's earlier writings, such as The Art of Being Ruled, that focussed on the plights of intellectuals and artists but were happy to overlook humanity at large. Paired with an inversion of power dynamics that is presented as a (predestined) dystopia, ${ }^{818}$ Monstre Gai continues to rely on the right-wing ideological matrix that informed The Childermass.

As with The Childermass, Monstre Gai (and to a lesser extent Malign Fiesta) are informed by very earthy political debates. There is an on-going meditation on which politics Pullman should favour, either as an individual or, more strategically, as an intellectual. His thoughts on the subject, now quoted at length, seem to contradict my initial statement that the sequels are built on the basis of a right-wing matrix:

He was not for the Right wing, he was for the Left wing, there was nothing to influence him in one direction rather than the other. But about one thing there was no question whatever: for a writer of his experimental sort it was to the Left wing that he must look, for sympathy, interest, and patronage. It had been like that in his earthly life: and in his unearthly life it was apparently just the same, only more so. As unattached as the "lone wolf" man, of the 
fierce modern "genius" type, believing not in God, in class, in party, but solely in himself, it was all one to him who it was supporting Pullman; anyone who did so was a good man. [...] He possessed prejudices, distinct from the official Pullman. In the present case, to go no farther, the Bailiff was not his favourite type of man. He did not like square-nosed men, for instance. An ethnic, ancestral self was responsible for that. But that merely ethnic self was not indulged. The interests of a literary god, James Pullman by name, were paramount. And most of his real prejudices were alien to all the philosophic attitudes of the Bailiff. Nevertheless, all his career-life he had been supported by persons identical with the Bailiff, and he had always lived with, been buzzed around and been rubbed against by, ideas which were the Bailiff's ideas (and many of them were his own, contradicting mere prejudice); so his present supernatural life was preordained. ${ }^{819}$

Pullman is drawn to the Left, but merely for strategic reasons. As he makes clear, his private self possesses prejudices and is opposed to the Bailiffs philosophical attitudes as well as to the Bailiff himself. His prejudice against 'square-nosed' people, a thinly veiled term for Jew, suggests Pullman antiSemitism. Yet what matters to Pullman is to attach himself to the faction that would offer support and patronage to him. As the quote shows, here he is absolutely indiscriminate, bestowing favourable judgement on any one irrespective of their political affiliation. In a way this mirrors The Art of Being Ruled as Lewis's study argued for the importance of a system that would prove most beneficial to artists. In the twenties, Lewis claimed that it would be authoritarian systems like fascism and 'sovietism' that would offer artists a safe environment to work as well as the necessary appreciation for their artistic output. Lewis was further convinced that no true artist could ever be in favour of democracy, as the system was particularly hostile to artistic creation. In Monstre Gai the intellectual Pullman entertains an entirely opportunistic stance. At the same time he has to acknowledge that despite personal differences it is the Left to whom 'he must look, for sympathy, interest, and patronage'. How much this clashes with the ideological stance of the private Pullman becomes apparent throughout the book when he is not absorbed by strategic musings. He abhors Third City for its basic income model, its stateimposed vegetarianism, car-bans, and its population of supposedly homosexual imbeciles. His disgust for homosexuals (an attitude he identifies as not 'progressive', the use of quotation marks further highlighting the disdain) and his behaviour towards women identify him as homophobic and sexist. When Pullman is under the Bailiffs patronage he even goes so far as to fear that he would become 'a traitor to the white race'. ${ }^{820} \mathrm{He}$ also explicitly criticised the Bailiff's left-wing policies twenty pages earlier: 'Pullman] knew there would be no wings in a Bailiff-world except left-wings: in the view of the "good old 
Bailey", he was sure, the sparrow parasitically infested the air-of no food value, and inclined to give elderly persons of the female sex something to live for!'. 821 The association of the sparrow with left-wing policies is indicative of Pullman's anti-left-wing stance: the lack of food value of the sparrow mirrors the vegetarian and unmanly inhabitants, its link to elderly females bestows on both the attribute of uselessness for a society. Moreover, it is by association also linked to the perceived imbecility of the inhabitants (consider: sparrowbrained). Pullman can be firmly situated on the Right. Moreover the text itself mirrors many of Pullman's prejudices, testifying to its inherent right-wing structure.

These observations do not contradict the political debate occurring at the end of book, in which Pullman is drawn to none of the four candidates. He muses:

So this enfeebled Power of Tradition [Catholicism], and its deadly enemy, the Marxist Power, joined forces to destroy this violent Middleman (a borrower from both the new and the old) [Fascism]. These earthly alliances were repeated undoubtedly here, Pullman reflected. The other Power which could be seen defending itself in this market-place, the Piazza, was gangster-wealth at its most irresponsible, presented by the Bailiff. ${ }^{822}$

While Pullman remains undecided, the text shows some tendencies. At its most obvious, the position of the Bailiff is fully marked as negative, which was also the position labelled as 'left-wing'. This is shortly afterwards confirmed by the Bailiff's ruthless killing of Hyperides, turning the Bailiff into the gay monster of the title. The Marxist Vogel, 'a rough-looking individual with the blood-shot eyes of a man whose only diet was Marx and cabbage', ${ }^{823}$ is the star of the crowd, which in Third City, of course, means to be the star of a large crowd of imbeciles, echoing Le Bon's argument on the inferiority of the crowd. Moreover, his name links him back to Pullman's remark about sparrows. Consequently Pullman loses interest in Vogel rather rapidly. The remaining two are pitched against each other, although, as father Ryan admits, they have a significant overlap. The Catholic Church has become, as Pullman suggests, the enfeebled Power of Tradition, which might be one of the reason why its members have flocked to the Fascists. ${ }^{824}$ However, the text devotes a lot of space to father Ryan's contribution in which he analyses and deconstructs fascism. This impresses Pullman, who resumes that Hyperideanism/Fascism

had a considerable superficial air of being on the right side; but, as Father Ryan said, when carefully examined its rightness merely consisted in barking at something which was worse than something else; that was all, but it left you in a chaos, and was a deceptive Rightness. ${ }^{825}$ 
Of course, 'right' here draws on its double meaning of correct and on the Right. This might, at first glance, seem as a turn away from the Right, but that reading does not hold true on closer inspection. The Hyperideans are not wrong for being on the Right; they are wrong for pretending to be on the Right, when they actually violate some of its dearest principles: order and tradition. This is father Ryan's central argument: the fascists cannot produce lasting values because they are moralists without a cause, destructive and pagan. This claim comes suspiciously close to Eliot's line of reasoning concerning fascism and so there is a sense that the political positions present in the debate are those of Lewis's close contemporaries. This does not mean one should read Pullman as Lewis, but more generally as the intellectual trapped in the political arena, puzzled as to which position s/he should take up. As Monstre Gai makes clear this political arena is not a level playing field and any decision may have unforeseeable consequences for the intellectual. The Bailiff, the least liked by Pullman, wields the most power and thus has to be courted or else Pullman might pay dearly. This is exemplified by the murder of Hyperides: he is not only killed but symbolically crucified with a nail driven into his throat and wearing a dunce cap. It is not the person Hyperides that was the target of this deed, but the rival intellectual and public orator: his speech is symbolically cut and his words are posthumously labelled foolish. The obvious similarities to Pound, who was then still inhabiting a room in a home for the criminally insane, might further explain the poignancy of the scene. The intellectual inhabits a vulnerable position in society and choosing a political position might make him/her even more vulnerable. Yet courting the ruler/ruling system in power is equally dangerous, as Pullman is going to notice shortly, and any political change might make the intellectual's position more precarious. Pullman's development from the Bailiff's puppet in The Childermass to a self-reflected nature in the sequels, who consciously accepts the Bailiff's patronage shows that awareness and self-determination do not automatically lead to liberty. In Lewis's writings of the twenties the intellectual, specifically the artist, was almost on par with the ruler: 'The good ruler, like the good artist, can be recognized at once by the inflexible discomfort of his life; isolation, further, being essential'. ${ }^{826}$ Ruling is, or should be according to Lewis, unpleasant as only this ensures that suitable people would take up ruling. The same would hold true for intellectual work:

The system of reprisal for the odious fact of rule - or, if you like, it can be regarded as a discipline to keep the ruler up to the mark [...] - should be extended to every form of superiority or excellence, political, social, or intellectual..$^{827}$ 
The Childermass duly reproaches Pullman for his mindless cooperation with the ruling authority: he is a puppet and part of the crowd. In the sequels Pullman becomes a nature and the lone wolf independent of the mass only to realise that this has made his positions more precarious: he is now less free then the puppet automata of the general population. The good intellectual has to act like a ruler, but, so the books suggest, always remains part of the ruled. This dilemma of the intellectual is not solved by a change of the political system; the whole of The Human Age illustrate that the dilemma is indeed eternal. While The Childermass sprung from the conviction that an intellectual who arranges himself/herself with the leading government constitutes a form of betrayal, the two sequels complicate this issue by laying bare the power dynamics of the relationship between intellectual and the ruling system. Despite being natures, intellectuals remain pawns in the political power struggle, with the added detriment that they are able to understand the moral dilemma in which they have to live. Pullman's final breakdown and ascension to heaven in $M a$ lign Fiesta indicates that this problem cannot be solved by earthly politics. However, this does not suggest that the sequels abandon earlier political convictions altogether. Thus Monstre Gai and Malign Fiesta do not rock the rightwing ideological matrix established by The Childermass but they do upset the position of the intellectual in that matrix. The death-blow dealt was targeted at the hubris of the intellectual not at the underlying right-wing political matrix, which remains virtually intact. 


\section{6. 'WHICH BOOK RED PILLED YOU?' RIGHT-WING RECEPTION}

In the previous chapters I have discussed at length the inherent right-wing structures in the writings of Pound, Eliot, and Lewis. Their artistic creation is inextricably bound to their ideological allegiance. Yet while the ideology of these writers and their literature has frequently come under scrutiny, the ideology of their readers has rarely received attention. ${ }^{828}$ Shifting the focus reveals how much the ideology of readers and critics has shaped the debate on the issue of right-wing Modernism. This holds true for readers and critics across the political spectrum. Jameson, whom I discussed at length in chapter 5 , identifies Lewis's ideology as essentially anti-Marxist, a reading that is closely tied to Jameson's own Marxist position. Critics reflecting on their own ideological position is rare indeed, but doing so does not automatically beget a more insightful approach to the ideology of the authors in question. Bridson is a case in point, when he writes:

As a convinced Left-winger, I declined to read any of his purely political prose during the thirties, as I had no desire to qualify my great admiration for his creative work both as a writer and as a painter. From what I gathered as to his political alignment at the time, it seemed to me likely that any such reading might merely have had that silly result. ${ }^{829}$

While remarkably open, Bridson seems unaware that the ideological commitment of Lewis might have more dire consequences than stifling the admiration of his readers. Lewis's (transient, as Bridson suggests) right-wing ideology merely poses an inconvenience for Bridson, and he seems oblivious that it could be anything more. This highlights a problem Julius has so aptly expressed in his study on Eliot, noting that 'there is a difference between reading a text that challenges the worth of one's ideas, and one that challenges the worth of one's person'. ${ }^{830}$ As I have shown repeatedly in this study, the structural right-wing 'othering' in these texts does not merely exclude certain groups as readers, but it pitches the text against these readers. This is aggravated when the slighted readers problematize the ideological tendencies in these works and are duly reproached for it. Julius, who experienced this first hand, rightly concludes that 'the uninsulted should not be too quick to give lessons in restraint to the insulted [...]. Nor should the uninsulted claim the right to determine whether an insult has been delivered. To do so is a further insult.... 831 The critical responses to right-wing structures in literature play an 
even greater role as they shape the legacy of these texts and the ideology within. Those who are not at the receiving end of the discursive violence inherent in these Modernist texts and who apologise, belittle or ignore it are (unconsciously) complicit in, or at best oblivious of, these ideological dynamics.

While unconscious complicity among critics is a serious issue that necessitates a comprehensive analysis, this study wants to bring attention to a group that has rarely been the centre of inquiry: namely the right-wing reception of Pound, Eliot, and Lewis. Already during their lifetime, these writers attracted a right-wing readership, who felt drawn to their writings not in spite but precisely because of its inherent ideology. Parts of Eliot and Pound's early right-wing reception have already come under scrutiny. New Criticism, whose tenets evolved closely in concord with Eliot's own criticism, has repeatedly been called out for its de-ideologising approach. For Pound, Alec Marsh has recently devoted a book-length study to one of the poet's most radical rightwing readers, John Kasper. What has been missing from critical research so far is a closer look at today's right-wing reception of Pound, Eliot, and Lewis. In this last chapter I want to fill this gap by analysing the trajectory of this right-wing reception. I will demonstrate that particularly Eliot's and Pound's differing early right-wing readerships prepared the ground for today's rightwing reception. Moreover in analysing various current right-wing sources, the continued relevance of Pound, Eliot, and Lewis for today's Right will become apparent. These Modernist writers, among others, seemingly embody the dominance of the intellectual tradition of the Right and offer a good vantage point to criticise liberal hegemony. The reason why today's right-wing reception has received little to no attention has as much to do with the inadequacy of existing research on the ideology of Modernism as it does with the uncritical acceptance of the ubiquitous stereotype of the unintellectual Right, especially the far right.

Few clichés are so persistent as the one about the unintelligent and uneducated (Far) Right. It has become so ingrained in the general discourse that it is seldom challenged and when it is - in fiction ${ }^{832}$ or reality - it still generates disbelief and is usually treated as an exception to the rule. Talking about the founding of the Nouvelle Droite, right-wing intellectual Alain de Benoist reminds his interviewer that in the France of the late 1960s and early 70s 'the term "left-wing intellectual" was considered a pleonasm, the term "right-wing intellectual" an oxymoron'. ${ }^{833}$ In a more recent example Kevin MacDonald ${ }^{834}$ shares his perception of the apparent split between reality and cliché: 'I have recently met a great many young, intelligent, well-educated, and well-spoken people at conferences dedicated to activism on behalf of the interests of white America - the exact opposite of the image of uneducated, violent males sporting swastikas and missing a couple of teeth that has been so carefully 
crafted by our hostile elites'. ${ }^{835}$ While the cliché proves persistent enough there is actually little evidence to support it. On the contrary, looking into historical right-wing movements one finds a plethora of intellectual circles, thinkers and generally educated people. And this holds true, it needs to be stressed, for all areas of the right-wing spectrum. The infamous Schutastaffel had ten times as many academics amongst its leading members than the general population of Germany. ${ }^{836}$ If National Socialism has disturbingly proven a contested point it is that brutality and high culture can happily coexist within one body - both the individual body and the body politic. Curiously the NS condemnation of the figure of the intellectual, as weak, effeminate and ultimately prototypically Jewish, might have helped to engender or at least cement the stereotype of the unintellectual right-winger. However, even before National Socialism was born, Georges Sorel fiercely attacked 'the intellectual', which in his case meant the decadent bourgeois intellectual: 'The Intellectuals are not, as is so often said, men who think: they are people who have adopted the profession of thinking, and who take an aristocratic salary on account of the nobility of this profession'. ${ }^{837}$ It is telling that Wyndham Lewis, in The Art of Being Ruled, already criticised Sorel's and Edouard Berth's willingness to lump together all intellectuals as their target of attack, while being themselves intellectuals:

It is especially strange that Sorel, Berth, and the syndicalists, with their great sense of reality where the worker was concerned - every worker, that is, except the intellectual worker - should have had so little sense and instinct where they spent their time in abusing the intellectual - themselves - from morning till night. ${ }^{838}$

Lewis then surmises that it is not the intellectual, who ought to be attacked, but those forces that undermine intellectuals. ${ }^{839}$ Moreover, very much in sync with syndicalism, which Sorel also advanced, Lewis pleads for intellectuals to consider themselves as workers and thus as yet another syndicate. This matches pleas from other artists like Pound and the Futurists to give artists and their demands proper recognition in a future (possibly fascist) government. In this way, the appeal of fascism and its cousin syndicalism to artists seems to spring from their innate acknowledgement of intellectuals and artists. ${ }^{840}$ It seems an ironic twist then that the far right would end up as the faction considered most devoid of intellect and education.

The previous chapters have shown the central importance of right-wing ideology for the works of Pound, Eliot, and Lewis. Their aesthetic projects developed in harmony with their ideological world-view, not in spite of it. Now my final chapter will turn from the past to the present and explore the role of literature and the intellectual tradition in today's Right. While I explored the complexities of the concept of right-wing ideology in my theory 
chapter, I have limited my focus in this chapter to what I henceforth term the New Far Right. This choice was motivated by two considerations. Firstly, it was important to break down the Right into a more manageable subgroup with a certain internal unity; and secondly the intellectual circles of the far right have rarely come under academic scrutiny. I use the New Far Right as an umbrella term for various far right-wing movements existing at the moment that work on similar premises and strive for similar aims using similar strategies. This does not, however, mean that they necessarily actively cooperate or support each other.

\section{Who is the New Far Right?}

To make sense of the term New Far Right, it is necessary to take a closer look at the New Right. The term 'New Right' first and foremost implies either an overcoming or a split from the Old Right. What exactly this Old Right is seems to be very much dependent on the context. It is therefore not surprising that the New Right may take on different meanings whether we talk about the Nouvelle Droite in France, the New Right in Britain ${ }^{841}$ or the Neue Rechte in Germany. I shall spend some more time with the Nouvelle Droite, as it were some of their key ideas that influenced New Right movements in other countries and could be considered characteristics for the general (European) New Right. The Nouvelle Droite in France emerged from a specific group, the Groupement de recherche et d'études pour la civilisation européenne (GRECE), under the leadership of Alain de Benoist, in the 1960s. Above all, it is their concept of metapolitics that has greatly influenced new right-wing discourses and activities. Metapolitics, as used by the New Right, refers to the strategy of, in more polemical terms, la guerre culturelle, ${ }^{842}$ based on the leftwing thinker Antonio Gramsci's ideas on hegemony. Gramsci, mainly in his Prison Notebooks, expanded the concept of hegemony to include 'how seemingly private or personal aspects of daily life are politically important aspects of the operation of power'. 843 Peter Ives writes that '[i]n a nutshell, Gramsci redefined hegemony to mean the formation and organization of consent'. ${ }^{844}$ Cultural hegemony, according to Gramsci, becomes a prerequisite for gaining and maintaining political power:

A social group can, and indeed must, already exercise "leadership" [i.e. hegemony] before winning governmental power (this indeed is one of the principal conditions for the winning of such power); it subsequently becomes dominant when it exercises power, but even if it holds it firmly in its grasp, it must continue to "lead" as well. ${ }^{845}$ 
Gramsci's take on the concept of hegemony lastingly influenced discourses on the political, as Ives aptly summarises:

Politics, for [Gramsci], cannot be conceived exclusively in narrow terms of the state and government but must encompass the wide range of human activity often seen as non-political, such as our everyday beliefs and behaviour, from the books we read and the films we enjoy to our religious feelings and perceptions of the world. It is Gramsci the theorist of cultural politics who garners attention not only from progressive activists and academics on the Left but even from the unlikely quarters of the Right. For example, Rush Limbaugh, the extreme right-wing American talk show host, discusses Gramsci in relation to what has been dubbed the 'culture wars' in the United States in the 1990s. He even argues that the Right must learn Gramsci's lessons. ${ }^{846}$

When Limbaugh discussed Gramsci in 1993, the European New Right on the continent had already learnt Gramsci's lesson. The Nouvelle Droite, and following it the gros of important segments of the New Right, target the discourse more than the parliament. This is particularly significant, not only because it already hints at the role literature may play in this, but because it compels us to shift our focus away from the Right as political actors in the very narrow sense to cultural actors. Not incidentally many members of the New Right are not part of existing political parties, but seem to see themselves as stimulants, guides or political inspiration. Richard Spencer, one of the leading figures of the 'Alt Right' who also claims to have coined the term, ${ }^{847}$ described 'his' movement's relationship with the Trump administration thusly: 'it is up to the alt-right to formulate the ideas and policies to guide the new administration [...] I think we can be the ones out in front, thinking about those things he hasn't quite grasped yet'. ${ }^{848}$ And while the Trump administration could pave the way for the Alt Right to enter politics, Spencer reflected that in the past 'the Alt Right for a long time has been more cultural, you could say metapolitical. It has been more metapolitical than political because it hasn't been connected to power in a way'. ${ }^{849}$ This focus on cultural hegemony seems to me a most crucial element of the New Right.

A second crucial characteristic of the New Right is its performative dissociation from the Old Right. This works in two ways and can best be demonstrated with the examples of the North American New Right and the Alt Right. Greg Johnson, a prominent figure of the North American New Right, in an article, aptly titled 'New Right vs. Old Right', reiterates multiple times the main difference between Old and New Right: 'The North American New Right, like the European New Right, is founded on the rejection of Fascist and National Socialist party politics, totalitarianism, terrorism, imperialism, and genocide'. ${ }^{850}$ A closer look at Johnson's article helps to put these 
words into context. First of all, his definition of the Old Right reveals that Fascism and National Socialism are not rejected per se:

For our purposes, the Old Right means Fascism, National Socialism, and other national-populist movements, which are the pre-eminent attempts to restore traditional hierarchical social forms within the context of modernity. Fascism and National Socialism were not merely reactionary, rear-guard resistances to modern egalitarianism by partisans of corrupt hierarchies. They represented a genuinely revolutionary impetus to restore vital, archaic, hierarchical values within the context of modern science, technology, and mass society. ${ }^{851}$

Obviously, restoring 'traditional hierarchical social forms' is an aim that the Old and New Right share, which Johnson also plainly states in another paragraph. Moreover, when he describes Fascism and National Socialism as 'not merely reactionary, rear-guarded resistances' but 'genuinely revolutionary', it betrays an underlying appreciation for these attempts to revert 'modern egalitarianism'. Very tellingly the above statement speaks not of Fascist and NS ideology, but of movements, leaving the possibility to separate ideas and their implementation. Moreover, the focus on totalitarianism, terrorism, imperialism, and genocide also seems to target means not ends. Another paragraph proves even more revealing: 'So how does the New Right differ from Fascism and National Socialism? This is a vital question, because of the intense stigmas attached to these movements since the Second World War. ${ }^{\prime} 852$ The main motivation for the split here seems to be an attempt to free oneself of stigma. The foundation of the (North American) New Right thus would be a strategic move. In this way, it resembles the Alt Right. According to Spencer, explaining in a video titled 'What is the Alt Right?', the Alt Right moniker came into existence out of a need to dissociate themselves from the Old Right, who in this context are the Conservative Right, but before any (fully fledged) ideological content was thought out for it. Quite tellingly, in the almost 25-minute long video monologue, Spencer is busy explaining what the Alt Right is not, losing almost no words on its actual ideological content. One can assume that 'Alt Right' has mostly strategic value, which taken together with its inherent vagueness might partially explain its considerable rise in prominence and popularity. ${ }^{853}$ Both the Alt Right and the North American New Right and ultimately the European New Right share a desire to carve out a new space for themselves in the right-wing spectrum both for strategic and ideological reasons. It therefore makes sense to group them together under the term New Far Right. What is worth pointing out is that the European New Right especially in its initial phase had a strong anti-Americanism at its core, which went hand in hand with its rejection of liberalism. The fact that these two were often lumped together made them somewhat unpalatable to the American Right 
and to a lesser extent to the British Right. Jonathan Bowden, in an interview with Spencer on 'The European New Right' elaborates on that point:

And they wanted to redefine the enemy away from the traditional enemies of the old Right. And the new enemy was global liberalism powered by America. And that appeared to be a Left-wing notion until you worked out what they were really saying and, in some ways, what they were attempting to smuggle back in a new guise. ${ }^{854}$

The anti-Americanism of the European New Right (as well as the unavailability of English translations of their works for quite some time) might be partially responsible why an American version of the New Right has seemingly only been forming within the last decade.

Another key trait which ties in with the performative abandoning of Old Right values is the replacement of biologist arguments with culturalist arguments, but leaving core notions untouched. This strategy is most obvious in the concept of ethnopluralism. Often credited to be invented by Henning Eichberg, ${ }^{855}$ a once prominent thinker of the Right who later supposedly switched camps, it stands for a theory of 'right-wing multiculturalism' that appreciates (international) cultural diversity but disapproves of cultural mingling. ${ }^{856}$ Ethnopluralism views cultures or ethnic groups as set entities bound to specific geographic spaces. It couples endorsement of a country's autochthonous population with a disdain for human migration and intermingling. In contrast to conventional Old Right ideology, ethnopluralism revolves around the concept of ethno-cultural identity instead of racial genetics. This is reflected in the term 'identitarian' as self-designation, replacing other more charged (and implicitly hierarchical) terms such as white supremacist. This can best be observed with groups like the Identitarian Generation, which was founded in France but has since become a pan-European movement, especially popular in Austria and Germany. The term has also become popular among the American New Far Right, with groups such as Identity Evropa or Spencer tweeting 'Identarians like me understand and respect Jews' impulse towards Zionism and the formation of a Jewish state'; and a couple of days earlier: 'What's wrong with loving being white? I am not a supremacist, by the way. I just love my people'. ${ }^{857}$ Each Volk, according to ethnopluralism, has its distinct innate ethno-cultural identity, ${ }^{858}$ which is threatened by immigration and any forms of universalism. What exactly defines ethno-cultural identity remains vague. Although adherents of ethnopluralism would agree that ethno-cultural identity consists of cultural and social practises, values, origin, religion and general way of life, they seldom explicate what this entails in practice. Almost backhandedly ethnopluralism implies that there exists a consensus on what constitutes ethno-cultural identity for a given Volk and that it is somehow fixed. Ethnopluralism's embrace of (supra- not inner-national) cul- 
tural diversity, often expressed by the phrase 'the right to differ', ${ }^{859}$ coupled with its stylisation of being a theory of defense rather than attack is supposed to designate it as non-racist and anti-imperialist. Another concept closely tied to ethnopluralism, namely 'the great replacement' (Der große Austausch), which interprets liberal multiculturalism as part of a process that aims at substituting the autochthonous population of European countries with people from nonEuropean (read: African and Asian/Middle Eastern) countries, with the blame for immigration being attributed to the European political establishment as well as the cultural elites. ${ }^{860}$ This again is meant to emphasise the defensive aspect of ethnopluralism as a strategy to safeguard identity, a reasoning that is more and more employed to legitimate the use of excessive violence, as demonstrated by the Christchurch massacre. ${ }^{861}$

What becomes apparent already is the significance bestowed upon language. Couching old concepts in new words and coming up with new selfdesignations are important parts of the New Far Right's formation. As a consequence some media outlets raised the question whether mainstream ${ }^{862}$ media should use the term 'Alt Right' or whether this would implicate them in the act of deception. ${ }^{863}$ The question remains unsolved but it can be seen as a testimony to the power of words and the correct denomination (a very Poundian idea). The decision to let the New Far Right speak in their own words in this chapter by chiefly using primary sources reflects my belief that language is a key factor in understanding the New Far Right. Bringing in right-wing language use not only helps to explain the internal differences within the Right but also their growing allure in today's Western societies. Moreover, language use also has to be understood in the context of (the strive for) cultural hegemony. What can be observed with the New Far Right is how not only a self-refashioning but also a remodelling (and reworking) of core concepts helped them to enter the acceptable, and thus hegemonic, discourse.

For my purposes, I use the term New Far Right as an umbrella term for all movements and individuals who adhere to the key concepts of the New Right and are part of the extra-parliamentary (oppositional) Right targeting discourse and cultural change, i.e. those who engage in the metapolitical project. ${ }^{864}$ At present, I would subsume movements such as the Nouvelle Droite, the Neue Rechte, the Identitarian movements in various European countries as well as the North American New Right and the Alt Right under the term New Far Right. The attribute 'far' denotes not only that they stand outside mainstream (party) politics but also that they (still) occupy a position largely outside the acceptable political discourse. All of this may be subject to change in the coming years largely depending on the successes or failures of the New Far Right itself. In the following I will look at the New Far Right's reception of Modernist literature by Pound, Eliot, and Lewis, a focus that may seem 
strange at first, but will help to make sense of recent developments among the New Far Right by analysing largely uncharted territory. First, I would argue, that the engagement with Modernist literature could be seen as part of their metapolitical project. Moreover, the renewed interest in right-wing artists does not only evoke a long-standing right-wing intellectual tradition but it also supports a process I will call 'identity formation', for lack of a better word. Just as Pound, Eliot, and Lewis made use of the intellectual tradition of the Right of the $19^{\text {th }}$ and early $20^{\text {th }}$ century, today's Right harks back to right-wing Modernists. In this respect they do not only serve as inspiration but also as validators for the ideological project of the New Far Right.

While the intent is straightforward enough, the results may only offer haphazard spotlights into a very heterogeneous and at times and in some ways impenetrable terrain. The wealth and breadth of available material makes navigating the sources challenging. To cite one example, based on a study by J. M. Berger, the years between 2012 and 2016 saw a huge proliferation of far right-wing Twitter accounts and followers, outweighing those of other extremist groups: 'American white nationalist movements have seen their followers grow by more than $600 \%$ since 2012 . Today, they outperform ISIS in nearly every social metric, from follower counts to tweets per day'. ${ }^{865}$ This almost exponential growth is not tied to the general statistics of Twitter users over the last four years; on the contrary, the growing numbers of far right-wing Twitter accounts defies the general trend, which has largely been one of stasis for the years 2014 to 2016.866 This project can in no way claim to present an exhaustive survey. Instead I focus on a small selection of examples, usually longer posts or articles, with the potential for a more thorough analysis. In reverse, this means that I had to drop many instances of more unconventional re-workings of literature especially new media forms, such as memes, tweets, tumblrs, Instagram posts and the like. For an outsider, it proves difficult to assess how much actual content lies beneath the façade of the many social media feeds of the Right. What I hope to offer is an analysis of how the New Far Right presents its current ideological project as part of a larger trajectory of the intellectual tradition of the Right.

\section{Early right-wing reception of Pound and Eliot}

Far right-wing responses to the works of Modernist authors are not a new phenomenon. This holds especially true for Pound and Eliot. Interestingly, Lewis does not seem to have drawn a prominent right-wing readership during 
his lifetime; on the contrary, of the three authors discussed here, he seems most popular on the Left. This might be due to his very idiosyncratic style and his reluctance to remain loyal to any political movement for very long. Consider for example that Lewis's book Hitler is often credited to be the first book-length study of its subject and was duly translated into German shortly after the original publication and subsequently presented to Hitler and other members of the Nazi leadership. However, things turned out differently than expected, as Bridson notes: 'Perhaps it was the severity of Lewis's criticism on the subject of art and culture which induced the Führer to have the German translation of Hitler pulped and burned when he came to power, and 'classical serenity' reigned in the Reich at last..... ${ }^{867}$ The case for Pound and Eliot is different. When Pound resided in Rapallo he was already surrounded by (politically) like-minded people, even Mussolini granted him an audience. This trend continued when Pound was institutionalised after his trial in the late 1940s. Now he collected a circle of ardent followers, jokingly referred to as the Ezuversity. While the politics of some of Pound's disciples has received critical attention, most notably John Kasper, others like Eustace Mullins and Noel Stock have often escaped censure. Noel Stock later critically reflected on his questionable reception of Pound's work, skewed by his own 'ideological proximity'. This oversight is even more pronounced when we look at criticism on Eliot's work. Here it was the school of New Criticism, which dominated Eliot scholarship for decades. Based on Eliot's own ideas on literature and society, they argued for the separation of the artistic work and context, ideology belonging firmly to the latter. As I have discussed above, Pound also profited from this de-ideologising treatment, when his nomination for the Bollingen prize was defended by critics who firmly insisted on separating poetry and its context. Comparing the early right-wing reception of Pound and Eliot I would argue that one can distinguish between two different approaches. Pound's early right-wing readers emphasised the political aspect of his writings. Pound's literature mattered to them because he successfully married aesthetics and (right-wing) politics, and the reception of Pound's literature was understood as both an aesthetic and political project. Eliot's early rightwing readership, the New Critics, despite agreeing with his ideology, sidestepped the issue to put the focus exclusively on the aesthetics. As a corollary the ideological structure of Eliot's writing has become somewhat of a blind spot, which made it more difficult to address it in subsequent scholarship. New Criticist approaches have also emphasised the self-referentiality of the language, an approach apt to capture the dynamics of Modernist writing, but problematic when the role of literature and language in power dynamics and discursive violence is to be assessed. In short, Pound's early reception attempted to make Pound's politics more visible, Eliot's early reception to 
make Eliot's invisible. Looking more closely at both cases will demonstrate how this shaped both authors' legacy and how it, in turn, influenced the reception by today's New Far Right.

When Pound was released from St Elizabeths hospital in Washington with the help of a joint effort of fellow writers and admirers, the tale was spread of the great poet who had been driven into the arms of fascism in search for artistic recognition; a narrative that implies that he could be easily wrenched from the fascist embrace by being awarded recognition from the appropriate set of people. Pound, of course, would have none of it: setting sail to Italy, greeted the waiting journalists upon arrival with a fascist salute proudly proclaiming 'all America is an insane asylum'. More than a decade at St Elizabeths did not change Pound's politics; on the contrary, it had reinforced his old conviction. The fact that Pound's right-wing allegiances did not wane after his hospitalisation is closely tied to the admirers who flocked to him not only for his poetry but also for his politics. The most (in)famous of these was probably the far-right activist John Kasper, possibly his most devoted disciple. Yet Kasper was not a literary devotee of Pound but primarily a political one. Thus his reception of Pound's works was made fruitful for his, not only Kasper's but also Pound's, political project. In this way Kasper's approach to Pound's poetry is quite similar to the metapolitical project of today's New Far Right. Literature became the means by which political change was to be effected. To do so Kasper followed different strategies. First, he used Pound's creative talent to directly support the cause (that being segregation, white nationalism and combatting Jewish influence) by, for example, asking Pound to write a poem to be used at a rally. Pound duly obliged. ${ }^{868}$ Moreover, Pound was also his political mentor and Kasper freely discussed his plans with Pound. Again, the evidence still available makes evident that Pound very often agreed with the actions of his young disciple, who in turn thrived on Pound's validation. Pound's endorsement did not only matter to Kasper because he looked up to the older poet, but because Pound's status as widely acknowledged yet shunned writer and intellectual added considerable weight to the cause. That Kasper was very well aware of this becomes evident when we see how often Kasper deliberately made explicit reference to Pound in his writing and speeches. ${ }^{869}$ Another project Kasper came up with was the 'Make it New' bookstore, which not only carried Pound's books but other authors Pound recommended, as well as books published by Kasper and his friends. Even though Pound never set foot in it, he was very closely involved in the project as he advised Kasper which books to sell and even which books should be written to complement the collection. It offered a low-threshold entry into right-wing politics with literature as the lubricant. Kasper's bookstore could rightly be regarded as a preliminary stage to later forms of 
right-wing activism targeting cultural hegemony and eschewing overt (party) politics. In Kasper's case they evolved into even more extreme forms of political involvement such as segregation rallies and possibly even bombings. Kasper, the white supremacist activist, is probably not what people have in mind when they think of Pound's ideal reader, but as Marsh suggests in some ways Kasper is exactly that:

All in all Kasper was Pound's most perspicacious reader, seeing through the elaborate and recondite surface of the poem to its radical, and therefore simple intent: to "save the republic." In curious ways, some literary, some political and historical, he was Pound's most important reader in the 1950s. ${ }^{870}$

And Kasper was not an isolated case.

Another devoted disciple of Pound's who would later become a prominent member of the far right was Eustace Clarence Mullins. He was a prominent figure in American anti-Semitic and extreme right-wing circles, for example, the neo-fascist American Renaissance Party. ${ }^{871}$ Mullin's bibliography shows him to be an avid anti-Semitist, who was convinced of the Jewish conspiracy especially in the world of finance, and saw the Jews as parasites (see Mullin's The Biological Jew). His tract 'The Secret Holocaust' also reveals him to be a Holocaust denier. Mullins published a book on Pound, called This Difficult Individual Ezra Pound, a melodramatic account of Pound's treatment at the hands of the system. While a biography of Pound, the book at the same time served a larger narrative of the oppression of dissenting voices. According to Mullins, it was actually Pound himself who told him to look into the Federal Reserve, a research which produced Mullins's most well-known book The Secret of the Federal Reserve. ${ }^{872}$ Similar to Kasper, Mullins made great use of Pound's status as a highly regarded writer. In the foreword to his book, Mullins repeatedly makes reference to Pound, emphasising the poet's instruction and guidance, his high status, as well as Pound's fate of being a victim of the system Mullins describes in the book. ${ }^{873}$ The research was partially financed by Pound, the final book published by Kasper and David Horton, while Pound wrote a short introduction for it. This shows that the 'Ezuversity' was more than just a circle of ardent Pound followers flocking to St Elizabeths for advice, but rather a network that pursued political goals. That Pound and some of his followers had established a network that was at least as political as it was poetical, still often goes unmentioned. Andrew Parker, for example, quotes Mullins to give an overview of critical responses on the question of Pound's anti-Semitism. Yet he fails to mention that Mullins's passionate defence of Pound, his insistence that 'the issue of anti-Semitism in his work is merely one of the desperate measures to which liberals resort in their ceaseless attempts to discredit him, ${ }^{874}$ is part of a bigger political project that in- 
volved not only Pound but also Mullins himself, because Mullins saw himself and Pound as victims who were being targeted for speaking the truth. ${ }^{875}$

The idea of Pound being the victim and his stay at St Elizabeths as a means to silence him - an argument that loses credibility when Pound's networks he forged during his stay are taken into account - can also be found at the very beginning of Wieland Schmied's study on Pound. This is not to suggest that Schmied can be compared to Mullins in terms of ideology, yet his book helps to perpetuate the idea that Pound was unfairly and 'under inhumane conditions detained in an American asylum', which Schmied then links to similar practices used in the Soviet Union. ${ }^{876}$ This comparison not only equates the U.S. with an authoritarian regime, but seems to exonerate Pound from any possible misdemeanour. Moreover, Schmied is more than happy to accept Pound's late 'suffering and atonement' and does not understand why Pound's involvement with Fascism still needs to be discussed even after the poet's death. ${ }^{877}$ Very skilfully Schmied constructs a portrait of Pound as the tormented poet hounded by a peculiar set of Furies: the state, his thoughts of artistic failure, and, even after his death, over-eager critics. Schmied thereby implies a reversal of the victim-attacker dichotomy. ${ }^{878}$ Even if Pound is not explicitly used for right-wing ends, an apologist stance like Schmied's is likely to hamper critical analysis.

One of the few critics who retracted his initial support for Pound is Noel Stock. In his book Reading the Cantos he offers a scathing reflection on the network the poet had established for himself on the lawns of St Elizabeths:

I will not dwell on the rubbish which we, his correspondents, fed to him, or the rubbish which he in turn fed to us. Some correspondents, I have no doubt, did better than this. But a good number of us, because we believed in him and (not least) sought his praise, helped to confirm him in the belief that he alone possessed a coherent view of the truth. It was his duty, therefore to hold out against The Enemy. I remember him speaking in all seriousness of the Cantos as a 'political weapon'. The Enemy understood this, hence the efforts to silence him—and a great deal more along the same lines. ${ }^{879}$

One can find those sentiments expressed here by Stock in the writings of Kasper, Mullins, and also Schmied, even though the latter did not belong to Pound's coterie. Stock did his own bit in supporting Pound; according to Marsh he used his connection to the New Times as well as his own magazine Edge as 'vehicle[s] for Pound's propaganda': 'In all, Stock published "eighty or more unsigned or pseudonymous items sent from St. Elizabeths in the middle $1950 \mathrm{~s} " .{ }^{880}$ In this way he took an active role in the proliferation of what one can only assume to be right-wing material. All of these examples show that the early right-wing reception of Pound was not only quite active but also ef- 
fective in what would nowadays be called the metapolitical project, actively encouraged by Pound himself. This continued even without Pound's interference. Marsh also mentions

the potential for members of the extreme Right to use Pound as an example of "a great American" as can be seen from books as diverse as Francis Parker Yockey's Imperium (1949) to Willis Carto's biographical calendar of Rightwing saints, Profiles in Populism (1982). In 1958 for example, G. L. K. Smith praised Pound, terming him "one of the greatest poets of this century" who was "known to be intelligently alert to the Jewish problem." "881

Evidently Pound always had a devoted readership on the far right.

Eliot's early right-wing readers followed a different path than those of Pound. I have called Eliot a 'conservative collaborator', whose political engagement was often conveyed by the gaps, evasions, and silences. He called for right-wing conservative change, but in his unspoken agreement he also backed more radical ideas. Therefore, it comes as no surprise that his early right-wing reception was on the surface equally evasive of ideology while it implicitly helped to foster right-wing ideology. By focussing solely on the aesthetics of literature, New Criticism can mask its approach as impersonal, supposedly objective, and therefore universal. At the same time it elevates its own unspoken ideology as the unquestioned norm. When Allan Tate calls poetry 'the symbolic citadel stormed by scientism, materialism, secularism, progressivism, utilitarianism, positivism, and other manifestations of modernity' it becomes not only obvious why the New Critics tried to server the connection between poetry and its contextual surroundings but it also explains the ideology behind this move. In his usual caustic language Eagleton sums up the New Criticist impulse as the "poem must be plucked free of the wreckage of history and hoisted into a sublime space above it'. 882 While it pretended to offer impersonal literary criticism, New Criticism was also a movement that gathered around a shared ideological set of ideas. That this cluster of ideas was more than just a vague notion of perceived ills of modernity and could actually be termed an agenda can be deduced from a publication called I'll Take My Stand: The South and the Agrarian Tradition written by a group calling themselves 12 Southerners, which includes prominent New Critics. ${ }^{883}$ The relationship between New Criticism and the Agrarian Movement is no secret but it is worth remembering how smooth the transition between both movements was. Already the title of the book, first published in 1930 and later republished in 1962, can be read as a rallying cry of resistance. It might not be a coincidence that the second edition overlapped with the most active phase of Pound's political coterie, a testimony to the growing inner-political tensions in the US. Predictably many of the tracts included in the book are written from a perspective of (self-)defence, seeing the US American South and what is styl- 
ised as the Southern tradition under attack. John Crowe Ransom, in his piece 'Reconstructed but Unregenerate', looks to a European conservatism that is rooted in harmony with nature and pitches it against an urbanised, progressive and mobile American way of life. Ransom's attack on deracination which he calls 'the strange discipline which individuals turn upon themselves, enticed by the blandishments of such fine words as Progressive, Liberal, and Forward-looking' 884 - betrays the implicit racial element in his argument. Read in conjunction with the essay by Frank Lawrence Owsley ${ }^{885}$ makes clear that the identity the 12 Southerners defend is racial just as much as it is cultural. It is no coincidence that Eliot's lecture series, which he turned into his most controversial essay After Strange Gods, was delivered at the University of Virginia under the auspices of many Agrarians. In this essay Eliot advocates for cultural homogeneity and the exclusion of the 'other', most notably Jews, that clearly echoes the position of the 12 Southerners in I'll Take My Stand. Thus it is not surprising that Allen Tate in I'll Take My Stand uses Eliot as a guide to modernity highlighting its self-defeating mechanism; what is more interesting is that Tate chose to use Eliot's poetry, rather than his essays, for his argument:

Probably Mr. T. S. Eliot meant to show this when he brought Tiresias into his poem "The Waste Land"; for the seer presents the bankruptcy of the modern formula as this is acted out in that most terrible scene in modern poetry-the brutally indifferent seduction of the typist by the "small houseagent's clerk." The seduction "works"; it works perfectly, too well; but the very working testifies to its failure. It can only be mechanically repeated over again and again. ${ }^{886}$

Obviously Eliot's poetry became the baseline for New Criticism not only because it perfectly met its formal requirements but also because it served the ideology of the founding New Critics. Eliot, of course, was wise to encourage New Criticism as it helped to de-ideologise his poetry, similar to his own effort in his other writings, in which he uses evasiveness and sophistry to sanitise political ideas from political action and its consequences. Both tactics have helped to make Eliot scholarship an intellectual battlefield of competing factions arguing over how much (deplorable) politics are presented in Eliot's works. Not all voices in this debate find Eliot's politics deplorable, which turns it into a highly complex discussion especially when ideological allegiances are not openly addressed. New Criticism, so I would argue, has proven to be a most useful cover for conservative and reactionary politics.

The issue that probably exemplifies this best is Eliot's anti-Semitism. Challenging Eliot's anti-Semitism can garner backlash from critics sympathetic to Eliot's politics but also from those who reject them and both positions can be accommodated under the header of New Criticism. A book that offers 
a good summary of this dispute is the second edition of Julius's T. S. Eliot, Anti-Semitism, and Literary Form, which includes a postscript collecting and refuting adverse responses to the book's initial claim, namely that Eliot's antiSemitism is an inseparable part of his literature. Already the first argument against Julius's study resonates with the New Criticist claim that poetry (in contrast to prose) does not make statements about the world. Moreover, the accusation of anti-Semitism is often misunderstood to be attributed to the poet and not to the poem. Therefore, common deflections include statements that Eliot's poems are either dramatic monologues or ironic. This follows the logic of New Criticism, which denies that even if Eliot's poems are read as dramatic they could still be anti-Semitic. Last but not least these arguments can be channelled into the familiar attack against censorship. Julius phrases this argument thus: 'To apply moral or political criteria to a literary work [...] implies a threat to artistic freedom. It leads, that is, to censorship. [...] Works of literature should never be censored; if they are to be censured, it should only be on aesthetic grounds. ${ }^{987}$ The debt to New Criticism can be palpably felt here. To insist that one could not only neatly separate form and content, but also that the critic's job is to criticise bad form yet not bad content replicates the theoretical claims of New Critics. This is by no means exhaustive and Julius lists many more examples how Eliot's poetry and sometimes even his antiSemitism is defended against what is perceived as unjust accusations. What becomes apparent here is that New Criticism helped to de-ideologise literature and, in a second step, to disparage critical readings that uncover ideological aesthetics.

This short digression was meant to expose the ways in which both Pound's and Eliot's poetry have profited from early right-wing reception. Pound gave credence to the American Far Right, while he in return received an avid following. In Eliot's case, New Criticism has shielded his poetry from accusations targeting the poems' right-wing ideology. Another strategy that has often been employed to 'protect' Pound and also Eliot from criticism is the reversal of the victim/aggressor dichotomy with poet and poem under attack from supposedly overzealous and allegedly overly emotional critics. This is frequently used in conjunction with a deliberate misreading of the target of the attack: when as in Julius's and other cases the poems are put on trial, the opposing side often sees the poet on trial, loudly decrying the unfairness of targeting the dead, i.e. those who can no longer defend themselves. Yet this argument overlooks the way in which Pound's and Eliot's literature was used by political movements. While Eliot and the Agrarian movement simply benefitted from each other's work and the reputation attached to it, Pound played an active part in American far right developments after the Second World War by mentoring, financing, and lending intellectual support to 
their agenda. It is this final point I took as the inspiration and guiding question for the main focus of this chapter: to what extent is literature by Eliot, Pound, and Lewis used by today's New Far Right to advance their political position, to legitimise their ideology and to lend cultural prestige to their undertaking? What seems to hold true for all the examples I have collected is that they follow the strategies of the early right-wing reception of Pound, while they also benefit from the legacy of New Criticism. Both tendencies in early right-wing reception paved the way for today's New Far Right. New Criticism has created the gap, which the New Far Right can now fill, pretending to commit a transgressive act to uncover hidden knowledge and silenced facts.

\section{Contemporary right-wing reception}

\section{Counter-Currents}

Founded in 2010, Counter-Currents is the name of a right-wing publishing house and its accompanying webzine, with the afore-mentioned Greg Johnson as its editor-in-chief. According to its self-description, 'Counter-Currents publishes, distributes, and promotes "Books Against Time". 888 However, the website is much more than the promotional arm of the publishing house. In fact, it serves as a virtual market place where opinions and ideas can be shared and exchanged, networks established and potential new 'recruits' can be enlisted. While Counter-Currents defines itself as part of the North American New Right, it is active in establishing links to other national and international rightwing movements. Counter-Currents seems to make a concerted effort not only of importing 'foreign' ideas, chiefly by offering translations of formerly hardto-obtain French New Right theory, but also exporting ideas by translating selected articles into other languages, a section that features twenty-two languages other than English. What distinguishes Counter-Currents from more popular (by popular I here mean well-known even outside the right-wing spectrum) right-wing sites like Breitbart and The Daily Stormer 889 is its selfstylisation as a vehicle of and for the intellectual Right; or in Johnson's own words: 'Counter-Currents is aimed at readers with IQs above 120'. ${ }^{890}$ In many ways Counter-Currents offers an ideal glimpse into the intellectual New Far Right. To limit my focus, I have selected two writers, Kerry Bolton and Jonathan Bowden, whose writings have been published by Counter-Currents. Both have written extensively on (some of) the authors featured in the present 
study. Kerry Bolton has collected his writings in a book called Artists of the Right: Resisting Decadence, which was published by Counter-Currents, yet his pieces on individual authors have also appeared on the Counter-Currents website as well as other websites such as wmw.oswaldmosely.com. Jonathan Bowden was a prolific writer and thinker of the New Far Right from Britain, who developed ties to the American New Far Right from 2009 onwards until his death a few years later. Counter-Currents seems to be the major American outlet of his works, (re-)publishing parts of his writings as well as offering transcripts of a number of his speeches. ${ }^{891}$

\section{Kerry Bolton: Artists of the Right}

Taking a closer look at the cover design, the title takes up half of the cover and summarises the book's central claim, namely that the artists collected therein both stood on the Right but also belong to the Right. The title thus announces what the book is trying to achieve, namely to 'construct[] a counter-canon', ${ }^{992}$ as James J. O'Meara notes in one of the blurbs on the back. The subtitle 'Resisting Decadence' places the writers in a specific context of a right-wing history of ideas. The concept of decadence proved to be one of the leitmotifs of the Anti-Enlightenment, or Classical tradition. Sternhell writes that 'from [Giambattista] Vico onwards, the idea of decadence was part and parcel of Anti-Enlightenment thought'. ${ }^{893}$ As the name suggest, the AntiEnlightenment tradition relied heavily on the rejection of core principles of the Enlightenment. By projecting decadence, a word suggesting depravity, corruption, and a general sense of downward movement, onto the other side (namely the Left or the liberal mainstream), they could advocate vigour, integrity and righteousness to counteract the 'decline of civilisation'. Decadence proved an ideal point of attack, as it is loose enough to cover a range of traits and presupposes that the attackers hold the moral high ground. ${ }^{894}$ When Bolton's book uses the phrase 'Resisting Decadence', it carries with it the legacy of that term, but it reverses the dichotomy of attacker and victim, thereby feeding into the familiar narrative of the Right of being under attack. Bolton gives this narrative a positive spin by suggesting perseverance and incorruptibility against the bearers of decadence. In this way, the subtitle is not only supposed to serve as a characterisation of the $20^{\text {th }}$ century writers of the Right featured in the book, but also of the $21^{\text {st }}$ century readers of the Right, to whom the book is addressed. The blurbs on the back help to inscribe the book into a narrative of defiance and self-aggrandisement. Artists of the Right is celebrated as 'a declaration of the manifest bankruptcy of [the Cultural Marxist] legacy', as 'a book that belongs on the shelf of every free-thinking patriot 
and defender of European man' and 'eye-opening, exhilarating, and inspiring. ${ }^{895}$ Jonathan Bowden's blurb adds that the book 'blows away the notion of right-wing philistinism and, instead leads to a radically different assessment of the arts during the first half of the twentieth century'. Bowden ends with yet another declaration of the book's subversive quality, maintaining that Bolton 'tends to include the material which is habitually left out or skirted over', suggesting to readers, that the book uncovers previously hidden knowledge. Yet very little of the actual research that went into the book could be described as truly original since Bolton relies heavily on well-established and mainstream literary criticism. The book's cover, and also in some ways its foreword to which I will turn my attention below, stylise Artists of the Right as offering new insights that would shake up academic orthodoxy, when, in fact, these authors' political allegiances were already discussed during their lifetime. Only O'Meara's comment indicates that Bolton challenges previous, and mainstream, literary criticism in its inability to come to terms with these artists' politics: '...no matter what your teachers told you, the great minds of the twentieth century were culturally, politically and spiritually of the Right'. For this is what Artists of the Right essentially does: it (re-)claims these artists for the Right. The fact that the book is sold and advertised to be much more than a reclaiming betrays an effort to not only educate its readers but to delegitimise old mainstream institutions ('culture makers', 'your teachers', in short, academia, media and the cultural industry). Challenging dominant cultural discourses (in this case about canonical Modernist authors) and its inherent production of knowledge is an integral part of the metapolitical project. By rebranding Artists of the Right as countering mainstream knowledge production, it can be made to function as the proverbial 'red pill', even without actually producing new knowledge,

Johnson supplied the foreword to the book, which revels in tearing down the Left's hypocrisy about their self-attributed cultural and moral superiority:

Leftists think that their belief in human equality makes them better than the rest of us. They are particularly wedded to the idea that they are not just the party of humanity but of the intellectual and artistic elites. Thus it is a profound embarrassment to the Left that some of the greatest creative minds of the twentieth century - including leading modernists - were men of the Right, and not just conservatives, but fascists, National Socialists, and fellow travelers. ${ }^{896}$

Beginning his foreword to a book called Artists of the Right with the word 'Leftists' suggests that the book is engaged in a debate with the dominant, supposedly left-wing, discourse based on the knowledge that the book won't have a left-wing audience. In fact, the very overt use of the us/them dichot- 
omy helps to address a specific right-wing audience. It remains unclear, however, whether the 'us' denotes an embattled minority or whether it is actually 'them', the Left who is the true minority compared to 'the rest of us'. This ambiguous reading encompasses both the idea of a silent majority that feels not represented by the dominant discourse as well as a more narrow understanding of 'us' as the New Far Right. Group-identity is created by way of an opposition to 'Leftists', which at this point comfortably brushes aside any possible fault lines within the Right, be they between the conservative and extreme end of the spectrum or the libertarian strand and something Johnson elsewhere calls 'West-Coast White Nationalism'. ${ }^{897}$ Moreover, Johnson touches upon a number of discourses I have discussed above: the competition over the moral high ground, the cliche of the intellectual superiority of the Left (and conversely the intellectual inferiority of the Right), and the challenge to mainstream knowledge production. The very first sentence launches a double attack against leftists because, while it at first glance only seems to be a snide remark at the Left's imagined moral superiority, it contains, in fact, an implicit counter-argument: if the Left really believed in human equality they would not 'tend to think [it] makes them better than the rest', or, in short, Leftists are hypocrites. Then he builds up the argument to finally land his supposed blow against the Left that 'some of the greatest creative minds [...] were men of the Right'. Yet Johnson says very little about the actual engagement of the Left with these authors (and their politics), and it remains unclear whether the 'profound embarrassment' stems from the sheer existence of right-wing intellectuals or from the dilemma of the Left's recognition of these artists' talent. ${ }^{898}$ Interestingly, opposed to the homogeneous Left, Johnson presents a Right that he is eager to diversify, listing 'not just conservatives, but fascists, National Socialists, and fellow travelers'. Of course, this could be read as yet another 'embarrassment' for the Left, since it is exactly the far right, from which the great creative minds have sprung. A more interesting reading would be to see this not only as a stab against the Left but also at conservatives, especially since Counter-Currents is situated on the far right, often berating conservatism for its inadequacy on many levels. ${ }^{899}$ While the title Artists of the Right implies a certain unity, Johnson deliberately emphasises the heterogeneity of the Right and implies a certain disdain for the conservative libertarian end of the right-wing spectrum. Another point Johnson brings up is the authors' canonical status. The paragraph describing the differing accomplishments of the ten writers is short but it serves an important function: the fact that they are generally acknowledged for being outstanding artists helps to validate the ideas they, and the Right who reclaim these artists, promote. If the Right can become the party 'of the intellectual and artistic elites' they could gain cultural hegemony. Reclaiming these artists therefore means post- 
humously detracting intellectual validity from the mainstream hegemony and would thereby unmask the supposed paucity (or maybe even hypocrisy) of it. Put simply, the greater the status of the author reclaimed the greater the loss for the other side. A final aspect that needs to be considered is how the authors discussed in the book are contextualised within their own time. Referencing Joseph S. Salemi, a poet and scholar who describes himself as 'a rightwing conservative Roman Catholic', 900 Johnson writes that 'the independence of mind that allowed these artists to break from Left-wing orthodoxy also prevented them from forming a new orthodoxy of the Right'. ${ }^{901}$ Here the position of these writers is equated with that of today's far right, both being portrayed as resisting or freeing themselves from left-wing orthodoxy. However, most of the writers in the book wrote from within the existing hegemony; there was no need to break from left-wing orthodoxy as this implies that these authors would have either formerly accepted it or that left-wing orthodoxy back then had been hegemonic enough to compel adherence. Neither was the case. ${ }^{902}$ Making the Modernist writers part of an imagined resistance against the decadence of left-wing orthodoxy, Johnson establishes a continuity within the intellectual tradition of the Right that goes beyond a reclaiming of the authors but rather sees today's New Far Right stepping into their footprints to continue the (meta-)political project these artists have initiated. Thus Bolton's Artists of the Right is more than 'a study of ten leading twentieth-century literary artists'; it has to be understood, as Johnson makes quite clear, as a part of the metapolitical project. ${ }^{903}$

I will now take a closer look at the two essays on Pound and Lewis. Similar to the other pieces in the book, both essays are looking at these artists mainly as political thinkers ${ }^{904}$ and they say very little about their artistic development and their works. If a poem or novel gets singled out for review, it is mostly used to illustrate a political argument. This, of course, stands in stark contrast to the book's title, which first and foremost identifies these men as artists. Bolton is not a literary scholar so this might partially explain the lack of serious engagement with the art (as opposed to the criticism) these men produced. There is a certain irony to the fact that a book that revels in the high reputation of these 'pioneering modernists' is unable or unwilling to make sense of Modernist literature and therefore has to resort to biographical details and obvious criticism. Bolton's rather superficial approach to poetics can be observed by taking a closer look at his chapter on Pound. In the entire 23-page essay, Bolton included only one poem, an abridged version of Canto XLV; and even this one example of Pound's artistic output features here as an explanation of Pound's economic theories: it 'is a particularly lucid exposition of how the usury system infects social and cultural bodies'. ${ }^{905}$ Bolton adds on the next page: 'We might with this poem in particular understand 
why Pound felt the problem of banking and credit to be of crucial concern to artists'. ${ }^{906}$ It seems Bolton has little use for Pound's poetry, unless it can be utilised to explain Pound's economic/political theory. He says nothing about the poetics of Canto XLV, and fails to mention the poem's position and function in the Cantos as a whole - he never even talks about the Cantos apart from mentioning that Pound was busy writing his magnum opus during various stages of his life. This might suggest that Pound's art, his being an artist, is only secondary, if not purely ornamental, to Pound being a right-wing thinker. When Bolton rushes through Pound's early formative years as an artist in London, he casually brings up Imagism and Vorticism, without once explaining the particulars of these art movements. Although he relates Vorticism to Futurism, stressing the feuds between both movements, he eventually degrades Vorticism to Pound's 'first major experience in revolutionary propagandizing and the first cause that placed him outside of orthodoxy'. ${ }^{907}$ The omission of Pound's poetic work stands in stark contrast to Bolton's final sentence of his Pound chapter, celebrating Pound as 'the last of a generation which had tried to create art and literature on an heroic scale'.908

So if it is not Pound's poetry, what part of Pound is Bolton interested in? The subheadings in his essay shed light on what Bolton deems important. These are: 'Democracy \& the Rise of Mass Man', 'Social Credit', 'Fascism', and 'Caged'. Subsumed under these four headings, Pound's life and work turns into a narrative of a right-wing intellectual who is at the end punished the 'caged' referring to his incarceration in the Pisan Prison camp and later St Elizabeths - for 'resisting decadence'. The most interesting issue for Bolton is Pound's views on economics and therefore he details Pound's embrace of Social Credit and his attack on usury as the root of all evil. Pound's support for fascism (the Italian variant but also the BUF) is also largely framed in economic terms, and it is in the context of Fascism that Canto XLV is introduced, adumbrated by Pound's words that 'USURY is the cancer of the world, which only the surgeon's knife of Fascism can cut out of the life of nations'. ${ }^{909}$ Interestingly, what is completely lacking from Bolton's reflection is Pound's take on the Jews. I have detailed above in my Pound chapter how closely the Jews were tied to usury in Pound's world-view, so much so that for the poet both instances had literally become inseparable, creating the hybrid 'Jewsury'. This was an almost life-long obsession for Pound and it pervades his writings from the 1930s onwards and features prominently in his radio broadcasts. Bolton manages to almost completely circumnavigate the topic, omitting all references to the Jews in Pound's writings save one: 'Pound stated that Roosevelt and his Jewish advisers had betrayed the American Revolution'. This is followed by a more ambiguous sentence reading: 'It was a theme he returned to in more detail during the war... ${ }^{210}$ It is entirely accurate 
that Pound did return to this theme during the war, but Bolton conveniently leaves out that 'in more detail' for Pound meant with greater focus on 'the Jewish question'. Instead Bolton draws attention to the Bank of England and 'people such as Alexander Hamilton' as culprits. Whatever the reason for Bolton's omission it is quite remarkable that a reclaiming of Pound for the New Far Right should pass over in silence the one issue that they usually deem most significant. However, as will become apparent later, Bolton is not the only one trying to defer attention from Pound's writings on the Jews.

Another issue that deserves attention is the question of sources. Bolton makes use of largely known sources that are easily accessible or obtainable. He did not unearth any new information, he did no archival work and the selection of sources is very limited. One could divide his sources into three categories. First, writings by Pound: the central writings for Bolton are Social Credit and Jefferson and/or Mussolini, there is one reference to Pound's Selected Poems and several articles he wrote for various magazines such as the BUF Quarterly. While Social Credit and Jefferson and/or Mussolini are, indeed, not Pound's most well known books, Social Credit saw a reprint, while Jefferson and/or Mussolini is often discussed and referenced in secondary literature on Pound. Nowadays both can be easily found online and downloaded, in fact, they are far from being inaccessible. ${ }^{911}$ The second category consists of texts coming from within the Right. People associated with the BUF, Oswald Mosley himself and others like Alexander Raven Thomson, belong to this category, as well as the critics I introduced earlier, Mullins and Stock. It is with regard to these sources that Bolton's book includes 'material which is habitually left out or skirted over'. However, looking into the text one realises that these sources do not introduce any new information or add significant depth to Bolton's essays. They are mainly used to supply biographical details, most of these quite well known, as well as to explain Social Credit and its link to fascism, again largely to reiterate familiar points. The aim of including right-wing sources does not seem to be to generate new knowledge on Pound but to connect Pound scholarship to its early right-wing reception. The third rather loose category is the one that encompasses 'conventional' scholarship, including Peter Ackroyd, the more controversial E. Fuller Torrey, Robert Skidelsky, and John Carey among others. Bolton's method is fully opportunistic, taking bits and pieces from these studies without engaging in any sort of dialogue with them. This is, in fact, true for most sources Bolton uses; he does not engage with the existing Pound scholarship but only uses it as a reservoir for facts and references. For the uninitiated reader, this might give the impression as if Pound scholarship has rarely touched upon the topics Bolton discusses here, which is, of course, not the case. 
All the flaws that mar Bolton's essay on Pound can also be found in his essay on Wyndham Lewis. Again, readers will find little of Lewis's literature and in the rare case they do it is brought into the discussion to explain Lewis's political theory. To approach literature as aesthetic product, or at least as something more than a creative exposition of politics, seems to be unnecessary or undesirable for Bolton. Also the selection of Lewis's literature is limited: Bolton quotes from Tarr, Rotting Hill, and 'If So the Man You Are'. Again, these examples are only used to further explain Lewis's political views and Bolton has no use for them as art, nor is he able to place them in their proper artistic context. How poor Bolton's knowledge of Lewis the artist is becomes glaringly apparent when we take a closer look at Bolton's inclusion of 'If So the Man You Are'. As with Pound's Canto XLV, Lewis's poem is not taken from the poem proper, but from The Penguin Book of Contemporary Verse, which devotes exactly three and a half pages to Lewis, and Bolton seems not to have bothered to seek out the full text. He quotes from the short given sample, once more leaving out a number of lines, but this time without any indication that he did so. His reading of the eleven lines is purely autobiographical, and focusses on Lewis the political thinker. Firstly, looking into 'If So the Man You Are' readers realise that the part quoted by Bolton belongs to the 'Enemy Interlude', thus it is Lewis's creative persona 'The Enemy' speaking. In fact, 'If So the Man You Are' can be read as a meditation on the role of the artist in society, (in this case) his having to navigate the Scylla of isolating oneself and the Charybdis of pandering to an audience. Lewis's Enemy persona is the successful enfant terrible who dares to walk alone and against the grain but who simultaneously captivates an audience: The 'Enemy Interlude' ends with the Enemy leaving the stage (which emphasises the performative aspect) 'smil[ing] in our direction, and bow[ing] as if to say, 'Have I played my part to your satisfaction?". No wonder the following canto resumes: 'I knew you'd like the Enemy! [...] I was sure you'd like him and that was why I brought him'. ${ }^{912}$ To reduce this complex poem to a simple autobiographical reading shows Bolton's insistence to read Lewis solely as 'the creative individual against the axis of the herd, of "High Finance, and Bolshevism". ${ }^{913}$ Contrary to the title and what Johnson writes in his foreword, it matters more that Lewis is a man of the Right instead of artist of the Right.

In this light it is even more puzzling that Bolton's selection of Lewis's theoretical/political writing is almost equally limited and seemingly random. As Lewis was an immensely prolific writer it would indeed be difficult to discuss even his more important writings in a 23-page essay. However, it seems strange that Time and Western Man should get a lot more attention than The Art of Being Ruled, and that when Bolton speaks about the latter he mainly uses a review written by Roy Campbell instead of Lewis's book. ${ }^{914}$ Of course, in the 
light of writing a decidedly right-wing review, it makes sense to bring in Campbell, who was a right-wing poet himself and who is also featured in Artists of the Right, to illustrate the existing cross-generational right-wing intellectual tradition within the arts. Interestingly, Campbell's piece offers a much more enlightening reading and he is much more aware of the seminal importance of The Art of Being Ruled. It is also noteworthy that Campbell's review was published in Blast 3, a laudatory anthology of Vorticist scholarship published under the editorship of Seamus Cooney, a book that can be considered 'mainstream' literary criticism. Moreover, Lewis's political writings of the thirties, especially books like Hitler, Left Wings Over Europe, and Count Your Dead: They Are Alive! receive scant attention. ${ }^{915}$ While Bolton might have pursued a certain strategy with his selection of books, it at least seems odd that he does not include or give more weight to books, which so ostensibly support his argument. One would think that especially The Art of Being Ruled would prove to be an ideal point of departure to declare Lewis a discerning critic of liberalism and its corollaries like feminism and thus a great thinker of the Right. Equally strange although less surprising is Bolton's complete omission of Lewis's greatest literary works, namely The Human Age trilogy, The Apes of God and Revenge For Love; obviously Bolton does not care for Lewis's art, but these books are not even mentioned, despite being overtly political. Instead a minor book like Rotting Hill is brought up twice and even quoted from. This gives Bolton's piece a flavour of being a revisionist study of Lewis, but a poorly thought-out one as all these works he skips would have offered plentiful material to bolster his argument.

Furthermore, even when Bolton includes and discusses one of Lewis's more political books, his analysis seems to circumnavigate the book's crucial points as becomes apparent when he examines Paleface, where Bolton either overlooks or consciously steers clear of the book's discussion of racial politics. For Lewis's book presents a critique of the then fashionable exoticism and primitivism and can be read as a strong exhortation for the protection and celebration of white identity. Yet this part is not included in Bolton's study even though it should be of interest to his cause and supports his main argument. Seeing that especially for the American New Far Right concepts such as white nationalism, 'generic whiteness' and ethnonationalism are quite important, ${ }^{916}$ how is it possible that Paleface is not celebrated as a discerning study, which has laid out a basis for these concepts already in 1929? Bolton seems to read Paleface differently; he, for example, claims: 'Lewis opposes the "melting pot" where different races and nationalities are becoming indistinguishable'. ${ }^{917}$ Yet Lewis writes in Paleface: 'it is not the Melting-pot I object to, but the depreciation and damage done to one of the ingredients. ${ }^{918}$ In fact, Lewis, in contrast to what Bolton claims, distinguishes between a racial melt- 
ing-pot and a melting-pot of nationalities. He speaks out against an interracial melting-pot, which includes a strong critique of imperialism and also of the aforementioned movements of exoticism and primitivism. On the other hand, he strongly advocates for a white melting-pot, more precisely a European melting-pot, in an effort to prevent further inner-European wars, but also to aim for a renewed white self-confidence:

My own view is that the Melting-pot should be set up in Europe, upon the spot. Instead of posters on our walls which say 'Join the Royal Air Force and See the World,' there should be posters (and offices in every district to deal with applicants) saying, 'Marry a Swiss and See the World,' or, more jocularly, 'Get spliced to a Finn, and Get About.' What can there be against it, except that it would be impossible to have wars any more in Europe? ${ }^{919}$

Compare Lewis's idea of the European (i.e. white) melting-pot with Richard Spencer's words when he tweeted: 'These nationalist models have been tried, for decades, and they have never achieved sustainable power. [...] We need to open ourselves up to different, supra-national models. A European political party? A global political party for White people?'920 While Spencer's 'white globalism' and Lewis's white melting-pot are radical concepts, the idea of a (partially) shared white identity seems central to the New Far Right. Yet instead Bolton closes his discussion of Lewis's Paleface with a meditation on cultural aspects, like jazz and the music industry.

From an outsider perspective it is difficult to ascertain how much deliberation went into writing these essays. Apart from the fact that they exhibit a number of flaws that betray inadequate research, they are, maybe more importantly, poorly put together to measure up to the task they set out for themselves. The case for Pound and Lewis as artists of the Right could have been made much stronger, especially if the proper sources would have been included, and it remains open why these essays did not put a stronger emphasis on art, unless Pound's and Lewis's identity as right-wing intellectuals is more important to today's Right than their literary output. Furthermore Bolton's inability to engage critically with the existing secondary literature on these two writers weakens his argument. Johnson writes about the 'profound embarrassment of the Left' in his foreword, yet Bolton almost never makes any attempt to connect his argument to the existing discourse on the topic, not even when he explicitly uses those sources that would offer an ideal target for such an attack. Thus in his Lewis essay he references Jameson's Marxist study Fables of Aggression, but instead of dismantling some of Jameson's (argumentative) flaws, Bolton only uses it to support the banal statement that Lewis 'is seldom spoken of in the same breath as Ezra Pound, James Joyce, T. S. Eliot, and others of his generation'. ${ }^{921}$ As with Pound the secondary sources Bolton uses for his piece on Lewis are severely limited, which might 
have been strategically done to evoke the impression to the uninitiated reader that there is very little research on the topic. While he claims that the Left has been shying away from this supposedly uncomfortable topic, it is actually Bolton who is evading a serious debate with scholars from the left and mainstream. Bolton's study pretends to be a serious engagement with artists of the Right, and is duly touted as such on cover and in the foreword, when it actually expends more space to biographic details than the core artistic projects of these men. Ironically Bolton reproduces the reading often found in more mainstream literary research on these poets, which separate the political individual from the artwork. Despite being called Artists of the Right the book does not make the claim that the literature these writers produced offers an aestethicised form of right-wing politics, an argument that would have challenged the existing discourse. Instead Bolton works through Pound's and Lewis's political writings to present them as right-wing intellectuals, even though that is more or less accepted knowledge. It seems thus that the emphasis is put on who (re-)produces this knowledge, for what purpose and for which intended audience. Bolton's book is not a project of knowledgeproduction but rather a project of knowledge-dissemination targeted at a certain audience. ${ }^{922}$ Its supposed merit alone rests in the fact that it is, as Salemi writes, 'unapologetic' about its subject matter.

\section{Jonathan Bowden}

Judging from his online presence at Counter-Currents Jonathan Bowden seems to have preferred the oratory to the written essay. This chapter will analyse three lectures given by Bowden at different 'New Right' ${ }^{923}$ meetings in London: one on Lewis held on 28 May 2006, one on Pound held on 11 June 2011 and one on Eliot given on 6 August 2011. The speeches can still be accessed on the Counter-Currents website, which also provides a transcript for each. I will be referring to these transcripts in this chapter, with occasional references to the video recordings of the lectures when necessary. This will be supplemented with a number of shorter written pieces mainly on Lewis also published on the Counter-Currents website. What will become apparent is that Bowden, similar to Bolton, focuses on these men's personality and life and less on their art - although he incorporates literary works into his talks. The central narrative around which Bowden's talks are structured is about how these men (and their legacy) persevered in a hostile environment. Their art serves as complementary evidence, but never takes centre stage.

Starting with Bowden's talk on Pound it is noteworthy that in contrast 
to Bolton, Bowden almost immediately introduces Pound's poetry, specifically his famous war poems from Hugh Selwyn Mauberley. Although Bowden says very little about the poems, apart from stating that they grew out of Pound's disillusionment with the war, there is a sense that Pound's poetry matters as poetry. It is towards the end of his talk that Bowden makes explicit why an engagement with artists like Pound would be beneficial for the New Far Right:

The other interesting thing-[...]-is Pound's link to the most eternally minded and important artists and intellectuals of his time. The radical right is regarded as a trajectory that has no connection with civility, or with art, or with culture. It is a tendency connected to thuggery in the mass mind and in the mass media mind. Whereas here you have exemplars of the civilization, people amongst the most significant individuals in their society who in the end, ended up put in the death cage, in an American penitential death cage for the views which he espoused as a free man on Italian radio. ${ }^{924}$

Pound as (a radical right-wing) artist matters because he serves as a counterexample to the common narrative of the radical Right as having no intellectual tradition. Moreover, Pound's brutal interment compared to his free life in Italy seemingly uncovers the supposed hypocrisy of liberalism as opposed to Fascist states. Similar to Bolton, Bowden portrays Pound constantly struggling against a system in crisis; a system, which during Pound's lifetime tried to contain him by incarcerating him and which today tries to hush over his politics. Again this is an over-simplification of the past and present handling of Pound, but it helps Bowden to construct the familiar narrative of the Right as a resistance movement. As Bowden never tires of reiterating, Pound 'remains uniquely controversial', his 'academic translations are still controversial', and Pound 'chose the most controversial political side that was then in existence and which he could have chosen'. By presenting Pound in this way, Bowden seems to suggest that already an engagement with Pound is an act of resistance or rebellion against the dominant system. Throughout his somewhat incoherent talk Bowden repeatedly describes Pound's revolt against existing rules, on a personal, poetic or political level. In this way Bowden can jump from current politics, to Pound's time at St Elizabeths, to Canto XLV, to a meditation on British versus American English and back to Pound's association with Kasper during the 1950s. There are no transitions between these individual topics and indeed parts of the talk lack a coherent argument. Consider the following paragraph on Pound and Kasper:

When he was asked about his relationship with the segregationist, John Kasper and Ezra Pound-Kasper would later be jailed for the bombing of a school when there were no children there which was desegregated and who ran a radical right bookshop in Greenwich Village of all places! An area that's open to alternative ideas. ${ }^{925}$ 
This anecdote ends on a cheap joke, which during the talk masks the fact that Bowden has not actually supplied any information on the two men's friendship. As with Bolton, Bowden does not provide any novel research or information; his talk solely rests on the already existing, and possibly largely mainstream, Pound scholarship. Furthermore, both accounts share a fervour for highlighting biographical details of Pound's hardship, his incarceration at Pisa for example. In other instances, however, the information he gives is simply incorrect: he talks about 'Dorothy Shakespear's bookshop called Shakespear[e] and Company' and later adds 'Dorothy Shakespear's Egoist Press and the journal The Egoist, which Pound helped her with' into the mix. None of this is correct, but this probably matters very little to the (intended) audience. ${ }^{926}$ Bowden regularly pulls the talk back into the realm of politics, trying to establish a connection between Pound's political struggle and the struggle of today's New Far Right. When introducing Pound's involvement with Social Credit, Bowden - in contrast to Bolton - shortly notes its connection to anti-Semitism, or, as he phrases it: 'what we might call politely the rejection of philo-Semitism', which predictably triggers laughter from the audience.927 This is the only direct reference to anti-Semitism in Bowden's talk and in the way it is formulated it does not really serve the purpose of addressing Pound's anti-Semitism. Instead it is aimed at modern politics, namely the Left's or the mainstream's ignorance or acceptance of supposed Jewish influence and consequently the allegedly enforced philo-Semitism. Likewise, when Bowden later retells the story of Pound arriving in Italy after his release from St Elizabeths, the audience erupts into applause upon hearing that Pound greeted the journalists with a Fascist salute and there is further laughter about Pound's quote 'America is an insane asylum'. ${ }^{928}$ Bowden is giving his audience the Pound they want. Although Bowden presents Pound as the 'controversial' artist who dared to step into the realm of politics - again something Bowden emphasises as challenging ${ }^{929}$ - he uses Pound to serve political ends. The incorporation of Pound's poetry, and the lack of direct quotes from his political writings, highlights Pound's central importance as a writer of literature. Interestingly, whereas Johnson in his foreword to Bolton revelled in these artists' literary complexities as a mark of honour for the right-wing intellectual tradition literary complexities that ironically proved too challenging for Bolton Bowden encourages his audience to read Pound and not be intimidated by the complexity of the poetry:

Pound is very difficult. Pound is very difficult to read, Pound relies upon an education which almost no one in Western societies is now given, even at the most elite level. But my view is that is a wrong way to read Pound. Most people they come across in the third line a cultural association which they don't understand, maybe from the classical world, and they think 'This isn't 
for me. I'm on the third line, and I'm already lost," and they put it aside. In actual fact, my view of writers like him, who use other cultural forms to think through, it's a shorthand for the[ir] own thinking, is not to be bothered about not getting the cultural reference, you continue with the work itself. So I would advise anyone to get Pound out of their local library and to have a look, liberals say, irrespective of the politics, and irrespective of the political radicalism. ${ }^{330}$

Reading Pound, so Bowden suggests, is not an idle pastime, but a way of steering people onto the right (in both senses) path: 'one thing that people should always look at are the elite artists and intellectuals who have aligned themselves with European renewal. Educate yourself, read for yourself, read and make decisions for yourself, turn the television off, and look at this sort of material'. ${ }^{931}$ Learning from Pound means tapping into a source of knowledge that rejected 'the shibboleths that now dominate: the belief in equality, the belief in mass uniformity, the belief that certain ideas are out of order and cannot be accepted...932

Bowden's talk on Wyndham Lewis is the earliest of the three talks. Judging from Bowden's other writings, Lewis is the artist he was invested in most, ${ }^{933}$ maybe because he fulfils all the criteria for being considered a radical Modernist artist and a man on the radical Right, who carefully cultivated his Enemy persona and was partially shunned by contemporaries and denied critical acclaim. While Bowden focuses more on Lewis as a paragon of 'courage', 'strength and glory', ${ }^{934}$ who went on creating art against all odds, he always comes back to how others hindered or demonized Lewis. He taps, as many others, into the myth that it was Hitler (which Bowden misdates) that broke Lewis's reputation and career. ${ }^{935}$ Generally Bowden is treading on well-worn paths; his talk on Lewis presents nothing new outside mainstream scholarship. Ironically, Bowden mentions O'Keefe's Some Sort of Genius, calling it 'a mildly liberal revisionist biography', ${ }^{36}$ before stating that it is 'factually true' and 'uncovers many things'. ${ }^{937}$ Yet it seems that Bowden's talk relies precisely on this 'mildly liberal revisionist' scholarship, or at least on mainstream conventional research, as the picture he paints of Lewis is nothing but conventional. Just as Bolton, Bowden does not really engage with existing Lewis criticism, even if this would play out in his favour. For example, as in Bolton's essay, reference is made to Jameson's Fables of Aggression, yet again the book's argument is completely ignored. Instead Bowden focuses on the book's subtitle, The Modernist as Fascist, as a validation for his earlier point that 'the Left' cannot and does not want to fathom the relation between right-wing ideology and Modernism: 'Of course, that in itself is a paradox, because to many minds the radical Right and modernity or radical modernism would appear, superficially speaking, to be antithetical'. ${ }^{938}$ The real paradox here seems to me that 
the publication of Jameson's study in 1979 counters Bowden's central narrative that these artists' political associations are routinely passed over. Despite this he tries to portray himself as fundamentally challenging mainstream criticism by relaying an anecdote how he once 'caused a lot of consternation' in a meeting of the Wyndham Lewis Society by declaring Lewis a radical rightwinger. Bowden resumes:

the whole criticism that surrounds him is evasive of [Lewis's politics]. There's a sort of black hole. It's like you don't mention the war, you know. You don't mention his political affiliations because they're tip-toeing around it all. ${ }^{939}$

Again this is not correct: at best it is an over-simplification of Lewis scholarship. Yet just as Bolton, Bowden seems to depend on this narrative of being able to expose these artists' political affiliation, because apart from this claim his talk presents little new insight into Lewis and his work.

He acknowledges a fair amount of Lewis's literary output, but has little to say on the actual books. Consider his presentation of Tarr. 'His first major novel was called Tarr, which of course is an anagram for "art" and "rat." He then digresses into discussing Lewis's aggressiveness as well as his relationship with Pound before resuming: 'But his first novel was Tarr'. ${ }^{941}$ With the exception of The Human Age all of Lewis's books receive this superficial treatment. Thus while Lewis is introduced as 'a man who believed in a Rightwing version of what we can now call the modernist project', Bowden fails to explain in what way Lewis's literature can actually be read as right-wing modernism. Even when Bowden talks about what seems to be his favourite Lewisian project, The Human Age, he does not clarify why this trilogy should matter to (right-wing) readers. Like Johnson he emphasises that modernist literature is complicated, stressing again and again what a difficult book The Childermass is:

Lewis began this enormous work with the Childermass in 1928, which was an extremist modernist book. I've read it three times. It's an incredibly difficult read, because he's attacking the reader the whole time. He writes these sentences where the stress is between punctuation marks in such a way that the majority of people will give it up after a couple of pages. ${ }^{942}$

One does get the impression that this insistence on Modernism's artistic complexity is a way of lauding the intellectual capacity of the right-wing intellectual tradition and in turn Bowden's own intellectual capacity. There is one exception where Bowden tries to relate the significance of The Childermass for a right-wing audience. In a separate article Bowden wrote on The Childermass he identifies the Bailiff as the book's main figure because he illustrates the hypocrisy of modern democracy, by being a strange hybrid of dictator and 
children's entertainer. ${ }^{943}$ In Bowden's reading The Childermass becomes a prescient allegory for the interrelatedness of the media industry, mass entertainment and democracy. This conglomerate panders to and relies on the infantilism of its audience. In this light, the obscurity of Modernist prose stands in direct opposition to the mass media entertaining and pacifying the democratic electorate. It furthermore serves as a validation of the ability to see through democratic 'hucksterism'. ${ }^{944}$ As the title of Bowden's piece suggests by linking The Childermass to Black Metal, ${ }^{945}$ the impenetrability and ferocity of the language makes the novel a tour de force, which only the bold will master. Lewis's Modernist style becomes an emblem for aggressiveness, strength and masculinity. Using Bowden's own words, Lewis is - also by virtue of being a Nietzschean - a 'cultured thug', 946 and those who withstand Lewis 'attacking the reader the whole time' will in turn, also become cultured thugs.

Despite Bowden's recurrent references to Lewis's literary output, it seems to be Lewis himself - the artist more than his art - who should serve as an inspiration for the audience. Bowden turns Lewis into personified resistance, whose literature needs to be read through the prism of Lewis's aggressive and cantankerous nature: 'Lewis almost had to be restrained from going around and hurling a brick through the window of Grayson \& Grayson, because he was like this. But that in some ways is a metaphor for his career, because he believed that art should be about strength and glory'. ${ }^{947}$ This adoration of Lewis's vigour reaches almost comical levels when Bowden elevates the most mundane - and artistically unimportant - things to make them look like outstanding feats. He never tires of exaggerating the 'physical' size of Lewis works: The Apes of God is 'the size of your average London telephone directory' and 'a gargantuan satire', ${ }^{948}$ The Human Age is 'an enormous sort of tetralogy' and, moreover, 'he painted at least 200 very large canvases'. ${ }^{949}$ Sheer quantity trumps quality in this approach. Even when Bowden judges the quality of a book, the underlying reasons are predictable enough and say very little about Lewis's role as the arbiter of right-wing Modernism. For example, Bowden writes: 'Tarr is an extraordinary novel, a Dostoevskian novel in many ways, written in these sort of bullet sentences'. ${ }^{950}$ What makes Tarr so extraordinary is not so much its innovative language use but the virtue of it being deemed 'too strong'. ${ }^{951}$ Bowden celebrates Lewis and his art because they are the antitheses to liberalism and a culture that 'has become so wet and so effete and so self-critical and so implausibly plausible and is terrified of making an affirmative statement about anything'. 952 Bowden's focus on Lewis's personality offers him the possibility to not only claim Lewis's works for the right-wing intellectual tradition, but to effectively counter conflicting embodiments of the intellectual. In this way the radical right-wing intellectual like Lewis is not presented as yet another intellectual but becomes a 
superior type of intellectual. In this way Bowden's talk is not only an introduction to Lewis but also a counter-attack against the widespread notion of the supposedly oxymoronic right-wing intellectual.

In the last of the three talks I will be looking at, Bowden introduces T. S. Eliot to his right-wing audience. While Eliot is definitely at home in the right-wing spectrum, he differs - in some cases considerably - from Lewis and Pound: he is conservative rather than radical, he was (and still is) firmly part of the (literary) establishment, and after his conversion in 1927 Christianity became the focal point of his ideological world-view. This matters, because Bowden's main argumentative strategy was to cast Lewis and Pound as radical rebels who resisted or revolted against the mainstream and establishment. ${ }^{953}$ Trying to make a similar case for Eliot would not be feasible, and thus Bowden has to change his strategy. This does not mean that he abandons one of his key arguments, namely his attack on the literary mainstream in order to brand himself as resisting mainstream discourse. That this tactic only works, again, by over-simplifying the debate revolving around Eliot's politics can be illustrated by analysing how Bowden engages with a study he decidedly objects to, namely Anthony Julius's T. S. Eliot, Anti-Semitism, and Literary Form. His criticism of Julius's study betrays that his knowledge of the book is at best limited. For Julius is quite open about his admiration of Eliot and his poetry, an admiration he is trying to bring in tune with his dismay about Eliot's anti-Semitism. ${ }^{954}$ To depict Julius's book as an intentional smear on Eliot's reputation is a superficial argument, although one that proved to be popular among literary critics. Again Bowden's line of argument works on the assumption that Julius's study was the epitome of the mainstream criticism's turn against Eliot: 'In the late 1990s, there was a concerted attempt to demonize Eliot based around a book called T. S. Eliot, Anti-Semitism, and Literary Form, which was produced by somebody called Anthony Julius'. This is especially remarkable since Julius's study is in some respects quite nuanced and pays respect to Eliot's literary talent. In his introduction, Julius writes: 'Indeed, as I seek to demonstrate in the following chapters, [Eliot's] poetry is one of anti-Semitism's few literary triumphs. ${ }^{955}$ When Bowden speaks of the concerted attacked, this creates the illusion of mainstream scholarship being a homogeneous bloc attacking Eliot, which in turn makes it easier for Bowden to depict his - or in generally the Right's - reclaiming of poets like Eliot as an act of resistance. Yet to produce this effect Bowden has to omit the considerable controversy and criticism Julius's study had caused among literary scholars. ${ }^{956}$ That mentioning of Eliot's anti-Semitism should be unsavoury for those parts of Eliot scholarship who uphold the legacy of New Criticism is understandable enough, but why would the New Far Right be upset to learn that Eliot was their 'ideological neighbour'?957 The answer to the latter ques- 
tion might be that while the New Far Right hope to challenge cultural hegemony they also depend on existing elements and structures. In this case the reclaiming of Eliot is contingent on Eliot being recognised as an outstanding poet by the mainstream. Studies like Julius's book are seen as a threat to Eliot's status even though some of his core arguments should not produce too much disagreement on the Right.

What is again remarkable in this talk is how little Eliot's poetry actually matters to Bowden's project of defending Eliot against the literary mainstream. Bowden heaps some very superficial criticism at existing Eliot scholarship, but he has nothing to offer in its stead. His engagement with Eliot's poetry - similar to his engagement with Pound's and Lewis's - is cursory, informed by little knowledge of the poetic work, and with little attempt to explore Eliot's poetics. For Bowden, Eliot's early poems embody 'nihilism and despair and inner despondency', they

very much despair at life, at existence. Don't just incarnate the disillusionment of the post-Great War generation, which suffered a catastrophic loss of faith in relation to Western traditions and structures at that time. It wasn't just a generational clash between those who had fought in the war and those who had ordered the bloodbath; it was a general and conceptual retreat from many hitherto adopted Western attitudes'. ${ }^{958}$

Notwithstanding Bowden's constant posturing as attacking mainstream scholarship, his own understanding of Eliot indeed follows the very conventional mainstream reading. If it was Bowden's aim to present a distinctly right-wing response to Eliot's art, he fails. This becomes especially apparent when he is directly commenting on Eliot's poetry. Early on in the lecture, he reads out parts of 'Prufrock', and his only comment on the poem is that it was penned before Pound's involvement. ${ }^{959} \mathrm{He}$ then moves on to The Waste Land, which would offer him ample evidence for his general argument. Yet his sloppy and inaccurate account of the poem's epigraph and dedication betray that his understanding of The $W$ aste Land is limited at best: 'There is this quote in Latin and Greek at the beginning of the poem where he basically talks about being honored by the greater craftsman.... ${ }^{960}$ Bowden's final verdict on the poem turns out accordingly: "The Wasteland" is probably the greatest expression of despair in the 20th century, and despair underlines quite a lot of Western artistic attitudes in the 20th century'. ${ }^{961}$ The hyperbole of the statement cannot mask its very conventionality. Later in his talk Bowden reads out the first part of 'Ash Wednesday', which is introduced with the words: 'Now, in the Four Quartets, for which he was awarded the Nobel Prize, Eliot draws out from the Christian tradition many associations which we need just briefly to have a look at. This is "Ash Wednesday". This is the first poem after the re-conversion'.962 Apart from the fact that to the uninitiated reader 
this seems to suggest that 'Ash Wednesday' belongs to the Four Quartets, Bowden seems to set out for an exploration of Eliot's trajectory as a Christian poet, but then never completes this line of argument. Instead he closes his reading of 'Ash Wednesday', which ends at line 25, by musing: "Having to construct something upon which to rejoice" is the belief that when there is no cultural future you turn back'.963 This reading, and Bowden makes this clear in the ensuing paragraphs with the help of another non-Eliot related example, is a critique of and conservative reaction to progressivism as a project of the liberal Left. ${ }^{964}$ Now while this example might show how Eliot can be meaningfully read by the New Far Right, his elaborations lack the depth and complexity Eliot's poetical work warrants. This superficial interaction with Eliot's poetry is continued when Bowden, at the end of his talk, reads out 'The Hollow Men' and summarises the poem's impact on the cultural lexicon, adding laconically: 'That's, of course, what poetry does'. ${ }^{965}$ The effect of poetry on the cultural lexicon would have been an interesting point to discuss, especially in the light of the metapolitical project, yet Bowden abandons the topic before it has properly started.

As with his talks on Lewis and Pound, it becomes again apparent that while literature is incorporated into these talks, it is not the actual literary texts that feed into the conception of these men as arbiters of the intellectual tradition of the Right. Bowden's talk on Eliot never really answers the question why his right-wing audience should explore Eliot's poetry apart from the fact that Eliot was a man of the Right. In some parts of his lecture Bowden seems to be at pains to justify why Eliot should be read at all: 'One is often asked with figures as difficult, abstruse, and elitist as Eliot what the point of them is. The point is that they are transcendent figures. The point is that they look upwards'. ${ }^{966}$ This is not only quite vague but it also seems to jar slightly with Bowden's earlier reading of Eliot as the poet of nihilism and despair. Maybe even more surprisingly, Bowden has little to say about Eliot's politics in general. He calls him an 'ultra-conservative dandy'967 and lauds him for representing a cultural vision of Western grandeur that could be termed antiSpenglerism from the Right. ${ }^{968} \mathrm{He}$ only makes reference to one of Eliot's political essays, After Strange Gods, and this mostly to portray Eliot yet again as a victim of backlash. Eliot, due to his Christian conservatism, is not the ideal representative of the more radical right-wing intellectual, and Bowden has his difficulties presenting the poet in a light that would make him sympathetic to his audience. Bowden superficial rendering of Eliot the thinker and poet yet again raises the question what purpose his talks on selected authors fulfil.

While this question is valid concerning all three of the talks I discussed, it is in his talk on Eliot where Bowden deems it necessary, maybe due to Eliot's less than ideal suitability for his venture, to elaborate further on this 
point. The reason why poets like Pound, Eliot, and Lewis matter to the Right is because they are participants in a cultural struggle that is not only connected to discursive hegemony but also to identity. In this way, Bowden suggests, metapolitics is an important concept not only in its ability to effect a shift in power but as something valuable in itself: 'Metapolitics is the idea that there is something more to politics than the distribution through power and odd companies of how British Gas operates in the post-privatized world'. ${ }^{969}$ And this is where art comes into play: 'If you believe that politics is more than that sort of zero sum game, you have to have some higher metaphysical vision which is grounded in things like religion or art. ${ }^{9} 970$ Based on this line of reasoning, Bowden will later in his lecture condemn conservatives, because they, more than any other faction on the political spectrum, have forgotten the inherent (as opposed to the monetised) value of art:

The Tories are completely culturally witless except in private life [...]. But there is a degree to which the Tories have never understood what the enemy is and who the enemy is. They've never understood the importance of culture. Only the Left and the extreme Right understand the importance of cultural struggle. The liberal center has inherited the extreme Left['s] partiality for it. ${ }^{971}$

There seems to be an inherent critique that it was the conservatives' blindness to or ignorance of the cultural battle that has done lasting damage, in the eyes of the New Far Right, to Western society even when the conservative Right had been in power. The left/liberal dominance in the field of arts or culture in general is a direct corollary of the conservatives' failed cultural policies. Bowden's introductory lectures to the artists of the Right are a way to familiarise his audience with 'their' intellectual tradition. Moreover they are also a way to re-introduce these writers as right-wing artists into the (general) cultural discourse. Bowden seems keenly aware that there exists an interpretative power struggle surrounding names like Pound, Eliot, and Lewis. This is why he seems so pre-occupied with Julius's (and others') attempts at (supposedly) demonising these authors. When Bowden berates conservatives for abandoning the cultural struggle, thus leaving the cultural field to the Left, it becomes apparent that what he sees himself doing with these talks is to engage in said cultural struggle. The reason why he needs and wants to re-claim these artists for the Right is twofold: their art offers a piece of (white right-wing) Western cultural identity and their status as canonized authors makes them important elements in the metapolitical project. In a rare moment of reflection, which almost seems like an admission of defeat, Bowden sums up the importance of arts and literature for the Right:

Many people on the Right are not interested in high culture, let's face it. But 
there's a degree to which the enemy on the other side knows full well the power that it can have and the way it can transform lives, values, psychologies, purposefulness, and identities. That's why it takes it away from people. If it was of no importance, there wouldn't be a stink around the names of some of the people that I talk about. [...] No one can dismiss the political allegiance of W. B. Yeats, the metapolitical tangentialism of T. S. Eliot, the open espousal of forms of pre-religionistic fascism by Wyndham Lewis, and the open advocacy of fascistic politics, never mind metapolitics, by Ezra Pound. These are not things you can have a laugh about. These are not things that can be deconstructed out of existence. Because the point of those theories is you break it all down, and then you reconstitute it again, because it's still there. And if it's still there, it's still powerful. It's still residential[.] It can still be used by the other side. It can still be used by our side, if we have the wit to do so. ${ }^{972}$

\section{The Occidental Quarterly}

Similar to Counter-Currents, The Occidental Quarterly (TOQ) has an offline existence and to a lesser extent an online existence. The former comes in the form of a magazine of the same name, subtitled Western Perspectives on Man, Culture and Politics, and is published by the Charles Martel Society. The current editor is the afore-mentioned Kevin MacDonald. The Southern Poverty Law Center has described TOQ as a '[s]lick, academic-looking journal edited by a Who's Who of the radical right', a review $T O Q$ proudly posted in its 'About'section. ${ }^{973}$ And indeed, TOQ has not only been associated in the past and present with influential figures of the Right but also flaunts its high intellectual profile. Of the thirteen current members among its staff, nine hold a Ph.D. and two a D. Arts. ${ }^{974}$ Predictably, the magazine follows an intellectual stance targeting the cultural elites in power, which they, the magazine's contributors, see as the main entity responsible for the supposed demise of the (white) Western world: 'There are quite a few reasons for the precarious state of our civilization and our people. But one of the main ones is that we have lost the intellectual and moral high ground to a cultural elite that is hostile to our people and our culture'. ${ }^{775}$ TOQ sets itself out 'to change the attitudes of White people so that they will feel confident identifying as White and explicitly asserting their interests as Whites'. ${ }^{976}$ Their primary focus lies on issues of politics, history and culture interwoven with categories such as race and identity. As an example, the issue for Spring 2017 contains articles on 'The IndoEuropean Genetic and Cultural Legacy in Europe' (by MacDonald), as well as 
writings on Carl Schmitt and T. S. Eliot among others. ${ }^{977}$ For my project I will analyse one of the more unusual contributions to $T O Q$, which was published on the now defunct blog of its website. ${ }^{978}$

An article from January 2013 offers an illuminating addition to the more biographical takes on Modernist artists from Bolton and Bowden, namely what could be termed a right-wing reading of Eliot's 'Gerontion'. A user named Yggdrasil, after the world tree in Nordic mythology, uploaded Eliot's 'Gerontion' to TOQ Online, at first without any commentary. After some initial negative responses questioning the relevance of the poem for today's right-wing movement, especially with regard to its pessimism and its obscurity, ${ }^{979}$ Yggdrasil submitted a detailed analysis of the poem and why it should still matter for today's Right. At first, however, Yggdrasil complains about the discrepancy between the movement's cries for metapolitical change and at the same time the ignorance of and a lack of interest in (high) culture:

I am always amused at the many within this movement who declare that we must transform the culture (a truly massive task) and that a change in political regime will follow. It would appear though that the only part of Western Culture these folks have truly spent much effort to understand would be Nietzsche and a few other German philosophers. [...] So in truth it is no surprise that the publication of T. S. Eliot's Gerontion only elicited two comments in a couple months, and the first, a rather typical condemnation of "pessimism"... 980

Similar to Bowden the appreciation of the importance of culture comes with a sense of defeat at the challenges set by the metapolitical project.

Undeterred Yggdrasil suggests the following reading for the poem, starting with the first two lines of the poem ('Here I am, an old man in a dry month/ being read to by a boy, waiting for rain'):

$[\mathrm{M}] \mathrm{y}$ take is that the narrator is listening to the radio, and the poetic image certainly has captured the essence of mass media even in its infancy, since all news readers are "boys" in the sense that the script they are reading from is controlled by people behind the scenes with an agenda.

The juxtaposition of the old man and the boy in these two lines are given a deeply political meaning by suggesting that the boy is controlled by an unseen power in the background. This already hints at familiar right-wing themes of the Jewish conspiracy and the ZOG (Zionist occupied government). Moreover, is also symbolises the juxtaposition of values:

It is also appropriate to think of the old man as Western Civilization, again being read to by a boy - a series of irresponsible, and in the civilizational sense, youthful follies and delusions of human equality and progress, so horribly debunked in the First World War... 
This reading pitches age-old wisdom, suggesting such things as tradition and heritage, against 'youthful follies': the youths slain in the Great War are also the youthful follies debunked by it. This in turn might explain why there is still a sense of 'mildly optimistic hope that something might change for the better', which Yggdrasil sees in the phrase 'waiting for rain'. What is noteworthy is that even though Yggdrasil argues for the poem's continuing relevance, the poem is read against the backdrop of the Great War, roughly the time of its composition. The argument that seems to be made here is that either today's situation is comparable to that of the beginning of the $20^{\text {th }}$ century, or that the beginning of the $20^{\text {th }}$ century set off a dynamic that continues until today. However, as Yggdrasil freely admits, lines 3-6 complicate the previous reading 'unless Western Civilization can be anthropomorphized into the first person "I". This doubt is brushed aside by a quick statement that the "narrator is admitting that he did not serve during the World War (One) and is not a hero' before Yggdrasil moves on to the lines offering 'a poetic image of overarching power':

The "decayed house" is of course, the Western or white world, and the phrase "the jew squats on the window sill, the owner" is the perfect image to capture the essence of the new owner of that world, an outsider squatting on the sill looking in, the parasitic rentier who is not about to squander its capital in advancing the cause of the West, but rather like a scavenger crow or vulture watching the slow death of its victim as it waits for a meal'.

Here the reading returns to the initial interpretation that saw its central persona symbolising the (white) Western world, which is beleaguered by enemy forces. The house serves as a convenient metaphor for the self, which is here equated with a white Western identity but also white Western culture/society in general. In this scenario, the Jew remains the perpetual outsider, who nevertheless wields tremendous power over white Western society/identity. Yggdrasil's reading incorporates a slew of conventional anti-Semitic clichés: The Jew as parasite (or other deplorable animals), who makes a profit by exploiting others (non-Jews) without producing anything of true value, and moreover, the Jew as in control (of the Western world) while secretly working to destabilise and ultimately destroy it. According to Yggdrasil's reading, the Jewish owner is solely responsible for the detrimental state of the house. The poem's following two lines ('Spawned in some estaminet in Antwerp, / Blistered in Brussels, patched and peeled in London') add further weight to this reading:

[they] refer[ directly to the "cheap cafe" cultural transmission belt of contempt for the host population that goes far beyond mere parasitism. [Eliot] could as well be referring to the "yeasty" hostility of cafe culture on the lower East Side of Manhattan of that day. And of course the spawn of this hos- 
tile culture then inevitably produces blisters, patches and the peeling of decay in the Capitols of our once vibrant race'.

The Jewish influence produces decay, going far beyond mere parasitism, because it accepts the death of its host. Interestingly, Yggdrasil takes the body imagery, as in the poem it is the Jewish body being spawned, blistered, patched and peeled, and applies it to culture. The sexual act with implied sexual transmitted diseases in the poem becomes the 'cultural transmission' in Yggdrasil's reading; the Jewish body in decay becomes the ruins in the Capitols. Moreover, Yggdrasil has now made the jump from the metaphorical noplace of the poem, although Yggdrasil read it as the Western white world, which in combination with the Great War would suggest Europe, to the very concrete 'East Side of Manhattan', yet another anti-Semitic cliché. While one could deplore that Yggdrasil's reading regularly incorporates conventional anti-Semitic clichés, this is exactly what the poem offers. 'Gerontion' taps into the anti-Semitic discourse of the $20^{\text {th }}$ century and Yggdrasil's reading shows quite well that this discourse is still alive and meaningful to a right-wing audience of the $21^{\text {st }}$ century.

Yggdrasil continues and reads lines 11 to 14 as an image of perseverance in times of 'decay and the devastation of war', perhaps suggesting that the woman tending the household offers a quasi-nostalgic glance at a world of clearly defined gender roles. By calling it a 'timeless routine of daily life' Yggdrasil suggests that this is, and should be, the normal and natural way of being. In this way, the traditional household becomes the root of resistance against the modern world. This reading is supported by the shift in mood Yggdrasil perceives in the following lines culminating in 'Came Christ the tiger' (line 20). Yggdrasil writes:

In the first two and one half lines [17-19] we see an allusion to the loss of faith and confusion of the modern era with its endless attempts to reconcile science with faith, but also with our self-imposed suffocating tolerance demanded by the emergence of civil society, in which everything that really matters must be compromised away or forgotten.

While the imagery of the poem remains vague, Yggdrasil's reading brings in issues of science, faith, tolerance demanded by civil society and a sense of loss of identity. Especially the latter two are common themes in right-wing discourse, yet it takes a certain interpretative effort to read the highly allusive lines 'Signs are taken for wonders. "We would see a sign": / The word within a word, unable to speak a word, / Swaddled with darkness...' as 'self-imposed suffocating tolerance demanded by civil society'. What should be noted though is how similar Yggdrasil's words are to Eliot's own description of modern (in Eliot's case, 1930s) society from After Strange Gods: 'where two or 
more cultures exist in the same place they are likely either to be fiercely selfconscious or both to become adulterate. [...] And a spirit of excessive tolerance is to be deprecated'. 981 Both share the same discourse. This also holds true for the issue of religion, in this case Christianity. Yggdrasil notes of lines 19-20: 'And then comes the lighting bolt out of our vigorous past', namely 'Christ the tiger'. This image stands in stark contrast to the eponymous old man of the poem who is 'dull' (1. 16) and has never fought (1. 4). Though the comparison between both figures is not made explicit, Yggdrasil here finds a metaphor for the degradation of the 'European race':

The poetic image of Christ the Tiger jolts us into recognition of how far we have fallen from the roots of our European race, fallen so far in fact that we are no longer able to embrace Christ the Tiger as our ancestors instinctively did over 1000 years ago. We are fascinated and yet repelled.

Christ the tiger is a reminder of the once glorious past that is associated with strength and a certain wildness compared to weakness and passivity. At the same time Yggdrasil seems to find hope in these lines as they seem to spell out the possibility of a rebirth, and thus a reawakening of white identity and the societal shifts this would supposedly entail.

Here ends Yggdrasil's reading of the poem, and despite the note 'to be continued', nothing has been added to it within the last four years. It nevertheless offers a glimpse into a specifically right-wing reading of Eliot's 'Gerontion'. What it demonstrates is that the poem offers its right-wing audience a wealth of specifically right-wing discourses. Moreover, these discourses have remained remarkably stable, so that even when the poem is put into a historical frame, for example, read in the context of the Great War, it can still be used as a powerful commentary on today's society. Yggdrasil's reading proves just how politically potent Eliot's poetry still is for the Right of the $21^{\text {st }}$ century. However, Yggdrasil's comment as a whole also betrays the lack of interaction with or interest for (high) culture among the New Far Right.982

\section{Sezession}

Sezession is a German far right magazine published by the Institut für Staatspolitik (IfS), which was founded by Götz Kubitschek, Karlheinz Weißmann and five other undisclosed members in May 2000.983 Its first number was issued in April 2003 with Kubitschek as editor-in-chief. It is nowadays considered to be the successor to Criticón, formally the major magazine of and for (German) right-wing intellectuals, which folded in 2007.984 Sezession describes itself as 'the major right-wing intellectual magazine in 
Germany'. ${ }^{985}$ It explicitly targets a self-proclaimed elite of readers who are able to grasp the complexity of the world and the nuances of right-wing, conservative thought. ${ }^{986}$ Moreover, the authors consider themselves as part of the metapolitical project, stating that Sezession has been responsible for thinking out, formulating and inserting into the discourse many of the things that seem or are elemental, uncompromising, non-negotiable and aggressive in the AfD or other projects of the 'national resistance' ${ }^{987}$ For this project I will examine an article called 'Faschismus und Avantgarde' [Fascism and the Avant-garde], by Götz Kubitschek from Sezession 34 from February 2010.

In his article Kubitschek describes the 'convergences and intertwining' of the avant-garde and fascism. ${ }^{988}$ What differentiates his article from Bowden and Bolton's engagements is not only its broader scope, but the fact that $\mathrm{Ku}$ bitschek makes an earnest attempt to approach the avant-garde as political art and not just as an assortment of artists interested in politics. He begins his piece with a strong statement: 'Those who speak of fascism, must not be silent about the artistic and literary avant-garde'. This establishes a clear link between political and artistic movement. What is interesting is that the wording is not 'those who speak of the avant-garde, must not remain silent about fascism' but rather the other way around. While the alternate version postulates that the avant-garde can only be grasped by looking at its connection to fascism, Kubitschek seems to suggest that fascism always has to be thought of in conjunction with the avant-garde. Moreover, there seems to be an implicit acknowledgment that fascism has brought forth these artistic movements: a thought that emerges when Kubitschek muses that it would have been strange if art had revolutionised itself without coming into contact with the political revolution at hand. ${ }^{989}$ When he boils down the avant-garde to five key characteristics - provocation, innovation, authority, pathos and selfreflexivity ${ }^{990}$ - they appear oddly ambiguous and could just as well describe a political movement, specifically the fascist movement as it was emerging in the early $20^{\text {th }}$ century. In this light it is not surprising that Kubitschek finds the avant-garde to be an inherently authoritarian movement: 'The exclusion and discrimination as part of the agon between rivalling artists makes the avant-garde an authoritarian movement: they were not interested in reaching consensus, but acted in a manly, hard, aggressive as well as arrogant fashion and against everything out of pure joy in enmity'. ${ }^{991}$ It seems here that $\mathrm{Ku}-$ bitschek too easily conflates the avant-garde and fascism and thereby leaves some of the complexities and internal contradictions unmentioned. Similar to Bowden and Bolton, Kubitschek seems to be primarily drawn to the avantgarde because of their similarity to an authoritarian movement, and especially their hard, manly, and aggressive stance, and only secondary due to the actual art they produced. Even though Kubitschek, in the course of his essay, 
touches upon different artworks/literary works of different authors his interest seems to be based on their proximity to fascism. Thus the opening suggest that it was the avant-garde that bestowed positive value upon fascism, later it is the avant-garde that becomes commendable because of its inherent authoritarian character. This would also explain why Kubitschek feels comfortable to include Pierre Drieu la Rochelle and Robert Brasillach, who were indeed fascists and collaborators, but do not really represent the French avant-garde. The same holds true for the inclusion of Yeats, Lawrence and to a lesser degree Eliot: while all three of them can be considered important voices of the right-wing canon, which Kubitschek tries to construct here, they cannot really be considered avant-garde. Kubitschek tries to consciously blur the association between these three writers and the avant-garde when he introduces them as 'rallying around the avant-garde intersection [i.e. the Vorticist movement]'. ${ }^{992}$ While this might be true for Eliot, as part of his 'Preludes' were published in BLAST 2, Kubitschek's claim that Eliot 'between the wars was sympathetic to fascism and National Socialism', ${ }^{993}$ is an exaggeration at best. Here Kubitschek seems to shy away from the finer nuances of political allegiance - seeing that Eliot does not fit into Kubitschek's earlier categories and moreover with Eliot being a conservative close to fascist ideology but growing sceptical of any of the fascist permutations - in favour of keeping his central narrative intact. Yeats had little to no connection to Vorticism, despite Pound being his secretary. Lawrence was not only Lewis's literary nemesis, but his distinct literary style placed him far away from the Vorticist and the avant-garde in general. Kubitschek's article once more demonstrates the pitfalls of exclusively relying on the concept of fascism for classifying the political allegiances of the avant-garde and modernism.

What makes Kubitschek's essay additionally interesting for this project, especially seeing that it was published in a German magazine, is his focus on Vorticism, which not only receives more space in the text than Futurism, but also has four separate pages devoted to its art. While a short introductory text explains Vorticism, nine illustrations adorn these pages including the covers of BLAST 1 and 2 as well as a sample page from the manifesto. This 'special feature', which disrupts the corresponding essay - it is inserted between pages 30 and 31 - seems to suggest an earnest interest in avant-garde art and not only the biographies of its artists. But this feature also betrays a certain sense of educational mission, informing the magazine's audience of this rather more obscure avant-garde movement. The virtue of Vorticism being little-known is that it can be reclaimed without much resistance. Kubitschek can direct readers to only one German language secondary source on Vorticism: an exhibition catalogue edited by Karin Orchard and published in 1996. The special feature on Vorticism can therefore also be read as an attempt to popularise 
this specific avant-garde movement. Embedded in an article on fascism and the avant-garde, however, it becomes clear that it is also presented as a specific right-wing art movement. What makes this even more interesting is that the small introductory text seems to agree with the Vorticists that their avantgarde movement was superior to Futurism: 'Rightly the Vorticists refused to be considered the English offshoot of the anarchic and expansive Italian Futurism'. ${ }^{994}$ It is suggested that the Vorticist 'concentration of energies around a shared core ${ }^{995}$ surpasses the chaotic Futurism, and maybe more importantly, that the strong national sentiment of Vorticism is to be preferred over the expansive, and thus equalising, Futurism. In this light it seems rather curious that Kubitschek decided to include a painting by C. R. W. Nevinson, a selfavowed Futurist. ${ }^{996}$ In general the feature contains very little information on the art and artists included. It also fully neglects Vorticist literature (apart from the reproduction from the manifesto), which seems odd, given that Pound is frequently brought up in both texts. This is not to deride what seems to be an earnest effort to introduce the largely unknown Vorticism to a German audience. Yet the way it is done - constructed in a way that seems to be professional while it is actually superficial and displaying a certain lack of understanding - seems to suggest less of an interest in Vorticism as art, but rather, yet again, as politics. Vorticism is important, and therefore should be known to the readers of Sezession, not because it was the only avant-garde movement England ever saw, but because it can be considered a right-wing avant-garde movement.

Kubitschek's piece on fascism and the avant-garde shows that there is an interest in revealing the 'ideological allegiances' of artists and art movements. While Kubitschek does not - in contrast to Johnson, Bowden, and Bolton - explicitly counteract left-wing/liberal/mainstream discourse, his article nevertheless constitutes an example of re-claiming the avant-garde for the Right. Although Kubitschek never specifically lauds fascism, his insistence about the connection between the avant-garde and fascism, while omitting the avant-garde's relation to other and previous art-movements, seems to be an attempt to attach some positive value to fascism at the detriment of democracy. These artists' reaction against democracy as well as the values of the Enlightenment, and the fact that they turned this reaction into great art, support this narrative and Kubitschek concludes: 'It [fascism] presented itself up until the late twenties not as a totalitarian - and this always means an exclusionary ${ }^{997}$ and exterminating - threat but as an attractive alternative to (the failed) democracy: attractive at least for artists due to its hierarchical structure and acceptable because it had not yet, in contrast to Bolshevism, committed genocide'. ${ }^{998}$ This conclusion conveniently ends before fascism turned its words into deeds. Kubitschek thereby normalises and rationalises fascism as 
acceptable and attractive in theory. Democracy, so Kubitschek almost casually notes, has already failed by the 1920s, a claim that seemingly does not need to be corroborated as it possibly functions as a premise among his readership. His inclusion of Bolshevism as the other non-democratic but unacceptable choice consciously ignores the large number of artists in favour of Bolshevism/communism and maybe unconsciously overlooks artists like Lewis who was in the beginning torn between communism and fascism. In this way, fascism was not only attractive and acceptable for artists but the connection between fascism and the avant-garde becomes a quasi-natural and logical given.

\section{CasaPound}

All the examples I have discussed so far followed a particular strategy: against the stereotype of the 'uneducated, violent males sporting swastikas and missing a couple of teeth' 999 they have cultivated brands that offer right-wing ideology in an intellectual and respectable format. They specifically target an intelligent and educated far right-wing audience. When addressing literature and the arts as part of the metapolitical project, there seems to be mostly an inward projection, i.e. the conversation remains among themselves. Even though the supposedly liberal mainstream discourse is often explicitly addressed they do not engage with it, and there seems to be little interest in engaging, with a liberal or mainstream audience. Thus the (re-)claiming of the authors discussed above is done for the benefit of their own group - aiming at identity formation, forging of a cultural consciousness, establishment of a right-wing intellectual tradition to name but a few of the possible benefits and not (yet) as a direct challenge of the political adversary or the mainstream. There are, of course, other different engagements with literature that can be found among the New Far Right. With the rise of new media, online communities and online activism became an important element in the recent growth of the New Far Right. Social media offer the possibility not only to address a large international audience but also to connect real-life forms of protest with online forms of engagement: in this way, what would be a small local event in real life can be blown out of proportion and immortalised online. Moreover, the internet's own special forms of communication, for example internet meme culture, ${ }^{1000}$ has in recent years greatly shaped the way the Right, or more precisely different groups on the right-wing spectrum, present themselves and interact with others. The most famous example at present is Pepe the frog, which has been seized primarily by American right-wing groups, especially the Alt Right, as a symbol and humorous online-ego, and 
then later merged with Kek, an Egyptian frog-shaped deity. ${ }^{1001}$ Even something as innocuous as cat memes can be 'intellectualised' and given a right-

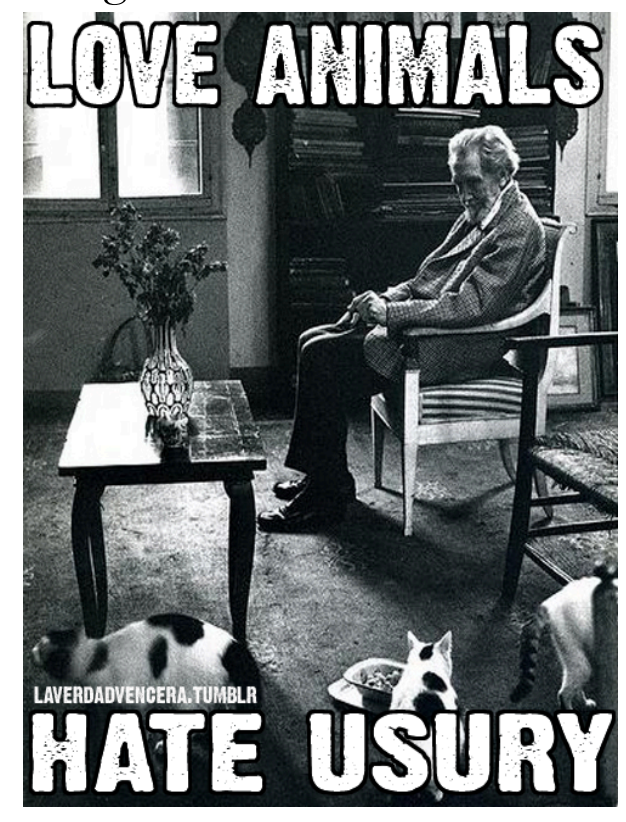

A meme featuring Ezra Pound and cats

wing spin, as the example, pictured here, shows. What makes this meme noteworthy is the way it relies on a certain amount of inside knowledge. For the slogan 'love animals - hate usury' only fully makes sense to those who can identify Ezra Pound and can contextualise 'hate usury' in Pound's writings that explicitly connect usury with Jews. In this light, the slogan quickly morphs into love animals - hate Jews'. This illustrates that memes can successfully be used to transgress boundaries of the sayable. At present it seems that exactly those movements that combine 'online culture' with intellectual content not only garner the most attention, but are also most successful in their metapolitical aims targeting the discourse with pop and high culture. How these strategies - the inclusion of subcultures or subcultural forms of communication, pop-cultural aesthetics and a carefully curated performance and appearance - can be used to advance a successful and exceptional real-life far right movement is demonstrated by the Italian CasaPound (CPI). Exuding from its core, the eponymous Casa Pound - a formerly squatted building in the centre of Rome, which is now owned by the movement as it was gifted to them by the then major of Rome, Giovanni Alemanno ${ }^{1002}$ - CasaPound has established a network of social, cultural and political locations and activities to unleash 'fascism for the third millennium'. There is no space here to analyse CasaPound in more detail. ${ }^{1003}$ Instead I wish to take a closer look at the role Pound the poet plays in and for the movement.

One has to admit, that at first glance it seems to be an odd choice that an Italian neo-fascist movement should name itself after the American poet Pound, seeing that they would have had plenty of possible Italian 'patrons' available. When Colin Liddell interviewed CPI leader Gianluca Iannone for the now defunct Alternativeright.com, Iannone explains the choice thusly:

Ezra Pound was a poet, an economist and an artist. Ezra Pound was a revolutionary and a fascist. Ezra Pound had to suffer for his ideas, he was sent to jail for ten years to make him stop speaking. We see in Ezra Pound a free man that paid for his ideas; he is a symbol of the "democratic views" of the winners. ${ }^{1004}$

What becomes apparent is that Pound was chosen because his person and life 
story resonated with the founders and leader of CasaPound; the man as artist, revolutionary and fascist again overrides the art that he produced. His being incarcerated by a democratic government makes him a doubly useful martyr figure as he (not only fought but also) suffered for his ideas and moreover his treatment at the hand of the US government seems to lay bare the nefarious duplicity of the supposedly tolerant democracy. ${ }^{1005}$ When Iannone speaks of 'the "democratic views" of the winners', he not only points to the adage that 'history is written by the winner' with an implicit suggestion that it can therefore also be falsified by the winners, but also implies that democracy itself is a sham. In this way, Pound constitutes the ideal figure for identification - more so than artists like Marinetti or D'Annunzio - since the backlash, persecution and condemnation he faced seem to mirror the experiences and selfperception of the far right in $21^{\text {st }}$ century democratic societies. What is also important is Pound's high status as an internationally recognised poet and significant figure of Modernism. There is, however, one thing that tarnishes this image, and that is the matter of anti-Semitism. Liddell asks Iannone: 'Ezra Pound is also a name routinely associated with Anti-Semitism. Some will automatically see the invocation of his name as a rallying cry for AntiSemitism. Could you clarify CasaPound's position with regard to the Jews and Israel?' To which Iannone answers: 'To associate Ezra Pound and antiSemitism is an absolute twist. It is the same for CasaPound, it has no sense'. Similar to other right-wing responses to Pound the issue of anti-Semitism is either shirked or denied, even though Pound's ideas on the Jews would probably find many sympathetic listeners among the New Far Right. Iannone uses the familiar strategy here of turning the narrative around to make the criticism of anti-Semitism a quasi-conspiracy theory. Curiously the one central idea that CasaPound has adopted from the writings of Pound is his stance on usury, which they, similarly to Pound, condemn in all its forms. ${ }^{1006}$ As I have explained above for Pound usury and the Jews were inextricably linked, and thus CasaPound's adoption of Pound's anti-usury stance seems to imply that they are at least aware of the connection. On their website, CasaPound has a page devoted to the poet, yet here again it is exclusively his life that is covered with the exception of a paragraph on Pound's ideas on usury (describing it as 'the root of modern wars and the strangulation of peoples'). ${ }^{1007}$ The connection between usury and the Jews is conveniently left out. Instead it is highlighted that Pound considered Fascist Italy as the only country taking a stand against international usurocracy ('l'usurocrazia internazionale'). Moreover Mussolini is portrayed as a supporter of Pound and his ideas: "Il mio amico Pound ha ragione. La rivoluzione è guerra all'usura"" ("My friend Pound is right. Revolution is war on usury.'). ${ }^{1008}$ CasaPound's fight against usury is presented as the continuation of Pound's (and Mussolini's) struggle, for which 
both had to pay dearly.

Despite CasaPound being an exceptional right-wing movement by addressing all spheres of private and public life, their engagement with Pound does not radically differ from the other intellectual right-wing groups. Pound is primarily presented through his life story and it is Pound the man who is celebrated rather than his artistic output. Although Pound is frequently presented as a poet, the poetry itself does not seem to matter. Despite this the reclaiming of Pound relies heavily on his being perceived as a great artist not only by the Right, but by the mainstream. His high status and international recognition matters because it seems to bestow authority and validity to his ideas. The fact that Pound had to suffer (at the hands of democracy and liberalism) for spreading his ideas but nevertheless persisted, makes him an ideal figure of identification for the New Far Right, which sees itself stigmatised, marginalised and oppressed by the same forces. Hence the narrative of Pound CasaPound offers seems to be effectively a narrative of themselves.

\section{Final thoughts}

The reception of literature among the New Far Right is admittedly a niche topic, although there is an awareness among parts of the New Far Right that this issue matters. In an interview with Alex Kurtagic, Johnson said that:

...we need to expose young, racially-conscious white artists to the great exemplars of the past. You don't have to go back too far before one discovers that practically all great thinkers and artists are "right wing extremists" by present-day standards. Beyond that, many of the greatest artists of the 20th century were on our side as well. That is a tradition that we need to recover. ${ }^{1009}$

Similarly, Andrew Joyce closes his article 'T.S. Eliot and the Culture of Critique' with the words:

While politics is crucial, we neglect the cultural war at our peril. To paraphrase the conclusion of my treatment of the campaign against Ezra Pound: Civilization, for all its greatness, is ultimately a fragile entity. It requires care, conservation, and occasional pruning. If our culture loses sight of its geniuses, we will be all the poorer for it - ideologically, spiritually, tactically, and culturally. We all have a duty to keep these figures and their work alive. Our ability to do so will ultimately determine whether there is life in our civilization yet, or whether we may be as Eliot's 'Hollow Men,' our voices forever "quiet and meaningless." 1010

Yet while metapolitics are central to the New Far Right's self-perception, the 
realm of culture, in which the metapolitical project operates, is so wide and diffuse that almost every subject can be accommodated under its header. It might also be due to the growing ascendancy of right-wing (populist) forces in Europe and the U.S. in recent years, that the New Far Right has partly shifted back its attention to actual (parliamentary) politics. Cultural hegemony becomes a secondary goal, when actual hegemony seems closer at hand. However, what remains a major issue for the New Far Right is the matter of respectability. The stereotype of the uneducated and unintelligent rightwinger proves to be surprisingly persistent. What makes the matter even more complicated for the New Far Right is that among its own kind intellectuality clashes with right-wing notions about such things as masculinity. It is not surprising that in right-wing portraits of artists, especially in my case of Pound and Lewis, their combativeness, aggressiveness, and sexual prowess are frequently evoked in conjunction with their intellectual and artistic capabilities. The right-wing avant-gardes (i.e. Futurism and Vorticism), with their performative competition, hardness, and virility become the ideal representative of a decidedly right-wing intellectual tradition into which the New Far Right likes to inscribe itself. The (re-)claiming of these artists by and for the Right still largely happens within the Right's own echo-chambers. The resistance against the mainstream discourse becomes a central tenet in the Right's narrative about literature, yet this narrative is rarely brought into actual mainstream discourse. Challenging the existing cultural hegemony remains thus a performative act and is not translated into an actual confrontation. What makes this rather puzzling is that in the specific field of Modernist literature, the mainstream discourse would actually be quite vulnerable to a sophisticated attack from the Right. Yet I could not find one instance where the liberal mainstream or the Left were directly challenged by the Right with the dilemma of having a high regard for art, which opposes their fundamental values. It seems that the Right's inward gaze fulfils a different function than simply reclaiming 'their' artists from a hostile hegemonic discourse. What almost all of my examples had in common was a preoccupation with Pound, Eliot, and Lewis as artists, thinkers, or simply intellectual men of the Right, and less a concern for the actual products of their labour. ${ }^{1011}$ Maybe what these men's biographies offer are positive narratives of right-wing intellectual life, which so crucially seems to be lacking from mainstream discourse. During a time when the New Far Right consider the concept of identity as the prime target of attack every re-telling of these artists' lives becomes a re-telling of who they, the New Far Right, are, how they perceive themselves and how they want to be perceived. 


\section{Do Civilized Peoples Execute THEIR POETS?}

When Robert Brasillach was put on trial for treason, his artistic ability and intellectual capabilities very much dominated the debate. For some his outstanding literary merit should have guarded him from accusations and punishment; others thought his superior intellect had made collusion with the National Socialists a more serious kind of treason. 'Do civilized peoples execute their poets?', Brasillach's lawyer invoked. In the case of Brasillach they did. ${ }^{1012} \mathrm{~A}$ number of artists and intellectuals across the political spectrum had petitioned to save Brasillach to no avail. Pound escaped a similar fate, and in his case an initiative by artists across the political spectrum proved successful, effecting his release from St Elizabeths. At the heart of both cases was the question of the responsibility of the artist in a political context. With the death of the author (in both ways) the focus can now be shifted onto the ideological structures in the literary work itself, asking in how far literature draws from right-wing discourses and, in turn, feeds back into them. Yet many critical readings of literature are often misconstrued as attacks on the (reputation of) deceased authors. This straw man argument obfuscates the more challenging questions such endeavour raises. If literature embraces and promotes right-wing ideology, if it is the locus of discursive violence, one should ask what the most appropriate response needs to be, especially in times when the political climate is veering to the Right. Criticising Bolton's book Artists of the Right I wrote that addressing these artists' right-wing ideology is in itself nothing that has not been done before, what matters is how their ideology is addressed. Since cultural practices are always inevitably political, it follows that not only is the literature itself political, but our handling of it is as well. I criticised literary scholars in this book, sometimes harshly, not merely because I disagree with their reading, but because their performative refusal to take ideological criticism seriously upholds a hegemonic system that constructs a supposedly neutral standpoint from which to assess these texts. As I made quite clear in the beginning, this neutral standpoint does not exist. Pretending that it does, demotes dissenting views into the realm of activism. This is not a critique of activism, but a critique of the problematic binary that pitches activism against supposedly objective scholarship. There is a place in the debate for those scholars who want to emphasise the complexity, polyphony, and textual 'openness' of these Modernist texts. This does neither contradict nor invalidate readings that stress how these texts lend themselves to ideological 
readings. Modernist texts wrote themselves into right-wing discourses, but they are more than right-wing literature.

Nevertheless, right-wing reception of Modernist literature should not be too hastily dismissed as trivial. The popularity of some Modernist writers, especially Pound, among the New Far Right should give pause to those scholars, who see little need to address the ideological structures in these texts. The fact that representatives of the New Far Right actively promote Pound's writings as political inspiration - for example Martin Sellner, Austrian head of the Identitäre Bewegung or Sam Woodward, member of the American terrorist organisation Atomwaffen Division and currently on trial for murder ${ }^{1013}$ - should warrant a more serious approach than simply asking whether they actually read Pound's writings. I would argue that the answer does not really matter and this is the wrong question to ask in the first place. What this question implies, however, is the assumption that this reception by the far right stands in contradiction to what Pound actually wrote. This is not the case. The Cantos and Pound's essays are congruent with many political ideas and actions embraced by today's far right, something they are aware of, whether they have read him or not. Pound, the writer as well as his writings, functions as a code for the necessity but also the dangers of fighting against a hostile system. An interpretation a close reading of the Cantos would corroborate. What makes Pound so popular among the New Far Right is that his story serves their particular narratives. The Cantos, although being extremely dense, complicated, and sometimes near unintelligible, can be read as a retelling of history with the individual resisting a system in crisis. The story of how the Cantos was written becomes part of the epic but also part of its myth. ${ }^{1014} \mathrm{~A}$ myth that has been in the making by multiple generations of right-wing readers. In this way Pound, but also writers like Lewis and Eliot, become part of an intellectual tradition of the Right, stylised as forerunners of today's right-wing resistance. Engaging with right-wing responses to these Modernist writers makes the ideological content of the literature palpable, but it also highlights the consequences and sometimes even complicity of inadequate and apologist approaches.

The legacy of right-wing ideology runs deep in the fabric of Western societies and some of its extreme forms dominate our collective memory. The appeal of fascism to writers and intellectuals has repeatedly come under scrutiny, but did not always lead to valuable insights into the matter. As argued above, the concept of fascism as an analytical category is often to blame due to its inherent flaws. Moreover, by treating it not only as the political other, but also quite often as a historical movement with a set end, the focus on fascism has obscured other more pertinent issues. Situating Pound, Eliot, and Lewis in the broad spectrum of the Right draws out the interconnectedness 
between writers, audience, and scholars. The reason these writers could be celebrated for racial and class cultural appropriation as well as for revelling in the strategic 'othering' of marginalised groups is that they wrote from the dominant position in a society where these aspects not only firmly belonged to the sayable but which functioned on similar paradigms. Furthermore, these writers' relevance to the New Far Right shows that the ideological potency of these texts outlived the era they were written in; the right-wing discourses, into which they inscribed themselves, remain largely accessible to today's Right. This has rarely been the focus of scholarly analysis possibly indicating the unwillingness to locate Pound, Eliot, and Lewis within a movement that is frequently imagined as the very antithesis of high culture. Yet with the birth and growth of the so-called New Right, i.e. the right-wing strand targeting cultural hegemony and cultural change, the relationship between today's far right and their right-wing intellectual ancestry has to be taken into account. Central to the reception of the New Far Right is their narrative of 'mainstream' academia as unwilling or unable to engage with these authors' ideology, enabling them to portray their reception as an act of performative resistance to academic orthodoxy. While the Right presents an overly simplified version of the scholarly debate surrounding the subject, they do point to a central dilemma. How should the presence of right-wing structures in a literature so central to modern literary history be handled? Focussing on the poetics while evading the politics risks complicity; focussing on the politics is often accused of sacrificing the complexity of the poetics. What is needed is a conversation that can acknowledge these authors' artistic achievements while still problematizing and challenging the inherent promotion of inequality and discursive violence. For in our failure to adequately address right-wing ideology, we will only give power to those who wish to see it thrive. 


\section{Introduction}

${ }^{1}$ Cf. for example Anne Bowler; 'Politics as Art: Italian Futurism and Fascism' and Ehrlicher, Hanno; Die Kunst der Zerstörung: Gewaltphantasien und Manifestationspraktiken europäischer Avantgarden, especially pages 69-72. Already Walter Benjamin had written about Futurism's allegiance to Fascism in his seminal study Das Kunstwerk im Zeitalter seiner technischen Reproduzierbarkeit, first published in 1936.

${ }^{2}$ Cf. Jay W. Baird; Hitler's War Poets: Literature and Politics in the Third Reich.

${ }^{3}$ The 'Konservative Revolution' is an umbrella term for various right-wing groups, who existed during the time of the Weimar Republic. They rejected concepts such as liberalism, democracy and egalitarianism, but also distanced themselves from the then existing traditional Right in Germany. Their ideological proximity to National Socialism remains a contested issue: while some see them as 'ideological trailblazer' for National Socialism, others, notably the German New Right, emphasise the autonomy of the Konservative Revolution. The self-perception of the German New Right is closely linked to the Konservative Revolution, as evidenced by the fact that some of the definite books on the topic have been written my members of the Right, such as Mohler, Armin and Karlheinz Weissmann; Die Konservative Revolution in Deutschland 1918-1932: Ein Handbuch.

${ }^{4}$ In his study Die Brücke ins Geisterreich: Künstlerische Avantgarde zwischen Kulturkritik und Faschismus, Peter Ulrich Hein demonstrates the compatibility of avant-garde ideas with National Socialist ideology in matters such as ideas about masculinity, mysticism, cultural rebirth as well as the belief in Nordic or Germanic superiority. Some artists endorsed National Socialism well beyond its establishment. Consider for example Kirchner's reply when he was asked to leave the academy: 'For thirty years I have been fighting with my work for a new, strong, and authentic German art and will continue for as long as I live' ['Seit nun bald dreißig Jahren kämpfe ich durch meine Arbeit für eine neue, starke und echte deutsche Kunst und werde das tun, solange ich lebe.'] quoted in Hein, 250.

${ }^{5}$ In a recent retrospective 'Emil Nolde - Eine deutsche Legende. Der Künstler im Nationalsozialismus', Nolde's ideological commitment and his subsequent 'selfexpurgation and legend creation' ['Selbstsäuberung und Legendenbildung', text from the exhibition] were explicitly addressed. In 1933 he denounced fellow artist Max Pechstein to an official of the Propaganda Ministry, worked on a 'deJewification plan', and his memoir Years of Struggle [Jahre der Kämpfe] contained various anti-Semitic passages. After the war, Nolde destroyed papers with political content and began to fashion himself into an artist persecuted by the Nazis, a narrative 
that remained unchallenged for many decades. When the exhibition was opened in April 2019, Angela Merkel chose to return the two Nolde paintings, which had adorned her office.

${ }^{6}$ Heidegger's Schwarze Hefte (Black Notebooks) are his collection of journals, in which he collected thoughts and observations. Written between 1931 and 1951, they were published in instalments in 2014, 2015, and 2018.

${ }^{7}$ Cf. Reed Way Dasenbrock; 'Paul de Man, the Modernist as Fascist'.

${ }^{8}$ This not only holds true for the Left but also for the Right, which I will discuss in more detail below when looking at the influence of Antonio Gramsci's theories on the New Right.

${ }^{9}$ David Carroll has written a detailed and comprehensive study on the French Right titled French Literary Fascism: Nationalism, Anti-Semitism, and the Ideology of Culture.

${ }^{10}$ Julius, Anthony; T.S. Eliot, Anti-Semitism, and Literary Form, 35.

${ }^{11}$ Eagleton, Terry; Criticism and Ideology: A Study in Marxist Literary Theory, 148.

${ }^{12}$ Consider for example the writers of the so-called 'Auden Group', i.e. W. H. Auden, Stephen Spender, Christopher Isherwood among others, who cultivated a seemingly benign representation of the lower classes. However, on closer inspection the lower classes in the works of these authors might be championed for their simplicity and principles, but at the same time they are objects of condescension, pity and desire rather than fully-rounded subjects with agency.

\section{Looking at the F-Word and Beyond}

${ }^{13}$ Despite its promising title, Hamilton study is deeply flawed. While it offers an overview that intellectuals' allegiance to fascism was a European wide phenomenon, he makes little effort to grasp the underlying motivations of the intellectuals involved. Thus he concludes: 'For most of the writers who were attracted by Fascism it was an amusing means of provocation, a feather with which to tickle the throats of the English liberals. Yet it must also be admitted that surprisingly few of these writers were English themselves' (268). Hamilton is unable to explain fascism's appeal apart from its shock value. This does not only betray Hamilton's lack of knowledge of the given context, in which these men wrote, but it also shows his general dismissiveness of the issue, given his study an apologist stance especially when it deals with intellectuals from England.

${ }^{14}$ Griffin, Roger; The Nature of Fascism, 2.

${ }^{15}$ Payne, Stanley; $A$ History of Fascism, page x.

${ }^{16}$ Eagleton, Terry; Ideology. An Introduction, xiii. 
${ }^{17}$ Robert Eccleshall, Alan Finlayson et al.; Political Ideologies. An Introduction, 3.

${ }^{18}$ Ibid, 1-2.

${ }^{19}$ Bell, Daniel; The End of Ideology. Despite its title, the focus of Bell's study is an analysis of the social changes and structures in the USA of the 1950s. Moreover, the main target of his attack seems to be Marxism and the intellectuals devoted to it.

${ }^{20}$ Cf. Bell 419.

${ }^{21}$ Bell, 437.

${ }^{22}$ Bell, 437.

${ }^{23}$ Emphasis in the original. Bell, 419. Bell notes that this view is 'mistakenly called pragmatism in politics'. Thus a key element of ideologies for Bell is their emotional aspect: 'the most important, latent, funcion [sic] of ideology is to tap emotion' (400). This clearly makes them inferior compared to the prudent and rational civil politics he advocates.

${ }^{24}$ Bell, 16. Curiously, although Bell explicitly rejects more inclusive concepts of ideology, some of his characterisations of ideology do fit into my perspective on ideology. For example, he writes that '[i]deology is the conversion of ideas into social levers' (400), which I would consider an apt description of the creative role of ideologies. Moreover, he states, while criticising too vague concepts of ideology, that 'ideology connotes a "myth" rather than just a set of values' (399). Ideologies, I would argue, are both.

${ }^{25}$ Eatwell, Roger and Anthony Wright (eds.) - Contemporary Political Ideologies, 11.

${ }^{26}$ Barry Spurr in his book 'Anglo-Catholic in Religion': T.S. Eliot and Christianity offers a good example when he pitches Denis Donoghue and Anthony Julius against each other: 'The Irish critic, Denis Donoghue rejects the charge, commenting that to call Eliot anti-Irish is 'as specious' as to call him anti-Semitic. Julius, in turn, rebukes Donoghue, accusing him of not 'caring' about anti-Semitism (p.40). One suspects that what Donoghue cares about is the truth' (260). A few pages later Spurr adds in an even more condescending tone: 'A self-proclaimed 'liberal' (see, for example, p.116), Julius, like so many of that paradoxical breed, extends his liberality only so far as you are prepared to agree with him.' (265).

${ }^{27}$ Freeden, Michael; Ideology: A Very Short Introduction, 2. Eatwell and Wright offer a very similar definition when they write that ideology provide[s] an ordered system of symbols which help[s] people understand life in terms of meaningful patterns, and help[s] give their behavior purpose' (10).

${ }^{28}$ Hulme, T. E.; Selected Writings, 175. 
${ }^{29}$ In: Eagleton; Ideology: An Introduction, 48. Freeden writes: 'Ideologies need, after all, to straddle the world of political thought and political action, for one of their central functions is to link the two.' (Ideologies and Political Theory, 76).

${ }^{30}$ Eagleton; Ideology: An Introduction, 45. Eagleton brings in 6 features ideologies are thought to possess: they are unifying, action-oriented, rationalizing, legitimating, universalizing and naturalizing.

${ }^{31}$ Backes, Uwe; Politische Extreme: Eine Wort- und Begriffsgeschichte von der Antike bis zur Gegenwart, 101.

${ }^{32}$ Consider, for example, Andreas Pečar, Damien Tricoire; Falsche Freunde: War die Auflelärung wirklich die Geburtsstunde der Moderne?

${ }^{33}$ Querfront strategies also became popular again in Germany after 1945. The Russian National Bolshevik Party, founded in 1993 and banned in 2007, might be another contender. Very often the common ideological core of these groups is the rejection of the democratic bourgeois order. However, it is debatable whether these examples constitute a true overcoming of the left/right dichotomy, as they very often are initiated on the political Right, and mostly embrace right-wing ideological elements.

${ }^{34}$ Bobbio, Norberto; Left and Right, 7.

${ }^{35}$ Van Dijk, Teun A.; Ideology: a Multidisciplinary Approach, 203.

${ }^{36}$ Freeden, Ideology: A Very Short Introduction, 64.

${ }^{37}$ The horseshow model emphasises the resemblance of the extreme Left and Right, and is especially popular in the field of extremist theory. Imagining the left/right binary as a horseshoe brings the extreme Left and Right together in their rejection of the dominant society and equates their means employed to achieve their political goal. One of the most prominent representatives of the extremist theory in Germany is Eckhard Jesse. What is problematic about the horseshow model is that it disregards power imbalances and too readily equates different forms of violence. Statistically, right-wing extremists not only employ more serious violent behaviour but they also frequently target already marginalised groups or individuals. Therefore, it might not be too surprising that many adherents of the horseshoe model come from a privileged position (they are usually white male and middle-class) who, above all, see extremist violence as disturbing the status quo.

${ }^{38}$ Ibid Backes; Rechtsextreme Ideologien in Geschichte und Gegenwart, 48-51; Downs, William M.; Political Extremism in Democracies: Combating Intolerance, 14; Caiani, Manuela et al.; Mobilizing on the Extreme Right: Germany, Italy, and the Unites States, 5.

${ }^{39}$ In right-wing ideology power distribution can be a highly ambivalent and controversial concept as perceived power distribution often differs from real power distribution. Moreover, power distribution can be subject to great flux even within one single strand of right-wing ideology, Nazism for example. Although power is a 
crucial concept in right-wing ideology, I would argue that power (distribution) is not the core by itself but part of the concept of inequality.

${ }^{40}$ Griffin, for examples, uses both terms as modes of action: ideology can assume a reactionary, progressive or revolutionary aspect according to whether it acts in a given situation as (a) a conformist, conservative, hegemonic force, (b) an idealistic, reforming, but 'systemic' force or (c) a utopian, subversive, 'extra-systemic' one' (Griffin, Nature of Fascism, 15).

${ }^{41}$ Morrison, 9.

${ }^{42}$ Morrison, The Poetics of Fascism, 44.

${ }^{43}$ As Payne put it in his list of the main interpretations of fascism: Payne, Fascism, 178 , and 190.

${ }^{44}$ The signifier 'fascism' refers to the Latin word fasces, meaning literally 'a bundle of sticks'. The fasces, even in ancient Roman times, have always been a symbol more than an actual object of utility. Thus, if one attempts to define fascism by referring back to the fasces one has simply substituted one signifier for another, since the underlying concept/signified for the term 'fasces' is equally unstable and dependent on interpretation.

${ }^{45}$ Even looking to the far right for a definition of fascism does not bring vastly different results: According to my research, the majority of the German New Right reject the term as a self-description. Instead, it is mainly used as designating the historical phenomenon, often limited to Italian Fascism, or ahistorically as a term of critique against anyone viewed as a political antagonist, for example, 'left-wing fascism'. Compare, for example, the entries for 'fascism' in Metapedia (a right-wing Wikipedia) and in Staatspolitisches Handbuch from the Institut für Staatspolitik, a far right-wing think-tank I discuss in chapter 6.

${ }^{46}$ Sternhell, The Birth of Fascist Ideology, 3.

${ }^{47}$ All ibid, 3.

${ }^{48}$ Sternhell, Birth of Fascist Ideology, 4.

${ }^{49}$ Griffin, The Nature of Fascism, 14.

${ }^{50}$ Paxton, 219, and Griffin, The Nature of Fascism, 14.

${ }^{51}$ Cf. Griffin, The Nature of Fascism, 14.

${ }^{52}$ Ibid., 14

${ }^{53}$ Sternhell, Birth of Fascist Ideology, 3.

${ }^{54}$ The term Anti-Enlightenment is problematic here since it again re-enforces the pattern of constructing fascism and its predecessors as the other. A number of right-wing thinkers of the $20^{\text {th }}$ century (especially Hulme and his contemporaries) have replaced Enlightenment and Anti-Enlightenment with Romantic and Classi- 
cal. I will adopt part of this classification, using Classical together with the more conventional Enlightenment as its opposite in an attempt to avoid term-based bias.

${ }^{55}$ Cf. Payne, Fascism: Comparison and Definition, 7, and Paxton, 219-220. Payne's three categories are 1) Fascist Negations, 2) Ideology and Goals, and 3) Style and Organization. In the first category he puts the familiar triad of antiliberalism, anticommunism and anticonservatism; the second focuses on the re-organisation of the state and society; the third emphasises aesthetics and mass-mobilisation as well as the veneration of masculinity, youth and the staging of the Fübrerprinzip. Paxton admits that his mobilizing passions 'belong more to the realm of visceral feelings than to the realm of reasoned propositions' (219). Again one finds emphasis on violence, the Fübrerprinzip and masculinity, but Paxton also stresses more complex elements, which I think really get at the core of fascist ideology, namely the belief in supremacy, perceived victimhood and a sense of decline and crisis. At the heart of these we find a core of inequality and thus it is these 'passions' we still find in contemporary right-wing movements.

${ }^{56}$ Italics in the original, Griffin, The Nature of Fascism, 26. He specifies palingenesis as a 'new birth occurring after a period of perceived decadence' (36).

${ }^{57}$ Consider such quotes as ' $\mathrm{Er}$ [der Jude] ist und bleibt ein Parasit, ein Schmarotzer, der wie ein schädlicher Bazillus sich immer mehr ausbreitet, so wie nur ein günstiger Nährboden dazu einlädt. Die Wirkung seines Daseins aber gleicht ebenfalls der von Schmarotzern: wo er auftritt, stirbt das Wirtsvolk nach kürzer oder längerer Zeit ab' (quoted in: Zentner, Christian; Hitlers Mein Kampf: Eine Kommentierte Auswabl; 150). Zentner maintains that in Mein Kampf, Hitler never talks about the annihilation of all the Jews in their physical existence. However, Hitler's determined stance on the parasitical and alien character of the Jews, can lead the reader to no other conclusion that for a thriving of the 'Arian race' the elimination of the Jews, in whatever form, was paramount. That this was intentional can be inferred from an early letter from Hitler from 1919 in which he muses that '[d]er Antisemitismus der Vernunft ... muß führen zur planmäßigen gesetzlichen Bekämpfung und Beseitigung der Vorrechte des Juden [...]. Sein letztes Ziel aber muß unverrückbar die Entfernung der Juden überhaupt sein.' (ibid, 168). This plan was ultimately made public in Hitler's Reichstagsrede on 30th January 1939: ,Ich will heute wieder ein Prophet sein: Wenn es dem internationalen Finanzjudentum innerhalb und außerhalb Europas gelingen sollte, die Völker noch einmal in einen Weltkrieg zu stürzen, dann wird das Ergebnis nicht die Bolschewisierung der Erde und damit der Sieg des Judentums sein, sondern die Vernichtung der jüdischen Rasse in Europa!' (ibid, 168).

${ }^{58}$ Hitler's Mein Kampf was the most widely distributed book in Germany during the late thirties and early forties. It is still a matter of debate whether it was also the most widely read. Especially after the war many people claimed that they owned a copy but have never read it. However, this debate reflects the defects of the Ger- 
man Aufarbeitung more than the actual matter at stake. Interestingly, non-German research was always more cautious when it came to assessing how widely read Mein Kampf really was, whereas German scholars usually followed the myth of the unread and unreadable bestseller. This myth, according to Othmar Plöckinger, was already started during the 1930s by no other than the Strasser movement, famous National Socialists who opposed Hitler. Plöckinger's study on Hitler's book opposes the idea of the unread book, evaluating, for example, library catalogues to show that it was indeed widely known and read. (cf. Plöckinger, Othmar; Adolf Hitlers „,Mein Kampf", especially $356-362$ and $419-429$. He goes on to state that due to the equation of Mein Kampf with national-socialist practice, not having read the book was interpreted as an act of resistance and thus the myth of the unread bestseller was fostered especially in Germany after 1945 (cf. 405).

${ }^{59}$ Cf., for example, Stone, Dan; Breeding Superman on eugenics and lethal chambers.

${ }^{60}$ These claims have been repeatedly challenged. The latest research done by the United States Holocaust Memorial Museum, a catalogue listing all physical sites of the Holocaust in the German Reich and German-controlled areas, corroborates the argument that even if people did not actively participate in the Holocaust they were very often passive collaborators aware of what was going on. With 42,500 facilities in total (and over 3000 in Berlin alone), 'the findings [leave] no doubt [...] that many German citizens, despite the frequent claims of ignorance after the war, must have known about the widespread existence of the Nazi camps at the time.' (Quoted in Lichtblau, Eric. 'The Holocaust Just Got More Shocking').

${ }^{61}$ Consider for example, the debate over whether Britain had done all it could to save the Jews, as claimed by William D. Rubinstein in The Myth of Rescue, or whether it had either failed to help or even refused to help, as argued by Julius Trials of the Diaspora.

${ }^{62}$ Julius, Trials of the Diaspora, xlviii.

${ }^{63}$ Julius, Trials of the Diaspora, 5.

${ }^{64}$ According to Julius rational enemies comprise those opponents who 'find themselves in conflict with a genuine Jewish project or stance' (3), which can be further differentiated into the involuntary rational type 'for whom the enmity is implicit in the given circumstances of his material existence' and the voluntary rational type 'for whom the enmity is a free choice' (3). The opportunistic enemies 'do not oppose Jewish projects [but] exploit Jewish weakness' (4). Included in this category are writers who 'exploit anti-Semitism for literary effect' (5).

${ }^{65}$ Julius, Trials of the Diaspora, 5.

${ }^{66}$ Julius, Trials of the Diaspora, 5.

${ }^{67}$ Also sometimes called The Protocols of the Meetings of the Learned Elders of Zion is a forged document that purports to be the factual minutes of the meeting of the Jewish elders while they discuss their plans for world domination. First published in 
Russia in 1903 it was quickly translated and published in many European countries. While it was soon exposed to be a forgery it continued to dominate anti-Semitic discourses in the Western world as it seemed to confirm conspiracy theories about Jewish strategies for global hegemony. It is still peddled in some right-wing circles as a factual document with the forgery claims seen as further proof of the Jewish conspiracy.

${ }^{68}$ Julius; Trials of the Diaspora, 53.

${ }^{69}$ Julius; Trials of the Diaspora, 5.

${ }^{70}$ Baumann, Zygmunt; Modernity and the Holocaust, 34.

${ }^{71}$ Cf. Julius; Trials of the Diaspora, 53.

${ }^{72}$ In fact, as Julius writes: 'In modern times, and until 1936, it was Italy and not England that had the mildest, in the sense of the least, anti-Semitism of the Western democracies.' (Trials of the Diaspora, 242).

${ }^{73}$ Consider, for example, the following excerpt from a text by Mussolini, in which he deplores the numerical decrease of the white race: '.... while the Whites in the USA have a miserable birth-rate-which would be even more so if it were not for the injection of more fertile races such as Irish, the Jews and the Italians-the Negroes are extremely fertile,...' (in Griffin, Roger (ed.); Fascism, 59). Here the Jews are not only classified as part of the white race but are also mentioned in conjunction with Italians without any indication of inequality.

${ }^{74}$ As suggested by Aly, Götz; Warum die Deutschen? Warum die Juden? Gleichheit, Neid und Rassenhass 1800-1939.

${ }^{75}$ Cf. Julius; Trials of the Diaspora, 140.

${ }^{76}$ Cf Julius; Trials of the Diaspora, 248.

${ }^{77}$ In: Kushner, Tony and Kenneth Lunn, Traditions of Intolerance: Historical perspectives on fascism and race discourse in Britain, 12-13. Cheyette is not alone in this analysis: '[Tony] Kushner writes that the dominant discourse regarding Jews in Britain was 'a liberal discourse demanding that the Jew should assimilate totally into British society'. Whilst one can also identify extreme, 'exclusionary anti-Semitism' - which argues that the Jews will always be alien and a threat to the British way of life - and 'social anti-Semitism' - typified by genteel golf club prejudice - it is 'assimilationist anti-Semitism' that derives most clearly from the British liberal tradition.' This is a tradition that does not tolerate violence against minorities, but in return demands their adoption of British ways' (Stone, Dan; Responses to Nazism in Britain, 19331939: Before $W$ ar and Holocaust, 79-80).

${ }^{78}$ Kushner; Tony and Kenneth Lunn, 13.

${ }^{79}$ Stone; Responses to Nazism in Britain, 1933-1939: Before War and Holocaust, 80. 
${ }^{80}$ ['...einer 'primitive' Ideologie und 'barbarischen’ Praxis...'] Cf. Geulen, Christian; Geschichte des Rassismus, 11. To clarify, Geulen rejects this simplified characterization of and sets out to demonstrate the complex interplay between racism and Western history.

${ }^{81}$ Institutional racism plays a role during the time a particular work is written and published, but also in later stages when it is reviewed, canonised, included in syllabi or not.

${ }^{82}$ Which, as if to stress this point, is also the name of a right-wing fashion brand.

${ }^{83}$ Cf. Geulen, 32-38.

${ }^{84}$ Geulen, 35.

${ }^{85}$ cf. Geulen, 71.

${ }^{86}$ As well as by Houston Stewart Chamberlain, author of Grundlagen des Neunzebnten Jahrbunderts (The Foundations of the Nineteenth Century), which was based on Gobineau's book, with the alteration that while Gobineau only had positive things to say about Jews, Chamberlain introduced a significant anti-Semitic element.

${ }^{87}$ Cf. Geulen, 74-75, and 92; also Stone, Breeding Superman, 95.

${ }^{88}$ One could argue, however, that eugenic practices are still very much alive. Debates around abortion (also especially late-term abortion) and reproduction are still very much influenced by discourses on race, class, and ability.

${ }^{89}$ Sternhell, Zeev; The Anti-Enlightenment Tradition, 8.

${ }^{90}$ Sorel, 209. On the topic of myths, compare this to a speech by Mussolini: 'We have created our myth. The myth is a faith, a passion. It is not necessary for it to be a reality. It is a reality in the sense that it is a stimulus, is hope, is faith, is courage. Our myth is the nation, our myth is the greatness of the nation! And to this myth, this greatness, which we want to translate into a total reality, we subordinate everything else.' (In: Griffin, Fascism, 44). The similarity is no coincidence, as Mussolini had read Sorel closely.

${ }^{91}$ Both, Sorel, 171.

${ }^{92}$ quoted in Sternhell; Birth of Fascist Ideology, 153.

93 'Futurist Manifesto' from 1909, in: Asholt, Wolfgang and Walter Fähnders (eds.); Manifeste und Proklamationen der europäischen Avantgarde, 5.

${ }^{94}$ The SS constitutes a good example: it was stylised as an elite unit 'which was not only communicated by its internal ideology and hierarchy, but also by the social structure of its members, its visual and public appearance' (Reichel, Peter; Der schöne Schein des Dritten Reiches: Faszination und Gewalt des Faschismus, 224). At the end of the 1930s it boasted 10-20\% nobility among its members, 30 \& of the SS had a university degree (compared to $3 \%$ of the general public) (cf. Reichel, 225), although a considerable amount of its members were also drafted from the working class 
(Hein, Bastian; Die SS: Geschichte und Verbrechen; 37). Moreover its members also had to fulfil certain physical qualities, such as being from Aryan, ideally, Nordic stock, at least $1.70 \mathrm{~m}$ in height (above average height for men during these times) as well as being in a good bodily disposition (cf. Hein; Die SS: Geschichte und Verbrechen; 3032). The final mark of distinction came in the form of the famous black uniforms designed by Hugo Boss, to visually separate them from the more plebeian brown and grey uniforms of the SA and Wehrmacht (cf. Koop, Andreas; NSCI: Das visuelle Erscheinungsbild der Nationalsozialisten 1920-1945, 134-135).

95 This observation resembles Walter Benjamin's idea of fascism as the aesthetisation of politics that offers the populace a part in the spectacle of politics instead of real political participation (cf. Benjamin, 47-50).

${ }^{96}$ One could even go further and see the democratic state as 'a synthesis of monarchical, aristocratic and democratic elements' (Backes; Politische Extreme: Eine Wortund Begriffsgeschichte von der Antike bis zur Gegenwart, 241).

${ }^{97}$ Julius, Anthony; T.S. Eliot, Anti-Semitism, and Literary Form, 33.

${ }^{98}$ Pounds famous retraction from anti-Semitism, which, for good reasons, is still debated. See for example Stoicheff, Peter; The Hall of Mirrors: Drafts \&Fragments and the End of Erra Pound's Cantos, 136.

${ }^{99}$ Farr, Barbara Storm; The Development and Impact of Right-Wing Politics in Britain, 1903-1932, 54.

100 Stone; Responses to Nazism in Britain, 1933-1939, 6-7.

101 Pugh, Martin; Hurrah for the Blackshirts!': Fascists and Fascism in Britain between the Wars, 2.

102 Pugh, 56.

103 Both quotes: Pugh 56 and 57.

${ }^{104}$ Both quoted in Stone, Responses to Nazism in Britain, 1933-1939, 80.

105 Pugh, 13.

106 Pugh, 28.

${ }^{107}$ British immigration policy described in Pugh, 232-233 and Julius, Anthony; Trials of the Diaspora: A History of Anti-Semitism in England, 318-320. A.J.P. Taylor has argued that '[e]ven England's anti-Semites [...] were offended by what the Nazis were doing to German Jewry' (quoted in Julius; Trials of the Diaspora: A History of Anti-Semitism in England; 303).

108 Julius, Trials of the Diaspora: A History of Anti-Semitism in England, 303-304. Cf. also: Bauerkämper, Arnd; Die »radikale Rechte« in Großbritannien;191 and Julius, Trials, $276-328$.

${ }^{109}$ Julius, Trials of the Diaspora: A History of Anti-Semitism in England, 470. 
${ }^{110}$ Eksteins, Modris; Rites of Spring: The Great War and the Birth of the Modern Age, 119.

${ }^{111}$ Ibid. Morgan, Kenneth O.; The Oxford History of Britain, 592.

${ }^{112}$ Cf. Thorpe, Andrew; Britain in the 1930s: The Deceptive Decade, 109.

${ }^{113}$ Cf. Surette, Leon; Dreams of a Totalitarian Utopia: Literary Modernism and Politics, 106.

${ }^{114}$ Especially in the case of Pound, there are many studies that would probably disagree, citing his confinement and the hostility Pound received. Eliot tried to make a similar claim for Lewis. As a matter of fact, Lewis came under patronage of the $\mathrm{BBC}$ and saw a great retrospective of Vorticism. Thus while he partially lived precariously, he was not shunned from the cultural scene. The same holds true for Pound: many artists rallied for his liberation, his writings and translation found an avid circle of readers and a number of laudatory studies about him were written already during his lifetime.

${ }^{115}$ Cf. Pugh, 287-319.

${ }^{116}$ Julius, Trials of the Diaspora, 330.

${ }^{117}$ Stone; Responses to Nazism in Britain, 1933-1939, 82.

${ }^{118}$ Equally ambivalent as the concept of power and arguably also linked to it is discrimination: who is using prejudice and who is being prejudiced? Who is entitled to privileges and who is not?

119 'Settings and allies' are an analytical filter from Paxton's study on fascism, in which he urged not to look at fascism in isolation but at it in its environment (both contextual as well as ideological) (cf. Paxton, 206-207).

${ }^{120}$ This pattern of explanation seems to be quite popular in the assessment of rightwing people in general (not only artists and writer but also other political figures). This myth of right-wing pathology, as I would call it, very often tries to find causal links between the political opinions held by a person and their respective personality and biographical background. I use the word pathology, because it hints at the fact that often a supposed personal or biographical anomaly is seen as responsible for certain ideological positions. Adorno's research into the authoritarian personality might be one of the reasons for the popularity of this approach. However, the myth of right-wing pathology shows significant internal contradictions and it ignores the larger right-wing discourse from which many writers drew.

${ }^{121}$ In: Hamilton, Alastair; The Appeal of Fascism: A Study of Intellectuals and Fascism, 1919 - 1945, xiii.

${ }^{122}$ Ibid., xiii. An argument very reminiscent of Walter Benjamin. 


\section{The Poem as Propaganda - Ezra Pound}

${ }^{123}$ Gross, Andrew S.; The Pound Reaction: Liberalism and Lyricism in Midcentury American Literature, 1.

${ }^{124}$ Quoted in: Morrison, Paul; The Poetics of Fascism: Ezra Pound, T. S. Eliot, Paul de Man, 44. For those interested in the individual responses of the jury members to the controversy the study by Gross is likely the best source.

${ }^{125}$ This is based on the 'mere words' rule used in treason trials: "That is true in the sense that the mere utterance of disloyal sentiments is not treason; aid and comfort must be given to the enemy. But the communication of an idea, whether by speech or writing, is as much an act as is throwing a brick, though different muscles are used to achieve different effects." (Rushing, Conrad L.; “Mere Words": The Trial of Ezra Pound', 130).

${ }^{126}$ Italics in the original, Barnhisel, Gregory; James Laughlin, New Directions, and the Remaking of Exra Pound, 6.

${ }^{127}$ In order as stated: Feldman, Matthew; 'The Pound-Case in Historical Perspective: An Overview'; Parker, Andrew; 'Ezra Pound and the Economy of AntiSemitism'; Lauber, John; 'Pound's “Cantos": A Fascist Epic'; Dasenbrock, Reed Way; Jefferson and/or Adams: A Shifting Mirror for Mussolini in the Middle Cantos'; Ferkiss, Victor; 'Ezra Pound and American Fascism'; and Goldblatt, Eli; 'Gender Matters in Pound's "Cantos".

${ }^{128}$ Quoted in Homberger, Eric (ed.); Ezra Pound: The Critical Heritage, 375.

${ }^{129}$ For my project I am using: Pound, Ezra; The Cantos of Ezra Pound (1970), New York: New Directions, 1993. All citations from the Cantos come from this edition and will be given in the form of (number of canto/page number). For sake of brevity I will use Arabic numerals for the individual cantos.

${ }^{130}$ Stock, Noel; Reading the Cantos: A Study of Meaning in Ezra Pound, 29.

${ }^{131}$ Makin, Peter; Pound's Cantos, 212.

${ }^{132}$ Wieland Schmied opens his book Ezra Pound: Ein Leben zwischen Kunst und Politik with a meditation on 'the tragic fate of the poet, interned under unbearable conditions in an American asylum (an obvious prototype for the future Soviet practice of isolating dissidents in sanatoriums)' [...tragischen Schicksal des unter unwürdigsten Bedingungen in einem amerikanischen Irrenhaus Internierten (offenbares Vorbild für die spätere sowjetische Praxis, Dissidenten in Nervenkliniken zu isolieren)], 7. Also compare Stock, 91-92.

${ }^{133}$ Chace, The Political Identities of Ezra Pound and T. S. Eliot, 37.

${ }^{134}$ Barnhisel, 108.

${ }^{135}$ Lauber, 3. 
${ }^{136}$ Thus I agree with Feldman stating: 'It also, in my view, suggests that a neat demarcation between propaganda, on the one hand, and poetry on the other, was not a distinction born of the war itself - let alone Pound's conception of his work but of Pound criticism after it. In February 1942, for example, Pound read two Cantos over the air - the second specifically referred to as Canto 46, which includes some of Pound's anti-Semitic conspiracy theories:' (93).

${ }^{137}$ Cf. Starkulla, Heinz W.; Propaganda: Begriffe, Typen, Phänomene, 59.

${ }^{138}$ Cf. Starkulla, 60-61.

${ }^{139}$ Cf. Starkulla, 70.

${ }^{140}$ 'I remember him speaking in all seriousness of the Cantos as a 'political weapon'. (Stock, 91).

${ }^{141}$ ['Er sah in der Gesellschaft also schon vorab den Feind seines Schaffens, während er sich andererseits als ihr Sprachrohr verstand. Der feine Unterschied, den er in seinen Werken zwischen der »Menschheit« und der »Masse« macht, spiegelt diese Sinnespaltung:...'] Hesse, Eqra Pound: Von Sinn und Wabnsinn, 340.

${ }^{142}$ Carey, John; The Intellectuals and the Masses: Pride and Prejudice Among the Literary Intelligentsia, 1800-1939, 16-17 and cf. Hesse; Ezra Pound: Von Sinn und Wabnsinn: 'Nothing is more evident than the fact that their works are conceived out of the intellectual alienation of their times, coming from a privileged standpoint in terms of education, which reproduces the existing class structure again in their literature and which is embodied in the stylistic devices of intellectual alienation, i. e. being individualist and not wishing to be understood by all' ['Nichts ist offenkundiger, als daß ihre Werke aus der geistigen Entfremdung von ihrer Zeit konzipiert sind, von einem Bildungsprivileg her, das die Klassenstruktur in der Literatur noch einmal reproduziert und sich durch die Stilmittel der geistigen Distanzierung ausdruckt, d. h. individualistisch unter Verzicht auf kollektives Gehör'] (349).

${ }^{143}$ Quoted in Heymann, 63.

${ }^{144}$ Consider his reply from 1933 to D. G. Bridson, who had suggested that 'Pound] has far too much of importance to say for him to rest content in the appreciation of a few. Human nature and intelligence being what it is, he would have been well advised to compromise by meeting his audience half way'; Pound answered: 'Perhaps Mr. Bridson would be generous enough to explain WHAT audience I ought to 'meet halfway. London, is, as you know, full of pimps who do not want to look either facts or ideas in the face. [...] Are these the vermin for whom one should write footnotes?' (Both quoted in: Homberger, 268).

${ }^{145}$ Emphasis in the original. ['Wenn er kraft seiner höheren Sensibilität »für« alle spricht, so spricht er doch beileibe nicht »zu« allen, sondern zur Minderheit der Begabten und Kultivierten, die sich hoch über das Niveau der unmündigen Masse erhebt und ihr politische und geistige Führung bietet.'] Hesse; Erra Pound: Von Sinn und Wahnsinn, 186. 
${ }^{146}$ Cf. Hesse: “'Gli uomini vivoni in pochi« (Machiavelli), [Pound] liked to quote, humanity only comes alive in a few superior individuals, while the rest stumbles through life in a semi-conscious state. Art and politics depend on these few, who in themselves concentrate the dull will of the people'. ['»Gli uomini vivoni in pochi« (Machiavelli), zitiert [Pound] mit Vorliebe, die Menschheit ist nur in ganz wenigen überdurchschnittlichen Exemplaren lebendig, alle andern dämmern bewußtseinsblind vor sich hin. Auf diese wenigen, in denen sich der dumpfe Mehrheitswille verdichtet, kommt es in der Politik wie in der Kunst allein an (Hesse, Von Sinn und Wahnsinn, 184).

${ }^{147}$ Quoted in Heymann, David C.; Ezra Pound. The Last Rower: A Political Profile, 63.

${ }^{148}$ Marsh, Alec; John Kasper and Eqra Pound: Saving the Republic, 159.

${ }^{149}$ Chace, xiii.

${ }^{150}$ Desai, Meghnad; The Route of All Evil: The Political Economy of Eqra Pound, 48.

${ }^{151}$ Quoted in Desai, 78.

${ }^{152}$ Cf. Chace, 33.

${ }^{153}$ Sieburth, Richard; 'In Pound We Trust: The Economy of Poetry/The Poetry of Economics', 166.

${ }^{154}$ Chace, The Political Identities of Exra Pound and T. S. Eliot, 33.

${ }^{155}$ Lauber, 14-15.

${ }^{156}$ Pound, Ezra; Selected Poems of Eqra Pound, 64.

${ }^{157}$ The 'Hell Cantos' do not spell out the names of the people they attack; substituting them with a dotted line instead, in which each dot stands for one letter, and only the final letter of each name given.

${ }^{158}$ Cf. Edwards, John Hamilton and William W. Vasse; Annotated Index to the Cantos of Ezra Pound, 254.

${ }^{159}$ As he writes in his short biography that prefaces: Pound; Selected Poems of Eqra Pound, viii.

${ }^{160}$ Pound, Ezra; Guide to Kulchur, 62. It should be noted that this reasoning, with an anti-Semitic twist added to it, is still fairly common in the right-wing scene.

${ }^{161}$ Cf. Alighieri, Dante; The Inferno of Dante Alighieri; Canto 12-30.

${ }^{162}$ The draining of the marshes also had symbolic value for Mussolini, who linked it to the Fascist repopulation efforts, the fertility of the land assuring sustenance to the growing population, while also serving as a metaphor: 'In a Fascist Italy where marshes have been drained, the land has been irrigated and cultivated; where life has become disciplined, there is space and food for another 10 million men.' (In: Griffin, Roger; Fascism, 59). 
${ }^{163}$ Desai, 41. Williams sheds some more light on why the Middle Ages served as positive example from history: 'Thus the Middle Ages had much that was missing from the contemporary world. The governments were strong and stable, and provided firm, but fair economic and political direction without interfering unnecessarily in people's lives. They, plus the absence of a middle class, ensured that society was unified and all members cared for. The medieval period had a few other features the Modernists liked; it was spiritually fulfilled, morally healthy, and aesthetically pleasing' (86).

${ }^{164}$ For example in Canto 38, 41, 87, 97, 100 as well as Canto 74 and 80 . Most of the time, there are only short references to each economist's name or a quote. Douglas is sometimes only alluded to by the initials of his first name. In canto 41, which also prominently features Pound's meeting with Mussolini, a mention of Douglas is followed by " "To strangle the bankers...?” / And Woergl in our time?' (41/205). Wörgl, a small town in Tyrol, started issuing stamp scrip during the Great Depression, effectively implementing Gesell's theory. It increased employment and revived the economy. Despite its success it was terminated after one year.

${ }^{165}$ North, Michael; The Political Aesthetic of Yeats, Eliot, and Pound, 151.

${ }^{166}$ Casillo, Genealogy of Demons, 221.

${ }^{167}$ Cf. Casillo, Genealogy of Demons, 70.

${ }^{168}$ Catherine Paul also remarks how Pound must have found the Fascist calendar appealing as it coincided with the birth year of English Modernism due to the publication of Ulysses and The Waste Land ('Italian Fascist Exhibitions and Ezra Pound's Move to the Imperial', 66).

${ }^{169}$ This is in tune with Pound's earlier pamphlets on money and economy, 'Social Credit: An Impact' and 'What Is Money For', written in 1935 and 1939 respectively, showing the poet's changing attitude towards German economic policies. In the former he criticises Schacht and has little to say about Germany in general; in the latter, Germany and National Socialism are linked to Fascist Italy. In fact, 'What Is Money For' with its focus on China, Western usury as well as its antidotes in the form of Douglas theory and fascist systems, reads like the companion piece to Canto 52 .

${ }^{170}$ The Mefo bills, named after the 'Metallurgische Forschungsgesellschaft', were promissory notes to facilitate the financing of public expenditures without having to rely on banks. As with the 'New Plan' the Mefo bills served as a means to conceal Germany's re-armament. In Pound's eyes, the Mefo bills might have seemed like a blow at banking and usury as well as the Finanæjudentum, which might further explain Schacht's presence in Canto 52.

${ }^{171}$ The plan, which was named Schacht-Rublee plan, was never successfully implemented. Shortly after negotiations began, Schacht was laid off as finance minister. Schacht was replaced by Helmuth Wohlthat and the negotiations (which had been 
unpopular with some Nazi officials to begin with) were interrupted by the Second World War and Germany's exterminatory practices. Schacht had been dismissed because he had criticised Hitler's policies on armament and finance. This shows that Schacht was difficult to place in terms of political policies. He abhorred the Reichspogromnacht and also helped a number of resistance fighters. At the same time he massively helped Hitler's government to battle inflation. His plan on Jewish property was both welcomed and rejected by the Jewish community. While it would have helped Jews emigrate it was also put in place to boost German export (cf. Schacht; The Magic of Money, 59-60).

${ }^{172}$ Buss, Claude; War and Diplomacy in Eastern Asia, 405.

${ }^{173}$ Quoted in Redman, 252.

${ }^{174}$ Cf. Casillo, Robert; The Genealogy of Demons: Anti-Semitism, Fascism, and the Myths of Eqra Pound, 260.

${ }^{175}$ Cf. for example, Casillo; The Genealogy of Demons, 5-7, or Desai, 116.

${ }^{176}$ Cf. Desai, 96.

${ }^{177}$ Casillo; Genealogy of Demons, 5.

${ }^{178}$ Terrell, 200.

${ }^{179}$ Parker, 111.

${ }^{180}$ Doob, Leonard (ed.); Ezra Pound Speaking: Radio Speeches of World War II, 133, 44, and 38 .

${ }^{181}$ Terrell, 724. James Wilhelm reads this canto in a similar vein, even detecting a sense of irony on Pound's part: 'By noting that the crime is "beyond race," Pound specifically shows that it is not limited to Jews, who were forced in the Middle Ages to assume the profession of moneylender because they were denied the ownership of land. The double standard of using the Jews for a condemned service and then blaming them for performing that service did not escape Pound's keen sense of irony' (The Later Cantos of Ezra Pound, 182). While the phrase 'beyond race' does indeed indicate that usury is not limited to Jews, this canto still seems to suggest that it was the Jews who brought this evil into the world. Moreover the phrase 'against race' seems to imply that usury is a crime that targets not people but races, an interpretation that fits a world-view that sees struggle between races as the core of history.

${ }^{182}$ Doob, 51. It is probably unnecessary to add that these remarks by Pound bear a striking resemblance to official NS propaganda.

${ }^{183}$ The inclusion of Eustace Clarence Mullins, who can be considered part of the Far Right, is not random but indicates a greater issue in Pound studies, namely the fact that many early Pound scholars did not only belong to his inner circle of ac- 
quaintances but also shared his ideology. I discuss Mullins and his relationship with Pound in chapter 6.

${ }^{184}$ Quotes are taken from Parker, 109-110. Parker considers himself part of the third group.

${ }^{185}$ Parker, 109.

${ }^{186}$ Desai, 1.

${ }^{187}$ Flory, 299.

${ }^{188}$ Lauber, 14.

${ }^{189}$ Casillo; Genealogy of Demons, 17.

${ }^{190}$ Julius, 53.

${ }^{191}$ Casillo; 'Plastic Demons: The Scapegoating Process in Ezra Pound', 358.

${ }^{192}$ Casillo; 'Plastic Demons: The Scapegoating Process in Ezra Pound', 359.

${ }^{193}$ Pound also saw this ideal in the Axis, as shown by an early copy of his translation of Confucius: 'By way of example, the FBI files show that Pound's Confucian translation into English, "The Unwobbling Pivot" from 1947, was originally published by the Saló Republic under the title L'Asse che non vacilla [The Axis Will Not Waiver]' (Feldman, 92).

${ }^{194}$ Cf. Edwards and Vasse, 45.

${ }^{195}$ Compare this passage from Weininger, which shares with Pound's Cantos the exact same imagery and prejudices concerning Jews and women: 'Men who are match-makers are always inherently Jewish; and here lies the greatest congruence between womanhood and Jewry. The Jew is always more lecherous, lewd, but also curiously, maybe in connection to his not really amoral nature, sexually less potent than the Aryan. Only Jews are real match-makers, and nowhere is match-making by men so popular as among the Jews. Admittedly match making is of great necessity among the Jews as there exists no other people who marry less for love: yet another proof for the soullessness of the absolute Jew. [Männer, die kuppeln, haben immer Judentum in sich; und damit ist der Punkt der stärksten Übereinstimmung zwischen Weiblichkeit und Judentum erreicht. Der Jude ist stets lüsterner, geiler, wenn auch merkwürdigerweise, vielleicht im Zusammenhange mit seiner nicht eigentlich antimoralischen Natur, sexuell weniger potent als der arische Mann. Nur Juden sind echte Heiratsvermittler, und nirgends erfreut sich Ehevermittlung durch Männer einer so ausgedehnten Verbreitung wie unter den Juden. Freilich ist eine Tätigkeit nach dieser Richtung hier dringender als sonst vonnöten; denn es gibt, wessen schon einmal gedacht wurde, kein Volk der Welt, in dem so wenig aus Liebe geheiratet würde wie unter ihnen: ein Beweis mehr für die Seelenlosigkeit des absoluten Juden.]', (emphasis in the original; Gescblecht und Charakter, 417). 
${ }^{196}$ Quoted in Torrey, E. Fuller; The Roots of Treason: Ezra Pound and the Secret of St. Elizabeths; 143.

${ }^{197}$ Casillo; Genealogy of Demons; 7.

${ }^{198}$ Pound was connected in differing degrees to people like John Kasper, David Horton, Eustace Mullins, Admiral John Crommelin and Pedro del Valle. It is difficult to establish the precise nature of their relationships: from what can be gathered Pound encouraged some of their actions and at least approved of others. Marsh has done an admirable job of analysing the Pound-Kasper relationship in his study John Kasper and Ezra Pound: Saving the Republic, which also shows that Pound was more than just a passive bystander.

${ }^{199}$ See for example, Julius, Trials of the Diaspora, 123-128.

${ }^{200}$ Lauber, 13.

${ }^{201}$ Doob, 146.

${ }^{202}$ Compare Pound's Geryon to this part from the Protocols: 'These learned men decided by peaceful means to conquer the world for Zion with the slyness of the Symbolic Snake, whose head was to represent those who have been initiated into the plans of the Jewish administration, and the body of the Snake to represent the Jewish people.... (140).

${ }^{203}$ Lauber, 12-13.

${ }^{204}$ Ferrall, Charles; Modernist Writings and Reactionary Politics; 68.

${ }^{205}$ This passage is a reference to Matthew 5.13 'Ye are the salt of the earth' and can also be read in combination with a statement from one of Pound's letters: 'New York is ganz verjudet' (Redman, 177).

${ }^{206}$ Commenting on the Protocols, Henry Ford, who had an English translation distributed in America, said: '...they fit in with what is going on. They are sixteen years old, and they have fitted the world situation up to this time. THEY FIT IT NOW.' (All caps in the original; quoted in: Protocols, 136).

${ }^{207}$ There is, in fact, a debate about how much Pound knew and cared about the plight of the Jews in Europe. Some letters reveal that he received information about the events in the German Reich, yet his replies show that this did not lead to a change of heart on his part nor to a re-evaluation of his convictions (cf., e.g. Redman, 178 and Marsh, 82).

${ }^{208}$ Redman, 178.

${ }^{209}$ A fact that becomes apparent when we consider the epic's popularity among the New Far Right.

${ }^{210} \mathrm{I}$ do not read his famous statement that he regretted his anti-Semitism as 'a stupid suburban prejudice' as a sincere reflection of his anti-Semitism. In fact, I agree with Peter Stoicheff that the regret seems as much about 'the conformity of anti- 
Semitism, its "suburban" aspect, as [...] with its racial intolerance' (The Hall of Mirrors: Drafts \&Fragments and the End of Eqra Pound's Cantos, 136). Stoicheff also details how Pound saw no need to edit out the anti-Semitism of his essays, which were reprinted in the 1960s.

${ }^{211}$ Pound; Guide to Kulchur, 16.

${ }^{212}$ Casillo; 'Anti-Semitism, Castration, and Usury in Ezra Pound'; 248.

${ }^{213}$ Doob, 70.

${ }^{214}$ Desai, 122.

${ }^{215}$ Julius, Anthony; T.S. Eliot, Anti-Semitism, and Literary Form; xiii.

${ }^{216}$ Julius, Anthony; Trials of the Diaspora: A History of Anti-Semitism in England; 184.

217 ....it is his singing of Pisa and his re-singing of the political themes that have dominated the poem' (Selby, Nick; Poetics of Loss in The Cantos of Ezra Pound; 193).

${ }^{218}$ Quoted in: Cookson, William; A Guide to the Cantos of Ezra Pound; xxviii.

${ }^{219}$ Casillo; Genealogy of Demons, 144.

${ }^{220}$ Casillo; Genealogy of Demons, 145.

${ }^{221}$ Quoted in Desai, 116.

${ }^{222}$ Casillo; Genealogy of Demons, 145.

${ }^{223}$ Cookson, 57-58.

${ }^{224}$ Pound; Jefferson and/or Mussolini, 91.

${ }^{225}$ Discussing Pound's indebtedness to the American tradition, Marsh sees in Pound an advocate of Jeffersonianism, which he defines as follows: 'Jeffersonianism is a belief in the independent producer as the model of citizenship and artistic integrity. It envisions history as a class-struggle between debtors and creditors, or otherwise put, "producers"-farmers, craftsmen, artists and small capitalists, and "exploiters"-invariably banks and financiers' (9). This could easily be linked to Mussolini's syndicalism-turned-fascism.

${ }^{226}$ Ten Eyck, David; Eæra Pound's Adams Cantos, 132.

${ }^{227}$ Ten Eyck, 132.

${ }^{228}$ Pound; Jefferson and/or Mussolini, 34.

${ }^{229}$ Wyndham Lewis has suggested something similar in The Art of Being Ruled, 93.

${ }^{230}$ Some scholars, for example Philip Bishop, have suggested that Mussolini was also 'the Cantos' ideal audience and the historical agent who would put their ideas into action' (539). While this is a tantalising idea, I would suggest from the trajectory of the Cantos that the ideal audience are the yet uninitiated but eager to learn: 
thus the Cantos shows what is going wrong, how it can be solved and who, at the moment of composition, is likely to solve it.

${ }^{231}$ The fact that the anecdote is said to be 'told by the mezzo-yit (i.e. half-Jew)', suggests that the financiers involved are also Jewish.

${ }^{232}$ Lawrence Rainey in his article 'Between Mussolini and Me' suggests that it was Pound's fascination for the emotional aspects of fascism that initially attracted him: The blind devotion ('If we take Pound's later recollection at face value, we can only feel that what impressed him about Marchetti was the intensity of his 'devotion' to Mussolini (10)) coupled with authoritarian violence ('And it was terror - the allure, the thrill, the prospect of terror - that attracted Ezra Pound to Fascism' (11)).

${ }^{233}$ Pound, Ezra; Jefferson and/ or Mussolini, 113.

${ }^{234}$ I will be using the translation by Richard Reid, which can be found in Cookson, 117-126.

${ }^{235}$ Interestingly, in Pounds 'official' translation of canto 72 the lines about the Moroccans as well as the term 'abortion' were left out, effectively toning down some of the vitriol of the attack.

${ }^{236}$ Cf., for example, Doob, 15, 38, 59 and 153.

${ }^{237}$ Doob, 51.

${ }^{238}$ Pound had picked up this tale from the Italian newspaper Corriere, which ran a story about this incident on 1 October 1944. Rainey concludes that the news report coincides 'in so many details as to leave no doubt that it was Pound's source. It is, of course, a transparent fabrication; no such incident ever occurred' (Rainey, Lawrence; Eqra Pound and the Monument of Culture: Text, History, and the Malatesta, 216).

${ }^{239}$ Selby, 192.

${ }^{240}$ Bush, Ronald; 'Modernism, Fascism, and the Composition of Ezra Pound's Pisan Cantos', 81.

${ }^{241}$ Ecbatana, capital of the Median empire (geographically located in today's Iran), was founded by the first king of Medes, Deïoces in the 6th century BCE; Wagadu was the name of the Ghanese empire, which lasted from ca. 300 to $1200 \mathrm{CE}$. The Cantos also mentions Gassir (actually Gassire), son of the king of the Fasa, the regional tribe, who becomes a bard, leading to the destruction of Wagadu (which was then rebuilt, hence ' 4 times was the city rebuilded, Hoo Fasa / now in the mind indestructible, Gassir, Hoooo Fasa' (74/450) in the Cantos (cf. Edwards and Vasse, 67, 76, and 241). Pound learnt about Wagadu and its history from Leo Frobenius, a German archaeologist and anthropologist, whose Erlebte Erdteile Pound read and recommended.

${ }^{242}$ Selby, 213. 
${ }^{243}$ The name 'Rock-Drill' is also telling. It is not only a reference to Jacob Epstein's famous sculpture of the same name, which embodied maybe more than any other artwork the tenets of Vorticism, but the name also suggests that the contents of this sections should be hammered into the heads of its readers.

${ }^{244}$ Demeter as the goddess for agriculture links back to the grain pools repeatedly introduced in the 'China Cantos' and the draining of the swamps to convert them into arable land.

${ }^{245}$ Cf. Houen, Alex; Terrorism and Modern Literature: From Joseph Conrad to Ciaran Carson, $172-184$ and Marsh's afore-mentioned study for a detailed reading of the Kasper-Pound correspondence. Also consider Marsh who writes that 'the fact that he [Pound] could have stopped Kasper, who worshipped the poet as a father, teacher, and Master, at any time had he thought that his young protégé had gone too far is hard to bear. But to scholars of Pound, the poet's support of Kasper and the racial politics they both espoused, the one as activist and the other as theorist, must be accepted...' (xv).

${ }^{246}$ Both quoted in Houen, 179.

${ }^{247}$ Quoted in Houen, 190. Marsh writes that 'we can read the canto [105] as Pound's heavily coded response to what he considered the judicial usurpations of the Warren Court and renewed "northern aggression" against the South. For at least in part, the poem responds to a specific request from Kasper for propaganda material to use in Crommelin's Alabama campaign dated April 10 [see Kasper's letter in the text above]' (Marsh, 126).

${ }^{248}$ Marsh, 128.

249 'Pound] neatly summarised this attitude in 'A Visiting Card' (1942) when he held up the material construction of the Roman state as being valuable because it was the concrete form to which divine 'armor' clung:

$\mathrm{R}$ O M A

$\mathrm{O} \quad \mathrm{M}$

$\mathrm{M} \quad \mathrm{O}$

A M O R

Above all this, the substantiality of the soul, and the substantiality of the gods. (SP, 327)' (Ten Eyck, 37).

${ }^{250}$ Selby, 226.

${ }^{251}$ Stoicheff, 5 and 65.

${ }^{252}$ Ferrall, 67.

${ }^{253}$ Quoted in: Casillo; Genealogy of Demons, 328. 
254 ['Avantgarde-Macho als ein internationaler Typ'] Hesse, Eva; Die Achse Avantgarde-Faschismus: Reflexionen über Filipo Tommaso Marinetti und Ezra Pound, 173.

${ }^{255}$ Cary Wolfe has also argued that despite some earlier poems in which Pound seems to challenge some normative gender ideals especially concerning masculinity his poetry in general showcases a 'reproduction of a structure of gender built upon an unequal, hierarchical dichotomy, regardless of which side of that dichotomy Pound may align himself with at any given moment' (The Limits of American Ideology, 96). Thus she summarises: 'what is most ideologically significant in Pound's politics of gender $[\ldots]$ is not so much his positioning of himself in particular poems as either masculine or feminine but rather his reproduction of the gender system itself, which structures, organizes, and contains those positions and sustains the mechanism of patriarchal power even where it seems most disowned' (13). The same holds true for the Cantos.

${ }^{256}$ Rainey, Monument of Culture, 47.

${ }^{257}$ Wolfe, 96.

${ }^{258}$ Dennis, Helen; 'Pound, Women and Gender', 170.

${ }^{259}$ Gourmont, Remy de; The Natural Philosophy of Love, 206.

${ }^{260}$ Gourmont, 206-207.

${ }^{261}$ Gourmont, 207.

${ }^{262}$ Cf. Casillo, 'Anti-Semitism, Castration, and Usury in Ezra Pound', 248.

${ }^{263}$ How important Pound deemed the foreskin can be deduced from a letter to William Carlos Williams: 'What the hell / history is written and character is made by whether and HOW the male foreskin produces a [sic!] effect of glorious sunrise or of annoyance in slipping backward. Someone diagnosed Shaw years ago by saying he had a tight foreskin / the whole of puritan idiocy is produced by badly built foreskin' (Quoted in Torrey, 144).

${ }^{264}$ Goldblatt, 44.

${ }^{265}$ Although, as the 'China Cantos' makes clear, Taoists and Buddhist are also often to blame. Hence they are likewise presented as effeminate.

${ }^{266}$ Goldblatt, 41.

${ }^{267}$ Goldblatt notes that 'Most of the other women who are mentioned in Cantos VIII through XI are victims' (42).

${ }^{268}$ James Wilhelm study The Later Cantos of Ezra Pound offers an interesting insight into Pound criticism which tries to tackle the problematic gender dynamics in the Cantos, but does not evolve beyond its good intentions. Wilhelm is trying to reveal the sexism in the Cantos, while - unconsciously and completely without irony - he also reproduces the sexism. Consider, for example, the following passages: "The troubadours here are more the makers of poems than the seducers of women, and 
the ladies are raised up a step by being the sources of much of their inspiration' (22) and 'Throughout the Pisan Cantos, Pound mentions temples, rivers, mountains, and cities, and he adds a vast list of the names of the artists whom he had known in Paris and London, along with their attractive women friends' (17). While Wilhelm tries to prove with these passages that the Cantos also present women in a favourable light, he does not seem to realize that these women still remain little more than attractive appendages.

${ }^{269}$ Cf. Durant, Alan; Ezra Pound: Identity in Crisis, 97.

${ }^{270}$ Makin, Peter (ed.); Ezra Pound's Cantos: A Casebook, 105.

${ }^{271}$ Gourmont, 208.

${ }^{272}$ Casillo, Genealogy of Demons, 212. Unintentionally Wilhelm subtly proves Casillo's point when he writes that: 'If Pound sees woman as truly infernal in any lasting sense, it is only woman as whore. [...] The worst females are the prostitutes mentioned obliquely in Cantos 19/88 and 22/105-6, or perhaps those stiff, wooden, un-sensual American-Puritan women of Canto 28/135, women who have a "ligneous solidness" that is not a part of the easy, flowing activity that Pound most admires. The prostitute, who lives and loves for gold, is cursed by Pound, although the woman who lives for love is not' (24-25). Wilhelm tries to show that it is not woman per se whom Pound dismisses but only certain types of women. Interestingly the women described here rival the Jews in description (either too sexual or asexual) or attributes (the love for gold), proving Casillo's point.

${ }^{273}$ Again Wilhelm's reading proves unintentionally revealing: 'Pound is forcing the reader to see the Greek [Helen] and the south French woman [Eleanor] as one. They are both seductive forces with "naked beauty" and "tropic skin" (7/26), objects which may lure men to their destruction. Helen of Troy caused the Trojan War, and Eleanor's marriage to Henry II of England after her divorce from Louis VII of France led to that interminable series of wars that plagued the two countries. The Greek verb helein (destroy) is a part of their names and also one side of their characters, although just one side' (21). Wilhelm not only validates Pound's reading of history in that both women are responsible for war, but he also mirrors Pound's inhuman imagery when he speaks of women as 'seductive forces' and 'objects'.

${ }^{274}$ Stock, 13

275 ['Die große Eleanor von Aquitanien, die er der Helena gleichsetzt und die als »Reina« (in Personalunion mit Elisabeth I. von England) in den späten »Cantos« wiederauftaucht, verurteilt er genau dort, wo sie sich gegen die herrschende Meinung über die Frauenrolle behauptete: »Eleanor - sie erlosch im britischen Klima« (VII/24), als nämlich ihr Gatte Heinrich [sw] Plantagenet die »schöne Rosamunde« der emanzipierten und intellektuellen Südfranzösin vorzog. Heinrich hatte freilich den öffentlichen Konsens seiner Zeit ebenso wie die (männliche) Geschichtsschreibung für sich.'] Hesse, Eva; Ezra Pound: Von Sinn und Wahnsinn, (298-299). 
${ }^{276}$ Goldblatt, 43. In this way Pound as writer of the Cantos can align himself with the league of extraordinary men, like Malatesta or Mussolini, he singles out for praise in his epic.

${ }^{277}$ Both Goldblatt, 51.

${ }^{278}$ Le Bon, Gustave; The Crowd: A Study of the Popular Mind, 17.

${ }^{279}$ [...daß W seelenlos ist, daß es kein Ich und keine Individualität, keine Persönlichkeit und keine Freiheit, keinen Charakter und keinen Willen hat.]; my translation (Weininger 269).

${ }^{280} \mathrm{Cf}$. Weininger, 401 . Weininger even goes so far as to deny women of their subjectivitiy, arguing that women revel in their status as coveted objects (391).

${ }^{281}$ Dennis, 281.

${ }^{282}$ In: Lusty, Natalya and Julian Murphet (eds.); Modernism and Masculinity, 235.

${ }^{283}$ Quoted in: Sieburth, 164.

${ }^{284}$ Which, as all people the poet persona meets in these Cantos are spirits of the dead could as well been herself. Yet by letting a man retell her story the woman again becomes the fabric of poetry; the muse but not the creator.

${ }^{285}$ Stoicheff, 5 .

${ }^{286}$ Quoted in Feldman, 97.

${ }^{287}$ Terrell, 200. I am aware that not all the glosses are written by Terrell, yet as he oversaw the compilation I will exclusively refer to him to avoid confusion.

${ }^{288}$ Terrell, 724.

${ }^{289}$ Cf.: Urban, Thomas; Katyn 1940: Geschichte eines Verbrechen, 69-112.

${ }^{290}$ Finaldi, Giuseppe; Mussolini and Italian Fascism 107.

${ }^{291}$ The BBC, the British Press and Time Magazine published the official Soviet version (Urban, 133-134).

${ }^{292}$ Cf. for example, Makin, Pound's Cantos, 114. As an interesting side note, Robert Brasillach published numerous articles on the massacre of Katyn, highlighting the Soviet perpetrators. Thus there were numerous sources where Pound could have learned about Katyn without having to rely on inside information.

${ }^{293}$ As Cookson rejects the label 'fascist' as too broad, the term 'Fascist', designating the supporters of Fascist Italy, is a precise term that basically follows the selfdenomination of the fascisti.

${ }^{294}$ Both quotes Cookson, 57-58.

${ }^{295}$ Cookson, 114. 
${ }^{296}$ Cookson, 126. He might have also overlooked that the O.E.D. notes this usage of the word as 'offensive'.

${ }^{297}$ This is supported by a quote from Pound biographer A. David Moody saying that 'Pound came to his anti-Semitism by way of his economics, more exactly through his war on usury ... but when not engaged in that war Pound was not antiSemitic. Hence our persistent difficulty: Pound was anti-Semitic; but at the same time he was not.' Firstly, it seems debatable whether Pound's anti-Semitism is limited to the realm of economics. Secondly, Moody's claim that Pound was at once anti-Semitic and not anti-Semitic seems to be mere wordplay to deflect from the issue. One wonders whether Moody would write the same about other antiSemites.

${ }^{298}$ Cookson, 115.

${ }^{299}$ Flory, 286.

${ }^{300}$ Flory, 286.

${ }^{301}$ Flory, 295-296.

${ }^{302}$ Flory, 298.

${ }^{303}$ Flory, 299.

${ }^{304}$ Flory, 300.

\section{T. S. Eliot - The Conservative Collaborator}

${ }^{305}$ Cf. Chinitz, David E.; T. S. Eliot and the Cultural Divide.

${ }^{306}$ In: Cheyette, Bryan; Race and Culture: Representations of "the Jew" in English and American Literature; 84)

${ }^{307}$. Shusterman even suggests that relegating Eliot to the realm of the past is a way for critics to boast their own undertaking, 'especially when doing so makes our own critical and theoretical enterprises seem all the more novel and impressive' (both Shusterman; T. S. Eliot and the Philosophy of Criticism; 156). Shusterman exhibits three of the common misunderstandings of studies on Eliot and ideology: namely, the inherent paradox of conservatism and poetic innovation, the lumping together of conservatism and a simple yearning for the past, and the idea that an assessment of Eliot's politics results from personal misgivings against the poet or some narcissistic reasons.

${ }^{308}$ Eagleton, Criticism and Ideology, 150.

${ }^{309}$ When it was first published, the title was misspelled as Ara Vos Prec, yet it is commonly referred to by its corrected title. The American edition was simply named Poems. 
${ }^{310}$ For example, the Stalinist Wroclaw Congress of Intellectuals (cf. Habedank, Klaus; Kultur- und Sozialkritik bei T. S. Eliot: Eine Untersuchung der Werke Eliots 190939; 199-200). Also Rossel Hope Robbins in the T. S. Eliot Myth considers Eliot's later essays 'an intellectual blueprint for clerico-fascism' (184)

${ }^{311}$ Most of these points can be found in his Virginia lectures published as After Strange Gods. Herein he states that ' $\mathrm{t}$ ] he population should be homogeneous; where two or more cultures exist in the same place they are likely either to be fiercely selfconscious or both to become adulterate. What is still more important is unity of religious background; and reasons of race and religion combine to make any large number of free-thinking Jews undesirable.' (19-20). Moreover, he claims that tradition 'represent[s] the blood kinship of "the same people living in the same place" (18) and deprecates the society he lives in as 'wormeaten with Liberalism' (13). Anthony Julius has noted Eliot's use of the pronoun 'we', thereby effectively excluding Jews from his addressees (cf. Julius, 1-2). Although Eliot later regretted After Strange Gods and did not allow it to be reprinted, similar convictions can be found in most of his other writings, as will be shown in this chapter.

${ }^{312}$ Harding, Jason; The Criterion: Cultural Politics and Periodical Networks in Inter-War Britain, 181-182.

313 ['Eliot, dessen oft wiederholter Grundsatz lautet, er sei „interested in political ideas, but not in politics“, ist wie kein zweiter den Lockungen dieses „escapism" erlegen. „Politics“ kann nur eines bedeuten, nämlich politische Praxis. In der politischen Praxis aber spielt gerade jenes Problem der Gewalttätigkeit eine entscheidene [sic] Rolle, mit dem er sich absolut nicht auseinandersetzen will. „Political ideas“ aber können losgelöst von jeder Realität diskutiert werden, in einer höchst reinlichen intellektuellen Sphäre, unbeschmutzt von irgendwelchen praktischen Tatsachen oder Erwägungen.'] Beer, 173.

${ }^{314}$ Quoted in Beer, 177. Italics in Beer.

${ }^{315}$ Quoted in Chace, 146.

${ }^{316}$ Quoted in Beer, 172, who also emphasises the incomprehensible choice on Eliot's part of the word benevolent to describe the actions of fascist regimes in 1928. Also notice Eliot's choice to use the first person plural.

${ }^{317}$ Eliot, T. S.; The Idea of a Christian Society, 20.

${ }^{318}$ Tonning, Erik; Modernism and Christianity, 67.

${ }^{319}$ Ibid., 67.

${ }^{320}$ Quoted in Asher, Kenneth; T. S. Eliot and Ideology, 88.

${ }^{321}$ This would also explain why Eliot's loyalty for Maurras, who was Catholic, remained unbroken. Eliot's Christianity also played a role in his evasion of accusation of anti-Semitism. One incident showing Eliot's rejection of the label anti-Semite is quoted by Robert Fleissner, who is quick to add his agreement and approval: 
"When asked pointblank if he was intentionally anti-Semitic, he matter-of-factly replied that, no, he was "not an anti-Semite" [...]. Bravo. True, the reason he gave was only that he was instead a Christian, and to some subtle minds such an elementary reasoning looks like a non-sequitur, but it was not so in terms of intent.' (T. S. Eliot and the Heritage of Africa: The Magus and the Moor as Metaphor, 97). It seems that Eliot consciously overlooks the centuries-old history of Christian anti-Judaism and anti-Semitism, see for example Julius, Trials of the Diaspora.

${ }^{322}$ Eliot, The Idea of a Christian Society, 20.

${ }^{323}$ Harrison, John R.; The Reactionaries, 149.

${ }^{324}$ Surette, 161.

${ }^{325}$ When the Vatican condemned Maurras, Eliot came to his defence and wrote in the Criterion in 1928: 'I have been a reader of the work of Maurras for eighteen years...' Quoted in: Ferrall, 98.

${ }^{326}$ Villis, Tom; Reaction and the Avant-Garde: The Revolt against Liberal Democracy in Early Twentieth-Century Britain, 3.

327 Tonning, 67.

${ }^{328}$ Tonning's use of the terms 'radical' and 'reactionary' are decidedly different from my understanding of the terms. He probably associates 'radical' with 'progressive' (just as Eliot's poetic form is seen as radically experimental and therefore progressive) and 'reactionary' with 'fascist'.

${ }^{329}$ Harding; The Criterion, 182.

${ }^{330}$ Quoted in Beer, 172.

${ }^{331}$ Quoted in Robbins, 66.

${ }^{332}$ Eliot, The Idea of a Christian Society , 15. The connection between an increased suffrage and oligarchy may seem perplexing at first, but they have to be understood in the light of right-wing logic. According to this logic, if suffrage is increased, many people become eligible to vote without being capable to understand and thus meaningfully engage in political participation (i.e. they are inherently unmündig). This in turn would increase the power of the wealthy few, who control the media, education and industry, as they would essentially 'instruct' the masses which way to vote. In this way the votes of the masses only amplifies the voices of a rich minority effectively creating a system similar to oligarchy.

${ }^{333}$ Eliot, The Idea of a Christian Society, 63.

${ }^{334}$ Surette, 188.

${ }^{335}$ Asher, 23.

${ }^{336}$ Chace, 160.

${ }^{337}$ Eliot, T. S.; Notes towards the Definition of Culture, 52 
338 Surette, 253.

${ }^{339}$ Quoted in Kojecky, Roger; T. S-Eliot's Social Criticism, 148.

${ }^{340}$ Kojecky, 200.

${ }^{341}$ Robbins, 69.

${ }^{342}$ Eliot, Notes towards the Definition of Culture, 103-104.

${ }^{343}$ Kojecky, 216.

${ }^{344}$ Eliot, Notes towards the Definition of Culture, 48.

345 Ibid.; 48.

${ }^{346}$ Eliot, The Idea of a Christian Society, 40.

${ }^{347}$ Robbins, 134.

${ }^{348}$ Chinitz, T. S. Eliot and the Cultural Divide, 63.

${ }^{349}$ Eliot, Notes towards the Definition of Culture, 16.

${ }^{350}$ Harrison, 160.

351 Studies discussing Eliot and anti-Semitism are plenty: Chace, The Political Identities of Erra Pound and T. S: Eliot, Cheyette, Brian; Constructions of 'The Jew' in English Literature and Society; Cooper, John Xiros; 'Anti-Semitism'; In: Jason Harding (ed.) - T. S. Eliot in Context; Craig, Cairns; Yeats, Eliot, Pound and the Politics of Poetry: Richest to the Richest, DuPlessis, Rachel Blau; Genders, Races and Religious Cultures in Modern American Poetry; Harding, The Criterion; Julius, T. S. Eliot, Anti-Semitism and Literary Form; Morse, Jonathan; 'T. S. Eliot Says Jew'; Ricks, Christopher; T. S. Eliot and Prejudice; Robbins, The T. S. Eliot Myth; Sloane, T. S. Eliot's Bleistein Poems: Uses of Literary Allusion in "Burbank with a Baedeker: Bleistein with a Cigar" and "Dirge"; Strauss, Walter; 'The Merchant of Venom?: T. S. Eliot and Anti-Semitism'; and Surette, Dreams of a Totalitarian Utopia.

352 The main culprits are 'Burbank with a Baedeker: Bleistein with a Cigar', 'Gerontion' and the deleted instalment from The Waste Land called 'Dirge'; but also 'A Cooking Egg' and the little known 'King Bolo' verses.

${ }^{353}$ Julius, Trials of the Diaspora, 53.

354 'Of course you can find what would now be called antisemitic remarks in his early work, but who didn't say such things at that time? One has to draw a distinction between what was said before and after 1934. Of course all these nationalistic prejudices are ridiculous, but disliking Jews isn't intrinsically worse than disliking Negroes or Americans or any other block of people. In the early twenties, Eliot's antisemitic remarks were about on a par with the automatic sneer one casts at Anglo-Indian colonels in boarding houses' (Quoted in Ricks, 64).

355 Julius; T.S. Eliot, Anti-Semitism, and Literary Form, viii. 
${ }^{356}$ Julius; T.S. Eliot, Anti-Semitism, and Literary Form, 35.

${ }^{357}$ I discussed this in my Pound chapter, noting that, for example, Cookson who continually downplays Pound's anti-Semitism, seems to find Eliot's rather disgusting (cf. Cookson, 114-115).

${ }^{358}$ See Ricks, 52 and Julius, T.S. Eliot, Anti-Semitism, and Literary Form, 168-171 for the details.

${ }^{359}$ Baumann, 32.

${ }^{360}$ Craig, 287. Even more condensed is Chace's verdict when he states that '[c] oncerned though he was with the reality of political forces, Eliot felt compelled to transcend those forces, to walk alone, to be suprapolitical.' (109)

${ }^{361}$ In Chinitz, David; A Companion to T. S. Eliot, 381.

${ }^{362}$ I am using Surette's description here, who writes: 'As is well known, Eliot became a diligent opponent of humanism, but - as we will see - only a lukewarm opponent of fascism.' (41).

${ }^{363}$ His Four Quartets seem almost obsessed with an idealised past, so much so that he re-introduced archaic language. In Eliot's essays the careful reader notices that the word 'maintain' is one of the more frequently used verbs.

${ }^{364}$ Ellman, Maud; The Poetics of Impersonality, 92.

365 The motif of death was also present in the initial but then discarded epigraph, an extract from Joseph Conrad's Heart of Darkness would have introduced the motif of death.

${ }^{366}$ Ellmann, 94.

${ }^{367}$ Harrison, 147.

${ }^{368}$ Miller, William Ian; The Anatomy of Disgust, 8-9.

${ }^{369}$ Miller; The Anatomy of Disgust, 206.

${ }^{370}$ Miller; The Anatomy of Disgust, 251. Compare this to Miller's analysis of the role of contempt in democracy: 'Contempt, it turns out, was assimilable to democracy. In fact, rather than subverting democracy, it assisted it by making generally available to the low as well as to the high a strategy of indifference in the treatment of others. Contempt thus came to underwrite the basic minimal respect for persons so crucial to democracy, the style of tolerance captured by the saying "live and let live" (206).

${ }^{371}$ Sianne Ngai reaches a similar, albeit a bit different, verdict writing: 'But perhaps the more obvious explanation for the asymmetrical attention to desire and disgust in literary and cultural theory is the latter's more spectacular appropriation by the political right throughout history as a means of reinforcing the boundaries between self and "contaminating" others that has perpetuated racism, anti-Semitism, homo- 
phobia, and misogyny.' (Ugly Feelings, 338-9). Ngai goes on to argue that the Left should not be shy in mobilizing disgust against such things as racism and misogyny. I am not quite convinced that the disgust inherent in such concepts as antiSemitism, racism, homophobia, and misogyny is the same feeling as the strong objection against those concepts.

${ }^{372}$ All quotations from The $W$ aste Land are taken from: Eliot, T. S.; The W aste Land: A Facsimile and Transcript of the Original Drafts. When a quotation in the text is followed by the lines in brackets it refers to the first published version of the poem, pages 133-149 in the Facsimile edition. Quotations from the earlier manuscripts are footnoted, with the page number referring to the transcribed version of the manuscript.

${ }^{373}$ Cooper, John Xiros; T. S. Eliot and the Ideology of Four Quartets, 32.

${ }^{374}$ And in line 66 flows 'up the hill and down king William street'.

${ }^{375}$ During the time of composition 'the church had already become a relic, isolated and dwarfed by the larger office blocks of the City's banks, since people no longer resided within the City and the church had lost its parishioners.' (Rainey, Lawrence; The Annotated Waste Land with Eliot's Contemporary Prose, 85).

${ }^{376}$ Asher, 40-41.

377 Eliot, After Strange Gods, 43, emphasis in the original.

${ }^{378}$ Ferrall identifies the speaker of those lines to be Marie based on the conjunction 'and', which gives it an 'affectless or monotonal quality' (94). Rainey links this passage to Dante's Inferno, when Dante first lays eyes on Satan. (Rainey, The Annotated Waste Land with Eliot's Contemporary Prose, 79).

${ }^{379}$ Normand, Tom; Wyndham Lewis the Artist: Holding the mirror up to politics, 81.

${ }^{380}$ Part V of The Waste Land still contains water, there is rain and the shore, but this water is no longer a threat and there is no danger of drowning.

${ }^{381}$ Cf. Beer, 126-127.

382 Drowning is the most common form of death in The Waste Land. Already the evocation of the Starnberger See in line 8, the site of the mysterious drowning of King Ludwig II, hints at this recurring theme.

${ }^{383}$ Trexler, Adam; 'Economics'; In Jason Harding (ed.) - T. S. Eliot in Context, 279. The dangers of plenitude are also already apparent in the poem's epigraph, as North observed: 'In the story of the sybil, who asks for as many years of life as there are grains of sand in a handful, plenitude turns into a curse, because she forgets to ask for eternal youth as well' (101).

${ }^{384}$ Kristeva, Julia; Powers of Horror: An Essay on Abjection; 96. Moreover, Kristeva relates these notions to anthropologist findings from Sir George James Frazer and other, which produces yet another link to The $W$ aste Land. Compare the following 
section: 'In a number of primitive societies religious rites are purification rites whose function is to separate this or that social, sexual, or age group from another one, by means of prohibiting a filthy, defiling element. It is as if dividing lines were built up between society and a certain nature, as well as within the social aggregate, on the basis of the simple logic of excluding filth, which, promoted to the ritual level of defilement, founded the "self and clean" of each social group if not of each subject' (65).

385 'The water quality of the estuary dramatically improved, with increased levels of dissolved oxygen that were now being measured. Fish populations, such as sprat, returned and people even bathed in the Thames off the Tower of London. [...] Following WWI there was a massive increase in the population of London, but conditions in the Thames remained reasonably healthy due to the overcapacity built into the sewage system by the Victorians' (Martin Attrill, 'How clean is the Thames?').

${ }^{386}$ Eliot, T. S.; Collected Poems and Plays 1909-1962; 177-178, 11. 27-9. However, the tradition he advocates in Four Quartets is, similarly to his idea that people should live where they are born, directed at other people, mostly the unconscious masses (Cf. Schmidthorst; Burkhard; Mythos und Primitivismus in der Lyrik von T. S. Eliot, W. B. Yeats und Eqra Pound: Zur Kulturkritik in der klassischen Moderne; 125-126). Schmidthorst concludes that 'this borderline-cynical elitist arrogance is undeniably a part of the intellectual profile of the poet, and coincides with Eliot's belief that the mass of humanity possesses only a minor capacity for reflexion as well as moral responsibility' ['Die an Zynismus grenzende elitäre Arroganz in dieser Äußerung ist ein aus dem intellektuellem Profil des Dichters nicht auszublendendes Element, das mit der Auffassung einhergeht, die Masse der Menschen besitze nur eine äußerst geringe Reflexionsfähigkeit und moralische Verantwortlichkeit'] (126).

${ }^{387}$ Eliot, The Idea of a Christian Society, 21.

${ }^{388}$ Brooker, Jewel Spears; 'Mimetic desire and the return to origins in The Waste Land in Laity, Cassandra and Nacy K. Gish (eds.); Gender, Desire, and Sexuality in T. S. Eliot, 144-145.

${ }^{389}$ Or as Patrick Query sums it up: 'Corruption, indifference, disappointment, violence and again bodies as mere collection of parts: this is the sexual palette of The Waste Land.' In: Chinitz, A Companion to T. S. Eliot, 355.

${ }^{390}$ Asher is one critic who gives 'cunts' as the original meaning (Asher, 44). As Sweeney has featured in a number of highly sexually charged works, two of which are set in a brothel, it makes the reading credible that the feet are a stand-in for vaginas. Rainey mentions that there is no evidence for this claim, cf. The Annotated Waste Land with Eliot's Contemporary Prose, 105.

${ }^{391}$ Cf. Smith, Grover; The Waste Land, 128.

${ }^{392}$ Eliot; The Waste Land; 23, 39. 
${ }^{393}$ There is one female figure, but it is suggested that she is no longer sexually active and/or able to reproduce.

${ }^{394}$ Ellmann, 93.

${ }^{395}$ Again a topic not limited to The Waste Land: 'In a revealing letter to the play's [The Family Reunion] director, E. Martin Browne, Eliot explained that Harry's attraction to a particular woman wars with his general idea that all women are unclean creatures.' (18). Also consider that this can be found in other right-wing art, such as Futurism: 'For it is not only the body in Futurist theory but, specifically, the female body that forms the landscape of decay and dis- order that afflicts Italian culture. Most critically, it is through the appropriation of specifically gendered metaphors of decadence and depravity that Futurism constructs the feminized Italian corpus as the site of both physical and moral contamination' (Bowler, 771).

${ }^{396}$ Lewis, Wyndham; Time and Western Man, 89.

${ }^{397}$ Barry, John; “'The Waste Land”: A Possible German Source', 429.

${ }^{398}$ Cf. Barry, 431.

${ }^{399}$ Eliot, The W aste Land, 148.

${ }^{400}$ Eliot, The Waste Land, 148.

${ }^{401}$ Pondrom, Cyrena; 'Conflict and Concealment: Eliot's Approach to Women and Gender', In: Chinitz, A Companion to T. S. Eliot, 329.

402 Eliot, T. S.; Complete Poems and Plays, 124.

${ }^{403}$ Michael Tratner argues similarly: "Women "are suspect, thought to be in league," perhaps united with the animal powers in a conspiracy to overthrow the cultural super-ego: in "Sweeney Among the Nightingales," the icon of masculine power, Agamemnon, lies dead, killed not merely by Clytemnestra but by a whole mob of nightingales, who drop "liquid siftings" on the shrouded corpse, an image of the triumph of the disgusting over the noble, of female over male, and of amorphous liquid mass over the leader's body.' (Modernism and Mass Politics: Joyce, Woolf, Eliot, Yeats; 105).

${ }^{404}$ Who could be read as Jewish; Cf. DuPlessis, 146 and 148.

${ }^{405}$ As DuPlessis has noted, he uses a similar strategy for Sweeney Agonistes: 'Eliot uses race and gender as unifiers for the disparate classes (and intelligence levels) of his (presumed) audience. In "Sweeney," the gender narrative of mordant misogyny, the racial-sexual narrative of cannibals (with a kind of swinging ragtime self-parody), and the racialized primitivism of the "HOO HOO HO" are put at the service of a cross-class address about guilt and horror lurking under normalcy.' (101).

${ }^{406}$ Eliot, The W aste Land, 39.

${ }^{407}$ Cf. Miller, Anatomy of Disgust, for example 68-70 and 154. In fact, as Miller stresses, all groups that usually fall under the category of the other are linked to bad 
odours: 'Christians, whites, the upper classes, and men have all complained through the centuries, often obsessively, about the smells of Jews, nonwhites, workers, and women' (245).

${ }^{408}$ Cf. Monroe, Jonathan; 'Idiom and Cliché in T. S. Eliot and John Ashbery'.

${ }^{409}$ The scene includes no explicit gender marker for both persons. If one includes the intertextual elements the picture remains ambiguous: The reference to Shakespeare's The Tempest might indicate a male speaker, while the eponymous game of chess is taken from Thomas Middleton's Women Beware Women, where it is two women playing the game. In the Editorial Notes of the transcript edition, Valerie Eliot notes that the middle scene of 'A Game of Chess' alludes to Dante's Paolo and Franscesca in Hell (Eliot, The Waste Land, 126). I have incorporated both possible readings.

${ }^{410}$ Laurie MacDiarmid reads this scene entirely differently, although as she admits she is influenced by autobiographical details of the Eliot marriage: 'His refusals to speak only spur her into a frenzy of asking. The entire tableau, paired with the image of Philomel, suggests the emotional (if not physical) rape of the husband' (T. $S$. Eliot's Civilized Savage: Religious Eroticism and Poetics; 160).

${ }^{411}$ Morrison, 92. Their names also sound vaguely similar and Morrison adds that Lil looking 'so antique' ties her to Philomel, whose rape is displayed 'above the antique mantel'.

${ }^{412}$ Again MacDiarmid sees the women here as potential aggressors against men: 'They use sex and sexuality to exchange men like commodities, to fight for dominance amongst themselves. "He's been in the army for four years, he wants a good time," says the scheming woman. "And if you don't give it him, there's others will, I said" (CPP 41)' (30). It is rather odd that MacDiarmid sees Lil, who is in danger of being left by Albert, and her acquaintance as scheming and exchanging men like commodities while they are obviously restricted by gender norms that dictate the rules of marriage and motherhood. In any case The $W$ aste Land portrays men and women engaged in a perpetual gender war.

${ }^{413}$ Using his typical elusiveness to navigate the question, he asks if it would not be preferable if their husbands earned enough so that women would not have the need to work in The Idea of a Christian Society: "Incidentally, the term 'relegation of women' prejudices the issue. Might one suggest that the kitchen, the children and the church could be considered to have a claim upon the attention of married women? or that no normal married woman would prefer to be a wage-earner if she could help it? What is miserable is a system that makes the dual wage necessary' (70).

${ }^{414}$ Tratner, 170-171.

${ }^{415}$ Compare, for example, Allen Tate's - a prominent member of the strongly conservative group Southern Agrarians and New Critic - reading of the scene: 'the seer 
presents the bankruptcy of the modern formula as this is acted out in that most terrible scene in modern poetry - the brutally indifferent seduction of the typist by the "small house-agent's clerk." The seduction "works"; it works perfectly, too well; but the very working testifies to its failure. It can only be mechanically repeated over again and again' (in: 12 Southerners; I'll Take My Stand: The South and the Agrarian Tradition; 159).

${ }^{416}$ Rainey, The Annotated Waste Land with Eliot's Contemporary Prose, 108.

${ }^{417}$ The only other working woman is the clairvoyante, and she is both incompetent and a hoax.

${ }^{418}$ Rainey, The Annotated Waste Land with Eliot's Contemporary Prose, 109. It also proves that Eliot's inclusion of the typist and her portrayal is far from innovative. It also shows that Rainey unwittingly disproves his earlier claims about the typist.

${ }^{419}$ Eliot; The $W$ aste Land, 33 and 45.

${ }^{420}$ Compare to this observation by Rachel Potter: 'In the absence of authority, [Eliot] concludes, art is rejected in favour of a debased culture: "[The] aversion for the work of art, [the] preference for the derivative, the marginal, is an aspect of the modern democracy of culture." ('T. S. Eliot, women, and democracy'; In: Laity, 227-228).

${ }^{421}$ This holds true for Eliot's oeuvre as a whole as Rachel Potter concludes, writing: 'However, Eliot's depiction of women as a shifting vehicle for his evolving political critique, initially of an individualistic liberal humanism, and later of mass democracy, recurs throughout his poetry and criticism (In Laity, 215).

${ }^{422}$ DuPlessis, Rachel Blau; 'Gender'; In: Harding, T. S. Eliot in Context, 298.

${ }^{423}$ Rainey, The Annotated W aste Land with Eliot's Contemporary Prose, 101-102.

${ }^{424}$ Arguably, there is only one non-threatening woman and that is Marie.

${ }^{425}$ Smith, 106-107.

${ }^{426}$ In Bush, Ronald; T. S. Eliot: The Modernist in History, 34.

${ }^{427}$ Tratner, 105.

${ }^{428}$ In: Laity, 225.

${ }^{429}$ In: Harding, T. S. Eliot in Context, 296.

${ }^{430}$ Eliot; T. S.; 'Marie Lloyd'; In: Eliot, T. S.; Selected Essays 1917-1932, 407.

${ }^{431}$ Cf. Monroe, 20.

${ }^{432}$ Monroe, 21.

${ }^{433}$ Also compare Morrison: 'The syntactic force of the poetry [in the first part of A game of Chess] dissipates amid the various reflections and sensations it catalogs, as it disposes of so much bric-à-brac in the language of Shakespeare ("the Chair she 
sat in"); Virgil ("laquearia"), and Milton, or Spenser as mediated by Milton ("sylvan scene"). The poetry, which is all texture and effect, mimes the content of a room that is all Culture and Cultural Ambition' (90).

${ }^{434}$ Rainey, The Annotated Waste Land with Eliot's Contemporary Prose, 88.

${ }^{435}$ See Rainey, The Annotated Waste Land with Eliot's Contemporary Prose, for references used, 95-99.

${ }^{436}$ Monroe, 24.

${ }^{437}$ Cf. Eliot; The Waste Land, 15, and 21.

${ }^{438}$ Chinitz, T. S. Eliot and the Cultural Divide, 43-44.

${ }^{439}$ Also note the initial title of the poem that became The Waste Land, namely the Dickensian quote 'He Do the Police in Different Voices'. This title highlights not only the polyphony of the poem but already hints at the problem of class appropriation. Seeing that the source of the quote is Charles Dickens, who became famous for his novels that employed a wide range of lower-class characters but are nevertheless not without their share of problematic depiction of the lower-classes, puts the class appropriation in The Waste Land into the complicated tradition of class discourses in English literature.

${ }^{440}$ It is also no coincidence that the final sentence of the whole section, a quote from Hamlet, denies the lower classes the focus position. Instead the literary reference links back to the first two scenes.

${ }^{441}$ This reading becomes even more compelling when the poem's Marie is compared to Countess Marie Larisch, the illegitimate daughter of Duke Ludwig Wilhelm and actress Henriette Mendel. She was part of the Austrian aristocracy, yet after her role in the murder-suicide of Archduke Rudolf and his mistress Mary, left her in disgrace and her social status sank continually forcing her to work as a cook and cleaning lady, before she died destitute (Cf. Rainey; The Annotated Waste Land with Eliot's Contemporary Prose; 77).

${ }^{442}$ Chinitz, T. S. Eliot and the Cultural Divide, 98.

${ }^{443}$ Eliot; The Waste Land;, 35 and 47. It was scrapped because Pound found it over the mark.

${ }^{444}$ Chinitz, T. S. Eliot and the Cultural Divide, 98.

${ }^{445}$ Chinitz, T. S. Eliot and the Cultural Divide, 42.

${ }^{446}$ Chinitz seems to suggest that the men in this scene are working class (cf. T. S. Eliot and the Cultural Divide; 43-44). I would disagree. The money they spend and their activities point to a middle class background 'top hats and all'.

${ }^{447}$ Eliot; The Waste Land, 5.

${ }^{448}$ Cf. Eliot; The Waste Land, 5. 
449 All: Eliot; The Waste Land, 5.

${ }^{450}$ Eliot; T. S.; Ara Vos Prec, 20 and 19 respectively.

${ }^{451}$ Eliot; Ara Vos Prec, 19.

452 Eliot; Collected Poems and Plays, 121.

453 Eliot; Ara Vos Prec, 19.

${ }^{454}$ Miller; Anatomy of Disgust, 197.

${ }^{455}$ An article from The New York Times from 24 ${ }^{\text {th }}$ September 1884 speaks of the 'fashionable London mania' (Unknown; 'Slumming in This Town').

${ }^{456}$ Odede, Kennedy; 'Slumdog Tourism'.

${ }^{457}$ DuPlessis, 153.

458 Schmidthorst has also observed that Eliot's obituary for Marie Lloyd, despite its seemingly positive depiction of the music hall, seems to imply that 'music halls and the lower class culture to which they belong are part of the remains of a more primitive level of civilisation' [weist [...] die eng mit der Kultur der working class verbundene music hall als Überbleibsel einer ursprünglichen Kulturstufe aus] (57). This example shows Eliot's linking of (lower) class, race, and ideas of the primitive that are also central to the Sweeney poems.

${ }^{459}$ I agree with Miller that disgust, despite all its negative impetus, also has an inherent allure. We are both drawn to and repelled by that which we find disgusting: 'Suppose instead that we take the comminglings and confusions of "fair is foul and foul is fair" seriously, which force upon us the idea that the disgusting itself has the power to allure. By this view the fair does not lurk behind a wall of disgust; the disgusting is precisely what is fair.' (Anatomy of Disgust, 111).

460 Tratner, 172.

461 Cooper, 63.

${ }^{462}$ It is noteworthy that Lil and Albert are the only ones in The Waste Land who have children; the other people from 'A Game of Chess' as well as Marie, the typist and many other characters are or seem to be childfree. In this way The $W$ aste Land implicitly repeats the common eugenic notion of the sterility of the upper and middle classes (more precisely the women of those classes) in contrast to the lower classes (cf. MacDiarmid 70-71). Also Pound had addressed this same topic in his poem 'The Garden': 'And she is dying piece-meal / of a sort of emotional anaemia. /And round about there is a rabble / Of the filthy, sturdy, unkillable infants of the very poor. / They shall inherit the earth. / In her is the end of breeding.' (Pound, Ezra; Selected Poems of Ezra Pound; 26, 11. 3-8).

${ }^{463}$ This can be linked back to Eliot's depiction of women as passive but sexualised beings unable to withstand their sexual urges thus inviting sexual transgressions. 
464 Quoted in: Childs 89-90.

${ }^{465}$ Quoted in Childs, 88.

${ }^{466}$ Cf. Schmidthorst, 74-75.

${ }^{467}$ Both quoted in Childs, Donald J.; Modernism and Eugenics: Woolf, Eliot, Yeats, and the Culture of Degeneration, 19.

${ }^{468}$ DuPlessis writes: 'In "Sweeney Agonistes," the aggressive performance style, the veiled quotation of precisely one African-American popular song, the portrait or threat of a horror, the cannibal materials, the appearance of "religion" or "mystery," the vaudeville and minstrel sources, and the interest in rhythm all resemble [Vachel Lindsay's poem] "The Congo." The preternatural popularity of Lindsay's work, with its dynamic audience appeal suggests that there was a serious cultural need for this kind of white ideology' (98).

${ }^{469}$ North, Michael; The Dialect of Modernism: Race, Language, and Twentieth-Century Literature, 1 .

${ }^{470}$ It was possibly no coincidence that the original epitaph to The Waste Land was the quote 'The horror! The horror!' taken from Heart of Darkness, a novel deeply mired in contemporary colonial and imperialist discourses.

${ }^{471}$ For example, in Sweeney Agonistes, Sweeney in an exchange with Doris says: 'I'll carry you off / To a cannibal isle! [...] I'll gobble you up. I'll be the cannibal. [...] I'll convert you! / Into a stew. / A nice little, white little, missionary stew.' (Eliot; Collected Poems and Plays; 121). Note the language and the emphasis of Doris being turned into a white missionary stew.

${ }^{472}$ DuPlessis, 151.

${ }^{473}$ Eliot; Ara Vos Prec, 16.

${ }^{474}$ Schmidthorst highlights how Eliot inserted the Sweeney figure into contemporary discourse of evolution and eugenics, most concisely in the title 'Sweeney Erect' which alludes both to rampant sexuality and evolutionary stages (cf. 73), but also by linking Sweeney to animals especially to orang-utans (cf. 72). Also note that orangutans were popularly associated with the Irish in contemporary caricatures.

475 DuPlessis, 152.

${ }^{476}$ DuPlessis, 152-153.

${ }^{477}$ Cf. Vincent Sherry: When he [Sweeney] later reappears in The Waste Land, it is to visit Mrs. Porter, the madam of a Cairo brothel known for infecting British soldiers with venereal diseases. The song of "Mrs. Porter and her daughter" was sung by troops in the Dardanelles campaign (Southam 168)'. In: Chinitz; A Companion to T. S. Eliot, 97.

${ }^{478}$ Cf. Rainey; The Annotated Waste Land with Eliot's Contemporary Prose, 102-103. 
North, The Dialect of Modernism, 10.

${ }^{480}$ North, The Dialect of Modernism, 1.

${ }^{481}$ Cf. Young, James, O.; Cultural Appropriation and the Arts, 7.

${ }^{482}$ A similar dynamic can be observed nowadays in the debate about ,blaccent', for example, in the debate involving musician Iggy Azalea.

${ }^{483}$ North, The Dialect of Modernism, 11.

${ }^{484}$ In Sweeney Agonistes, Sweeney chants: 'We all gotta do what we gotta do / We're gona sit here and drink this booze / We're gona sit here and have a tune / We're gona stay and we're gona go / And somebody's gotta pay the rent' (Eliot; Collected Poems and Plays; 125). Moreover, the whole play is laced with minstrel-style performances of different songs.

${ }^{485}$ Quoted in Tratner, 100.

${ }^{486}$ DuPlessis, 133.

${ }^{487}$ DuPlessis, 101.

${ }^{488}$ Sanders, Charles: “'The Waste Land”: The Last Minstrel Show'; 27 and 26 respectively.

${ }^{489}$ Cf. Sanders, 24 and 26. Eliot wrote a tribute to Marie Lloyd after her death, calling her 'the greatest music-hall artist of her time in England' (Selected Essays, 405). Despite this, halfway through the essay the argument veers from tribute to criticism of society, pitching music hall culture against the new technological progress - cinema, gramophones and auto-mobiles presented as anti-culture - and ends in a gloomy prediction of the death of 'the entire civilized world' (408). Sanders refers to the following quote: 'The middle classed have no such idol: the middle classes are morally corrupt. That is to say, their own life fails to find a Marie Lloyd to express it; nor have they any independent virtues which might give them as a conscious class any dignity. The middle classes, in England and elsewhere, under democracy, are morally dependent upon the aristocracy, and the aristocracy are subordinate to the middle class, which is gradually absorbing and destroying them' (407). Note the qualifier 'under democracy'.

${ }^{490}$ North, Dialect of Modernism, 10.

${ }^{491}$ Sanders, 36. Also note his use of 'our' to draw in the reader into a fuzzy feeling of a 'common humanity'.

492 North, Dialect of Modernism, 81.

${ }^{493}$ Chinitz; T. S. Eliot and the Cultural Divide, 106.

${ }^{494}$ Quoted in: North, 78.

495 Ibid; 78.

${ }^{496}$ Quoted in North, The Dialect of Modernism, 78. 
${ }^{497}$ Emphasis in the original. Quoted in Chinitz, T. S. Eliot and the Cultural Divide, 79.

${ }^{498}$ Moreover, while Eliot conceded that artists are able to learn from the savage, the artist is also the first person to see how the savage ... can be improved upon; he is the last person ... to yield to the weak credulity of crediting the savage with any gifts of mystical insight or artistic feeling that he does not possess himself (quoted in: Irmscher, Christoper; Masken der Moderne: Literarische Selbststilisierung bei T. S. Eliot, Eqra Pound, Wallace Stevens und William Carlos Williams; 157). This shows that the supposedly primitive is, like the lower classes, something to be used for the creation of art but not to be valued for its own sake.

${ }^{499}$ DuPlessis, 126.

${ }^{500}$ Chinitz; T. S. Eliot and the Cultural Divide 73.

${ }^{501}$ Chinitz; T. S. Eliot and the Cultural Divide; 75.

${ }^{502}$ Chinitz; T. S. Eliot and the Cultural Divide; 29.

${ }^{503}$ Quoted in: Bornstein, George; 'When Race Meets Religion: Blacks, Jews, and Modernist Fictions' 23.

${ }^{504}$ North, The Dialect of Modernism, 82.

505 "I am not an anti-Semite and never have been,' Eliot insisted. 'It is a terrible slander on a man.” (Ricks, 61).

${ }^{506}$ Eliot; Ara Vos Prec, 14.

${ }^{507}$ Sloane, 25.

${ }^{508}$ Redman, 186.

${ }^{509}$ Sloane, 128.

${ }^{510}$ That the poem with Eliot's most prominent Jewish figure(s) is set in Venice can be read as a reference to Shakespeare's Merchant of Venice. In this way, 'Burbank' inscribes itself into the long tradition of anti-Semitic English literature.

${ }^{511}$ Eliot, Ara Vos Prec, 14, lines 14-16.

${ }^{512}$ Cf. DuPlessis, 150.

${ }^{513}$ This depiction of Jews not merely as carriers of disease but of Jews as disease was widespread during the time of composition (not only in Germany but also in Britain). Lara Trubowitz has noted how important '[t]his subtle but crucial conceptual transformation-from the Jew as importer of infection into the Jew as principle of contagion, the disease itself-' proved to be for the passing of the Aliens Act of 1905 (Civil Antisemitism, Modernism and British Culture 1902-1939; 36).

${ }^{514}$ Compare with Tratner, who writes: 'The lowest of the low is the Jew because Jews where the symbol of a cultureless people in their acceptance of Diaspora: they are the essence of "heterogeneity," of adulteration' (111). 
${ }^{515}$ Eliot, Ara Vos Prec, 14, lines 17-19.

516 Sloane has gone to great length to analyse these lines. She has, for example, traced the expression 'Jew's eye' and unearthed that it named an (either real or fictional anti-Semitic practice of torturing Jews to extort money from them). Furthermore, she discusses the question whether Bleistein is, in fact, dead or alive. While it makes for a compelling reading, it has no great effect on my reading of Bleistein as an anti-Semitic representation and thus I will not go further into detail. (cf. Sloane 109-110, 158).

517 Apart from the illustration above; note, for example, the then common assumption that Jews were particularly susceptible to disease, especially trachoma, as was claimed by Dr Francis Tyrell, surgical officer at the Royal London Ophthalmic Hospital (cf. Trubowitz, 36-37).

${ }^{518}$ In a similar but different reading Schmidthorst sees in Bleistein's posture traces of the evolutionary process, thus suggesting that the development of upright walk constitutes a difficult and ultimately reversible developmental stage' [Die Spuren des biologischen Evolutionsprozesses zeigen sich auch in Bleisteins Körperhaltung, die die Ausbildung des aufrechten Ganges als eine mühevolle und durchaus wieder reversible Entwicklung erscheinen läßt:...] (71).

${ }^{519}$ DuPlessis, 148.

${ }^{520}$ Fleissner, 95. And who goes on to conclude that 'this drawback does not have to mean that Eliot really was anti-Semitic...' because that would mean that many other authors and artists could also be labelled anti-Semitic, for example 'such a favourite among Jews as the musical composer Richard Wagner, and then where do we draw the line?' (95). From today's perspective it is rather amusing that Fleissner would have chosen Richard Wagner of all people in an attempt to illustrate the ridiculousness of anti-Semitic accusation of artists.

${ }^{521}$ A comparison which the title already invites. Julius adds: "Burbank' adopts the anti-Semite's doctrines of the unity and wickedness of the Jewish people, and the trans-historical struggle between Jews and Gentiles' (T.S. Eliot, Anti-Semitism, and Literary Form; 98).

${ }^{522}$ Consider again Julius: 'The poem does not damn Klein and Bleistein in order to praise Burbank. His brooding is as debased as his romance' (T.S. Eliot, Anti-

Semitism, and Literary Form; 100).

${ }^{523}$ In Julius; T.S. Eliot, Anti-Semitism, and Literary Form; 37.

524 'Dirge' was initially part of The Waste Land, yet was removed before publication, possibly at Pound's behest. It is reproduced in the facsimile and transcript edition of The $W$ aste Land referred to earlier.

525 'Hence the poem's rendering of the decomposing nostrils as lace, and the substituting of one form of vagrancy for another; not toes peeping through ragged 
shows, but bones through ragged toes. The Jew is in death as he is in life: both plutocrat and pauper, flashy (hence the 'lace') and indigent (hence the 'ragged')' (Julius, T.S. Eliot, Anti-Semitism, and Literary Form; 126-127).

${ }^{526}$ Sloane, 146.

${ }^{527}$ Both: Cheyette, Constructions of 'the Jew' in English Literature and Society; 257.

${ }^{528}$ Julius, T.S. Eliot, Anti-Semitism, and Literary Form, 123.

${ }^{529}$ Julius, T.S. Eliot, Anti-Semitism, and Literary Form, 85.

${ }^{530}$ Julius, T.S. Eliot, Anti-Semitism, and Literary Form; 99.

${ }^{531}$ Sloane, 207.

${ }^{532}$ DuPlessis, 146.

${ }^{533}$ Translation: 'And other liked to call themselves Fischbein, Herz and Mond and Stern. And Dreifuß, Blaß and Fels and Stein. And Schloß and Großmann and also Klein.' Bauer, Elvira; Tran keinem Fuchs auf grüner Heid und keinem Jud bei seinem Eid; 9.

${ }^{534}$ However, as Julius has shown, Eliot had used similar names in his original draft of The Waste Land for Jewish characters, namely Lady Kleinwurm and little Ben Levin (cf. Julius, T.S. Eliot, Anti-Semitism, and Literary Form, 104).

${ }^{535}$ Eliot, Ara Vos Prec, 16, line 23. Ricks notes: 'Rachel neé Rabinovitch' invites the further suspicion that one devious motive for, or aspect of, such a marriage is that in changing one's name one will disguise one's Jewishness. Some such thoughts as these must swirl in with the line.' (Ricks, 30).

${ }^{536}$ In: Kushner, 12-13.

${ }^{537}$ Eliot, Ara Vos Prec, 15, line 26.

${ }^{538}$ Cf. DuPlessis, 147.

${ }^{539}$ DuPlessis, 148. A similar yet less detailed observation is made by Crawford, Robert; The Savage and the City in the Work of T. S. Eliot; 113.

${ }^{540}$ Eliot, Ara Vos Prec; 15, line 28.

${ }^{541}$ Compare also Julius, T.S. Eliot, Anti-Semitism, and Literary Form, 103.

${ }^{542}$ Eliot, Ara Vos Prec; 15, line 29.

${ }^{543}$ Julius, T.S. Eliot, Anti-Semitism, and Literary Form; 104.

${ }^{544}$ Sloane, 62.

${ }^{545}$ Cf. ibid.; 62.

${ }^{546}$ Also see Sloane, 167-168. 
547 This also corresponds to Eliot's own notes originally attached to The $W$ aste Land , where he states that 'the Phoenician Sailor [...] is not wholly distinct from Ferdinand Prince of Naples...' (Eliot; The Waste Land, 148).

${ }^{548}$ To add insult to injury, Eliot was still happy to read 'Gerontion' at a poetry recital in September in 1943, that is during a time when Jews across Europe were rounded up and exterminated by virtue of declaring them an inferior form of life (cf. Julius, T.S. Eliot, Anti-Semitism, and Literary Form; 213). In Julius's own words: 'Many Jews were beyond insult by then' (ibid.).

${ }^{549}$ Also note that by the use of water imagery Jews are linked to women and the feminine. Again this was a common trope during Eliot's time and can also be found in Pound and Lewis.

${ }^{550}$ Julius, T.S. Eliot, Anti-Semitism, and Literary Form; 18.

${ }^{551}$ Julius, Trials of the Diaspora, 184.

${ }^{552}$ And according to Julius a further insult as crabs are not kosher (cf. Julius, T.S. Eliot, Anti-Semitism, and Literary Form ; 133).

${ }^{553}$ Both, Cheyette, Constructions of 'the Jew' in English Literature and Society; 264.

${ }^{554}$ Eliot, Ara Vos Prec; 17, lines 27-30

${ }^{555}$ Eliot, Ara Vos Prec; 17, line 32.

${ }^{556}$ Eliot, The Waste Land, 121. Both are additionally defined by their eyes, heavy eyes and protrusive in the other.

${ }^{557}$ An affiliation between 'Burbank' and 'Gerontion' is also indicated by intertextual reference as Sloane points out: 'Eliot replaced Gerousia with Gerontion, a title that more easily evokes Gerontus, the Jewish money-lender of Robert Wilson's The Three Ladies of London (1584). Wilson's ladies are Love, Lucre, and Conscience. In the play, which uses many themes also found in The Merchant of Venice, Gerontus lives in Turkey, and his name is from Greek geron (old man). The Christian Mercadorus, who owes Gerontus money, goes to England to evade paying. When Gerontus takes the case to court, Mercadorus converts to Islam to avoid paying the debt. We can perhaps add to the long list of similarities between Gerontion and Burbank that each evokes a play about a Jewish moneylender cheated by Christians, Wilson's The Three Ladies of London in one case and Shakespeare's Merchant of Venice in the other.' (353).

${ }^{558}$ Eliot, Ara Vos Prec 11.

${ }^{559}$ Asher, 40-41. Both are not part of Eliot's concept of tradition. Yet, while Sweeney could become part of tradition by leaving the 'uncultured' lower classes, the Jew will remain the perpetual outsider even if assimilated.

${ }^{560}$ Cf. Schmidthorst, 75.

${ }^{561}$ Kushner, 161. 
${ }^{562}$ Cf. DuPlessis, 199.

563 Julius, T.S. Eliot, Anti-Semitism, and Literary Form, 195.

${ }^{564}$ Quoted in: Ricks, 64.

565 Sloane, 193-194.

566 This has remained a popular strategy in right-wing discourse, which often nowadays conflates people of colour with apes. Compare this to Eliot who uses not only primates, but also pigs, rats, vertebrates, and protozoic slime (arguably not an animal but notable as the living organism farthest removed from humans).

567 Sanos, Sandrine; The Aesthetics of Hate: Far-Right Intellectuals, Antisemitism, and Gender in 1930s France; 90. Furthermore she adds: "Decadence," "degradation," "decrepitude," "debasement": those are the words that appeared most often, almost compulsively, in the prose of Combat and L'Insurgé journalists' (90-91).

\section{No Men in No-Man's Land - Wyndham Lewis}

${ }^{568}$ Anspaugh, Kelly; 'Another Look at Lewis, Joyce and Woolf', 365-366.

${ }^{569}$ Loewenstein, Andrea Freud; Loathsome Jews and Engulfing Women: Metaphors of Projection in the Works of Wyndham Lewis, Charles William, and Graham Greene, 151; versus: Ivan Phillips: 'Political Incorrectness Gone Sane: Lewis, Race, and Gender' In: Gasiorek, Andrzej and Nathan Waddell; Wyndham Lewis: A Critical Guide, 121. Phillips is making a similar argument for The Jews: Are They Human? (Ibid.; 121).

570 'Towards the end of 1938 Lewis wrote a book about the Jews that is the most powerful philosemitic statement made by any modernist writer - or indeed any writer - at this time.' (Munton, Alan; 'Wyndham Lewis: From Proudhon to Hitler (and back): the Strange Political Journey of Wyndham Lewis'; 6); versus: Loewenstein, 141.

${ }^{571}$ Hegarthy, Terence; Wyndham Lewis the Writer: A Preoccupation with the Real'; 338.; and: Materer, Timothy; Wyndham Lewis the Novelist, 167.

${ }^{572}$ Nadel speaks of the irresistible attraction fascism had for Lewis. (Nadel, Ira B.; “The Real History of the ERA': Joyce, Lewis and Fascism', 31). Despite the title of his study, Jameson seems to feel more comfortable with the label of anti-Marxist for Lewis, rather than fascist (Jameson; Frederic; Fables of Aggression: Wyndham Lewis: The Modernist as Fascist, 15-16); revolutionary conservative: Lafferty; David; 'Castor Oil for Conservatives: Wyndham Lewis's and "Count Your Dead: They Are Alive! Bolsho-Tory” Politics', 26ff; reactionary: Brown, Nicholas; Utopian Generations: The Political Horizon of Twentieth-Century Literature, 130; Actually Bridson sees him even more in the political centre: ' $[\mathrm{u}]$ nwilling as he might have been to admit it —along with Baldwin and Chamberlain, Attlee and Churchill, Lewis clearly remained in the middle-right of centre maybe, but none the less in the middle. He would commit 
himself to neither extreme' (Bridson, D. G.; The Filibuster: A Study of the Political Ideas of Wyndham Lewis, 181).

${ }^{573}$ Head, Philip; Some Enemy Fight-Talk: Aspects of Wyndham Lewis on Art and Society, 58-65.

${ }^{574}$ Gasiorek and Waddell, 3; and Munton, as evidenced by the title of his paper 'Wyndham Lewis: From Proudhon to Hitler (and back): the Strange Political Journey of Wyndham Lewis'.

${ }^{575}$ Gasiorek and Waddell, 3; versus: Nadel. 31 and Jameson, 183.

${ }^{576}$ Chace, William; William Chace: 'On Lewis's Politics: The Polemics Polemically Answered'; In Meyers, Jeffrey; Wyndham Lewis: A Revaluation, 163-164.

${ }^{577}$ Quoted in: Bridson, 97.

${ }^{578}$ Frederic Jameson describes Hitler 'as notorious as [it] is unread' (179), while Nathan Waddell talks about Lewis's 'inflammatory books [...] susceptible to "hearsay interpretations" and bemoans the supposed fact that "many critics have not actually read these books [...] yet nevertheless feel qualified to condemn them' (in: Miller, Tyrus; Cambridge Companion to Wyndham Lewis, 87). Ivan Phillips chimes into the debate suggesting that those who attack Lewis for his politics have seldom read the books on which they rest their charges (cf. Phillips, Ivan; 'In his Bad Books: Wyndham Lewis and Fascism', 108).

${ }^{579}$ Cf. Lewis; Wyndham; Rude Assignment, 196.

580 This experience left in him the persistent maxim to avoid future war involving Western Europe at all costs - he, however, had not become a full pacifist as his reaction to the Abyssinian War show. In Left Wings Over Europe Lewis writes 'that the industrious and igneous Italian rather than the lazy, stupid, predatory Ethiopian, should eventually control Abyssinia is surely not such a tragedy' (164-165), showing that Lewis could be supportive of war aggression if it was based on ideological assumptions he shared.

${ }^{581}$ In Rude Assignment Lewis quotes from Orwell's piece: 'The intellectual struggle between Stalinists and anti-Stalinists goes on and on, with frequent sensational defections from one side or the other. Wyndham Lewis, I am credibly informed, has become a Communist or at least a strong sympathiser, and is writing a book in praise of Stalin to balance his previous books in favour of Hitler.' Lewis dryly comments that 'this curious fairy-story exported to America was a record in silliness, if not in malevolence' (both Lewis, Rude Assignment, 78).

${ }^{582}$ Consider, for example, Munton's statement that 'when The Vulgar Streak was published in 1941, George Orwell praised its understanding of class in Britain. In private Lewis described himself as a communist, though we must have some doubts as to what he thought that meant.' (6) Munton offers no sources for the latter claim. According to another essay by Munton, Orwell had, already in 1938, 
claimed Lewis for the left-wing side (In: Gasiorek and Waddel, 76).

${ }^{583}$ Lewis, Rude Assignment, 211.

${ }^{584}$ Lewis, Rude Assignment, 67.

${ }^{585}$ Lewis, Rude Assignment, 168.

${ }^{586}$ Lewis, Rude Assignment, 221-222.

${ }^{587}$ Establishing intellectuals as a distinct class helps Lewis to address the then widespread attacks on intellectuals by right-wing intellectuals such as Sorel and Berth. I will take up this point in more detail in chapter 6.

${ }^{588}$ The source of these terms and the division is Goethe, whose words preface the chapter 'What the Puppets Want' in The Art of Being Ruled.

${ }^{589}$ Lewis, Wyndham; The Art of Being Ruled, 125. Or again on page 151: 'For in the mass people actually wish to be automata: they wish to be conventional: they hate you teaching them or forcing them into "freedom": they wish to be obedient, hardworking machines, as near dead as possible - as near dead (feelingless and thoughtless) as they can get, without actually dying.' In essence this idea matches Pound's and Eliot's understanding of the subconscious masses versus the select few.

${ }^{590}$ This is effected by the shift on the desires of the 'puppets' triggered by democratic ideals: 'But the theory or philosophy of What the Public Wants would never have come into existence without (1) the democratic, "enlightened" régime of modern Europe; and (2) the censure of the moralist, criticism of the philosopher, inhumanity of the scientist, and superbia of the napoleonism of Nietzsche.' (Lewis, The Art of Being Ruled, 80).

${ }^{591}$ Lewis; The Art of Being Ruled, 127. It can be assumed that Lewis here uses 'racial' as pertaining to species as he makes clear in his examples: '[a] beaver does not compare itself with a walrus or an antelope' (127). For Lewis, most white people would be classed as puppets.

${ }^{592}$ Lewis; The Art of Being Ruled, 247.

${ }^{593}$ Lewis; The Art of Being Ruled, 248 and 249 respectively.

${ }^{594}$ Lewis; The Art of Being Ruled, 250.

${ }^{595}$ Lewis; The Art of Being Ruled, 250.

${ }^{596}$ Erin G. Carlston has summed up Lewis's take on gender quite aptly:

Lewis articulates strongly hierarchical and gendered theories of aesthetics and politics while calling into question the very meaning(fulness) of gender in terms that can approximate the radical antiessentialism of third-wave feminism, or even Judith Butler's theory of gender as performance. In particular, although his treatment of women characters and inscriptions of femininity often remain congealed in hostile and relatively uninteresting stereotype, his discussions of men and masculinity can 
open onto much wider vistas. Lewis's critique of masculinity lays bare the workings of masculinist power, denaturalizes male privilege, and represents manliness as an anxious, generally unsuccessful performance with ludicrous - and potentially lethal - consequences (In: Miller, Tyrus; Cambridge Companion to Wyndham Lewis 126).

${ }^{597}$ Lewis; The Art of Being Ruled, 92.

${ }^{598}$ Lewis; The Art of Being Ruled, 244.

599 'Traditionally women and children are the most helpless and ill-equipped categories of mankind. Up to the present, equality of opportunity has not been achieved, and they are still the most credulous and influenceable of us. It is natural, therefore, that a great political power, interested only in domination and nothing else, would seize on them as its most readily manipulated tools. By flattery and coercion it would discipline their ignorance and weakness into an organized instrument of social and political domination.' (The Art of Being Ruled;185).

${ }^{600}$ According to Lewis, women, children and child-like people are easier to influence and coerced; moreover, the emancipation of women is a boon to the industry as they can be employed for lower wages than men.

${ }^{601}$ Lewis; The Art of Being Ruled, 218.

${ }^{602}$ See for example Lewis The Art of Being Ruled 195-196 and Hitler 97. This argument can be found almost verbatim in Weininger's book Geschlecht und Charakter, where Lewis possibly lifted it from, or, at least, found his conviction validated. In his study Geschlecht und Charakter, Weininger writes that 'many posts in stores, accounting, postal and other communication services, any place where a merely mechanical skill is employed, are being given to women, because the female is less sophisticated and therefore has less demands than the male; capitalism has realised earlier than science that women can also be paid less as they have a lower cost of living.' [...daß viele Stellen in Geschäftsläden, in der Buchhaltung, Im Post-, Telegraphen- und Telephondienste, wo immer eine rein schablonenmäßige Tätigkeit beansprucht wird, mit Vorliebe an Frauen vergeben werden, weil W viel weniger differenziert und eben darum bedürfnisloser ist als M, der Kapitalismus aber lange vor der Wissenschaft das weggehabt hat, daß man die Frauen ihrer niedrigeren Lebenshaltung wegen auch schlechter bezahlen dürfe'] (284). The similarity of Lewis's and Weininger's arguments may be a testimony to Weininger's great influence on Lewis, yet it might also testify to - and is further proven by Weininger's postmortem fame - the great popularity and ubiquity of these thoughts.

${ }^{603}$ Carlston, Erin G.; 'Women, Masculinity, and Homosexuality in Lewis' In: Miller, Cambridge Companion to Wyndham Lewis, 126.

${ }^{604}$ Brown 130.

${ }^{605}$ With some notable exceptions, such as Charles Ferrall who charts Lewis's ideological journey thusly: 'Ideologically, his first but never dissolved marriage was to the romantic primitivism of liberal democracy. However, after the General Strike of 
1926, Lewis became more preoccupied with communism and when Hitler came to power in 1933 he devoted much of his new ideological attention to fascism' (136). Here not only the timing seems to be skewed but Ferrall's general assessment of Lewis's ideology during the 1920s.

${ }^{606}$ Jameson, 18. Nicholas Brown has similarly noted this and moreover explains why it does not only show Lewis's pre-mature awareness but also his later attraction to critics of the Left: 'All these critiques [of the cult of the primitive, the manufacture of the public as an instrument of social control, the patriarchal family as an antiquated and repressive institution, the educationalist state, ideologies of progressivism and the related notion of a hypostatized human nature] we are accustomed to think of not only as much later developments, but also specifically in terms of Left analyses of liberalism: indeed, as has been pointed out before, it is as a critic of liberalism that Lewis is most sympathetically understood' (129).

${ }^{607}$ Munton, Alan; 'Introduction: Wyndham Lewis Our Contemporary'; In: Jaime, Carmelo Cunchillos; Wyndham Lewis The Radical: Essays on Literature and Modernity, 910. Toby Foshay has also addressed Jameson's critique: 'The notion that antiMarxism is the "structural center," whether conscious or unconscious, of Lewis's work [as Jameson claims] misses the point' He continues: 'Lewis opposed all egalitarianism and collectivism, whether democratic or socialist. His classicist and rightist sympathies were rooted in a commitment to fundamental difference, to the irreducible uniqueness of the artist in society, the mind in the body, the genius among the common run of humanity. He opposed democratic mass collectivism, socialism, feminism, homosexuality, primitivism, historicism (the "time cult"), and modernist subjectivism in its aestheticist reduction of significant content to experimental form. He opposed all erasing of distinct lines of demarcation between objects, social classes, races, sexes, states of mind, categories. Dualism, the tension of opposites, was an instinctive and visceral response of Lewis's in every sphere of life, a response which he deliberately cultivated and theoretically and polemically promulgated' (Wyndham Lewis and the Avant-Garde: The Politics of the Intellect; 18-19). While I agree with the general notion that Lewis's right-wing allegiance has at its core 'a commitment to fundamental difference', Foshay's list is too inclusive: Lewis's stance towards socialism is more complex as is his attitude towards the category gender.

${ }^{608}$ Lewis; The Art of Being Ruled, 35.

${ }^{609}$ Cf. Lewis; The Art of Being Ruled, 69-70.

${ }^{610}$ CF Lewis; The Art of Being Ruled, 42, 82, 148 and 151.

${ }^{611}$ Cf. Lewis; The Art of Being Ruled, 75 and 82.

${ }^{612}$ Lewis; The Art of Being Ruled, 35. Although in a later chapter he states that 'in the abstract I believe the sovietic system to be the best' (320), fascism seems to him more suited to his country. 
${ }^{613}$ Lewis; The Art of Being Ruled, 71.

${ }^{614}$ Lewis; The Art of Being Ruled, 321.

${ }^{615}$ Lewis; The Art of Being Ruled, 320-321 and 321 respectively.

${ }^{616}$ Cf. Lewis; The Art of Being Ruled, 69, 75, and 134.

${ }^{617}$ Munton, 4. Munton offers a rather bizarre conclusion in his essay writing that: '[t] he impossible political places he visited but withdrew from should alert his readers to the fact that he was trying out ideas, not defining a political position. Lewis's politics are offered by him in such a way as to ask for a response' (24).

${ }^{618}$ It is debatable how much socialism there was in National Socialism. Even if the use of the concept was merely employed to attract the working class to the newfound NSDAP, it signifies that socialism was not something deemed utterly incompatible, but something that could be made use of, or even partially incorporated.

${ }^{619}$ Lewis; The Art of Being Ruled, 321.

${ }^{620}$ I agree with Vincent Sherry when he writes: 'As a Marxist, however, Jameson reduces Lewis's political options to the binary dialectic model: the spectre of communism has generated the single, predictable antithesis of fascism, which the Enemy must seize as the only available alternative. Yet Lewis's resistance to such conventional partisan divisions locates the essence of his political identity. Authority is his one value, and if it is properly (optically) established, it matters not one whit to him which partisan stripe it wears' (Eqra Pound, Wyndham Lewis and Radical Modernism, 102).

${ }^{621}$ In Rude Assignment he writes: 'Personally I would rather muddle along with the democratic rulers of the West' (165).

${ }^{622}$ Stockton, Sharon; 'Aesthetics, Politics, and the Staging of the World: Wyndham Lewis and the Renaissance', 496.

${ }^{623}$ Lewis, Time and Western Man, 404. Lewis flaunted a very idiosyncratic orthography and used italics and unusual capitalisation frequently. In this chapter all deviations from the norm (be it spelling or typography) in Lewis's quotes are his own and will not be further indicated. The 'he' here refers to Bertrand Russell, whose book, Our Knowledge of the External World, Lewis viewed as an example of 'the timeview in all its pristine brilliance and naïveté' (Lewis, Wyndham; Time and Western Man, 395).

${ }^{624}$ Hegarthy, 338.

${ }^{625}$ For an explanation of the concept ethnopluralism, see chapter 6.

${ }^{626}$ However, a few years later Lewis would speculate in Hitler that maybe there is a natural inequality among different cultures: 'When we consider the intellectual 'darkness' of Africa (with the exception of the Nile Valley) - the similar unre- 
sourcefulness of the negritic south of India, the absolutely stationary condition of the Australian 'aborigine' (in whom, because of his isolation, it is suggested, we have a paradigm of average humanity, when left to its own devices) - there is something to be said for the european-the 'aryan'- 'Whites' - those people who in the remote past brought civilization to India, and possibly to Chaldea and to China too. It appears that any such notion must remain the merest speculation, for too little information so far is available, we are told, to do more than guess. All I am suggesting is that it is not in itself a ridiculous notion, as it is too much the habit - in the anti-'aryan' West- to assert' (134-135).

${ }^{627}$ Cf. Lewis, Paleface, for example, 4 and 22-26.

${ }^{628}$ Cf. Lewis, Paleface, 23-25. Both, Stoddard and Grant constructed a racial history that saw white people under threat from people of colour. Stoddard bemoans the fact that white people are too absorbed with 'domestic dissensions' to notice the impending threat from outside (vii), which, so Grant reasons, coupled with racial mixing, leads to 'suicide pure and simple, and the first victim of this amazing folly will be the white man himself' (xxxii). While Lewis's Paleface has a slightly different focus than these studies it nevertheless rests on the same assumptions of whites, and white power and hegemony, being under threat.

${ }^{629}$ 'As to 'Racial Equality,' what that 'equality' really implies, Tredrup [character from Hans Dominik's Atlantis] learns from his impressive friend, the great german industrialist - who is not the dupe, of course, of such a word as equality - 'und dann hatte Uhlenkort zu ihm gesprochen-lange eindringlich, bis es auch ihm klar geworden. Die Bedeutung der Frage: Gleichberechtigung der Rassen—Gleichbedeutend mit dem Abstieg der weissen Rasse. Erste Stufe eines Abstieges, der weiter und weiter zum Unterliegen fübren musste.' (quoted in: Lewis,; Paleface; 50). Similar allegations can also be found in Lewis's other writings concerning feminism and homosexuality. Again these arguments are still very much in circulation among today's Right.

${ }^{630}$ Cf. Lewis, Paleface, 276-7.

${ }^{631}$ In: Gasiorek and Waddell, 121.

${ }^{632}$ WL Time and Western Man, 24.

${ }^{633}$ WL Time and Western Man, 34.

${ }^{634}$ WL Time and Western Man, 201.

${ }^{635}$ Lewis, Time and Western Man, 25-26

${ }^{636}$ For example, Brown mentions that '[i]ndeed, somewhat bizarrely, some of the fictional dialogue spoken by the proto-fascist Hyperidians in early drafts of The Childermass finds its way back into Lewis's mouth in his nonfiction treatise Time and Western Man' (27-28). Daniel Schenker sees the Hyperideans repeating Lewis's arguments from The Art of Being Ruled and Time and Western Man (Wyndham Lewis: Religion and Modernism; 155), while David Trotter sees Alectryon as carrying on 'where 
The Art of Being Ruled had left off (Paranoid Modernism: Literary Experiment, Psychosis, and the Professionalization of English Society; 344-345).

${ }^{637}$ Campbell, SueEllen; The Enemy Opposite: The Outlaw Criticism of Wyndham Lewis; 18.

${ }^{638}$ Chace, commenting on The Revenge for Love, writes: 'And this has the effect, which is perhaps his unique contribution to the political novel, of completely neutralizing ideology itself. Even the human aspiration to political life is rightfully seen valueless' (in: Meyers, 155).

${ }^{639}$ Neilson, Brett; 'History's Stamp: Wyndham Lewis's The Revenge for Love and the Heidegger Controversy', 29.

${ }^{640}$ Wagner, Geoffrey; Wyndham Lewis: A Portrait of the Artists as Enemy, 305-306.

${ }^{641}$ Lewis; Rude Assignment, 199. Of course, compared to the reception of other books, like The Apes of God, it was indeed peaceful.

${ }^{642}$ Based on Shlomith Rimmon-Kenan narratological model The Childermass can be described as having a narrator-focalizer who perceived the focalized from without. Apart from this the novel is in large parts dominated by dialogue. All of this taken together creates an atmosphere of unreliability, uncertainty and opacity.

${ }^{643}$ Miller, Tyrus; Late Modernism: Politics, Fiction, and the Arts Between the World Wars, 111.

${ }^{644}$ A term coined by Frederic Jameson, see his chapter in Fables of Aggression 'Agons of the Pseudo-couple', 35-61.

${ }^{645}$ Wagner, 294.

${ }^{646}$ As many critics point out Pullman seems obviously modelled on Joyce, while Satters appears to be an unflattering portray of Gertrude Stein. Lewis attacked both writers (in Time and Western Man and Men Without Art) for being followers of the time-cult and especially Stein with her infantilized language as purveyor for the youth-cult.

${ }^{647}$ Lewis; Wyndham; The Childermass, 30, 37, and 41.

${ }^{648}$ Lewis; The Childermass, 50.

${ }^{649}$ Lewis, Wyndham; Men Without Art, 98.

${ }^{650}$ Lewis; The Childermass, 32. Munton has also observed this dynamic: 'Pullman begins to explain, in a schoolmasterly way, their surroundings. It becomes slowly apparent to the attentive reader that he is an advocate of the world-view of the Bailiff, whilst Satters, foolish as he often is, has a commonsense scepticism that gives him a far more perceptive view of the Bailiff's strategies of domination, even though he cannot fully articulate their significance' (in Jaime 177).

${ }^{651}$ Lewis; The Childermass, 32. 
${ }^{652}$ In: Gasiorek and Waddell (eds.), 74.

${ }^{653}$ Lewis; The Childermass, 85.

${ }^{654}$ Lewis; The Childermass, 146.

${ }^{655}$ Lewis; The Childermass, 146-147.

${ }^{656}$ Lewis; The Childermass, 147.

${ }^{657}$ In a way Satters is made to be disgusting. Considering the dynamics of disgust I explored in my chapter on Eliot, Satters despite his perceptiveness comes across as the more repugnant character.

${ }^{658}$ Whose Gentlemen Prefer Blondes was wildly successful during the 1920s and consequently received its share of criticism from Lewis.

${ }^{659}$ Jameson, 59.

${ }^{660}$ Lewis; The Childermass, 156.

${ }^{661}$ Cf. Benjamin, 47-48.

${ }^{662}$ Gasiorek and Waddell (eds.), 74-75.

${ }^{663}$ Welzer, Harald; Täter: Wie aus ganz normalen Menschen Massenmörder werden; 148. ['Der Vollzug der Tat stiftet Gemeinsamkeit; die Zuschauer bestätigen durch ihre Anwesenheit, dass das, was sich in der Arena abspielt, in Ordnung ist. Es gibt keine Intervention von außen, die angetan wäre, das praktische Einverständnis im Töten aufzubrechen. Überhaupt wird die aktive Dimension des Zuschauens bei Gewalthandlungen prinzipiell unterschätzt: Zuschauer bestätigen durch ihre pure Präsenz und durch ihr Nichteingreifen, dass der Referenzrahmen, in dem die Akteure sich bewegen, in Geltung ist und nicht in Frage steht.'], italics in the original.

${ }^{664}$ This also serves as an answer to the questions Scott Klein asks about The Childermass: "What political role is played by the observer - such as Pullman - who stands on the sidelines, as chorus, but never involves himself in the 'show' itself?" (in: Gasiorek and Waddell (eds.), 194-195).

${ }^{665}$ Lewis; Rude Assignment, 184. 'Culture' here for Lewis denotes the more restricted meaning of cultivation of character, mind and faculties as well as the arts that are products and source for such cultivation.

${ }^{666}$ In The Art of Being Ruled Lewis maintains that the puppets predominantly seek entertainment and sensationalism (125-130), which he says should be respected by the ruling system and not attempted to be changed. This is part of his greater argument against egalitarianism. The Bailiff in The Childermass embodies the deceitful ruler by pretending to pander to egalitarianism while setting up a completely inegalitarian system.

${ }^{667}$ The term, according to the OED, can designate a low-ranking soldier or an unskilled labourer, sometimes also a debtor held in servitude. 
${ }^{668}$ Cf. Lewis; The Art of Being Ruled, 148.

${ }^{669}$ Cf. Brown, 146

${ }^{670}$ Klein in: Gasiorek and Waddell (eds.), 195.

${ }^{671}$ Brown, 147.

${ }^{672}$ Lewis; The Childermass, 42.

${ }^{673}$ Lewis; The Childermass, 43. Italics in the original.

${ }^{674}$ In his polemical essay Benda argues that the intellectuals of his time had abandoned critical and impartial reasoning in favour of political involvement. His attack was predominantly aimed at nationalist and right-wing intellectuals such as Charles Maurras, Maurice Barrès, Gabriele D'Annunzio and Heinrich von Treitschke. The Childermass suggests that complicity with the ruling system/ideology counts as treason of the intellectual, not political involvement per se.

${ }^{675}$ Lewis; The Art of Being Ruled, 75. Lewis reiterates this point ten years later in Left Wings Over Europe, which shows that this assumption had a lasting validity for his assessment of political systems and might partially explain Lewis's on-going support for right-wing movements in the 1930s:

So the hypnotized automaton of democracy, through not knowing that he is not free, is, if anything, in greater danger than the plain servant of the state (servant - not 'gentleman-help' and co-partner, or any democratic make-believe of that sort). And he is in a less dignified position for he is a perpetual dupe, enslaved by words. 'We rule people by words!' When he said that, Disraeli was describing a typical democracy (98).

${ }^{676}$ In Meyers, 128.

${ }^{677}$ Schenker, writing on Lewis and Religion, notes: 'Discussions at the Bailiffs court rarely mention God, but return again and to the same social and political issues that Lewis addressed in his non-fiction writings. (How odd, for example, that the souls of the dead should be divided into fascist, communist, and liberal democratic factions.)' (Schenker, Daniel; 'Favoring the Divine: Wyndham Lewis's “The Human Age", 65).

${ }^{678}$ Munton in: Meyers, 128.

${ }^{679}$ Munton in: Gasiorek and Waddell (eds.), 74

${ }^{680}$ Brown, 135.

${ }^{681}$ Schenker, Wyndham Lewis: Religion and Modernism, 151.

${ }^{682}$ Wagner, 58.

${ }^{683}$ Lewis; The Childermass, 160 and 331-2. This is further complicated by the Bailiff changing shape momentarily: 'In this attitude a greatly enlarged mask of Chaplin, but deeply-pigmented, in sickly-sweet serio-comic mockery, it shakes above the 
audience.' Pullman reacts as readers expect it by now: 'Now that is the real Bailiff. [...] I think he's extraordinarily handsome don't you?' (230-231) Later one of the Bailiffites exclaims: 'He's a real White Man isn't he the old Bailie?' (249) No one, as Munton correctly realised, can be trusted here.

${ }^{684}$ Lewis; The Childermass, 327-328.

${ }^{685}$ Klein in Gasiorek and Waddell (eds.), 194.

${ }^{686}$ Klein in Gasiorek and Waddell (eds.), 194-5.

${ }^{687}$ In a discarded manuscript of the first chapters, god visits Sammael (i.e. Satan) in hospital.

${ }^{688}$ In fact, I think The Enemy of the Stars offers a number of similarities to The Childermass (and is much closer to it in style and content) than Monstre Gai and Malign Fiesta and it would be worth to devote a comparative study to both texts.

${ }^{689}$ 'The idea of the state moved into every heart and roused enthusiasm. To serve the state, this worldly god, became the new form of worship and cult' ['Der Gedanke des Staates zog in alle Herzen ein und weckte Begeisterung. Ihm zu dienen, diesem weltlichen Gott, das wurde der neue Gottesdienst und Kultus.'] Stirner, Max; Der Einrige und sein Eigentum; 105. Stirner postulates that the basis of political liberalism is the concept of abstract humanity, and thus the state or nation, replacing actual individuals: 'The true human is the nation, the single individual always remains an egoist. Therefore, shed your singularity, which houses egoist inequality as well as unrest, and dedicate yourselves to true humanity, the nation and the state.' ['Der wahre Mensch ist die Nation, der einzelne aber stets ein Egoist. Darum streift eure Einzelheit oder Vereinzelung ab, in der die egoistische Ungleichheit und der Unfriede haust, und weiht euch ganz dem wahren Menschen, der Nation oder dem Staat.'] 104.

${ }^{690}$ Stirner writes: 'Human/humanity and justice are ideas, spectres, for which everything will be sacrificed: [...] The human/humanity is not a person, it is an ideal, a spectre.' ['Mensch und Gerechtigkeit sind Ideen, Gespenster, denen zuliebe alles geopfert wird: [...] Der Mensch ist ja keine Person, sondern ein Ideal, ein Spuk.'] 82. For Stirner it is the French Revolution that epitomises the sacrifice of actual individual humans for the greater humanity: 'Because the revolutionary priestlings and schoolmasters served humanity, they would cut the throats of actual humans. [Weil die revolutionären Pfaffen und Schulmeister dem Menschen dienten, darum schnitten sie den Menschen die Hälse ab.'] 84.

${ }^{691}$ Lewis; The Art of Being Ruled, 375.

${ }^{692}$ Lewis; The Childermass, 64.

${ }^{693}$ Again the descriptions of the Hyperideans differ. In the early phase of the political spectacle when Pullman and Satters find themselves involuntarily among them the text identifies them by their 'white folds of a classic drapery' and Pullman 
states: 'We've got into the middle of the Ku Klux Klan!' (Lewis; The Childermass, 178). Later, however, the Hyperideans are described as dressed in black cloaks with some being naked except for a girdle (316). The choice to make their cloaks black could be seen as a nod to Italian Fascists. Moreover, the presence of Scandinavian elements, like horned helmets, and swastikas disturb the classical references.

${ }^{694}$ Lewis; The Childermass, 179.

${ }^{695}$ Consider the following dialogue:

'That set—-the high-brow circus you know, [Pullman remarks], the followers of the so-called philosopher Hyperides, not that that's his name either.'

'Isn't it?' Satters is gazing listlessly at the false sun. 'What is it?'

'Jones, I should think' (Lewis; The Childermass, 179).

However, readers should have already become suspicious about the veracity of Pullman's statements.

${ }^{696}$ Lewis; The Childermass, 188.

${ }^{697}$ Schenker, Wyndham Lewis: Religion and Modernism, 155.

${ }^{698}$ Lewis; The Childermass, 192-196 and 329-339.

${ }^{699}$ Lewis; The Childermass, 361.

${ }^{700}$ Lewis; The Childermass, 316.

${ }^{701}$ Lewis; The Childermass, 324-325.

${ }^{702}$ His name is shortly mentioned along with a dozen names of other Hyperideans fifty pages earlier. Yet his name, similar in sound and origin to many others, did not at this point betray his noteworthiness.

${ }^{703}$ Lewis; The Childermass, 368.

${ }^{704}$ Lewis; The Childermass, 367.

${ }^{705}$ Obviously, this cannot have been Lewis's model as the now infamous uniforms designed by Hugo Boss have only been introduced in the 1930s (cf. Koop, 134135).

${ }^{706}$ Cf. Koop, especially chapter 1.1 'Das Hakenkreuz', 34-41.

${ }^{707}$ There is one unidentified Hyperidean, '[a] giant with a metal swastika sewn upon his breast, who leads the unpolished horde, bellow[ing]' for revolution' mentioned roughly 50 pages earlier. Despite the similarity this does not seem to be Alectryon, so it would mean that there are at least some Hyperideans wearing Nazi insignia (Lewis; The Childermass, 318).

${ }^{708}$ Lewis; The Childermass, 326.

${ }^{709}$ Lewis; The Childermass, 368. 
${ }^{710}$ Lewis; The Childermass, 331.

${ }^{711}$ Compare this with Reichel's chapter 'Aestheticisation of the Extraordinary: the SS', especially: 'This [the drawing up of a frontier between the normal and the abnormal] led to an aesthetic, political and scientific stereotyping and stigmatisation. National Socialism merged Jews, homosexuals, the mentally ill and petty criminals, communists and gypsies into a 'damned race' of others, awaiting death. On the other side of this utopian aesthetic were the 'political soldiers' of the SS, who not only embodied this vision of terror as well as the beauty cult, but also fulfilled it. The murderous excess was preceded by an aesthetic excess.' [Dies lief auf eine ästhetische, politische und naturwissenschaftliche Stereotypisierung und Stigmatisierung zugleich hinaus. Der Nationalsozialismus faßte alle zusammen: Juden, Homosexuelle, Geisteskranke und Gewohnheitsverbrecher, Kommunisten und Zigeuner - zu einer »verfluchten Rasse« von Außenseitern, auf die der Tod wartete. Denn die andere Seite jener utopischen Ästhetik waren die »politischen Soldaten« der SS, die diese Vision des Schreckens und den Schönheitskult nicht nur verkörpern, sondern auch verwirklichen sollten. Dem mörderischen Exzeß ging der ästhetische voraus.]' (Reichel, 231).

${ }^{712}$ Lewis; The Childermass, 370.

${ }^{713}$ Lewis; Time and Western Man, 9.

${ }^{714}$ The Bailiff claims Alectryon is 'a Breton baronette with an English barmaid for a mother' who is 'cosmopolitan', due to his travels' and has 'continental politics'. Alectryon corrects him saying that he 'was a Breton duke's son with an English Big-Steel Jewess for mama - [he] had a magnate-mother but [his] papa was poor.' It is difficult to say which version is more creditable. Nevertheless, more importantly, the Bailiff initially refuses Alectryon because he is 'a Dago' and not 'Anglo-Saxon'. Only when Polemon offers to swap Alectryon for Terpsion, a Welsh man, the Bailiff (in panic) accepts Alectryon. (Lewis; The Childermass, 369-374) This absurd scene can be read as a debate between the nationalist and internationalist view. It further ridicules the Bailiff for being hypocritical in the realm of race, as he employs and praises people of colour but objects to white people from other European countries. This reasoning comes from Lewis's Paleface, which sees the then supposedly widespread interest in other cultures as a misguided exoticism at the expense of a unified white race.

${ }^{715}$ Both were also the names of publications emanating from these groups, which again comments on the role of intellectuals in politics.

${ }^{716}$ Lewis; The Childermass, 375.

${ }^{717}$ In Hitler, for examples, Lewis writes: "The Punch and Judy of the Whig and Tory was of the same order of humbug, neither less nor more, as the 'Dictatorship of the Proletariat.' The Czar Stalin is the dictator, and he says 'Le Proletariat, c'est moil' American Democracy is another political façade of that sort' (195). 
${ }^{718}$ Cf. Lewis; The Childermass, 375-394.

${ }^{719}$ Lewis; The Childermass, 393.

${ }^{720}$ In the sequels this ideological position will be held by higher-ranking characters, but importantly, in each book the governing official with the highest rank holds this exact same view.

${ }^{721}$ Lewis; The Childermass, 394.

${ }^{722}$ Lewis; The Childermass, 394.

${ }^{723}$ Sorel saw violence as both destructive and constructive, because already the act of violence produces positive values such as vigour and valour thus replacing weakness and cowardice; cf. Sorel, chapter 6 'Ethics of Violence' and Appendix 2 'Apology for Violence'.

${ }^{724}$ Lewis; The Childermass, 395.

${ }^{725}$ Lewis; The Childermass, 400. Addressing parliament, Mussolini declared: 'In the last few days not only Fascists, but many citizens have been wondering "is there a Government" [...] Are they men or are they puppets?' (In: Griffin, Roger; Fascism, $50)$.

${ }^{726}$ Lewis; The Childermass, 400.

${ }^{727}$ Lewis; The Childermass, 401.

${ }^{728}$ The word 'puppet' is the favourite insult among the Bailiff's opponents. Moreover, the word, and similar phrases like 'automaton' are also used in the description of the characters. For example, Alectryon approaches the tribune to enter the debate 'almost as an automaton' (Lewis; The Childermass; 369). Note that this usage is also reminiscent of Mussolini, who, for example, in a speech to the Chamber of Deputies in 1925, attacked the government with the words: 'Are they men or are they puppets?" (Griffin; Fascism, 50).

${ }^{729}$ Cf. for example Dasenbrock: 'Lewis is not attempting to design an ideal society or even to improve this one; what he is attempting to do is provide us with a survival guide, an art of being ruled, for the modern liberal democracies he criticizes so severely. What this means is that Lewis is developing in The Art of Being Ruled not a consistent ideology but a complex critique of ideology' (in: Golsan, Richard J.; Fascism, Aesthetics, and Culture, 87).

${ }^{730}$ Dasenbrock in: Golsan, 93.

${ }^{731}$ Ayers, David; Wyndham Lewis and Western Man; 126.

${ }^{732}$ Even in the sequel Monstre Gai women have to live in a separate city, but readers at least get a glimpse at one female character.

${ }^{733}$ A notable exception is Erin G. Carlston's contribution 'Women, Masculinity, and Homosexuality in Lewis'. Paul Edwards's comment that ' $[a]$ persuasive and 
comprehensive account that takes Lewis's complex and conflicted attitudes to women, gender, and sexuality as central has yet (at least to my knowledge) to be written; given that the feminist revolution in literary studies is probably the most transformational since the 1970s, this is surprising.' shows that this is a crucial absence in the study of Lewis as a whole (in: Gasiorek and Waddell (eds.), 227).

${ }^{734}$ In: Golsan, 87.

${ }^{735}$ Carlston notes that 'although his treatment of women characters and inscriptions of femininity often remain congealed in hostile and relatively uninteresting stereotype, his discussions of men and masculinity can open onto much wider vistas. Lewis's critique of masculinity lays bare the workings of masculinist power, denaturalizes male privilege, and represents manliness as an anxious, generally unsuccessful performance with ludicrous - and potentially lethal - consequences' (In: Miller, Tyrus; Cambridge Companion to Wyndham Lewis, 126).

${ }^{736}$ Lewis; The Art of Being Ruled, 247.

${ }^{737}$ Lewis; The Art of Being Ruled, 249.

${ }^{738}$ This does not mean that Lewis was not susceptible to gender stereotyping and his misogynist tendencies are ample testimony to that. Some examples from The Art of Being Ruled show how entrenched Lewis's own gender biases were. Thus he writes: 'Traditionally women and children are the most helpless and ill-equipped categories of mankind. Up to the present, equality of opportunity has not been achieved, and they are still the most credulous and influenceable of us' and later on he speaks of the 'natural feminine hostility to the intellect' (185 and 244).

${ }^{739}$ Lewis; Men Without Art, 131-132.

${ }^{740}$ Brown writes: 'All these critiques [such as the cult of the primitive, the manufacture of the public as an instrument of social control, the patriarchal family as an antiquated and repressive institution, the educationalist state, ideologies of progressivism and the related notion of a hypostatized human nature] we are accustomed to think of not only as much later developments, but also specifically in terms of Left analyses of liberalism: indeed, as has been pointed out before, it is as a critic of liberalism that Lewis is most sympathetically understood' (129).

${ }^{741}$ Hegarthy wrote in 1982 that '[f]ifty years ago he picked out the raw pattern that has grown into today's society, although he insisted that he wrote merely from observation of his own time and circumstances'. (338) Today this is still to a certain extent true, although Hegarthy is far too enthusiastic about Lewis 'prophecies'. What Lewis is usually credited with are some of the following issues: he problematized the educationalist state, he dismantled the problematic exoticism of his time, he criticised and analysed the workings of capitalism and he inspired McLuhan's concept of the global village. However, in many cases, these issues are part of a larger argument, which often but not always, defends right-wing ideological concepts. 
${ }^{742}$ Lewis; The Art of Being Ruled, 218.

${ }^{743}$ Lewis; The Art of Being Ruled, 250.

${ }^{744}$ Lewis; The Art of Being Ruled, 199.

${ }^{745}$ Lewis; The Art of Being Ruled, 244.

${ }^{746}$ Cf. Munton in: Meyers, 121 and 131. Are we to believe that the Hyperideans are gay by virtue of them 'being Greek'? When Munton persists in reading the Hyperideans as gay this seems to contradict his own more astute interpretation of the text that in the novel no one can be trusted.

${ }^{747}$ Wagner 294. David Peter Corbetts, more correctly I think, reads them as sexually ambiguous (Trotter, 344).

${ }^{748}$ In the sequels it is explicitly spelled out that at least Pullman is quite revolted by the homosexuals around him. It might be, that by receiving agency, thus becoming a nature, he also becomes 'a real man'.

${ }^{749}$ Lewis; The Childermass, 53 and 57.

${ }^{750}$ Lewis; The Childermass, 317.

${ }^{751}$ Lewis: The Childermass, 312.

${ }^{752}$ Lewis; The Childermass, 308.

${ }^{753}$ Lewis; The Childermass, 310.

${ }^{754}$ Lewis; The Childermass, 311.

${ }^{755}$ Cf. Lewis; The Art of Being Ruled; 199 and Time and Western Man, 34-35.

${ }^{756}$ This is continued in Monstre Gai where Third City is almost completely populated by gay men. The double meaning of 'gay' gives the title in this light a second, more disturbing, meaning. Hewitt suggests that 'the transvestite is the emblem of modern Western democratism - a ruler disguised as the ruled, a man disguised as a woman. The reappearance of the transvestite in Hitler, then, is the disguised reappearance of the democratic' ('Wyndham Lewis: Fascism, Modernism, and the Politics of Homosexuality', 536). These 'no-men' in The Childermass might play the same role and are symbols for the democratic nature that rules the Bailiff's court.

${ }^{757}$ Munton in Meyers, 131.

${ }^{758}$ Lewis, The Childermass, 196.

${ }^{759}$ Lewis; The Childermass, 384-385.

${ }^{760}$ Lewis; The Childermass, 388.

${ }^{761}$ Lewis; Hitler, 22.

${ }^{762}$ Reading both books side by side, it seems that Alectryon is the idealized Nazi, swastika-belt included, who Lewis would later see come to life in Berlin in the 
1930s. Reading both books in juxtaposition helps to make sense of the more enigmatic novel. What I am suggesting is the following: as I discussed above Alectryon's character seems to be overall positive despite some negative traits. Looking at Hitler I see a validation of this reading: not because Alectryon is like the Nazis Lewis observes in Berlin in 1930, but vice versa, because the Nazis are like Alectryon. Also Hewitt sees a continuing thread from The Art of Being Ruled to Hitler in the motif of inversion: "Inversion" - as both phenomenon and structure - is a continuing obsession in Lewis's work - and it is only in terms of the later Hitler writings that the political machinations of The Art Of Being Ruled can be understood' ('Wyndham Lewis: Fascism, Modernism, and the Politics of Homosexuality', 528). What I argue here is that this thread also runs through The Childermass, and in particular through Alectryon.

${ }^{763}$ Trotter, 344-345. Trotter also notes in his study that Lewis, among other Modernists, 'regarded masculinity above all as a form of symbolic capital' (10).

${ }^{764}$ Wagner, 58. Wagner refers to the Greek myth in which the young man Alectryon falls asleep while on guard for Ares and Aphrodite. Since it was the sun god who walked in on the couple, Ares punished Alectryon by turning him into a rooster, always announcing the appearance of the sun. Apart from the homonym cock Wagner makes use of, Hyperides sending Alectryon into the debate transforms it into an intellectual cockfight. Also note that the Bailiff was likened to a chicken earlier in the novel.

${ }^{765}$ Cf. Lewis; The Childermass, 385.

${ }^{766}$ Lewis; The Art of Being Ruled, 92.

${ }^{767}$ These two characters, notably different from the Bailiffites, challenge the Bailiff and are killed as a consequence.

${ }^{768}$ Jameson, 20-21.

${ }^{769}$ Wagner writes: 'Satters and Pulley we detest, and should detest, from the start' to which is shortly afterwards added 'they are both male homosexuals' (294). Munton sees the homosexuality of the Hyperideans as their 'limiting feature': 'the Hyperideans' reality is limited by their chosen 'Greek' identity as homosexuals; they can never become sufficiently complex to be 'real' (in: Meyers 131).

${ }^{770}$ Consider for example, the overly positive D. G. Bridson who states:

An occasional pinch of malice notwithstanding, Lewis had always been scrupulously fair to the Jews in all his books. Even in his most sustained attacks upon what he regarded as false doctrine-as in the case of his favourite adversary, Bergson-he had never been tempted to bring race in the argument. He had spoken in very friendly terms about many Jewish intellectuals, and when he found occasion to mention the Jewish race as such, it had always been in respectful terms (212). 
Also Alan Munton, as usual, finds only positive things to say about Lewis: 'Towards the end of 1938 Lewis wrote a book about the Jews that is the most powerful philosemitic statement made by any modernist writer - or indeed any writer - at this time' (6).

${ }^{771}$ Although, as Andrea Loewenstein suggests, his treatment of Jews could be considered as a paranoid element within his greater political argument:

Lewis's work reveals a similarly narcissistic paranoid system. At its base is a conspiracy spearheaded by women - in league with (depending upon the occasion) feminine homosexual men, Jews, children, nonwhites, members of the working class, communists, and various other groups. The white male, especially the white male artist and genius (of whom Lewis himself may be the only example of his time), is the victim and designated prey of this conspiracy (120).

A few pages later she sums up Lewis's anti-Semitism in the light of The Jews: Are They Human?, 'Lewis's hatred of Jews thus never had the phobic, obsessional quality we find in his misogyny or his homophobia' (141).

${ }^{772}$ This would explain his use of anti-Semitic stereotyping in his book The Jews: Are They Human?, which despite the first impression the title gives is a tract in defense of Jews written during the first peaks of the continental Judenverfolgung. Ferrall has aptly summarised the problem with this particular book when he writes that 'Lewis's anti-antisemitism is not a form of philosemitism and for that reason barely disturbs the crudest of antisemitic stereotypes:...' (152).

773 Trubowitz in Miller, Tyrus, Cambridge Companion to Wyndham Lewis ;113. Moreover, in her study Civil Antisemitism she writes: 'Over the course of his work in the 1930s, Wyndham Lewis addresses—at times polemically, at other times with vigilant delicacy, and at still other times with distressing bigotry — the nature of modern anti-Semitic rhetoric in Britain' (145).

${ }^{774}$ In Hitler he considers the Judenfrage a 'mere bagatelle', which should not hold back the Blutsgefühl between Brits and Germans (42). In Left Wings Over Europe, published in 1936, he speculates, in an attempt at cross-class empathy no doubt: '...a Durham miner must often have wished he were a Jew in the past six months; and no Jew can ever have wished himself a Durham miner.' (248)

${ }^{775}$ David Ayers; Wyndham Lewis and Western Man, 134.

${ }^{776}$ Loewenstein's study focuses on this aspect. In her introduction she writes: 'My subsequent close readings of the work of Wyndham Lewis, Charles Williams, George Orwell, Evelyn Waugh, Aldous Huxley, Hugh Massingham, and William Gerhadi confirmed the anomaly I had observed in [Henry] Greene. In the works of all these authors, male Jews seemed to reproduce either by parthogenesis or by attaching themselves to Gentile women: there were no female Jews to be seen. In 
addition, each male Jewish character seemed to exist in close proximity to, in reference to, or in opposition to one or more Gentile female characters.' (6).

${ }^{777}$ Weininger was Jewish himself, and his troubled inner-conflict between his own Jewishness and his disdain of what he considered innate Jewishness, might have led to his suicide at the very early age of 23 , only two years after the publication of the book that would eventually make him famous, but more crucially it might have lent credibility to his argument in many readers' eyes.

${ }^{778}$ Lewis; The Childermass, 297.

${ }^{779}$ Lewis; Paleface, 65.

${ }^{780}$ Lewis; The Childermass, 379.

${ }^{781}$ Wagner, 47.

${ }^{782}$ Lewis; The Childermass, 211-213. This episode takes place in the first quarter of the political spectacle. It starts unannounced, after Bailiff described how he shaped and transformed the Time Flats, which indicates that he has creative power over the place, if his words can be trusted. The episode itself serves no immediate function for the trials. Instead it highlights the performativity of the political spectacle. The inclusion of German words already hints at a change of idiom here. This new idiom could be read as a mock-Yiddish English mix or hint at the Joycean parody that follows on the ensuing pages. Both readings can be connected with reference to Joyce's character Leopold Bloom.

${ }^{783}$ Lewis; The Childermass, 157-162 and 242ff. Again consider Ayers: ,These others, however, serve to extend the Orientalism which is associated with the Bailiff [...] and to enforce a parallel between the bourgeois state and oriental despotism' (Wyndham Lewis and Western Man, 127).

${ }^{784}$ Lewis; The Childermass, 249.

${ }^{785}$ Cf. Lewis; The Childermass, 372-373.

${ }^{786}$ Lewis; Paleface, 258.

${ }^{787}$ Brown, 130-131.

${ }^{788}$ However, I am not alone in my reading of the Bailiff as Jewish. Consider, for example, David Ayers writing that ' $[\mathrm{t}]$ he Bailiff is depicted as a Punch-like figure, his hooked nose and stooped posture recalling those of the malignant Jewish figures that litter Lewis's creative works from the 1928 revision of Tarr onward...' ('Lewis's Cultural Criticism'; In: Miller, Tyrus; Cambridge Companion to Wyndham Lewis, 146).

${ }^{789}$ Cf. Lewis; The Childermass, 160-161 and 331.

${ }^{790}$ Lewis; Wyndham; Malign Fiesta, 32. 
${ }^{791}$ The introduction of the Judenstern was inaugurated on 1 September 1941 by the 'Polizeiverordnung über die Kennzeichnung der Juden'. Paragraph 1 details who has to wear it and how: '(1) Juden, die das sechste Lebensjahr vollendet haben, ist es verboten, sich in der Öffentlichkeit ohne einen Judenstern zu zeigen.

(2) Der Judenstern besteht aus einem handtellergroßen, schwarz ausgezogenen Sechsstern aus gelbem Stoff mit der schwarzen Aufschrift "Jude". Er ist sichtbar auf der linken Brustseite des Kleidungsstücks fest aufgenäht zu tragen.' The practice that visually stigmatised Jews as the other was easily communicated via countless photographs and quickly branded itself into public knowledge and cultural memory. While it does have a long tradition - Sloane writes: 'When Jews were required to wear distinctive clothing or markers, the color was almost always yellow, a constant from the Middle Ages to Auschwitz and Treblinka' (135) - it is most commonly associated with the Nazi persecution of the Jews.

${ }^{792}$ As Neilson observes, this is also an attribute Lewis repeatedly used: 'The Revenge for Love does not explicitly make this association, but Lewis's characterization of Isaac Wohl, the Jewish art forger who prefers "to be somebody else than 'to be himself," (230) closely parallels a Nazi anti-Semitism that characterized Jews as "infinitely mimetic beings, or, in other words, the site of an endless mimesis, which is both interminable and inorganic, producing no art and achieving no appropriation" (Heidegger 96)' (38).

${ }^{793}$ Julius, Trials of the Diaspora, 53.

${ }^{794}$ In fact, David Ayers sees the stand-off between Bailiff and Hyperides as 'the moment of mythic confrontation between Jew and Aryan' (Wyndham Lewis and Western Man, 126).

${ }^{795}$ Lewis; The Childermass, 195.

${ }^{796}$ When using the phrase 'protozoic slime' in any search engine almost all results link to Eliot's infamous poem.

${ }^{797}$ Lewis; The Childermass, 195. Fittingly, the Bailiffites use 'Bloody Male' as an insult against Hyperides (ibid).

${ }^{798}$ Lewis; Hitler, 41.

${ }^{799}$ Loewenstein, 152.

${ }^{800}$ Loewenstein, 151-152.

${ }^{801}$ Italics in the original; Protocols, 174 and 148 . The text continues: '... the intellectuals could not make anything out of the uttered words in their abstractness, [...] did not see that in nature there is no equality, cannot be freedom' (148). This reasoning corresponds to right-wing thought and portrays the Zionist Elders as consciously promoting false ideology in which they themselves do not believe, just as the Bailiff does in The Childermass. To the right-wing readers of the Protocols this again highlighted the undeniable truth of right-wing ideology. 
${ }^{802}$ What is more, a short scene in the first part of the novel also hints at another similarity between Pullman and the Bailiff. When Pullman becomes little miss Pullman, the governess, new hair starts to grow on his head most noticeably a sidecurl: 'A large ribbed curl develops gradually upon his right temple' (The Childermass 54). Thus the new hair-growth to mark his shift to the feminine equals or at least incorporates the hairstyle of orthodox Jews. Again the Jew and the feminine are connected. That this change involves Pullman rather than Satters is not only explained by his adherence to the Bailiff, but can also be read as yet another snipe at Joyce, on whom Pullman is partially modelled, or more precisely on Joyce's protagonist Leopold Bloom. Interestingly Lewis saw Bloom as the epitome of a Jewish cliché:

He possesses all the recognized theatrical properties of "the Jew" up-to-date - he is more feminine than la femme, shares her couvade, the periodicity of her intimate existence is repeated mildly in his own; he counts the beer bottles stacked in a yard he is passing, computing with glee the profit to be extracted from that commerce; but such a Jew as Bloom, taken together, has never been seen outside the pages of Mr. Joyce's book. And he is not even a Jew most of the time, but his talented irish author' (Lewis; Time and Western Man, 98-99.).

${ }^{803}$ Both sequels are conventional satires in the sense that for readers it is most of the time clear which characters and actions to condemn and with whom readers should sympathise. In this way they offer a more straightforward ideological reading. On the contrary in The Childermass it was usually clear whom to abhor, but less clear with whom to agree. The whole issue of mis/trust makes The Childermass especially complex turning it into a satire that has the potential to strike at all political factions.

${ }^{804}$ Cf., for example, Julian Murphet 'Lewis and Media', in: Miller, Tyrus; Cambridge Companion to Wyndham Lewis.

${ }^{805}$ 'It can be said with confidence that the structure of Lewis's politics is not "Right all the way," and not "Right-Left-Right," but "Left-Right-Left." (Munton, 3).

${ }^{806}$ Schenker; Wyndham Lewis: Religion and Modernism, 140-141.

${ }^{807}$ Lewis; Monstre Gai, 173-174.

${ }^{808}$ The fact that the Yenery is a malfunctioning ghetto underlines the fact that women should not be left to rule, and if they do, the effects are detrimental. This implicitly supports Lewis's earlier argument that the feminine principle coincides with the ruled.

${ }^{809}$ Lewis; Monstre Gai, 175.

${ }^{810}$ Compare it for example to 'fridging', a popular trope in comic books, where women have violence done to them, are killed, and more often than necessary are dismembered and put in fridges (hence the name) in order to further a male charac- 
ter's development, implying that men's hurt or protective instinct triggered by the deed is more profound than women's lives. Examples of this trope were collected on a website created by writer Gail Simone aptly titled 'Women in Refrigerators' (http://lby3.com/wir/).

${ }^{811}$ Vegetarianism was already a topic for Lewis in The Art of Being Rule, see, for example, 56-65.

${ }^{812}$ Lewis; Monstre Gai, 157.

${ }^{813}$ Lewis; Monstre Gai, 157

${ }^{814}$ Miller, Anatomy of Disgust, 9.

${ }^{815}$ Lewis; Monstre Gai, 160-161.

${ }^{816}$ Even though as has been often shown homophobia in a person does not necessarily imply that the same person is heterosexual.

${ }^{817}$ Lewis; Monstre Gai, 165.

${ }^{818}$ Monstre Gai paints a picture of society that has turned (some of) the existing hegemonies and the heterosexual matrix upside down. Third City is not only a place where homosexuality, vegetarianism, universal basic income and a car-free lifestyle have become the norm, but as the novel makes unmistakably clear, it presents a degenerate future version of British society as it existed back then. Readers are constantly reminded that Third City should be understood as a dystopia and not a utopia, a reading that only successfully works within a right-wing ideological matrix.

${ }^{819}$ Lewis; Monstre Gai, 146.

${ }^{820}$ Lewis; Monstre Gai, 197.

${ }^{821}$ Lewis; Monstre Gai, 127.

${ }^{822}$ Lewis; Monstre Gai, 219-220.

${ }^{823}$ Lewis; Monstre Gai, 218.

${ }^{824}$ Compare this to Pound's Canto LII in which the toothless Church is superseded by the new fascist axis.

${ }^{825}$ Lewis; Monstre Gai, 221.

${ }^{826}$ Lewis; The Art of Being Ruled, 93.

${ }^{827}$ Lewis; The Art of Being Ruled, 93-94.

\section{6. 'Which Book Red Pilled You?' - Right-Wing Reception}

${ }^{828}$ The title quote comes from Richard Spencer; @RichardBSpencer; tweet; 22 January 2017. The term 'red pilled' was adapted from The Matrix and is now firmly part of the right-wing lingo. Spencer even went so far as to declare it a key concept 
of the otherwise not yet well defined Alt Right: 'If there are two things- two root concepts - that define the Alt Right, they are identity and the red pill, that is, the concept of race and belonging and the ethic of seeing through the pretty lies of our time' (Emphasis in the original; Spencer, Richard; 'Why Trump Must Champion Universal Healthcare', 23 March 2017 <https://altright.com/2017/03/23/whytrump-must-champion-universal-healthcare/ $>$ ). To be red pilled thus means to realise that the so-called dogmas of the current system (liberalism, democracy, diversity etc.) are fake and detrimental to the individual as well as the community.

${ }^{829}$ Bridson, xi.

${ }^{830}$ Julius; T. S. Eliot, anti-Semitism and Literary Form, 2.

${ }^{831}$ Julius, 311-112.

${ }^{832}$ For a fictional example consider Jonathan Littell's novel The Kindly Ones. Littell's novel, however, is not free from cliché as he makes his protagonist a sexual deviant, another persistent stereotype.

${ }^{833}$ ['»Linksintellektueller« galt als Pleonasmus, »Rechtsintellektueller« als Oxymoron'] ('1979 - Der Sommer der Nouvelle Droite: Ein Gespräch mit Alain de Benoist'; in: Sezession 31, 11).

${ }^{834}$ MacDonald, a now retired professor for psychology, whose main contribution to right-wing intellectual debates is his The Culture of Critique Series, which he describes as 'books on Judaism within a modern evolutionary perspective' (http://www.kevinmacdonald.net/books.htm). In more detail, MacDonald considers several intellectual and political movements of the 20th century, such as, 'the shift in immigration policy favoring non-European peoples', as a 'group evolutionary strategy by Jews in their competition for social, political and cultural dominance with non-Jews' (taken from: MacDonald, preface to The Culture of Critique, 1; $<$ http://www.kevinmacdonald.net/PrefacePPB.pdf $>$ ). As a result, anti-Semitism could be seen as a logical response to this Jewish group evolutionary strategy. His study has proven influential on the Right and he is currently editor of The Occidental Quarterly as well as The Occidental Observer, both imprints of the Charles Martel Society, and a director of the radical right American Freedom Party.

${ }^{835}$ Kevin MacDonald in a foreword to Greg Johnson's New Right versus Old Right, San Francisco: Counter Currents Publishing, 2013.

${ }^{836}$ Cf. Reichel, 225.

${ }^{837}$ Sorel, 162, footnote 19; italics in the original. Also see p. 228 and 274.

${ }^{838}$ Lewis; The Art of Being Ruled; 353; italics in the original.

${ }^{839}$ For Lewis, these forces are essentially capitalism, democracy and the Enlightenment notion of human equality; cf. Lewis, The Art of Being Ruled, 373-375. 
${ }^{840}$ In his essay on Paul de Man, Dasenbrock also remarks upon fascism's inherent attractiveness for artists: '...three key aspects of fascist ideology appealed to intellectuals inside and outside Italy: fascism as a modernizing dictatorship, as a form of socialism critical of Marxism, and as a theory of politics with room in it for art and the artist. [...] But the Corporatist ideology of fascism [...] has clear socialist roots and explains much of the appeal of fascism to intellectuals' (11).

${ }^{841}$ The strongly neoliberal British New Right, which is commonly associated with or linked to Thatcherism, seems to be somewhat of an exception compared to its continental cousins. When I use the term 'New Right' in this chapter it will refer to the continental European New Right, unless specified otherwise.

${ }^{842}$ A term used on the cover of the GRECE magazine éléments in August 1979.

${ }^{843}$ Ives, Peter; Language and Hegemony in Gramsci; 71.

${ }^{844}$ Ives, 2. Yet he is quick to add that this is at best a simplification of Gramsci's take on hegemony.

${ }^{845}$ Gramsci, Antonio; Selections from the Prison Notebooks; 57-58.

${ }^{846}$ Ives, 4-5.

${ }^{847}$ Mostly likely Paul Gottfried, a paleoconservative thinker, has to be credited for coining the term 'alternative right' (see for example: Siegel, Jacob; 'Paul Gottfried: The Alt-Right's Jewish Godfather' or Johnson, Greg; 'The Alt Right Means White Nationalism...or Nothing at All') with Spencer simply taking it over as a selfdescription and morphing it into the catchier 'Alt Right'. In any case, it was definitely Spencer who popularised the term and who is generally associated with it.

${ }^{848}$ Goldstein, Joseph; 'Alt-Right Gathering Exults in Trump Election With NaziEra Salute'.

${ }^{849}$ Allsup, James; 'Richard Spencer: The Alt Right's Future in Trump's America', 1.2.2017, 0:58-1:05.

${ }^{850}$ Greg Johnson, 'New Right vs. Old Right'.

${ }^{851}$ Greg Johnson, 'New Right vs. Old Right'.

${ }^{852}$ Greg Johnson, 'New Right vs. Old Right'.

${ }^{853}$ One other quite banal reason is Spencer himself. His 'popularity' among the mainstream media seems to be a direct result of his defying the right-wing stereotype.

${ }^{854}$ Spencer, Richard and Jonathan Bowden; 'The European New Right', podcast, 9. January 2012; originally hosted on radixjournal.com, which is no longer online. Transcript can still be found on Counter-Currents: <https://www.countercurrents.com/2016/08/the-european-new-right/>. 
${ }^{855}$ For a short introduction on Eichberg see Assheuer, Thomas and Hans Sarkowicz; Rechtsradikale in Deutschland: Die alte und die neue Rechte; 154-155.

${ }^{856}$ In the American context one can also find 'Ethnonationalism', which seems to be essentially the same as ethnopluralism. Greg Johnson, for example, defines ethnonationalism as 'the idea that every distinct ethnic group should enjoy political sovereignty and an ethnically homogeneous homeland or homelands'. Furthermore, it is opposed to (liberal) multiculturalism and thus 'the best way to ensure peace and good will among peoples and preserve human racial, cultural, and religious diversity' (http://www.counter-currents.com/2012/06/frequently-askedquestions-part-1/).

$857 @$ RichardBSpencer; tweet; 23 January 2017.

${ }^{858}$ Another important issue is the concept of race. In the US the New Far Right is quite open to emphasise the central role of race: 'Race is an indispensable source of identity for individuals around the world and one of the most consistent and revealing predictive mechanisms in the social sciences' (Spencer, Richard and F. Roger Devlin; 'Race - Stalking the Wild Taboo'). Sometimes it is used as the single defining element (consider such terms as 'generic whiteness'. In Europe the emphasis on race is less pronounced, but the reference to a country's autochthonous population implies whiteness.

859 'There exists a right to differ. Every ethnic group has the right to preserve its culture, its rituals and tradition, ergo its ethno-cultural identity'. ['Es gibt ein Recht auf Verschiedenheit. Jede Ethnie hat das Recht, ihre Kultur, ihre Bräuche und Traditionen, also ihre ethnokulturelle Identität, zu erhalten.'] (https://www.identitaerebewegung.de/category/faq/).

${ }^{860}$ The German Identitäre Bewegung writes on their website: 'Thus our protest is directed against the politicians responsible, who sacrifice the happiness of the autochthonous population as well as of migrants for their ideological and economic interests. The political and social elites with their flawed political measures are the driving force behind uncontrolled mass immigration' ['Darum richtet sich unser Protest stets gegen die Verantwortlichen in der Politik, die unser aller Glück - das der Einheimischen wie der Migranten - ihren eigenen ideologischen oder wirtschaftlichen Interessen opfern. Es sind die politischen und gesellschaftlichen Eliten, die durch falsche politische Maßnahmen die unkontrollierte Masseneinwanderung immer weiter vorantreiben.'] (https://www.identitaerebewegung.de/category/faq/). Among the Far Right this 'process' is also often referred to as 'white genocide'. Apart from immigration is has a strong focus on reproductive issues, such as miscegenation and higher birth rates of non-white people. Thus genocide in this context translates into being 'bred out of existence' rather than being actively exterminated.

${ }^{861}$ In the manifesto of the shooter, fittingly titled The Great Replacment, this dynamic of replacement is posited as the trigger for the massacre. Using terms like 'the in- 
vaders' help to situate the attacker as a defender of his homeland and 'his people', an argument that already betrays völkisch notions. Here, the manifesto clearly shows the underlying racism of ethnopluralism, as race, especially whiteness, is the constitutive element of what the attacker terms 'his people'

${ }^{862}$ The term 'mainstream' is an important yet problematic term. As I have argued in my theory chapter, 'the middle' does not necessarily represent the midpoint between left and right but the seat of power. The mainstream could be seen as denoting the majority in the middle of the political spectrum, yet more important is its connection to power which compels a certain adherence. When the Right uses the term 'mainstream' it usual refers to the hegemonic discourse, which is often imagined to be dominated by the liberal elites (in some rare instances also by conservative elites). It is, of course, arguable and subject to change what the 'true' politics of the mainstream are. What is crucial for this chapter, is that the New Far Right deems the 'mainstream', those who are in power, from which they want to dissociate themselves, but which they after all want to become.

${ }^{863}$ Consider for example the debate in The Guardian about the use of the term 'altright'. In an opinion piece titled 'White nationalists? Alt-right? If you see a Nazi, say Nazi', Lindy West deplored the media's cooperation in rebranding the far right by their use of terms such as 'alt-right' or the general use of euphemisms. A couple of days later The Guardian style editors released an article explaining 'Alt-right: why the Guardian decided not to ban the use of the term' because 'it exists as a term that is used in the world, particularly in the US, and it is the media's job to describe and reflect the world as it is'. It furthermore specified that the use of the term 'alt-right' had to be 'followed by the brief but broad description of it being a far-right movement'. Similar discussions were featured in other media again showcasing that language is one of the key factors of the New Far Right.

${ }^{864}$ This means that the individuals and movements included in this chapter do not (at the moment of writing) participate in parliamentary politics. At present also none of the groups featured here have their political stance fully represented by a governing party in their home countries.

${ }^{865}$ J. M. Berger, Nazis vs. ISIS on Twitter: A Comparative Study of White Nationalist and ISIS Online Social Media Networks', 3. Berger's study is limited to Nazi and White Nationalist Twitter accounts, thus it might be a bit rash to extrapolate his findings to other groups on the right-wing spectrum. His follow-up study 'The Alt-Right Twitter Census: Defining and Describing the Audience for Alt-Right Content on Twitter' offers a more qualitative analysis of right-wing social media presence.

${ }^{866}$ Between the first quarter of 2012 and the fourth quarter of 2016 the number of monthly active Twitter users in the US has doubled (from 34 million users to 67 million users). However, since mid-2014 the numbers have been relatively stable between 63 and 67 million. (https://www.statista.com/statistics/274564/monthly- 
active-twitter-users-in-the-united-states/). This roughly corresponds to the development of international monthly active users (from 138 million in 2012 to 319 by the end of 2016 as well as a stalling in growth from 2015 onwards). (https://www.statista.com/statistics/282087/number-of-monthly-active-twitterusers/).

${ }^{867}$ Bridson, 116. Bridson does not give a source for this, and there is a chance that it was Lewis himself who brought this into the debate in order to deflect from his earlier support of National Socialism.

${ }^{868}$ Marsh, 126.

${ }^{869}$ Consider the following: 'Later in the same speech, Kasper spoke of the nonchoice facing Americans in elections featuring two "hollow pumpkins"--: "the hollow Pumpkin on a pole in the White House" and the man who ran against him in the November elections, Adlai Stevenson. These remarks can be used as a gloss for lines in Canto 85, "This 'leader,' gouged pumpkin/ that they hoist on a pole" (85/565). Although his audience must have found Kasper's imagery extravagant, this is what The Cantos sound like when sent into action. One can be sure that Kasper's speeches routinely alluded to Pound's poem in this way.' (Marsh 183).

${ }^{870}$ Marsh, xvi.

${ }^{871}$ Cf. Marsh, 5.

${ }^{872}$ 'In 1949, while I was visiting Ezra Pound who was a political prisoner at St. Elizabeth's Hospital, Washington, D.C. (a Federal institution for the insane), Dr. Pound asked me if I had ever heard of the Federal Reserve System. I replied that I had not, as of the age of 25 . He then showed me a ten dollar bill marked "Federal Reserve Note" and asked me if I would do some research at the Library of Congress on the Federal Reserve System which had issued this bill' (Mullins, Eustace; Secrets of the Federal Reserve, 2).

873 'This book was from its inception commissioned and guided by Ezra Pound. Four of his protégés have previously been awarded the Nobel Prize for Literature, William Butler Yeats for his later poetry, James Joyce for "Ulysses" Joyce never received a Nobel prize], Ernest Hemingway for "The Sun Also Rises", and T.S. Elliot [sic!] for "The Waste Land". [...] Pound played a major role in the inspiration and in the editing of these works -- which leads us to believe that this present work, also inspired by Pound, represents an on-going literary tradition. [...] His third and final vindication is this work, which documents every aspect of his exposure of the ruthless international financiers to whom Ezra Pound became but one more victim...' (Mullins, 3).

${ }^{874}$ Quoted in: Parker, 109.

${ }^{875}$ The book was seized and the entire edition of 10,000 copies burned by government agents led by Dr. Otto John. The burning of the book was upheld April 21, 1961 by judge Israel Katz of the Bavarian Supreme Court. The U.S. Govern- 
ment refused to intervene, because U.S. High Commissioner to Germany, James B. Conant (president of Harvard University 1933 to 1953), had approved the initial book burning order. This is the only book which has been burned in Germany since World War II' (Mullins, 2-3).

${ }^{876}$ Schmied, 7: 'unter unwürdigsten Bedingungen in einem amerikanischen Irrenhaus Internierten (offenbares Vorbild für die spätere sowjetische Praxis, Dissidenten in Nervenkliniken zu isolieren)...'.

${ }^{877}$ Schmied, 85.

${ }^{878}$ The rhetorical trick of making the critics of fascists the real fascists is quite common. Here is an example from Wyndham Lewis's second autobiography: 'The thinker or the artist can no longer, it is affirmed, be permitted 'to dissociate himself from the community'. This may be paraphrased as follows: no unofficial, or private, or outside criticism [...] is to be tolerated. [...] Such type of thinking, by whatever name it may go, is merely fascism' (Rude Assignment, 75). Schmied does not formulate it as clearly, but his recurrent insistence of the unfairness of Pound's treatment and his silence on Pound's own politics, suggest an implicit analogy.

${ }^{879}$ Stock, 91-92.

${ }^{880}$ Marsh, 4.

${ }^{881}$ Marsh, 27.

${ }^{882}$ McDonald, Gail; 'Eliot and the New Critics'; In: Chinitz; $A$ Companion to T. S. Eliot, p. 413. Also compare Terry Eagleton's comment on New Criticism: 'If poetry was to be the new organic society in itself, the final solution to science, materialism, and the decline of the 'aesthetic' slave-owning South, it could hardly be surrendered to critical impressionism or soggy subjectivism' (Eagleton, Terry; The Ideology of the Aesthetic, 47).

${ }^{883}$ The 12 Southerners were a group of twelve American poets, essayists and novelists with close ties to the Southern United States, who included John Crowe Ransom, Donald Davidson, Frank Lawrence Owsley, John Gould Fletcher, Lyle H. Lanier, Allen Tate, Herman Clarence Nixon, Andrew Nelson Lytle, Robert Penn Warren, John Donald Wade, Henry Blue Kline, and Stark Young.

${ }^{884} 12$ Southerners, 6.

${ }^{885}$ Owsley's text is rife with overt racism. Consider for example the following passage: 'Negroes had come into the Southern Colonies in such numbers that people feared for the integrity of the white race. For the negroes were cannibals and barbarians, and therefore dangerous. No white man who had any contact with slavery was willing to free the slaves and allow them to dwell among the whites. Slaves were a peril, at least a risk, but free blacks were considered a menace too great to be hazarded. Even if no race war occurred, there was dread of being submerged and absorbed by the black race. Accordingly, all slaveholders and non-slaveholders who 
objected to slavery, objected even more to the presence of the free negro' (77). While it might be possible that not all of the 12 Southerners subscribed to this sort of stark racism there remains no doubt that when they speak of the Southern tradition and the connection between the people and the soil they speak of white people only.

${ }^{886} 12$ Southerners, 159.

${ }^{887}$ Julius; T.S. Eliot, Anti-Semitism, and Literary Form; 304, emphasis in the original.

${ }^{888}<$ http://www.counter-currents.com/about/>.

${ }^{889}$ At the time of writing (March 2017) Breitbart.com is (supposedly) the 49th most visited site in the US, while its global rank is currently 233. The site has seen a sharp spike in visitors since the Trump election in 2016 (cf.: http://www.alexa.com/siteinfo/breitbart.com). On its Facebook page, Breitbart states that it has 45 million monthly readers (last checked March $20^{\text {th }}$ 2017). Andrew Anglin's The Daily Stormer is, according to himself, 'the world's most viewed alt-right web site', a claim the SPLC corroborates stating that 'in July, four months before Trump's win, The Daily Stormer had become the most popular Englishlanguage website of the radical right', although neither gives any figures. (https://www.splcenter.org/fighting-hate/intelligence-report/2017/eye-stormer).

In November 2016 Anglin wrote that his site had 'approximately 140,000 unique visitors a day' (<http://www.dailystormer.com/support-the-daily-stormer/>). The reliability of these figures is a matter of debate. Josh Harkinson, in an article for Mother Jones, compared the Alexa rankings of Breitbart, The Daily Stormer and Stromfront to figures supplied by the analytics firm comScore, which seems to confirm that Breitbart and The Daily Stormer inflate the number of visitors. For The Daily Stormer comScore shows less than hundred thousand unique monthly visitors in mid-2016 and no growth, a far cry from Anglin's claim of four million visitors; for Breitbart comScore analysed a growth from 13 to 19 million unique visitors between February and October 2016, considerably less than the numbers Breitbart published (Harkinson, Josh; 'White Supremacist Sites Claim Their Traffic Is Booming. Actually, No'). According to the figures Johnson released in April 2017, Counter-Currents sees a steadily increasing readership, starting with 6,145 unique monthly visitors at its inception in June 2010 growing to 187,296 unique monthly visitors in March 2017. In 2016 the website had roughly 1,6 million unique monthly visitors. Interestingly the growth in readership is quite linear and stable; it thus seems that CounterCurrents relies less on external political events to attract (new) visitors. For example the 2016 presidential election triggered no significant rise in readership (<https://www.counter-currents.com/2017/04/counter-currents-nanr-newslettermarch-2017/>)

890 Greg Johnson, 'A Message to New Readers' (http://www.countercurrents.com/2016/12/a-message-to-new-readers/). One should note that Johnson's use of the traditional IQ scale (instead of saying that the website is aimed at 
educated readers or the like) could be seen as an implicit nod to research that claims that there is a link between race and IQ; see for example: The Bell Curve by Richard J. Herrnstein and Charles Murray (who is conservative but not on the far Right), which has become a staple in right-wing debates on race, as well as books by Richard Lynn such as The Global Bell Curve, The Chosen People: A Study of Jewish Intelligence and Achievement, IQ \& Global Inequality, and Race Differences and Intelligence, all of which are issued by Washington Summit Publishers, the sister organisation of the National Policy Institute, of which Spencer is currently president and director. At present their website wnw.washsummit.com is no longer active.

${ }^{891}$ His other works are published by Wermod and Wermod, a right-wing venture with Alex Kurtagic as its editor-in-chief. Bowden also featured in a 15-part podcast with Richard Spencer from 2012, and can now be found at radixjournal.com/podcasts.

${ }^{892}$ A counter-canon here would entail not the deconstruction of the mainstream canon to introduce previously unrecognised literature by marginalised voices but the production of an alternative ideologically motivated canon which would include largely well-known authors but which highlights their ideological allegiance to the (Far) Right.

${ }^{893}$ Sternhell, Zeev; The Anti-Enlightenment Tradition, 330.

${ }^{894}$ See Theory chapter 19-20.

${ }^{895}$ Blurbs by Charles Krafft, Leo Yankevich and James J. O’Meara in that order. Bolton, Kerry; Artists of the Right, Back cover.

${ }^{896}$ Foreword by Greg Johnson, in Bolton, iii.

897 'West-Coast White Nationalism is [Johnson's] term for the blending of white racial consciousness with liberal or Left-wing positions on such issues as capitalism, environmentalism, zoning, abortion, drug legalization, homosexuality, and religious pluralism. [...] A more accurate term for West-Coast White Nationalism might be the Racially-Conscious Left, although it is a non-egalitarian outlook, and if the LeftRight split is on the essential issue of equality versus inequality, then the Racially Conscious Left really isn't Left-wing at all. But it may be as far to the Left as one can reasonably go.' (Johnson, Greg; 'What Is “West-Coast White Nationalism"?' $<$ http://www.counter-currents.com/2012/06/frequently-asked-questions-part$2 />)$.

${ }^{898}$ In how far the political allegiances of these authors constitutes an 'embarrassment to the Left' is debatable. While I would agree with Johnson that there exists a dilemma for part of the Left of acknowledging these authors' literary achievements despite the inherent ideology; for parts of the Left the traditional canon and its predominantly white male writers have long lost authority. The problem here is that Johnson brushes over the heterogeneity of the Left (and the liberal mainstream which he certainly includes) and does not see or care about the differing opinions 
on the matter among the Left, possibly because this would also weaken his argument.

${ }^{899}$ Consider for example: 'The reason that White Nationalists develop out of conservatism is that conservatism itself is not an adequate framework for the preservation of the white race. It is not intellectually adequate, because it is beholden to race-blind universalism and egalitarianism. It is not institutionally adequate, because even if the conservative movement would fight for our race, it loses every important battle.' (italics in the original; Johnson, Greg; 'What is the relationship of the [North American New Right] to conservatism?' <http://www.countercurrents.com/2012/06/frequently-asked-questions-part-2/>).

${ }^{900}$ In an interview with Michael R. Burch. Also consider the following statement from Salemi concerning his politics: 'It's not just pro-Israeli neocons who are trying to force their will on the world. It's liberals in general, with their insufferable need to make the planet safe for equality, feminism, gay rights, democracy, and all their other pet causes. American liberals are now in full imperialist mode, ready to go anywhere in the world to impose the liberal worldview and agenda on recalcitrant and benighted populations. Hillary Clinton is a horrifyingly authoritarian bitch, and her presidency would be as warmongering as Hitler's Third Reich.' ('Interview with Dr Joseph Salemi', The Hyper Texts).

${ }^{901}$ Johnson, in: Bolton, iii.

${ }^{902}$ Johnson's reading here clashes very nicely with 'traditional' literary scholarship on these writers, where one often finds the common explanation that the prejudices these men upheld were just the norm during their time.

${ }^{903}$ Bolton, Back cover.

${ }^{904}$ Which might be due to their being originally published in a book called Thinkers of the Right: Challenging Materialism.

${ }^{905}$ Bolton, 113.

${ }^{906}$ Bolton, 114.

${ }^{907}$ Bolton, 100. I would also disagree with Bolton that Pound started the Vorticist movement and that Henri Gaudier-Brzeska was the 'original impetus'. In all likelihood, it was Lewis who was the mastermind behind Vorticism. Even though Pound did come up with the name, it was Lewis who was editor of BLAST and who contributed extensively to it, compared to Pound.

${ }^{908}$ Bolton, 119; this is a direct quote from Peter Ackroyd's Ezra Pound and His World.

${ }^{909}$ Quoted in Bolton, 112.

${ }^{910}$ Both Bolton, 109. 
${ }^{911}$ This is of course subject to copyright terms and might have changed since Bolton wrote these essays. I checked one of the biggest digital libraries, archive.org, which hosts a digital downloadable copy of both texts. The currently available version of Social Credit was uploaded on 24 February 2011, Jefferson and/or Mussolini on 27 April 2016. A noteworthy detail about the latter text is the username of the person, who uploaded the file, 'Redpilled_Reader', which shows that it is the Right, who is interested in the survival and accessibility of these texts (<https://archive.org/details/JeffersonAndOrMussoliniPound1935>).

${ }^{912}$ Both quotes from 'If So the Man You Are'; in: Lewis, Wyndham; Collected Poems and Plays, 59 and 60 respectively.

${ }^{913}$ Bolton, 141. An error, which inadvertently damages Bolton autobiographical reading even further, is his apparent misdating of Lewis's poem. Included in his subchapter, titled 'Return to England' dealing with Lewis's life after the Second World War, Bolton writes: 'A post-war poem, "If So the Man You Are," autobiographically continues to reflect some of Lewis's abiding themes;' (140-141). Yet, 'If So the Man You Are' is not a post-war poem in the context of the Second World War; it was published in 1933. So why does Bolton assume 'If So the Man You Are' to be a post-war poem? The answer might be again Bolton's use of sources. Turning to The Penguin Anthology of Contemporary Verse one realises that its editor, Kenneth Allott, did not include the poems' dates of publication. In the chapter on Lewis he brings in a short statement by Lewis about his poetry, and these notes are from 1948 (Cf. Allott, Kenneth; Penguin Book of Contemporary Verse 1918-60, 72), the date Bolton wrongly assumes to be the publication date of 'If So the Man You Are' (as stated in his footnote).

${ }^{914}$ Bolton uses one quote from The Art of Being Ruled as opposed to four references to Campbell's article.

915 There is one quote from Left Wings Over Europe, one which does not even reflect the main argument of the book. About Hitler Bolton writes: 'An early appreciation entitled Hitler was published in 1931, sealing Lewis's fate as a neglected genius' (133). It fits Bolton's central narrative that Lewis was unfairly shunned by the mainstream for his 'unsavory' politics, but this very curt brushing over also seems to suggest that Bolton has not actually read the book and thus cannot make any definite statements about its contents. Count Your Dead: They Are Alive! is simply not mentioned at all.

${ }^{916}$ Consider, for example, Johnson on the topic: 'White Nationalism makes the most sense in the context of European colonial societies like the United States, in which older white ethnic identities have been undermined through the blending of distinct European immigrant stocks, creating an ever more blended, generic white identity. [...] In Europe, where old national and regional identities remain robust, generic whiteness and White Nationalism, if adopted as one's primary identity and political philosophy, would actually promote the breakdown of distinct identities 
and the homogenization of Europe. However, a sense of European identity can still supervene upon more compact national and regional identities.' (<https://www.counter-currents.com/2012/06/frequently-asked-questions-part$1 />)$. So while Lewis talks about the European melting pot there would be a way to relate this to (contemporary) America.

${ }^{917}$ Bolton, 138.

${ }^{918}$ Lewis; Paleface; 257.

${ }^{919}$ Lewis; Paleface; 276.

$920 @$ RichardBSpencer; tweet; 7 May 2017. Note that Spencer often uses 'European' denoting 'white', thus a European political party means a political party of and for European whites.

${ }^{921}$ Bolton, 120.

${ }^{922}$ The fact, that in the meantime Counter-Currents published a follow-up book, titled Some More Artists of the Right, which includes T. S. Eliot, can be seen as evidence that this audience exists.

${ }^{923}$ New Right here refers to the 'London New Right', 'a forum created by Jonothon Boulter and Troy Southgate', which was chaired by Bowden until 2012 (http://www.jonathanbowden.co.uk/about.html). In a now defunct yahoo group, they spell out their aim as: 'New Right is strongly pan-European, defiantly elitist and necessarily metapolitical' (<http://groups.yahoo.com/group/new_right $>$ now archived), thus they can be subsumed under the term 'New Far Right'. The group is no longer active.

${ }^{924}$ Bowden, Jonathan; 'Ezra Pound'.

${ }^{925}$ Ibid. Bowden actually uses the word 'friendship' not relationship in his speech; and the audience reacts with laughter to the anecdote of Kasper's bookshop in Greenwich Village. Kasper was never charged about his potential involvement - he was said to have procured the dynamite - in the bombing of Hattie Cotton Elementary School in Nashville. Also note how Bowden downplays the bombing ('when there were no children there') while overemphasising its level of desegregation ('which was desegregated'), when in fact, prior to the bombing the school had admitted exactly one black student, a six-year old girl.

926 The original 'Shakespeare and Company' was founded by Sylvia Beach, while the shop now in existence was founded by George Whitman, initially called 'Le Mistral', and later re-named to 'Shakespeare and Company' in honour of Sylvia Beach. The Egoist Press was set up by Harriet Shaw Weaver; while the periodical The Egoist, formerly The New Freewoman, was founded by Dora Marsden. Weaver financially supported the magazine and later became its editor; only the name change is said to have been Pound's idea who also worked as an editor. 
${ }^{927}$ See video 'Jonathan Bowden - 'Ezra Pound'. $33^{\text {rd }}$ New Right Meeting' roughly 16:12-16:17.

${ }^{928}$ Ibid; $34: 56$ and further.

${ }^{929}$ Consider the following quote: 'Pound was unusual in that as an artist he should have no right to talk about these matters about which he could be presumed to know little. Cross the margin, cross the line into politics' (Bowden, 'Ezra Pound').

${ }^{930}$ Bowden; 'Ezra Pound'.

${ }^{931}$ Bowden; 'Ezra Pound'.

932 Bowden; 'Ezra Pound'.

${ }^{933}$ Bowden has written separate articles on Lewis's Tarr, The Childermass and Apes of God, which can all be accessed on Counter-Currents.

${ }^{934}$ Bowden, Jonathan; 'Elitism, British Modernism and Wyndham Lewis'

935 A claim that can easily be refuted. It seems that today's criticism is much more obsessed with Hitler than contemporary criticism was; cf. chapter 5 on Lewis.

${ }^{936}$ Bowden; 'Elitism, British Modernism and Wyndham Lewis'.

${ }^{937}$ Bowden; 'Elitism, British Modernism and Wyndham Lewis'.

${ }^{938}$ Bowden; 'Elitism, British Modernism and Wyndham Lewis'.

${ }^{939}$ Bowden; 'Elitism, British Modernism and Wyndham Lewis'.

${ }^{940}$ An observation Bowden is also keen to mention in his separate article 'Wyndham Lewis Tarr: An Exercise in Right-Wing Psychology', although he never specifies why this should be important.

${ }^{941}$ Bowden; 'Wyndham Lewis'.

${ }^{942}$ In another article on the book he introduces The Childermass as 'probably one of the most difficult [novels] written in the last century', and later remarking again upon its 'unreadability'. (Bowden, Jonathan; 'Wyndham Lewis' Childermass: Black Metal, Without the Music').

${ }^{943}$ Cf. Bowden; 'Wyndham Lewis' Childermass: Black Metal, Without the Music'.

${ }^{944}$ Which can be related back to the whole idea of 'red pilling' the people, i.e. to make them, in Spencer's words, 'see[ through the pretty lies of our time'.

${ }^{945}$ It is no coincidence that Bowden would associate The Childermass with Black Metal (and not with any other similar music genre), as especially Black Metal is often rightly or wrongly associated with far right-wing ideology and even has its own right-wing subgenre, National Socialist Black Metal (or NSBM for short). As an example: Alex Kurtagic, editor-in-chief of Wermod and Wermod, which publishes a large segment of Bowden's writings, also founded the record label Supernal Music, which specialises in Black Metal, and Kurtagic's artworks have also been featured 
on album covers of Black Metal bands, such as Dimmu Borgir. The relationship between Black Metal and right-wing ideology is more complex than the space of a footnote permits; a more detailed analysis can be found in Christian Dornbusch and Hans-Peter Killguss; Unbeilige Allianzen: Black Metal zwischen Satanismus, Heidentum und Neonazismus.

${ }^{946}$ I've taken this phrase from a foreword by Johnson for Bowden's (posthumous) essay collection Pulp Fascism: 'Jonathan Bowden said that greatness lies in the mind and in the fist. Nietzsche combined both forms in the image of the warrior poet. For Jonathan, it was the image of the cultured thug.' (v).

${ }^{947}$ Bowden; 'Elitism, British Modernism and Wyndham Lewis'

${ }^{948}$ Both in Bowden, Jonathan; 'Wyndham Lewis' The Apes of God', in which a few lines later he also speaks of the novel as 'a gargantuan effort'.

${ }^{949}$ Both in: Bowden; 'Elitism, British Modernism and Wyndham Lewis'.

${ }^{950}$ Bowden; 'Elitism, British Modernism and Wyndham Lewis'.

${ }^{951}$ Cf. Bowden; 'Elitism, British Modernism and Wyndham Lewis': 'One publisher, Grayson \& Grayson, a publisher that no longer exists, was sent the manuscript of Tarr by Lewis and they returned it saying, "We can't publish your book, because it's too strong." Too strong!'.

${ }^{952}$ Bowden; 'Elitism, British Modernism and Wyndham Lewis'.

${ }^{953}$ Consider for example: 'Eliot's a less sexy person to talk about from the perspective of the people in this room and the traditions that a group like this could be said to feed upon, but that doesn't mean that he shouldn't be looked at and, if you like, is to the Left of Pound and Lewis by quite a considerable way, and yet in actual fact he's still to the Right of most other tendencies that exist' (Bowden, Jonathan; T. S. Eliot, Part 1').

${ }^{954}$ In his final paragraph to the book, Julius writes: '[Litvinoff's 'To T. S. Eliot'] is a work divided by love and dismay, in which Litvinoff wrestles to find in the language of his despiser the means by which he may both honour and challenge him. [...] 'To. T. S. Eliot' is a work of resistance and respect. I wish my book to be regarded as another such work.' (T.S. Eliot, Anti-Semitism, and Literary Form; 218)

955 Julius; T.S. Eliot, Anti-Semitism, and Literary Form; 33.

${ }^{956}$ Cf. Julius; T.S. Eliot, Anti-Semitism, and Literary Form; 'Postscript: Fourteen propositions responding to critics'; 302-335.

${ }^{957}$ An article by Andrew Joyce, another right-wing intellectual, may bestow some light on this issue. Titled ,T. S. Eliot and the Culture of Critique' it tries to refute Julius's argument. Ironically Joyce does so by recounting Eliot's 'real-life interactions' with Jews and attempts to demonstrate how they were translated into his poetry. Thus while he criticises Julius for his supposedly personal attack on Eliot, he 
uses biographical evidence to refute this attack. (<https://www.theoccidentalobserver.net/2016/12/06/t-s-eliot-and-the-cultureof-critique-part-two/ $>$ ).

${ }^{958}$ Bowden; 'T. S. Eliot'.

${ }^{959}$ Cf. Bowden; 'T. S. Eliot'.

${ }^{960}$ Bowden; 'T. S. Eliot'. What Bowden refers to are two separate things: there is the dedication to Pound, followed by a line in Provencal, 'il miglior fabbro', taken from Dante. The 'quote in Latin and Greek' is the story from the Satyricon of the immortal Sybil wishing for the release of death.

961 Bowden; 'T. S. Eliot'.

962 Bowden, Jonathan; 'T. S. Eliot'.

963 Bowden; 'T. S. Eliot'.

${ }^{964}$ Cf. Bowden; 'T. S. Eliot'.

965 Bowden; 'T. S. Eliot'.

${ }^{966}$ Bowden; 'T. S. Eliot'. He specifies this idea earlier in his talk: 'This is why hierarchical elitism is so important, because if there is nothing above you, then there's nothing to look forward to, there's nothing to transcend to, there's nothing to abide by that is beyond and outside one's often quite trivial concerns. The mass of people today live completely buried in their trivial concerns, and most forms of culture are forms of entertainment. Eliot represented one of the last generations where the more classical and restorationist attitudes toward culture prevailed'.

${ }^{967}$ Bowden; 'T. S. Eliot'.

968 'We see in Pound and Eliot's generation the belief that the Western world can revive, that Spengler's doctrine of the decline of the West in 1918 and thereafter, need not be fulfilled. Whether they favored a form of caesarism to come up from below and rescue the West and its impasse socio-economically in the 1930s-or whether they believed in forms of classical and restorationist conservatism, with an existing elite toughening its game and imposing upon society a vision more conduit with structures in the past, which would have been Eliot's cultural vision-is neither here nor there. But all of them represent in some ways the last flowering of a particular type of Western intellectuality the likes of which you don't see in the postwar period.' (Bowden; 'T. S. Eliot, Part 1'). This view seems to apply to postconversion Eliot rather than pre-conversion Eliot.

${ }^{969}$ Bowden; 'T. S. Eliot'.

${ }^{970}$ Bowden; 'T. S. Eliot'.

${ }^{971}$ Bowden; 'T. S. Eliot'.

${ }^{972}$ Bowden; 'T. S. Eliot'. 
973 Original quote can be found here: < https://www.splcenter.org/fightinghate/intelligence-report/2002/death-truth-telling-gentleman>; in the context of TOQ it can be found here: <http://www.toqonline.com/about/>.

${ }^{974}$ Cf. <http://www.toqonline.com/about/> Also consider the following selfadvertisement: 'You will not only find the articles fascinating and informative, you will also be supporting the work of scholars who are part of a community defending our people and our culture with the highest level of integrity and intellectual sophistication'. $<$ http://www.toqonline.com/blog/today-subscribe-to-theoccidental-quarterly $/>$.

$975<$ www.toqonline.com/blog/today-subscribe-to-the-occidental-quarterly- $>$.

${ }^{976}$ Ibid. This line of reasoning continues as follows: 'Politically aware Whites must understand that the elites that dominate culture and the political process in the West are intellectually and morally bankrupt. The domination of the mass media and the academic world by elites that are hostile to White identity and interests is a major barrier for educated Whites to act on behalf of their interests'.

977 Cf. <http://www.toqonline.com/wp-content/uploads/2017/03/toqspring2017-cover-big-795x1122.jpg >.

${ }^{978}$ When I wrote this thesis the blog had already been neglected with the most recent article dating from 18 April 2016. It seems that the blog was purged or relocated to TOQ's sister site The Occidental Observer during the redesign of the TOQ website. Seeing that digital reprints of articles from previous TOQ issues are now published on The Occidental Observer it is probably the latter. The post on Eliot's 'Gerontion' was not migrated. One can, however, still access it through the Wayback Machine.

${ }^{979}$ These two critical comments are no longer available on the TOQ website. They seemed to have been deleted along with a number of other comments; an issue I address in more detail below. An archived version of the post reveals the original twelve

comments: <http://web.archive.org/web/20140312215748/http://www.toqonline.com/blog /gerontion-by-t-s-eliot/>.

980 Archived version of the blog post can be found here: <http://web.archive.org/web/20140312215748/http://www.toqonline.com/blog /gerontion-by-t-s-eliot/>. All further quotes by 'Yggdrasil' are taken from this source.

${ }^{981}$ Eliot; After Strange Gods; 19-20.

${ }^{982}$ What seems interesting in this light is the decision of the moderator of TOQ Online to delete nine of the original twelve comments under this post. This removed all the negative voices, but it also erased some of the more positive comments. 
${ }^{983}$ Cf. < https://staatspolitik.de/institut>. Institut für Staatspolitik could be translated to Institute for National Policy. I am not aware of any connections between the American National Policy Institute and the Institut für Staatspolitik despite the similarity in name, ideological orientation and function.

${ }^{984}$ Cf. < https://staatspolitik.de/institut>.

${ }^{985}$ ['die bedeutendste rechtsintellektuelle Zeitschrift in Deutschland'] $<$ https://sezession.de/konzept $>$.

${ }^{986}$ Cf. ibid ['Ziel unserer Zeitschrift ist es nicht, möglichst viele Leser zu erreichen. Wichtig sind uns die richtigen Leser, und das sind diejenigen, denen die Komplexität der Welt und die Differenziertheit gerade des rechten, konservativen Denkens nicht verborgen geblieben sind']. Sezession currently has 3000 regular subscribers.

${ }^{987}$ Cf. Ibid. ['Vieles, was an der AfD und an anderen Widerstandsprojekten grundsätzlich, kompromißlos, nicht verhandelbar und angriffslustig wirkt und ist, wurde in unserer Zeitschrift vorausgedacht, ausformuliert und in die Debatte erst eingespeist']. This also shows the proximity of Sezession to the AfD. The term 'national resistance' is a translation of the German term 'Nationaler Widerstand', which is a term coined by the German Far Right as a self-designation. Also compare the selfconception of the Sezession to Spencer when he claimed that it is up to the alt-right to formulate the ideas and policies to guide the new administration [...] I think we can be the ones out in front, thinking about those things he hasn't quite grasped yet' (cf. Goldstein, Joseph; 'Alt-Right Gathering Exults in Trump Election With Nazi-Era Salute').

988 ['Annäherungen und Verschlingungen'], Kubitschek, Götz; 'Faschismus und Avantgarde'; 28.

${ }^{989}$ Cf. Kubitschek, 28.

${ }^{990}$ Cf. Kubitschek, 28.

991 ['Die Aus- und Abgrenzung im Zeichen solcher Agonalität machte die Avantgarde zu einer autoritären Bewegung: man war nirgends auf Konsens aus, sondern agierte männlich, hart, aggressiv und arrogant und gegen jeden anderen Entwurf allein schon um der Gegnerschaft willen'], Kubitschek, 29.

${ }^{992}$ Kubitschek, 31.

${ }^{993}$ Kubitschek, 31.

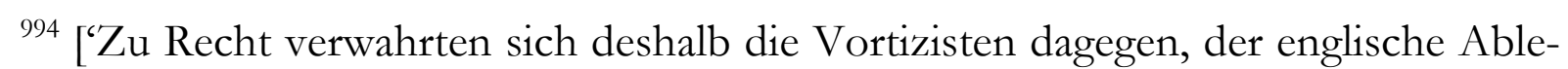
ger des anarchischen und expansiven italienischen Futurismus zu sein.'] Kubitschek, n. p.

${ }^{995}$ ['die Konzentration von Kräften um einen gemeinsamen Mittelpunkt'] Kubitschek, n.p. 
${ }^{996}$ Despite one of Nevinson's pictures being published in BLAST 2, it was his cooperation with Marinetti on a manifesto that triggered what was to become the Vorticist group to position themselves as distinct from Futurism.

${ }^{997}$ It is noteworthy that Kubitschek here implies that the exclusionary tendency of fascism was part of its negative side, while he earlier commended the avant-garde's exclusionary tendency. This way lauding the avant-garde and their supposed qualities such as manliness, aggressiveness and arrogance allows Kubitschek to equally laud authoritarian qualities without explicitly praising the corresponding authoritarian political movements. Attaching these authoritarian traits to the avant-garde gives them intellectual validity and presents them as productive and creative forces.

${ }^{998}$ Kubitschek, 31.

${ }^{999}$ MacDonald in: Johnson; New Right versus Old Right.

${ }^{1000}$ Internet meme culture revolves around the creation, sharing and reworking of memes, i.e. a unit carrying an idea, concept, or social practice often in the form of an image macro, hashtag, gif or video. The interactive nature of the Internet facilitates the rapid transmission and the considerable impact of individual memes, which explains their relevance for the fields of marketing, politics and 'the culture war'. Angela Nagle has written a book-length study on the subject of the Right and internet meme culture titled Kill All Normies: Online Culture Wars from 4Chan and Tumblr to Trump and the Alt-Right.

${ }^{1001}$ Originally created by Matt Furie as a 'peaceful frog-dude' for his 'Boy's Club' on Myspace it is now almost exclusively associated with right-wing online culture (Cf. Hunt, Elle; 'Pepe the Frog creator kills off internet meme co-opted by white supremacists'). It is now even listed in the Anti-Defamation League's 'Hate Symbols Database' (<https://www.adl.org/education/references/hate-symbols/pepethe-frog $>$ ). The later addition of Kek was more coincidental: the term 'kek' originates from gaming culture and was a synonym/translation for 'lol' (laughing out loud) in World of Warcraft. Only when the connection was made to the Egyptian frog deity, Kek and Pepe became linked. The idea of Kek as a deity is often humorously upheld, for example in such phrases as 'Praise Kek'.

${ }^{1002}$ Cf. Koch, Heiko; Casa Pound Italia: Mussolinis Erben; 106.

${ }^{1003}$ For further reading one can turn to Heiko Koch's Casa Pound Italia: Mussolinis Erbenwho analyses the movement from a distinctly left-wing perspective or Martin Lichtmesz's article 'Casa Pound' in Sezession 34 for a right-wing perspective.

${ }^{1004}$ Colin Liddell; 'In the House of Pound'; AlternativeRight.com (published 5 February 2012). AlternativeRight.com was shut down essentially after a conflict of interest between Spencer and Liddell. Spencer went on to set up altright.com, while Liddell created alternative-right.blogspot.com as a sequel to the old website, which also has an archive with many of the older articles from the original side. 
${ }^{1005}$ Fittingly Pound's short biography on the Casa Pound website features a paragraph that paints a consciously misleading picture of Pound's trial and his time at $\mathrm{St}$ Elizabeths. They write that after his return to the US he was declared crazy, which is true but conveniently omits that the insanity plea was a strategy of the defence to save Pound from worse punishment. As discussed above his time at St Elizabeth was not as dire as portrayed here ('segregated in complete isolation', in fact, Pound's segregation from other inmates was a privilege dealt to him).

${ }^{1006}$ In the interview Iannone states: 'Usury is the worst thing. It is the head of the octopus. It is it that initiated the wars that are starting around the Mediterranean Sea, which generates illegal immigration and destruction. It is it which creates unemployment, debts. It is it that threatens the future of our children, which make them weak and ready for the massacre.'.

${ }^{1007}$ ['Sviluppa la sua teoria sull'usura come fonte delle guerre moderne e dello strangolamento dei popoli.'] < https://www.casapounditalia.org/ezra-pound/>. $1008<$ http://www.casapounditalia.org/p/ezra-pound.html>.

${ }^{1009}$ Kurtagic, Alex; 'Interview with Greg Johnson'.

${ }^{1010}$ Joyce, Andrew; 'T.S. Eliot and the Culture of Critique';

$<$ https://www.theoccidentalobserver.net/2016/12/06/t-s-eliot-and-the-cultureof-critique-part-two/>.

1011 This seems to correspond to the current dearth of what one could call rightwing art production; there is very little contemporary right-wing art, i.e. art that offers an aestheticised version of right-wing ideology; exceptions like Alex Kurtagic's Mister and novels by Harold Covington duly noted. Here again comments by Johnson such as '[o]ne of my aims for Counter-Currents/North American New Right is to foster and promote a white artistic movement' shows that there is an awareness for the importance of (right-wing) art production' (Kurtagic; 'Interview with Greg Johnson').

\section{Do Civilized Peoples Execute Their Poets?}

${ }^{1012}$ Cf. Carroll; French Literary Fascism, 273-274. Brasillach was executed by firing squad on 6 February 1945.

${ }^{1013}$ In his article 'Unravelling Atomwaffen: Exposing America's New Nazi Militants', Jake Hanrahan included a screenshot that shows a reading list recommended by Woodward, who writes: 'Since I promised you all a reading list of various materials that shaped my political philosophy, here you go -'. It features Pound's Cantos, and Machiavelli's The Prince, among staples of the New Far Right.

1014 This was also commercially exploited. An edition of the Pisan Cantos features a picture of the outdoor cells of the Pisan prison camp, linking the poems back to the place of their genesis, but also to the theme of incarceration. 


\section{BIBLIOGRAPHY}

12 Southerners; I'll Take My Stand: The South and the Agrarian Tradition [1930]; New York: Harper and Row, 1962.

Adorno, Theodor W.; Studien zum autoritären Charakter (Frankfurt am Main: Suhrkamp, 1973.

Alighieri, Dante; The Inferno of Dante Alighieri; translated by John Aitken Carlyle; edited by Herman Oelsner; London: J. M. Dent, 1903.

Ayers, David; Wyndham Lewis and Western Man; Houndsmill et al.: Macmillan, 1992.

Allot, Kenneth; Penguin Book of Contemporary Verse 1918-60 (1962), new revised edition; Harmondsworth: Penguin, 1968.

Allsup; James; 'Richard Spencer: 'The Alt Right's Future in Trump's America'; Interview; Youtube.com; 1 February 2017;

Aly, Götz; Warum die Deutschen? Warum die Juden? Gleichbeit, Neid und Rassenhass 1800-1939; Frankfurt am Main: Fischer, 2011.

Anspaugh, Kelly; 'Another Look at Lewis, Joyce and Woolf; In: Twentieth Century Literature, Vol. 40, No. 3 (Autumn, 1994), pp. 365-378.

Asher, Kenneth; T. S. Eliot and Ideology; Cambridge: Cambridge University Press, 1995.

Asholt, Wolfgang and Walter Fähnders (eds.); Manifeste und Proklamationen der europäischen Avantgarde; Sonderausgabe; Stuttgart and Weimar: Verlag J. B. Metzler, 2005.

Assheuer, Thomas und Hans Sarkowics; Rechtsradikale in Deutschland: Die alte und die neue Rechte; München: Verlag C.H. Beck 1990.

Attrill, Martin; 'How clean is the Thames?'; transcript of a paper given at Gresham College, 16 October 2006.

Green, Lisa J.; African American English: A Linguistic Introduction; Cambridge: Cambridge University Press, 2002.

Backes, Uwe (Hrsg.); Rechtsextreme Ideologien in Geschichte und Gegenwart, Köln et al.:Böhlau Verlag, 2003.

Backes, Uwe; Politische Extreme: Eine Wort- und Begriffsgeschichte von der Antike bis zur Gegenwart, Göttingen: Vandenhoeck \&Ruprecht, 2006.

Baird, Jay W.; Hitler's War Poets: Literature and Politics in the Third Reich; Cambridge: Cambridge University Press, 2008.

Barnhisel, Gregory; James Laughlin, New Directions, and the Remaking of Ezra Pound; Amherst and Boston: University of Massachusetts Press, 2005. 
Barry, John; “The Waste Land“: A Possible German Source' In: Comparative Literature Studies, Vol. 9, No. 4 (Dec., 1972), pp. 429-442.

Bauer, Elvira; Tran keinem Fuchs auf grüner Heid und keinem Jud bei seinem Eid; Nürnberg: Stürmer Verlag, 1936.

Bauerkämper, Arnd; Die »radikale Recbte« in Großbritannien; Götting: Vandenhoeck \& Ruprecht, 1991.

Baumann, Zygmunt; Modernity and the Holocaust, Ithaka, New York: Cornell University Press, 1989.

Beer, Ernst; Thomas Stearns Eliot und der Antiliberalismus des XX. Jabrbunderts; Wien: Wilhelm Braumüller Universitäts-Verlangsbuchhandlung Gesellschaft m. b. H., 1953.

Bell, Daniel; The End of Ideology (1960); Cambridge (Mass.): Harvard University Press, 1988.

Benjamin, Walter; Kunstwerk im Zeitalter seiner technischen Reproduzierbarkeit (1936); Frankfurt am Main: Suhrkamp, 2007.

Berger, J. M.; 'Nazis vs. ISIS on Twitter: A Comparative Study of White Nationalist and ISIS Online Social Media Networks', Program on Extremism at George Washington University; September 2016.

Bishop, Philip E.; “'And Will the World Take Up Its Course Again?”: Paranoia and Experience in the Pisan Cantos'; In: Texas Studies in Literature and Language, Vol. 31, No. 4, Convention, Ideology, and Desire in Twentieth-Century Literature (Winter 1989), pp. 536-553.

Blakeney Williams, Louise; Modernism and the Ideology of History: Literature, Politics, and the Past; Cambridge: Cambridge University Press, 2002.

Bobbio, Noberto; Left and Right; transl. by Allan Cameron, Polity Press 1996.

Bolton, Kerry; Artists of the Right; edited by Greg Johnson; San Francisco: Counter-Currents Publishing, 2012.

Bornstein, George; 'When Race Meets Religion: Blacks, Jews, and Modernist Fictions'; In: Studies in the Novel, Vol. 34, No. 2 (summer 2002), pp. 221 228.

Bowden, Jonathan, Pulp Fascism; edited by Greg Johnson; San Francisco: Counter-Currents Publishing, 2013.

Bowden, Jonathan; 'Elitism, British Modernism and Wyndham Lewis'; lecture; $8^{\text {th }}$ New Right Meeting; 28 May 2006; transcript can be found at Counter-Currents.com.

Bowden, Jonathan; 'Ezra Pound'; lecture; 33 ${ }^{\text {rd }}$ New Right Meeting; 11 June 2011; transcript can be found at: Counter-Currents.com

Bowden, Jonathan; 'Ezra Pound'. 33rd New Right Meeting'; YouTube; 30 November 2013. 
Bowden, Jonathan; 'T. S. Eliot; lecture; 34th New Right Meeting; 6 August 2011; transcript can be found at: Counter-Currents.com.

Bowden, Jonathan; 'Wyndham Lewis Tarr: An Exercise in Right-Wing Psychology'; Counter-Currents.com; 2011.

Bowden, Jonathan; 'Wyndham Lewis' Childermass: Black Metal, Without the Music'; Counter-Currents.com; 26 November 2010.

Bowden, Jonathan; 'Wyndham Lewis' The Apes of God'; Counter-Currents.com; 21 July 2011.

Bowler, Anne; 'Politics as Art: Italian Futurism and Fascism' In: Theory and Society, Vol. 20, No. 6 (Dec., 1991), pp. 763-794.

Braun, Stephan, Alexander Geisler, Martin Gerster (Hrsg.); Strategien der extremen Rechten: Hintergründe - Analysen - Antworten; Wiesbaden: VS Verlag für Sozialwissenschaften, 2009.

Bridson, D. G.; The Filibuster: A Study of the Political Ideas of Wyndham Lewis (1972); London: Bloomsbury Publishing, 2013

Brown, Nicholas; Utopian Generations: The Political Horizon of Twentieth-Century Literature; Princeton and Oxford: Princeton University Press, 2005.

Burch, Michael R.; 'Interview with Dr Joseph Salemi'; The Hyper Texts, no date given;

Bush, Ronald (ed.); T. S. Eliot: The Modernist in History; Cambridge: Cambridge University Press 1991.

Bush, Ronald; 'Modernism, Fascism, and the Composition of Ezra Pound's Pisan Cantos'; In: Modernism/Modernity 2.3 (1995) 69-87.

Buss, Claude W.; W ar and Diplomacy in Eastern Asia; New York: The Macmillan Company, 1941.

Caiani, Manuela, Donatella della Porta, and Claudius Wagemann; Mobilizing on the Extreme Right: Germany, Italy, and the Unites States; Oxford: Oxford University Press, 2012.

Campbell, SueEllen; The Enemy Opposite: The Outlaw Criticism of Wyndham Lewis; Athens: Ohio University Press, 1988.

Carey, John; The Intellectuals and the Masses: Pride and Prejudice Among the Literary Intelligentsia, 1800-1939; London: Faber and Faber, 1992.

Carroll, David; French Literary Fascism: Nationalism, Anti-Semitism, and the Ideology of Culture; Princeton: Princeton University Press, 1995.

Casillo, Robert; 'Anti-Semitism, Castration, and Usury in Ezra Pound'; In: Criticism, Vol. 25, No. 3 (summer, 1983), pp. 239-265.

Casillo, Robert; 'Damage Control in the Pound Industry: Response to Dasenbrock'; In: American Literary History, Vol. 1, No. 1 (Spring, 1989), pp. 240-243.

Casillo, Robert; 'Plastic Demons: The Scapegoating Process in Ezra Pound'; 
In: Criticism, Vol. 26, No. 4 (fall, 1984), pp. 355-382.

Casillo, Robert; The Genealogy of Demons: Anti-Semitism, Fascism, and the Myths of Ezra Pound; Evanston: Northwestern University Press, 1988.

Chace, William M.; The Political Identities of Eqra Pound and T. S. Eliot; (Stanford: Stanford University Press, 1973.

Cheyette, Bryan (ed.); Between 'Race' and Culture: Representations of "the Jew" in English and American Literature; Stanford: Stanford University Press, 1996.

Childs, Donald J.; Modernism and Eugenics: Woolf, Eliot, Yeats, and the Culture of Degeneration; Cambridge: Cambridge University Press, 2001.

Chinitz, David E.; T. S. Eliot and the Cultural Divide; Chicago: University of Chicago Press, 2003.

Chinitz, David; A Companion to T. S. Eliot, Malden and Oxford: WileyBlackwell, 2009.

Cookson, William; A Guide to the Cantos of Erra Pound (1985); London: Anvil Press Poetry, 2001.

Cooper, John Xiros; T. S. Eliot and the Ideology of Four Quartets; Cambridge: Cambridge University Press, 1995.

Craig, Cairns; Yeats, Eliot, Pound and the Politics of Poetry: Richest to the Richest, London and Canberra: Croom Helm, 1982.

Crawford, Robert; The Savage and the City in the Work of T. S. Eliot (1987); Oxford: Clarendon Press, 1990.

Dasenbrock, Reed Way; 'Jefferson and/or Adams: A Shifting Mirror for Mussolini in the Middle Cantos'; In: ELH, Vol. 55, No. 2 (Summer, 1988), pp. 505-526.

Dasenbrock, Reed Way; 'Paul de Man, the Modernist as Fascist'; In: South Central Review, Vol. 6, No. 2, Fascist Aesthetics (Summer, 1989), pp. 618.

Dennis, Helen M.; 'Pound, Women and Gender'; In: The Cambridge Companion to Erra Pound; Edited by Ira B. Nadel; Cambridge: Cambridge University Press, 1999; 264-283.

Desai, Meghnad; The Route of All Evil: The Political Economy of Eqra Pound; London: Faber and Faber, 2006.

Dijk, Teun A. van; Ideology: a Multidisciplinary Approach; London et al.: Sage Publications, 1998.

Doob, Leonard (ed.); Ezra Pound Speaking: Radio Speeches of World War II; Westport: Greenwood Press, 1978.

Dornbusch, Christian und Hans-Peter Killguss; Unheilige Allianzen: Black Metal zwischen Satanismus, Heidentum und Neonazismus; Hamburg/Münster: Unrast Verlag, 2005. 
Downs, William M.; Political Extremism in Democracies: Combating Intolerance; Houndmills: Palgrave Macmillan, 2012.

DuPlessis, Rachel Blau; Genders, Races and Religious Cultures in Modern American Poetry 1908-1934; Cambridge: Cambridge University Press, 2001.

Durant, Alan; Eqra Pound: Identity in Crisis; Brighton: The Harvester Press, 1981.

Eagleton, Terry; Criticism and Ideology: A Study in Marxist Literary Theory; London and New York: Verso [1976] 2006.

Eagleton, Terry; Ideology. An Introduction; London: Verso, 1991.

Eagleton, Terry; The Ideology of the Aesthetic, Oxford: Wiley-Blackwell, 1990.

Eatwell, Roger and Anthony Wright (eds.); Contemporary Political Ideologies; second Edition; London and New York: Pinter, 1999.

Eatwell, Roger and Noël O'Sullivan (eds.); The Nature of the Right: European and American Politics and Political Thought since 1789; London: Pinter, 1989.

Eccleshall, Robert, Alan Finlayson et al.; Political Ideologies. An Introduction; $3^{\text {rd }}$ edition; London et al.; Routledge, 2003.

Echikson, William; 'Their message is urgent: The holocaust survivor and his 7,000 pieces of antisemitic propaganda'; TheGuardian.com; 27 March 2017 ;

Edwards, John Hamilton and William W. Vasse; Annotated Index to the Cantos of Ezra Pound (1957); Berkeley et al.: University of California Press, 1974.

Ehrlicher, Hanno; Die Kunst der Zerstörung: Gewaltphantasien und Manifestationspraktiken europäischer Avantgarden; Berlin: Akademie Verlag, 2001.

Eksteins, Modris; Rites of Spring: The Great War and the Birth of the Modern Age (1989); Boston and New York: Mariner Books, 2000.

Eliot, T. S.; After Strange Gods: A Primer of Modern Heresy: The Page Barbour Lectures at the University of Virginia 1933 (London: Faber and Faber 1934.

Eliot, T. S.; Collected Poems and Plays 1909-1962 (1963); London: Faber and Faber, 2002.

Eliot, T. S.; Complete Poems and Plays; London: Faber and Faber, 1969.

Eliot, T. S.; Notes towards the Definition of Culture (1948); London: Faber and Faber, 1962.

Eliot, T. S.; The Idea of a Christian Society; London: faber and faber, 1939.

Eliot, T. S.; The Waste Land: A Facsimile and Transcript of the Original Drafts (1971); edited by Valerie Eliot; London: Faber and Faber, 2010.

Eliot, T. S.: Ara Vos Prec, London: John Rodker; 1919

Eliot, T. S.: Selected Essays 1917-1932; London: Faber and Faber; 1932.

Ellmann, Maud; The Poetics of Impersonality; Sussex: The Harvester Press, 1987.

Falter, Jürgen W. and Hans-Gerd Jaschke and Jürgen R. Winkler; Rechtsextremismus: Ergebnisse und Perspektiven der Forschung; Opladen: Westdeutscher 
Verlag, 1996.

Farr, Barbara Storm; The Development and Impact of Right-Wing Politics in Britain, 1903-1932; Garland Publishing, Inc.: New York and London, 1987.

Feldman, Matthew; "The "Pound Case" in Historical Perspective: An Archival Overview'; In: Journal of Modern Literature, Vol. 35, No. 2 (Winter 2012), pp. 83-97.

Ferkiss, Victor C.; 'Ezra Pound and American Fascism' in: The Journal of Politics, Vol. 17, No. 2 (May, 1955), pp. 173-197.

Ferrall, Charles; Modernist Writings and Reactionary Politics; Cambridge: Cambridge University Press, 2001.

Finaldi, Giuseppe; Mussolini and Italian Fascism; Harlow: Pearson Education Limited, 2008.

Fleissner, Robert F.; T. S. Eliot and the Heritage of Africa: The Magus and the Moor as Metaphor, New York et al.: Peter Lang, 1992.

Flory, Wendy; 'Pound and Anti-Semitism'; in: The Cambridge Companion to Ezra Pound; edited by Ira B. Nadel; Cambridge: Cambridge University Press, 1999, 284-300.

Foshay, Toby Avard; Wyndham Lewis and the Avant-Garde: The Politics of the Intellect, Montreal \& Kingston: McGill-Queen's University Press, 1992.

Freeden, Michael; Ideologies and Political Theory; Oxford: Clarendon Press, 1998.

Freeden, Michael; Ideology: A Very Short Introduction; Oxford: OUP, 2003.

Gasiorek, Andrzej and Nathan Waddel (eds.); Wyndham Lewis: A Critical Guide; Edinburgh: Edinburgh University Press, 2015.

Geulen, Christian; Geschichte des Rassismus; Bonn: Bundeszentrale für politische Bildung, 2007.

Goldblatt, Eli; 'Gender Matters in Pound's "Cantos"”; In: Journal of Modern Literature, Vol. 15, No. 1 (Summer, 1988), pp. 35-53.

Goldstein, Joseph; 'Alt-Right Gathering Exults in Trump Election With NaziEra Salute'; New York Times, 20 November 2016

Golsan, Richard J. (ed.); Fascism, Aesthetics, and Culture; Hanover and London: University Press of New England, 1992.

Gourmont, Remy de; The Natural Philosophy of Love; translated by Ezra Pound; New York: Boni and Liveright, 1922.

Gramsci, Antonio; Selections from the Prison Notebooks (1971); edited and translated by Quintin Hoare and Geoffrey Novel Smith; New York: International Publishers, 1992.

Grant, Madison; The Passing of the Great Race or the Racial Basis of European History; New York: Charles Scribner's Sons, 1916.

Griffin, Roger (ed.); Fascism; Oxford: Oxford University Press, 1995.

Griffin, Roger; The Nature of Fascism (1991); London et al.: Routledge ; 1996. 
Gross, Andrew S.; The Pound Reaction: Liberalism and Lyricism in Midcentury American Literature; Heidelberg: Universitätsverlag Winter, 2015.

Guardian Style Editors; 'Alt-right: why the Guardian decided not to ban the use of the term', TheGuardian.com; 30 November 2016.

Habedank, Klaus; Kultur- und Sozialkritik bei T. S. Eliot: Eine Untersuchung der Werke Eliots 1909-39; Hamburg: Hartmut Lüdke Verlag, 1974.

Hamilton, Alastair; The Appeal of Fascism: A study of Intellectuals and Fascism, 1919 - 1945; London: Anthony Blond, 1971.

Hanrahan, Jake; 'Unravelling Atomwaffen: Exposing America's New Nazi Militants'; Medium.com; 26 June 2018.

Harding, Jason (ed.); T. S. Eliot in Context; Cambridge: Cambridge University Press, 2011.

Harding, Jason; The Criterion: Cultural Politics and Periodical Networks in Inter-War Britain; Oxford: Oxford University Press, 2002.

Harris, Geoffrey; The Dark Side of Europe: The Extreme Right Today; New Edition; Edinburgh: Edinburgh University Press, 1994.

Harrison, John R.; The Reactionaries; London: Victor Gollancz LTD, 1966.

Head, Philip; Some Enemy Fight-Talk: Aspects of Wyndham Lewis on Art and Society; Borough Green, Kent: Green Knight Editions, 1999.

Hegarthy, Terence; 'Wyndham Lewis the Writer: A Preoccupation with the Real'; In: The Massachusetts Review, Vol. 23, No. 2 (Summer, 1982), pp. 335-348.

Hein, Bastian; Die SS: Geschichte und Verbrechen; München: Beck, 2015.

Hein, Peter Ulrich; Die Brücke ins Geisterreich: Künstlerische Avantgarde zwischen Kulturkritik und Faschismus Reinbek: Rowohlt, 1992.

Hesse, Eva; Die Achse Avantgarde-Faschismus: Reflexionen über Filipo Tommaso Marinetti und Ezra Pound; Zürich: Verlags AG Die Arche, 1991.

Hesse, Eva; Ezra Pound: Von Sinn und Wahnsinn; München: Kindler, 1978.

Hewitt, Andrew; 'Wyndham Lewis: Fascism, Modernism, and the Politics of Homosexuality'; In: ELH, Vol. 60, No. 2 (Summer, 1993), pp. 527-544.

Heymann, David C.; Ezra Pound. The Last Rower: A Political Profile; London: Faber and Faber, 1976)

Homberger, Eric (ed.); Eqra Pound: The Critical Heritage (1972); reprint; London and New York: Routledge, 1997.

Houen, Alex; Terrorism and Modern Literature: From Joseph Conrad to Ciaran Carson; Oxford: Oxford University Press, 2002.

Hulme, T. E.; Selected Writings; edited by Patrick McGuiness; Manchester : Carcanet ; 1998. 
Irmscher, Christopher; Masken der Moderne: Literarische Selbststilisierung bei T. S. Eliot, Ezra Pound, Wallace Stevens und William Carlos Williams; Würzburg: Verlag Königshausen \& Neumann, 1992.

Ives, Peter; Language and Hegemony in Gramsci; London: Pluto Press, 2004. Jaime, Carmelo Cunchillos (ed.); Wyndham Lewis The Radical: Essays on Literature and Modernity; Bern, Berlin et al: Peter Lang, 2007.

Hunt, Elle; 'Pepe the Frog creator kills off internet meme co-opted by white supremacists'; TheGuardian.com; 8 May 2017.

Jameson, Frederic; Fables of Aggression: Wyndham Lewis: The Modernist as Fascist (1979); London: Verso, 2008.

Johnson, Greg; 'New Right vs. Old Right; Counter-Currents.com; 11 May 2012.

Johnson, Greg; 'The Alt Right Means White Nationalism... or Nothing at All'; Counter-Currents.com; 30 August 2016.

Johnson, Greg; New Right versus Old Right, San Francisco: Counter-Currents Publishing, 2013

Jones, Owen; Chavs: The Demonization of the Working Class (2011); London: Verso, 2012.

Joyce, Andrew; 'T. S. Eliot and the Culture of Critique; The Occidental Observer, 6 December 2016.

Julius, Anthony; Trials of the Diaspora: A History of Anti-Semitism in England; Oxford: UOP, 2010)

Julius; Anthony; T.S. Eliot, Anti-Semitism, and Literary Form; London: Thames \& Hudson, 1995.

Koch, Heiko; Casa Pound Italia: Mussolinis Erben; Münster: Unrast, 2013.

Kojecky, Roger; T. S. Eliot's Social Criticism; London: faber and faber, 1971.

Koop, Andreas; NSCI: Das visuelle Erscheinungsbild der Nationalsozialisten 19201945 (2008); Mainz: Verlag Hermann Schmidt, 2012.

Kristeva, Julia; Powers of Horror: An Essay on Abjection; New York: Columbia University Press, 1982.

Kubitschek, Götz; 'Faschismus und Avantgarde'; Sezession 34; February 2010; 28-31.

Kurtagic, Alex; 'Interview with Greg Johnson'; WermodandWermon.com; 24 November 2010.

Kushner, Tony and Kenneth Lunn (eds.); Traditions of Intolerance: Historical Perspectives on Fascism and Race Discourse in Britain; Manchester: Manchester University Press, 1989.

Lafferty, David; 'Castor Oil for Conservatives: Wyndham Lewis's and "Count Your Dead: They Are Alive! Bolsho-Tory" Politics'; In: Journal of Modern Literature, Vol. 36, No. 2, Aesthetic Politics-Revolutionary and Counter-Revolutionary (Winter 2013), pp. 25-43. 
Laity, Cassandra and Nancy K. Gish (eds.); Gender, Desire, and Sexuality in T. S. Eliot, Cambridge: Cambridge University Press, 2004.

Lauber, John; 'Pound's “Cantos”: A Fascist Epic'; In: Journal of American Studies, Vol. 12, No. 1 (Apr., 1978), pp. 3-21.

Le Bon, Gustave. The Crowd: A Study of the Popular Mind; New York: Macmillan, 1896.

Lewis, Wyndham; The Art of Being Ruled (1926); Santa Rosa: Black Sparrow Press, 1989.

Lewis, Wyndham; The Art Apes of God (1930); Santa Rosa: Black Sparrow Press, 1981.

Lewis, Wyndham; The Childermass (1928); London: John Calder and New York: Riverrun Press, 2000.

Lewis, Wyndham; Collected Poems and Plays. Edited by Alana Munton, Manchester: Carcanet, 1979

Lewis, Wyndham; Hitler (1931); New York: Gordon Press, 1972.

Lewis, Wyndham; The Jews: Are They Human?; London: George Allen \& Unwin Ltd, 1939.

Lewis, Wyndham; Left Wings Over Europe: or, How to Make a War About Nothing (1936); New York: Gordon Press, 1972.

Lewis, Wyndham; Malign Fiesta (1955); London: John Calder, 1965.

Lewis, Wyndham; Men Without Art (1934); Santa Rosa: Black Sparrow Press, 1987.

Lewis, Wyndham; Monstre Gai (1955); London: John Calder, 1965

Lewis, Wyndham; Paleface: The Philosophy of the Melting Pot (1929); New York: Gordon Press, 1972.

Lewis, Wyndham; Rude Assignment: A narrative of my career up-to-date; London, New York et al.: Hutchinson \& Co, 1950.

Lewis, Wyndham; Time and Western Man (1927); Santa Rosa: Black Sparrow Press, 1993.

Lichtblau, Eric. 'The Holocaust Just Got More Shocking'; New York Times; 1 March 2013.

Lichtmesz, Martin; 'Casa Pound'; Sezession 34; February 2010; 22-26.

Liddell, Collin; 'In the House of Pound'; AlternativeRight.com; 5 February 2012. [no longer online]; Reprint at: Counter-Currents.com.

Lipset, Seymor Martin and Stein Rokkan; Party System and Voter Alignments: Cross-National Perspectives; Free Press, 1967.

Loewenstein, Andrea Freud; Loathsome Jews and Engulfing Women: Metaphors of Projection in the Works of Wyndham Lewis, Charles William, and Graham Greene; New York and London: New York University Press, 1993. 
Lusty, Natalya and Julian Murphet (eds.); Modernism and Masculinity; Cambridge: Cambridge University Press, 2014.

MacDiarmid, Laurie J.; T. S. Eliot's Civilized Savage: Religious Eroticism and Poetics; New York \& London: Routledge, 2003.

Makin, Peter (ed.); Eqra Pound's Cantos: A Casebook; Oxford: Oxford University Press, 2006.

Makin, Peter; Pound's Cantos (1985); Baltimore and London: the John Hopkin's University Press, 1992.

Marsh, Alec; John Kasper and Eqra Pound: Saving the Republic, London et al.: Bloomsbury, 2015.

Materer, Timothy; Wyndham Lewis the Novelist; Detroit: Wayne State University Press, 1976.

Meyers, Jeffrey (ed.); Wyndham Lewis: A Revaluation; London: The Athlone Press, 1980.

Miller, Tyrus (ed.); Cambridge Companion to Wyndham Lewis; Cambridge: Cambridge University Press, 2016.

Miller, Tyrus; Late Modernism: Politics, Fiction, and the Arts Between the World Wars; Berkeley, Los Angeles, London: University of California Press, 1999.

Miller, William Ian; The Anatomy of Disgust, Cambridge, Massachusetts and London, England: Harvard University Press, 1997.

Mohler, Armin and Karlheinz Weissmann; Die Konservative Revolution in Deutschland 1918-1932: Ein Handbuch; 6. Überarbeitete und erweiterete Auflage; Graz: Ares Verlag, 2005.

Monroe, Jonathan; 'Idiom and Cliché in T. S. Eliot and John Ashbery'; In: Contemporary Literature, Vol. 31, No. 1 (Spring, 1990), pp. 17-36.

Morgan, Kenneth O.; The Oxford History of Britain (1988); updated version; Oxford: Oxford University Press, 2001.

Morrison, Paul; The Poetics of Fascism: Ezra Pound, T. S. Eliot, Paul de Man; New York, Oxford: Oxford University Press, 1996.

Morse, Jonathan; 'T. S. Eliot Says "Jew"'; In: American Literary History, Vol. 10, No. 3 (Autumn, 1998), pp. 497-507.

Mullins, Eustace; Secrets of the Federal Reserve (1952); Reprint; New York: John McLaughlin, 1983.

Munton, Alan; 'Wyndham Lewis: From Proudhon to Hitler (and back): the Strange Political Journey of Wyndham Lewis'; In: Revue électronique d'études sur le monde Anglophone, 4.2 | 2006: Revolving Commitments in France and Britain, 1929-1955.

Nadel, Ira B.; 'The Real History of the ERA': Joyce, Lewis and Fascism'; In: The Canadian Journal of Irish Studies, Vol. 14, No. 1 (Jul., 1988), pp. 29-35. 
Nagle, Angela; Kill All Normies: Online Culture Wars from 4Chan and Tumblr to Trump and the Alt-Right, Winchester, UK and Washington, USA: Zero Books, 2017.

Neilson, Brett; 'History's Stamp: Wyndham Lewis's The Revenge for Love and the Heidegger Controversy'; In: Comparative Literature, Vol. 51, No. 1 (Winter, 1999), pp. 24-41.

Ngai, Sianne; Ugly Feelings, 2nd edition; Cambridge, Massachusetts, and London, England: Harvard University Press, 2007.

Normand, Tom; Wyndham Lewis the Artist: Holding the Mirror up to Politics; Cambridge: Cambridge University Press, 1992.

North, Michael; The Dialect of Modernism: Race, Language, and Twentieth-Century Literature; Oxford: Oxford University Press, 1994.

North, Michael; The Political Aesthetic of Yeats, Eliot, and Pound; Cambridge: Cambridge University Press, 1991.

Odede, Kennedy; 'Slumdog Tourism'; The New York Times, 9 August 2010.

Paul, Catherine E.; 'Italian Fascist Exhibitions and Ezra Pound's Move to the Imperial'; In: Twentieth Century Literature, Vol. 51, No. 1 (Spring, 2005), pp. 64-97.

Paxton, Robert O.; The Anatomy of Fascism (2004); London: Penguin Books, 2005.

Payne, Stanley; A History of Fascism: 1914-1945; London: UCL Press; 1997.

Payne, Stanley; Fascism: Comparison and Definition (1980); Madison, Wis.: University of Wisconsin Press, 1980.

Pearlman, Daniel; "The Anti-Semitism of Ezra Pound (A review of: "Ezra Pound Speaking": Radio Speeches of World War II by Leonard W. Doob)'; In: Contemporary Literature, Vol. 22, No. 1 (Winter, 1981), pp. 104-115.

Pečar, Andreas und Damien Tricoire; Falsche Freunde: War die Aufklärung wirklich die Geburtsstunde der Moderne?; Frankfurt/New York: Campus, 2015.

Phillips, Ivan; 'In his Bad Books: Wyndham Lewis and Fascism'; In: The Journal of Wyndham Lewis Studies, 2: 105-34..

Plöckinger, Othmar; Adolf Hitlers „Mein Kampf“; München: R. Oldenburg Verlag, 2006.

Pound, Ezra; Guide to Kulchur (1938); London: Peter Owen Limited, 4th impression, 1966.

Pound, Ezra; Jefferson and/or Mussolini (1935); London: Liveright, Stanley Nott, 1936.

Pound, Ezra; Selected Poems of Ezra Pound; New York: New Directions, 1957.

Pound, Ezra; The Cantos of Ezra Pound (1970), New York: New Directions, 1993. 
Pugh, Martin; 'Hurrah for the Blackshirts!': Fascists and Fascism in Britain between the Wars; London: Jonathan Cape, 2005.

Rainey, Lawrence S.; 'Between Mussolini and Me'; In: London Review of Books. Vol. 21 No. $6 \cdot 18$ March 1999, 22-25.

Rainey, Lawrence S.; Ezra Pound and the Monument of Culture: Text, History, and the Malatesta Cantos; Chicago: University of Chicago Press, 1991.

Rainey, Lawrence; The Annotated Waste Land with Eliot's Contemporary Prose; Yale: Yale University Press, 2005.

Redman, Tim; Ezra Pound and Italian Fascism; Cambridge: Cambridge University Press, 1991.

Reichel, Peter; Der schöne Schein des Dritten Reiches: Faszination und Gewalt des Faschismus (1991); München and Wien: Carl Hanser Verlag, 1992.

Ricks, Christopher; T. S. Eliot and Prejudice; London: Faber and Faber 1988.

Robbins, Rossell Hope; The T. S. Eliot Myth; New York: Henry Schuman, 1951.

Rubinstein, William D.; The Myth of Rescue: Why the Democracies Could Not Have Saved More Jews from the Naris (1997); London and New York: Routledge 2000.

Rushing, Conrad L.; "Mere Words": The Trial of Ezra Pound'; In: Critical Inquiry, Vol. 14, No. 1 (Autumn, 1987).

Sanders, Charles; “The Waste Land”: The Last Minstrel Show'; In: Journal of Modern Literature, Vol. 8, No. 1 (1980), pp. 23-38.

Sanos, Sandrine; The Aesthetics of Hate: Far-Right Intellectuals, Antisemitism, and Gender in 1930s France; Stanford: Stanford University Press, 2013.

Schacht, Hjalmar; The Magic of Money; translated by Paul Erskine; London: Oldbourne, 1967.

Schenker, Daniel; 'Favoring the Divine: Wyndham Lewis's "The Human Age"'; In: Religion \& Literature, Vol. 20, No. 2 (Summer, 1988), pp. 57 74.

Schenker, Daniel; Wyndham Lewis: Religion and Modernism; Tuscaloosa and London: University of Alabama Press, 1992.

Schmidthorst, Burkhard; Mythos und Primitivismus in der Lyrik von T. S. Eliot, W. B. Yeats und Ezra Pound: Zur Kulturkritik in der klassischen Moderne; Heidelberg: Universitätsverlag Winter 2004.

Schmied, Wieland; Ezra Pound: Ein Leben zuischen Kunst und Politik; Innsbruck: Haymon Verlag, 1994.

Selby, Nick; Poetics of Loss in The Cantos of Ezra Pound; Lewiston, Queenstown, Lampeter: The Edwin Mellen Press, 2005.

Sherry, Vincent; Ezra Pound, Wyndham Lewis and Radical Modernism; Oxford: Oxford University Press, 1993. 
Shusterman, Richard; T. S. Eliot and the Philosophy of Criticism; New York: Columbia University Press, 1988.

Sieburth, Richard - 'In Pound We Trust: The Economy of Poetry/The Poetry of Economics'; In: Critical Inquiry, Vol. 14, No. 1 (Autumn, 1987), pp. 142-172.

Siegel, Jacob; 'Paul Gottfried: The Alt-Right's Jewish Godfather'; Tablet Magazine; 29 November 2016.

Sloane, Patricia; T. S. Eliot's Bleistein Poems: Uses of Literary Allusion in "Burbank with a Baedeker: Bleistein with a Cigar" and "Dirge"; Lanham et al.: International Scholars Publications, 2000.

Smith, Grover; The Waste Land; London: George Allen \& Unwin, 1983.

Sorel, Georges; Reflections on Violence (1912); translated by T. E. Hulme; Mineola, New York: Dover Publications, 2004.

Spencer, Richard and F. Roger Devlin; 'Race - Stalking the Wild Taboo'; AltRight.com; 6 July 2016.

Spencer, Richard and Jonathan Bowden; 'The European New Right'; Podcast; RadixJournal.com; 9 January 2012; [no longer online]; transcript can be found at: Counter-Currents.com

Spencer, Richard; 'Why Trump Must Champion Universal Healthcare'; AltRight.com; 23 March 2017.

Starkulla, Heinz W.; Propaganda: Begriffe, Typen, Phänomene; Baden-Baden: Nomos, 2015.

Sternhell, Zeev; Neither Right Nor Left: Fascist Ideology in France. Princeton: Princeton University Press, 1996.

Sternhell, Zeev; The Anti-Enligbtenment Tradition (2006/2009 translation); translated by David Maisel; New Haven et al.: Yale University Press, 2010.

Sternhell, Zeev; The Birth of Fascist Ideology (1989/1994 translation) Princeton, NJ: Princeton Univ. Press ; 1994.

Stirner, Max; Der Ein₹ige und sein Eigentum; Erftstadt: area verlag; 2005.

Stock, Noel; Reading the Cantos: A Study of Meaning in Erra Pound (1967); London: Routledge, 2011.

Stockton, Sharon; 'Aesthetics, Politics, and the Staging of the World: Wyndham Lewis and the Renaissance'; In: Twentieth Century Literature, Vol. 42, No. 4 (Winter, 1996), pp. 494-515

Stoddard, Lothrop; The Rising Tide of Color Against White World-Supremacy; New York: Charles Scribner's Sons, 1920.

Stoicheff, Peter; The Hall of Mirrors: Drafts \&Fragments and the End of Exra Pound's Cantos; Ann Arbor: University of Michigan Press 1998.

Stone, Dan; Breeding Superman: Nietssche, Race and Eugenics in Edwardian and Interwar Britain; Liverpool: Liverpool University Press, 2002. 
Stone, Dan; Responses to Nazism in Britain, 1933-1939: Before War and Holocaust, Houndmills: Palgrave Macmillan, 2003.

Strauss, Walter; 'The Merchant of Venom?: T. S. Eliot and Anti-Semitism'; In: South Central Review, Vol. 14, No. 3/4, Fascism \& Culture: Continuing the Debate (Autumn - Winter, 1997), pp. 31-44.

Surette, Leon; Dreams of a Totalitarian Utopia: Literary Modernism and Politics (Montreal \& Kingston: McGill-Queen's University Press, 2011.

Tatum, Bevery Daniel; "Why Are All the Black Kids Sitting in the Cafeteria Together?": And Other Conversations About Race; New York: Basic Books, 1997.

Ten Eyck, David; Ezra Pound's Adams Cantos; London et al.: Bloomsbury, 2012.

Terrell, Carroll F.; A Companion to The Cantos of Eqra Pound (1980); Berkeley: University of California Press, 1993.

Thorpe, Andrew; Britain in the 1930s: The Deceptive Decade; Oxford: Blackwell Publishers, 1992.

Tonning, Erik; Modernism and Christianity; Houndmills: Palgrave Macmillan 2014.

Torrey, E. Fuller; The Roots of Treason: Eqra Pound and the Secret of St. Elizabeths; New York: McGraw-Hill Book Company, 1984.

Tratner, Michael; Modernism and Mass Politics: Joyce, Woolf, Eliot, Yeats; Stanford: Stanford University Press, 1995.

Trotter, David; Paranoid Modernism: Literary Experiment, Psychosis, and the Professionalization of English Society; Oxford: Oxford University Press, 2001.

Trubowitz, Lara; Civil Antisemitism, Modernism and British Culture 1902-1939; New York: Palgrave Macmillan, 2012.

Unknown; '1979 - Der Sommer der Nouvelle Droite: Ein Gespräch mit Alain de Benoist'; Sezession 31; August 2009; 8-12.

Unknown; 'Slumming in this Town: A Fashionable London-Mania Reaches New-York; New York Times; 24 September 1884; Archived.

Harkinson, Josh; 'White Supremacist Sites Claim Their Traffic Is Booming. Actually, No.'; MotherJones.com; 23 November 2016.

Unknown; Protocols of the Meetings of the Learned Elders of Zion; translated by Victor Marsden; Expanded Edition; Chicago: The Patriotic Publishing Co., 1934.

Urban, Thomas; Katyn 1940: Geschichte eines Verbrechens; München: C. H. Beck Verlag, 2015.

Villis, Tom; Reaction and the Avant-Garde: The Revolt against Liberal Democracy in Early Twentieth-Century Britain; London, New York: Tauris Academic Studies, 2006. 
Wagner, Geoffrey - Wyndham Lewis: A Portrait of the Artists as Enemy; London: Routledge \& Kegan Paul, 1957.

Weininger, Otto; Geschlecht und Charakter: Eine prinzipielle Untersuchung (1903); München: Matthes \& Seitz Verlag 1980.

Welzer, Harald; Täter: Wie aus ganz normalen Menschen Massenmörder werden (2005); 5. Auflage; Fischer Verlag, 2011.

West, Lindy; 'White nationalists? Alt-right? If you see a Nazi, say Nazi"; TheGuardian; 22 November 2016;

Wilhelm, James J.; The Later Cantos of Eqra Pound; New York: Walker and Company, 1977.

Wolfe, Cary; The Limits of American Ideology in Pound and Emerson; Cambridge: Cambridge University Press, 1993.

Young, James O.; Cultural Appropriation and the Arts; Malden: Blackwell Publishing 2008.

Zentner, Christian: Adolf Hitlers Meine Kampf: Eine kommentierte Auswabl; Berlin: List Paul Verlag, 1992.

\section{Image Sources}

Image 1: From: Bauer, Elvira; Trau keinem Fuchs auf grüner Heid und keinem Jud bei seinem Eid; Nürnberg: Stürmer Verlag, 1936, 6.

Image 2: meme 'Pound and cats'; originally from: laverdadvencera.tumblr.com [defunct]; reposted at 'Pound, Ezra; Jefferson and/or Mussolini', part 1; $28^{\text {th }}$ October 2013, Counter-Currents.com. 
Ezra Pound, T. S. Eliot, and Wyndham Lewis have all, to varying degrees, been the subject of studies that explore their ideology. All too often, however, these studies have not tackled the issue adequately, limiting their analytical approach to fascism or other phenomena such as anti-Semitism. Frequently, they have also sought to exculpate these writers or to normalise their political tendencies in an effort to circumnavigate the dilemma of how to address the paradox of right-wing artists who are both harbingers and opponents of the imagined trajectory of progressive modernity. This interdisciplinary study analyses the connections between literary Modernism and right-wing ideology. Moreover, it is the first academic study to explore the reception of these Modernist authors by today's far right, seeking to understand in what ways they use strategic readings of Modernist texts to legitimise right-wing ideology. By raising fundamental questions about the relationship between aesthetics and politics, this study ultimately challenges its readers to see their cultural practices as political. It wants to make visible and problematize the interdependencies of right-wing ideology and cultural production as well as reception in order to explain the (far) Right as a phenomenon deeply rooted in European history and cultural development. It thus lays bare the misconceptions, the gaps as well as the complicity in the debate about right-wing ideology in literature.

\section{Logos Verlag Berlin}

ISBN 978-3-8325-4972-5 